\title{
LOS FRESCOS DE PALOMINO EN LA BÓVEDA DE LA IGLESIA DE LOS SANTOS JUANES DE VALENCIA: ESTUDIO Y APLICACIÓN DE UN NUEVO SOPORTE
}

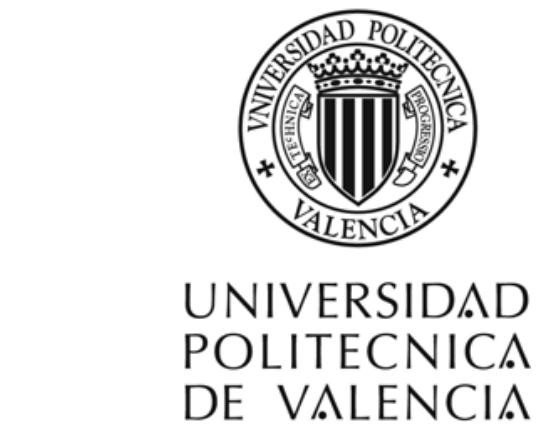

Tesis doctoral europea presentada por:

$M^{a}$ Pilar Soriano Sancho

Dirigida por:

Pilar Roig Picazo

Julia Osca Pons

PROGRAMA DE DOCTORADO:

Conservación y Restauración del Patrimonio Histórico-Artístico

DEPARTAMENTO:

Conservación y Restauración de Bienes Culturales

CENTRO:

Universidad Politécnica de Valencia. 

A mi iaia,

que hace más de 20 años ya sabía que yo iría a "San Carlos" 
Quiero expresar mi agradecimiento a todos aquellos que me han apoyado durante este largo tiempo de elaboración de la tesis.

Gracias a mi familia, por estar ahí y apoyarme en todo momento. Gracias a Alberto, por ayudarme a que la tesis no se convirtiese en el centro de mi vida.

Gracias a María, a Gema y a Inma, por los ánimos que me han dado y por ayudarme en el andamio y fuera de él.

Gracias a Eva por darme esos consejos de última hora, que me han sido tan útiles.

Gracias a Juan, por la ayuda desinteresada que me ha mostrado en todo momento. ¡Y gracias a su impresora!

Gracias a Esther por esas largas charlas durante las comidas.

Gracias a Tona, porque sin su ayuda no hubiera conseguido ese material tan preciado para mi tesis.

Gracias a Josele, a Merche y a Iñaki. Gracias a Marisa, por el trabajo extra que le ha supuesto procesar todas las mediciones colorimétricas.

Gracias a Carmina Fletcher y a Pablo, por permitirme utilizar esas magníficas cartas de Domingo Fletcher.

Gracias a Jose, por sus consejos en temas de maquetación.

Gracias a Juana, Maite, Luís y Alex.

Gracias a Ignasi, por ayudarme con la cámara de envejecimiento.

Gracias a Vanni Tiozzo y a Federico Carò, por conseguirme el papel de fractura predeterminada.

Gracias a Teresa y a Julio, por su ayuda en el laboratorio de análisis físico-químicos.

Gracias al Instituto de Restauración del Patrimonio, por dejarme ese espacio en el que he pasado tantas horas trabajando en la tesis.

Y sobre todo gracias a Pilar, por haberme permitido llegar hasta aquí, y muchisimas gracias a Julia, por aguantarme hasta el final y por poner tanto de su parte, y sacar tiempo de donde no lo había para dedicarlo a mi tesis.

Gracias a todos. 



\section{ÍNDICE}

INTRODUZIONE / INTRODUCCIÓN.

OBJETIVOS Y METODOLOGÍA.

1 LAS PINTURAS MURALES DE PALOMINO EN LA IGLESIA DE LOS 25 SANTOS JUANES DE VALENCIA.

2 LOS ARRANQUES DE PINTURAS MURALES.

2.1. Razones para la realización de un arranque.

2.2. Técnicas de arranque de pintura mural.

3 EVOLUCIÓN HISTÓRICA DE LAS TÉCNICAS DE ARRANQUE.

4 NUEVOS SOPORTES MURALES.

4.1. Revisión de diferentes tipos de soportes usados a lo largo de la historia.

4.2. Revisión de diferentes tipos de estrato de intervención.

5 EXPERIMENTACIÓN PRÁCTICA.

5.1. Propuestas de intervención para la eliminación del antiguo soporte de las pinturas de la bóveda de la Iglesia de los Santos Juanes de Valencia.

5.5.1.Análisis de diferentes sistemas de separación.

5.5.2. Aplicación de los sistemas tradicionales de arranque.

5.5.3.Ensayos de sistemas de protección.

5.1.3.1. Ensayos con probetas de pinturas murales al fresco.

5.1.3.2. Ensayos con probetas de pinturas murales arrancadas por medio de strappo. 
5.5.4. Materiales ensayados.

5.1.4.1. Telas.

5.1.4.2. Adhesivos.

a. Reversibilidad.

A1. Fotografías ultravioleta.

A2. Mediciones colorimétricas.

A3. Macrofotografías.

A4.Espectroscopia Infrarroja por transformada de Fourier.

5.5.5.Propuesta de protección de un fragmento de las pinturas de Palomino en la Iglesia de los Santos Juanes de Valencia.

5.2. Ensayos de nuevos soportes.

5.5.1. Soporte.

5.5.2. Capa de intervención.

5.5.3. Adhesivos.

5.5.4. Experimentaciones prácticas.

5.5.5. Propuesta de aplicación de un nuevo soporte a un fragmento de las pinturas de Palomino en la Iglesia de los Santos Juanes de Valencia.

5.3. Ensayos de sistemas de anclaje del soporte al muro.

5.5.1.Propuesta de aplicación de un sistema de anclaje en un fragmento de las pinturas de Palomino en la Iglesia de los Santos Juanes de Valencia.

6 APLICACIÓN DEL PROCESO SOBRE UN FRAGMENTO DE PINTURA MURAL DE LA BÓVEDA DE LA NAVE CENTRAL DE LA IGLESIA DE LOS SANTOS JUANES DE VALENCIA.

7 CONCLUSIONI I CONCLUSIONES. 
9.1. Anexo I. Correspondencia de D. Domingo Fletcher.

9.2. Anexo II. Tablas de las probetas de análisis de diferentes concentraciones de los adhesivos.

9.3. Anexo III. Tablas de fotografías con luz 294 ultravioleta.

9.4. Anexo IV. Tablas de mediciones colorimétricas.

9.5.1.Mediciones colorimétricas de las probetas de laboratorio.

9.5.2. Mediciones colorimétricas del fragmento de pintura mural arrancada de la bóveda de la nave central de la iglesia de los Santos Juanes.

9.5. Anexo V. Tablas de análisis de muestras con Espectroscopia I.R. por transformada de Fourier.

9.5.1.Análisis de muestras tomadas de las probetas.

9.5.2. Análisis de muestras tomadas de los adhesivos utilizados, en estado puro.

9.5.3. Comparativa de las muestras tomadas de las probetas y de los espectros de cada adhesivo.

9.6. Anexo VI. Tablas de mediciones de peso de probetas.

9.7. Anexo VII. Comparativa de fotografías tomadas a través de microscopio óptico antes y después de la limpieza del panel, y después de la desprotección. 

La presente tesis doctoral se ha llevado a cabo gracias a la concesión de una beca del plan de Formación de Profesorado Universitario, del Ministerio de Educación, Cultura y Deporte, durante el periodo comprendido entre abril de 2000 y octubre de 2003. Este periodo formativo se vió enriquecido con la estancia en L' Università Internazionale dell'Arte di Firenze, en Italia, del 31 de enero al 31 de marzo de 2002, gracias a la concesión de una Ayuda para realizar estancias breves en España o el extranjero. Gracias a esta ayuda se ha tenido la oportunidad de adquirir una visión de la formación de restauradores distinta de la que se conocía hasta ese momento, y por lo tanto permitió incrementar la formación como restauradora y como persona.

En 2003 tuve la oportunidad de llevar a cabo parte de la investigación que conduciría al desarrollo de esta tesis, en uno de los centros más relevantes en el campo de la conservación y la restauración europea, el Istituto Centrale per il Restauro de Roma, donde pude conocer de nuevo otro aspecto de la enseñanza de la restauración, lo que me permitió, además de obtener conocimientos muy fructíferos para esta tesis, crecer como docente. Esta estancia se desarrolló del 2 de noviembre al 20 de diciembre de 2003, pero esta vez con financiación propia.

Gracias a estas estancias en centros europeos y la colaboración de diferentes expertos en la elaboración de la presente tesis doctoral, puedo optar a la mención de Doctor europeus.

Los trabajos de investigación se han desarrollado en el Departamento de Conservación y Restauración de Bienes Culturales de la Universidad Politécnica de Valencia, vinculada con el Taller de Análisis e Intervención de Pintura Mural del Instituto de Restauración del Patrimonio de esta misma univesidad.

Gracias a ello he participado en múltiples obras de restauración de pintura mural, lo cual ha ayudado en el desarrollo de mayores conocimientos sobre el tema, para aplicarlos a la presente tesis doctoral. Del mismo modo he participado en diversos proyectos de investigación, desarrollo e innovación, y convenios:

"Desarrollo de la investigación arquitectónica, pictórica, escultórica, ornamental, y propuesta de intervención para la recuperación Integral de la Basílica de la Virgen de los Desamparados de Valencia";

"Proyecto de intervención en las cúpulas, tambor y linterna de la Basílica de la Virgen de los Desamparados de Valencia";

"Ensayos No Destructivos por Ultrasonidos en Restauración y Conservación de Bienes Culturales: Aplicación a la Bóveda de la Iglesia de los Santos Juanes";

"Conservación y Restauración de la Decoración Pictórica Mural de la Cúpula de la Capilla del Santísimo Cristo. Oliva"; 
"Restauración de los restos de pintura mural al fresco sitas en la nave central de la iglesia de los Santos Juanes de Valencia" ${ }^{1}$.

La participación en estos proyectos nos ha permitido investigar con mayores conocimientos prácticos que de otro modo no se hubiera conseguido.

${ }^{1}$ Convenio suscrito entre la Iglesia de los Santos Juanes de Valencia y el Instituto de Restauración de Bienes Culturales, con la aprobación de la Consellería de Cultura de la Generalitat Valenciana, y con financiación de la Universidad Politécnica de Valencia. (En vigencia desde enero de 2004).

Directora del proyecto: Pilar Roig Picazo

Participantes: Clavel Piá, Inmaculada; Gómez Chaparro, Gema; Martínez Bazán, Ma Luisa; Osca Pons, Julia; Palumbo, María; Regidor Merino, Jose Luis; Regidor Ros, José Luis; Sánchez Pons, Mercedes; Soriano Sancho, Pilar; Zalbidea Muñoz, Maria Antonia. 



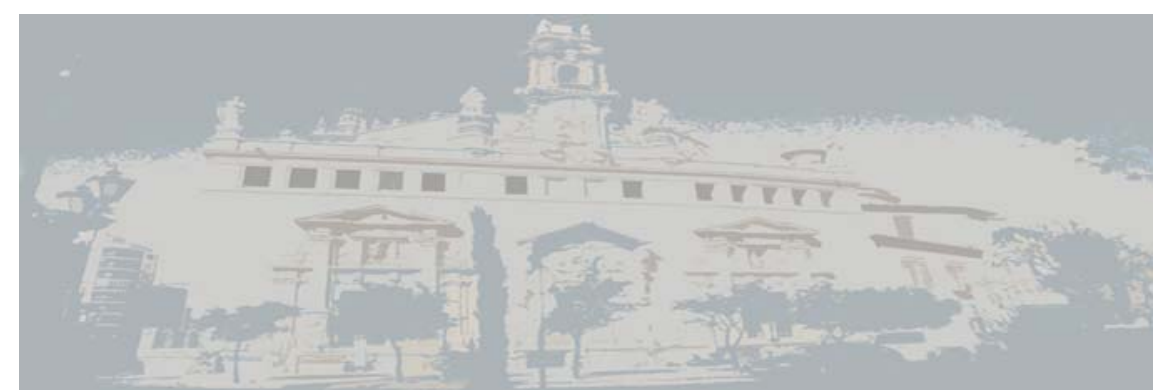

INTRODUZIONE

INTRODUCCIÓN 




\section{INTRODUZIONE}

Parte della ricerca eseguita per elaborare questa tesi di dottorato, si sviluppa negli studi di nuovi supporti per dipinti murali strappati, per applicare il più adatto agli affreschi della volta della navata principale della chiesa di Santos Juanes di Valencia.

Perciò, questa tesi si sviluppa nel marco della ricerca che ha il suo origine nei Progetti I+D+I che la Commissione Interministeriali di Sciencia e Tecnología (CICYT) ha concesso nel Progetto Nazionale di Ricerca e Sviluppo, all'equipe di ricerca diretto dalla Dottoressa Pilar Roig Picazo, per il restauro della Chiesa di Santos Juanes di Valencia.

Questi progetti sono:

- "Ricomposizione di una pittura murale mediante trattamento computerizzato dell'immagine, basato nella ricerca sullo stato primitivo ed attuale. Applicazione ad un problema reale" (PAT_910372), con durata da 1991 a 1993.

* "Restituzione digitale d'una pittura murale: determinazione dell'ipotesi plastica scala 1/1. Sviluppo di tecniche di rimessa dell'immagine su un supporto stabile: applicazione alla volta di Santos Juanes" (SEC94-0549), con durata da 1994 a 1997.

- "Trattamento digitale d'immagini rimesse in supporto stabile, come base del restauro degli affreschi della chiesa di Santos Juanes di Valencia" (PB 96-1060), con durata da 1997 a 2000.

Ed in progetti di ricerca finanziati dal Vicerrettorato de Ricerca, Sviluppo ed Innovazione dell'Università Politecnica di Valencia:

* "Prove non distruttive con ultrasuoni nel restauro e conservazione dei Beni Culturali: applicazione alla volta della Chiesa di Santos Juanes", con durata da 2003 a 2005.

E nei contratti di ricerca $(I+D+I)$ con ditte private:

* "Accordo tra la Reale Parrochia di Santos Juanes di Valencia, I' Istituto de Restauro del Patrimonio e I'Università Politecnica di Valencia per il Restauro dei resti della pittura murale ubicata nella volta della navata centrale della Chiesa dei Santos Juanes di Valencia", con durata da 2003 a 2004.

- "Accordo tra l'Arcivescovado di Valencia, il comune di Valencia, la ditta Aguas de Valencia e l'Università Politecnica di Valencia per il Restauro delle pitture murali di Palomino nella volta della Reale Parrochia dei Santos Juanes di Valencia", con durata da 2005 a 2008. 


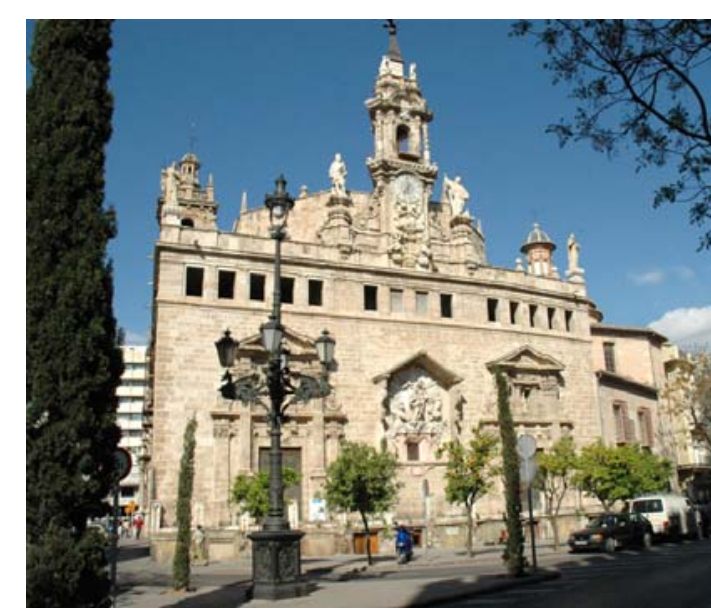

Fig. 1. Facciata principale della Chiesa di Santos Juanes di Valencia.

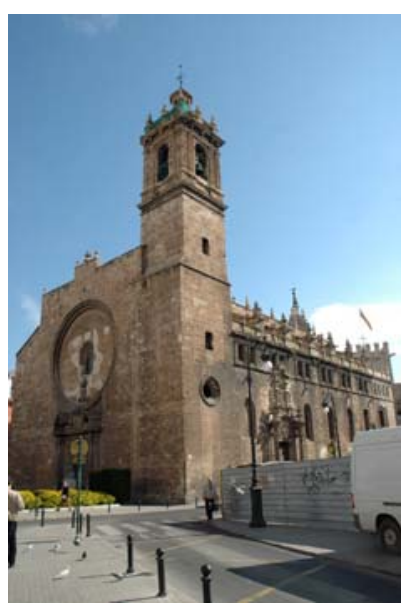

Fig. 2. Facciate laterale e dal retro della Chiesa di Santos Juanes di Valencia.

Siccome il tema della tesi versa sull' applicazione di un nuevo supporto ai dipinti murali strappati della volta della navata centrale della chiesa dei Santos Juanes di Valencia, e per capire meglio lo stato di conservazione dell'opera, che fu strappata e rimessa su un nuevo supporto negli anni 60, è necesario intraprendere lo studio di questi tipi di trattamenti di restauro dagli inizi fino ad oggi.

Potremmo dividere la tesi in cinque parti, anche se si struttura in più capitoli.

Nella prima parte si spiega brevemente la storia delle pitture su cui facciamo il presente lavoro, addiritura il loro statu di conservazione attuale.

Nella seconda parte si define il processo di distacco di pittura murale come metodo di restauro; si fa una descrizione delle diverse tecniche que si possono utilizzare, e si intraprende una ricerca sull' evoluzione storica di questi processi in Italia ed in Spagna.

Nella terza parte, sviluppiamo la ricerca prattica su diversi materiali, metodologie e tecniche per mezzo di campioni di laboratorio per dedurre, per mezzo di questi, quale sarebbe il migliore metodo di stacco del frammento di pittura originale che stiamo studiando, dal supporto su cui la misero negli anni 60.

Estratte le pertinenti conclusioni, applicheremo il processo scelto come il più adatto sul frammento di pintura originale, rimuovendo il supporto attuale, che non è piú adatto. 
Nella quarta parte si sviluppa lo studio sui diversi supporti che si possono applicare ai dipinti murali distaccati, facendo una rassegna tanto dei materiali utilizzati attraverso la storia, come i nuovi materiali che potrebbero essere utilizzati, frutto di questa ricerca; per finire con la conclusione su quale è il supporto più adatto a queste pitture. Questa parte include lo studio su provette di laboratorio di diversi supporti ed adesivi per la restiruzione al luogo originale delle pitture distaccate. Così come i sistemi differenti d'ancoraggio di questi supporti alla volta.

Per finire, stabiliamo una serie di conclusioni degli esperimenti teorici e prattici sulle provette di laboratorio. Le conclusioni estratte, conducono alla realizzazione prattica dell'opera: un frammento di pittura murale strappata dalla volta della navata centrale della chiesa dei Santos Juanes di Valencia.

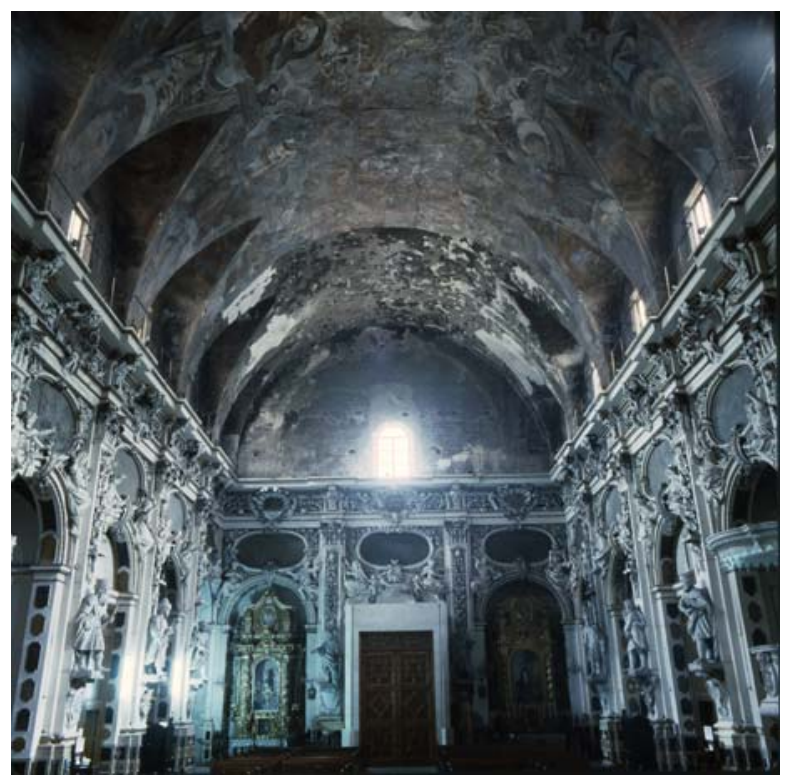

Fig. 3. Immagine generale della navata centrale della chiesa di Santos Juanes. 


\section{INTRODUCCIÓN}

Parte de la investigación llevada a cabo para la elaboración de esta tesis doctoral, se centra en el estudio de nuevos soportes de pintura mural arrancada, para aplicar el que consideremos más adecuado a las pinturas arrancadas de la bóveda de la nave central de la Iglesia de los Santos Juanes de Valencia.

Por ello esta tesis se desarrolla en el marco de la investigación que tiene su origen en los siguientes proyectos de I+D+I, concedidos por la Comisión Interministerial de Ciencia Y Tecnología (CICYT) dentro del Plan Nacional de Investigación y Desarrollo, y dirigidos por la Dra. Pilar Roig Picazo:

- "Recomposición de una pintura mural mediante tratamiento informatizado de la imagen, basado en la investigación de su estado primitivo y actual. Aplicación a un problema real" (PAT_91-0372), con vigencia de 1991 a 1993.

* "Restitución digital de una pintura mural: concreción de la hipótesis plástica a escala 1/1. Desarrollo de técnicas de transferencia de la imagen a soporte estable: su aplicación a la bóveda de Santos Juanes" (SEC94-0549), con vigencia de 1994 a 1997.

* "Tratamiento digital de imágenes transferidas a un soporte estable, como base de la restauración de las pinturas murales al fresco de la iglesia de los Santos Juanes de Valencia" (PB 96-1060), con vigencia desde 1997 hasta 2000.

Así como en proyectos de investigación financiados por el Vicerrectorado de Investigación, Desarrollo e Innovación de la Universidad Politécnica de Valencia:

* "Ensayos No Destructivos por Ultrasonidos en Restauración y Conservación de Bienes Culturales: Aplicación a la Bóveda de la Iglesia de los Santos Juanes", con vigencia de 2003 a 2005

$Y$ en los contratos de investigación $(I+D+I)$ con entidades privadas:

* "Convenio suscrito entre la Real Parroquia de los Santos Juanes de Valencia, el Instituto de Restauración del Patrimonio y la Universidad Politécnica de Valencia para la Restauración de los restos de pintura mural al fresco sitas en la nave central de la Iglesia de los Santos Juanes de Valencia", vigente de 2003 a 2004.

* "Convenio suscrito entre el Arzobispado de Valencia, Ayuntamiento de Valencia, Aguas de Valencia y la Universidad Politécnica de Valencia para la Restauración de las pinturas murales de Palomino en la Bóveda de la Real Parroquia de los Santos Juanes de Valencia", vigente de 2005 a 2008.

Dado que el tema de la tesis se centra en la aplicación de un nuevo soporte a las pinturas murales arrancadas de la bóveda de la nave central de la iglesia de los Santos Juanes de Valencia, y para entender mejor el estado en que se encuentra la obra, que fue arrancada y colocada en un nuevo soporte entre 1958 y 1963, se hace necesario abordar el estudio de este tipo de tratamiento de restauración desde sus inicios hasta hoy.

La tesis se divide en cinco partes, aunque se estructura formalmente en un mayor número de capítulos.

En la primera parte de esta memoria de tesis se hace un resumen de la evolución histórica y material de las pinturas que nos ocupa, profundizando en su estado de conservación actual.

En un segundo bloque se han analizado las diferentes técnicas de arranque de pinturas murales empleadas a lo largo de la historia, abordando de una manera más detallada la evolución histórica de este proceso "restaurativo" en Italia y en España. 
El tercer bloque está dedicado a la parte experimental de esta investigación, donde se exponen los resultados de los ensayos realizados sobre probetas de laboratorio con diferentes materiales, métodos y técnicas. El objetivo básico de esta parte experimental ha sido determinar el mejor método de separación de los fragmentos de pintura original respecto al soporte en el que se encuentran actualmente (fruto de la intervención realizada sobre la pintura entre 1958 y 1963 . Teniendo en cuenta las conclusiones extraídas en los ensayos de laboratorio, se ha llevado a la práctica el procedimiento de separación elegido sobre un fragmento de pintura original, despojándolo de su actual soporte, que resulta inadecuado, para aplicarle uno nuevo.

En el cuarto bloque se expone y desarrolla el estudio realizado sobre las diferentes posibilidades de sustitución del actual soporte que presenta la pintura objeto de esta tesis. Se ha realizado un revisión bibliográfica de los tratamientos empleados en situaciones similares y de las posibilidades existentes, haciendo un repaso tanto de los materiales tradicionales usados a lo largo de la historia, como de nuevos materiales más actuales, susceptibles de ser utilizados para la problemática que nos ocupa; El objetivo de la experimentación realizada en este bloque es determinar el soporte más adecuado para estas pinturas, teniendo en cuenta todos los condicionantes la rodean. Se expone aquí la experimentación realizada en laboratorio sobre probetas de pintura mural, para la cual se han construído soportes de diferente tipología, y se han ensayado distintos tipos de adhesivos para la recolocación de la pintura arrancada a su lugar de origen. Se incluye una propuesta de posibles sistemas de anclaje de dichos soportes a la bóveda.

Por último, y tras el análisis de las conclusiones derivadas de la experimentación práctica sobre probetas de laboratorio, se ha aplicado el tratamiento elegido sobre un fragmento de la obra original, extraída de la zona intervenida en los años 60. 



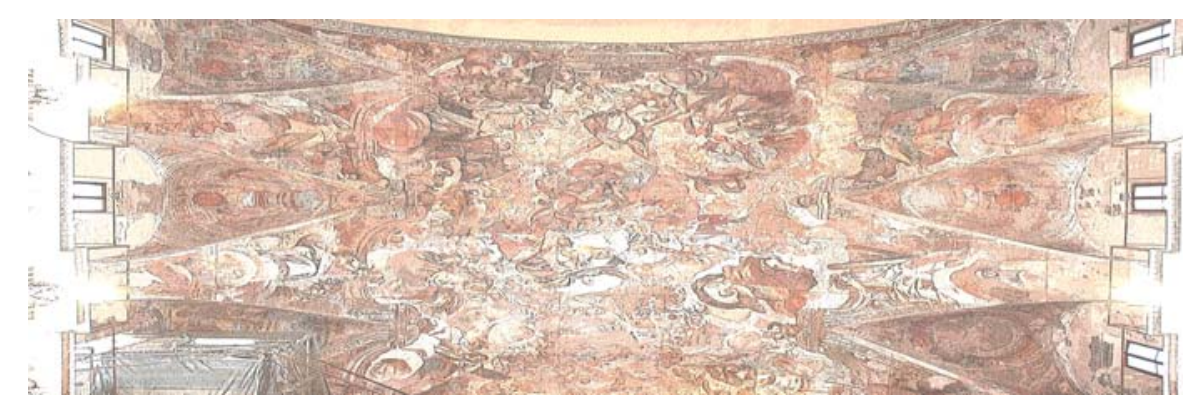

OBJETIVOS Y METODOLOGÍA 



\section{OBJETIVOS Y METODOLOGÍA DE LA TESIS}

El objetivo principal de esta tesis doctoral es determinar el soporte más adecuado para la pintura mural de la bóveda de la nave central de la Iglesia de los Santos Juanes de Valencia que fue arrancada en una desafortunada intervención entre los años 1958-1963 tras el incendio que sufrió la iglesia. Para ello se ha realizado un estudio de las posibilidades existentes para esta problemática, se ha diseñado una experimentación práctica con el objeto de concretar un tipo de soporte y finalmente se ha construido éste, Las conclusiones extraídas tras la aplicación del soporte se han extrapolado al resto de pinturas arrancadas de la bóveda, con el fin de conferir a la obra una continuidad que asemeje lo más posible al original, teniendo en cuenta el estado de conservación de la parte de la bóveda que no fue arrancada y que en este momento se encuentra en fase de restauración.

Para conseguir este objetivo principal, se han desarrollado los siguientes puntos:

* Se ha realizado una revisión de las técnicas tradicionales de arranque de pintura mural, con el fin de hacer una valoración del actual estado de conservación que presenta la pintura objeto de esta investigación.

* Se ha llevado a cabo un estudio sobre los soportes aplicados a lo largo de la historia a pinturas murales arrancadas.

- Se ha estudiado y establecido qué tipo de protección resultaría más adecuado para separar esta obra de su actual soporte de madera que, como explicaremos más adelante, no resulta adecuado.

* Se ha determinado qué tipo de soporte resultaría más adecuado para estas pinturas.

- Se ha concretado el sistema de anclaje más adecuado para reubicar en la bóveda los fragmentos de pintura mural arrancada y colocada en su nuevo soporte.

Para la consecución de los dos primeros puntos, se ha realizado una completa revisión bibliográfica, la cual se expone en los primeros capítulos de esta memoria de tesis.

Para establecer el tipo de protección más adecuado para separar esta obra de su actual soporte de madera, se han tomado como referencia los datos extraídos de la revisión bibliográfica, estudiando tratamientos similares empleados a lo largo de la historia, y a partir de ellos se han elaborado una serie de probetas de laboratorio para determinar los materiales que se usarán posteriormente en la obra real. 
Uno de los temas más preocupantes es la reversibilidad y posible permanencia de los adhesivos que se usen en la protección de la pintura antes de separarla de su soporte. Con el fin de controlar la posible permanencia de estos adhesivo en la superficie pictórica tras la desprotección, se han realizado diversas pruebas tales como análisis óptico a través de un microscopio mediante el posterior registro fotográfico; análisis óptico mediante luz ultravioleta con posterior registro fotográfico; análisis colorimétricos comparativos del antes y después de la aplicación del adhesivo en las probetas; análisis por espectroscopia de I.R. por transformada de Fourier de muestras tomadas de las probetas protegidas con diferentes adhesivos, comparándolas con los espectros de los adhesivos puros utilizados.

Para establecer qué tipo de soporte resulta más adecuado para estas pinturas, se han elaborado una serie de probetas tomando como referencia los tipos de soportes que se han usado a lo largo de la historia. A partir de estas probetas se han extraído conclusiones con el fin de elaborar otra serie de probetas con las características más adecuadas. Estas probetas se han analizado detenidamente y se han descartado las que han resultado inadecuadas, ensayando en una cámara de envejecimiento las que han quedado como posible soporte para esta obra. De las conclusiones extraídas se ha concretado un soporte válido a aplicar a las pinturas arrancadas de la bóveda de la Iglesia de los Santos Juanes de Valencia.

En el último punto de esta investigación, en el que se pretende establecer qué tipo de anclaje resulta más adecuado para reubicar en la bóveda los fragmentos de pintura mural arrancada y colocada en su nuevo soporte, se han estudiado varias propuestas y sistemas de anclaje. No obstante, de las propuestas planteadas y estudiadas, de entre las cuales se ha optado provisionalmente por una de ellas, hemos de señalar que ésta podría ser modificada en función de las necesidades concretas que se pudieran plantear en el supuesto de que abordara realmente la restauración. Hay que tener en cuenta que la problemática de la obra es tan compleja que no es posible adelantarse a las circunstancias concretas que muy probablemente surjan cuando se aborde realmente la restauración integral de este gran conjunto pictórico mural.

Por último, y como conclusión de las investigaciones teórico-prácticas llevadas a cabo, en esta tesis, se ha aplicado a los fragmentos de pintura mural arrancada y colocada en un nuevo soporte la protección considerada más adecuada, con el objeto de separar la pintura de su actual soporte de madera. Una vez separada, se ha tratado el reverso y se ha aplicado a estos fragmentos de pintura un nuevo soporte, reubicándolos finalmente en la bóveda. 



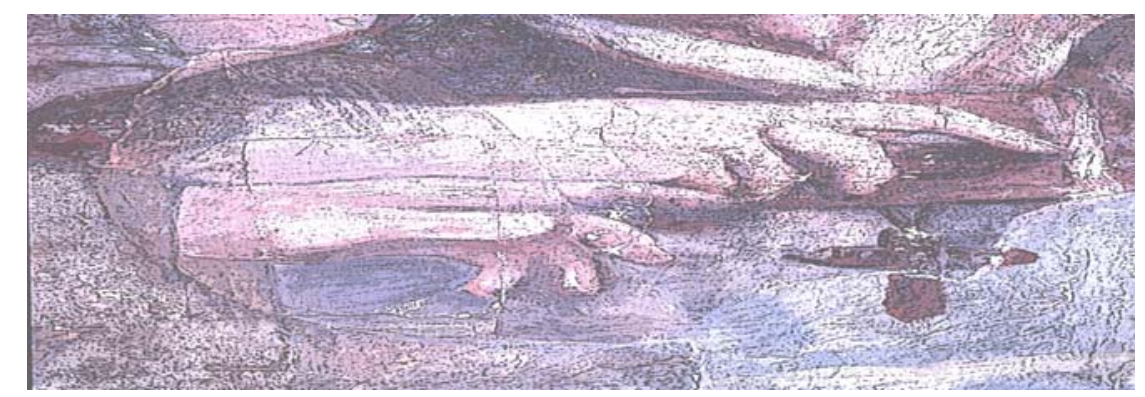

CAPÍTULO I

LAS PINTURAS MURALES DE PALOMINO EN LA IGLESIA DE LOS SANTOS JUANES DE VALENCIA 




\section{LAS PINTURAS MURALES DE PALOMINO EN LA IGLESIA DE LOS SANTOS JUANES DE VALENCIA}

Como hemos señalado, el objetivo básico de esta investigación es establecer las características de un nuevo soporte más adecuado que el actual para las pinturas de Antonio Palomino en la Iglesia de los Santos Juanes. Por ello se han estudiado las características actuales de dichas pinturas para saber qué tipo de tratamiento necesitan, y cuál de la amplia gama de soportes existentes resultaría más adecuado para estas pinturas. En concreto, esta investigación se ha centrado sobre uno de los fragmentos de pintura ${ }^{2}$ que se ha extraído de la bóveda y ha sido trasladado a los laboratorios del Taller de Análisis e Intervención en Pintura Mural del Instituto de Restauración del Patrimonio de la Universidad Politécnica de Valencia. No obstante, aunque las investigaciones a nivel práctico se centren en este fragmento, el estudio debe realizarse pensando en la obra completa, no sólo en su aplicación a un fragmento aislado.

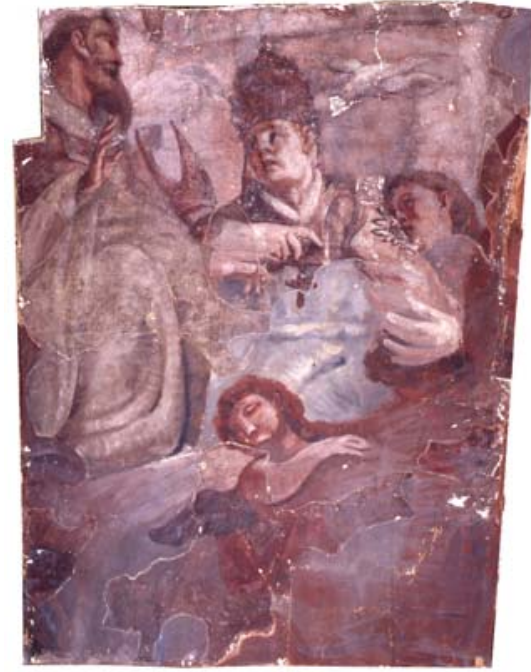

Fig. 4. Anverso del fragmento de pintura mural arrancada objeto de este estudio.

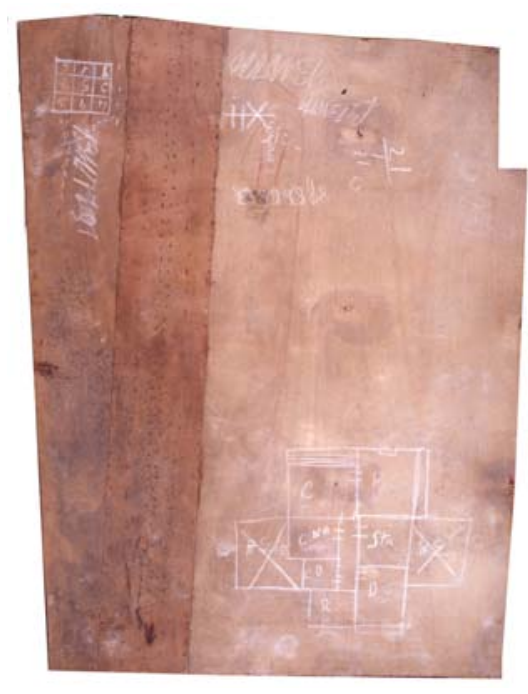

Fig. 5. Reverso del fragmento de pintura mural arrancada de la bóveda de la Iglesia de los Santos Juanes de Valencia.

\footnotetext{
${ }^{2}$ El no 8 en el diagrama de fragmentación de la bóveda en paneles. Véase Fig. 20.
} 
Aunque este panel mide unos $3 \mathrm{~m}^{2}$ aproximadamente, como veremos más adelante, cada uno de los paneles presenta una forma y unas dimensiones distintas, lo que resultat de gran imprtancia para el planteamiento de un tratamiento u otro de aplicación de un nuevo soporte.

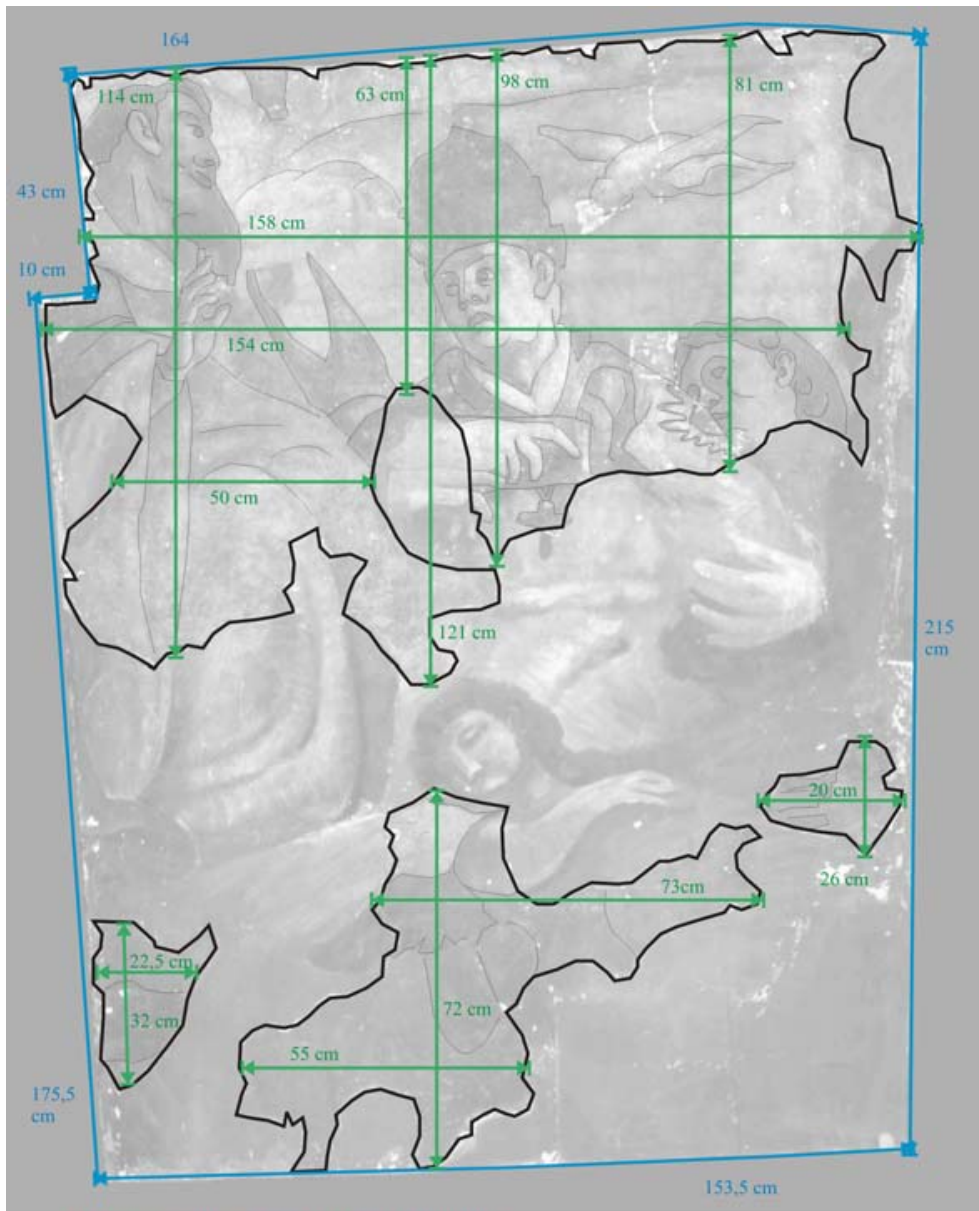

$\longleftrightarrow$ DIMENSIONES DE LA PINTURA ORIGINAL

$\longleftrightarrow$ DIMENSIONES DEL PANEL. DE MADERA

Fig. 6. Diagrama del panel objeto de este estudio en el que se representa gráficamente las medidas de cada uno de los fragmentos, así como las del conjunto del panel. 


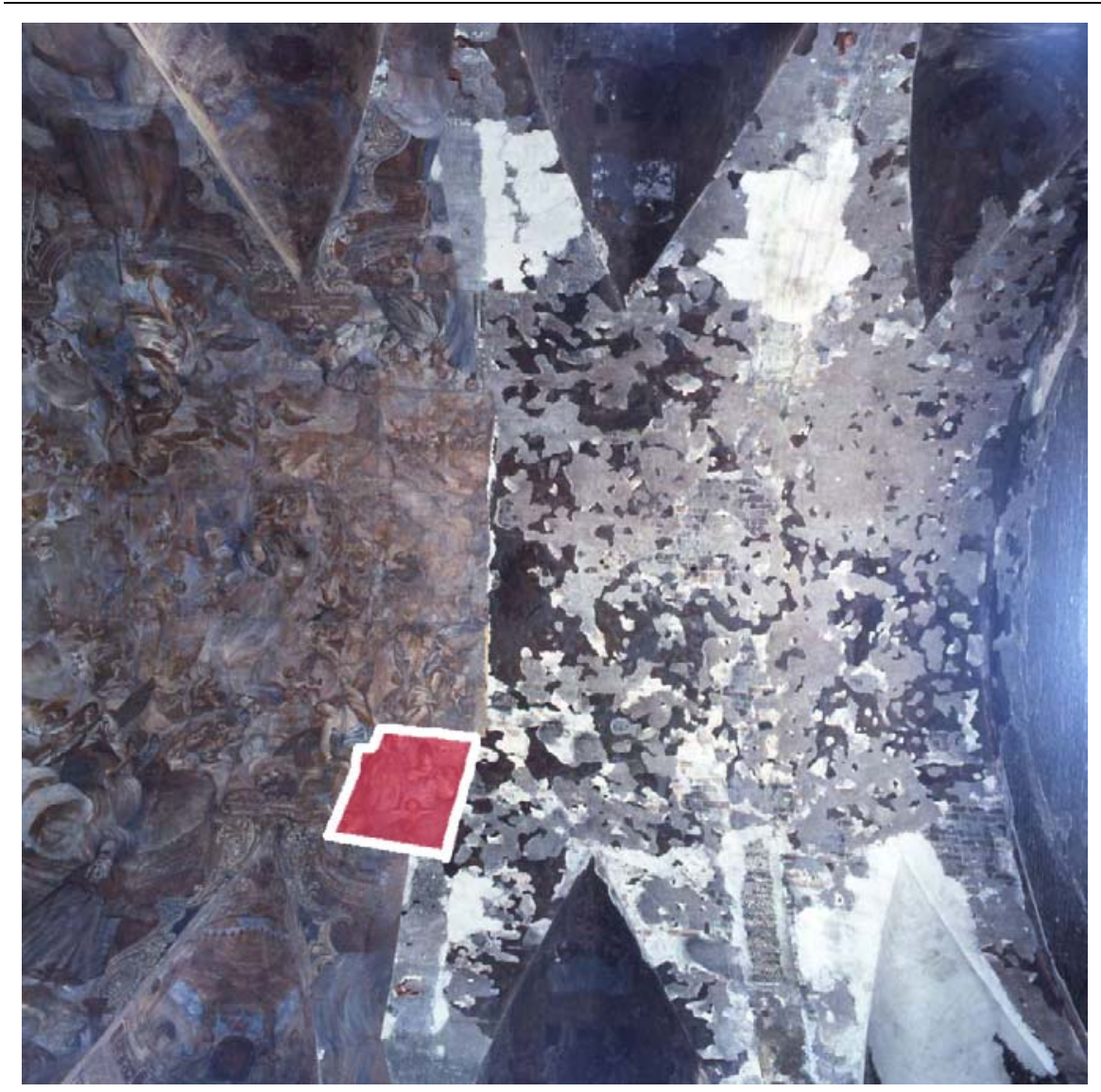

Fig. 7. Ubicación del fragmento objeto de esta investigación, en el conjunto de la bóveda.

Las pinturas murales de la bóveda de la nave central de la Iglesia de los Santos Juanes de Valencia, fueron pintadas por Antonio Palomino entre 1699 y 1701. La obra presenta unas características particulares, pues, habiendo sido pintadas al fresco, sobre intonaco de cal y arena, presenta unos morteros preparatorios internos a base de yeso -y no de cal- como cabría esperar en una ortodoxa técnica al "buon fresco".

\footnotetext{
${ }^{3}$ Los análisis y pruebas efectuadas hasta el momento, han permitido conocer la composición cualitativa y cuantitativa de las diferentes capas de preparación. Estos resultados han supuesto un interesante hallazgo ya que revelan la utilización, por parte del autor, de técnicas de ejecución artística diferentes a las tradicionalmente empleadas en la realización de pintura al fresco. Por otra parte, los resultados obtenidos ponen de manifiesto la existencia de alteraciones que afectan en diverso grado a los diferentes compuestos químicos que constituyen los morteros y capas de preparación. Estos procesos de degradación han sido causados principalmente por el incendio de $1936 \mathrm{La}$ intensidad y magnitud del mismo ha producido como consecuencia la alteración en profundidad de las capas de preparación constituidas principalmente por yeso que, de este
} 
En primer lugar, debemos tener en cuenta que se trata de una pintura de grandes dimensiones, que se asienta sobre una bóveda de cañón ligeramente parabólica, rematada lateralmente con lunetos, que se construyó para decorar el gran espacio de la nave central y ocultar la estructura gótica que actualmente subyace al conjunto pictórico. Las pinturas ocupan una superficie de alrededor de $700 \mathrm{~m}^{2}$., siendo las dimensiones en planta: $31^{\prime} 52 \mathrm{~m}$ de longitud hasta el arco toral del presbiterio; 16 '76 m de anchura; y 21'50 de altura hasta la cornisa. La altura libre en el centro de la bóveda es de aproximadamente $21^{\prime} 50 \mathrm{~m}$. La bóveda está formada por tres roscas de ladrillo, puestos en plano y tomados con yeso. Cada dos metros presenta un anillo de refuerzo mediante un arco tabicado sobre el trasdós de la bóveda. En estos puntos de la bóveda el espesor sobrepasa los $15 \mathrm{~cm}$.

En segundo lugar hay que entender el estado de conservación actual de las pinturas conociendo la historia y evolución material que éstas han sufrido a lo largo de su existencia. De ahí la importancia de abordar también en próximos capítulos en qué consisten las técnicas de arranque de pintura mural a lo largo de la historia, así como el estudio de la evolución histórica de los diferentes soportes.

Las pinturas murales de la bóveda de la nave central de la Iglesia de los Santos Juanes de Valencia, fueron pintadas por Antonio Palomino durante el periodo comprendido entre 1699 y 1701.

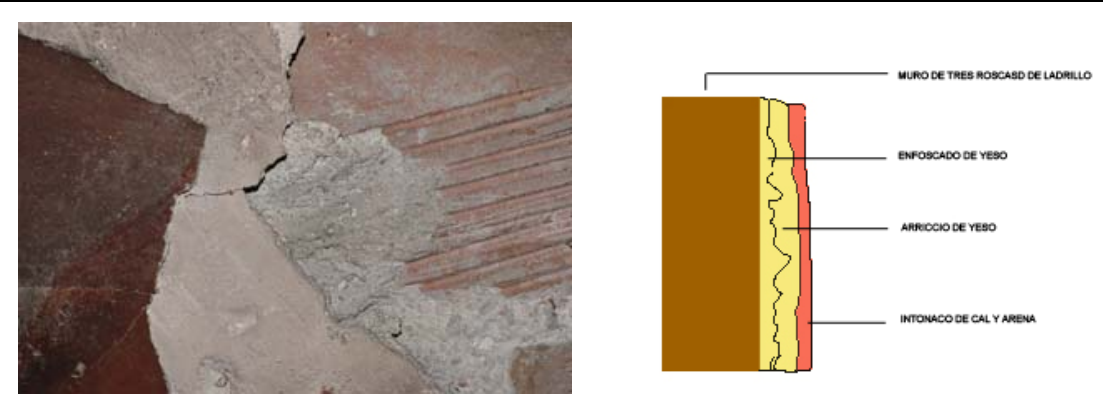

Fig. 8. Estratos que conforman la pintura mural al fresco de la bóveda de la Iglesia de los Santos Juanes.
Fig. 9. Diagrama de los estratos de los frescos de la bóveda.

Los incendios han marcado la evolución constructiva del edificio, pero también marcaron de forma decisiva el estado de conservación de las

modo, a sufrido diversos procesos de deshidratación transformandolo en basanita y anhidrita. 
pinturas. Fue un gran incendio provocado durante la Guerra Civil en 1936 el causante de la destrucción interna del templo y de las pinturas, siendo el desencadenante directo de una desafortunada intervención de restauración realizada entre 1958 y 1963. El incendio fue de tal magnitud que las pinturas murales de la nave central, presbiterio, capilla de la Comunión, y el resto de elementos escultóricos y ornamentales quedaron notablemente deteriorados, así como la propia fábrica de la iglesia, que quedó seriamente dañada.

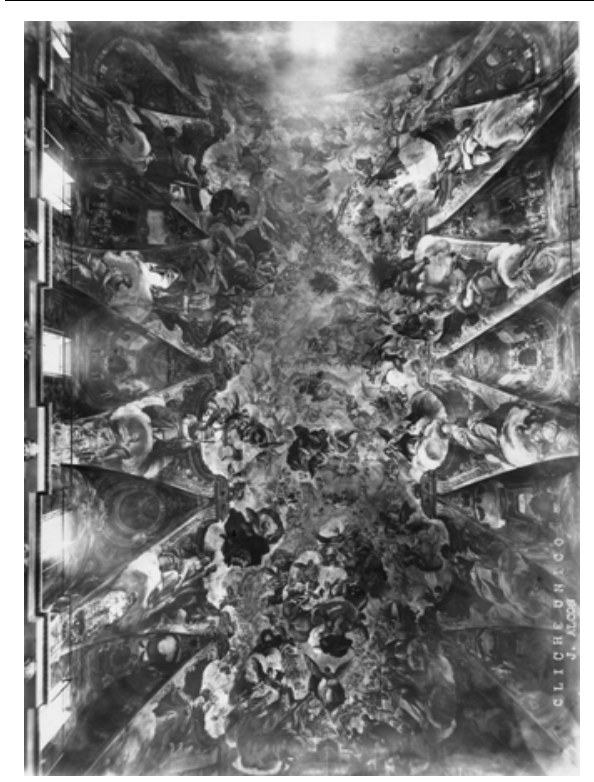

Fig. 10. Fotografía general de la bóveda antes del incendio de 1936. Cliché único del fotógrafo Alcón.

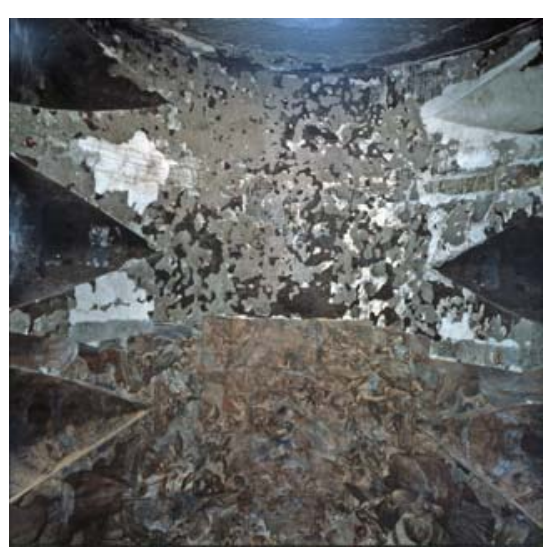

Fig. 11. Fotografía de la bóveda en la que vemos, en la parte superior, la pintura que quedó tras el incendio de 1936, y en la mitad inferior, la parte de la bóveda que se arrancó en los años 60 y se colocó en soportes de madera

Según un informe realizado en 1943 por Roig d'Alós ${ }^{4}$, las pérdidas ocasionadas en las pinturas de la bóveda central por el incendio se cifraban en torno a un $30 \%$. Las del presbiterio fueron las más afectadas, perdiéndose casi en su totalidad.

\footnotetext{
${ }^{4}$ ROIG PICAZO, Pilar; BosCh REIG, Ignacio. La iglesia de los Santos Juanes de Valencia. Proceso de intervención pictórica 1936-1990. Servicio de Publicaciones de la Universidad Politécnica de Valencia. Valencia, 1990.
} 
A finales de marzo de 1958, se había estudiado el estado de conservación de las pinturas, por el restaurador catalán D. José Gudiol ${ }^{5}$, por lo que se decidió empezar los trámites para la puesta en marcha de su restauración.

El 17 de Julio de 1958, D. Domingo Fletcher (Delegado del Servicio de Defensa del Patrimonio Artístico Nacional) escribe una carta ${ }^{6}$ a $D$. Alejandro Ferrant (Arquitecto Conservador de Monumentos de la Zona Levante) en la que le cuenta que ha mantenido una reunión con el cura párroco, "porque el Sr. Arzobispo desea saber qué planes hay respecto a las pinturas de aquella Iglesia y qué ha de hacerse después de arrancadas". Es el mismo Domingo Fletcher el que explica "que se arrancaban para poderlas limpiar mejor y fortalecerlas y que luego serían devueltas y si había posibilidad se montarían en su sitio y que si no en una especie de cuadro para que el público, en la misma Iglesia de los Santos Juanes, pudiera admirar lo que se ha salvado". No obstante, en esta fecha de 17 de julio de 1958 no se tenía aún el permiso para la ejecución de las obras de arranque y restauración: "el Sr. Cura no se atreve a dejar sacar las pinturas sin orden de sus superiores, por temor a que los feligreses puedan encresparse y creer que las ha enajenado. $Y$ el Sr. Arzobispo, por su parte no da la orden mientras no tenga una comunicación de $\mathrm{Vd}$. explicándole lo que se va a hacer con las pinturas y teniendo la seguridad de que éstas volverán a Valencia".

Con el fin de que el Sr. Arzobispo diera la orden de proceder al tratamiento de las pinturas de la Iglesia de los Santos Juanes, dos días más tarde, el 19 de Julio de 1958, D. Domingo Fletcher le escribió:

"En las primeras exploraciones practicadas, a fines de marzo, en la bóveda de la Iglesia de los Santos Juanes de esa Ciudad, se tuvo la impresión, por el técnico especialista D. José Gudiol y por el que suscribe, de que las pinturas de Antonio Palomino, que tan maravillosamente la decoraban, no podían salvarse por el mal estado en que habían quedado después de ser incendiado el templo durante la dominación marxista". Siendo en estas fechas cuando empieza la restauración: "Iniciados, ahora, los trabajos encaminados a la recuperación de esta incomparable obra de pintura mural por el Sr. Gudiol y sus operarios especializados, se intentó la limpieza y consolidación de las pinturas que el fuego había destrozado teniendo que renunciar a realizarlo directamente por desprenderse las capas de pintura a causa de la calcinación sufrida por la bóveda a que estaban adheridas. Esto ha obligado a arrancarlas cuidadosamente pegándolas en lienzos que permitirán su perfecta restauración y limpieza, para de nuevo volver a colocarlas en su lugar. Todas estas manipulaciones son imprescindibles y exigen que los trabajos de restauración limpieza y trasplante a nuevos lienzos para su reintegración, sean efectuados en

\footnotetext{
${ }^{5}$ Véase ANEXO I. Carta no 9 perteneciente a la correspondencia entre D. Domingo Fletcher y el Excmo. y Rvdmo. Sr. Arzobispo de Valencia. Cedida por la Familia Fletcher.

${ }^{6}$ Véase ANEXO I. Carta no 7. 17 de julio de 1958.
} 
el taller del Sr. Gudiol de Barcelona donde tiene los medios adecuados para ello. Se tienen fundadas esperanzas de que estas pinturas han de recobrar toda su original belleza y su conservación será absoluta. Por cuanto queda expuesto, el que suscribe ruega a V.E. se digne autorizar el traslado de los fragmentos de pintura que fueran arrancados a Barcelona a los fines indicados".

Parece ser que el Arzobispo concedió el permiso para arrancar las pinturas, porque el 12 de agosto "se van arrancando trozos de pintura para proceder después a su restauración en el taller del Sr. Gudiol en Barcelona. Este me dijo que se llegarán a arrancar unos $180 \mathrm{~m}^{2}$ y que a pesar de su estado catastrófico se podrá salvar gran parte de esta importante obra de pintura". Aunque no se sabía hasta donde se podría arrancar porque "naturalmente que con el dinero de que disponemos nos quedaremos empeñados en más de otro tanto de las 150.000 pts. Por lo que el próximo año habremos de lograr una cantidad superior. El Sr. Gudiol se presta a continuar la obra a pesar de las deudas que con él contraeremos. Esto hará posible que en la próxima primavera se vuelvan a colocar, por lo menos, una parte de las pinturas ya restauradas".

El 18 de septiembre de 1958, ya se habían arrancado $200 \mathrm{~m}^{2}$ de pinturas de la bóveda, correspondientes al tramo más cercano al presbiterio, y $688^{\prime} 5 \mathrm{~m}^{2}$ de pinturas del presbiterio (éstas últimas, actualmente en paradero desconocido). Después las pinturas fueron trasladadas a Barcelona, donde empezaron el tratamiento: "todo lo que se arrancó de la pintura de Palomino de la bóveda de los Santos Juanes se halla en el taller del Sr. Gudiol, en Barcelona, y han empezado a transportar a lienzo las pinturas y nada más puedo decirle de esto, por ahora. Nos hemos gastado mucho más del dinero que nos entregará cuando sea aprobado mi proyecto quedando con un enorme déficit para el año que viene. Era preciso que la consignación se duplique por lo menos para poder hacer algo". ${ }^{9}$

En el taller de los Gudiol, en Barcelona, desde septiembre de 1958 hasta julio de 1960, se trabajó sobre las pinturas de la bóveda de Palomino en la iglesia de los Santos Juanes, recolocándolas en lienzos adheridos a nuevos soportes de chapas de madera.

En Julio de este mismo año se enlucía con yeso el tramo de bóveda donde se habían arrancado las pinturas, y en septiembre de 1960 se recolocarían en la bóveda: "He escrito al aparejador, Sr. Mira, para que prepare el andamiaje montado en los Santos Juanes para repasar el tramo de la bóveda donde han de colocarse en el mes de septiembre las

\footnotetext{
${ }^{7}$ Véase ANEXO I. Carta no 9. 19 de julio de 1958.

${ }^{8}$ Véase ANEXO I. Carta ${ }^{\circ} 11.12$ de agosto de 1958.

${ }^{9}$ Véase ANEXO I. Carta ${ }^{\circ} 13.18$ de septiembre de 1958.
} 
pinturas de Palomino que fueron arrancadas y que se terminan de restaurar ahora". ${ }^{10}$

Los trabajos realizados en Barcelona consistieron, según Josep Gudiol $^{11}$, en limpiar superficialmente la pintura con agua jabonosa. Seguidamente se aplicó una primera capa de cola, caliente y no muy líquida, se extendió con una brocha sobre un área reducida de la pintura y se cubrió con dos telas de algodón. Dichas telas se lavaron primero para quitarles el apresto y evitar su encogimiento. Luego con pincel se puso otra capa de cola más fluida, ya que la segunda tela sólo era para reforzar. Se empleó el método del strappo. Para fijar la película pictórica al nuevo soporte se utilizó caseinato cálcico y tela de lino.

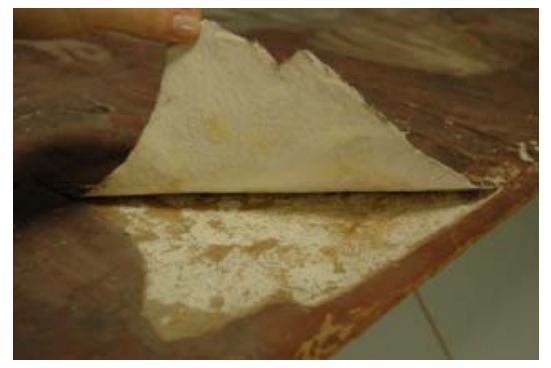

Fig. 12. Restos de caseinato cálcico adheridos a la madera de soporte.
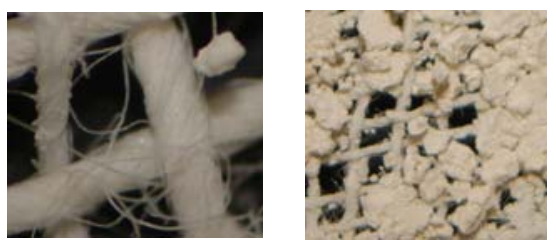

Fig. 14 y 15. Macrofotografías de fibras de la gasa de refuerzo del reverso de la pintura arrancada, con restos de caseinato cálcico.

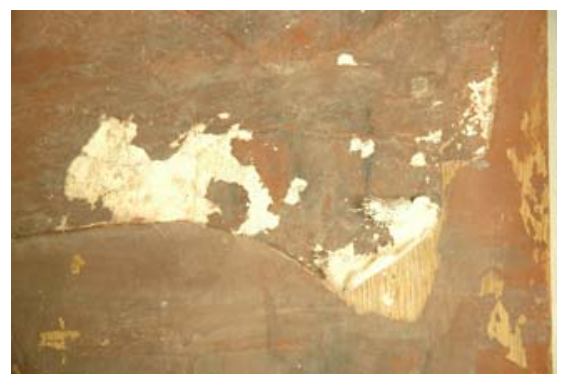

Fig. 13. Fragmentos de tela adherida a la madera que conforma el soporte.
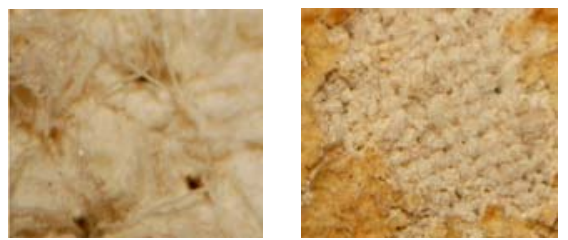

Fig. 16 y 17. Macrofotografía de fibras de la tela de refuerzo del reverso de la pintura arrancada, con restos de caseinato cálcico.

\footnotetext{
${ }^{10}$ Véase ANEXO I. Carta no 15.19 de julio de 1960.

${ }^{11}$ En los años 80 Pilar Roig Picazo se entrevistó en el mismo taller donde se trabajó sobre los paneles arrancados, con Josep Gudiol, ante la imposibilidad de hacerlo con su hermano Ramón Gudiol, responsable de la obra. Entrevistó también a los restauradores que colaboraron con ellos, don Andrés Arturiol Estany y Jesús Marull Dalmau.
}

ROIG PICAZO, Pilar. La iglesia de los Santos Juanes de Valencia. Proceso de intervención desde el año 1936 hasta nuestros días. En Actas del VI congreso de Conservación de Bienes Culturales. Tarragona, 29 de mayo al 1 de junio de 1986. Generalitat de Catalunya. Departament de Cultura. Centre de Conservació i Restauració de Béns Culturals Mobles. Barcelona, 1988. 
El desprendimiento de las telas adheridas a la película pictórica, se realizó mediante agua caliente y vapor, técnica habitual en este tipo de procesos. Una vez eliminada completamente la cola, se colocó la pintura sobre soportes de madera contrachapada de $3 \mathrm{~mm}$ de espesor, en paneles de $2 \times 1$ metro, aproximadamente, sin utilizar ningún tratamiento especial con biocidas para contribuir a la buena conservación de la pintura.

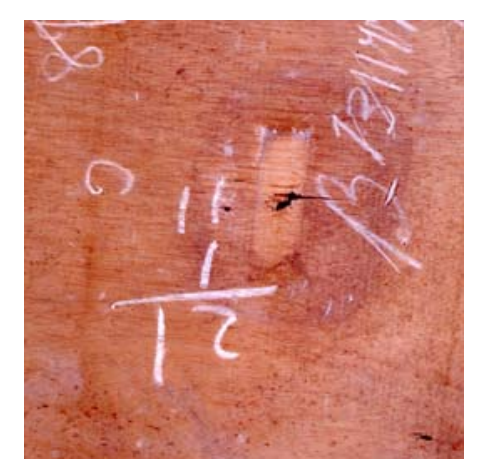

Fig. 18. Anotaciones en el reverso del contrachapado de madera que conforma el soporte de esta pintura arrancada.

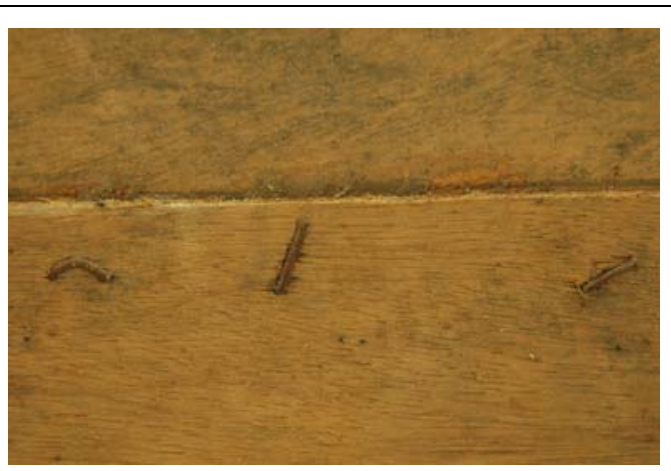

Fig. 19. Detalle de los clavos que unen los distintos fragmentos que madera contrachapada que conforman el soporte.

La cola empleada para unir la pintura al soporte fue una conocida comercialmente como Glutin (posiblemente compuesta por derivados de la metilcelulosa y de características similares a una cola de empapelar), aplicada a brocha y pasando posteriormente un rodillo de imprenta de goma para presionar y homogeneizar la superficie.

Tras la colocación de las pinturas en su nuevo soporte, el proceso de restauración pasó por varias fases: las lagunas se masillaron con una preparación de blanco de España y cola animal; las juntas de unión entre los diferentes paneles se rellenaron con una masilla a base de cera; para la reintegración se utilizaron pigmentos naturales y barniz; no se usó ningún fijativo o barniz final. 


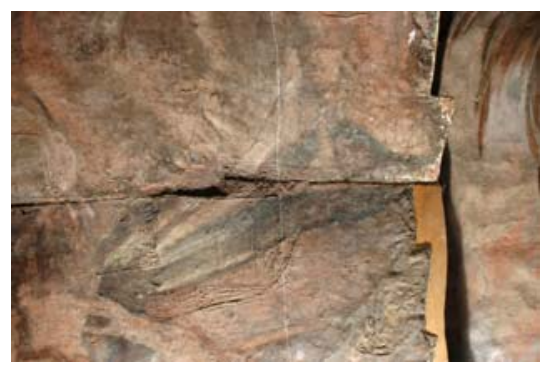

Fig. 20. Detalle de repintes en las zonas de unión.

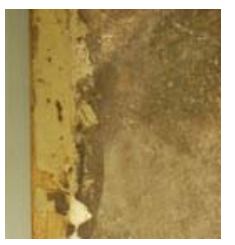

Fig. 22. Detalle de la masilla de cera que servía para unir los tableros entre sí.

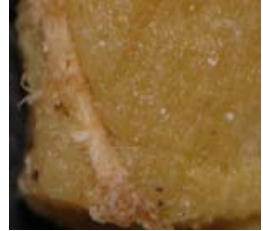

Fig. 23.

Macrofotografía de un fragmento de cera de los bordes de la pintura.

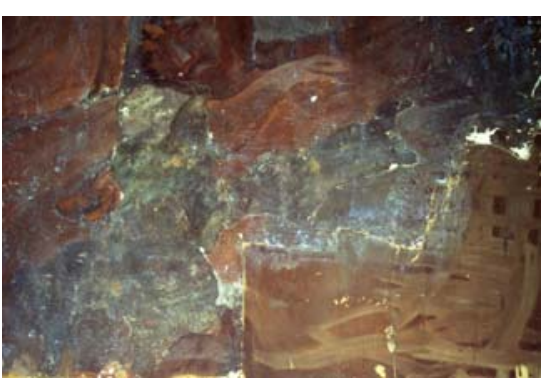

Fig. 21. Fotografía de I.R. en la que se aprecia la pintura original en falso color.

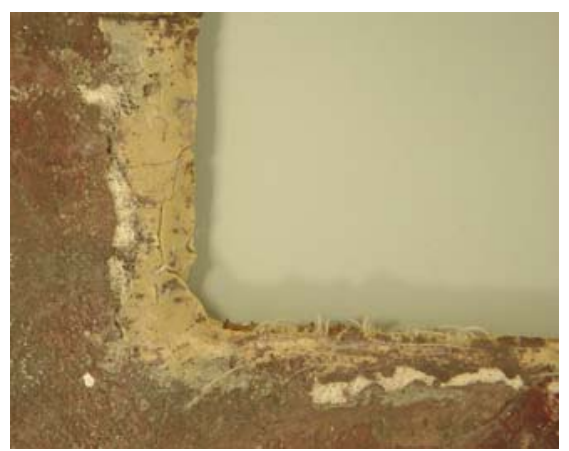

Fig. 24. Una zona de unión entre dos paneles, masillada con cera.

Acabados estos trabajos, en octubre de 1960, las pinturas (ya en su soporte de madera) fueron trasladadas de nuevo a Valencia para su reubicación en la bóveda. El sistema de reubicación que se utilizó fue un clavado de los paneles a unos tacos de madera colocados en la propia bóveda; intentando acoplar los paneles a la curvatura de la misma y las uniones entre ellos, se rellenaron con una masilla de cera. La sujeción y estabilidad actual de estos paneles respecto a la bóveda donde se sujetan es deficiente. 


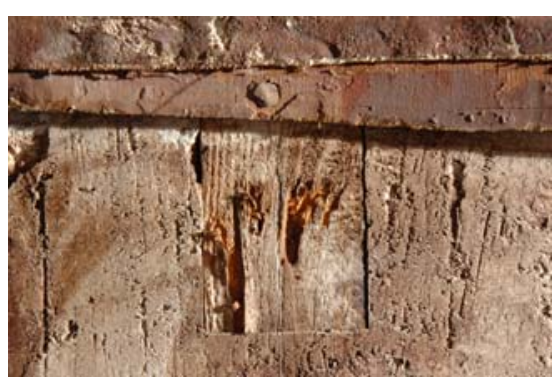

Fig. 25. Detalle de uno de los tacos de madera donde queda clavado el soporte.

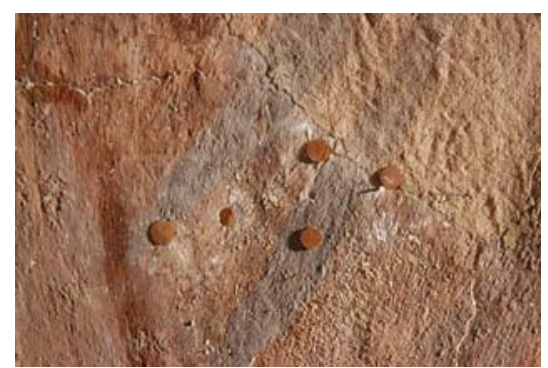

Fig. 27. Detalle de clavos que atraviesan pintura original para anclar el panel al muro.

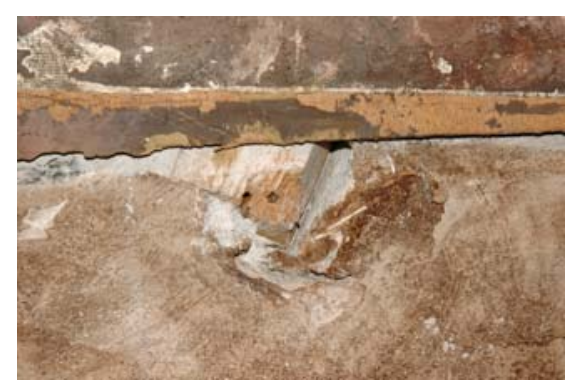

Fig. 26. Detalle de otro taco de madera encastrado en el yeso con el que enlucieron la bóveda tras los arranques en los años 60.

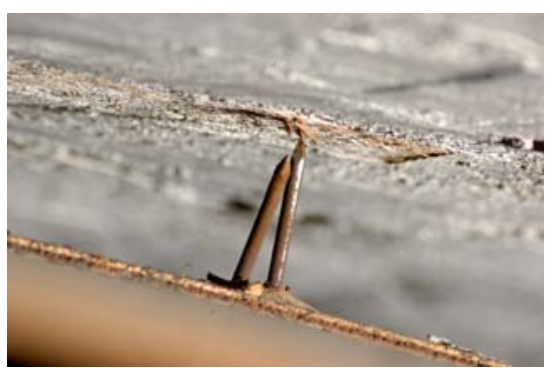

Fig. 28. Detalle de clavos que se han separado del taco de madera al que en algún momento estuvieron clavados.

En algunas zonas los paneles han llegado a separarse totalmente de la bóveda, y se considera necesaria una revisión urgente del sistema de anclaje, pues el actual es totalmente inadecuado y potencialmente peligroso.

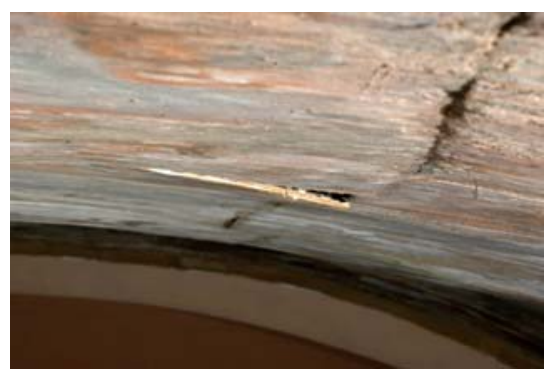

Fig. 29. Detalle de separándose de la bóveda.

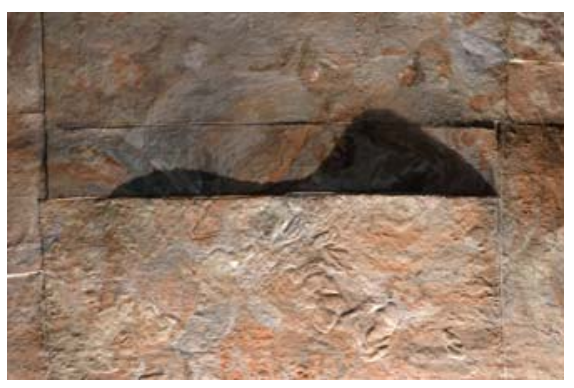

Fig. 30. Detalle con luz rasante de uno de los paneles separados de la bóveda. 
A 14 de noviembre de 1960 ya se habían recolocado las pinturas arrancadas de la Iglesia de los Santos Juanes: "He tenido carta del Sr. Gudiol manifestándome ha terminado su trabajo de instalación en las obras de los Santos Juanes en las pinturas restauradas de Palomino. Está desilusionado por la falta de interés que, dice, han mostrado los valencianos por esta obra tan importante. -“ ${ }^{12}$

Vista que la información publicada en el diario LAS PROVINCIAS en 23 de octubre, el 19 de noviembre de 1960, D. Domingo Fletcher, se dirige a este diario para ofrecer una información más completa a cambio de que se publique:

"El pasado 23 de octubre se publicó en ese diario, tan acertadamente dirigido por $\mathrm{Vd}$. (carta dirigida al director de LAS PROVINCIAS), una interesante información sobre las obras de restauración de las pinturas de Palomino en la Iglesia de los Santos Juanes. La Iglesia de los Santos Juanes, por ser Monumento Histórico Artístico, está atendido, dentro de las posibilidades generales, por el Servicio de Defensa del Patrimonio Artístico Nacional, viéndosele prestado el máximo interés por parte del Excmo. Sr. Director General de Bellas Artes, D. Antonio Gallego Burin, y del IImo. Sr. Comisario General del expresado servicio, D. Francisco Iñiguez, quienes han realizado diversas visitas a la Iglesia en cuestión para conocer personalmente las posibilidades de restauración que ofrecían las pinturas, pues, contra el criterio de quienes pretendían rascar la bóveda y pintarla de nuevo, deseaban salvar lo más posible de la obra de Palomino. Realizados los estudios oportunos y lograda la debida autorización, se arrancaron $150 \mathrm{~m} 2$ de pinturas, trasladándolas a los talleres del técnico reconstructor Sr. Gudiol quien, después de llevar a feliz término la delicadísima tarea de limpieza y consolidación, las ha reintegrado a su primitivo lugar en la bóveda de nuestra Iglesia. En esta tarea han intervenido, asó mismo y como informaba el artículo en cuestión, D. Alejandro Ferrant, Arquitecto Conservador de Monumentos de la Cuarta Zona, y el Aparejador del Patrimonio Artístico, D. F. Mira Bas. El Patrimonio ha invertido en las obras de los Santos Juanes la cantidad de 552.344,80 pts, estando en proyecto el arrancar nuevas zonas de pinturas para restaurarlas y que vuelvan a lucir toda su belleza, como las ya salvadas hasta el presente". ${ }^{13}$

Finalizada la primera fase de restauración, se inició una segunda, en marzo de 1961, con el arranque de otros $150 \mathrm{~m}^{2}$ de pintura, los cuales a 20 de mayo de 1962 ya estaban en el taller de Gudiol en Barcelona: "En Barcelona he visto lo que hasta ahora se lleva restaurado de las pinturas, de Palomino, de los Santos Juanes, que completarán lo ya colocado, pues como Vd. sabe, he presentado un proyecto para que en el tramo de los pies, dos o tres, quede visible, la bóveda gótica al derruir la que sirvió para pintar Palomino". ${ }^{14}$ Se pretendía en esta época derruir una vez

\footnotetext{
${ }^{12}$ Véase ANEXO I. Carta n 16. 14 de noviembre de 1960.

${ }^{13}$ Véase ANEXO I. Carta no 17. 19 de noviembre de 1960

${ }^{14}$ Véase ANEXO I. Carta no 18. 20 de mayo de 1962.
} 
finalizada la tercera fase de arranque de las pinturas, el último tramo, en el que quedaba menor cantidad de pintura.

El 12 de julio de 1962: "dentro de pocos días serán trasladadas desde Barcelona a Valencia, las pinturas, ya restauradas, por Gudiol, para ser colocadas en la bóveda de los Santos Juanes". ${ }^{15}$

El 30 de julio de 1962, el Ministerio de Educación General, a través del Director General de Bellas Artes, aprueba "el proyecto que se propone a fin de dejar visible la bóveda gótica de 1368 que antes del revestido barroco de este templo podía contemplarse, destruir la bóveda de ladrillo que la oculta; efectuar el arranque y restauración de los fragmentos de pintura a fin de salvar los que se puedan, etc."16

En septiembre de este mismo año, se propone exponer en la misma iglesia las pinturas arrancadas: "de las pinturas arrancadas en el cascarón de la iglesia por el Sr. Gudiol nos proponíamos tenerlas expuestas, una vez restauradas, en algún lugar de la propia Iglesia y tal vez pudiera yo sufragar este gasto si al liquidar me quedara dinero para ello. Es lo único que puede ya hacer con las pinturas de Palomino, pues el resto de los tramos de los pies de la Iglesia están achicharrados y los Sres. Gudiol, estimaron, conmigo, que no merecía la pena intentar nada. Por ello mi proyecto presentado y aprobado recientemente propone la destrucción de la falsa bóveda en que pintó Palomino, para dejar al descubierto la gótica que hoy se oculta".

Antes de terminar de arrancar una zona de la bóveda pintada, se empieza a trabajar para conseguir financiación para derruir el fragmento de bóveda de los pies de la iglesia:

"Hace unos días tuve el gusto de escribirle referente al asunto de los Santos Juanes y ahora vuelvo sobre el particular porque el Sr. Cura de dicha Iglesia vino ayer a verme para consultarme sobre un oficio recibido del Ministerio, feche de salida el 4/9/62 y fecha de redacción el 30/7/62, en el que se habla de la concesión de 449.998,76 pts. destinadas a "dejar visible la bóveda de ladrillo que la oculta; efectuar el arranque y restauración de los fragmentos de pintura a fin de salvar los que se quedan, etc.". El citado Sr. Cura me preguntó si se trataba de una nueva asignación, manifestándole por mi parte que lo más seguro es que esta concesión sea la correspondiente a lo que ya se ha hecho, pero sin podérselo afirmar categóricamente, por lo que le prometí escribirle a Vd solicitando la información necesaria para orientar a este Sr.". ${ }^{18}$

Y estaban decididos a derrumbar la parte de la bóveda correspondiente a la zona de los pies de la iglesia, es decir, la que no se arrancó, y se está restaurando en estos momentos. Se había conseguido

\footnotetext{
${ }^{15}$ Véase ANEXO I. Carta no 19. 12 de julio de 1962.

${ }^{16}$ Véase ANEXO I. Carta no 20. 30 de julio de 1962.

${ }^{17}$ Véase ANEXO I. Carta $n^{\circ} 21.17$ de septiembre de 1962

${ }^{18}$ Véase ANEXO I. Carta $n^{\circ} 22.18$ de septiembre de 1962.
} 
el permiso, y se había conseguido financiación: "Con relación a lo que me pregunta respecto a los Santos Juanes puedo decirle que efectivamente las 449.998,76 pesetas son de una nueva asignación para las obras que Vd. indica, pero como de la consignación anterior no tendré dinero suficiente para abonar al Sr. Gudiol el importe de las pinturas últimamente colocadas, habrá de mermarse algo de esta nieva cantidad. De todas maneras creo que todo o casi todo podrá hacerse. Creo tendremos tiempo durante nuestra visita de hablar de esto con el Sr. Cura Párroco y con Vd." ${ }^{19}$ Posiblemente este fuera el motivo de que se mantuviera intacta la cúpula, la falta de dinero para la operación de arranque y recolocación de las pinturas, obligaría a gastar la cantidad reservada para el derrumbe de parte de la bóveda.

Finalmente, en una tercera fase se arrancaron otros $100 \mathrm{~m}^{2}$, estando ya finalizado el proceso de arranque el 25 de junio de 1963: "he tenido noticias del Sr. Mira diciéndome que el sábado pasado terminó el Sr. Gudiol de arrancar lo poco que creo queda de la pintura de Palomino de los Santos Juanes" ${ }^{\prime 20}$.

"El día 17 se transportarán desde Barcelona las pinturas, ya restauradas por el Sr. Gudiol, de la bóveda de los Santos Juanes. Hoy por teléfono he convenido con el Sr. Blanco y con el Sr. Mira tengan personal para descargarlas y poder iniciar su colocación al día siguiente". ${ }^{21}$

En mayo de 1965, una vez terminadas de arrancar las pinturas de Palomino, todavía quedan trabajos por hacer en la iglesia: "durante mi estancia en Valencia veré con el Sr. Blanco, Francisco, lo que vamos a hacer en los Santos Juanes y al propio tiempo lo que haya hecho el Sr. Gudiol con las restauradas pinturas de Palomino". ${ }^{22}$

Y fue en junio de 1965 cuando se terminaron definitivamente los trabajos de recolocación de las pinturas en la bóveda: "Ayer se despidió el Sr. Gudiol, pues su trabajo había terminado definitivamente. Solo resta un poco para terminar esta etapa, que seguramente al escribir estas líneas estará liquidada". ${ }^{23}$

Será en 1967 cuando se desestime la idea de derribar parte de la bóveda para dejar vista la bóveda original gótica, gracias a la carta que escribe el Sr. Cura Párroco de la iglesia de los Santos Juanes al Sr. D. Alejandro Ferrant:

"Respetable y distinguido Sr.: Me apresuro a escribirle estas letras al enterarme, por el maestro de obras Sr. Blanco, del proyecto de derribar la parte final de la bóveda del templo, en donde el fuego

\footnotetext{
${ }^{19}$ Véase ANEXO I. Carta n 23. 19 de septiembre de 1962.

${ }^{20}$ Véase ANEXO I. Carta n० 25. 25 de junio de 1963.

${ }^{21}$ Véase ANEXO I. Carta no 31. 11 de mayo de 1965.

${ }^{22}$ Véase ANEXO I. Carta $n^{\circ}$ 33. 25 de mayo de 1965.

${ }^{23}$ Véase ANEXO I. Carta n ${ }^{\circ} 34.3$ de junio de 1965.
} 
destruyó casi totalmente las pinturas de Palomino, para dejar al descubierto la primitiva estructura gótica.

Deseo vivamente hacerle constar que la noticia ha causado desagrado no sólo a mi personalmente sino también al clero de la parroquia y a los mismos feligreses; aparte la reacción desfavorable que me imagino va a producir en los medios artísticos valencianos. Esta solución ya se propuso hace tiempo y, entonces, se desechó por no guardar armonía con el resto del templo.

Precisamente el Decreto de 21 de febrero de 1947, por el que se declaró la Iglesia Monumento Histórico-Artístico, basaba la determinación en estas palabras del preámbulo: "lo fundamental de dicho templo..., es la total decoración barroca". Es decir, que en esa total decoración barroca descansa su carácter de monumento históricoartístico. Lo que no hace sino recoger la opinión de los eruditos y tratadistas, como v.g. la autorizada de D. Elías Tormo, que escribe: "El interior del templo es único en España por la postiza, pero total e íntegra unidad de su lujosísima decoración barroca".

Le suplico con todo interés se haga cargo de cuanto le expongo. Es preferible dejar la bóveda con un color neutro, ya que desgraciadamente no pueden restaurarse las pinturas de Palomino, que truncar esa preciosa unidad del conjunto.

Además, ha de tener en cuenta que al derribar la zona final, le llevaría un gran trastorno al culto, ocasionaría enormes molestias a los fieles y se tendría que volver a limpiar la Iglesia, una vez terminadas las obras. También ha de considerarse el extraordinario gasto que significaría derribar esta parte de la bóveda, frente a la rapidez y economía con que podría pintarse en color neutro que es, por otra parte, lo que se había acordado en definitiva al ser rechazada por antiestética, la solución de descarnar al bóveda.

Espero encontrar en Vd. una favorable acogida a mis palabras $y$ tengo la seguridad de que no se llevará a cabo tal proyecto". ${ }^{24}$

Y la historia de la bóveda sabemos cómo continúa, pues, como era voluntad del párroco, no llegó a derribarse el final de la bóveda. En lo que se equivocaban en aquellos tiempos era en la imposibilidad de recuperar los pocos fragmentos de pintura de Palomino que quedaban, pues actualmente, el equipo de restauración de pintura mural del Departamento de Restauración de Bienes Culturales de la Universidad Politécnica de Valencia, está demostrando lo contrario, trabajando en la recuperación y restauración in situ de los escasos fragmentos de pintura que quedan sobre la bóveda de esta iglesia.

Volviendo al arranque de las pinturas de la bóveda, sabemos que aunque en todas las fases se procedió de la forma ya explicada, y teóricamente, la única variación fue el equipo de restauradores que participaba en los trabajos, el aspecto cromático y formal que actualmente presentan las pinturas evidencia claras diferencias de

\footnotetext{
${ }^{24}$ Véase ANEXO I. Carta no 43. 21 de mayo de 1967.
} 
tratamiento entre cada una de las fases mencionadas, siendo la última la menos afortunada.

Por todo lo expuesto, consideramos imprescindible este estudio, cuyo objetivo principal es obtener un soporte ideal para estas pinturas, así como el sistema de anclaje al muro. Para ello, hemos hecho una valoración de los diferentes soportes aplicados a arranques de pintura mural $^{25}$.

Las características más destacadas de estas pinturas y que se deben tener en cuenta a la hora de elegir un nuevo soporte, son:

- Gran tamaño de la bóveda.

- Curvatura del soporte mural original.

- Pinturas ya arrancadas por fragmentos.

- Soporte inadecuado, que condiciona el tamaño del nuevo futuro soporte.

- Gran tamaño de los fragmentos.

- Gran número de fragmentos, que requiere un estudio muy detallado de su recolocación.

- Gran pérdida de película pictórica original.

- Exceso de tratamientos de estucado y repintes.

El interés de este estudio recae en el gran tamaño de la bóveda, que se nos presenta con dos tercios de la pintura arrancada y adherida a un soporte de contrachapado de madera, debiendo recolocar en un nuevo soporte $450 \mathrm{~m}^{2}$ de pintura arrancada, y además adaptarlo a la curvatura de la superficie de la bóveda, lo que requiere un estudio detallado del sistema de anclaje del nuevo soporte a la superficie mural.

Las pinturas además, no se encuentran arrancadas de una pieza, sino divididas en 90 fragmentos y adheridas a soportes de madera. Este fraccionamiento de la pintura condiciona directamente la elaboración de un nuevo soporte. Y aún dificulta más el trabajo el hecho de que cada uno de los fragmentos tenga un tamaño diferente, alrededor de los $2 \mathrm{~m}$ de altura y 1'5 $\mathrm{m}$ de anchura.

A estos fragmentos de pintura mural arrancada y colocada en soportes de madera, los llamamos a lo largo de todo este texto, "paneles".

\footnotetext{
${ }^{25}$ Véase Capítulo IV. 


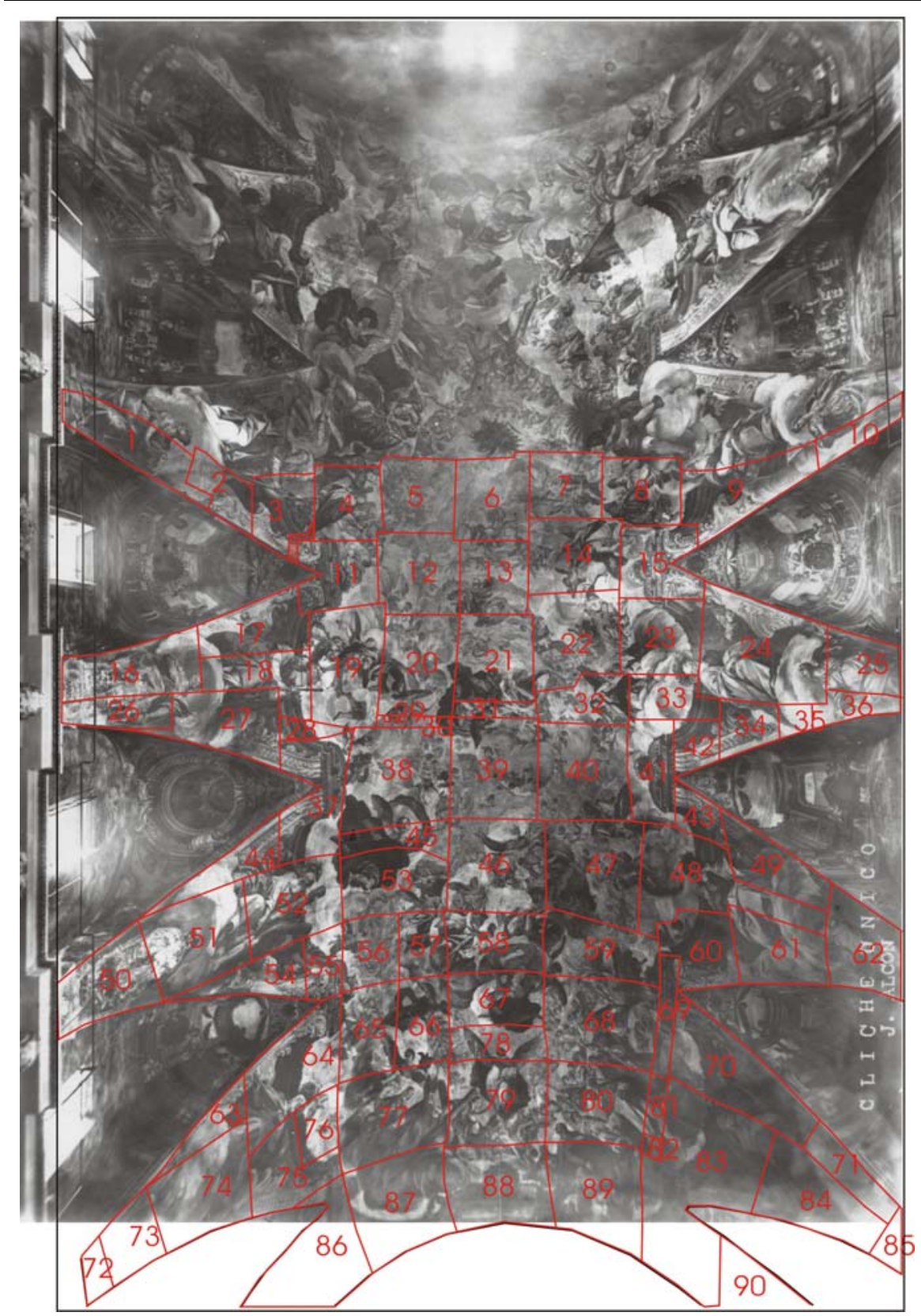

Fig. 31. Diagrama de división del conjunto de la bóveda en los 90 paneles de pintura mural arrancada. 
La gran pérdida de película pictórica original a causa de los diferentes incendios que sufrió el templo, hizo necesario estucar y reintegrar la superficie, pero hoy, estos estucos y repintes resultan inadecuados, ya que cubren parte de la película pictórica original, y se realizaron con materiales no adecuados para la problemática de esta obra. tales como pigmentos al barniz, ceras, estucos de base natural, y otros, que habría que eliminar antes de proceder al tratamiento de recolocación en un nuevo soporte.

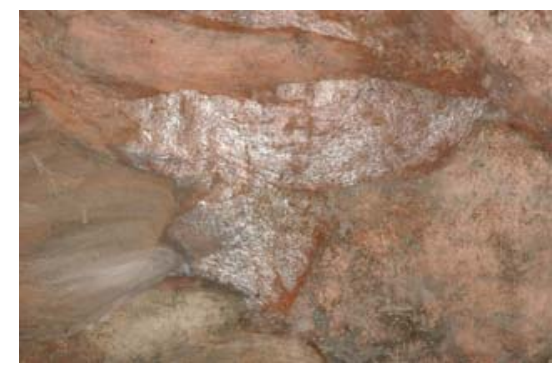

Fig. 32. Detalle de las zonas brillantes que corresponden a repintes sobre la pintura.

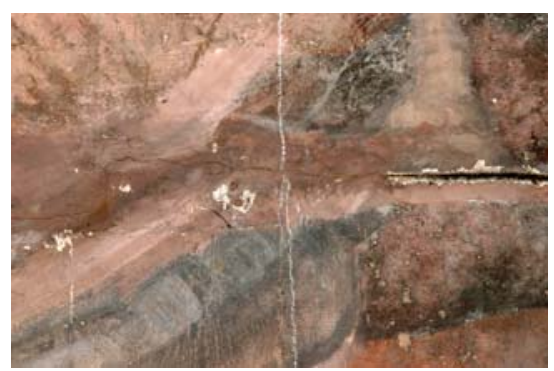

Fig. 33. Detalle de los repintes en las zonas de unión entre paneles.

Es importante tener en cuenta el conjunto de la obra a la hora de pensar en cualquier tratamiento que se haga sobre este fragmento, ya que no se trata de un fragmento aislado, sino de parte de una obra de gran envergadura. Además, una problemática añadida que presenta esta obra es el diferente tratamiento que ha sufrido, ya que un tercio de la obra no fue arrancada en los años 60. En la actualidad se está interviniendo la zona que no llegó a ser restaurada tras el incendio de 1936, con el objeto de recuperar los restos que aun permanecen el la bóveda ${ }^{26}$

También es importante tener en cuenta que dentro de cada uno de los paneles, encontramos fragmentos de pintura original junto con grandes lagunas que han sido repintadas. El planteamiento de un nuevo soporte para estas pinturas va a depender, entre otros factores, de la cantidad de lagunas que presenta el conjunto de la obra, así como la cantidad de fragmentos de pintura original que hay en cada uno de los paneles.

\footnotetext{
${ }^{26}$ La restauración se está llevando a cabo dentro de un convenio de investigación firmado entre la Fundación de la Comunidad de Valencia Aguas de Valencia, y LUBASA, con la UPV, para la "Restauración de las pinturas murales de Palomino en la Bóveda de la Real Parroquia de los Santos Juanes de Valencia".
} 
Por este motivo se han documentado todas las lagunas repintadas presentes en la zona de paneles de pintura mural arrancada. El siguiente diagrama presenta la ubicación de cada una de las lagunas repintadas.

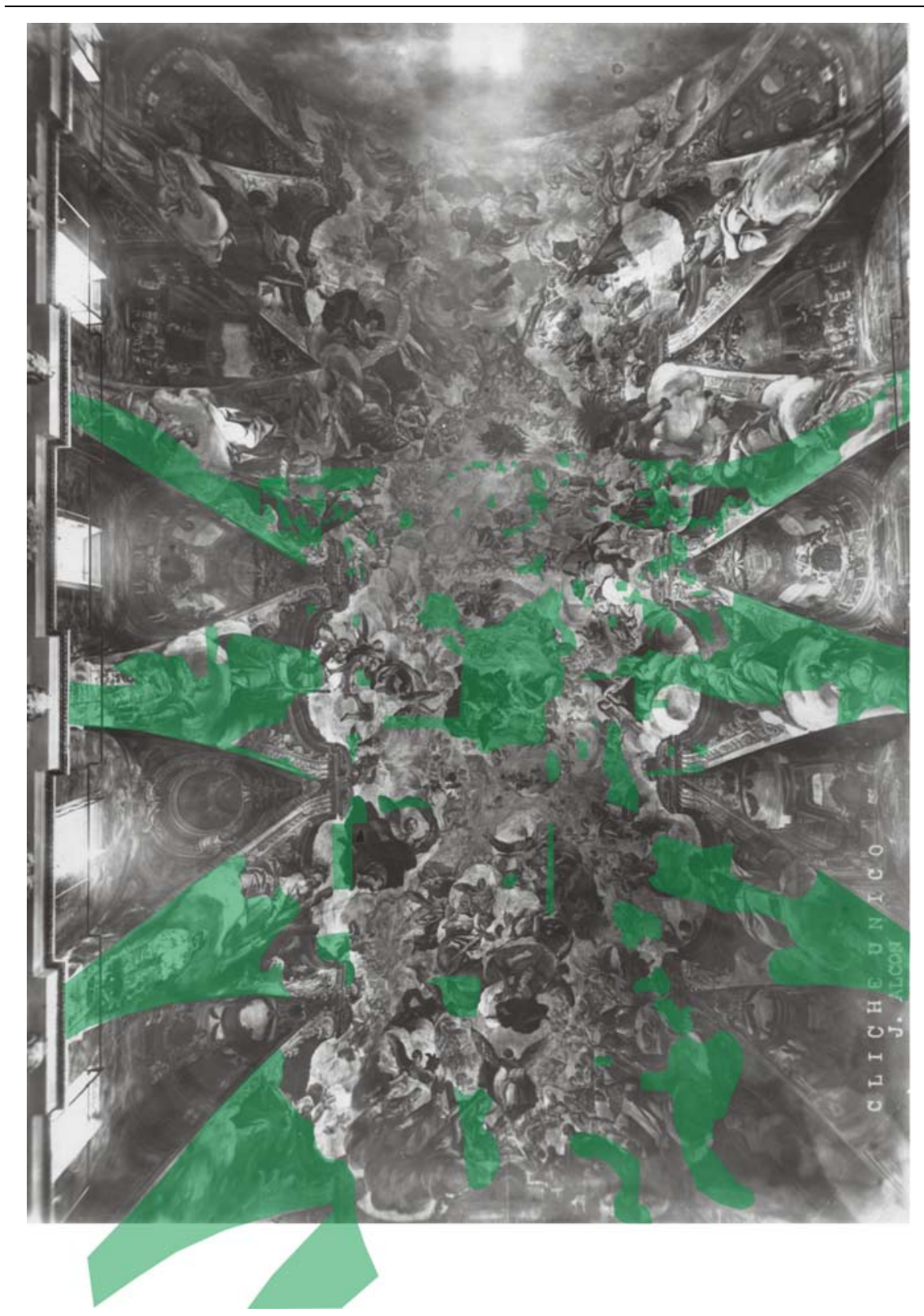

Fig. 34. Diagrama de ubicación de las lagunas repintadas en el conjunto de la bóveda. 
Se puede observar en este diagrama que la zona de pérdidas de película pictórica, alcanza un $30 \%$ del total, aproximadamente. Ello nos lleva a plantear un tratamiento de las lagunas similar al que se realizará en la parte de la bóveda que no fue arrancada. Como veremos, este factor va a influir directamente en la elección concreta del soporte más adecuado para estas pinturas.

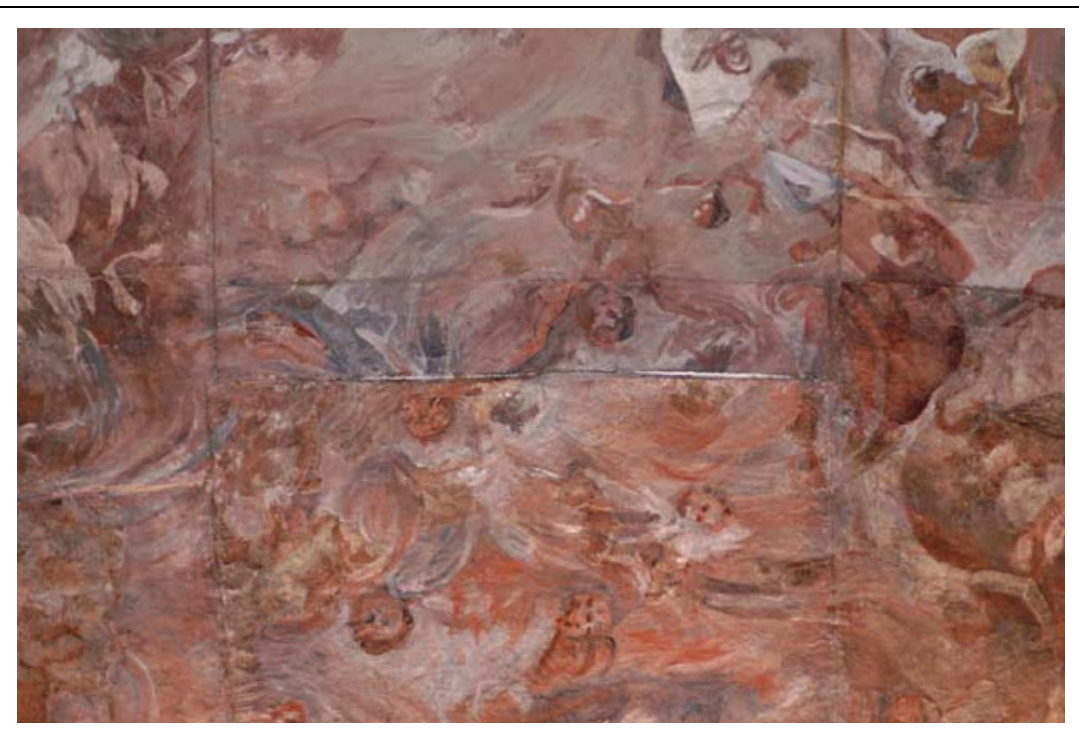

Fig. 35. Fotografía de la intersección de tres paneles que están repintados prácticamente en su totalidad. 



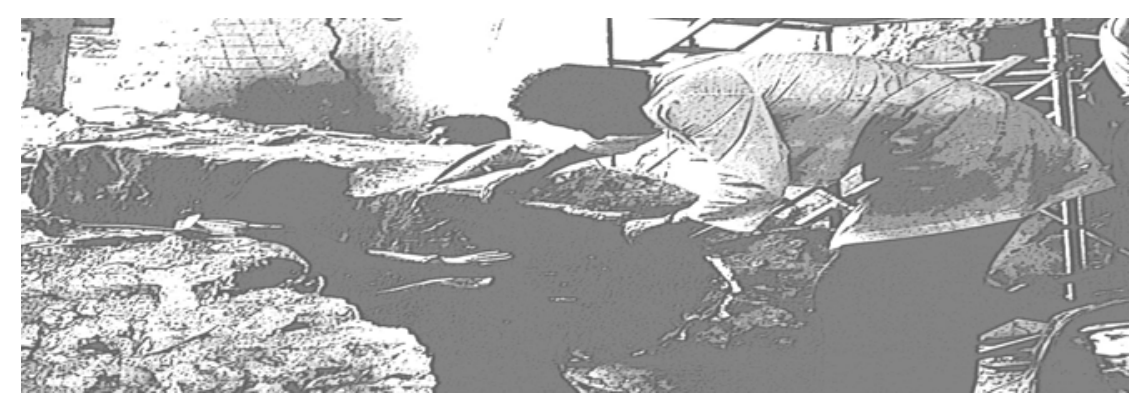

CAPÍTULO II LOS ARRANQUES DE PINTURAS MURALES 




\section{LOS ARRANQUES DE PINTURAS MURALES}

Como hemos explicado, es imprescindible abordar un estudio detallado de este tratamiento, para entender el estado de conservación en que se encuentran las pinturas arrancadas de la bóveda de la iglesia de los Santos Juanes, objeto de este estudio.

El arranque de pintura mural es un tratamiento de restauración muy usado por los especialistas a lo largo de la historia. Consiste en separar la película pictórica, con o sin intonaco, arriccio y muro, para solucionar problemas en el soporte, o simplemente con el fin de trasladar la pintura de un lugar a otro.

Hubo una época en que se usó esta técnica de manera abusiva. Hoy se considera que los problemas que se solucionaban con este tratamiento pueden ser abordados con otros muchos tratamientos de restauración menos agresivos.

Al usar este tipo de tratamiento, la pintura mural pierde una de sus características intrínsecas, que la diferencian de otras técnicas artísticas, y es precisamente el carácter de mural. La película pictórica está unida intrínsecamente al muro, y, si es despojada de éste, deja de ser estrictamente pintura mural ${ }^{2 \dagger}$. Tradicionalmente se aplicaba la pintura sobre un nuevo soporte, generalmente de madera, que luego pasó a ser de tela, por su fácil movilidad, evolucionando así las técnicas de arranque.

Este tratamiento en la actualidad ha quedado en desuso precisamente por este motivo, porque la pintura mural deja de ser "pintura mural". Únicamente se aplica en casos en los que es absolutamente necesario para la conservación de la obra, como se establece en la Carta Internacional sobre la Conservación y la Restauración de Monumentos y de Conjuntos Histórico-Artísticos (1964), de Venecia, artículo 7:

"El monumento es inseparable de la historia de que es testigo y del lugar en el que está ubicado. En consecuencia, el desplazamiento de todo o parte de un monumento no puede ser consentido nada más que cuando la salvaguarda del monumento lo exija o cuando razones de un gran interés nacional o internacional lo justifiquen. Artículo $8^{\circ}$ - Los elementos de escultura, pintura o decoración que son parte integrante de un monumento sólo pueden ser separados cuando esta medida sea la única viable para asegurar su conservación".

El Internacional Council of Monuments and Sites (ICOMOS) redacta en 2003 los PRINCIPIOS PARA LA PRESERVACIÓN,

\footnotetext{
${ }^{27}$ MORA, Paolo ; MORA, Laura ; PHILIPPOT, Paul. La conservazione delle pitture murali. II edizione a cura di Bresciani s.r.I. Editrice Compositori. Bologna, 2001.
} 
CONSERVACIÓN Y RESTAURACIÓN DE PINTURAS MURALES. Ratificados por la $14^{\mathrm{a}}$ Asamblea General del ICOMOS, en Victoria Falls, Zimbabwe, octubre de 2003, En su Artículo 6 dice:

"Medidas de Emergencia. En situaciones de urgencia, es necesario recurrir a tratamientos de emergencia para salvaguardar las pinturas murales. Pero los materiales y las técnicas que se empleen deben permitir un tratamiento posterior. Tan pronto como sea posible, deben aplicarse medidas idóneas de conservación, con autorización de las autoridades competentes.

Los arranques y traslados de pinturas murales son operaciones peligrosas, drásticas e irreversibles, que afectan seriamente a su composición física, así como a su estructura material y a sus valores estéticos. Por tanto, tales actuaciones sólo resultan justificables en casos extremos, cuando todas las opciones de aplicación de otro tratamiento in situ carecen de viabilidad. Si se presenta una de estas situaciones, es mejor que las decisiones relativas a los arranques y traslados sean tomadas por un equipo de profesionales, y no por la persona encargada del trabajo de conservación. Las pinturas arrancadas deberán ser repuestas en su emplazamiento original siempre que resulte posible.

Deberán adoptarse medidas especiales para la protección y mantenimiento de las pinturas arrancadas, así como para prevenir su robo y dispersión".

Hay otros casos en que no es estrictamente necesario arrancar la totalidad de la obra, sino que se puede arrancar únicamente el fragmento de pintura afectado por cualquier deterioro que requiera este tratamiento y después será reubicado en su lugar de origen, con lo que estaríamos hablando de "arranques parciales".

En el campo de la conservación y restauración, un arranque de pintura mural consiste en separar la pintura de su soporte, ya sea únicamente la película pictórica, ya sea ésta con parte de su revoque o incluso con parte del muro que la alberga.

Como señalan Mora y Philippot $^{28}$, el arranque de pinturas murales se debe esencialmente a cuatro errores de juicio. En primer lugar la división de las artes en el siglo XIX ignora la importancia de la unión de la pintura mural con la arquitectura. El segundo error sería una falta de sensibilidad por la estructura. En tercer lugar, la curiosidad del histórico del arte en busca de las sinopias, que por sacarlas a la luz, favorece la intervención del strappo, probablemente innecesaria para la salvaguardia de la obra. $Y$ el cuarto error consiste en extraer una pintura de su lugar de origen excesivamente húmedo, justificando el tratamiento como necesario para la conservación de la obra; mientras habría sido mejor para la pintura eliminar la humedad del muro, erradicando así el problema de raíz.

\footnotetext{
${ }^{28}$ MORA, Paolo; MORA, Laura; PHILIPPOT, Paul. La conservazione delle pitture murali. II edizione a cura di Bresciani s.r.I. Editrice Compositori. Bologna, 2001.
} 
Sin embargo Calvo ${ }^{29}$, expone una defición más básica:

"ARRANQUE. Tratamiento excepcional de desprendimiento de pintura mural, por problemas de conservación o por derribo de edificios. Los arranques, además de sacar la obra de su contexto anulando parte de su significado, provocan importantes alteraciones físicas por la destrucción de sus componentes materiales. También se realizan arranques en mosaicos, como último recurso para su conservación. Para las diferentes técnicas específicas - arranque de sólo película pictórica (strappo), arranque con enlucido (stacco), o arranque con muro (stacco a massello) - es frecuente encontrar la denominación italiana por ser allí donde se han desarrollado estas técnicas.

El arranque sólo de la superficie pintada (strappo) es una operación muy arriesgada que se debe realizar excepcionalmente, pues la película pictórica queda reducida a escaso espesor. Permite enrollar la pintura arrancada en rulos, sobre la tela de protección adherida previamente para el arranque, y deja a la vista la sinopia o dibujo preparatorio.

Para el arranque de la pintura con enlucido (stacco) debe existir una buena adherencia entre las capas. Conserva mejor las rugosidades y texturas originales de la técnica anterior, así como la calidad y luminosidad del fresco.

El arranque con parte o la totalidad del muro de soporte (stacco a massello), se realiza cuando son pinturas sobre piedra o enlucidos especialmente frágiles. Se debe colocar un armazón y es necesario el empleo de medios mecánicos por su peso".

Un arranque de pintura mural es pues una separación traumática de la película pictórica respecto a su soporte. Si se separa la película pictórica con el intonaco, el arranque recibe el nombre de strappo; si, se arranca también el arriccio se denomina stacco, mientras que si se arranca junto con la totalidad o parte del soporte mural, se llamará stacco a massello ${ }^{30}$.

\subsection{RAZONES PARA LA REALIZACIÓN DE UN ARRANQUE.}

A lo largo de la historia de la conservación y restauración de bienes culturales, se han ido utilizando técnicas, materiales y procesos que en ciertas épocas se han usado o aplicado de forma indiscriminada, mientras que en otros tiempos se ha considerado que esos mismos materiales o técnicas no eran adecuados para el mismo tipo de obras.

En cierta medida, lo mismo ocurre con las técnicas de arranque de pintura mural y con los soportes usados para sustituir al muro, soporte original de la pintura. A medida que van avanzando los conocimientos y

${ }^{29}$ CALVO, Ana. Conservación y restauración. Materiales, técnicas y procedimientos. De la A a la Z. Ed. del Serbal. Barcelona, 1997.

${ }^{30}$ Véase punto 2.3 de este mismo capítulo. 
las investigaciones, unos materiales o procesos se van desechando, introduciéndose otros considerados más adecuados.

Ya en 1825 Cicognara se posiciona en contra de los arranques de pintura mural, aportando ciertas observaciones de carácter técnico, diciendo que la cal que hay sobre la pintura al fresco forma una especie de velo, una pátina natural que se pierde con el strappo, lo que hace perder transparencia a la pintura, por la ejecución inoportuna de arranques demasiado finos ${ }^{31}$.

Sin embargo la técnica del strappo se ha llevado a cabo numerosas veces con el fin de redescubrir las sinopias presentes en los revoques internos. Hubo una gran euforia por parte de historiadores del arte en este sentido, ya que podían conocer los dibujos preparatorios de los autores gracias a estas sinopias, sacrificando con ello el carácter mural de la pintura arrancada. Este posible estudio de las sinopias $-y$ decimos posible, porque la sinopia se encuentra en los estratos internos, y por ello no se sabe si existe hasta que se extraen los estratos superiores- no es justificación para este tratamiento.

"En realidad, si se quiere salvar la pintura antigua, deberán generalizarse al máximo sus traslados". Cesare Brandi ${ }^{32}$ escribía esta frase en su Teoría de la Restauración, en 1963. Cesare Brandi fue el director del Instituto Central de Restauración de Roma desde 1939 hasta 1959, época en la que, sobre todo en Italia, se realizaron arranques de pintura mural de forma masiva. De hecho ha habido un cambio en la opinión sobre el tema de los arranques de pintura mural desde entonces, cuando Cesare Brandi afirmaba: "Se ha dicho, y conscientemente, que la experiencia aconseja la máxima generalización del arranque de las pinturas antiguas; añadimos ahora que ese traslado se debe efectuar especialmente con las pinturas en buenas condiciones. [...], en realidad se recurre a arrancarlas sólo en los casos de extrema urgencia con operaciones en caliente que, como en el cuerpo humano, son sin duda las más arriesgadas."

Doce años más tarde ya se había abandonado la idea de arrancar las pinturas murales en buen estado, y Arturo Díaz Martos ${ }^{33}$, en 1975 señalaba: "Cuando se han agotado todas las posibilidades de evitar los agentes de deterioro existentes en el soporte mural, o cuando circunstancias especiales, como derribos obligados por catástrofes, no permiten ninguna solución para conservar las pinturas en el soporte de

\footnotetext{
${ }^{31}$ CONTI, Alessandro. Storia del restauro e della conservazione delle opere d'arte. Electa Editrice. Milano, 1973. Pág. 199.

${ }^{32}$ BRANDI, Cesare. Teoría de la restauración. Versión española de María Ángeles Toajas Roger. Alianza Forma. Madrid, 1992. Pág. 85.

${ }^{33}$ DíAZ MARTOS, Arturo. Restauración y conservación del arte pictórico. Arte Restauro, S.A. Madrid, 1975.
} 
origen, se tendrá que recurrir a trasladar las pinturas a otro nuevo soporte".

Otros autores habla de la conveniencia de efectuar un stacco frente a un strappo, aunque el primero presente mayor complicación técnica, ya que garantiza la permanencia de las características materiales y estéticas de la obra gracias a mantener parte del soporte original ${ }^{34}$. En el strappo la obra pierde definitivamente su soporte original que, junto al arriccio, confería a la pintura mural sus peculiares características de transparencia, solidez y luminosidad. Teniendo en cuenta estas consideraciones es preferible la técnica de stacco, pero si el muro está muy descohesionado o contiene sustancias contaminantes, entre las soluciones drásticas de arranque, es preferible recurrir al strappo. [...] El strappo además, puede permitir la recuperación de eventuales sinopias, que son muy importantes, ya sea por su valor histórico-artístico como para la comprensión del proceso creativo de la obra.

Ana $\mathrm{M}^{\mathrm{a}}$ Macarrón ${ }^{35}$, menciona otros detractores de los arranques y traslados de pintura mural, entre ellos Goethe y Meyer, quienes en un informe sobre el restaurador Hartmann, elogian el hecho de que no hubiera mencionado ni recomendado "este peligroso traslado de cuadros". Otro detractor es sir Charles Lock Eastlake, director y conservador - restaurador de la National Gallery desde 1855 hasta 1865, quien no admitía arranques en el museo más que en caso de absoluta urgencia.

Hoy, en el campo de la conservación y restauración, existe la opinión consensuada de que el arranque de una pintura mural está justificado sólo en el caso en que sea estrictamente necesario intervenir con este tipo de tratamiento para salvar la obra, y siempre que se haya estudiado y descartado todas las posibilidades de realizar otro tipo de tratamiento menos traumático para la misma.

Algunos ejemplos de casos en los que puede ser necesario realizar un arranque de la pintura son:

* Cuando el inmueble en el que se encuentra la pintura va a ser demolido.

- Cuando los problemas estructurales o de humedad del muro no permiten otro tipo de intervención, como cuando la presencia de sales ${ }^{36}$ es tal que está degradando completamente el soporte. En el caso, por ejemplo de la

\footnotetext{
${ }^{34}$ BOTTICELLI, Guido. "Trasferimento dal supporto originale: stacco e strappo" capitolo IX. En Metodologia di restauro delle pitture murali. Centro Di della edifimi srl. Firenze, 1992. Pág. 113.

${ }^{35}$ MACARRÓN MIGUEL, Ana Ma . Historia de la Conservación y la restauración. Desde la antigüedad hasta el siglo XX. Ed. Tecnos. Madrid, 2002. Pág. 218.

${ }^{36}$ Pero con nitratos y cloruros (sales solubles) se deja la pintura en su sitio.
} 
iglesia de la Santa Croce en Florencia, donde se han dejado un trozo de la pintura sin arrancar para demostrar lo que pasa si no se arranca una pintura que necesita este tipo de tratamiento. Cuando existe esta problemática, se realizará un strappo si no hay cohesión entre la película pictórica y su soporte. Sin embargo, se procederá a la ejecución de un stacco cuando el color y el intonaco son todo uno y es difícil separarlos.

* Cuando por reformas o modificaciones estructurales en el edificio se debe trasladar la obra a otro lugar. También en caso de terremotos, inundaciones, etc., con peligro de derrumbe del edificio que alberga la obra.

Pero, ¿qué justificación tendrían hoy los arranques que se llevaron a cabo en los años 60 en dos tercios de la bóveda de la nave central de la Iglesia de los Santos Juanes de Valencia? Hoy podemos entender cuáles fueron los motivos que llevaron al equipo de los hermanos Gudiol a realizar este tipo de tratamiento que es considerado por todos inadecuado en esta obra concreta, pero los criterios, circunstancias, materiales y conocimientos han cambiado. Ya en la época en que fueron arrancadas estas pinturas, se decidió no arrancar el tercio de bóveda que faltaba, por considerar que no quedaba suficiente pintura como para aplicar ni este ni otro tipo de tratamiento. El hecho de que no se arrancaran las pinturas de éste último tramo de la bóveda, ha permitido que hoy se pueda abordar una restauración sobre la pintura original de Palomino $^{37}$.

\subsection{TÉCNICAS DE ARRANQUE DE PINTURA MURAL}

Existen tres técnicas de arranque de pintura mural, y dado que empezaron a desarrollarse en Italia, se suelen denominar con su nombre italiano. Son:

- Stacco a massello.

- Stacco.

- Strappo.

La técnica que más nos interesa en este estudio es el strappo ${ }^{38}$, pues es la técnica de arranque que se efectuó sobre las pinturas de la Iglesia de los Santos Juanes. No obstante, haremos un breve repaso de las otras dos técnicas para conocer las diferencias que existen entre ellas.

\footnotetext{
${ }^{37}$ Véase la Introducción.

${ }^{38}$ Aunque técnicamente sería un stacco. Puesto que el fresco no se divide en película pictórica y soporte, cuando se realiza un arranque, con la película pictórica, se arranca también parte del intonaco. Pero tanto el procedimiento como los materiales utilizados para separar las pinturas de Palomino en la iglesia de los Santos Juanes en Valencia, fueron los de la técnica del strappo.
} 
El stacco a massello consiste en arrancar la película pictórica mural con su soporte, incluido el muro, ya sea éste último entero, o parte de él. Como veremos en el próximo capítulo, es la primera técnica de arranque de pintura mural conocida y ofrece las máximas garantías de conservación de las características murales y monumentales de la pintura, así como los eventuales relieves que contenga la pintura.

Esta técnica está especialmente recomendada en pinturas con mucho relieve, en pinturas realizadas directamente sobre el soporte (roca, piedra, ladrillo...) y en pinturas situadas en lugares húmedos.

Hoy ha quedado en desuso porque el peso del conjunto limita el tamaño de ejecución, pero hay casos particulares en los que se recurre todavía a esta técnica ${ }^{39}$.

El primer paso para ejecutar un arranque de una pintura mural, incluyendo tanto los morteros de soporte como el muro, es proteger la película pictórica. Dado que no es imprescindible la contracción de la cola, se puede usar una mayor variedad de adhesivos, no siendo imprescindible el empleo de adhesivos a base de gelatina con alto poder de contracción, imprescindibles en las técnicas de strappo. Seguidamente se procede a encajonarla en un molde de madera, que es el material tradicional aunque actualmente se usan otros materiales, como puede ser la espuma de poliuretano ${ }^{40}$. Seguidamente, se rellena el hueco existente entre la pintura protegida y el molde de madera, con yeso ${ }^{41}$, para conseguir un molde perfecto que se adapte a las irregularidades del mortero original.

El muro se corta practicando incisiones en sus bordes laterales, pues el inferior se corta para insertar una guía metálica que lleva el molde de madera en la parte baja, y se excava una galería detrás de la pintura, de modo que la pintura quede sostenida únicamente por el borde superior que aún no se ha cortado. En este punto, en que la pintura se apoya en la parte inferior, se corta el borde superior y se sujeta la pintura por medio de puntales. Se transporta la pintura con todo su soporte, dentro de su molde, mediante la ayuda de poleas o grúas.

El grosor del soporte puede ser disminuido por el reverso para facilitar la manipulación, llegando incluso a quedarse únicamente con el

\footnotetext{
${ }^{39}$ Ver página 273 de: MORA, Paolo; MORA, Laura; PHILIPPOT, Paul. La conservazione delle pitture murali. II edizione a cura di Bresciani s.r.I. Editrice Compositori. Bologna, 2001.

${ }^{40}$ ROIG PICAZO, Pilar y BOSCH REIG, Ignacio. Arranque y traslado de una pintura mural a un nuevo soporte y espacio arquitectónico. Primera parte y segunda parte. En R\&R Restauración y Rehabilitación. No 21 y 22 octubre y noviembre 1998. Edita Prensa Española General de Revistas, S.A. Madrid, 1998.

${ }^{41}$ Ver dibujo 47 en la página 275 de MORA, Paolo; MORA, Laura; PHILIPPOT, Paul. La conservazione delle pitture murali. II edizione a cura di Bresciani s.r.I. Editrice Compositori. Bologna, 2001.
} 
enlucido, aunque no tendría sentido invertir tanto esfuerzo en llevar a cabo un stacco a massello, si no se va a conservar el soporte.

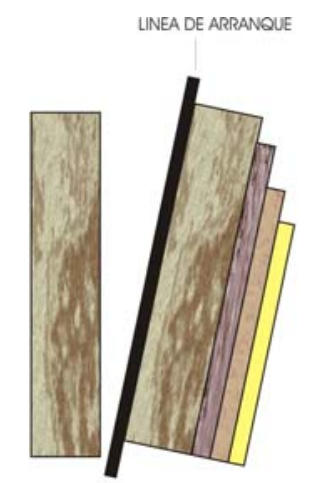

Fig. 36. Diagrama explicativo de los estratos que se arrancan en un stacco a massello.

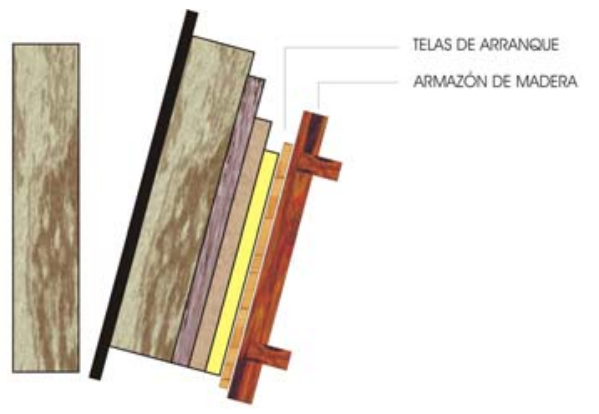

Fig. 37. Diagrama explicativo de los estratos de protección que se aplican a la pintura para llevar a cabo un stacco a massello.

El stacco es una variante de la técnica anterior, y consiste en arrancar la película pictórica con parte de su soporte, que puede ser únicamente el intonaco, o el intonaco y el arriccio. De este modo se conservan las características propias de la pintura mural. Una de las ventajas de arrancar únicamente el intonaco, es que se deja ver sobre el arriccio la sinopia, si la hay. Pero hay que proceder con extremo cuidado para no perderla definitivamente. Una premisa indispensable para efectuar un stacco es que la cohesión entre intonaco y película pictórica, sea fuerte. En caso contrario, se debe proceder a la consolidación preliminar del intonaco ${ }^{42}$.

Se procede protegiendo la película pictórica con dos capas de tela, una de algodón y la siguiente de lino o cáñamo, adheridas con una cola natural de origen animal, como la cola de conejo, cola fuerte de carpintero, cola Zurich... ${ }^{43}$ También esta técnica permite la utilización de adhesivos alternativos a la cola animal, como el Paraloid B-72.

Las telas, que deben sobresalir de todo el perímetro de la zona que se va a arrancar, se clavan a un panel de madera que haga de soporte provisional de la pintura, una vez sea extraída del muro. Este soporte

\footnotetext{
42 MORA, Paolo y Laura; PHILIPPOT, Paul. La conservazione delle pitture murali. II edizione a cura di Bresciani s.r.I. Editrice Compositori. Bologna, 2001. Pág. 277.

${ }^{43}$ Si se trabaja en un ambiente relativamente seco, se puede sustituir la cola por colletta italiana, que no contrae al secar. Mientras que se trabaja en un ambiente húmedo en el que se corre el riesgo de que la cola no seque, se sustituye por un adhesivo del tipo resina con solvente.
} 
provisional puede ser también de conglomerado, o cartón ondulado recubierto por resina expandida que recoja exactamente las irregularidades del muro. Si la pintura es muy delicada se puede acolchar este soporte provisional de madera para amortiguar el golpe en el momento de la extracción.

Una vez la cola seca, se introducen por los extremos de la pintura unas láminas metálicas para facilitar la separación de los estratos pictóricos del muro. Para ayudar a esta tarea, se golpea la superficie con un martillo de goma o de madera. Las barras se deben dirigir hacia el muro, y la operación se empieza de abajo arriba con el fin de evitar acumulación de polvo y desechos del intonaco a medida que se va separando.

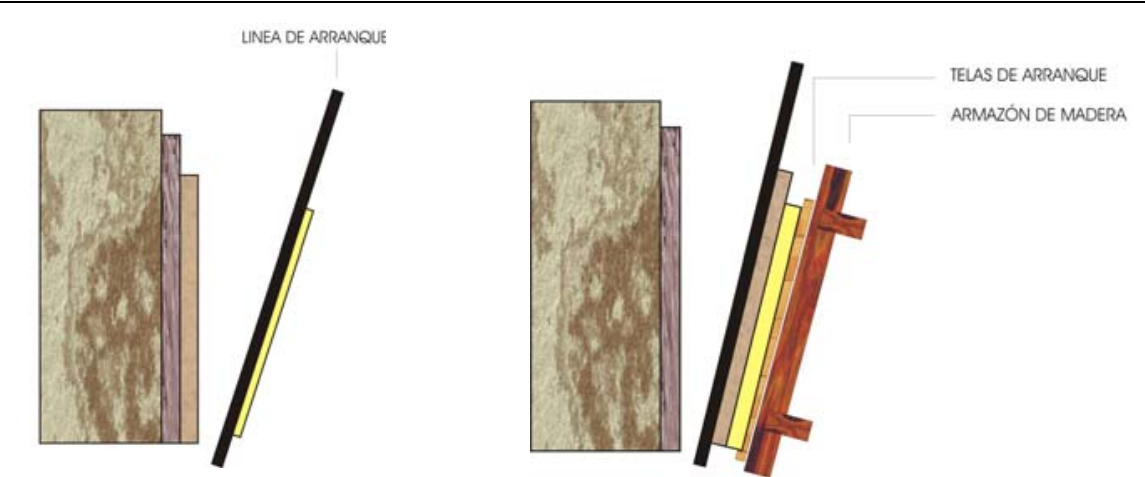

Fig. 38. Diagrama explicativo de los estratos que se arrancan en un stacco.

Fig. 39. Diagrama explicativo de los estratos de protección que se aplican para un stacco.

El strappo es la técnica más usada a lo largo de la historia, y consiste en arrancar únicamente la película pictórica, por lo que se puede aplicar incluso a zonas curvas. Se procede protegiendo la película pictórica con dos capas de tela, la primera de algodón y la siguiente de lino. El adhesivo a utilizar para la adhesión de las telas es la cola natural de origen animal, pero con la particularidad de que se ha de preparar a concentraciones muy altas, dado que es muy importante para el buen resultado de la técnica el poder de contracción de dicho adhesivo, pues al contraer las telas con la cola, se llevan detrás la película pictórica. Se puede golpear con el martillo de goma la superficie para ayudar al desprendimiento. A diferencia de las técnicas descritas anteriormente, para realizar correctamente un strappo, el único adhesivo a utilizar es la cola animal, con un gran poder de contracción. En este caso no es necesario construir una caja o un bastidor para transportar la obra, ya que como consta únicamente de película pictórica adherida a las telas, éstas pueden ser enrolladas en rulos para su trasporte o traslado. 
Uno de los inconvenientes de esta técnica es que no siempre se consigue arrancar la película pictórica completa, quedando una impronta de lo que se arranca, sobre el intonaco que queda en el muro. Como nos dicen Paolo y Laura Mora, y Paul Philippot ${ }^{44}$, "la pintura, perdiendo una parte, aunque sea mínima, de su estrato subyacente, se encuentra forzosamente reducida y modificada en su aspecto, tanto que el nuevo soporte nunca podrá sustituir exactamente el fondo original y ese efecto de transparencia en superficie".

$Y$ aunque en el intonaco no se apreciasen restos de color, una mínima cantidad de película pictórica desaparecería en el tratamiento del reverso.

Además, estas variaciones en el grosor del estrato pictórico, el poder de reflexión del estrato subyacente y los residuos de los adhesivos utilizados para el arranque, que permanecen en el estrato pictórico, modifican inevitablemente el aspecto estético de la obra. Esto es lo que ha ocurrido a las pinturas de la bóveda de la nave central de la Iglesia de los Santos Juanes de Valencia.

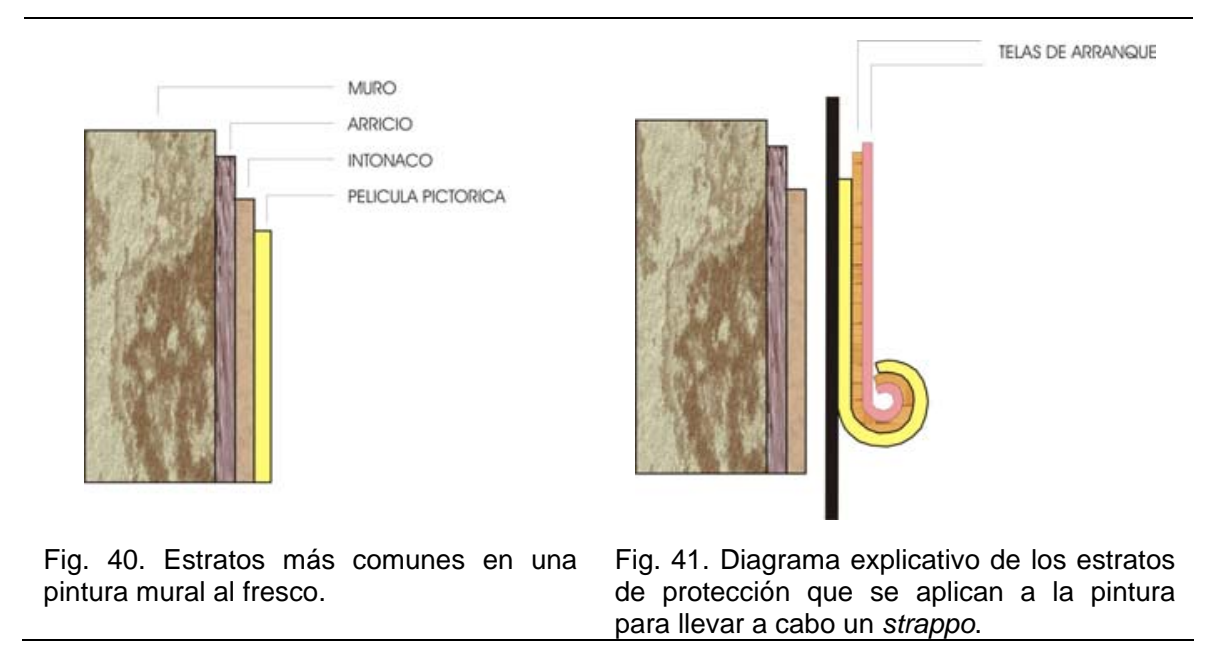

\footnotetext{
${ }^{44}$ MORA, Paolo y Laura; PHILIPPOT, Paul. La conservazione delle pitture murali. II edizione a cura di Bresciani s.r.l. Editrice Compositori. Bologna, 2001. Pág. 280.
} 

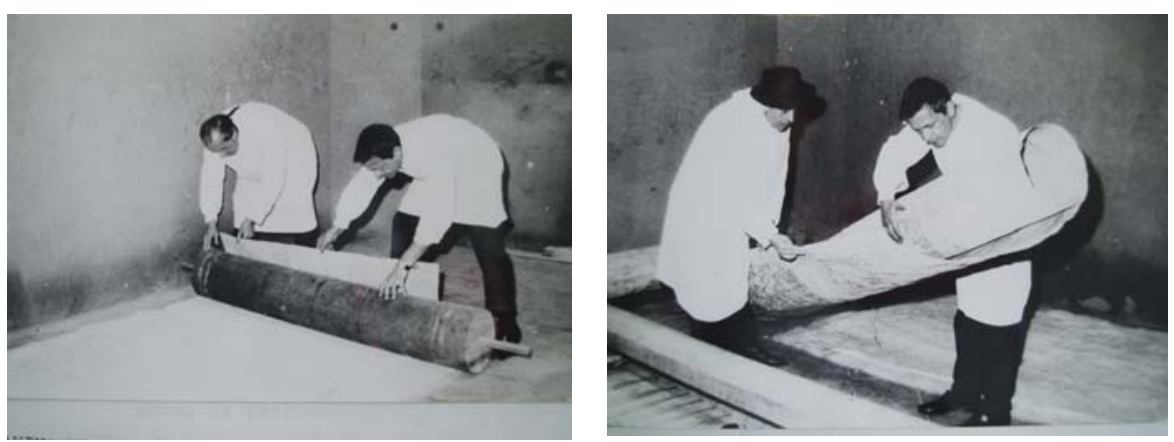

Fig. 42. Imágenes de don Luís Roig D’Alós y su equipo enrollando las printuras murales arrancadas por medio de Strappo, de la Casa Ferraz, en Valencia.

Podemos encontrar una buena definición de estas técnicas de arranque de pintura mural en un diccionario italiano ${ }^{45}$ que define estos términos con las siguientes palabras:

\section{STACCO - STACCO A MASELLO}

Intervento di rimozione di un dipinto murale e del suo intonaco da una superficie architettonica. Quando assieme al dipinto viene rimossa anche parte della struttura muraria l'operazione è definita stacco a massello. [...]. Esso consente di conservare intatte le caratteristiche della superficie dipinta, le irregolarità e le eventuali decorazione in rilievo, ma comporta, a causa del peso considerevole, il sezionamento in parti di ridotta estensione e la parziale distruzione della parete. La complessità dell'intervento indusse già nell Settecento ad approntare il sistema dello stacco limitato allo strato di intonaco su cui insiste il dipinto e operato, dopo aver protteto la superficie con tele, incidendo el perímetro della zona da rimuovere e distaccandola poi gradatamente per mezo di lunghe lame metalliche. II dipinto, una volta staccato, viene ridotto a spesore homogeneo e fatto aderire a un nuovo supporto rigido [...]. Perfezionando un'ulteriore tecnica - in cui primi esperimeni dattano all'inizio del Settecento - , dal secolo scorso si optò sovente per lo strappo, limitandosi cioè as asportare la sola pellicola pittorica.

Il distacco dai dipinti dal muro da sempre è stato considerato intervento a carattere conservativo e pertanto auspicato ognivolta la struttura del supporto sembrava non offrire sufficienti garanzie, ma nell'ultimo ventennio si è tentato di porre un freno al dilapare l'operazione, sia perché quasi sempre ne implica l'allontanamente della sede naturale; e vi si ricorre solo in casi di forza Maggiore quali

${ }^{45}$ VV.AA. Dizionario della pittura e dei pittori. Vol. S-T. Giulio Einaudi Editore. Torino, 1994. Págs. 316-317 y 391. 
terremoti, alluvioni, ecc, preferedo piuttosto risanare le strutture murarie e curare la manutenzione degli edifici.

\section{STACCO-STACCO A MASELLO}

Intervención de extracción de una pintura mural de y su intonaco de su superficie arquitectónica. Cuando junto a la pintura viene extraída también parte de la estructura mural, la operación se define como stacco a massello [...]. Ello permite conservar intactas las características de la superficie pintada, las irregularidades y las eventuales decoraciones en relieve, pero comporta, debido al considerable peso, la fragmentación en partes de reducidas dimensiones y la parcial destrucción del muro. La complejidad de la intervención indujo ya en el setecientos a desarrollar el sistema del stacco limitado al estrato del intonaco sobre el que se encuentra la pintura y llevado a cabo, después de haber protegido la superficie con telas, incidiendo el perímetro de la zona a arrancar y separarla gradualmente por medio de largas láminas metálicas. La pintura, una vez arrancada, se reduce a un espesor homogéneo y se adhiere a un nuevo soporte rígido [...]. Perfeccionando una ulterior técnica - cuyos primeros experimentos datan de principios del siglo XVI- durante el siglo XIX se optó a menudo por el strappo, limitándose a separar únicamente la película pictórica.

El arranque de pinturas del muro ha estado siempre considerado una intervención de carácter conservativo y por lo tanto realizado cada vez que la estructura del soporte parece no ofrecer suficientes garantías, pero en los últimos veinte años se ha procurado poner freno a este tratamiento, porque casi siempre implica el alejamiento de su sede natural; y se recurre a él sólo en caso de fuerza mayor como terremotos, inundaciones, etc. Prefiriendo sobretodo, sanar las estructuras murales y mejorar la manutención de los edificios.

\section{STRAPPO}

Intervento di rimozione di un dipinto murale da una superficie architettonica limitato al distacco della sola pellicola pittorica. I primi esperimenti di strappo noti sono dal napoletano Majello (De Domenici) e del ferrarese Conti (Baruffaldi) e datano al 1720 e al 1725. Lo strappo a diferenza dello stacco, può essere eseguito solo se la coesione tra pellicola pittorica e intonaco è scadente, in quanto è la maggiore adesione che si stabilisce tra la superficie dipinta e le tele che vengono incollate al di sopra a consentire la buona riuscita dell'operazione. Pratticata un'incisione lungo il perímetro della zona da rimuovere, si inizia a "strappare" dal basso, tirando la tela adesa al dipinto, e si procede arrotolando man mano su un cilindro la parte distaccata. Dopo un'accurata pulitura del verso, la pellicola pittorica viene munita da un nuovo supporto, fessiblile (tela) o rigido. II metodo permette di opperare su superficie anche molto ampie senza sesionarle (fino a $50 \mathrm{mq}$ ), ma non consente di ritenere ne le tipiche irregolarità e le decorazioni in rilievo, ne le caratteristiche ottiche conferite dall'intonaco originario. Risultato dello strappo è pertanto la perdita dei requisiti propri del dipinto; inoltre non sempre si ottiene il distacco homogeneo della pellicola pittorica nel suo intero spessore - è noto l'imperversare della moda del "doppio strappo" (Cavenaghi). Il metodo ha goduto di grande favore anche perché permette il recupero della sinopia, vantaggio questo che l'ha spesso fatto preferire allo stacco anche quando tecnicamente sconsigliabile. La tendenza attuale è di limitare il distacco delle opere, privilegiando piuttosto la conservazione in situ e rivolgendo 
l'intervento al risanamento del supporto murario e all'eliminazione delle cause del deterioramento.

\section{STRAPPO}

Intervención de extracción de una pintura mural de una superficie arquitectónica limitada a arrancar únicamente la película pictórica. Los primeros experimentos notables de strappo son del napolitano Majillo (De Domenici) y del ferrares Conti (Baruffaldi) y datan de 1720 y 1725 . El strappo a diferencia del stacco, se puede llevar a cabo sólo si la cohesión entre película pictórica e intonaco no es buena, en cuanto que es la mayor adhesión que se establece entre la superficie pictórica y las telas que se adhieren a la superficie, la que consigue el éxito de la operación. Practicada una incisión a lo largo del perímetro de la zona a arrancar, se comienza a tirar desde abajo, tirando la tela pegada a la pintura, y se va enrollando poco a poco sobre un cilindro la parte arrancada. Después de una cuidadosa limpieza del reverso, la película pictórica viene provista de un nuevo soporte, flexible (tela) o rígido. El método permite trabajar también sobre superficies muy grandes sin seccionarlas (hasta $50 \mathrm{~m}^{2}$ ), pero no permite conservar las típicas irregularidades y las decoraciones en relieve, ni las características ópticas conferidas por el intonaco originario. Resultado del strappo es por tanto la pérdida de los requisitos propios de la pintura; por otro lado no siempre se obtiene el arranque completo de la película pictórica en su entero espesor - es de destacar el imperversar de la moda del "doble strappo" (Cavenaghi). El método ha gozado de grandes favores también porque permite la recuperación de las sinopias, ventaja lo ha hecho preferir al stacco, aunque técnicamente fuese desaconsejable. La tendencia actual es de limitar el arranque de las obras, priorizando sobre todo la conservación in situ y dirigiendo la intervención al saneamiento del soporte mural y a la eliminación de las causas de deterioro.

Estas definiciones describen las técnicas de arranque de pintura mural tal y como se entienden en la actualidad, pero es necesario hacer un repaso de las descripciones que han hecho a lo largo de la historia diversos autores, tanto italianos como españoles.

\section{En 1725 Baruffaldi habla de la técnica usada por Contri ${ }^{46}$ :}

"La maniera d'operare che tenea il Contri con questo segreto era questa. Copriva la pittura con una tela, bene inverniciata di un certo suo bitume o colla, la quale tenacemente s'attaccava al muro; poscia che aveva coperto la detta pintura, batteva ben bene la detta tela sul muro con un mazzuolo di legno; quinde tagliava la calce intorno a la tela proprio como si fa ancor oggi- e la puntellava con tande, affinché non alzasse alcuan vescica, solendo prima ben bene coi noni delle dita esplorare se il muro dipinto sonasse, o desse indizio di fare o d'avere vescica alcuna, perchè, in questo caso, non arrischiava il segreto; e dopo di ciò, lasciatala bene asciugare ed incorporare per alcuni giorni, levava diligentemente e pian piano, con tutte due le mani la detta tela, la quale tirava seco tutta la superficie dipinta nel muro. Questa inmediatamente riponea su d'una tavola ben piana e lascia, e poi il suo studio era d'applicarvi posteriormente un'altra tela, impressa e inverniciata anch'essa d'una composizione più tenace della prima. Al di

${ }^{46}$ PROCACCI, Ugo. La tecnica dei dipinti murali e il loro distacco. Del catalogo: Affreschi da Firenze dal XIII al XVI secolo. Palazzo Reale, aprile-giugno 1971. Milano, 1971. 
sopra vi mettea dell'arena, e qualche peso ancora, per ugualmetne comprimerla e in questo stato lasciava l'opera per una settimana senza più farvi altro; e poscia, levando i pesi e l'arena, e rovesciando tutto questo lavoro sulla medesima tevola ben piata, lavava con acqua calda la prima tela, onde, staccando la prima colla, restava la pittura nel suo prospetto com'era prima sul muro bella e fresca: anzi, più netta di prima, perchè questa colla attirava anche la polvere, che, col tratto del tempo, si fosse attacata alla detta pittura; e se v'era qualche difetto di sfregio o scrostatura o segno di calcatura fatta dal pittore con punta o altro nel disegnarla pur questa vi rimaneva come sul muro vedevasi da prima".

En 1819 un fascículo conmemorativo ${ }^{47}$ describe la técnica de strappo seguida por Filippo Baldi entre 1817 y 1818, años en los que realizó un centenar de arranques de pintura mural:

"...egli copre da prima li a fresco con un finissimo cambrich molle di particolare preparazione, che lo ataca a quelli fortemente. A poco a poco, e più o meno sollecitamente, secondo la varia temperatura dell'aria, si va rasciugando finché, divenuto tutto secco, da se stesso si distacca e cade portando seco tutta la superficie colorata, della quale appena resta qualche traccia sul non tocco intonaco della muraglia. A quel momento si può vedere ed ammirare ciò che Paolo stesso né vide, né avrebbe creduto visibile giammai, il rovescio cioè delli suoi dipinti. Per raddrizzarli ricopre questo rovescio di nuovo cambrich, molle preparazione, ch'è ben facile pensare diversa dalla prima, e pone il tutto sotto un peso uniforme, e ve lo lascia finché siasi ben disseccato. Allora si vede la pittura raddrizzata e fortemente aderente al secondo cambrich, essendo ritornato affatto bianco il primo. Con nuovo cemento unisce poi al troppo facile cambrich una forte tela, e così assicura all'opera una costante durazione".

En 1825 Cicognara escribe una crítica del uso la técnica del arranque de pintura mural, describiendo el procedimiento que se usaba en la época:

"Vuolsi in questo luogo anche svelare uno dei perniciosi trovati con quale si sredette da alcuni prevenire in parte gli esposti inconvenienti; poiché al evitare la frattura della superficie cristallizzata, e a procurare una facile adesione di quella alla prima tela per distaccarla dal muro, credettero proficuo bagnarla con latte misto all'acido solforico fumante: ma non avvertirono che l'azione dell'acido fumante sull'intonaco calcare è di cangiare in carbonato di calce in solfato, e per conseguenza decomponendo la superficie, possono, e debbono accadere più inconvenieti, e tutti gravissimi; primieramente il confondere assieme le tinte col più leggero moto o strofinamento cagionato dall'operatore, o dalla stessa indispensabile effervescenza portandole ad un visibile instantaneo stato di opacità; in terzo luogo con cangiare in solfato una sola epidermide del colore, può accadere che questa sola si stacchi colla pronta adesione al glutine sovrapposto, restando poi una parte del

\footnotetext{
${ }^{47}$ CONTI, Alessandro. Storia del restauro e della conservazione delle opere d'arte. Electa
} Editrice. Milano, 1973. Pág. 196. 
colore aderente all'intonaco, siccome si è più d'una volta osservato in luoghi dove siasi adoperato questo metodo in tali distacchi'A8.

En 1864 Carlo Ruspi $^{49}$ propone un método para arrancar pinturas murales y transportarlas a lienzo, basado en la manera de hacer de los napolitanos:

"El método adoptado por los napolitanos: practican primero un trazo entorno a la pintura, sea cual sea su grandeza encastran en él un sólido bastidor de madera construido a modo de caja, el cual penetre en el interior del muro, tan grueso como sea el soporte que se quiere cortar. Cubren la superficie entera con una hoja de papel humedecida, para que se quede pegada; y colocándole encima una tabla grande, cuanto sea la pintura, hecha con forma de tapa, la fijan al nombrado bastidor con clavos de hierro de manera que permanezcan apartados de la pintura una onza o más. Herméticamente cerrada tal tapa, se vierte en el vano entre ésta y el papel, yeso líquido, y después que se haya endurecido, con láminas de hierro apropiadas, saquen el encalado que contiene la pintura, o sierren en muro en el grosor que quieran".

En 1894 se publica por primer vez un libro que sería reeditado ${ }^{50}$ en numerosas ocasiones, se trata de /l Restauratore di dipinti, de Giovanni Secco Suardo ${ }^{51}$. Es un verdadero manual para el restaurador, que incluye desde recetas hasta consejos para desarrollar el arte de la restauración de pinturas. El capítulo que más interesa revisar en esta investigación, como es obvio, resulta aquel en el que habla sobre las técnicas de arranque de pinturas murales, después de hacer un repaso a la historia conocida hasta entonces sobre las nombradas técnicas. Después de señalar que la mayoría de los expertos en efectuar arranques, mantienen sus técnicas en secreto, explica que ha llegado a ciertas conclusiones de los pasos a seguir:

"Per eseguire il trasporto di un fresco sono necessarie di colle, l'una che serva a trar seco la pittura, l'altra a mantenerla assicurata alla tela. La prima dev'essere solubile nell'acqua affinchè si possa con facilità ammollire allorchè devesi ritogliere dalla pittura quella tela che vi si applicò per poterla strappar dal muro: l'altra invece deve essere insolubile nell'acqua acciò non si ammollisca allorquando stacassi la tela interinale. Lo scegliere la prima non era cosa difficile, poichè subito mi si presentò all'idea la colla di lagnaiuolo, detta colla forte, o tedesca, la quale presenta tutte le qualità occorrenti: ma non così fu dell'altra,

\footnotetext{
${ }^{48}$ CONTI, Alessandro. Storia del restauro e della conservazione delle opere d'arte. Electa Editrice. Milano, 1973. Pág. 199.

${ }^{49}$ RUSPI, Carlo. Metodo per distaccare gli affreschi dai muri e riportarli sulle tela proposto dal cavalier Carlo Ruspi e pubblicato per cura di Ercole Ruspi. Tipografia Enrico Sinimberghi. Roma, 1864. Págs. 12-13.

${ }^{50}$ Hay ediciones de 1894, 1918, 1927, 1979 y 1992. Todas ellas de la editorial Hoepli, de Milán.

51 SECCO-SUARDO, G. "Del trasporto dei dipinti dal muro" capitolo III. II restauratore dei dipinti. Ulrico Hoelpi. Milano, 1927. Págs. 220-223.
} 
avendo avuto presente la necessità di escludere qualsiasi sostanza grassa, oleosa o resinosa, le quali non fanno che pregiudicare ai dipinti. Quindi, dopo aver vagato molto e provato moltissime cose, mi sovveni di Cennino Cennini, il quale insegna fare una colla tenacissima con calce e cacio. Ma quella colla è sì difficile da maneggiarse, specialmente perchè asciuga con incredibile prontezza, che sarebbe impossibile valersene al nostro intento. Ritenni adunque la massima che la caseina unita alla calce poteva darmi buon risultato, e mi accinsi a svariati sperimenti. E qui mi piace accenere un fenomeno chimico che mi si presentò, e dal quale non conosco ancora la causa. Se io disciolgo la calce nell'acqua e vi aggiungo della colla forte, ho un risultato solubilissimo nell'acqua. Se disciolgo della calce nel latte, ho un risultato solubile nell'acqua esso pure, ma non così prontamente: se invece disciolgo della calce nel latte e vi aggiungo una dosse di colla forte, ottengo un risultato insolubile nell'acqua. Visto questo fenomeno provai a valermene per assicurare il fresco alla tela stabile: ma vidi che, nel mentre mi permetteva di disciogliere la colla pura della prima tela senza sciupare la pittura, non era però tenace a sufficienza per potermi garantire della conservazione. Allora pensai di aggiungere al latte una dose maggiore di caseina, a mi riuscì, ma quella dissoluzione aveva un nonh so che di renitente a lasciarse maneggiare, che mal si prestava. Provai dunque ad aggiungervi anche una piccola dose di colla, ed allorai miei voti furono pienamente coronati. In questo modo ottiensi un mastice che s'assomiglia moltissimo alla biacca macinata ad olio, che per conseguenza è scorrevolissimo, che non asciugando che non in capo a molte ore, permette dii maneggiarlo a piacere, e nel medesimo tempo che è talmente tenace ed insolubile da reggere imperterrito anche lasciato immerso nell'acqua per delle settimane. Ed'è di questo che io mi valgo per attaccare alla tela stabile le pitture a fresco che ho staccate dal muro, come indicherò fra breve".

Además, Secco Suardo hace referencia a tratados de otros pintores, de los cuales difiere en gran medida, como es el caso de Orsino Deón ${ }^{52}$, quien asegura que no existe dificultad para los conocedores de este arte, en el proceso de demolición de un muro, que, habiendo protegido bien la pintura que contiene, ésta permanecerá intacta después del proceso. Establece también, y en este aspecto Secco Suardo no difiere, en que en el tratamiento del reverso hay que evitar el uso de materiales untuosos, que podrían provocar la aparición de manchas a través de la pintura por el anverso. Hace mención también de obras arrancadas por Succi y Gallizioli, las cuales ha estudiado, llegando a la conclusión de que habían hecho uso de adhesivos solubles en agua para arrancar la pintura, y una "masilla" insoluble para readherir la obra a una tela estable; mientras que Rizzioli, siguiendo el camino opuesto, las telas usadas para el arranque las adhiere con resinas, y la obra a la tela estable -de nuevo soporte, se entiende-, con yeso. Un dato novedoso que introduce Secco Suardo, es el pigmentado del caseinato cálcico

\footnotetext{
52 Pintor, restaurador de los museos nacionales de Francia, ex Presidente de la sociedad de pintores restauradores, miembro de la sociedad libre de las bellas artes, etc.
} 
aplicado en el reverso de una obra arrancada, según la coloración original del anverso, con el fin de reforzar estos colores, que de otro modo resultarían demasiado blanquecinos, por la transparencia del blanco del caseinato cálcico ${ }^{53}$.

En 1947, el restaurador Ramón Gudiol explicó la técnica que utilizaba para llevar a cabo los arranques de pintura mural, en una entrevista realizada por Ignacio Elizalde para la revista Razón y $\mathrm{Fe}^{54}$ :

"De teoría simple, pero de práctica trabajosa y complicada $\{. .$. Protección previa de la superficie que se quiere arrancar con trozos de telas impregnados de substancias, de un poder adhesivo y cohesivo superior al que la sostiene en el muro. Generalmente a base de caseína, extraída del queso y de grasas; naturalmente, no de quesos ni de grasas sintéticas... Unos buenos tirones y la pintura se desprende íntegra. La pintura está ahora al revés. Otro trozo de tela preparado con pasta especial más fuerte que el anterior y protegido con tablas. Se levantan las tiras protectoras de la capa exterior. Y ya está la pintura trasladada al lienzo. Es la sencilla técnica de la calcomanía, que tantas veces, niños, hemos realizado. Requiere mucha experiencia y sobre todo mucha paciencia. No todo sale como se quiere. Tenemos que inyectar las tablas, plancharlas, estucarlas. Es necesario conocer la técnica de los maestros antiguos para que no desmerezca el color, no salgan manchas, no se pierdan los tonos. Cada cuadro es un enigma, un problema que resolver..."

En 1966, Gino Piva ${ }^{55}$ escribe que para trasladar una pintura al fresco de un lugar a otro sólo se conocía en la antigüedad un medio: "aquel que consistía en aislar un fragmento de muro sobre el que apoya la pintura, adelgazarlo, si era excesivamente grueso, y cortarlo y enmarcarlo en barras de hierro para transportar al mismo tiempo muro y pintura". Esta descripción corresponde a la técnica del stacco a massello.

En 1988, Géraldine Albers y Philippe Morel, describen la técnica del strappo, haciendo una revisión de Cicognara, Forni, Mora y Philippot, del siguiente modo:

"Inanzitutto s'incolla sulla superficie un facing formato da una tela $d$ lino sovrapposta as una tela di cotono, tele divise in quadrati le cui giunte si sovrappongono, per il cotono, ed in bande longitudinali senza sovrapposizione peri I lino (al quale ora si preferiste la canapa). L'adesivo è a base di colla animale (di pesce) diluita con aceto bianco (ad una colla di ossa, molto meno aderente, si aggiungono actualmente

\footnotetext{
${ }^{53}$ Ver página 244 de SECCO-SUARDO, G. "Del trasporto dei dipinti dal muro" capitolo III. II restauratore dei dipinti. Ulrico Hoelpi. Milano, 1927. Págs. 220-223.

54 ELIZALDE, Ignacio. "Una técnica curiosa" en Razón y Fe. Revista mensual hispanoamericana publicada por los Padres de la Compañía de Jesús. Año 47. Tomo 135. Madrid, 1947.

55 PIVA, Gino. "Il trasporto dei dipinti nel sistema antico e moderno, secondo le opere di Secco-Suardo e del professore R. Mancia" L'arte del restauro. Editore Ulrico Hoelpi. Milano, 1966. Pág. 86.
} 
certi prodotti, tra cui la melassa che, per la sua azione plastificante, produce seccandosi una contrazione dello strato di pintura che ne favorisce il distacco). Il lino è applicato alla tela di cotono con un'analoga colla addizionata di farina di frumento. Quando tutto è secco, si batte la superficie con un mazzuolo, si intaglia il perimetro dell'affrescoed il facing viene strappato con lo strato pittorico che si distacca dall'intonaco. Dopo la ripulitura del rovescio, vi si applica uno strato di colla di pesce, poi un altro di stucco (o di gesso) ed infine un adesivo (composto da latte scremato -caseina-, da calce sienta, colla di pesce, siero e albume di uovo) che permetterà di fissare lo strato di pintura su un nuevo spporto di tela di lino (questo backing viene ora sistemato su dei supporti rigidi e sofisticati). Poi si leva il facing con l'ausilio di acqua trepida",56.

Esta descripción difiere del resto en cuanto a los materiales utilizados. Por ejemplo, el adhesivo utilizado no es cola de conejo, sino de pescado, que, contrariamente a lo escrito en esta descripción, es más débil que el primero. También es digno de mención el adhesivo que utiliza para la adhesión de la pintura al nuevo soporte de tela de lino: una mezcla de caseinato cálcico con cola de pescado, suero y clara de huevo, cuando lo normal es usar únicamente caseinato cálcico. ¿Realmente se utilizaban estas mezclas o se trata de un error de interpretación de estos autores?

\footnotetext{
${ }^{56}$ ALBERS, Géraldine; MOREL, Philippe. "Pelegrino Tibaldi e Marco Pino alla Trinità dei Monti. Un affresco ritrovato, Pietro Palmaroli e le origini dello "stacco". En Bolletino d'Arte 48. Anno LXXIII. Serie IV. Marzo-Aprile 1988. Istituto Poligrafico dello Stato. Roma, 1988. Págs. 17-72.
} 



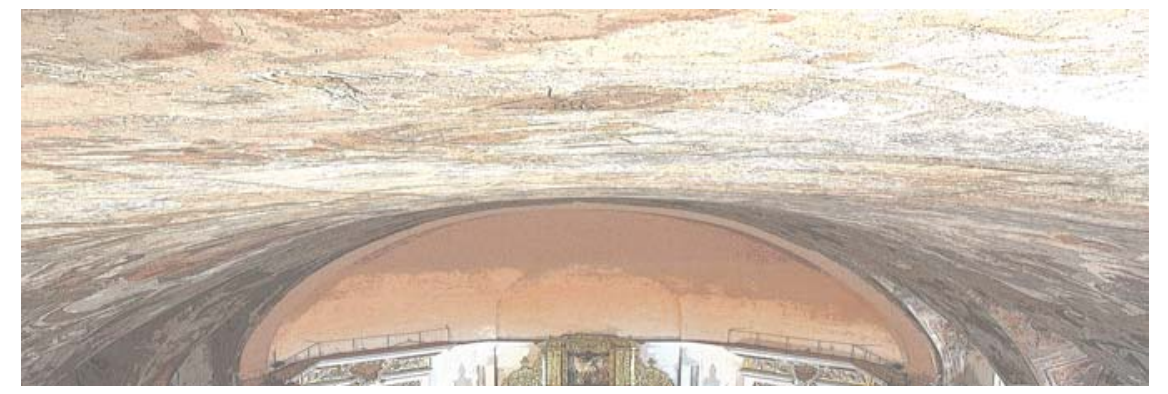

CAPÍTULO III

EVOLUCIÓN HISTÓRICA DE LAS TÉCNICAS DE ARRANQUE 




\section{EVOLUCIÓN HISTÓRICA DE LAS TÉCNICAS DE ARRANQUE}

Los primeros testimonios del uso de estas técnicas de arranque de pintura mural los encontramos en los textos de Vitruvio ${ }^{57}$ en el año 59 a.C. y Plinio el Viejo $^{58}$, ya en el primer siglo de nuestra era. Aunque ninguno de los dos hace referencia al procedimiento, sino que comentan que ciertas pinturas han sido arrancadas de sus lugares de origen en Gracia y transportadas a Roma.

Gracias a las excavaciones de Pompeya y Herculano se sabe que los romanos transportaban pinturas murales cuando cambiaba el gusto por un estilo diferente en las decoraciones de sus casas. Se eliminaban las partes más importantes de las decoraciones murales para sustituirlas por otras que eran pintadas en casetones de madera y colocadas después en el vano dejado en el muro por la anterior pintura arrancada ${ }^{59}$.

Según Maiuri ${ }^{60}$, no se sabe si inserían en el muro también el bastidor de madera, porque como Pompeya fue cubierta por lava, se quemaron todas las estructuras lígneas. Mientras que eh Herculano, que no fue

${ }^{57}$ VITRUVIUS MARCUS POLLIO. De architectura libri decem. Libro II, Cap. VIII. (Los 10 libros de la arquitectura. Traducción de José Luís Olivar Domingo. Alianza Forma. Madrid, 2000).

[...] en Esparta, ciertas pinturas fueron arrancadas de cuajo de las paredes $y$, ensambladas en cajones de madera, fueron trasladadas a la curia, como elemento decorativo, siendo ediles Varrón y Murena.

58 PLINIO SEGUNDO, Cayo. Historia Natural. Visor libros 1998. México. Trasladada y anotada por el doctor Francisco Hernández. Págs. 150 y 165.

Plinio el Viejo, en su Naturalis Historiae habla de la imposibilidad de transportar una famosa pintura que representaba "Atlante y Elena" de tiempos de Lanuvio, por las condiciones del intonaco, no obstante el vivo deseo de Poncio:

[...] De la misma suerte han durado en Lanuvio, donde están juntas Atalanta y Helena, pintadas desnudas de mano de un mismo artífice, una y otra de figura hermosísima, pero la una como virgen, y es cierto que no se han movido ni maltratado con las ruinas del templo. Poncio, legado del emperador Cayo, procuró quitarlas y llevárselas encendido de luxuria, si se lo permitiera la naturaleza del asiento en que estavan pintadas.

[...] En Lacedemonia cortaron la obra de los aposentos que estavan en paredes de ladrillos, por la excelencia de su pintura, encerrándola en cercos y bastidores de madera, y así lo llevaron a Roma Murena y Varrón para adornar el comicio, siendo ediles; la qual obra, como por sí fuese admirable, trasladada admirava más.

${ }^{59}$ CONTI, Alessandro. Storia del restauro e della conservazione delle opere d'arte. Electa Editrice. Milano, 1973. Pág. 31.

60 MAIURI, Amadeo. Ercolano. Itinerari dei Musei e monumenti d'Italia. Ministero della Pubblica Istruzione. Direzione Generale delle antichità e Belle Arti. Istituto Poligrafico dello Stato. Libreria dello Satato. Roma, 1954. Pág. 40. 
cubierta por lava sino por barro y cenizas, se ha encontrado una pintura encajetada en un bastidor de madera al muro. Las pinturas encontradas de menos de $40 \mathrm{~cm}$., no tienen restos de encajonado de madera, probablemente por sus reducidas dimensiones.

Estos traslados de pintura fueron frecuentes hasta los últimos tiempos de la República, como las decoraciones etruscas del templo de Ceres en Roma, que fueron cortados y montados en cuadros enmarcados al ser restaurado el templo ${ }^{61}$.

En 1474 se realiza el primer arranque conocido, mediante la técnica del stacco a massello; se trata del traslado de una pintura al fresco de Piero Della Francesca, que representa la Resurrección, de una pared a otra de la sala del Palazzo Comunale di San Sepulcro ${ }^{62}$.

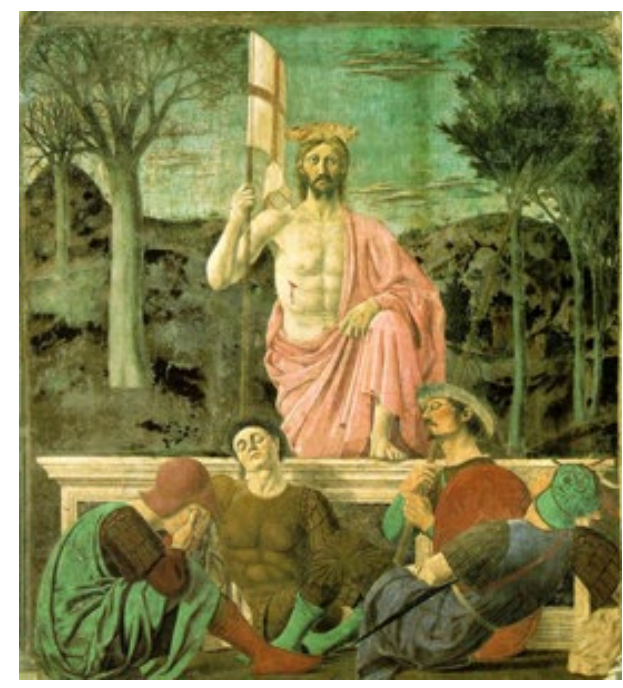

Fig. 43. La Resurrección, de Piero Della Francesca. Pintura al fresco arrancada mediante la técnica de stacco a massello.

En 1507 se arranca un fragmento de una pintura que representaba Santa Ana con la Virgen y el Niño, del Palazzo Caracciolo, y se traslada a la iglesia Della Anunziata de Roma ${ }^{63}$.

\footnotetext{
${ }^{61}$ MACARRón MIGUEL, Ana Ma. Historia de la Conservación y la restauración. Desde la antigüedad hasta el sigloo XX. Ed. Tecnos. Madrid, 2002. Pág. 33.

${ }^{62}$ BOTTICELLI, Guido. "Trasferimento dal supporto originale: stacco e strappo" capitolo IX. En Metodologia di restauro delle pitture murali. Centro Di della edifimi srl. Firenze, 1992.

${ }^{63}$ BOTTICELLI, Guido. "Trasferimento dal supporto originale: stacco e strappo" capitolo IX. En Metodologia di restauro delle pitture murali. Centro Di della edifimi srl. Firenze, 1992.
} 
En el Renacimiento, Vasari ${ }^{64}$ nombra algunas noticias referidas a arranques así como la utilización de criterios para determinar la salvaguardia o la destrucción de la obra. En la vida de Spinello Aretino que se arrancó una obra de este artista, en el intervalo entre la impresión de la primera y la segunda edición, es decir, poco después de $1550^{65}$ : un Nostra Donna, che porge a Cristo fanciullino una rosa, era tenuta, et è, come figura bellisima e devota, in tanta venerazione appreso gli Aretini, che, senza guardare a niuna difficoltà o spesa, quando fu gettata per terra la chiesa di Santo Stefano, tagliarono intorno a esa il muro, e, allacciatolo insegnodamente, la portarono nella città, collocandola inuna chiesetta per onorarla, come fanno con la medesima devozione che prima facevano.

Poco después de su descubrimiento entre 1604 y 1605, los frescos de la época de Augusto, Nozze Aldobrandini, fueron restaurados in situ, y arrancados después para trasladarlos al Quirinal, en Roma ${ }^{66}$.

Alessandro Conti, en las páginas 118 a 121 de su libro Storia del restauro e della conservazione delle opere d'arte ${ }^{67}$, hace un repaso de los arranques más importantes que se realizaron en Italia durante el siglo XVII.

Según Proccaci68, al principio del siglo XVIII Giovanni Bottari nos recuerda que "una bella copoletta di Bernardino Poccetti nell'antico Palazzo degli Spini, [...] fu traslatata in un sito al comodo più opportuno". Se trata de una capilla entera con pinturas al fresco que fue trasladada con sus muros de un lado a otro del palacio.

En el siglo XVIII se descubre la técnica del strappo. Conti afirma que es Antonio Contri di Ferrara el verdadero descubridor de esta técnica de arranque ${ }_{70}^{69}$. Buraffaldi habla de Contri como "pittore e rilevatore di Picture dai muri" ${ }^{70}$.

\footnotetext{
64 VASARI, Giorgio. La vida de los más excelentes arquitectos, pintores y escultores italianos desde Cimabue a nuestros tiempos (Antología). Editorial Tecnos, S.A. Madrid, 1998.

${ }^{65}$ PROCACCI, Ugo. Del distacco degli affreschi e della loro conservazione. Firenze, 1957.

${ }^{66}$ BOTTICELLI, Guido. "Trasferimento dal supporto originale: stacco e strappo" capitolo IX. En Metodologia di restauro delle pitture murali. Centro Di della edifimi srl. Firenze, 1992.

${ }^{67}$ CONTI, Alessandro. Storia del restauro e della conservazione delle opere d'arte. Electa Editrice. Milano, 1973. Págs. 118-121.

${ }^{68}$ PROCACCI, Ugo. Del distacco degli affreschi e della loro conservazione. Firenze, 1957.

${ }^{69}$ CONTI, Alessandro. Storia del restauro e della conservazione delle opere d'arte. Electa Editrice. Milano, 1973. Pág. 120.

${ }^{70}$ PROCACCI, Ugo. Del distacco degli affreschi e della loro conservazione. Firenze, 1957.
} 
El 23 de junio de 1739, Alcubierre ${ }^{71}$, arqueólogo de Carlos de Borbón encargado de las excavaciones de Pompeya y Herculano, refiriéndose a unas pinturas murales encontradas en dichas excavaciones, escribe:

[...] el dicho estatuario dize que en Roma y más en Inglaterra se aprecian muchísimo estas pinturas, las quales se quitan de semejantes parajes. Y si S.M. lo aprueva verá él mismo de sacar dos pedazos que el uno tendrá 6 pal. Y medio de largo y el otro dos pal. Y medio, todos dos con pal. Y medio de altura; sobre lo qual espero las órdenes de V.E...

[...] Y ya el marmolero que corta las pinturas sacó ayer tarde la una de las dos que participé a V.E. que es en la que están los cábrios, y tiene 4 pal. y medio de largo y un palmo y medio de ancho, y hoy se está travajando en quitar la tierra por atrás y ajustarle la piedra de Génova para poderle poner en su caja. Y haviendo dicho al mismo estatuario quanto manda V.E. sobre que se saquen inmediatamente las demas pinturas de las grutas, las quales estan señaladas conforme se han de cortar, me ha ofrecido que no se empleará en otra cosa el marmolero, hasta haver concluido de executarlo.

\section{El 28 de febrero de 1761 escribe:}

[...] se ha cortado el friso y sacado tambien los dos cuadros de pintura rotos que sabado $p$. pasado después del reporte dí parte á V.S. tambien sus medidas y representaciones que se havian de sacar, y son los dos señalados con la cruz que se ha llevado al estudio de Canart. ${ }^{72}$

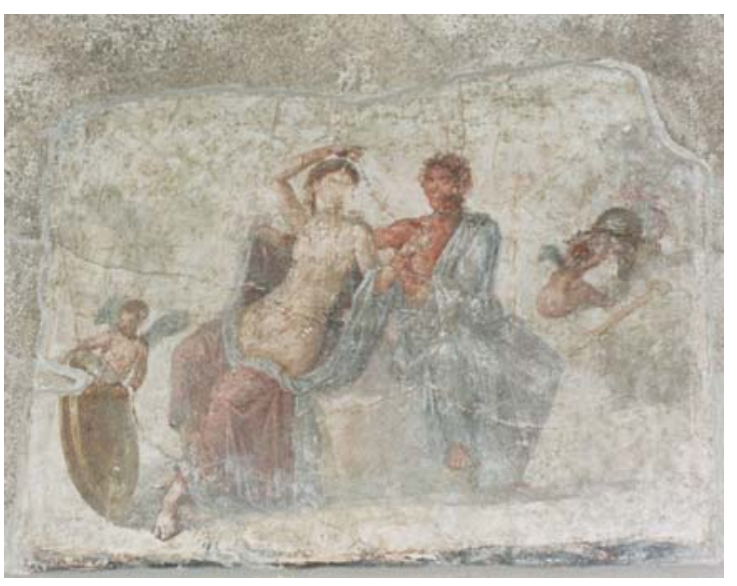

Fig. 44. Una de las pinturas murales arrancadas de Pompeya.

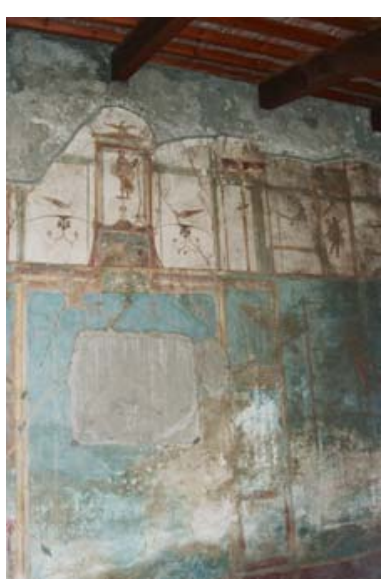

Fig. 45. Vacío en una pared pompeyana tras el arranque de la escena principal.

\footnotetext{
${ }^{71}$ D'ALCONZO, Paola. Picturae excisae. Conservazione e restauro dei dipinti ercolanesi e pompeiani tra XVIII e XIX secolo. L'Erma di Bretschneider. Roma, 2002. Pág. 16

${ }^{72}$ RUGGIERO 1885, pág. 340, 343. 
En Nápoles, siguen utilizando, gracias a los trabajos ininterrumpidos en las excavaciones vesubianas, la técnica del stacco a massello, que aun un siglo después sería conocida como "el método de los napolitanos", técnica mediante la cual inserían un bastidor de madera a modo de caja u horma, con el fin de proteger al máximo la pintura y evitar roturas. Mientras, en el resto de Italia se sigue investigando sobre la técnica del strappo, para conseguir arrancar únicamente la película pictórica, y el stacco, que se desarrollan durante el siglo XVIII, ideadas a la vista de los inconvenientes del stacco a massello, que era una técnica arriesgada y complicada.

Según las primeras noticias que tenemos, el primero en llevar a cabo un strappo fue, en 1725, Antonio Contri (Ferrara 1650, Cremona 1732), quien se llevó a la tumba el secreto de la técnica, por lo que por muchos es considerado el verdadero inventor de la técnica Giacomo Succi, activo durante la $2^{\mathrm{a}}$ mitad del siglo XVIII, quien relegó sus conocimientos de la técnica a sus hijos Pellegrino y Domenico. Según Gino Piva, Giacomo Succi di Imola fue quien perfeccionó el sistema ideado por Contri, en la época en que estaban activos los hijos de Succi $^{73}$. Otros seguidores siguieron perfeccionando esta técnica, entre ellos Girolamo Contoli, pero casi todos seguían procedimientos diferentes inventados por ellos mismos, y se esforzaban en mantener sus técnicas en secreto.

Según Secco Suardo $^{74}$, los que perfeccionaron en el arte del arranque fueron los que sabían que no debían utilizar materiales oleosos ni barnices. Por otro lado estaban los que no conocían este "secreto" y no hicieron más que dañar las obras sobre las que intervenían. Entre ellos se encuentra la francesa Madame Bazzet, quien deterioró varias obras en Toscana y Roma, que poco después de ser recolocadas en telas tras el arranque, se separaban de ésta. En cambio los frescos arrancados por Stefano Barezzi y por Speri, sufrían la aparición de manchas, debido a las sustancias grasas que empleaban.

Entre aquellos que hicieron progresos positivos se encuentra Antonio Boccalari, que efectuó diversos arranques en Florencia, Milán, Modena...con resultados siempre positivos.

Pero es en la $2^{\mathrm{a}}$ mitad del siglo XVIII cuando la técnica del strappo vive su mayor apogeo,"...en contra de algunos, como Leopoldo Cicognara, que temen por las obras en sentido técnico o porque puedan

\footnotetext{
${ }^{73}$ PIVA, Gino. "Il trasporto dei dipinti nel sistema antico e moderno, secondo le opere di Secco-Suardo e del professore R. Mancia" L'arte del restauro. Editore Ulrico Hoelpi. Milano, 1966. Pág. 87.

74 SECCO-SUARDO, G. "Del trasporto dei dipinti dal muro" capitolo III. II restauratore dei dipinti. Ulrico Hoelpi. Milano, 1927. Pág. 220.
} 
ser trasportadas al extranjero...." ${ }^{75}$. Se difunde también en esta época la técnica del stacco.

En Toscana, el primero en utilizar estas técnicas fue Giovanni Rizzoli di Cento, quien usó diferentes tipos de cola en función de cada caso concreto, así, utilizó además de cola animal, resinas naturales, como la goma laca, sobre frescos con retoques a seco.

En 1787, el Gran Duque Pietro Leopoldo ${ }^{76}$, debiendo cambiar de domicilio, dio orden al pintor y restaurador Santi Pacini de arrancar, para evitar su pérdida, una pintura al fresco con la Virgen y el Niño, reliquia de Cennino. Se trata de un arranque de la película pictórica. No se sabe cómo estaba la obra, pero hoy queda apenas una sombra, posiblemente debido al poco éxito del procedimiento de arranque.

Las "Memorias enciclopédicas romanas""7 de 1809 dedican un artículo al "secreto químico" con el que el médico Nicola Martelli había conseguido transportar algunos frescos, y aprecian, sobre todo, la nueva frescura de las pinturas, que antes del arranque se encontraban incomparablemente más pálidas.

En 1818 para evitar el arranaque masivo de pinturas, con fines comerciales, la Reggenza Provvisoria del Governo Veneto, promulga el siguiente decrete: "non potranno effettuarsi questi distacchi se non sarà stato regolarmente comprovato che la muraglia a cui il dipinto è attacato è per crollare, oppure formi parte di qualche edifizio destinato ad essere demolito, o non sarà dimostrato che il dipinto possa soffrire danno seguitando ad esistere nella medesima, e finalmente se non esisterà qualche altro grave motivo per effettuare el distacco"78. Existía un miedo por parte de las autoridades a que estas pinturas que estaban siendo arrancada, en pocos años se desprendiesen de sus nuevos soportes, provocando pérdidas irreversibles.

En 1866 se publicó el primer manual de restauración, escrito por Secco-Suardo, en el que también se hacen menciones a estas técnicas ${ }^{79}$. Y no mucho más tarde, el también tratadista Ulisse Forni ${ }^{80}$, confirmará lo dicho por Secco-Suardo.

\footnotetext{
${ }^{75}$ CONTI, Cristina. Lo stacco e lo strappo delle pitture murali nei casi di incontroversa necessità: vantaggi e svantaggi dei due procedimenti. Tesi di diploma del Corso Triennale. Relatori: Dott. Cristina Danti. Res. Antonello Pandolfo. Opificio delle Pietre Dure e Laboratorio di Restauro. Firenze, 1984.

${ }^{76}$ PROCACCI, Ugo. Del distacco degli affreschi e della loro conservazione. Firenze, 1957.

${ }^{77}$ GUATTANI, G.A. Memorie enciclopediche romane sulle belle arti, antichità ... Salomon BAV. Roma, 1809

${ }^{78}$ CONTI, Alessandro. Storia del restauro e della conservazione delle opere d'arte. Electa Editrice. Milano, 1973. Pág. 193.

79 SECCO-SUARDO, G. "Del trasporto dei dipinti dal muro" capitolo III. II restauratore dei dipinti. Ulrico Hoelpi. Milano, 1927.
} 
A finales del siglo XIX Valentino Bernardi, autor de otro tratado de restauración, entró en polémica con Secco-Suardo con respecto a la técnica del strappo.

El siglo XX es la época en la que mayor proliferación tienen las técnicas de arranque, sobre todo el strappo, siendo el mismo Cesare Brandi (padre de la teoría de la restauración actual), un gran defensor de estos tratamientos: "[...] ni una pintura mural cuyas condiciones exijan el arranque deberá trasladarse a un muro, ni una pintura sobre roca habrá de ser colocada de nuevo sobre una roca. $Y$ no solamente esto, sino que ni siquiera será obligatorio el soporte rígido, en cuanto que lo que sí que resulta necesario es mantener íntegro el aspecto y no tanto la estructura. Las pinturas se contemplan, pero no se tocan: es a la vista y no al tacto donde se ofrecen y se experimentan. [...] si se quiere salvar una pintura antigua, deberán generalizarse al máximo sus traslados., ${ }^{, 81}$

Entre 1950 y 1960, sobre todo en la región italiana de la Toscana, surge la moda de arrancar pinturas murales con el fin de sacar a la luz los dibujos preparatorios, la sinopia, no estando seguros de su existencia hasta que se termina el proceso de arranque. ${ }^{82}$ Además en los años '60 se usó mucho en Italia la técnica del arranque para salvar obras degradadas por eventos bélicos $y$, sobre, tras las inundaciones de Florencia en 1966, cuando se desbordó el río, causando grandes daños en muchas obras de arte ubicadas en esa zona.

En España las técnicas de arrancar pinturas murales llegaron algo más tarde que a Italia. El primer arranque del que se tiene noticia es el de las escenas grotescas de la casa de campo de Goya, en 1873, con un resultado muy deficiente, posiblemente por la dificultad de arrancar pinturas al óleo, así como por la falta de dominio de la técnica ${ }^{83}$. Las Pinturas Negras de Goya, por decisión del propietario de la finca, la "quinta del sordo", el Barón Émile d'Ėrlanger, fueron arrancadas por Salvador Martínez Cubells, trasladadas a lienzo, y consolidada la pintura, produciéndose marcas del lienzo en la pintura. Conocemos su ubicación original por el Inventario de Antonio Brugada realizado a la muerte de Goya: en la planta baja había siete, ocho en la superior, y una que fue vendida al Marqués de Salamanca. El fotógrafo J. Laurent, entre 1863 y 1867, hizo fotografías antes del arranque en las que aparece una cenefa rodeando la obra a modo de marco y un papel pintado en la pared, apreciándose en algunas las grietas del muro que recorren las obras y

\footnotetext{
${ }^{80}$ FORNI, Ulisse. Manuale del pittore restauratore. Firenze, 1866.

81 BRANDI, Cesare. Teoría de la restauración. Alianza Forma. Madrid, 1992. Versión española de María Ángeles Toajas Roger. Págs. 84 y 85.

${ }^{82}$ CONTI, Alessandro. Manuale di restauro. Einaudi editori. Torino, 1996. Pág. 175.

${ }^{83}$ ELIZALDE, I. "Una técnica curiosa" en Razón y Fe. Revista mensual hispanoamericana publicada por los Padres de la Compañía de Jesús. Año 47. Tomo 135. Madrid, 1947.
} 
las cenefas, lo que atestiguan el mal estado de los muros, que afectaba a las pinturas ${ }^{84}$.

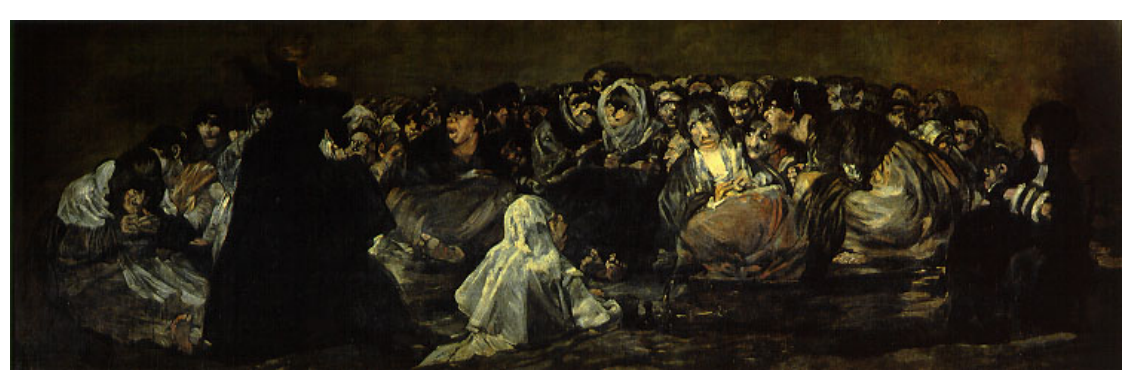

Fig. 46. Una de las pinturas murales de Goya, arrancadas en 1873 de la "Quinta del Sordo".

La técnica del arranque se perfeccionó cuando se quiso salvar las pinturas de los ábsides románicos en las iglesias pirenaicas. En 1929 el Museo de Barcelona acudió a un especialista italiano, Franco Steffanoni, miembro de una familia que se dedicaba a este trabajo en Bérgamo desde hacía siglos. Vino con su discípulo Arturo Cividini, quién se quedó en España hasta 1936, desarrollando el arte de esta técnica de restauración, en la casa Amatller del barcelonense paseo de Gracia. Y Dalmati, restaurador también oriundo de Bérgamo. También contribuyó a su desarrollo Manuel Grau, que estudió en Milán con el profesor Mauro Peliccioli, discípulo de Steffanoni. Arturo Cividini transmitió sus conocimientos sobre la técnica a Ramón Gudiol, quien trabajó hasta su muerte en todo el territorio español arrancando pinturas murales y trasladándolas a lienzo.

Ramón Gudiol Ricart, era el hijo pequeño de un hermano de monseñor Gudiol, quien fue fundador y director del Museu de Vic, y el principal responsable de la vocación de restaurador de Ramón Gudiol Ricart. El primer taller de restauración de los Gudiol, que se inauguró en mayo de 1942, se ubicaba en el Carrer Ample $n^{\circ} 4$ de Barcelona ${ }^{85}$. El hermano mayor de Ramón Gudiol, el historiador Josep Gudiol Ricart, era director del Museu Amatller d'Art Hispànic, estrechamente vinculado al Arxiu Mas de fotografía. Aunque, siendo historiador, también se dedicaba a la restauración, sobre todo arranque y limpieza de pinturas murales. Y

\footnotetext{
${ }^{84}$ MACARRón MIGUEL, Ana Ma. Historia de la Conservación y la Restauración. Desde la antigüedad hasta el siglo XX. Ed. Tecnos. Madrid, 2002. Pág. 218.

${ }^{85}$ GUDIOL COROMINAS, Eulàlia. Josep Gudiol Ricart. Patronat d'estudis osonencs. Vic, 1997.
} 
fue él quien dio oficio a su hermano pequeño, Ramón ${ }^{86}$. El equipo de los Gudiol estaba formado por Ramón y Josep Gudiol Ricart, Ramón Gudiol Serra, Andreu Asturiol Estany, José Cruz Calderón, Nicasio y Francesc Arraiza, padre e hijo, y el alemán Kart Staub.

Durante la guerra civil española una de las tareas más importantes que se llevaron a cabo en el taller de los Gudiol fue el arranque y traslado a nuevo soporte de las pinturas murales de la sala Capitular de Sixena, después del incendio sufrido durante la guerra. Así como el traslado del ábside de Osormort que se encontraba en el Centro de Restauración de Sant Cugat, para ser trasladado a un nuevo soporte y devuelto al Museo Diocesano de Vic. También trabajaron en Sant Pau de Casserres, Sant Quirze de Pedret, Cardona, Santa Coloma d'Andorra, Astorga...

En 1943, Josep Gudiol estuvo en Pamplona, con el fin de arrancar y restaurar las pinturas murales de Olite.

El taller de los Gudiol fue el que más metros de pintura mural trató en aquella época. Trabajaron también en el arranque de las pinturas murales románicas de la iglesia del Brull, en la comarca de Osona; el atri de Cardona, el ábside de Toses...

Llevaron a cabo también segundos arranques para conservar las sinopias, como es el caso del ábside de Santa Maria de Taüll.

En 1970 se inauguraba el Museo Diocesano de Jaca, con pinturas murales románicas procedentes del Pirineo d'Osca. Pinturas que había arrancado Ramón Gudiol, bajo la supervisión de su hermano Josep.

Un ejemplo más detallado del trabajo que realizaron los hermanos Gudiol lo encontramos en las pinturas que representan a María Magdalena y la Leyenda de los tres vivos y los tres muertos, que se encontraban en la iglesia de San Juan y San Pablo de Peñafiel, tapiadas en época desconocida, medio ocultas y bastante deterioradas.

\footnotetext{
${ }^{86}$ GUDIOL COROMINAS, Eulàlia. Josep Gudiol Ricart. Patronat d'estudis osonencs. Vic, 1997.

${ }^{87}$ XARRIÉ, Josep Maria. Restauració d'obres d'art a Catalunya. Publicacions de l'Abadia de Montserrat. Barcelona, 2002. Págs. 75-77.
} 


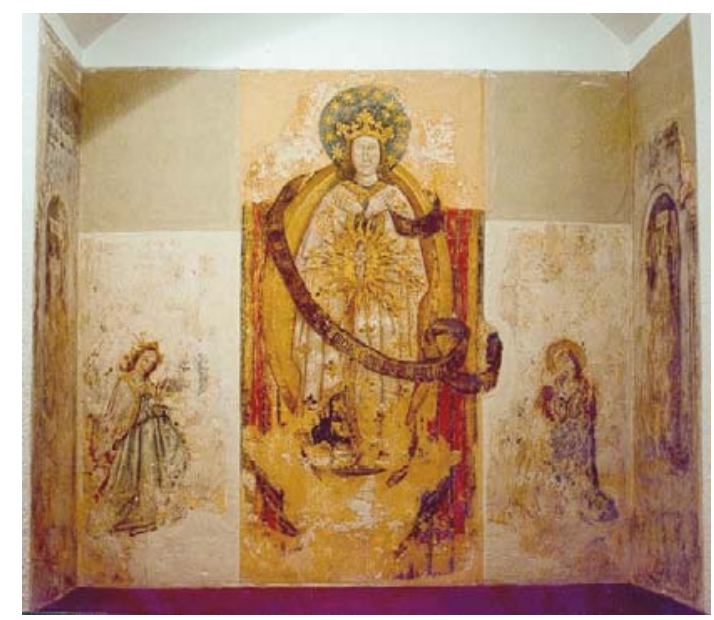

Fig. 47. Pinturas góticas que representan a María Magdalena, arrancadas de la iglesia de San Juan y San Pablo de Peñafiel

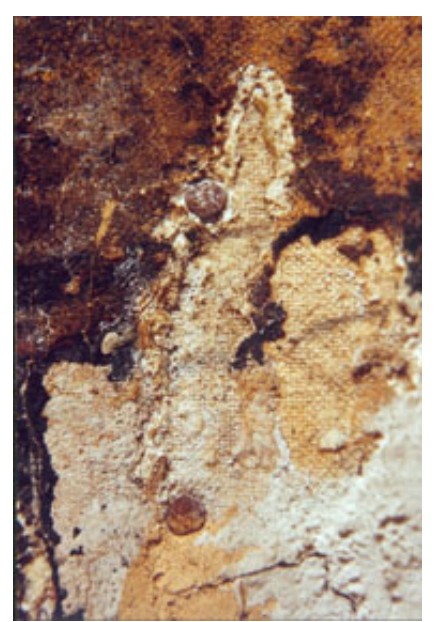

Fig. 48. Detalle de los clavos que unen a su soporte la pintura arrancada.

El 5 de junio de 1940 se presentó en el convento el señor Alcalde de Peñafiel con un oficio del gobernador civil de Valladolid, acompañado de don Ramón Gudiol Ricart, "el técnico encargado de procurar conseguir se salven las pinturas de la Iglesia del convento de San Pablo, las que, por su valor y por el estado de destrucción en que desgraciadamente se encuentran, es necesario procurar levantar, a fin de conservarlas luego en el Museo Arqueológico Provincial. Le estimaré a usted, concluía el gobernador, dé toda clase de facilidades a dicho señor para que pueda realizar la misión que se le encomienda...-- J. Rivero".

Don Ramón Gudiol procedió, durante el verano de 1940 al arranque de las pinturas murales, según la técnica ${ }^{88}$ aprendida en la escuela de Vich, del italiano Cividini; con la ayuda del hoy padre Pasionista en Peñafiel, don Heraclio Merino, que contaba entonces con 14 años.

"En una perola grande, calentaron agua con un hornillo eléctrico, cuando ésta estaba suficientemente caliente, añadían cola de carpintero (deducido esto por la descripción de don Heraclio: cola de aspecto gelatinoso, marrón y que desprendía un olor desagradable), que había que remover hasta su total disolución, momento en que don Heraclio sujetaba un perolillo más pequeño en el que el Sr. Gudiol vertía cola y luego iba mojando dentro trozos de tela muy tupida y gruesa de unos $30 \mathrm{~cm}^{2}$. Los escurría y los iba colocando sobre la pintura, teniendo muy presente que quedaran las uniones de una tela y

88 ELIZALDE, Ignacio. "Una técnica curiosa" en Razón y Fe. Revista mensual hispanoamericana publicada por los Padres de la Compañía de Jesús. Año 47. Tomo 135. Madrid, 1947. 
otra bien pegadas. Lo dejaban secar, y cuando ya estaba bien seco, por la misma contracción de la cola, se había desprendido la parte superior, y sólo había que estirar, enrollando las pinturas como si fueran un cartón. $Y$ así se las llevó don Ramón Gudiol. Pasando después a manos del Museo Arqueológico de Valladolid, tal como nos las encontramos en la actualidad." 89

Y otro ejemplo importante que podemos encontrar sobre pinturas murales arrancadas, es el que se trata directamente en esta tesis doctoral: las pinturas de la bóveda y presbiterio de la nave central de la Iglesia de los Santos Juanes de Valencia. Como ya se ha explicado más detalladamente en capítulos anteriores, dichas pinturas fueron realizadas por Antonio Palomino durante el periodo comprendido entre 1699 y 1701, siendo posteriormente arrancadas en los años 60 por el taller catalán de los hermanos Gudiol. Se hizo un arranque con cola orgánica por trozos de unos $2 \times 1$ m., aproximadamente. El reverso se consolidó con caseinato cálcico y fragmentos de tela de algodón con dos tipos de gramaje y luego se adhirió con cola de empapelar a una chapa de madera. Los estucos se realizaron con blanco de España y cola orgánica y los repintes con pigmentos minerales y barniz. Para recolocarlo en la bóveda se clavó directamente con clavos gruesos de hierro y tacos de madera.

En 1961, el taller de restauración del Museu d'Art de Catalunya, arrancaba las pinturas murales del siglo XIII, encontradas en la calle de Montcada de Barcelona. Josep $\mathrm{M}^{\mathrm{a}}$ Xarrié, que participó en esta intervención, describe el procedimiento seguido ${ }^{90}$. Como tratamiento previo antes de la adhesión de las telas para el arranque consistió en limpiar la superficie pictórica, y seguidamente protegerla con una mano de goma laca incolora y descerada, procedente de Asia, e importada de Inglaterra. Esta goma laca era la misma que usó Mauro Pellicioli en su intervención de La Última Cena, de Leonardo en Milán. La tela de algodón para proceder al arranque, se hervía dos veces para eliminar así el apresto, se cortaba en fragmentos de $30 \times 30 \mathrm{~cm}$. y se planchaba, peinando los bordes para evitar posibles marcas en la pintura una vez arrancada. Colgadas de las vigas a una distancia prudencial del muro se dispusieron lámparas de infrarrojos, para preparar el muro para recibir las telas con cola caliente. Las telas se aplicaban de abajo arriba, para evitar micro-arranques donde cayeran gotas de cola, impregnadas de cola muy caliente. Se dejaba secar durante una noche con las lámparas infrarrojas, y al día siguiente se aplicaba las telas con una trama más cerrada. La tercera jornada de trabajo, después de repetir el secado con las lámparas infrarrojas, se procedió al strappo, golpeando previamente la superficie para facilitar el desprendimiento. Enrollando las telas

\footnotetext{
${ }^{89}$ Testimonio directo del Padre Heraclio Merino.

${ }^{90}$ XARRIÉ, Josep Maria. Restauració d'obres d'art a Catalunya. Publicacions de l'Abadia de Montserrat. Barcelona, 2002. Págs. 143-144.
} 
arrancadas, se trasladaron al taller de restauración del Palacio Nacional. Allí fue rebajado el reverso, hasta conseguir una capa fina y uniforme, se adhirieron las nuevas telas, en dos capas, con caseinato cálcico con el aditivo de un $10 \%$ de acetato de polivinilo, y se eliminaron las telas del arranque con agua caliente. El nuevo soporte fue un bastidor de madera con sus correspondientes travesaños, y una capa de $5 \mathrm{~cm}$. de contrachapado de ocumé marino.

También usaron la goma laca para proteger las pinturas al temple de cola del pintor Torrens, en el Depósito de Pescadores de Vilanova; como tratamiento previo al arranque.

Estos son algunos de los muchos ejemplos que podemos encontrar de arranques de pinturas murales llevados a cabo en España.

Más tarde, ya sea en Italia, ya sea en España, se ha empezado a tomar conciencia de que la pintura mural, siempre que sea posible debe permanecer en el muro, conservando así todas sus características intrínsecas, por lo que hoy en día son escasas las intervenciones de arranques de pintura mural, reservándose exclusivamente a situaciones en las que se trata de una intervención absolutamente imprescindible. 



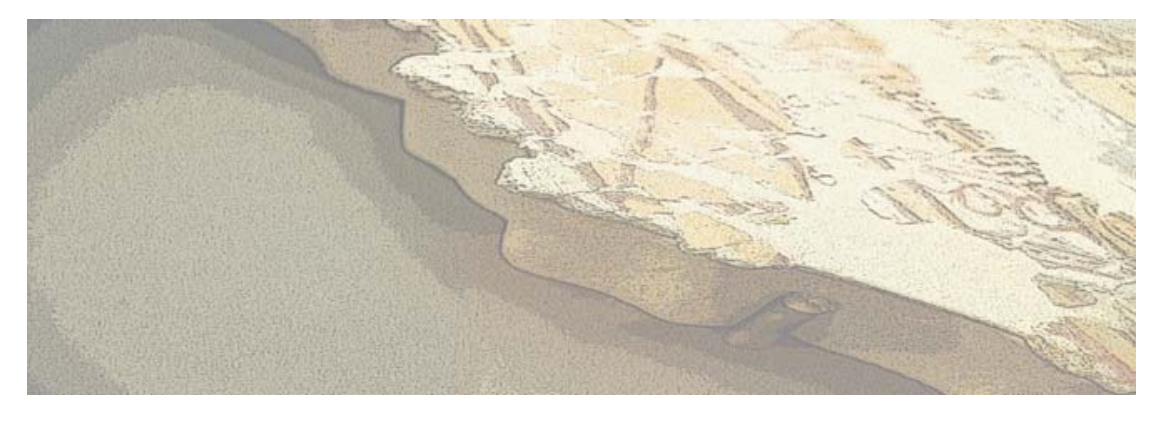

CAPÍTULO IV

NUEVOS SOPORTES MURALES 




\section{NUEVOS SOPORTES MURALES}

Antes de decidir cuál será el soporte más adecuado para las pinturas que nos ocupan, una vez eliminado el anterior, que como explicaremos en el próximo capítulo, resulta inadecuado, hay que hacer un repaso tanto de las características de un soporte ideal, como de los tipos de soportes que se han aplicado a lo largo de la historia a pinturas murales arrancadas.

Cuando se arranca una pintura mural es necesario confeccionar un nuevo soporte que la albergue, ya sea exenta del muro donde se encontraba en origen o ya sea recolocada en ese mismo lugar pues no podemos privar a una obra de su soporte.

Ya se trate de un caso u otro, las características de ese soporte serán diferentes, pero se pueden establecer una serie de características comunes que debería tener el soporte ideal para cualquier pintura arrancada, sin olvidar que frente a una obra concreta, habrá que tener en cuenta sus características particulares.

Estas características comunes deben atender a los siguientes puntos:

- Ligereza. Teniendo en cuenta que las obras arrancadas suelen tener grandes dimensiones, cuanto menor sea el peso del soporte, más fácil será de manejar la obra cuando esté unida a éste.

- Flexibilidad o adaptabilidad a la superficie. El nuevo soporte debe permitir a la obra conservar las deformaciones propias de su estructura, así como la forma de la superficie. En el caso de obras arrancadas de cúpulas o bóvedas, el soporte debería poder ser construido de tal manera que pueda reproducir las irregularidades de la pintura.

- Estabilidad dimensional. El coeficiente de dilatación ${ }^{91}$ de los componentes del mortero de una pintura mural, es relativamente débil, comparado con muchas materias plásticas, pero no es muy diferente de los metales, y es poco inferior de coeficiente de dilatación de los plásticos laminados a base de fibra de vidrio. Por lo tanto el nuevo soporte debe tener un coeficiente de dilatación térmica débil, similar al del estrato pictórico, para evitar que éste se separe de su nuevo soporte, bajo el efecto de variaciones de la temperatura ambiente. Mientras que el estrato pictórico no sufre variaciones con los cambios de humedad.

\footnotetext{
${ }^{91}$ MORA, Paolo y Laura; PHILIPPOT, Paul. La conservazione delle pitture murali. II edizione a cura di Bresciani s.r.I. Editrice Compositori. Bologna, 2001. Pág. 286.
} 
- Coeficiente de dilatación térmica mínimo. Debe evitarse siempre la condensación de humedad sobre la superficie pictórica, por lo que el material del nuevo soporte debe ser insensible a las variaciones de temperatura de la pared donde se encuentra ubicada dicha obra. Por ello la conductividad y la capacidad térmica del soporte deben ser lo más débiles posible.

- Grosor igual o inferior al del mortero original de la pintura. Es evidente que si una obra arrancada se recoloca en su lugar de origen, el grosor de ésta no debe superar el del mortero circundante, con el fin de evitar posibles desniveles que distorsionarían las calidades óptimas de la obra. Por ello, su soporte será igual o inferior al espesor del mortero original.

- Reversibilidad. Se trata de conferir reversibilidad ya no a los materiales utilizados simplemente, sino también al tratamiento de aplicación de un nuevo soporte. Se trata de poder separar, en un momento dado, la pintura de su nuevo soporte, con el mínimo de tratamientos y lo más fácilmente posible.

- Impermeabilidad o aislamiento de la pintura de las causas de alteración que pueden provenir del soporte arquitectónico. Si el soporte es impermeable, evita que pase la humedad a través del muro hacia la pintura, por lo que se evitará de igual modo todas las alteraciones provocadas por la humedad.

- Resistencia a los agentes atmosféricos. Aunque la obra sea ubicada en un lugar con condiciones favorables, es necesario que todos los materiales que componen el nuevo soporte presenten el máximo de resistencia a los agentes atmosféricos, sobre todo a la elevada humedad y a acción de los rayos ultravioleta.

- Resistencia a los agentes biológicos. Inmunidad al ataque de microorganismos, tales como hongos, mohos y algas. Aunque existen fungicidas y biocidas que pueden ser aplicados a los materiales susceptibles de ser atacados por estos microorganismos, la efectividad de estos productos a largo plazo no está probada, por lo que es preferible recurrir a materiales que resistan a los agentes biológicos.

- Resistencias mecánicas. El soporte debe ofrecer las características de protección contra las posibles deformaciones de la película pictórica por golpes en el nombrado soporte. Debe poder absorber eventuales accidentes de transporte o montaje sin sufrir deformaciones o roturas.

- Resistencia a disolventes y al agua. La obra arrancada y colocada en un nuevo soporte puede necesitar con el tiempo algún tratamiento de limpieza, por lo que dicho soporte debe ser 
capaz de soportar la acción de los disolventes usados comúnmente en tratamientos de pinturas murales.

- Facilidad de fabricación y coste mínimo. El restaurador debería poder fabricar fácilmente el soporte requerido, así como conseguir los materiales adecuados para ello con relativa facilidad. Otro punto muy importante a tener en cuenta es el coste de los materiales, que evidentemente dependerá del tamaño de la obra tratada. Aun así, se procurará que los materiales sean lo más económicos posible dentro de los requerimientos de la obra.

- Ignífugo. La resistencia al ataque del fuego es también muy importante a la hora de elegir los materiales para elaborar un soporte adecuado para una pintura mural arrancada. En caso de sufrir un incendio, el soporte debe ser lo más ignífugo posible, con el fin de no deteriorar más la obra.

\subsection{REVISIÓN DE DIFERENTES TIPOS DE SOPORTE USADOS A LO LARGO DE LA HISTORIA}

A lo largo de la historia se han utilizado una gran diversidad de materiales para la elaboración de nuevos soportes aplicados a pinturas murales arrancadas. Éstos se pueden dividir en dos grandes grupos, los soportes flexibles o semirrígidos y los soportes rígidos.

A su vez dentro de los soportes rígidos, podemos encontrar diferencias entre soportes rígidos tradicionales, con materiales naturales, y soportes rígidos con materiales sintéticos y estrato de intervención. Se muestra a continuación una clasificación de los tipos de soportes que podemos encontrar:

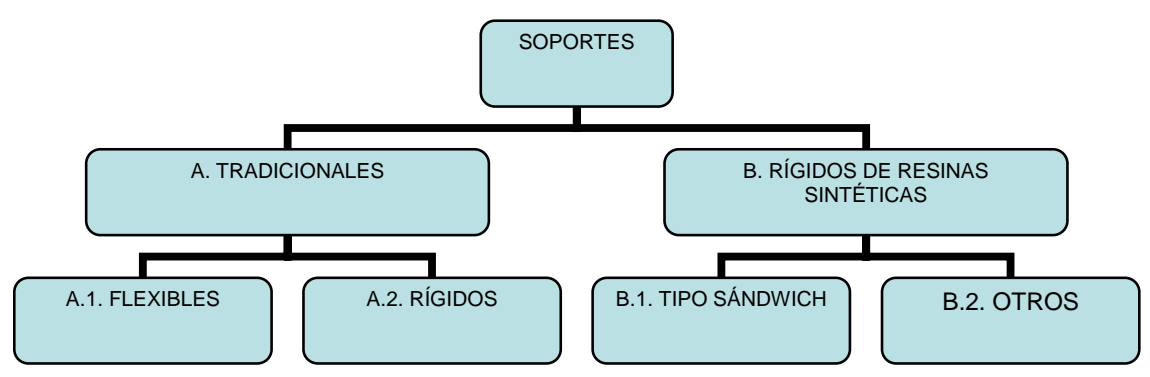



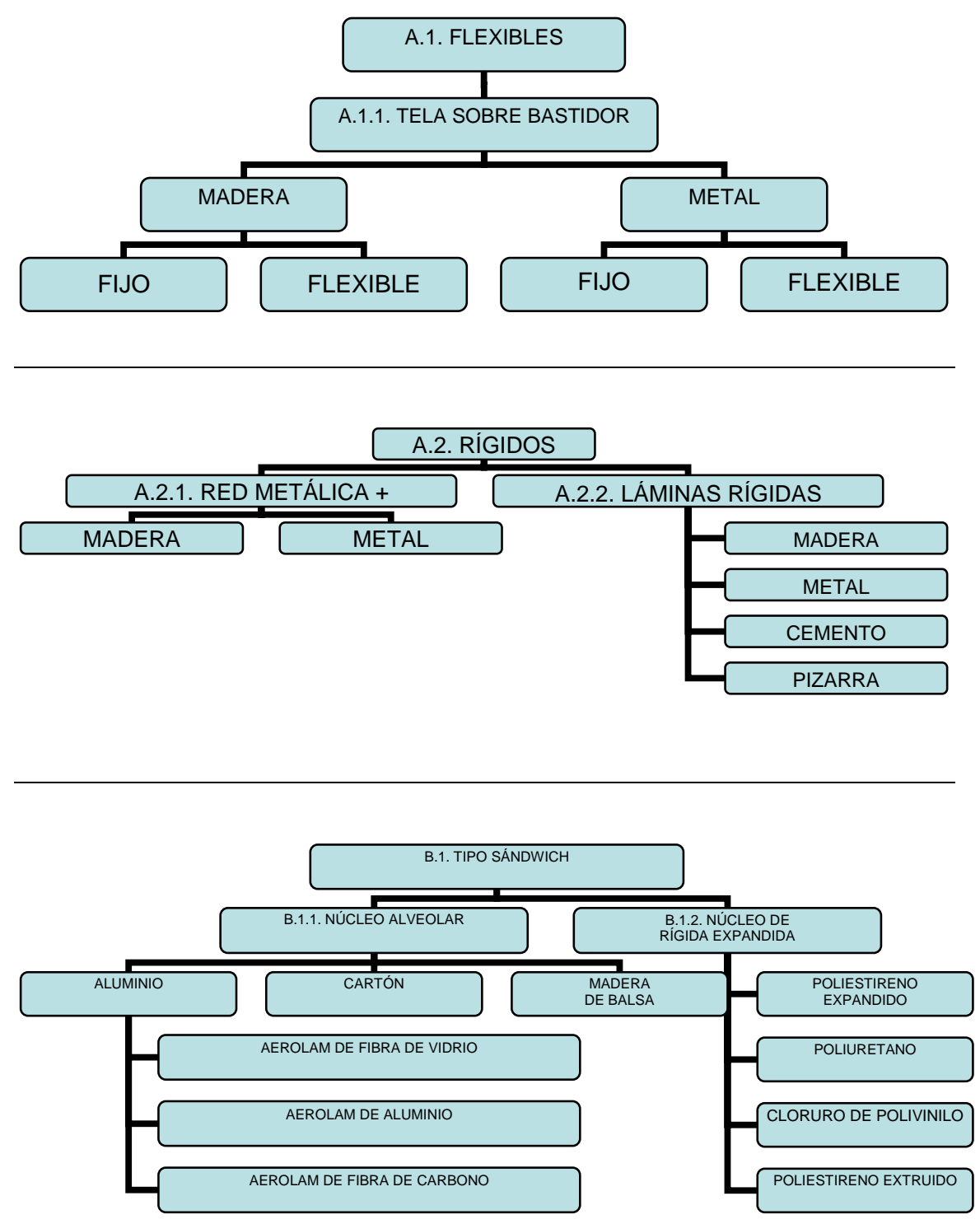


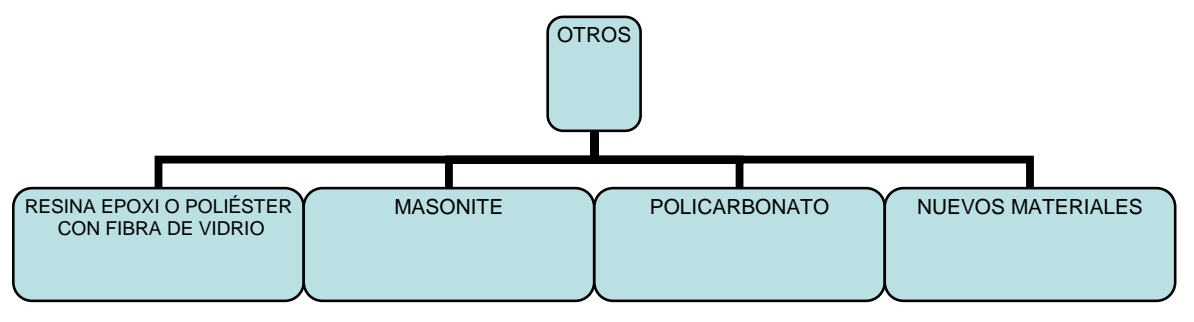

- A. Soportes tradicionales.

A.1. Flexibles.

A.1. 1. Tela sobre bastidor de:

a. Madera: fijo o elástico.

b. Metal: fijo o elástico.

A.2. Rígidos.

A.2. 1. Red metálica + yeso sobre bastidor de:
a. Madera.
b. Metal.

A.2. 2. Láminas rígidas.
a. Madera: contrachapado, madera laminada.
b. Metal: hierro, adero inoxidable.
c. Conglomerado de cemento: fibrocemento Eternit ${ }^{92}$.
d. Pizarra.

\footnotetext{
${ }^{92}$ Ver: http://www.eternit.com.pe/pages/ete_ptanques.asp
} 
B. Soportes rígidos de resinas sintéticas.

B.1. Tipo sándwich.

B.2. 1. Núcleo alveolar.

a. Núcleo de aluminio.

- Aerolam® de fibra de vidrio.

- Aerolam® de aluminio.

- Aerolam® de fibra de carbono.

b. Núcleo de cartón.

B.2. 2. Núcleo de espuma rígida expandida.

a. Poliestireno expandido ${ }^{93}$.

b. Poliuretano ${ }^{94}$.

c. Cloruro de Polivinilo expandido semirrígido $^{95}$.

B.2. Otros.

B.2. 1. Resina epoxi o pliéster con vibra de vidrio.

B.2. 2. Masonite.

B.2. 3. Policarbonato.

B.2. 4. Nuevos materiales.

${ }^{93}$ Ver las características técnicas en el Libro blanco de la Asociación Nacional de Poliestireno Expandido: http://www.anape.es. Se ha utilizado el de $1^{\prime} 7 \mathrm{~mm}$ de espesor.

${ }^{94}$ Extraído del interior de cartón pluma de $1^{\prime} 7 \mathrm{~mm}$ y de $1 \mathrm{~mm}$ de espesor. Ver características técnicas en http://www.poliuretanos.com.

${ }^{95}$ Se ha utilizado el CADORITE, distribuido por CTS España. 


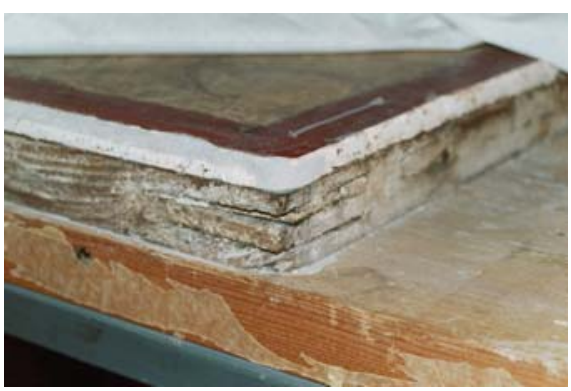

Fig. 49. Bastidor de madera con encañado y yeso.

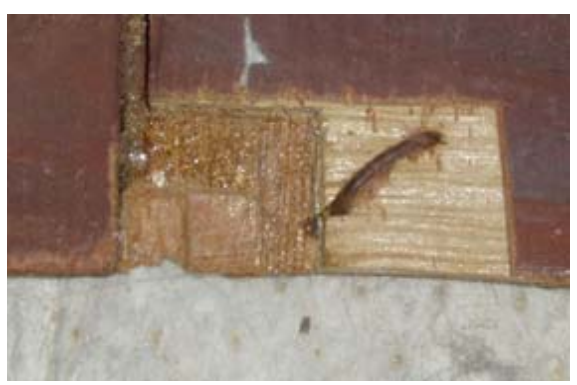

Fig. 51. Contrachapado de madera.

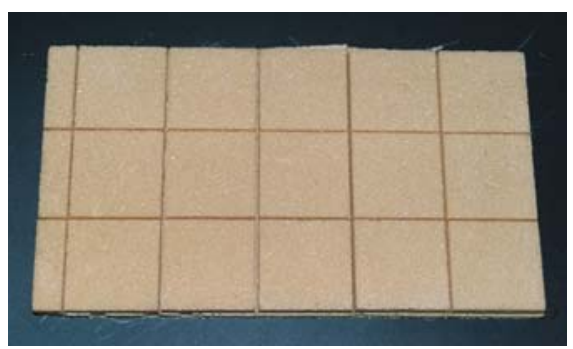

Fig. 53. Cloruro de polivinilo expandido semirígido ${ }^{96}$.

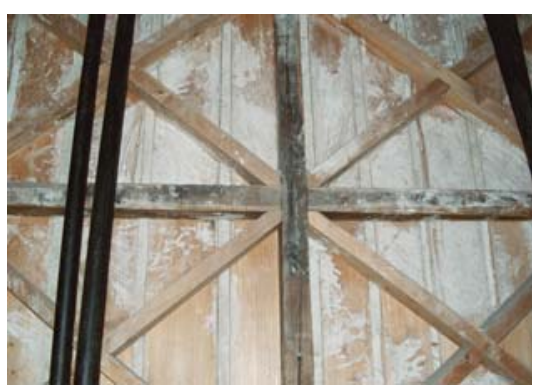

Fig. 50. Bastidor de madera con láminas de madera y yeso y refuerzos metálicos.

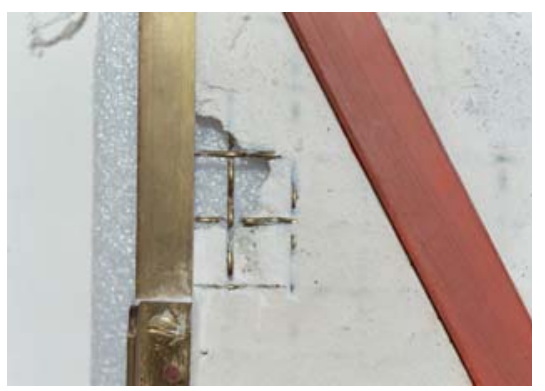

Fig. 52. Bastidor de madera con red metálica y yeso.
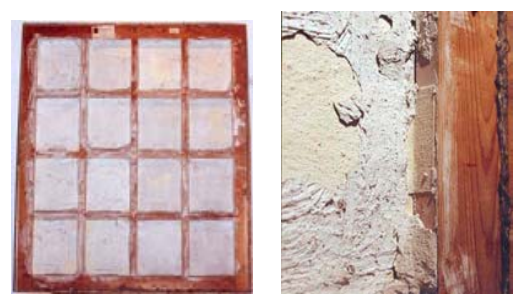

Fig. 54. Bastidor de madera y soporte de tela.

${ }^{96}$ Se ha utilizado el CADORITE, distribuido por CTS España. 


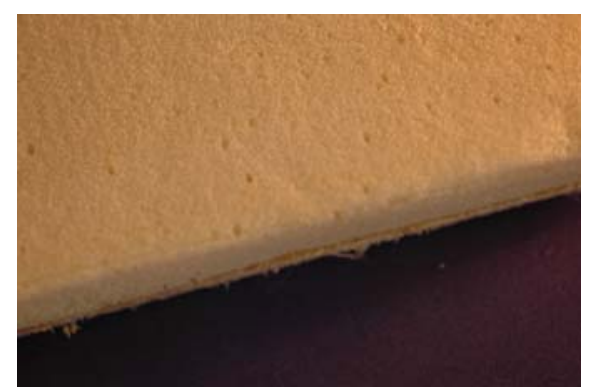

Fig. 55. Poliuretano ${ }^{97}$.

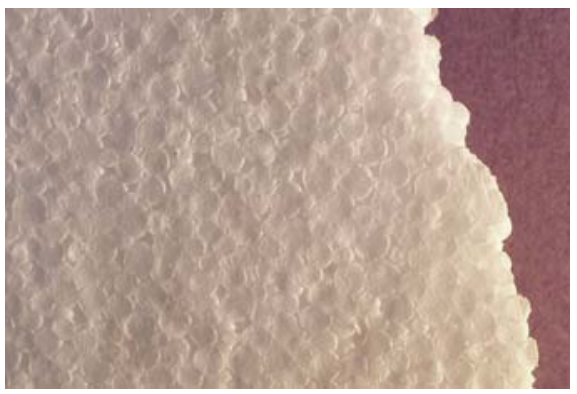

Fig. 57. Poli estireno expandido ${ }^{99}$.

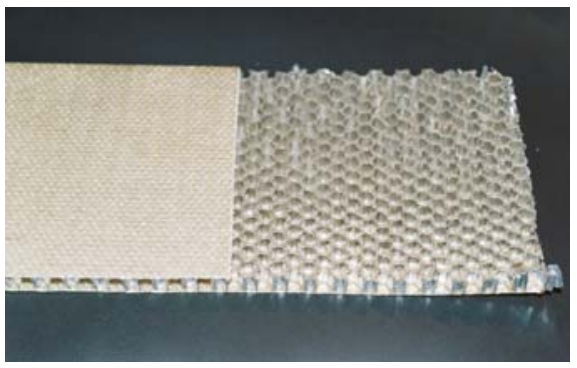

Fig. 59. Aerolam® de fibra de vidrio.

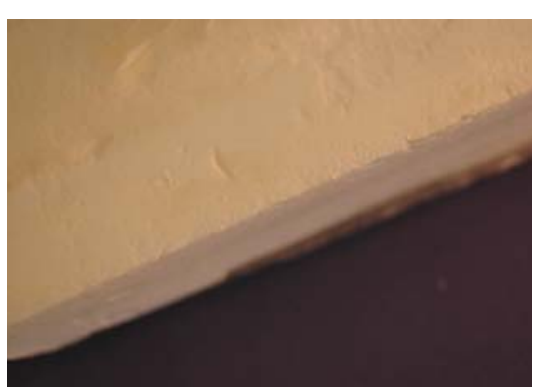

Fig. 56. Poli estireno extruído ${ }^{98}$.

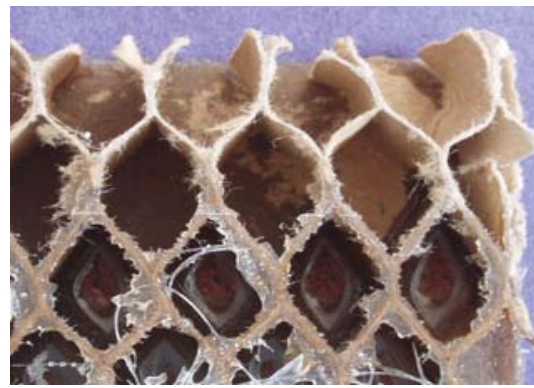

Fig. 58. Soportes de nido de abeja de papel.

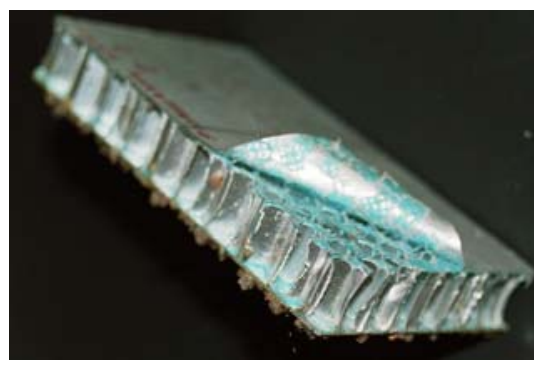

Fig. 60. Aerolam® de aluminio.

\footnotetext{
97 Extraído del interior de cartón pluma de $1^{7} 7 \mathrm{~mm}$ y de $1 \mathrm{~mm}$ de espesor. Ver características técnicas en http://www.poliuretanos.com.

98 Se ha utilizado el de $2 \mathrm{~mm}$ de espesor. Ver características técnicas en http://www.ediltec.es.

${ }^{99}$ Ver las características técnicas en el Libro blanco de la Asociación Nacional de Poliestireno Expandido: http://www.anape.es. Se ha utilizado el de 1'7 mm de espesor.
} 


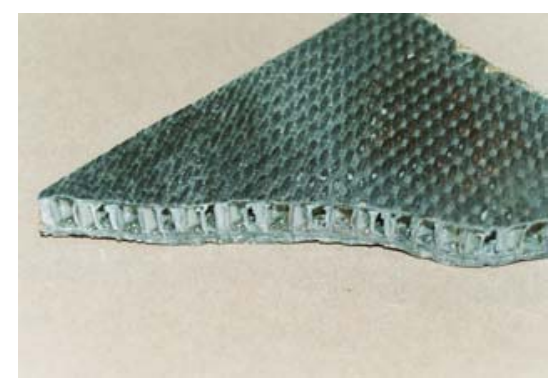

Fig. 61. Aerolam ${ }^{\circledR}$ de fibra de carbono.

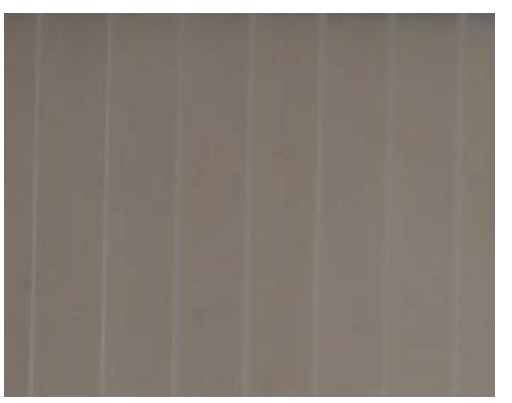

Fig. 62. Policarbonato.

Franco Manzini ${ }^{100}$, hace una reflexión sobre la evolución que han sufrido los nuevos soportes aplicados a pinturas murales arrancadas, haciendo un repaso de los diferentes materiales usados a lo largo de un corto periodo de tiempo.

Rodríguez Sancho ${ }^{101}$ hace un repaso de la evolución de los soportes para traslados de pinturas murales arrancadas. No obstante, a partir de 1995, fecha del citado artículo, se desarrollan otro tipo de soportes que cabe nombrar.

\section{A.1.1.a. Soporte flexible de tela sobre bastidor de madera.}

Después de aplicar nuevos soportes muy pesados para obras murales arrancadas, se pensó que se podían trasladar pinturas murales a lienzo, de modo que de un soporte rígido, como es el muro, la obra pasa a tener un soporte textil, con todos los inconvenientes que ello conlleva, pues el soporte textil sufre movimientos de contracción, que la obra mural no ha sufrido nunca. Puede variar incluso la forma de la obra, las irregularidades que suelen presentar las obras murales, quedan en este soporte eliminadas, pues además es el soporte típico utilizado en épocas pasadas para trasladar pinturas murales arrancadas mediante la técnica del strappo, técnica que ya conlleva la desaparición de éstas características intrínsecas de las pinturas murales. Las telas que conforman el nuevo soporte son tensadas en un bastidor, normalmente de madera y, si la obra es de grandes dimensiones, se puede encontrar

\footnotetext{
${ }^{100}$ VV.AA. Restauri in Piamonte 1968/1971. Soprintendenza alle Gallerie e alle opere d'Arte del Piamonte. Torino-Galeria Sabando. Maggio 1971. Ed. D’Arte Fratelli Pozzo.Torino, 1971.

101 RODRÍGUEZ SANCHO, Isabel. Evolución de los soportes para reforzar y trasladar pinturas. Algunos ejemplos (primera parte). En Pátina. Escuela superior de conservación y restauración de bienes culturales de Madrid. Junio 1995. №7. Madrid, 1995.
} 
un gran número de travesaños, formando por el reverso una cuadrícula similar a la de los engatillados en obras sobre tabla. Muchas veces, entre cada uno de éstos recuadros, se adhería o bien estopa con yeso o bien fragmentos de tela con yeso, con el fin de unir los travesaños del bastidor a la tela del soporte, y evitar así excesos de movimiento de dicha tela.

En Italia, después de la experiencia negativa con los soportes de cemento, el Istituto Centrale per il Restauro, retomó los soportes de tela tensada a un bastidor de madera, pero ideó un bastidor con sistema de tensión elástico y automático. Así, colocó en soportes de madera pinturas como las arrancadas de L'Aula Isiaca ${ }^{102}$, o de la Casa di Livia al Palatino ${ }^{103}$, así como otras muchas pinturas, como las de la Tomba del Colle ${ }^{104}$.

En España, todavía en 1984, se trasladaban pinturas murales arrancadas sobre soportes de tela tensados en un bastidor. Por ejemplo, se trasladó una pintura mural de grandes dimensiones, de Manuel Millares, sobre una tela tipo Velásquez tensada en un bastidor de madera de pino de $3 \mathrm{~cm}$. de grosor, en forma de cuádruple cruz travesaño central y con montantes ${ }^{105}$.

También podemos tomar como referencia de nuevos soportes, aquellos que se usan para trasladar pinturas sobre lienzo que cubre paredes y muros, pues, en esencia, se tratan como si fuesen pinturas murales. Un ejemplo lo encontramos en las telas vaticanas de Pietro da Cortona, sitas en Urbino ${ }^{106}$. Estas pinturas fueron adheridas a una serie de sucesivas capas de tela, con Beva O.F.Gel.

\footnotetext{
${ }^{102}$ BORRELLI VLAD, Licia. "II distacco della parete absidata dell'Aula Isiaca". En Bollettino dell'Istituto Centrale del Restauro. 27-28. Istituto poligrafico dello atato. Roma, 1957.

103 BORRELLI VLAD, Licia. "Distacchi e restauri di pitture della casa di Livia al Palatino". En Bollettino dell'Istituto Centrale del Restauro. 19-20. Istituto poligrafico dello Stato. Roma, 1955. Págs. 107-121.

104 BORRELLI VLAD, Licia. "Il distacco di due frammenti della tomba del Colle". En Bollettino dell'Istituto Centrale del Restauro. 27-28. Istituto poligrafico dello Stato. Roma, 1957. Págs. 33-37.

105 MÉNDEZ MANZANO, Agustín; MORET GARCíA-MAURIÑo, Aureliano. Traslado a lienzo de una pintura mural de grandes dimensiones original de Manuel Millares. En actas del IV congreso de Conservación de Bienes Culturales. Palma de Mallorca. 29 de octubre al 1 de noviembre de 1982. instituto de conservación y restauración de obras de arte. Comité Español del ICOM. Gráficas solana. Madrid, 1984.

${ }^{106}$ FAZI, Benedetta; VITTORINI, Bruno. Nuove tecniche di foderatura. Le tele vaticane di
} Pietro da Cortona ad Urbino. Nardini editore. Firenze, 1995. 


\section{A.1.1.b. Soporte de tela sobre bastidor metálico.}

En 1958 se aplicaban ya en el Istituto Centrale per il Restauro, bastidores metálicos para la sujeción y tensado de pinturas murales arrancadas, como una tumba que se arrancó en Tarquinia ${ }^{107}$.

\section{A.2.1.a. Encañado y yeso sobre bastidor de madera.}

En la antigüedad los soportes eran bastidores de madera con encañado y yeso. Hoy en día se ha desestimado este tipo de soporte por ser demasiado pesado, por quemar con facilidad y porque el yeso, con exceso de humedad provoca la aparición de eflorescencias salinas, que como es sabido, son muy perjudiciales para las pinturas murales.

\section{A.2.1.a. Red metálica y yeso sobre bastidor de madera.}

En 1915 se llevaron a cabo una serie de arranques de pintura mural al fresco en la iglesia de San Miniato al Monte, en Florencia ${ }^{108}$. Estas pinturas, arrancadas por medio de stacco, fueron colocadas en un nuevo soporte de yeso reforzado con un bastidor con red metálica. Con la humedad el yeso se estaba trasformando en sulfato cálcico activo, por lo que a mitad de los años 60 se sustituyeron los soportes, por otros de masonite, rebajando el yeso por el reverso hasta llegar a la película pictórica.

En 1919 Domenico Fiscali empleó un soporte de red metálica clavada sobre un bastidor, de madera o metal, rellena de una argamasa de yeso ${ }^{109}$.

En los años 40, se habían trasladado unas pinturas murales arrancadas de los ábsides de Sant Sadurní d'Osormort y de Sant Martí del Brull, al Museo Episcopal de Vic ${ }^{110}$. Estas pinturas fueron adheridas a

107 BORRELLI VLAD, Licia. "Il distacco delle pitture di una tomba tarquiniese di recente scoperta". En Bollettino dell'Istituto Centrale del Restauro. 34-35. Istituto poligrafico dello Stato. Roma, 1958. Págs. 71-85.

108 CARANI, Maria Lucia. "Restauri in San Miniato al Monte a Firenze: il problema della ricollocazione degli affreschi e delle sinopie". En Kermes, arte e tecnica del restauro. Anno III no 7. Gennaio/aprile 1990. Cronache del restauro. Nardini editore. Firenze, 1990. Pág. 20.

109 RODRÍGUEZ SANCHO, Isabel. Evolución de los soportes para reforzar y trasladar pinturas. Algunos ejemplos (primera parte). En Pátina. Escuela superior de conservación y restauración de bienes culturales de Madrid. Junio 1995. №7. Madrid, 1995. Pág. 84.

110 XARRIÉ, Josep Maria. "Els nous suports dels absis romànics del Museu Episcopal de Vic". En RESCAT. Butlletí de Restauració de Béns Mobles. No 6. Desembre 1998. Generalitat de Catalunya. Departament de Cultura. Barcelona, 1998. 
dos capas de tela de algodón por el reverso mediante caseinato cálcico, y este conjunto a su vez, adherido a un soporte de yeso de $3 \mathrm{~cm}$. de grosor. En 1998, cuando se retomó su restauración para trasladarlas a otro soporte, se vio que este soporte de yeso resultaba inadecuado, ya que habían aparecido gran cantidad de hongos -más del $60 \%$ de la superficie- entre el soporte de yeso y la pintura, pues el adhesivo utilizado para unir el reverso de la pintura con el soporte de yeso, era un engrudo de harina con cola animal, producto higroscópico, al igual que el yeso, siendo además, éste último muy poroso y absorbe todavía más la humedad. Dicho soporte ha sido sustituido en el Servei de Restauració de Béns Mobles, por un nuevo soporte en aluminio, con el fin de evitar todos los problemas derivados de la utilización del yeso o la madera.

Entre 1950-55 en Florencia se siguió utilizando en abundancia el soporte de red metálica y yeso, hasta que empezaron a apreciarse los primeros problemas ocasionados por la utilización de este tipo de materiales, como la oxidación de la red metálica, que manchaba la superficie además de aumentar de volumen el metal provocando el desprendimiento de parte del yeso, o como la aparición de sales en las pinturas, provenientes del yeso. Fue a partir de ésta época cuando se empezó a experimentar con otros materiales, primero el cemento, después productos sintéticos...

En España también se usó este tipo de soporte, aunque a veces se sustituía el yeso por un mortero de cal y arena. Más delante de enriquecía este mortero con alguna cola, que podía ser caseinato cálcico, o caseinato cálcico adicionado con una pequeña proporción de acetato de polivinilo, para darle elasticidad. ${ }^{111}$

En el Centre de Restauració de Béns Mobles de Barcelona, en el que trabajaba ya en los años 70 Josep $\mathrm{M}^{\mathrm{a}}$ Xarrié, a veces añadían un $10 \%$ de acetato polivinílico al caseinato cálcico aplicado al reverso. ${ }^{112}$

\section{A.2.1.b. Red metálica sobre bastidor metálico.}

En 1957 se aplicó, en el Istituto Centrale per il Restauro, a las pinturas arrancadas de la Casa dei Grifi, un soporte de red metálica con una cama de caseinato cálcico, y bastidor metálico ${ }^{113}$.

\footnotetext{
111 FERRER MORALES, Ascensión. La pintura mural. Su soporte, conservación, restauración y las técnicas modernas. Universidad de Sevilla. Sevilla, 1995. Pág. 126.

${ }^{112}$ XARRIÉ, Josep Maria. Restauració d'obres d'art a Catalunya. Publicacions de l'Abadia de Montserrat. Barcelona, 2002. Pág. 144.

113 BORRELLI VLAD, Licia. "Il distacco delle pitture del Grande cubiculo della casa dei Grifi". En Bollettino dell'Istituto Centrale del Restauro. 27-28. Istituto poligrafico dello Stato. Roma, 1957. Págs. 132-140.
} 


\section{A.2.2.a. Contrachapado de madera.}

Durante los años 40 a 60 del siglo XX en el taller catalán de los hermanos Gudiol las pinturas arrancadas eran traspasadas a un nuevo soporte definitivo mediante la aplicación al reverso de caseinato cálcico, compuesto por nueve partes de cal y una de caseína. Esta proporción resulta más débil que la usada tradicionalmente (3 partes de cal y una de caseína), lo que hacía de esta pasta adhesiva un elemento mucho más penetrante en el mortero original. Si este adhesivo no cumplía sus funciones correctamente en alguna de las zonas, provocando desprendimientos de película pictórica, aplicaban cera caliente y a continuación, plancha o espátula caliente, a modo de consolidante. También usaban varias capas de gasa, en sustitución a la tradicional tela de algodón ${ }^{114}$. El soporte que utilizaban era, o bien el típico de tela tensada en un bastidor, o contrachapado de madera ${ }^{115}$.

Todavía en 1995 se usaba el bastidor de madera reforzado, como soporte de pinturas murales arrancadas. Conxa Armengol, Mireia Fages, Pere Rovira i Silvia Samaniego, explican en su artículo "Recuperació $i$ restauració de pintures murals a l'oli de Pere Viver"116 , cómo aplican a unas pinturas al óleo, arrancadas por medio de stacco, un soporte consistente en un bastidor de madera unido al reverso de la pintura por medio de un adhesivo poliuretánico (Bostik); este bastidor de madera queda reforzado en su interior por un enrejado de aluminio galvanizado, y relleno de espuma de poliuretano. Todo el conjunto es cerrado por el reverso por medio de un aglomerado (DM) hidrófugo, encolado al bastidor.

\section{A.2.2.b. Lámina de acero inoxidable sobre bastidor metálico.}

En 1958 los frescos que pintó Foppa en la capilla Cavalcabò de Santa Maria en Brescia, fueron transportados sobre bastidores metálicos, con finas láminas de acero inoxidable y después fueron adaptadas al muro practicando unas hendiduras para insertar el bastidor y que la pintura quedara a nivel con el resto.

\footnotetext{
114 XARRIÉ, Josep Maria. Restauració d'obres d'art a Catalunya. Publicacions de l'Abadia de Montserrat. Barcelona, 2002. Pág. 78.

${ }^{115}$ Ver el punto 9.1.1 del capítulo 9.

116 ARMENGOL, Conxa; FAGES, Mireia; ROVIRA, Pere; SAMANIEGo, Silvia. "Recuperació i restauració de pintures murals a l'oli de Pere Viver", en V Reunió Tècnica de conservació i Restauració. Museu Marítim de Barcelona 20 i 21 d'octubre de 1995. Edita el Grup Técnic. Associació professional dels conservadors-restauradors de Catalunya. Barcelona, 1998
} 
En 1959 aplicaron un soporte similar pero más ligero y descomponible, a las pinturas de dos capillas de la iglesia milanesa de san Pietro in Gessate, pintadas por Montorfano.

También Parrini, Casazzo y Pizzigoni ${ }^{117}$ nombran la utilización de placas de metal como soporte de algunas pinturas murales arrancadas, concretamente estos soportes, de aluminio querían subsanar los defectos de deformación que sufrían los soportes de madera.

Podríamos considerar una variante de este tipo de soporte, las estructuras de aluminio que se usan para trasladar pinturas murales de gran formato con formas no planas, como es el caso de las pinturas románicas de Sant Sadurní d'Osormort y Sant Martí del Brull ${ }^{118}$.

\section{A.2.2.c. Conglomerado de cemento. Fibrocemento "Eternit"}

En los años 40 se empiezan a usar placas de cemento para aplicar pinturas murales arrancadas. Se usaban planchas de fibrocemento "Eternit" unidas a un bastidor de madera por el reverso. Este tratamiento se aplicó en 1949 para trasladar los frescos del "Trionfo della Morte" del Camposanto de Pisa, encolando láminas de cemento-amianto a placas de Eternit de casi $15 \mathrm{~mm}$ de espesor. ${ }^{120}$ Este tipo de soporte no resulta adecuado en cuanto que el cemento-amianto, además del excesivo peso, puede sufrir roturas y deformaciones, incluso por su propio peso, además la alta concentración de yeso lo hace un material propicio a la formación de sales. Además el amianto es un producto altamente cancerígeno, por lo que estte material ha quedado en desuso.

\footnotetext{
${ }^{117}$ PARRINI, Paolo L.; CASAZZA, Ornella; PIZZIGONI, Giuseppe. "I materiali compositi nel restauro científico degli affreschi: il supporto delle sinopie di Masaccio e Masolino". En Quaderni del restauro. La Capella Brancacci. La scienza per Masaccio, Masolino e Filipino Lippi. Olivetti. Milano, 1992. Pág. 186.

${ }^{118}$ TONEU, M. "Prócés d'adaptació de les pintures romàniques de Sant Sadurní d'Osormort i Sant Martí del Brull en els nous suports d'alumini" En Rescat $n^{\circ} 12$. Butlletí del Servei de Restauració de Béns Mobles. Generalitat de Catalunya. Barcelona, 2002. Págs. 8-9.

${ }^{119}$ Ver: http://www.eternit.com.pe/pages/ete_ptanques.asp

${ }^{120}$ PARRINI, Paolo L.; CASAZZA, Ornella; PIZZIGONI, Giuseppe. "I materiali compositi nel restauro científico degli affreschi: il supporto delle sinopie di Masaccio e Masolino". En Quaderni del restauro. La Capella Brancacci. La scienza per Masaccio, Masolino e Filipino Lippi. Olivetti. Milano, 1992. Pág. 186.
} 


\section{A.2.2.d. Pizarra.}

En 1927, Secco Suardo explica cómo se aplicaban nuevos soportes de pizarra a pinturas murales al óleo, barniz o cera arrancadas, que se fijaban a dicha pizarra con yeso. ${ }^{121}$

"In tre generi principali possonsi classificare le pitture che si seguiscono sul muro, cioè: $1^{\circ}$ dipinti all'olio, a vernice ed a cera; $2^{\circ}$ dipinto a tempera ed a guazzo; $3^{\circ}$ dipinti a buon fresco. Intorno ai due primi non mi tratterrò che pochissimo, ritenendo che il più sicuro modo di trasportargli da un luogo ad un altro è quello di segare il muro e serrarlo con cerchi di ferro; qualora il dipinto sia di piccola estensione; procurare di conservarne il solo intonaco, che verrà poi assicurato col gesso sopra una ardesia o lavagna."

\section{B.1.1.a. Aerolam ${ }^{\circledR}$ de fibra de vidrio.}

Como ejemplo mencionamos el arranque realizado en 1988 un equipo formado por miembros de la Universitat de València y la Universidad Politécnica de Valencia, de las pinturas murales de la capilla de L'Universitat de València ${ }^{122}$, que fueron transferidas a nuevos soportes de estructura alveolar a base de fibra de vidrio y resina epoxi, con celdillas de aluminio.

Otro ejemplo es el arranque realizado en 1996 de una pintura mural de Joaquín Michavila, en las instalacines del BBV de la plaza del Ayuntamiento de Valencia.

Para proteger el conjunto pictórico, se usó una estructura tipo metálica que formaba una cuadrícula de varillas sobre una lámina de madera. Para asegurarse de que formaran una unidad, se rellenó dicha cuadrícula con espuma de poliuretano. Una vez arrancada y tratada por el reverso con caseinato cálcico y la aplicación de una tela de lino, la obra fue colocada en un nuevo soporte de Aerolam ${ }^{\circledR}$, con una capa de intervención de lino y "Spherecore ${ }^{\circledR}$ "123 de fibra de vidrio, adherida al nuevo soporte con resina epoxi, y al reverso de la pintura arrancada con

\footnotetext{
${ }^{121}$ SECCO-SUARDO, G. "Del trasporto dei dipinti dal muro" capitolo III. II restauratore dei dipinti. Ulrico Hoelpi. Milano, 1927. Pág. 208.

122 MONRAVAL, Magdalena; KROUGLY, Laurence. "Las pinturas murales de la Capilla de la Universitat de València. Estudi general. Proceso de arranque y salvamento (1988)". En VIII Congrés de Conservació i Restauració de Béns Culturals. Ponències i Comunicacions. València, 20, 21, 22, 23 setembre 1990. Generalitat Valenciana. Actas recopiladas por Pilar Roig Picazo. UPV. Conselleria de Cultura, Educació i Ciència. València, 1990.

${ }^{123}$ El Spherecore es un material elaborado a base de fibras de vidrio muy finas, con microesferas termoplásticas.
} 
resina acrílica ${ }^{124}$. Se reforzó el conjunto con una estructura metálica sustentante que garantizase el comportamiento autoportante de la obra.

En 1998 se arranca un zócalo mural de un palacio civil islámico en Játiva (Valencia) ${ }^{125}$ y se le construye un nuevo soporte de Aerolam ${ }^{\circledR}$ tratado con resina epoxi, polvo de mármol y microesferas huecas, para otorgarle mayor rugosidad y favorecer un mejor agarre de la obra. Se aplica una capa de intervención de fibra de vidrio con resina epoxi. La unión de la pintura arrancada al soporte se realiza con resina epoxi.

En 1998, el Centre de Restauració de Béns Mobles de Barcelona después de arrancar una pintura mural de época romana, mediante la técnica del stacco a massello, rebaja el reverso con un pequeño martillo neumático de escultor, para seguidamente, aplicar tres capas de cal, arena y una emulsión acrílica. Cuando todavía estaba mordiente la última capa de esta mezcla, se aplicó un soporte de fibra de vidrio y aluminio de $12 \mathrm{~mm}$ de grosor, reforzándose todo el conjunto con un marco de acero inoxidable. Para asegurar que este marco sujetara la totalidad del conjunto, se practicaron diez orificios laterales en los que se introdujeron pernos de acero inoxidable.

En 1999 durante una Misión Arqueológica Española ${ }^{126}$ en Tell Halula (Siria) se arrancaron para unas pinturas murales, mediante stacco a massello. Para proceder al arranque se protegieron las pinturas con una primera capa de papel japonés ${ }^{127}$ y un posterior engasado, adhiriendo todas las capas con resina acrílica en disolvente muy volátil. Como capa de intervención entre el nuevo soporte y la pintura, se utilizó un mortero hidráulico (mortero de reposición Parrot's Mix $4 ®$, de Industrial Química

124 VV.AA. Arranque y traslado a un nuevo soporte de la pintura mural realizada por Joaquín Michavila. Universidad Politécnica de Valencia. Valencia 1998.

ROIG PICAZO, Pilar y BOSCH REIG, Ignacio. "Arranque y traslado de una pintura mural a un nuevo soporte y espacio arquitectónico. Primera parte". En R\&R Restauración y Rehabilitación. No 21 octubre 1998. Edita Prensa Española General de Revistas, S.A. Madrid, 1998.

ROIG PICAZO, Pilar y BOSCH REIG, Ignacio. "Arranque y traslado de una pintura mural a un nuevo soporte y espacio arquitectónico. Segunda parte". En R\&R Restauración y Rehabilitación. No 22 noviembre 1998. Edita Prensa Española General de Revistas, S.A. Madrid, 1998.

${ }^{125}$ ESCRIG MORENO, Ma José; PUERTES TORRENT, Consuelo. "Arranque, restauración y reintegración informatizada de un zócalo mural de un palacio civil islámico en Játiva (Valencia)". En XII Congreso de Conservación y Restauración de Bienes Culturales. Alicante del 28 al 31 de octubre de 1998. Ed. Generalitat Valenciana. Conselleria de Cultura Educació i Ciència, Direcció General de Patrimoni Artístic. Octubre 1998. Pág. 637.

126 GÓNZALEZ PASCUAL, Margarita. "La conservación del suelo pintado con figuras humanas más antiguo del Próximo Oriente”. En Pátina. Escuela superior de conservación y restauración de bienes culturales de Madrid. Junio 1999. Época II no 9. Iluminación y conservación. Madrid, 1999. Pág. 14.

${ }^{127}$ El papel japonés previene la impresión de la trama de la gasa en la superficie pictórica. 
Parrot, S.A.), de un espesor variable entre 2 y $3 \mathrm{~cm}$, ya que servía también como capa de nivelado. Que consistía en un panel prefabricado con núcleo de nido de abeja en aluminio y exterior revestimiento mediante un triple estratificado de tejido de vidrio y resina epoxi (Panel Stifflight serie PGN®. CTS. España). Como adhesivo del nuevo soporte se utilizó resina estructural epoxídica.

En 2001, en el Centre de Restauració de Béns Mobles de Barcelona ${ }^{128}$, se utilizó como nuevo soporte una placa de Aerolam ${ }^{\circledR}$, siendo la capa de intervención un compuesto de cinco partes de Perlite ${ }^{\circledR}$ y una de Primal ${ }^{\circledR}$ AC-33, adherida al Aerolam ${ }^{\circledR}$ con resina epoxi Araldite ${ }^{\circledR}$ M, endurecedor Araldite ${ }^{\circledR}$ HY956 y sílice micronizado Aerosil ${ }^{\circledR}$, para espesar la mezcla.

En este mismo centro ${ }^{129}$ en 2002 se optó por el aluminio como soporte para otras pinturas arrancadas. A este aluminio (aleación H1050), de 2 i 3 mm de espesor, se le adhirió una capa de intervención de fieltro con Tylosse 10000 al $4 \%$ en agua, que a su vez está adherida al reverso de la pintura arrancada, con Primal AC-33 al $50 \%$ en agua.

\section{B.1.1.a. Aerolam ${ }^{\circledR}$ de aluminio.}

En 2002 se publica el resumen de la restauración de las pinturas murales de Giotto, de la Basílica Superior de Asís ${ }^{130}$, en las que se aplica un soporte de Aerolam ${ }^{\circledR}$ con todos sus estratos en aluminio. El estrato de intervención aplicado ha sido un mortero compuesto por cal apagada y arena, con una carga de sílice expandida (Perlita $®)$, y una red sintética dentro, para facilitar la remoción en caso necesario. Para facilitar la adhesión de este estrato de intervención a la superficie metálica del soporte, se ha aplicado sobre ésta última un estrato de gránulos de cuarzo adheridos mediante resinas sintéticas (Araldite).

Sin embargo para los fragmentos de los arcos ${ }^{131}$, el procedimiento es diferente: los fragmentos protegidos por el anverso son tratados por el

\footnotetext{
${ }^{128}$ RANESI, R. "Arrancament i restauració de pintures murals romanes d'una domus del carrer Pere Martell de Tarragona". En Rescat $n^{\circ}$ 9. Butlletí del Servei de Restauració de Béns Mobles. Generalitat de Catalunya. Barcelona, 2001. Pág. 5.

129 TONEU, M. "Prócés d'adaptació de les pintures romàniques de Sant Sadurní d'Osormort i Sant Martí del Brull en els nous suports d'alumini" En Rescat $n^{\circ} 12$. Butlletí del Servei de Restauració de Béns Mobles. Generalitat de Catalunya. Barcelona, 2002. Pág. 9.

130 BASILE, Giuseppe; P. Nicola GIANDOMENICO. “Dall'utopia alla realtà. Notizie dal cantiere dei dipinti in frammenti della Basílica Superiore di San Francesco in Assisi". En Convengo internazionale di studi. 26-28 settembre 2002. Tipografía Metastasio. Assisi, 2002.

131 BASILE, Giuseppe; P. Nicola GIANDOMENICO. “Dall'utopia alla realtà. Notizie dall cantiere dei dipinti in frammenti della Basílica Superiore di San Francesco in Assisi". En Convengo internazionale di studi. 26-28 settembre 2002. Tipografía Metastasio. Assisi, 2002. Pág. 32.
} 
reverso con un tejido de gasa de algodón adherido con un empasto fluido de 2 partes de cal apagada, 1 de resina acrílica (Primal B60A) y $1 / 2$ de arena amarilla finísima. Los fragmentos así reforzados por el reverso son aplicados sobre una red de cloruro de polivinilo mediante una resina acrílica (Primal B60A), dejando sobrantes de red en los márgenes para facilitar el anclaje al muro.

\section{B.1.1.a. Aerolam ${ }^{\circledR}$ de fibra de carbono.}

Actualmente se han usado también placas de Aerolam pero con fibra de carbono en sustitución de la tradicional fibra de vidrio. La fibra de carbono es mucho más estable que la fibra de vidrio, por lo que confiere un soporte más duradero, pero, su elevado precio, lo hace un material poco utilizado en restauraciones con un modesto presupuesto.

\section{B.1.1.b. Núcleo alveolar de cartón.}

En 1957 Stefan Slabczynsky ${ }^{132}$ construyó uno de los primeros soportes con núcleo alveolar. Este soporte consistía en un núcleo con forma de nido de abeja de papel Kraft y láminas externas de masonite.

En 1971 Guido y Gianluigi Incola y Roberto $\operatorname{Arosio}^{133}$, hacen un estudio de los soportes rígidos en resina de poliéster con núcleo de nido de abeja, así como los soportes rígidos metálicos para pinturas arrancadas mediante la técnica del stacco. El primer tipo de soporte cosiste en englobar una estructura de cartón en forma de nido de abeja, entre dos estratos de mat de fibra de vidrio de gramaje 600, con resina de poliéster Gabraster. El cartón debe ser impregnado en una resina ignífuga, del tipo Sunber Plast 2. En el borde se aplica un listón de madera para facilitar el tensado de las telas que han sido aplicadas al reverso de la pintura arrancada. Los soportes rígidos metálicos para pinturas arrancadas mediante stacco, están constituidos por una lámina metálica anticorodal de $1 \mathrm{~mm}$ de espesor y un perfil metálico también anticorodal, de 2'5 cm, que supone a la vez el acabado de la lámina y el marco del conjunto.

Entre 1971 y 1972, Pilar Roig Picazo, bajo la dirección del entonces Director del Instituro de Restauración de Madrid, Gratiniano Nieto, realizó, para la fundación Juan March, gracias a una beca concedida por

\footnotetext{
132 Jefe de Restaruación de la Tate Gallery. Ver RODRíGUEZ SANCHO, Isabel. Evolución de los soportes para reforzar y trasladar pinturas. Algunos ejemplos (primera parte). En Pátina. Escuela superior de conservación y restauración de bienes culturales de Madrid. Junio 1995. №7. Madrid, 1995. Pág. 90.

${ }^{133}$ VV.AA. Restauri in Piamonte 1968/1971. Soprintendenza alle Gallerie e alle opere d'Arte del Piamonte. Torino-Galeria Sabando. Maggio 1971. Ed. D’Arte Fratelli Pozzo.Torino, 1971. Págs. 19-23.
} 
dicha fundación, un estudio teórico práctico sobre arranques de pintura mural y aplicación a un nuevo soporte. Este nuevo soporte fue de resina epoxi y fibra de vidrio con núcleo alveolar de nido de abaja de cartón.

En 1976 se construyó, en The Art Institute of Chicago, un soporte con núcleo de nido de abeja de papel laminado con contrachapado de madera.

Los laboratorios de Torino y Aramego son los centros que más han investigado sobre soportes de nido de abeja de cartón con resina poliéster. Este tipo de soporte gana resistencia si se protege con resina fenólica.

Una variante de este tipo de soportes es el que se elaboró para pinturas ya arrancadas y trasladadas sobre tela. Es un sistema que consiste en insertar entre las celdillas del núcleo alveolar, a modo de capa de intervención, unas piezas de poliuretano con forma cónicocilíndrica. Este sistema permite adherir la pintura original al nuevo soporte únicamente en las piezas de poliuretano.

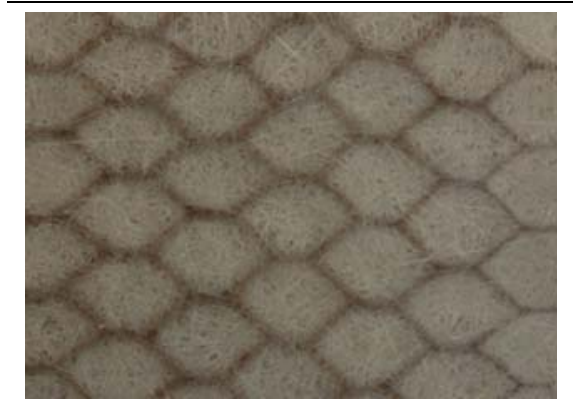

Fig. 63. Estructura alveolar de cartón con el refuerzo de fibra de vidrio y resina por ambas partes.

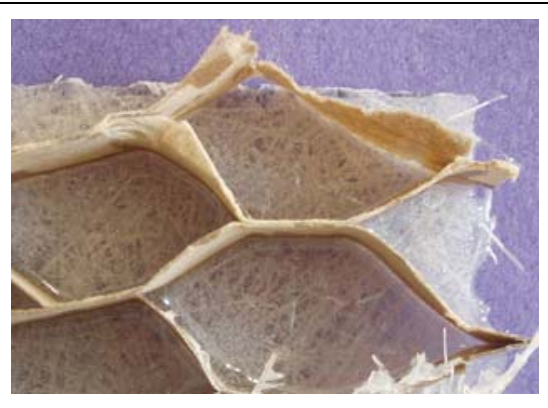

Fig. 64. Estructura alveolar de cartón con el refuerzo de fibra de vidrio y resina por una sola cara.

\section{B.1.2.a. Poliestireno expandido ${ }^{134}$.}

En 1960 el Istituto Centrale per il Restauro de Roma, aplica sobre una placa de poliestireno expandido Ilamada comercialmente Frigolit, las pinturas arrancadas de la tumba etrusca Scrofa Nera. También se usó el mismo material para recolocar, en 1963, las pinturas arrancadas de la Cripta de S. Ansano a Spoleto ${ }^{135}$. Estas pinturas fueron consolidadas por

\footnotetext{
${ }^{134}$ Ver las características técnicas en el Libro blanco de la Asociación Nacional de Poliestireno Expandido: http://www.anape.es. Se ha utilizado el de $1^{\prime} 7 \mathrm{~mm}$ de espesor.

135 RASPI SERRA, J. "Nuovi supporti per affreschi staccati". En Bollettino dell'Istituto Centrale del Restauro. Istituto poligrafico dello Stato. Roma, 1965.
} 
el reverso siguiendo el método tradicional de aplicación de una gasa con caseinato cálcico.

La Escuela Taller de Restauración de Pintura Mural de Aragón ${ }^{136}$, en 2004, realizó un soporte inerte para unas pinturas murales romanas. Dado que las pinturas provenían de una bóveda bastante curvada, antes de proceder a la elaboración del nuevo soporte, se realizó una contraforma de poliestireno extruido sobre la que se depositaban las placas de Aerolam. El estrato de intervención elegido fue el poliestireno expandido de mayor densidad que se encuentra en el mercado: $35 \mathrm{Kg} \cdot / \mathrm{m}^{3}$.

\section{B.1.2.b. Poliuretano.}

Suele ser el componente interior del cartón pluma, que ya se empezó a usar en los años 70, tanto de soporte, reforzado con fibras de vidrio y resinas, como con la función de estrato de intervención, pues es muy reversible, al poderse cortar por medio de un alambre ${ }^{137}$.

La primera vez que lo aplicó el Istituto Centrale per il Restauro fue en las pinturas arrancadas de La Tomba delle Olimpiadi, en $1957^{138}$. Se trataba de una hoja de plástico expandido semirrígido, poliuretano expandido llamado Molopren.

\section{B.1.2.c. Cloruro de polivinilo expandido semirrígido ${ }^{139}$.}

Las espumas sintéticas reforzadas se utilizaban tanto como capa de intervención como también de soporte. En los años 60 se utilizó este tipo de soporte para el traslado de gran cantidad de pinturas murales italianas, bajo la tutela del Istituto Centrale per il Restauro. Se usaron láminas de cloruro de polivinilo unidas con tornillos a bastidores metálicos, así como láminas de poliuretano o de poliestireno expandido. Más adelante se introduce el uso de fibra de vidrio y resina de poliéster para sustituir los pasados armazones metálicos. El Istituto Centrale per il Restauro comenzó en 1957 las investigaciones sobre este tema, que se prolongaron hasta 1963.

\footnotetext{
${ }^{136}$ MORALES RAMíREZ, Susana. "Finalización de la restauración del techo abovedado de la Casa de los Delfines. Realización del soporte inerte". En Kausis. Revista de la Escuela Taller de Restauración de pintura mural de Aragón. № 2. Diciembre 2004. Ed. Revista de la Escuela Taller de Restauración de pintura mural de Aragón. Zaragoza, 2004.

137 FERRER MORALES, Ascensión. La pintura mural. Su soporte, conservación, restauración y las técnicas modernas. Universidad de Sevilla. Sevilla, 1995. Pág. 127.

138 RASPI SERRA, J. "Nuovi supporti per affreschi staccati". En Bollettino dell'Istituto Centrale del Restauro. Istituto poligrafico dello Stato. Roma, 1965.

${ }^{139}$ Se ha utilizado el CADORITE, distribuido por CTS España.
} 
En 1959 se empezó a emplear las láminas de cloruro de polivinilo $(P \vee C)^{140}$, material que supone una gran ventaja tanto respecto al acero como respecto al masonite (que se había usado muchísimo en Toscana) en cuanto a su ligereza, pues pesa cerca de $4 \mathrm{Kg} . / \mathrm{m}^{2}{ }^{2}$, en un espesor de $3 \mathrm{~mm}$.; así como a la flexibilidad y adaptabilidad a las eventuales irregularidades del muro, si se trata este material a $50^{\circ} \mathrm{C}$ con llama oxhídrica $^{141}$

También sobre PVC y bastidores metálicos ligeros se trasladaron numerosas pinturas, como la capilla de Santa Corona en la Iglesia de Santa Maria delle Grazie, en Milán, en 1961; la ex Capella della Madonna, en la misma iglesia, en 1963; en la iglesia de San Teodoro de Pavia, en 1963; y en otras muchas iglesias entre 1963 y 1966.

Se introdujo más adelante en este campo el uso de resinas de poliéster Gabraster, que pronto se prefirió al uso del PVC, ya que se podía adquirir tanto en láminas muy finas como en estado líquido, que mezcladas con fibra de vidrio, permitía modelar soportes de cualquier forma. Se usaba también para recubrir paneles de contrachapado, como fue el caso de las pinturas de Romanino en la iglesia de Santa Maria della Neve en Pisogne (Brescia); bastidores metálicos revestidos de hojas de resina, en el Battistero di Catiglione Olona. Paneles de contrachapado con perfiles metálicos, fueron protegidos con un estrato de resina para la recolocación de los frescos del Oratorio di Albizzate (Varese). Para la recolocación de los frescos arrancados de la capilla de la Vergine in Santa Maria delle Grazie, en Varallo, se usaron paneles de resina epoxídica.

Entre 1962 y 1966, se hicieron varias investigaciones, con sus experimentos prácticos para resolver el problema de las grandes superficies irregulares y curvilíneas, bóvedas, cúpulas, arcos, etc. Se pretendía reconstruir la forma y el espesor del mortero original, el intonaco sobre el que se asentaba la pintura.

Los primeros experimentos se llevaron a cabo para recuperar la decoración pictórica de una pechina del ábside de Robbio Lomellina, donde se empleó el PVC expandido semirrígido de células cerradas, en una lámina de $5 \mathrm{~mm}$ de espesor, (comercializado como Airex), comprendido, a modo de sándwich, entre dos estratos de mat de fibra de vidrio impregnado en resina Gabraster catalizada. Se usó para modelar el soporte un molde o contraforma de la pechina de madera.

En el Duomo de Lodi, se siguió el mismo proceso pero directamente sobre la superficie original.

\footnotetext{
${ }^{140}$ La iniciativa del empleo de este material como nuevo soporte para pinturas murales arrancadas, fue Ottemi Della Rotta, milanés que trabajó en la recuperación de pinturas murales trabajando para la Sovrintendenza alle Galerie della Lombardia.

${ }^{141}$ Ver aplicación de la llama oxhídrica en el próximo capítulo.
} 
En 1965 en el Oratorio di Albizzate (Varese), como contraforma para realizar el nuevo soporte se ha utilizado una estructura de madera extraída directamente del muro, es decir, después del arranque, el intonaco se desprendió, dejando el muro a vistas. Directamente sobre el muro se aplicaron tiras de contrachapado de madera, que fueron recubiertas por una capa de resina de poliéster, que cuando endureció, permitió que se extrajese todo junto, y aplicando resina por el otro lado, se había creado una contraforma para elaborar el nuevo soporte, incluyéndola en éste.

En 1966 se aplicó un nuevo soporte a una bóveda entera, sin necesidad de contraforma, en la iglesia de Santa Maria alle Grazie, en Milán. Una vez arrancadas, mediante strappo las pinturas murales, y nivelado el soporte del muro, se aplica, con el adhesivo Bostik ${ }^{142}$, una lámina muy fina (1-2 $\mathrm{mm}$ ) de cloruro de polivinilo plastificado expandido, que se adhiera bien a las irregularidades del muro. Sobre este estrato, que se deja rebosar en los bordes para facilitar la reversibilidad, se construye y modela el verdadero soporte, aplicando un primer estrato de mat de fibra de vidrio impregnado de resina de poliéster (a pincel), sobre ésta se aplica el PVC-Airex, impregnado en la misma resina. El cloruro de polivinilo expandido se aplica a tiras, para que se adapte más fielmente a la forma del muro, y en algunas zonas entre tira y tira, se coloca un perfil anticorodal, para anclar el futuro soporte. Encima se aplica un nuevo estrato de matt con resina epoxi o poliéster, igual que el anterior. Unos días después se desprende todo, y tras la adhesión de la pintura arrancada con las telas de refuerzo en el reverso, a modo tradicional, se recoloca, anclando el conjunto ganchos perimetrales colocados en el reverso del nuevo soporte. Estos ganchos permiten la remoción del conjunto en cualquier momento.

En 1967 se usó el mismo procedimiento en la capilla de Santa Margherita, en Crea (Alejandría), y en 1970 en la iglesia de San Giovanni ai Campi en Piobesi (Turín), donde se ha empelado un estrato de Airex más fino y se ha interpuesto entre el soporte y la pintura una lámina de cloruro de polivinilo expandido, con el fin de favorecer la reversibilidad del procedimiento.

\section{B.2.1. Resina epoxi o poliéster con fibra de vidrio.}

En 1996 el Departamento de Educación y Cultura del Gobierno de Aragón $^{143}$ optó por un soporte para pintura mural arrancada compuesto

\footnotetext{
${ }^{142}$ Ver ficha técnica en Anexo.

${ }^{143}$ MONFORTE ESPALLARGAS, Alfonso. "Conservación, restauración y reposición del conjunto mural de la ermita de San Fructuoso. Bierge. (Huesca)". En XI Congreso de Conservación y Restauración de Bienes Culturales. Castellón 3, 4, 5 y 6 de octubre de 1996. Servei de publicacions. Diputació de Castelló. Castelló, 1996. Pág. 971.
} 
por fibra de vidrio y resina epoxi, siendo la capa de intervención de Acetato de polivinilo (PVA), cal y Perlita.

En 1999 el Centro de Conservación y Restauración de Bienes Culturales de Castilla y León ${ }^{144}$, aplicó un nuevo soporte autoportante, con tarlatana de fibra de vidrio adherida con Primal $₫$ AC-33 (espesado con tolueno) sobre un molde de yeso, de modo que al eliminar el yeso, quedaba el soporte autoportante, que viene reforzado con resina epoxídica Fetadit@ 55/63 y manta de fibra de vidrio, con adición de Aeroxil $₫$ como agente tixotrópico.

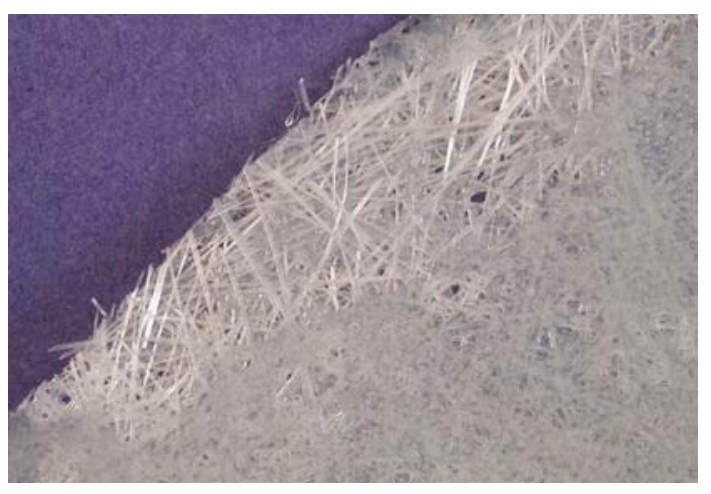

Fig. 65. Fibra de vidrio con resina epoxi.

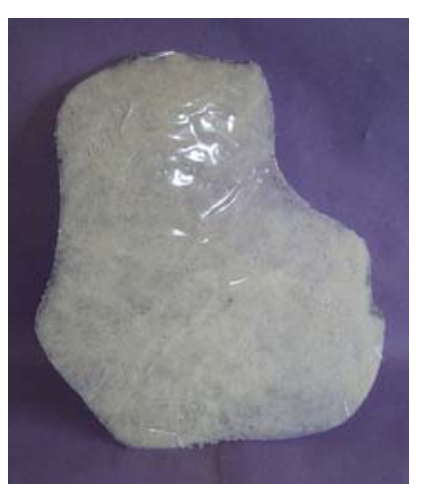

Fig. 66. Soporte de fibra de vidrio y resina epoxi.

\section{B.2.2. Masonite.}

En 1957 se experimentó el primer sistema de soporte rígido reversible sobre las pinturas de la Tumba de Olimpiadas, de Tarquinia. Este sistema consistía en adherir una plancha de masonita a un bastidor realizado con piezas de aluminio, pegadas o soldadas. Sobre este estrato se adhería la resina expandida que actuaba como capa de intervención y la pintura, que había sido reforzada por el reverso con telas, se pegaba con acetato de polivinilo.

\section{B.2.3.Policarbonato.}

El policarbonato es el material que se usa en la actualidad en centros de restauración para confeccionar nuevos soportes para pinturas

\footnotetext{
144 ESCUDERO, C. y otros. Catálogo de obras restauradas. Centro de conservación y Restauración de Bienes Culturales de Castilla y León. Junta de Castilla y León. Consejería de Educación y Cultura. Valladolid, 1999. Pág. 247.
} 
murales arrancadas. Un ejemplo de la utilización de este material es como el Centre de Restauració de Béns Mobles de Barcelona.

\section{B.2.4. Nuevos materiales.}

En los últimos años se está investigando con nuevos materiales más resistentes que los nombrados hasta ahora. Por ejemplo, las últimas tendencias habían sido utilizar fibras de vidrio de distintos tipos, pero ya en 1992, se empezó a conocer la degradación que sufren estas fibras, que puede conducir a deformaciones estructurales en los soportes fabricados con este tipo de fibra. En su sustitución se empezó a investigar con:

- Fibra de carbono y matriz termoendurecible.

- Fibras aramídicas y resinas epoxídicas.

Todos estos materiales responden a las características de rigidez, ligereza, excepcional resistencia a la rotura, a la flexión, a la temperatura y a las variaciones dimensionales con uniformidad de prestaciones debido a particulares sistemas de elaboración.

Utilizando estos materiales se intervino en "El crucifijo de Cimabue", al que se le aplicó un nuevo soporte tipo sándwich de núcleo de espuma de poliuretano y dos estratos externos de fibra de carbono con resinas epoxídicas. Como capa de intervención se aplicó papel de fractura predeterminada ${ }^{145}$, de la casa Syremont.

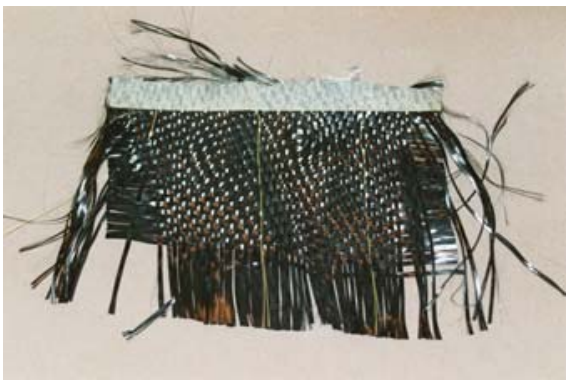

Fig. 67. Tejido de fibra de carbono.

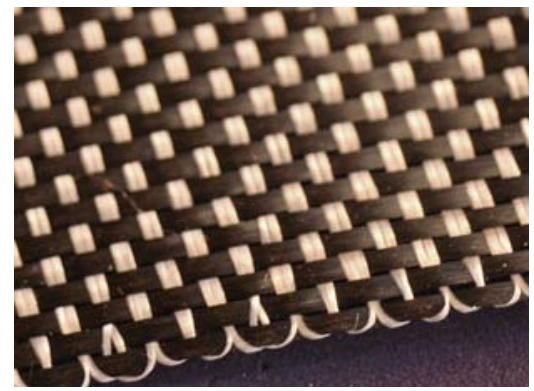

Fig. 68. Tejido de trama de fibra de carbono y urdimbre de fibra de vidrio.

\footnotetext{
${ }^{145}$ Es un papel formado por dos estratos de fibras naturales y un tercero de fibras sintéticas que se sitúa entre aquellos. Esta diferencia en los materiales de las tres capas, permite una fácil separación entre ellas.
} 


\subsection{REVISIÓN DE DIFERENTES TIPOS DE ESTRATOS DE INTERVENCIÓN}

En 1965 el Istituto Centrale per il Restauro de Roma empezó a experimentar la introducción de un estrato intermedio entre el soporte y la pintura mural arrancada. Esta capa recibe el nombre de "estrato de intervención". La finalidad de este elemento es facilitar la eliminación de dicho soporte en cualquier momento, sin la necesidad de destruirlo o de rebajarlo por el reverso - tratamiento costoso y perjudicial para la obra-.

Este estrato de intervención, inicialmente se realizaba con materiales de origen sintético, como poliestireno o poliuretano expandido. Son materiales muy ligeros y de fácil destrucción, pero la inflamabilidad y esta facilidad de destrucción no garantizaban la seguridad de la obra, por lo que se siguió investigando con otros materiales, como el amianto o el cloruro de polivinilo $(P V C)^{146}$.

En el Laboratorio di Restauro di Firenze, usaban como estrato de intervención el mismo estrato de caseinato cálcico que se aplica al reverso de las pinturas murales arrancadas, o una mezcla de resinas acrílicas (tipo Vinavil o Crilar 113), adicionadas con cargas. El caseinato cálcico se puede eliminar en cuanto que se fractura fácilmente, mientras que para la eliminación de resinas acrílicas se requiere la impregnación con disolventes orgánicos, proceso que puede perjudicar a la obra.

Pero en 1972 investigan, junto con el Istituto Centrale per il Restauro y la empresa Montedison, la elaboración de un estrato de intervención de papel. Este material, que recibe el nombre de "carta a frattura predeterminata" ${ }^{147}$, consta de tres estratos: dos de papel de fibras naturales que engloban a un tercero de fibras sintéticas a base de polietileno o polipropileno, según el tipo. Estas fibras, constituidas por polímeros termoplásticos insensibles a las variaciones de humedad, confieren al estrato de intervención de papel de fractura predeterminada un aumento de la estabilidad dimensional. Al estar la capa intermedia compuesta por polímeros apolares, no se mezclan fácilmente con la celulosa, lo que permite una cómoda separación de los estratos, cumpliendo así la función de estrato de intervención en pinturas murales arrancadas y colocadas

\footnotetext{
${ }^{146}$ BOTTICELLI, Guido. Metodologia di restauro delle pitture murali. Centro Di della edifimi srl. Firenze, 1992.

147 PARRINI, Paolo; MILANO, Mario. "Carte a frattura predeterminata a base di fibrilla sintetiche poliofeniliche". En Atti del Convengo sul Restauro delle opere d'arte. Orificio delle Pietre Dure e Laboratorio di Restauro di Firenze. Volume I. Edizioni Polistampa. Firenze, 1981. Págs. 301-305 y 547-549.
} 
sobre un nuevo soporte. Es un material que ha sido altamente estudiado para cumplir esta función, pues fue creado ex profeso.

A su vez, en el Istituto Centrale per il Restauro utilizaban el corcho natural como estrato de intervención entre pinturas murales arranchadas y nuevos soportes de Aerolam®.

Se ha estudiado también la posibilidad de aplicar por el reverso de la obra arrancada, un mortero similar al original. Este mortero está compuesto por Aluminato cálcico o de bario, que forma un tipo de espuma mineral. La mezcla está compuesta por:

30\% polvo de mármol o arena tamizada.

$33 \%$ hidróxido cálcico (grassello).

34\% Primal AC-33 (o similar).

2,7\% hidróxido de bario (octohidrato).

$0,3 \%$ aluminio en polvo.

Para conseguir este estrato se hace un molde de madera del grosor deseado, 3-4 mm. La mezcla se pasa por un cedazo antes de añadir el aluminio, el qual se debe remover bien. Se humedece la madera de base para que no absorba tanto y se vierte, dejando la superficie lisa con un listón de madera.

Esta mezcla tiene una reacción exotérmica, desarrollando hidrógeno y convirtiéndose en una espuma ligera. Una vez seco se lija hasta el espesor deseado.

Otros materiales usados como estrato de intervención son: el fieltro, el muletón (tela de algodón), la espuma de poliuretano.

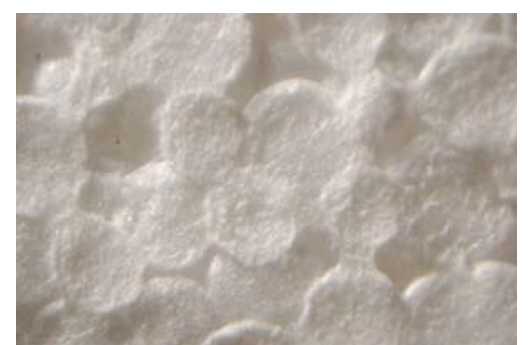

Fig. $\quad 69$. Imagen de poliestireno expandido tomada a través de microscopio óptico.

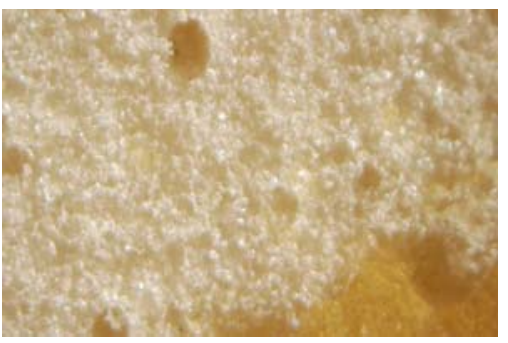

Fig. 70. Imagen de lámina poliuretánica tomada a través de microscopio óptico. 


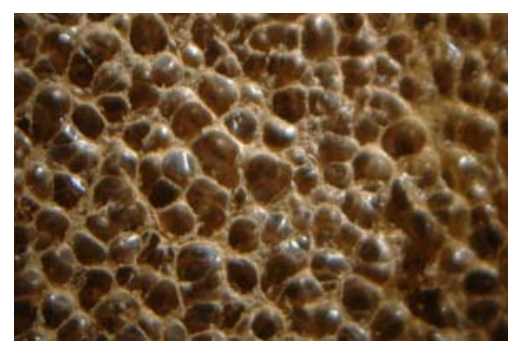

Fig. 71. Imagen de PVC expandido tomada a través de microscopio óptico.

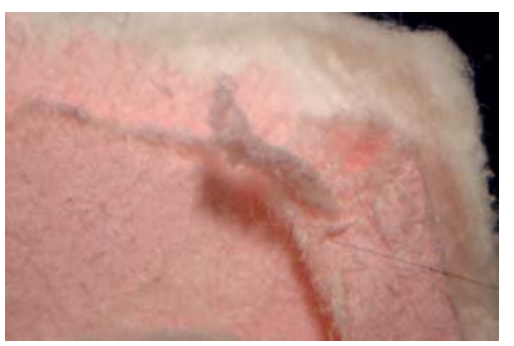

Fig. 73. Imagen de papel de fractura predeterminada tomada a través de microscopio óptico.

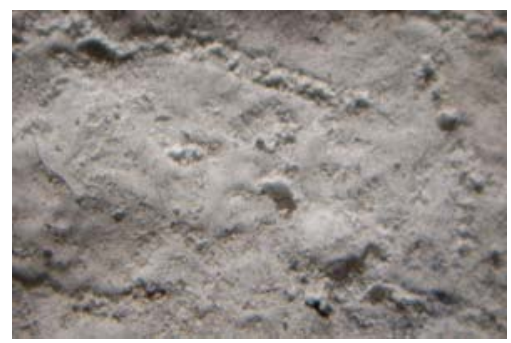

Fig. 75. Imagen de aluminato de bario tomada a través de microscopio óptico.

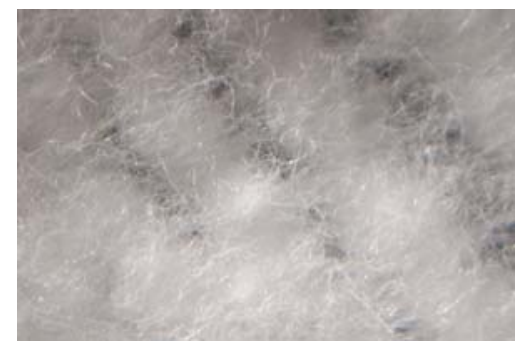

Fig. 77. Imagen de muletón de algodón tomada a través de microscopio óptico.

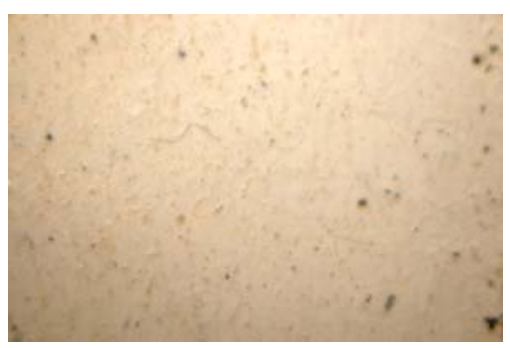

Fig. 72. Imagen de caseinato cálcico tomada a través de microscopio óptico.

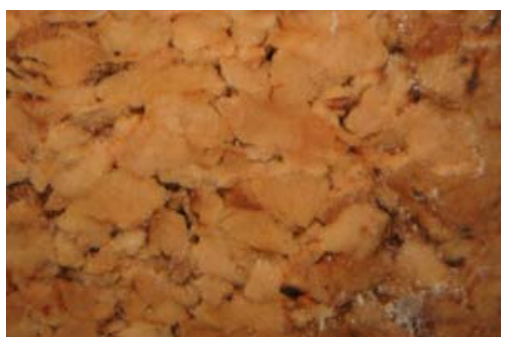

Fig. 74. Imagen de corcho natural tomada a través de microscopio óptico.

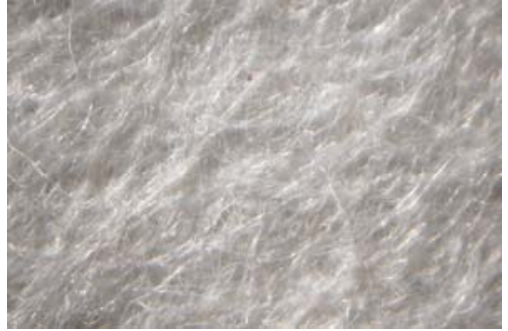

Fig. 76. Imagen de fieltro tomada a través de microscopio óptico.

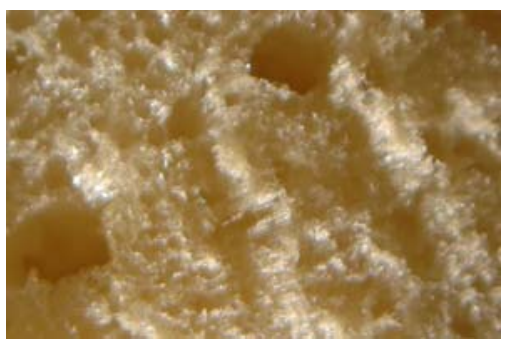

Fig. 78. Imagen de espuma de poliuretano tomada a través de microscopio óptico. 




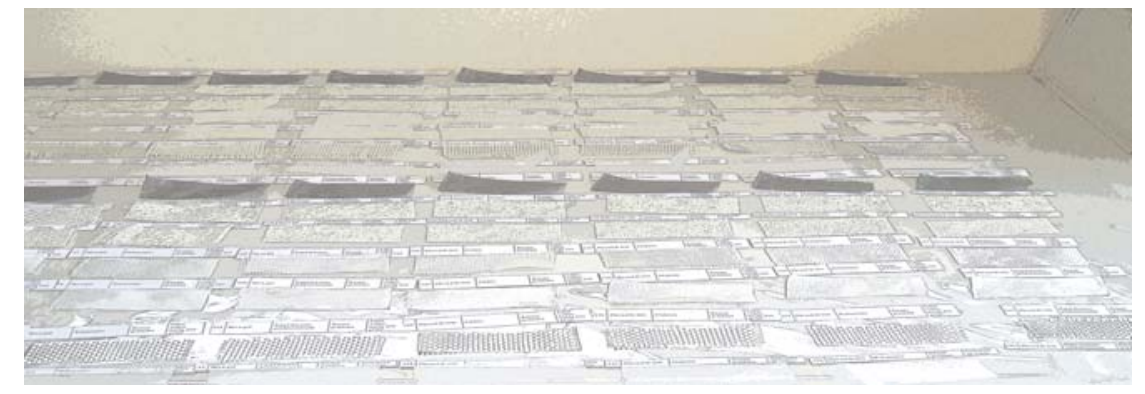

CAPÍTULO V

EXPERIMENTACIÓN PRÁCTICA 




\section{EXPERIMENTACIÓN PRÁCTICA}

\subsection{PROPUESTAS DE INTERVENCIÓN PARA LA ELIMINACIÓN DEL ANTIGUO SOPORTE DE LAS PINTURAS DE LA BÓVEDA DE LA IGLESIA DE LOS SANTOS JUANES DE VALENCIA}

Las pinturas murales de Palomino en la Iglesia de los Santos Juanes de Valencia, después de ser arrancadas mediante la técnica del strappo, fueron colocadas en un nuevo soporte de contrachapado de madera. Como paso previo a la aplicación del nuevo soporte de madera, el reverso fue tratado con caseinato cálcico y un estrato de gasa de algodón, y en algunas zonas, a modo de refuerzo, se aplicó tela de lino. Por lo tanto la obra se encuentra estratificada del siguiente modo:

\begin{tabular}{|l|l|}
\hline Barniz & $\begin{array}{l}\text { Sólo en algunas zonas, a modo de } \\
\text { veladuras de color }\end{array}$ \\
\hline $\begin{array}{l}\text { Película pictórica y } \\
\text { repintes }\end{array}$ & $\begin{array}{l}\text { Que consolida el reverso y adhiere } \\
\text { las telas de refuerzo }\end{array}$ \\
\hline Caseinato cálcico & \\
\hline $\begin{array}{l}\text { Gasa de algodón }+ \\
\text { caseinato cálcico }\end{array}$ & Glutin \\
\hline Tela de lino & $3 \mathrm{~mm}$. de grosor aproximadamente. \\
\hline Adhesivo celulósico & $\begin{array}{l}\text { Contrachapado de } \\
\text { madera }\end{array}$ \\
\hline
\end{tabular}

El actual soporte no resulta adecuado ya que, se sustenta en una gran variedad de artículos que así lo califican, así como numerosas investigaciones que en un momento dado determinaron que otro tipo de soporte resultaba más adecuado.

Como hemos visto en capítulo III, un nuevo soporte para una pintura mural arrancada, debe cumplir ciertas características, como son: ligereza, grosor igual o inferior al del mortero original de la pintura, flexibilidad, coeficiente de dilatación térmica mínimo, adaptabilidad a la superficie, gran poder de sujeción, estabilidad a 
las deformaciones, inmunidad al ataque de microorganismos, resistencia a los deterioros ocasionados por la humedad, y que sea ignífugo.

El soporte que alberga actualmente las pinturas arrancadas de la bóveda de la iglesia de los Santos Juanes, la madera, a pesar de su escaso grosor, es demasiado pesado, lo que provoca tensiones y movimientos. No es flexible, por lo que no se adapta perfectamente a la curvatura de la bóveda. Al ser un material higroscópico, varía con los cambios de temperatura y humedad, por lo que no es estable a las deformaciones. Es susceptible de sufrir ataques de insectos xilófagos, y otros microorganismos, como hongos, mohos y demás bacterias. No cumple tampoco con la última de las características requeridas en un soporte ideal.

Si tenemos en cuenta que el caseinato cálcico se aplica normanlmente al reverso de las pinturas murales arrancadas, sobre todo en el caso de strappo, como es el que nos ocupa; y observando que se encuentra en mal estado de conservación debería ser eliminado, pero sustituido de nuevo por el mismo tipo de tratamiento, por lo que el único elemento que nos queda ajeno a la obra por el reverso, es la lámina de contrachapado de madera.

Por todo lo expuesto, consideramos que el soporte de madera debe ser eliminado o separado de la obra original.

Se pretende en este capítulo estudiar el sistema más adecuado de eliminación de ese soporte inadecuado, para posteriormente llevar dicho tratamiento a término y poder así determinar qué soporte resultaría más adecuado para esta obra.

\subsubsection{ANÁLISIS DE DIFERENTES SISTEMAS DE SEPARACIÓN.}

Para determinar el sistema más adecuado para separar el fragmento de pintura mural arrancada de su actual soporte es necesario revisar los sistemas propuestos en anteriores investigaciones ${ }^{148}$.

En éstas, se propusieron diferentes métodos de separación de ambos estratos. Estos tratamientos son:

1. Arranque de los fragmentos con respecto al conjunto soporte-repintes.

\footnotetext{
${ }^{148}$ SÁNCHEZ PONS, Mercedes. Revisión de Técnicas y criterios en torno a la reintegración de pinturas murales al fresco. Aplicación en las pinturas murales de la bóveda de la iglesia de los Santos Juanes de Valencia. CD-Rom. Universidad Politécnica de Valencia. Valencia, 2002.
} 
2. Separación de los fragmentos originales del conjunto soporte- repintes mediante acción mecánica y química gradual.

3. Eliminación del soporte actual desde el reverso, mediante desbastado mecánico del mismo.

El primer tratamiento propuesto implica la realización de un strappo de una pintura que a su vez ha sido arrancada mediante la técnica del strappo, lo que supondría castigar de nuevo, e innecesariamente la obra. Pero no descartamos este tratamiento, pues debemos valorar si, en comparación con otros métodos, conviene llevarlo a cabo a pesar de los inconvenientes que presenta.

El segundo tratamiento supone la separación de los fragmentos originales del conjunto de su soporte mediante acción mecánica y química gradual. Este sistema implica una protección previa de la superficie pictórica, para seguidamente, ir separando la pintura con las respectivas capas de tela, gasa y caseinato cálcico. Plantea además un sistema por medio del cual ir enrollando la pintura a medida en un rulo de cartón o poliestireno expandido, que se va separando del soporte de madera. El inconveniente que plantea este tratamiento es que la protección aplicada sobre la superficie pictórica debe ser flexible, lo que puede provocar daños de movimiento en la pintura, tales como grietas, descamaciones o pérdida de cohesión entre la película pictórica y el refuerzo del reverso de gasa y tela con caseinato cálcico, ya que éste último no se caracteriza por su flexibilidad.

Se plantea también, como alternativa al uso del rulo en el que ir enrollando la pintura a medida que se separa de su soporte, el uso de un sistema de suspensión de la pintura desde el techo, aunque esta opción podría resultar muy complicada aplicarla a la totalidad de los fragmentos de pintura mural arrancada.

En el tercer tratamiento se plantea el desbastado mecánico del soporte desde el reverso, protegiendo por el anverso únicamente los fragmentos originales. Se ha descartado este sistema porque se trata de un proceso muy lento y además usa instrumentos mecánicos que, por su vibración, pueden disgregar tanto la película pictórica como el estrato de caseinato cálcico.

De estos tres tratamientos propuestos, hemos extraído un cuarto que aúna lo mejor de cada uno de ellos. Se propone aplicar un tratamiento que protegiese la obra como si se fuera a efectuar un strappo, pero separarla de su soporte de madera mediante acción mecánica controlada. Esta protección debería ser con un poder adhesivo bastante más débil del utilizado para esta técnica de arranque, pero lo suficientemente alto como para mantener íntegra la obra durante los procesos de separado de su actual soporte y 
aplicación en uno nuevo. Sabemos que el adhesivo empleado para unir el nuevo soporte de contrachapado de madera a las pinturas arrancadas, fue Glutin, un adhesivo celulósico. Aunque en los análisis físico-químicos llevados a cabo, no se logra identificar la composición de este adhesivo, sabemos que es soluble al agua ${ }^{149}$, dato que facilita la acotación de nuestras investigaciones.

Por lo tanto consideramos más adecuada la aplicación de un sistema de protección semi-rígida sobre la película pictórica, que permita proteger la obra y manipularla durante el tiempo que dura la separación de su antiguo soporte y la colocación sobre un nuevo soporte más adecuado.

El primer paso antes de llevar a cabo este proceso es comprobar la solubilidad de la pintura y su resistencia al agua, para llegar a una conclusión acertada del adhesivo empleado para la protección.

Un ejemplo de un tipo de tratamiento parecido lo encontramos en Asís ${ }^{150}$, para recuperar los miles de fragmentos en los que habían quedado divididas las pinturas murales de Giotto en la Basílica Superior, y poderles aplicar un nuevo soporte, se protegió la superficie pictórica con dos estratos de papel japonés y alcohol polivinílico. En otros casos los fragmentos han sido protegidos con doble papel japonés y una de gasa y una resina acrílica ${ }^{151}$. Sin embargo, para proteger la película pictórica de los fragmentos provenientes de los $\operatorname{arcos}^{152}$, se usó papel japonés y Tylose® el $20 \%$ en agua.

\subsubsection{APLICACIÓN DE LOS SISTEMAS TRADICIONALES DE} ARRANQUE. "STRAPPO DE UN STRAPPO".

El tratamiento que se pretende efectuar es lo más parecido a un arranque parcial de una pintura. Sólo que en este caso la pintura ya ha sido arrancada. Se trata pues de "arrancarla" de su actual soporte de madera. No se pretende llevar a cabo un arranque propiamente dicho, sino realizar una protección sobre la superficie pictórica

\footnotetext{
${ }^{149}$ Se han efectuado pruebas de solubilidad con agua.

${ }^{150}$ BASILE, Giuseppe; P. Nicola GIANDOMENICO. "Dall'utopia alla relata. Notizie dall cantiere dei dipinti in frammenti della Basílica Superiore di San Francesco in Assisi". En Convengo internazionale di studi. 26-28 settembre 2002. Tipografía Metastasio. Assisi, 2002. Pág. 26: IL RESTAURO DELLA VELA DI SAN GIROLAMO.

${ }^{151}$ VV.AA. Guida al recupero, ricomposizione e restauro di dipinti murali in frammenti. L'esperienza della Basílica di San Francesco di Assisi. I.C.R. Roma, 2001. Pág. 82.

152 BASILE, Giuseppe; P. Nicola GIANDOMENICO. "Dall'utopia alla relata. Notizie dal cantiere dei dipinti in frammenti della Basilica Superiore di San Francesco in Assisi". En Convengo internazionale di studi. 26-28 settembre 2002. Tipografía Metastasio. Assisi, 2002. Pág. 30: IL RESTAURAO DEI DIPINTI IN FRAMMENTI DEL COSTOLONE DI SAN GIROLAMO.
} 
original, basándonos en las técnicas tradicionales de los arranques de pintura mural. El objetivo prioritario es conseguir un estrato de telas y adhesivo lo suficientemente rígido como para impedir fracturas en la película pictórica, pero lo suficientemente elástico como para permitir la fácil separación del soporte de madera.

Para llegar a extraer conclusiones sobre cuál es el mejor método a utilizar para separar esta pintura de su soporte lígneo, hemos recurrido a experimentaciones prácticas con diferentes materiales, sobre probetas de pinturas similares a la original.

Los dos principales objetivos que se pretenden conseguir son:

* Averiguar qué tipo de protección resulta más adecuada por sus propiedades de rigidez y flexibilidad.

- Averiguar cuál es el adhesivo que menos restos deja en la superficie pictórica y menos cambios provoca en el aspecto de la misma.

Para conseguir el primer objetivo se propone la elaboración de probetas de laboratorio que imiten las características de la obra que vamos a tratar.

Estas características son:

* Película pictórica de $1 \mathrm{~mm}$ de espesor, con gran número de lagunas y desgaste superficial.

- Reverso tratado con caseinato cálcico y dos estratos de tela, una de algodón más tupida y otra, de gasa de algodón, que es la que está directamente en contacto con el reverso de la pintura.

* Dicha pintura con su refuerzo por el reveso se encuentra adherida a un soporte de madera de $3 \mathrm{~mm}$ de espesor, por medio de un adhesivo celulósico (Glutin).

Hemos elaborado pues 12 probetas con estas características, para realizar ensayos con los diferentes adhesivos y telas con el fin de extraer conclusiones para poder aplicar la protección más adecuada al fragmento de pintura mural arrancada de la iglesia de los Santos Juanes de Valencia.

En cuanto al segundo objetivo que se plantea, una vez aplicadas las protecciones sobre las probetas, separadas de su soporte de madera y desprotegidas éstas, se proponen diversos ensayos para conocer si han quedado restos de adhesivo en la superficie pictórica o si ha variado su aspecto cromático. Estos ensayos son:

* Observación a través de luz ultravioleta, mediante la captura de fotografías con luz ultravioleta reflejada. 
* Mediante la comparativa de mediciones colorimétricas de las probetas antes de ser aplicadas las protecciones y una vez eliminadas éstas.

- Comparativa con fotografías a través de microscopio, realizadas antes de la aplicación del adhesivo de protección y después de su eliminación.

- Análisis de muestras por medio de Espectroscopia de Infrarrojos por transformada de Fourier.

\subsubsection{ENSAYOS DE SISTEMAS DE PROTECCIÓN}

Se han llevado a cabo dos tipos de probetas:

\subsubsection{Ensayos con probetas en pinturas murales al fresco.}

Se trata de pinturas similares al original pintadas hace aproximadamente 3 años con la técnica al fresco sobre mortero de cal y arena y arricio de yeso. Sobre ellas se han aplicado diferentes telas de protección y adhesivos. Los adhesivos se han aplicado en distintas proporciones.

El objetivo de la experimentación con estas probetas es averiguar cuál es la proporción más adecuada de cada uno de los adhesivos utilizados para la protección. Se ha aplicado en todos los casos una capa de gasa de algodón entre la pintura y el siguiente estrato de tela de protección.

Los adhesivos utilizados han sido:

- Paraloid B-72, disuelto en acetona;

- Carboximetilcelulosa disuelta en agua desionizada;

- Alcohol polivinílico disuelta en agua desionizada;

- Cola de gelatina ${ }^{153}$ disuelta en agua desionizada;

- Plexisol P-550.

- Una mezcla de carboximetilcelulosa y alcohol polivinílico disuelta en agua desionizada.

\footnotetext{
${ }^{153}$ Cola animal de gelatina (3 kg. Por 2 litros de agua) rectificada con melaza de caña para conferirle elasticidad, hiel de buey para conferirle mayor tensión superficial y un biocida.
} 
PROBETAS PARA ESTABLECER LAS PROPORCIONES DE LOS ADHESIVOS

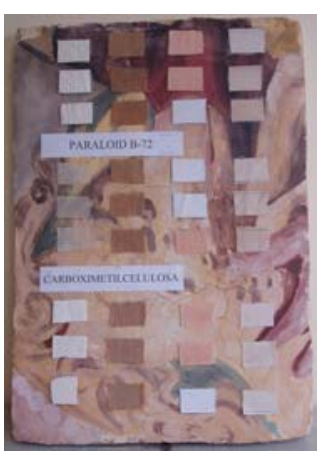

Fig. 79. Paraloid B-72 y carboximetilcelulosa.

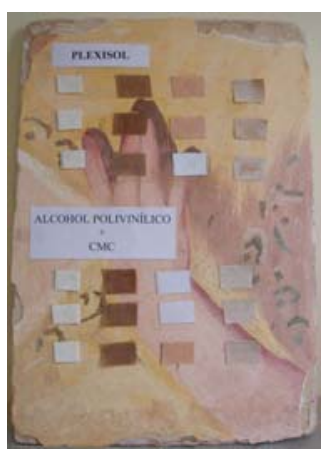

Fig. 80. Plexisol P-550 y mezcla de carboximetilcelulosa y alcohol polivinílico.

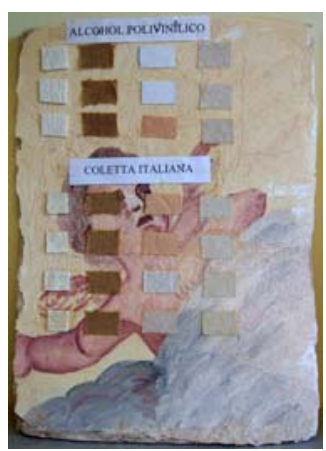

Fig. 81. Alcohol polivinílico y cola de gelatina.

Tras la valoración de los resultados obtenidos en estas probetas, hemos decidido utilizar, las proporciones de los adhesivos especificadas en la siguiente tabla:

\begin{tabular}{|c|c|c|c|c|}
\hline $\begin{array}{l}\text { CANTIDAD } \\
\text { ADHESIVO }\end{array}$ & ADHESIVO & + & $\begin{array}{l}\text { CANTIDAD } \\
\text { DISOLVENTE }\end{array}$ & DISOLVENTE \\
\hline $15 \mathrm{gr}$. & Paraloid B-72 & + & $50 \mathrm{ml}$. & Acetona \\
\hline $3 \mathrm{gr}$. & $\begin{array}{l}\text { Carboximetilc } \\
\text { elulosa }\end{array}$ & + & $100 \mathrm{ml}$. & $\begin{array}{l}\text { Agua } \\
\text { desionizada }\end{array}$ \\
\hline $5 \mathrm{gr}$. & $\begin{array}{l}\text { Alcohol } \\
\text { polivinílico }\end{array}$ & + & $50 \mathrm{ml}$. & $\begin{array}{l}\text { Agua } \\
\text { desionizada }\end{array}$ \\
\hline $8 \mathrm{ml}$. & $\begin{array}{l}\text { Cola de } \\
\text { gelatina }\end{array}$ & + & $50 \mathrm{ml}$. & $\begin{array}{l}\text { Agua } \\
\text { desionizada }\end{array}$ \\
\hline $20 \mathrm{ml}$. & $\begin{array}{l}\text { Plexisol } \\
\text { P-550 }\end{array}$ & + & $50 \mathrm{ml}$. & White Spirit \\
\hline $\begin{array}{l}5 \mathrm{gr} . \\
2 \mathrm{gr} .\end{array}$ & $\begin{array}{l}\text { Alcohol } \\
\text { polivinílico } \\
\text { Carboximetil- } \\
\text { celulosa }\end{array}$ & $\begin{array}{c}+ \\
(\mathrm{al} \\
50 \%)\end{array}$ & $\begin{array}{l}50 \mathrm{ml} . \\
50 \mathrm{ml} .\end{array}$ & $\begin{array}{l}\text { Agua } \\
\text { desionizada }\end{array}$ \\
\hline
\end{tabular}




\subsubsection{Ensayos con probetas de pinturas murales arrancadas por medio de strappo.}

Hemos arrancado fragmentos de pinturas murales al fresco realizadas sobre mortero de cal y arena ex profeso hace aproximedamente 10 años -por lo que consideramos que ya están lo suficientemente carbonatadas como para poder extraer conclusiones que se adapten a pinturas murales al fresco reales-, siguiendo el método tradicional de cola fuerte de carpintero. Estos arranques se han realizado con el fin de conseguir 12 probetas con las que ensayar diferentes telas de protección y diferentes adhesivos con las proporciones obtenidas en los ensayos anteriores. Estas probetas, que se han elaborado intentando que se asemejen lo más posible a la obra que estamos tratando, han servido tanto para hacer pruebas de protección y separación de su soporte de madera, como para estudiar un nuevo soporte, confeccionando a cada una de ellas uno distinto. Estas nuevas probetas se han adherido a fragmentos de madera contrachapada con un adhesivo celulósico similar al Glutin, comercializado bajo el nombre de Glutolin $77^{154}$.

A continuación, se muestra una tabla explicativa de los tipos de protección llevados a capa sobre estas probetas, así como las observaciones que de estas experimentaciones se derivan.

\begin{tabular}{|c|c|c|c|c|}
\hline $\begin{array}{l}\text { PART } \\
\text { E No }\end{array}$ & ADHESIVO & $\begin{array}{l}1^{\mathrm{a}} \\
\text { ESTRATO }\end{array}$ & $2^{\circ}$ ESTRATO & OBSERVACIONES \\
\hline $\begin{array}{l}1.1 . \\
\text { Arriba }\end{array}$ & $\begin{array}{l}3 \text { gr. CMC + } \\
100 \mathrm{ml} . \\
\text { Agua } \\
\text { desionizada } \\
\text {. }\end{array}$ & $\begin{array}{l}\text { Gasa de } \\
\text { algodón }\end{array}$ & Spherecore & $\begin{array}{l}\text { Protección débil } \\
\text { respecto a la pintura, } \\
\text { pero el estrato de } \\
\text { Spherecore se ha } \\
\text { adherido muy bien a } \\
\text { la gasa. Una vez } \\
\text { separada de la } \\
\text { madera con la ayuda } \\
\text { de una espátula, la } \\
\text { pintura queda } \\
\text { bastante rígida. }\end{array}$ \\
\hline \multicolumn{2}{|c|}{ DESPROTECCIÓN } & \multicolumn{3}{|c|}{$\begin{array}{l}\text { Se ha desprotegido con la acción de vapor de agua. Se } \\
\text { desprotege bien, con facilidad y sin dañar la pintura. }\end{array}$} \\
\hline $\begin{array}{l}1.2 . \\
\text { Abajo }\end{array}$ & $\begin{array}{l}3 \text { gr. CMC + } \\
100 \text { ml. } \\
\text { Agua } \\
\text { desionizada } \\
\text {. }\end{array}$ & $\begin{array}{l}\text { Gasa de } \\
\text { algodón }\end{array}$ & Arpillera & $\begin{array}{l}\text { Protección muy débil. } \\
\text { Una vez separada de } \\
\text { la madera con la } \\
\text { ayuda de una } \\
\text { espátula, la pintura } \\
\text { queda bastante } \\
\text { rígida. }\end{array}$ \\
\hline
\end{tabular}

${ }^{154}$ Metilcelulosa reforzada con resinas sintéticas. 


\begin{tabular}{|c|c|c|c|c|}
\hline \multicolumn{2}{|c|}{ DESPROTECCIÓN } & \multicolumn{3}{|c|}{$\begin{array}{l}\text { Se ha desprotegido con la acción de vapor de agua. Se } \\
\text { desprotege bien, con facilidad y sin dañar la pintura. }\end{array}$} \\
\hline $\begin{array}{l}2.1 . \\
\text { Arriba }\end{array}$ & $\begin{array}{l}3 \text { gr. CMC + } \\
100 \mathrm{ml} \\
\text { Agua } \\
\text { desionizada }\end{array}$ & $\begin{array}{l}\text { Gasa de } \\
\text { algodón }\end{array}$ & Fieltro & $\begin{array}{l}\text { Protección muy débil. } \\
\text { Una vez separada de } \\
\text { la madera con la } \\
\text { ayuda de una } \\
\text { espátula, la pintura } \\
\text { queda muy } \\
\text { fragmentada por la } \\
\text { débil protección. Se } \\
\text { hace necesario } \\
\text { aportar humedad } \\
\text { para regenerar el } \\
\text { Glutolin, pero esta } \\
\text { humedad, si llega a la } \\
\text { protección, también } \\
\text { la reblandece. }\end{array}$ \\
\hline \multicolumn{2}{|c|}{ DESPROTECCIÓN } & \multicolumn{3}{|c|}{$\begin{array}{l}\text { El fieltro necesita mucho aporte de humedad para su } \\
\text { desadhesión. Inicialmente se humecta con agua y después } \\
\text { se aplica vapor de agua. Se elimina bien la protección, } \\
\text { pero se han perdido pequeños fragmentos de pintura. }\end{array}$} \\
\hline $\begin{array}{l}2.2 . \\
\text { Abajo }\end{array}$ & $\begin{array}{l}3 \text { gr. } \mathrm{CMC}+ \\
100 \mathrm{ml} \\
\text { Agua } \\
\text { desionizada }\end{array}$ & $\begin{array}{l}\text { Gasa de } \\
\text { algodón }\end{array}$ & $\begin{array}{l}\text { Loneta de } \\
\text { algodón }\end{array}$ & $\begin{array}{l}\text { Protección muy débil. } \\
\text { Una vez separada de } \\
\text { la madera con la } \\
\text { ayuda de una } \\
\text { espátula, la pintura } \\
\text { queda bastante } \\
\text { fragmentada. }\end{array}$ \\
\hline \multicolumn{2}{|c|}{ DESPROTECCIÓN } & \multicolumn{3}{|c|}{$\begin{array}{l}\text { Primero se elimina la loneta de algodón en seco y después } \\
\text { la gasa mediante la aplicación de vapor de agua. Se } \\
\text { eliminan los restos de adhesivo con agua y esponja. Se } \\
\text { elimina bien la protección, pero se han perdido pequeños } \\
\text { fragmentos de pintura. }\end{array}$} \\
\hline $\begin{array}{l}3.1 . \\
\text { Arriba }\end{array}$ & $\begin{array}{l}8 \mathrm{ml} . \\
\text { Cola de } \\
\text { gelatina + } \\
50 \mathrm{ml} . \text { Agua } \\
\text { desionizada } \\
.\end{array}$ & $\begin{array}{l}\text { Gasa de } \\
\text { algodón }\end{array}$ & Fieltro & $\begin{array}{l}\text { Protección débil de } \\
\text { la gasa, que ha } \\
\text { quedado poco } \\
\text { adherida a la } \\
\text { pintura, meitnras } \\
\text { que al fieltro queda } \\
\text { muy bien adherida. } \\
\text { Una vez separada } \\
\text { de la madera con la } \\
\text { ayuda de una } \\
\text { espátula, la pintura } \\
\text { se mantiene rígida. }\end{array}$ \\
\hline \multicolumn{2}{|c|}{ DESPROTECCIÓN } & \multicolumn{3}{|c|}{$\begin{array}{l}\text { El fieltro necesita mucho aporte de humedad para su } \\
\text { desadhesión. Inicialmente se humecta con agua y después } \\
\text { se aplica vapor de agua. Se elimina bien la protección. }\end{array}$} \\
\hline $\begin{array}{l}3.2 . \\
\text { Abajo }\end{array}$ & $\begin{array}{l}8 \mathrm{ml} . \\
\text { Cola de } \\
\text { gelatina + } \\
50 \mathrm{ml} \text {. Agua } \\
\text { desionizada } \\
\text {. }\end{array}$ & $\begin{array}{l}\text { Gasa de } \\
\text { algodón }\end{array}$ & $\begin{array}{l}\text { Loneta de } \\
\text { algodón }\end{array}$ & $\begin{array}{l}\text { Buena protección. } \\
\text { Una vez separada } \\
\text { de la madera con la } \\
\text { ayuda de una } \\
\text { espátula, la pintura } \\
\text { se mantiene rígida. }\end{array}$ \\
\hline
\end{tabular}




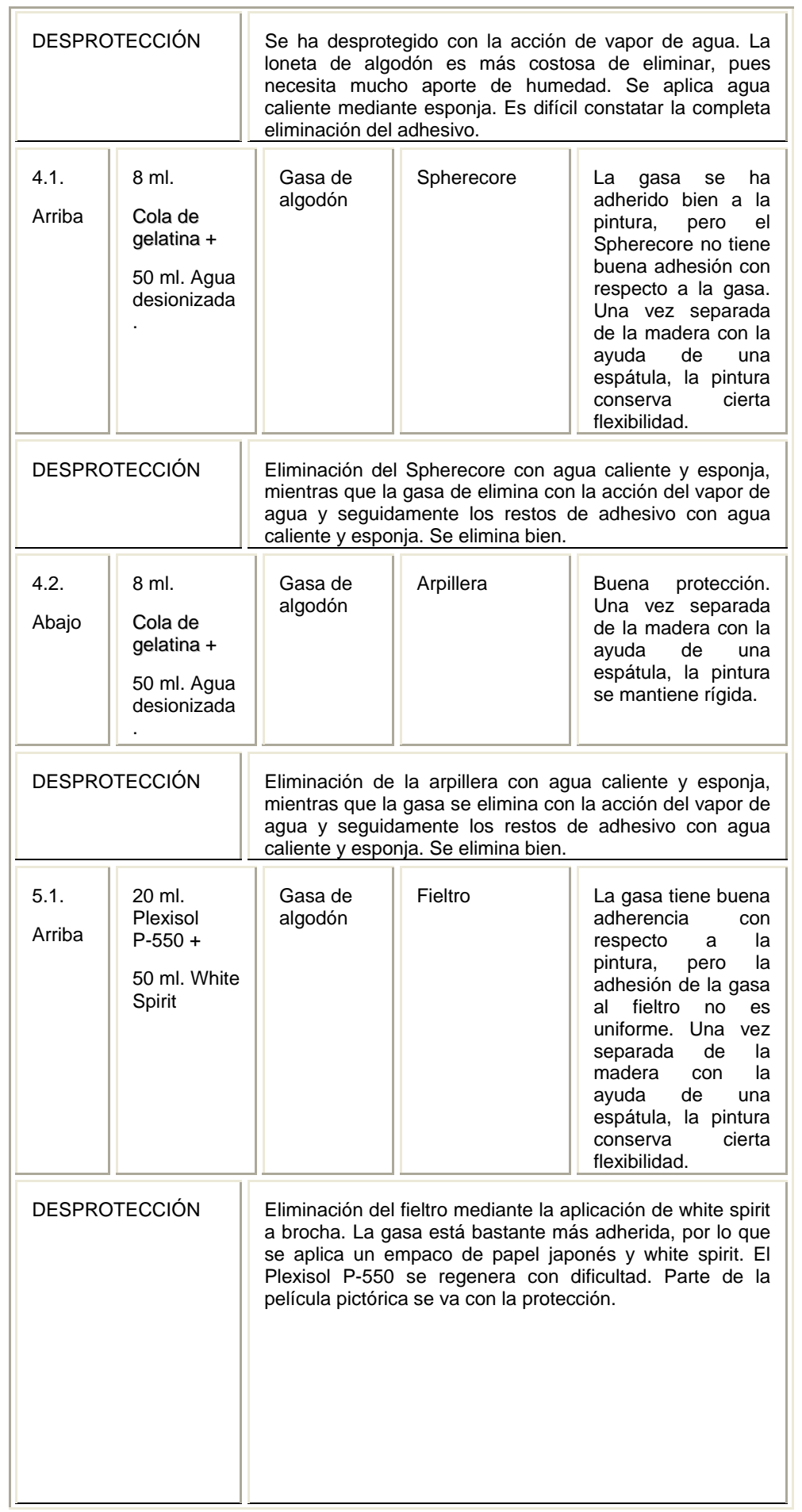




\begin{tabular}{|c|c|c|c|c|}
\hline $\begin{array}{l}5.2 . \\
\text { Abajo }\end{array}$ & $\begin{array}{l}50 \mathrm{ml} \text {. White } \\
\text { Spirit }\end{array}$ & $\begin{array}{l}\text { Gasa de } \\
\text { algodón }\end{array}$ & $\begin{array}{l}\text { Loneta de } \\
\text { algodón }\end{array}$ & $\begin{array}{l}\text { La gasa tiene buena } \\
\text { adherencia } \\
\text { respecto a la } \\
\text { pintura, pero la } \\
\text { adhesión de la } \\
\text { loneta a la gasa no } \\
\text { es uniforme. Una } \\
\text { vez separada de la } \\
\text { madera con la } \\
\text { ayuda de una } \\
\text { espátula, la pintura } \\
\text { queda bastante } \\
\text { rígida. }\end{array}$ \\
\hline \multicolumn{2}{|c|}{ DESPROTECCIÓN } & \multicolumn{3}{|c|}{$\begin{array}{l}\text { Eliminación de la loneta mediante la aplicación de white } \\
\text { spirit a brocha. La gasa está bastante más adherida, por lo } \\
\text { que se aplica un empaco de papel japonés y white spirit. E } \\
\text { Plexisol P-550 se regenera con dificultad. Parte de la } \\
\text { película pictórica se va con la protección. }\end{array}$} \\
\hline $\begin{array}{l}6.1 . \\
\text { Arriba }\end{array}$ & $\begin{array}{l}20 \mathrm{ml} . \\
\text { Plexisol } \\
\text { P-550 + }\end{array}$ & $\begin{array}{l}\text { Gasa de } \\
\text { algodón }\end{array}$ & Spherecore & $\begin{array}{l}\text { La adhesión de la } \\
\text { gasa es buena, por } \\
\text { el contrario, la de } \\
\text { Spherecore, no lo } \\
\text { es. Una vez } \\
\text { separada de la } \\
\text { madera con la } \\
\text { ayuda de una } \\
\text { espátula, la pintura } \\
\text { conserva cierta } \\
\text { flexibilidad. }\end{array}$ \\
\hline \multicolumn{2}{|c|}{ DESPROTECCIÓN } & \multicolumn{3}{|c|}{$\begin{array}{l}\text { Eliminación del Spherecore en seco, con la ayuda de un } \\
\text { poco de white spirit. Desprotección mediante la aplicación } \\
\text { de white spirit a brocha y un empaco de papel japonés y } \\
\text { white spirit. El Plexisol P-550 se regenera con dificultad. }\end{array}$} \\
\hline $\begin{array}{l}6.2 . \\
\text { Abajo }\end{array}$ & $\begin{array}{l}20 \mathrm{ml} . \\
\text { Plexisol } \\
\text { P-550 + }\end{array}$ & $\begin{array}{l}\text { Gasa de } \\
\text { algodón }\end{array}$ & Arpillera & $\begin{array}{l}\text { La adhesión de la } \\
\text { gasa es débil, y la } \\
\text { de la arpillera es } \\
\text { débil y poco } \\
\text { homogénea. Una } \\
\text { vez separada de la } \\
\text { madera con la } \\
\text { ayuda de una } \\
\text { espátula, la pintura } \\
\text { queda demasiado } \\
\text { flexible. }\end{array}$ \\
\hline \multicolumn{2}{|c|}{ DESPROTECCIÓN } & \multicolumn{3}{|c|}{$\begin{array}{l}\text { Eliminación de la arpillera en seco, con la ayuda de un } \\
\text { poco de white spirit. Desprotección mediante la aplicación } \\
\text { de white spirit a brocha y un empaco de papel japonés y } \\
\text { white spirit. El Plexisol P-550 se regenera con dificultad. }\end{array}$} \\
\hline $\begin{array}{l}7.1 . \\
\text { Arriba }\end{array}$ & $\begin{array}{l}5 \mathrm{gr} \text {. Alcohol } \\
\text { polivinílico + } \\
50 \mathrm{ml} \text { agua }\end{array}$ & $\begin{array}{l}\text { Gasa de } \\
\text { algodón }\end{array}$ & Spherecore & $\begin{array}{l}\text { Protección muy } \\
\text { débil. El estrato de } \\
\text { Spherecore se ha } \\
\text { separado } \\
\text { completamente. } \\
\text { Una vez separada } \\
\text { de la madera con la } \\
\text { ayuda de una } \\
\text { espátula, la pintura } \\
\text { queda my } \\
\text { desprotegida. }\end{array}$ \\
\hline
\end{tabular}




\begin{tabular}{|c|c|c|c|c|}
\hline \multicolumn{2}{|c|}{ DESPROTECCIÓN } & \multicolumn{3}{|c|}{$\begin{array}{l}\text { Dado que el Spherecore se ha separado, únicamente hay } \\
\text { que eliminar la gasa y el adhesivo. Se utilizará para ello, } \\
\text { vapor de agua y agua caliente aplicada a esponja. Se } \\
\text { desprotege bien. }\end{array}$} \\
\hline $\begin{array}{l}7.2 . \\
\text { Abajo }\end{array}$ & $\begin{array}{l}5 \text { gr. Alcohol } \\
\text { polivinílico + } \\
50 \mathrm{ml} \text { agua }\end{array}$ & $\begin{array}{l}\text { Gasa de } \\
\text { algodón }\end{array}$ & Arpillera & $\begin{array}{l}\text { Protección muy débil. } \\
\text { El estrato de arpillera } \\
\text { se ha separado } \\
\text { completamente. Una } \\
\text { vez separada de la } \\
\text { madera con la ayuda } \\
\text { de una espátula, la } \\
\text { pintura queda muy } \\
\text { desprotegida. }\end{array}$ \\
\hline \multicolumn{2}{|c|}{ DESPROTECCIÓN } & \multicolumn{3}{|c|}{$\begin{array}{l}\text { Dado que la arpillera se ha separado, únicamente hay que } \\
\text { eliminar la gasa y el adhesivo. Se utilizará para ello, vapor } \\
\text { de agua y agua caliente aplicada a esponja. Se } \\
\text { desprotege bien, pero se ha perdido pintura. }\end{array}$} \\
\hline $\begin{array}{l}8.1 . \\
\text { Arriba }\end{array}$ & $\begin{array}{l}5 \text { gr. Alcohol } \\
\text { polivinílico + } \\
50 \mathrm{ml} \text { agua }\end{array}$ & $\begin{array}{l}\text { Gasa de } \\
\text { algodón }\end{array}$ & Fieltro & $\begin{array}{l}\text { Protección muy débil. } \\
\text { El fieltro se adhiere } \\
\text { débilmente a la gasa, } \\
\text { pero la adhesión de la } \\
\text { gasa a la pintura es } \\
\text { muy escasa. Una vez } \\
\text { separada de la madera } \\
\text { con la ayuda de una } \\
\text { espátula, la pintura } \\
\text { queda } \\
\text { desprotegida. muy }\end{array}$ \\
\hline \multicolumn{2}{|c|}{ DESPROTECCIÓN } & \multicolumn{3}{|c|}{$\begin{array}{l}\text { Se ha desprotegido con la acción de agua caliente y vapor } \\
\text { de agua. El fieltro está muy adherido a la gasa, por lo que } \\
\text { se intenta separar los dos estratos a la vez. Se desprotege } \\
\text { bien, con facilidad y sin dañar la pintura. }\end{array}$} \\
\hline $\begin{array}{l}8.2 . \\
\text { Abajo }\end{array}$ & $\begin{array}{l}5 \text { gr. Alcohol } \\
\text { polivinílico + } \\
50 \mathrm{ml} \text {. agua }\end{array}$ & $\begin{array}{l}\text { Gasa de } \\
\text { algodón }\end{array}$ & $\begin{array}{l}\text { Loneta de } \\
\text { algodón }\end{array}$ & $\begin{array}{l}\text { Protección muy débil } \\
\text { porque no protege la } \\
\text { pintura, aunque las } \\
\text { telas entre sí han } \\
\text { quedado muy unidas y } \\
\text { rígidas. Una vez } \\
\text { separada de la madera } \\
\text { con la ayuda de una } \\
\text { espátula, la pintura } \\
\text { queda } \\
\text { fragmentada. }\end{array}$ \\
\hline \multicolumn{2}{|c|}{ DESPROTECCIÓN } & \multicolumn{3}{|c|}{$\begin{array}{l}\text { Se ha desprotegido con la acción de agua caliente y vapor } \\
\text { de agua. La loneta se puede separar en seco. Se } \\
\text { desprotege bien, con facilidad y sin dañar la pintura. }\end{array}$} \\
\hline $\begin{array}{l}9.1 . \\
\text { Arriba }\end{array}$ & $\begin{array}{l}15 \text { gr. } \\
\text { Paraloid B- } \\
72+ \\
50 \mathrm{ml} . \\
\text { Acetona }\end{array}$ & $\begin{array}{l}\text { Gasa de } \\
\text { algodón }\end{array}$ & Fieltro & $\begin{array}{l}\text { La gasa se adhiere bien } \\
\text { a la pintura, pero el } \\
\text { fieltro no se ha } \\
\text { adherido nada. Una vez } \\
\text { separada de la madera } \\
\text { con la ayuda de una } \\
\text { espátula, la pintura } \\
\text { conserva } \\
\text { flexibilidad. }\end{array}$ \\
\hline
\end{tabular}




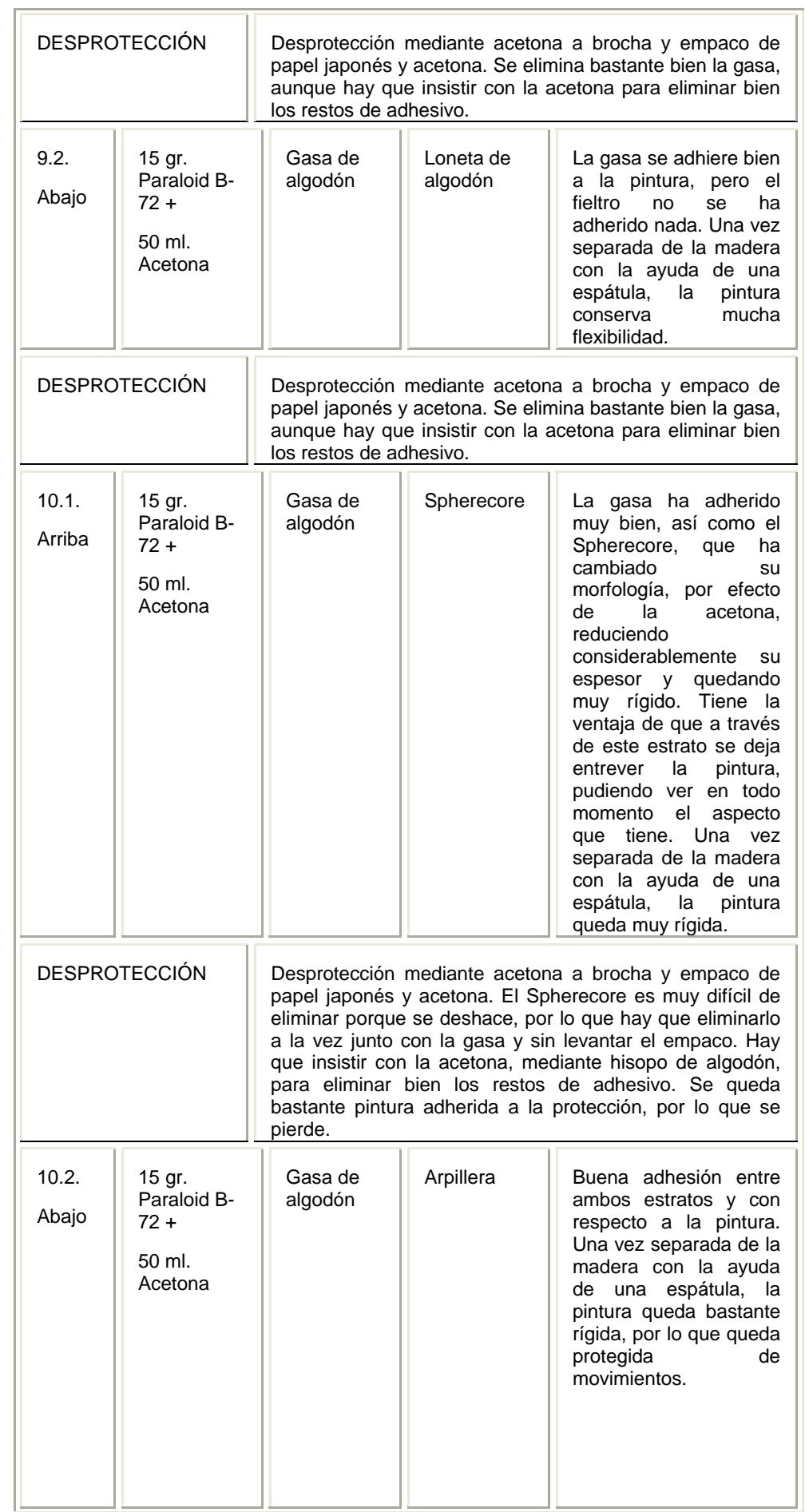




\begin{tabular}{|c|c|c|c|c|}
\hline \multicolumn{2}{|c|}{ DESPROTECCIÓN } & \multicolumn{3}{|c|}{$\begin{array}{l}\text { Desprotección mediante acetona a brocha y empaco de } \\
\text { papel japonés y acetona. La arpillera se elimina en seco. } \\
\text { Hay que insistir con la acetona, mediante hisopo de } \\
\text { algodón, para eliminar bien los restos de adhesivo. Se } \\
\text { queda bastante pintura adherida a la protección, por lo que } \\
\text { se pierde. }\end{array}$} \\
\hline $\begin{array}{l}11.1 . \\
\text { Arriba }\end{array}$ & $\begin{array}{l}\text { CMC (3 gr. } \\
+100 \mathrm{ml} \text {. } \\
\text { Agua } \\
\text { desionizada } \\
\text { ) al } 50 \% \text { en } \\
\text { Alcohol } \\
\text { polivinílico } \\
\text { ( } 5 \text { gr. }+50 \\
\text { ml. Agua) }\end{array}$ & $\begin{array}{l}\text { Gasa de } \\
\text { algodón }\end{array}$ & Spherecore & $\begin{array}{l}\text { Buena adhesión del } \\
\text { Spherecore a la gasa, } \\
\text { pero algo más débil la } \\
\text { adhesión de la gasa } \\
\text { con respecto a la } \\
\text { pintura. Una vez } \\
\text { separada de la madera } \\
\text { con la ayuda de una } \\
\text { espátula, la pintura } \\
\text { queda flexible. }\end{array}$ \\
\hline \multicolumn{2}{|c|}{ DESPROTECCIÓN } & \multicolumn{3}{|c|}{$\begin{array}{l}\text { El Spherecore se puede eliminar el seco, tirando de él. La } \\
\text { gasa se elimina mediante la acción de agua caliente. Se } \\
\text { elimina bien, con facilidad y sin dañar la pintura. }\end{array}$} \\
\hline $\begin{array}{l}11.2 . \\
\text { Abajo }\end{array}$ & $\begin{array}{l}\text { CMC (3 gr. } \\
+100 \mathrm{ml} . \\
\text { Agua } \\
\text { desionizada } \\
\text { ) al } 50 \% \text { en } \\
\text { Alcohol } \\
\text { polivinílico } \\
\text { ( } 5 \text { gr. }+50 \\
\text { ml. Agua) }\end{array}$ & $\begin{array}{l}\text { Gasa de } \\
\text { algodón }\end{array}$ & Arpillera & $\begin{array}{l}\text { Buena adhesión de la } \\
\text { gasa a la pintura. } \\
\text { Adhesión débil y poco } \\
\text { homogénea de la } \\
\text { arpillera a la gasa. Una } \\
\text { vez separada de la } \\
\text { madera con la ayuda } \\
\text { de una espátula, la } \\
\text { pintura queda bastante } \\
\text { rígida. }\end{array}$ \\
\hline \multicolumn{2}{|c|}{ DESPROTECCIÓN } & \multicolumn{3}{|c|}{$\begin{array}{l}\text { La arpillera se puede eliminar el seco, tirando de ella. La } \\
\text { gasa se elimina mediante la acción de agua caliente. Se } \\
\text { elimina bien, con facilidad y sin dañar la pintura. }\end{array}$} \\
\hline $\begin{array}{l}12.1 . \\
\text { Arriba }\end{array}$ & $\begin{array}{l}\text { CMC (3 gr. } \\
+100 \mathrm{ml} . \\
\text { Agua } \\
\text { desionizada } \\
\text { ) al } 50 \% \text { en } \\
\text { Alcohol } \\
\text { polivinílico } \\
\text { (5 gr. + } 50 \\
\text { ml. Agua) }\end{array}$ & $\begin{array}{l}\text { Gasa de } \\
\text { algodón }\end{array}$ & Fieltro & $\begin{array}{l}\text { Adhesión débil de ambos } \\
\text { estratos. Una vez } \\
\text { separada de la madera } \\
\text { con la ayuda de una } \\
\text { espátula, la pintura queda } \\
\text { más o menos flexible. }\end{array}$ \\
\hline \multicolumn{2}{|c|}{ DESPROTECCIÓN } & \multicolumn{3}{|c|}{$\begin{array}{l}\text { El fieltro se separa en seco. La gasa se elimina mediante } \\
\text { la acción de agua caliente. Se elimina bien, con facilidad y } \\
\text { sin dañar la pintura. }\end{array}$} \\
\hline $\begin{array}{l}12.2 . \\
\text { Abajo }\end{array}$ & $\begin{array}{l}\text { CMC (3 gr. } \\
+100 \mathrm{ml} . \\
\text { Agua } \\
\text { desionizada } \\
\text { ) al } 50 \% \text { en } \\
\text { Alcohol } \\
\text { polivinílico } \\
(5 \text { gr. + } 50 \\
\text { ml. Agua) }\end{array}$ & $\begin{array}{l}\text { Gasa de } \\
\text { algodón }\end{array}$ & $\begin{array}{l}\text { Loneta } \\
\text { de } \\
\text { algodón }\end{array}$ & $\begin{array}{l}\text { Buena adhesión de la } \\
\text { gasa a la pintura. } \\
\text { Adhesión débil y poco } \\
\text { homogénea de la loneta a } \\
\text { la gasa. Una vez separada } \\
\text { de la madera con la ayuda } \\
\text { de una espátula, la pintura } \\
\text { queda más o menos } \\
\text { rígida. }\end{array}$ \\
\hline \multicolumn{2}{|c|}{ DESPROTECCIÓN } & \multicolumn{3}{|c|}{$\begin{array}{l}\text { La loneta se separa en seco. La gasa se elimina mediante } \\
\text { la acción de agua caliente. Se elimina bien, con facilidad y } \\
\text { sin dañar la pintura. }\end{array}$} \\
\hline
\end{tabular}




\subsubsection{MATERIALES ENSAYADOS.}

Los principales materiales a tener en cuenta a la hora de elegir la protección más adecuada de la pintura antes de proceder a su separación del soporte se pueden agrupar en dos grupos:

* Telas de protección.

* Adhesivos.

Aunque de igual importancia son los instrumentos usados para la separación propiamente dicha, que se estudiarán en el punto 5.1.7 de este mismo capítulo.

En cuanto a las telas, hay que tener en cuenta los siguientes factores:

- Buena estabilidad y resistencia a los diferentes adhesivos.

- Que confiera una superficie lo bastante rígida como para proteger la pintura pero lo bastante flexible como para permitir cierta flexión por levantamiento durante la separación de la pintura respecto a su soporte de madera.

Mientras que a la hora de elegir el mejor producto para adherir estas telas a la superficie pictórica, habrá que tener en cuenta los siguientes factores:

$\rightarrow$ Penetrabilidad.

- Facilidad de aplicación.

+ Compatibilidad con la obra.

* Grado de reversibilidad.

- Restos que quedan en la obra.

* Inocuidad.

\subsubsection{TELAS.}

Una vez revisadas todos los ensayos con probetas de pinturas murales, se pueden extraer conclusiones, para llegar a decidir cuál sería el estrato de protección más conveniente para la obra que nos ocupa.

Se ha aplicado un estrato de gasa de algodón entre la pintura y la tela que se aplcia como segundo estrato de protección. Estas otras telas utilizadas son: tela de algodón (veladina), tela de algodón (muletón), arpillera y Spherecore ${ }^{\circledR}$. 


\subsubsection{ADHESIVOS}

Se requiere un adhesivo que sea muy reversible, que penetre poco pero que adhiera lo suficiente como para proteger correctamente la pintura. Y además que no sea soluble en el disolvente que se usará para facilitar la separación de la obra de su soporte.

Los adhesivos ensayados son:

* Cola de gelatina.

* Carboximetilcelulosa.

- Alcohol polivinílico.

* Paraloid B-72. Disuelto, en este caso, en acetona.

* Plexisol P-550.

Para la elección del adhesivo de protección hay que tener en cuenta diversos factores:

* Compatibilidad con la obra. Todos los adhesivos ensayados son compatibles con la obra.

- Reversibilidad.

\section{A. Reversibilidad.}

Se estudia en este apartado el modo en que puede ser eliminado cada uno de los materiales utilizados, así como los disolventes o instrumentos necesarios para su eliminación. Se trata de estudiar empíricamente la cantidad de restos que quedan de cada adhesivo, en las probetas usadas para la experimentación práctica.

Este aspecto es fundamental, ya que si permaneciesen restos de adhesivo de las protecciones en la superficie de la pintura original, con el tiempo, podrían aparecer manchas o cambios de color que distorsionarían aún más la visión óptima de las pinturas. Para cuantificar los restos de adhesivo sobre la superficie de pintura de las probetas, se han seguido cuatro métodos distintos, que son:

- Observación a través de luz ultravioleta, mediante la captura de fotografías con luz ultravioleta reflejada.

- Comparación de las mediciones colorimétricas de las probetas antes de ser aplicadas las protecciones y una vez eliminadas éstas.

- Comparación las fotografías capturadas con microscopio óptico, realizadas antes de la aplicación 
del adhesivo de protección y después de su eliminación.

* Análisis de muestras por medio de Espectroscopia de Infrarrojos por transformada de Fourier.

\section{A.1. Fotografías ultravioletas ${ }^{155}$.}

Las fotografías se han tomado con una cámara réflex digital: Nikon D100. A 200 ASA, un diafragma de 5'6, y la velocidad entre 4", 6" y 8".

La fuente de luz provenía de cuatro tubos de luz ultravioleta a la derecha y otros cuatro tubos a la izquierda de las probetas, con el fin de que éstas reflejaran homogéneamente la radiación ultravioleta.

De este análisis no hemos extraído conclusiones definitivas sobre los adhesivos, puesto que en ninguna de las fotografías se aprecian florescencias diferentes por restos de adhesivos ensuperficie. No obstante, consideramos que estos análsis no son concluyentes de que no existen restos de adhesivo en ninguna de las probetas, por lo que se sigue ensayando con el resto de ensayos expuestos a continuación.

\section{A.2. Mediciones colorimétricas.}

Se han realizado mediciones colorimétricas con el medidor ESPECTROFOTÓMETRO MINOLTA CM-2600d ${ }^{156}$.

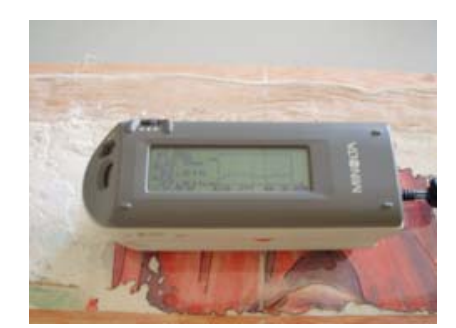

Fig. 82. Espectrofotómetro Minolta CM-2600d.

\footnotetext{
${ }^{155}$ Véase tabla con las fotografías ultravioletas en el Anexo III.

${ }^{156}$ El Procesado de los datos colorimétricos los ha llevado a cabo la Dra. Ma Luisa Martínez Bazán. Véanse las tablas de las mediciones colorimétricas realizadas, en el Anexo IV.
} 
En dichas mediciones se ha evidenciado cuáles son las probetas que mayor cambio colorimétrico han sufrido al aplicarles el adhesivo de protección.

Se muestra en estas dos tablas los 10 valores de mayor que presentan un mayor cambio cromático así como los 10 que representan un menor cambio.

\begin{tabular}{|c|l|l|l|}
\hline $\begin{array}{c}\text { ORDEN DE MAYOR } \\
\text { DIFERENCIA } \\
\text { CROMÁTICA }\end{array}$ & $\begin{array}{c}\text { No DE } \\
\text { MUESTRA }\end{array}$ & $\begin{array}{c}\text { NOMBRE } \\
\text { DE } \\
\text { MUESTRA }\end{array}$ & ADHESIVO \\
\hline $1^{\circ}$ & 39 & Ac9.5 & Paraloid B-72 \\
\hline $2^{\circ}$ & 40 & Ac10.1 & Paraloid B-72 \\
\hline $3^{\circ}$ & 37 & Ac9.3 & Paraloid B-72 \\
\hline $4^{\circ}$ & 26 & Ac6.3 & $\begin{array}{l}\text { Plexisol } \\
\text { P-550 }\end{array}$ \\
\hline $5^{\circ}$ & 21 & Ac5.4 & Plexisol \\
\hline $6^{\circ}$ & 38 & Ac9.4 & Paraloid B-72 \\
\hline $7^{\circ}$ & 41 & Ac10.3 & Paraloid B-72 \\
\hline $8^{\circ}$ & 27 & Ac6.4 & $\begin{array}{l}\text { Plexisol } \\
\text { P-550 }\end{array}$ \\
\hline $9^{\circ}$ & 16 & Ac4.4 & $\begin{array}{l}\text { Cola de } \\
\text { gelatina }\end{array}$ \\
\hline $10^{\circ}$ & 29 & Ac7.1 & $\begin{array}{l}\text { Alcohol } \\
\text { polivinílico }\end{array}$ \\
\hline \hline
\end{tabular}

\begin{tabular}{|c|l|l|l|}
\hline $\begin{array}{c}\text { ORDEN DE MENOR } \\
\text { DIFERENCIA } \\
\text { CROMÁTICA }\end{array}$ & $\begin{array}{c}\text { No DE } \\
\text { MUESTRA }\end{array}$ & $\begin{array}{c}\text { NOMBRE } \\
\text { DE } \\
\text { MUESTRA }\end{array}$ & ADHESIVO \\
\hline $50^{\circ}$ & 15 & Ac4.3 & $\begin{array}{l}\text { Cola de } \\
\text { gelatina }\end{array}$ \\
\hline $49^{\circ}$ & 43 & Ac11.1 & $\begin{array}{l}\text { CMC + } \\
\text { Alcohol } \\
\text { polivinílico }\end{array}$ \\
\hline $48^{\circ}$ & 2 & Ac1.3 & CMC \\
\hline $47^{\circ}$ & 8 & Ac2.5 & CMC \\
\hline $46^{\circ}$ & 3 & Ac1.4 & CMC \\
\hline $45^{\circ}$ & 48 & Ac12.4 & $\begin{array}{l}\text { CMC + } \\
\text { Alcohol } \\
\text { polivinílico }\end{array}$ \\
\hline $44^{\circ}$ & 31 & Ac7.4 & $\begin{array}{l}\text { Alcohol } \\
\text { polivinílico }\end{array}$ \\
\hline $43^{\circ}$ & 46 & Ac11.5 & $\begin{array}{l}\text { CMC + } \\
\text { Alcohol }\end{array}$ \\
\hline & & \\
\hline
\end{tabular}




\begin{tabular}{|c||l|l|l|}
\hline & & & polivinílico \\
\hline $42^{\circ}$ & 11 & Ac3.4 & $\begin{array}{l}\text { Cola de } \\
\text { gelatina }\end{array}$ \\
\hline $41^{\circ}$ & 7 & Ac2.3 & CMC \\
\hline
\end{tabular}

A partir de estos resultados, entre otros, podemos deducir cuál será el adhesivo más adecuado para el proceso de protección de la pintura.

El inicio de la siguiente tabla muestra las mediciones colorimétricas tomadas sobre colores de probetas que han sufrido un importante cambio cromático, seguramente por presencia de restos de adhesivo que han variado los valores que habían sido tomados antes de proteger las probetas con dicho adhesivo.

Mientras que los adhesivos que menor residuo han dejado en la superficie pictórica se encuentran al final de la tabla.

Puede observarse que en el inicio de la tabla predominan los adhesivos acrílicos, como el Paraloid B-72 o el Plexisol P-550; mientras que al final de la tabla, entre los adhesivos que menor cambio cromático han provocado sobre los colores de las probetas, se encuentran, en mayor número, la Carboximetilcelulosa, seguida de una mezcla de CMC y alcohol polivinílico, y de la cola de gelatina.

Por tanto, concluiremos diciendo que en esta prueba, los adhesivos que han variado en menor medida los colores de las muestras, son la mezcla de Carboximetilcelulosa y alcohol polivinílico, y la cola de gelatina. No obstante, antes de concluir cuál será el adhesivo más adecuado para el proceso que nos ocupa, debemos tener en cuenta otros factores, como los cambios ópticos, que observaremos a través de las fotografías de las probetas tomadas a través del microscopio, así como la cantidad de restos de adhesivo que quedan en la superficie pictórica, que conoceremos a través de análisis de muestras tomadas de las probetas, por Espectroscopia de Infrarrojos por trasformada de Fourier. 


\begin{tabular}{|c|c|c|c|}
\hline \multicolumn{4}{|c|}{$\begin{array}{c}\text { CORRESPONDENCIA ENTRE MUESTRAS Y ADHESIVOS ORDENADAS } \\
\text { POR MAYOR DIFERENCIA CROMÁTICA }\end{array}$} \\
\hline $\mathbf{N}^{\circ}$ & Nombre & orden & ADHESIVO \\
\hline 39 & Ac9.5 & $1^{\circ}$ & PARALOID B-72 \\
\hline 40 & Ac10.1 & $2^{\circ}$ & PARALOID B-72 \\
\hline 37 & Ac9.3 & $3^{\circ}$ & PARALOID B-72 \\
\hline 26 & Ac6.3 & $4^{\circ}$ & PLEXISOL P-550 \\
\hline 21 & Ac5.4 & $5^{\circ}$ & PLEXISOL P-550 \\
\hline 38 & Ac9.4 & $6^{\circ}$ & PARALOID B-72 \\
\hline 41 & Ac10.3 & $7^{\circ}$ & PARALOID B-72 \\
\hline 27 & Ac6.4 & $8^{\circ}$ & PLEXISOL P-550 \\
\hline 16 & Ac4.4 & $9^{\circ}$ & COLA DE GELATINA \\
\hline 29 & Ac7.1 & $10^{\circ}$ & ALCOHOL POLIVINÍLICO \\
\hline 28 & Ac6.6 & $11^{\circ}$ & PLEXISOL P-550 \\
\hline 22 & Ac5.5 & $12^{\circ}$ & PLEXISOL P-550 \\
\hline 42 & Ac10.4 & $13^{\circ}$ & PARALOID B-72 \\
\hline 24 & Ac5.7 & $14^{\circ}$ & PLEXISOL P-550 \\
\hline 30 & Ac7.2 & $15^{\circ}$ & ALCOHOL POLIVINÍLICO \\
\hline 18 & Ac4.7 & $16^{\circ}$ & COLA DE GELATINA \\
\hline 33 & Ac8.4 & $17^{\circ}$ & ALCOHOL POLIVINÍLICO \\
\hline 35 & Ac8.6 & $18^{\circ}$ & ALCOHOL POLIVINÍLICO \\
\hline 25 & Ac6.1 & $19^{\circ}$ & PLEXISOL P-550 \\
\hline 19 & Ac5.1 & $20^{\circ}$ & PLEXISOL P-550 \\
\hline 36 & Ac9.1 & $21^{\circ}$ & ALCOHOL POLIVINÍLICO \\
\hline 20 & Ac5.3 & $22^{\circ}$ & PLEXISOL P-550 \\
\hline 14 & Ac4.2 & $23^{\circ}$ & COLA DE GELATINA \\
\hline 47 & Ac12.1 & $24^{\circ}$ & $\begin{array}{l}\mathrm{CMC}+\mathrm{ALCOHOL} \\
\text { POLIVINÍLICO }\end{array}$ \\
\hline 23 & Ac5.6 & $25^{\circ}$ & PLEXISOL P-550 \\
\hline 49 & Ac12.6 & $26^{\circ}$ & $\begin{array}{l}\mathrm{CMC}+\mathrm{ALCOHOL} \\
\text { POLIVINÍLICO }\end{array}$ \\
\hline 32 & Ac8.1 & $27^{\circ}$ & ALCOHOL POLIVINÍLICO \\
\hline 5 & Ac1.6 & $28^{\circ}$ & $\mathrm{CMC}$ \\
\hline
\end{tabular}




\begin{tabular}{|c|c|c|c|}
\hline 45 & Ac11.3 & $29^{\circ}$ & $\begin{array}{l}\text { CMC + ALCOHOL } \\
\text { POLIVINÍLICO }\end{array}$ \\
\hline 44 & Ac11.2 & $30^{\circ}$ & $\begin{array}{l}\text { CMC + ALCOHOL } \\
\text { POLIVINÍLICO }\end{array}$ \\
\hline 1 & Ac1.2 & $31^{\circ}$ & $\mathrm{CMC}$ \\
\hline 13 & Ac4.1 & $32^{\circ}$ & COLA DE GELATINA \\
\hline 9 & Ac3.1 & $33^{\circ}$ & COLA DE GELATINA \\
\hline 6 & Ac2.1 & $34^{\circ}$ & CMC \\
\hline 34 & Ac8.5 & $35^{\circ}$ & ALCOHOL POLIVINÍLICO \\
\hline 17 & Ac4.5 & $36^{\circ}$ & COLA DE GELATINA \\
\hline 12 & Ac3.5 & $37^{\circ}$ & COLA DE GELATINA \\
\hline 50 & Ac12.7 & $38^{\circ}$ & $\begin{array}{l}\text { CMC + ALCOHOL } \\
\text { POLIVINÍLICO }\end{array}$ \\
\hline 10 & Ac3.3 & $39^{\circ}$ & COLA DE GELATINA \\
\hline 4 & Ac1.5 & $40^{\circ}$ & $\mathrm{CMC}$ \\
\hline 7 & Ac2.3 & $41^{\circ}$ & CMC \\
\hline 11 & Ac3.4 & $42^{\circ}$ & COLA DE GELATINA \\
\hline 46 & Ac11.5 & $43^{\circ}$ & $\begin{array}{l}\text { CMC + ALCOHOL } \\
\text { POLIVINÍLICO }\end{array}$ \\
\hline 31 & Ac7.4 & $44^{\circ}$ & ALCOHOL POLIVINÍLICO \\
\hline 48 & Ac12.4 & $45^{\circ}$ & $\begin{array}{l}\text { CMC + ALCOHOL } \\
\text { POLIVINÍLICO }\end{array}$ \\
\hline 3 & Ac1.4 & $46^{\circ}$ & CMC \\
\hline 8 & Ac2.5 & $47^{\circ}$ & CMC \\
\hline 2 & Ac1.3 & $48^{\circ}$ & CMC \\
\hline 43 & Ac11.1 & $49^{\circ}$ & $\begin{array}{l}\text { CMC + ALCOHOL } \\
\text { POLIVINÍLICO }\end{array}$ \\
\hline 15 & Ac4.3 & $50^{\circ}$ & COLA DE GELATINA \\
\hline
\end{tabular}

\section{A.3. Macrofotografías.}

Se han efectuado fotografías tanto antes de aplicar el tratamiento consolidante, como después de su aplicación, y después de la desprotección de las probetas, por lo que se establece una comparativa de tres fotografías de cada una de las probetas. Aunque lo que realmente nos interesa es la comparación entre las fotografías de antes de la aplicación de la protección, es decir, cuando ya se ha aplicado el hidróxido de bario, y las fotografías de las probetas una vez desprotegidas. 
El microscopio utilizado ha sido: KYOWA HWF 10x/23, a 4'5 aumentos y 0,7 aumentos.

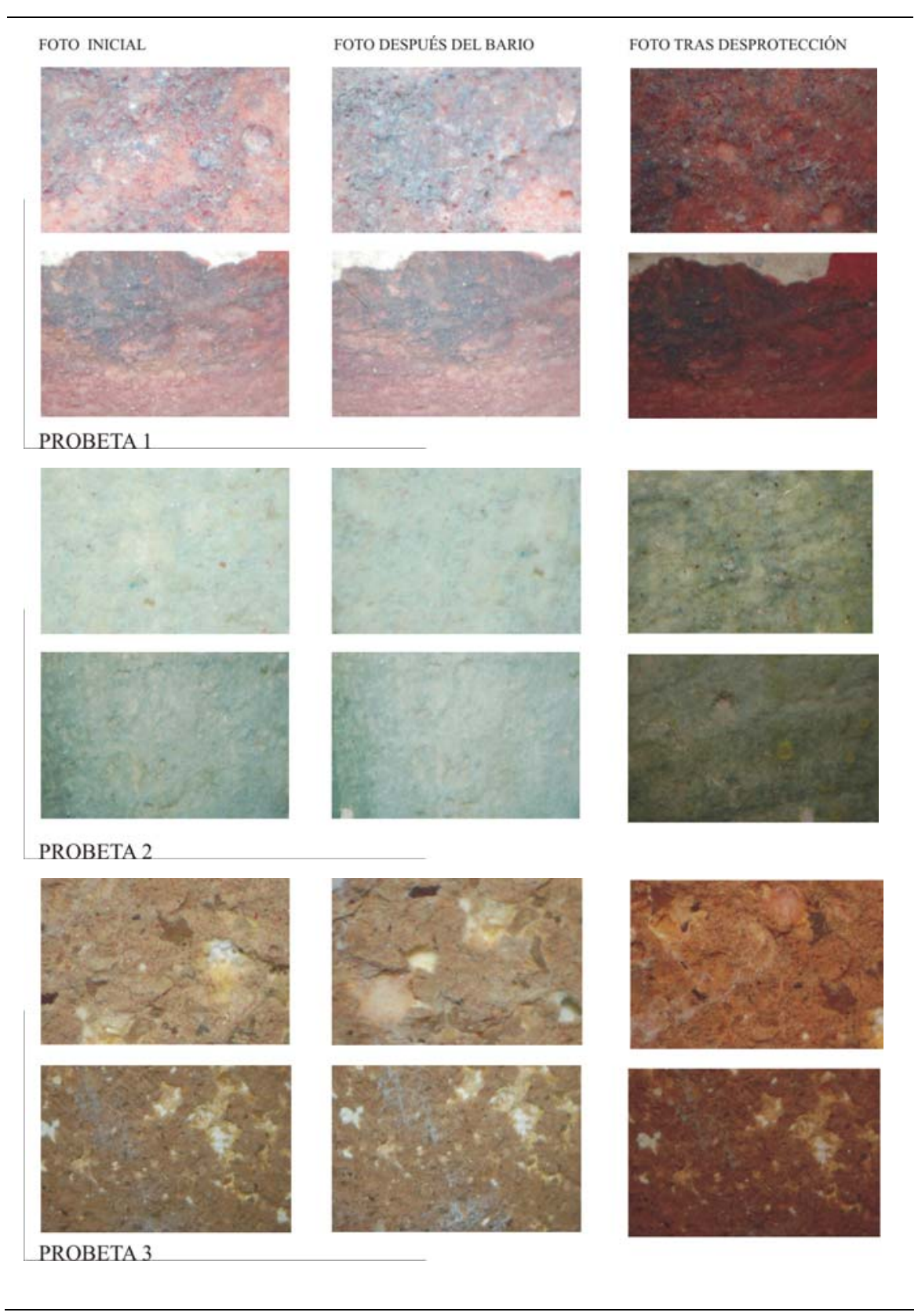



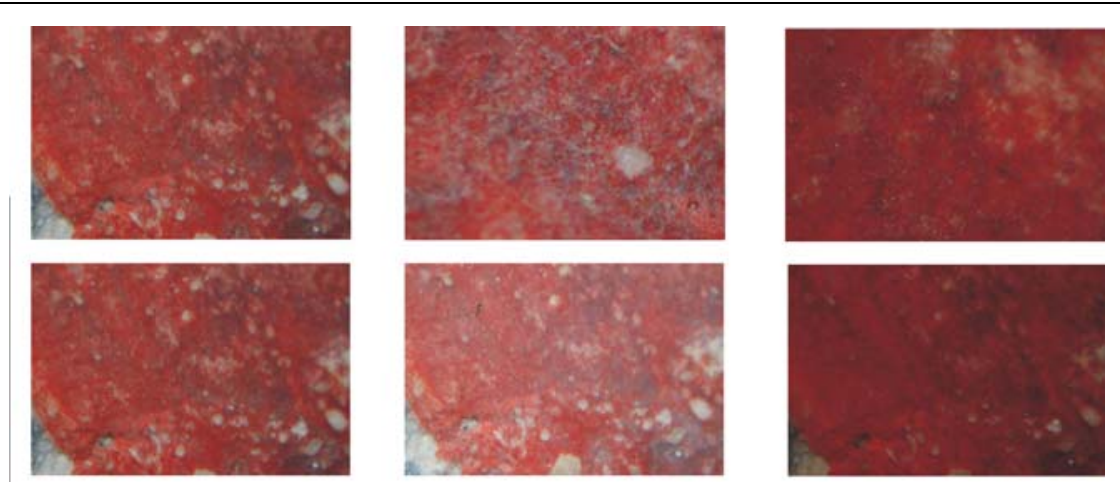

PROBETA 4
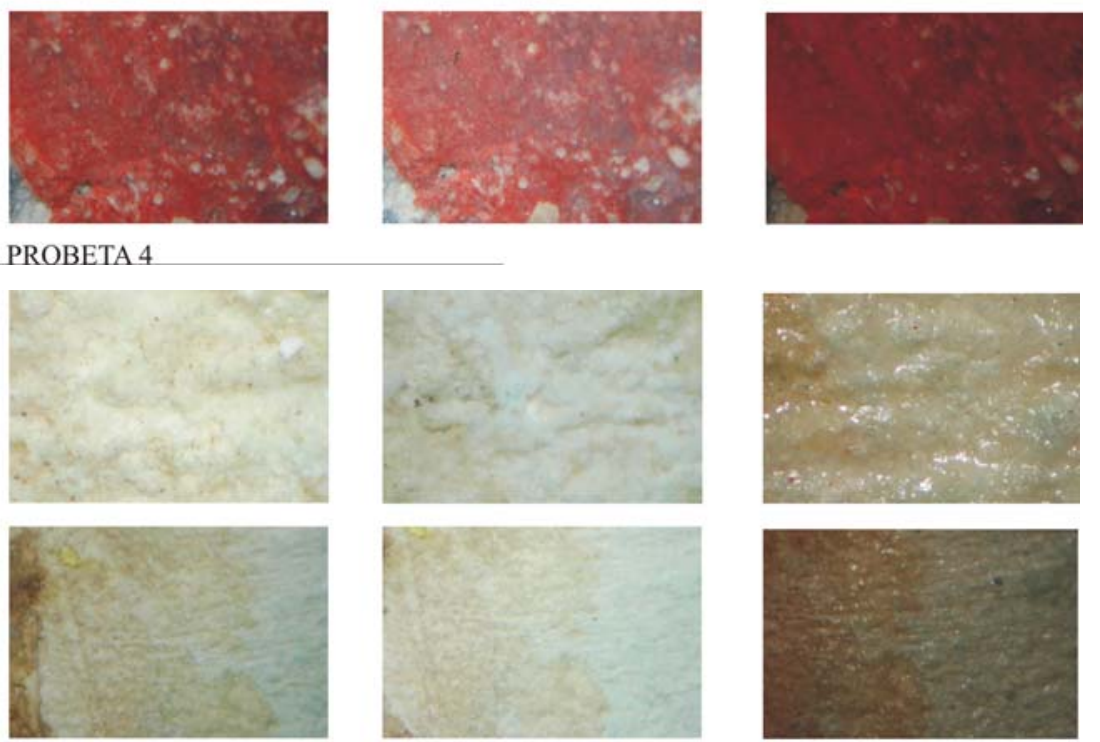

PROBETA 5
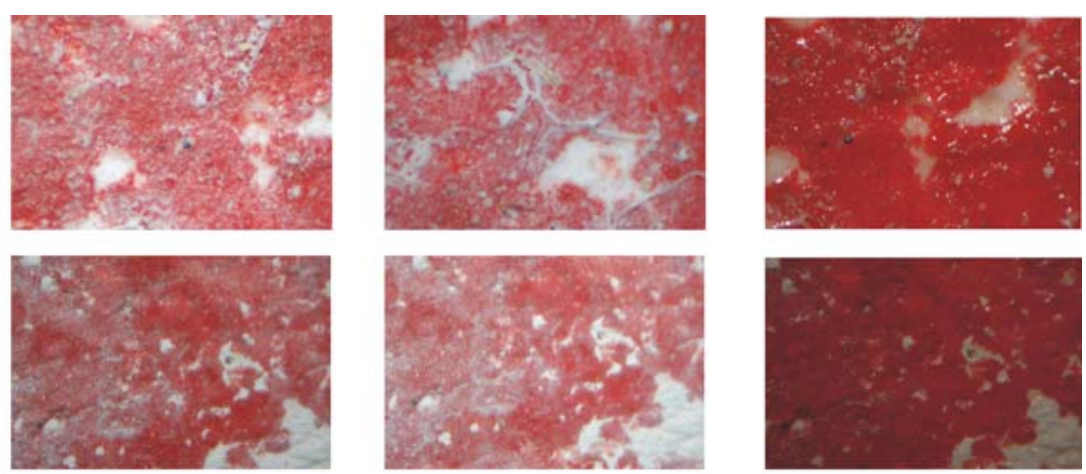

PROBETA 6 


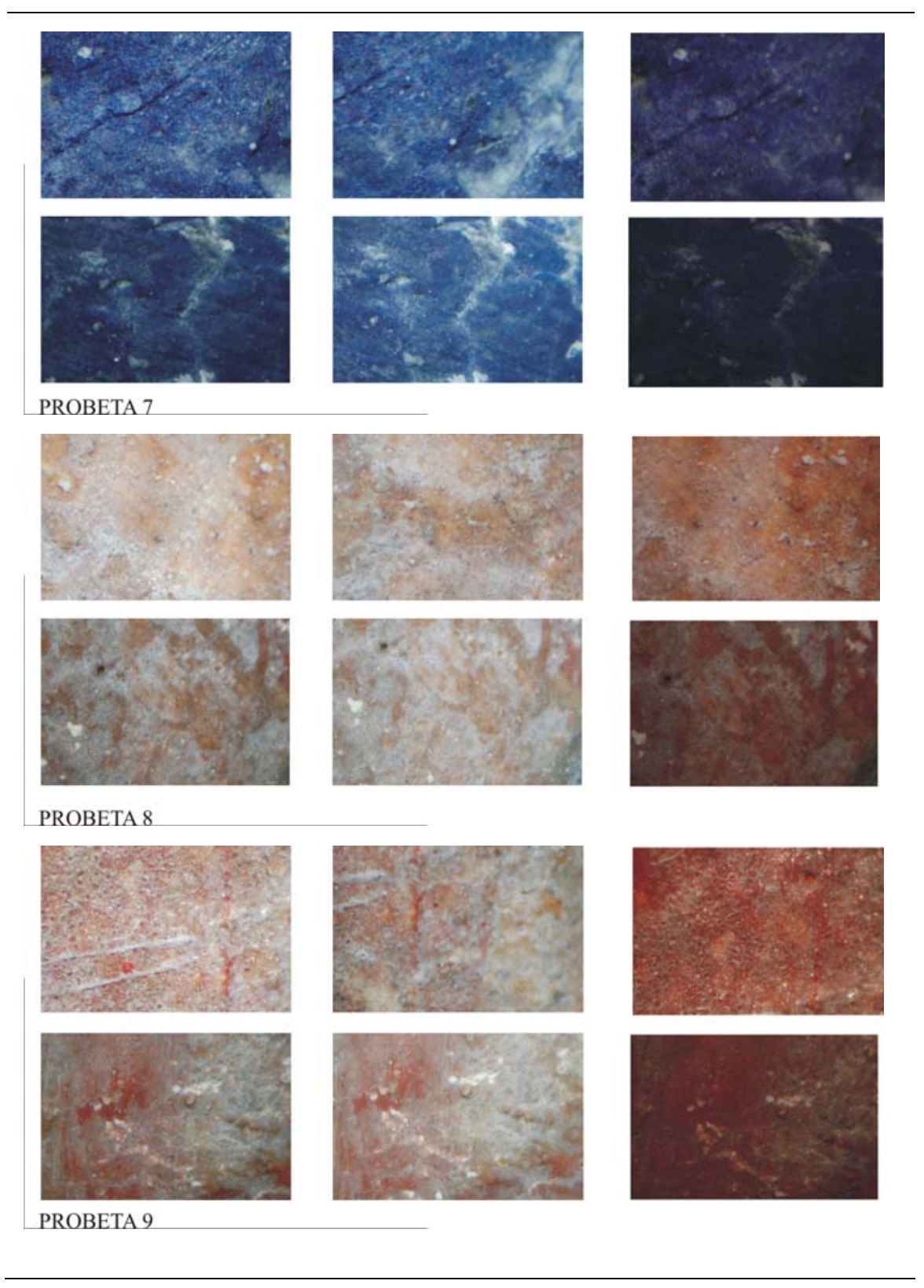



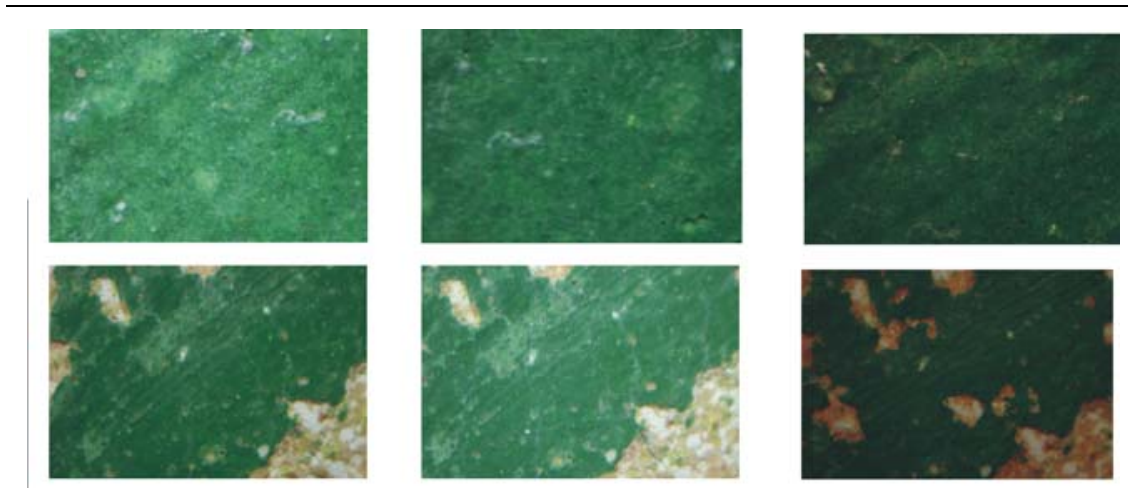

PROBETA 10
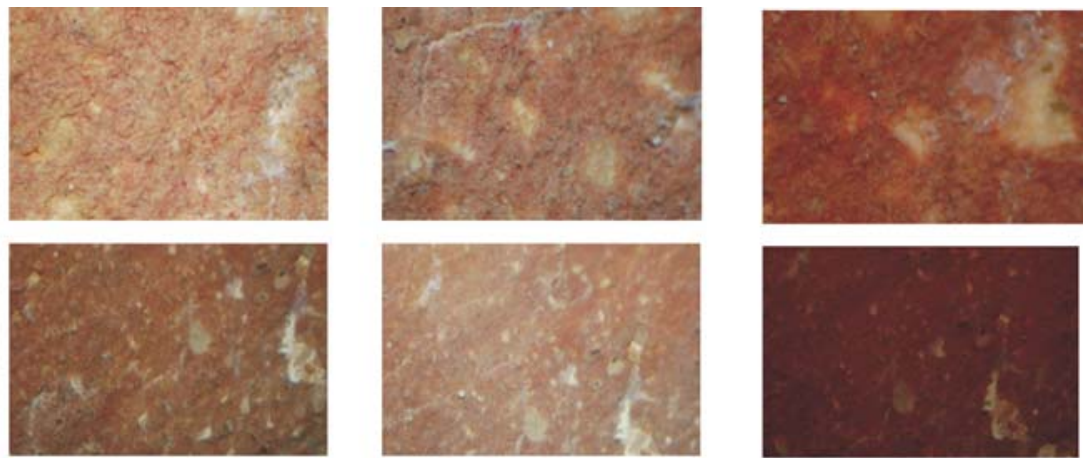

PROBETA 11
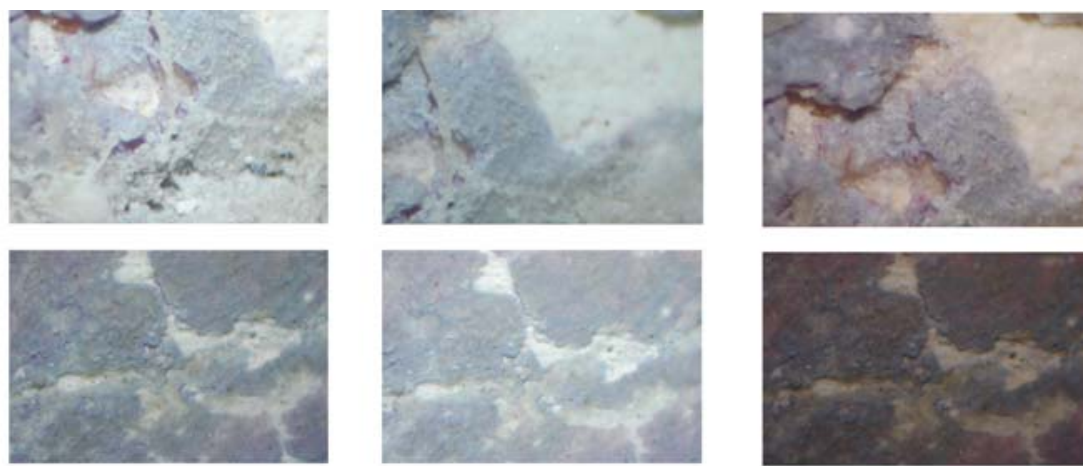

PROBETA 12 
De la comparación de estas fotografías podemos extraer las siguientes conclusiones:

\begin{tabular}{|c|c|c|}
\hline $\begin{array}{c}\mathbf{N}^{\circ} \\
\text { PROBETA }\end{array}$ & ADHESIVO & OBSERVACIONES \\
\hline 1 & CMC & $\begin{array}{l}\text { En las fotografías finales el color se ve más } \\
\text { saturado. }\end{array}$ \\
\hline 2 & $\mathrm{CMC}$ & $\begin{array}{l}\text { En las fotografías finales se aprecian manchas } \\
\text { amarillas y puntos rojos. }\end{array}$ \\
\hline 3 & Cola de gelatina & $\begin{array}{l}\text { En las fotografías finales el color se ve más } \\
\text { saturado. }\end{array}$ \\
\hline 4 & Cola de gelatina & $\begin{array}{l}\text { En las fotografías finales el color se ve más } \\
\text { saturado. }\end{array}$ \\
\hline 5 & Plexisol P-550 & $\begin{array}{l}\text { En las fotografías finales el color se ve más } \\
\text { saturado, y destaca el exceso de brillo. }\end{array}$ \\
\hline 6 & Plexisol P-550 & $\begin{array}{l}\text { En las fotografías finales el color se ve más } \\
\text { saturado, y destaca el exceso de brillo. }\end{array}$ \\
\hline 7 & $\begin{array}{l}\text { Alcohol } \\
\text { Polivinílico }\end{array}$ & Se mantiene más o menos invariable. \\
\hline 8 & $\begin{array}{l}\text { Alcohol } \\
\text { Polivinílico }\end{array}$ & $\begin{array}{l}\text { En las fotografías finales el color se ve un poco } \\
\text { más saturado, pero prácticamente es } \\
\text { inapreciable. }\end{array}$ \\
\hline 9 & Paraloid B72 & $\begin{array}{l}\text { En las fotografías finales el color se ve más } \\
\text { saturado, y destaca el exceso de brillo. }\end{array}$ \\
\hline 10 & Paraloid B72 & $\begin{array}{l}\text { En las fotografías finales el color se ve más } \\
\text { saturado. }\end{array}$ \\
\hline 11 & $\begin{array}{l}\text { CMC + Alcohol } \\
\text { Polivinílico }\end{array}$ & Se mantiene más o menos invariable. \\
\hline 12 & $\begin{array}{l}\text { CMC + Alcohol } \\
\text { Polivinílico }\end{array}$ & Se mantiene más o menos invariable. \\
\hline
\end{tabular}




\section{A.4. Análisis por Espectroscopia Infrarroja por Trasformada de Fourier ${ }^{157}$.}

Se han realizado análisis de Espectroscopia Infrarroja por transformada de Fourier, sobre muestras tomadas de las probetas para detectar si existen restos de adhesivo en ellas.
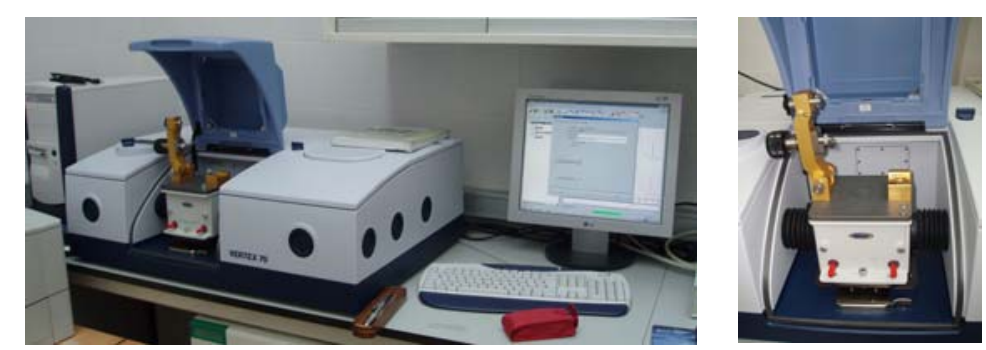

Figs. 83 y 84 . Aparato en el que se han realizado los análisis de Espectroscopia Infrarroja por transformada de Fourier, de muestras tomadas de las probetas de laboratorio.

Estas muestras se han comparado con otras extraídas de los adhesivos utilizados para las protecciones, pero en estado puro y sólido.

Para obtener resultados se han comparado los gráficos de una muestra de adhesivo puro con las cuatro muestras de las probetas en las que se usó dicho adhesivo. El mismo procedimiento se ha seguido con el resto de muestras de adhesivos, que suman un total de 5: Carboximetilcelulosa, Coletta italiana, Plexisol, alcohol polivinílico y Paraloid B-72.

En los gráficos nombrados ${ }^{158}$, podemos observar que es común a todos ellos la banda situada a 1430, correspondiente a $\mathrm{CO}_{3}^{2-}$, que sería el carbonato cálcico $\mathrm{CaCO}_{3}$, componente principal de los morteros de cal y arena, a 876 y $710 \mathrm{~cm}^{-1}$ y la banda a $1000 \mathrm{~cm}^{-1}$ correspondiente a silicatos.

Sin embargo, en cada uno de ellos aparecen bandas a diferentes ongitudes de onda que corresponden a restos adhesivos. A continuación mostramos los gráficos

${ }^{157}$ Se ha utilizado la Reflectancia Total Atenuada: F.T.I.R con A.T.R. El aparato empleado ha sido un Vertex 70, con el software OPUS, del laboratorio Fisíco-Químico del Instituto de Restauración del Patrimonio, bajo la dirección de la Dra. Teresa Doménech Carbó y la colaboración de Julio Del Hoyo Menéndez.

${ }^{158}$ Véase la totalidad de los gráficos en el Anexo V. 
comparativos de cada uno de los adhesivos puros con una muestra sacada de cada una de las probetas.

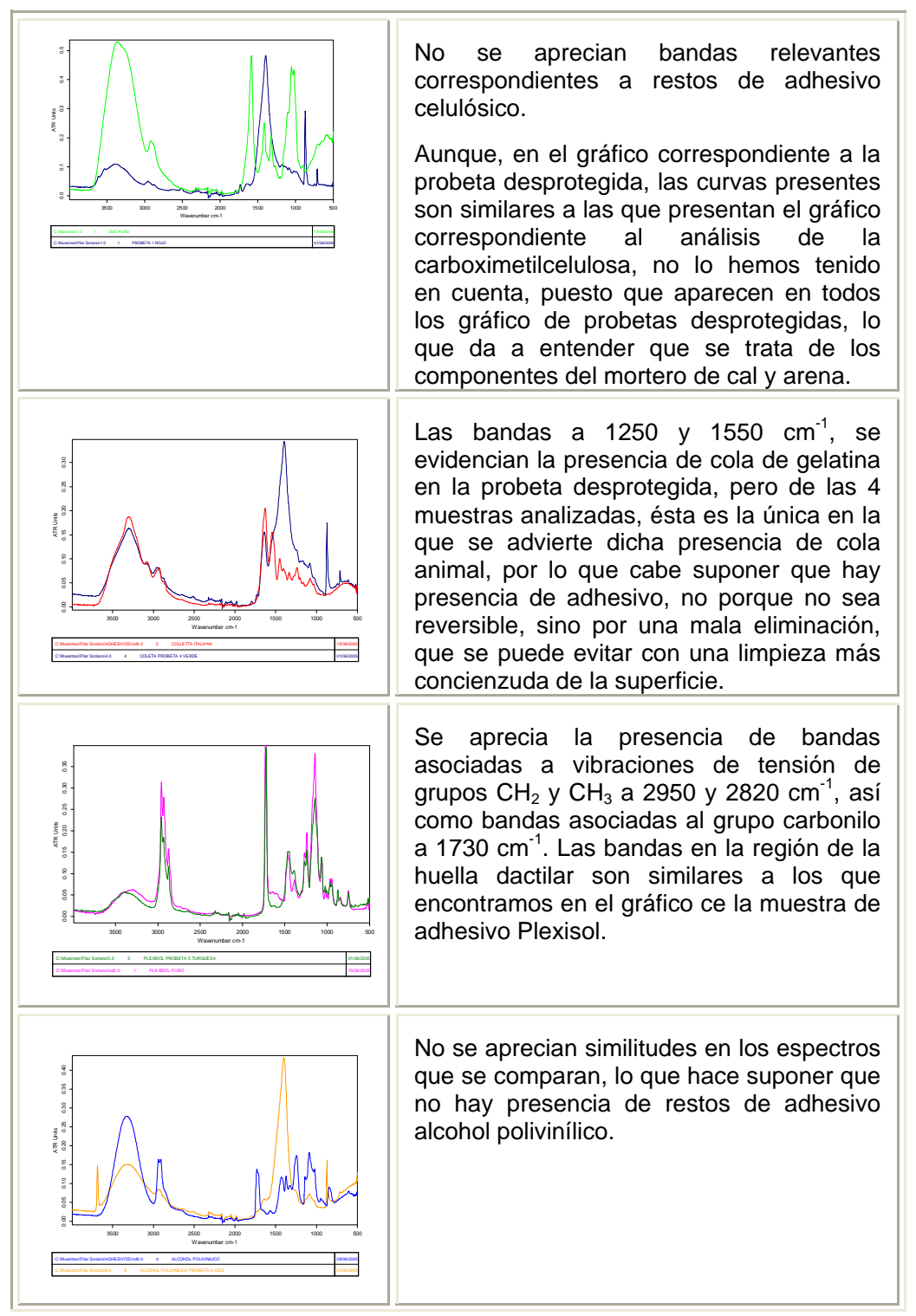




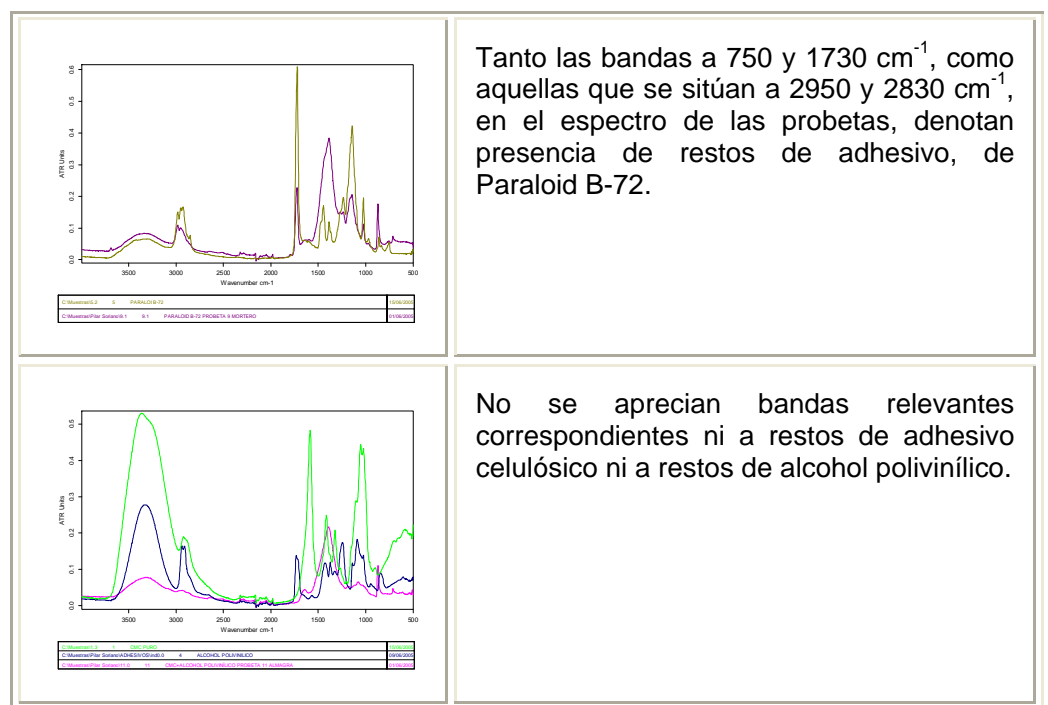

De los diferentes análisis llevados a cabo, se puede deducir que los adhesivos que menos restos dejan en la superficie pictórica, y por lo tanto los más reversibles, son la carboximetilcelulosa, el alcohol polivinílico, la mezcla de carboximetilcelulosa y alcohol polivinílico, y la cola de gelatina. No obstante, como expondremos más adelante, tanto las protecciones de carboximetilcelulosa como las de mezcla de carboximetilcelulosa con alcohol polivinílico, son demasiado débiles para realizar una buena protección de la superficie pictórica de esta obra, por lo que, aunque se aprecien más cambios colorimétricos y en las gráficas aparezcan más picos similares, consideramos que la protección más adecuada para estas pinturas, debería realizarse con cola de gelatina.

\subsubsection{PROPUESTA DE PROTECCIÓN DE UN FRAGMENTO DE LAS PINTURAS DE PALOMINO EN LA IGLESIA DE LOS SANTOS JUANES DE VALENCIA.}

Antes de decidir los materiales a utilizar se deben hacer pruebas de solubilidad tanto de la película pictórica original, como del adhesivo que la une a su soporte, pues de ello dependerá el uso de un adhesivo u otro, así como el uso de un disolvente concreto para efectuar la separación. 


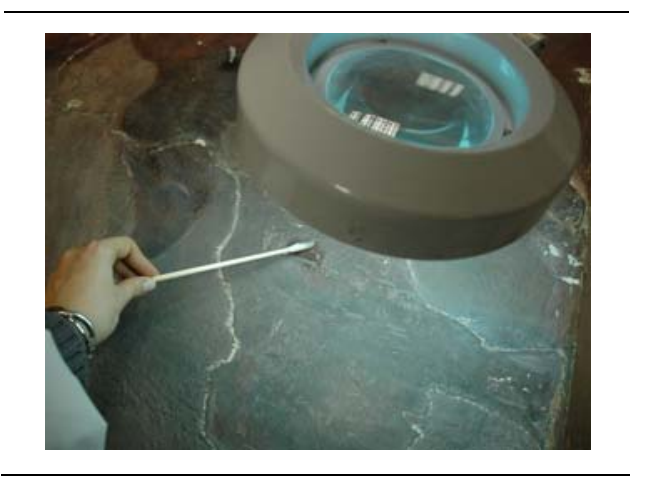

Fig. $85 . \quad$ proceso de

realización de las pruebas de solubilidad en la superficie de la pintura arrancada de la iglesia de los Santos Juanes.

Estas pruebas se han hecho con agua y acetona. $Y$ se sitúan en los siguientes puntos del fragmento de pintura tratada:

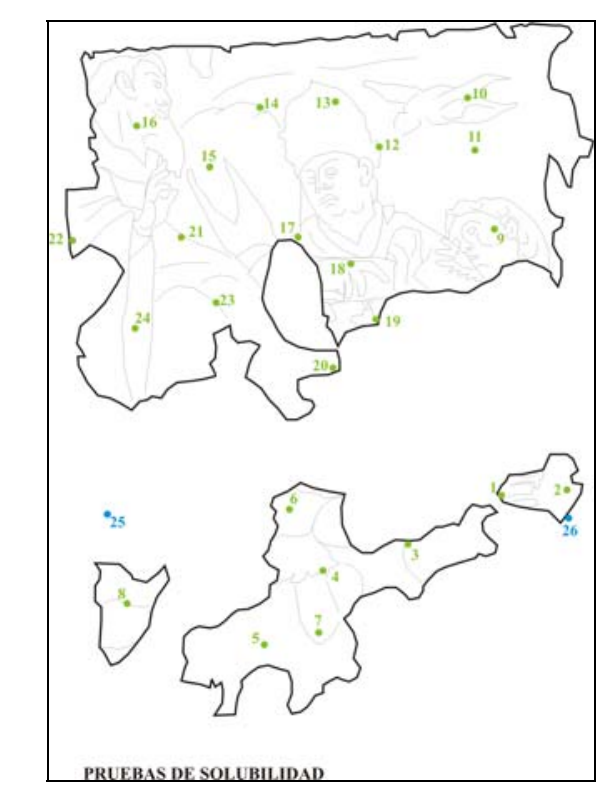

Fig. 86. Diagrama de localización de las pruebas de solubilidad en el fragmento de pintura arrancada de la iglesia de los Santos Juanes.

Tras el estudio llevado a cabo sobre probetas de laboratorio, para determinar qué método y materiales son los más adecuados para aplicar a esta obra, se ha concluido lo siguiente:

Teniendo en cuenta todos los factores nombrados anteriormente relativos a la facilidad de aplicación, compatibilidad con la obra y reversibilidad de los adhesivos, los considerados como más adecuados para el proceso requerido, por cumplir todas estas características serían la carboximetilcelulosa, el alcohol polivinílico o incluso una mezcla de carboximetilcelulosa y alcohol polivinílico. 
No obstante, no sólo se deben tener en cuenta los resultados de los ensayos realizados, sino también el poder adhesivo de las diferentes protecciones aplicadas.

Teniendo en cuenta este último factor, y tras los ensayos realizados, se ha comprobado que estos tres adhesivos no cumplen correctamente con la función de adherencia requerida, por lo que, aunque sean los adhesivos que menos restos dejan en la pintura y los que menos cambios cromáticos provocan, debemos elegir una protección con mayor poder adhesivo.

De los adhesivos analizados, el que menos cambios cromáticos ha provocado en las probetas y menos restos ha dejado en las pinturas, después de los adhesivos ya descartados, ha sido la cola de gelatina.

La cola de gelatina, aunque rectificada, es además, similar a la cola utilizada para efectuar el arranque.

Por otro lado, de las telas analizadas, las que ofrecen una mayor protección a la vez que permiten cierta flexibilidad de la obra en el momento de la separación de su soporte, son la gasa de algodón como primer estrato, en contacto con la superficie pictórica, y una tela de algodón de trama más cerrada como segundo estrato, que es el que aporta la suficiente rigidez a la protección.

\subsection{ENSAYOS DE NUEVOS SOPORTES.}

Un nuevo soporte para una pintura mural arrancada está constituido por diversos estratos, los cuales están formados por materiales que pueden ser diferentes en cada uno de estos soportes, según la época, como hemos visto en el capítulo anterior, o según las características de la obra a tratar.

Con el objeto de experimentar en la práctica con los distintos materiales usados tanto en el pasado como en la actualidad para efectuar este tipo de soporte, se ha elaborado un muestrario de diferentes tipos de soportes de los conocidos como no tradicionales ${ }^{159}$.

En principio, se descarta el modo de proceder con los soportes de compensado de madera, muy perjudiciales porque hinchan en presencia de humedad, usados en los años 60 . Así como bastidores de metal con

\footnotetext{
${ }^{159}$ Se ha tenido en cuenta la experimentación llevada a cabo por Isabel Rodríguez Sancho en su artículo: RODRÍGUEZ SANCHO, Isabel. "Soportes rígido-inertes para el traslado de pinturas. Estudio de su deformación estructural al ser sometidos a la acción degradante de la humedad y temperatura en una cámara de niebla salina". En $X$ Congreso de Conservación y Restauración de Bienes Culturales. Cuenca, del 29 de septiembre al 2 de octubre de 1994. Edita Andrés Escalera y Mª Carmen Pérez. Cuenca, 1994.
} 
un enrejado metálico y yeso, que al oxidar con la humedad hacía caer el yeso y por lo tanto la pintura adherida a él.

Cada una de estas probetas está formada por tres componentes principales, el soporte, la capa de intervención y los adhesivos que unen las diferentes capas.

\subsubsection{SOPORTE.}

El material de soporte es el que "sujeta" propiamente la obra arrancada una vez está adherida a él.

Puesto que partimos de la base de que vamos a ensayar únicamente con soportes rígidos de resinas sintéticas, pues descartamos para esta obra la utilización de soportes tradicionales, podemos clasificar los distintos tipos de soporte en:

- Tipo sándwich.

Núcleo alveolar.

Núcleo de espuma rígida expandida.

- Otros.

Para la elaboración de las primeras probetas se ha trabajado con los siguientes materiales:

Comerciales:

- Aerolam ${ }^{\circledR}$ (Ciba Geigy) de diferentes espesores ${ }^{160}$.

- Policarbonato. El policarbonato es un polímero termoplástico con buena resistencia al impacto y más ligero que el PMM. La presentación de este material es en planchas alveolares, que consta de 2 ó 3 paredes paralelas unidades transversalmente por paredes del mismo material. El grosor de las placas, que se puede encontrar en el mercado es de 4 a $16 \mathrm{~mm}$. Esta placa está protegida, por la parte que se expone al exterior, por una película que protege de los rayos UV al resto del material para evitar su degradación. El policarbonato celular tiene una opacidad total a las radiaciones de longitud de onda larga. Las múltiples paredes de que consta la placa, forman una cámara de aire dentro de los canales internos que hacen aumentar el poder aislante en un porcentaje muy elevado, respecto al mismo material en placa sencilla. Es un

\footnotetext{
${ }^{160}$ Aerolam ${ }^{\circledR}$ F-Board (con capa externa de fibra de vidrio) de la casa Ciba Geigy, que se comercializa con las medidas estándar: $2440 \times 1220 \mathrm{~mm}$. Y de grosor se ha utilizado de 13 '8 mm. y $5 \mathrm{~mm}$.
} 
material muy ligero, comparado con el grosor de la placa; aproximadamente es 10 a 12 veces menos que el vidrio, a igualdad de espesor. El policarbonato tiene una gran resistencia al impacto. Estas placas pueden adaptarse en frío a estructuras con perfiles curvos de radio suave. La duración de las placas de policarbonato celular está garantizada por los fabricantes en 10 años. Se ralla con los objetos punzantes. Se ha utilizado el de $8 \mathrm{~mm}$ de espesor.

Preparados en el laboratorio. Envuelto en resina epoxi ${ }^{161}$ y fibra de vidrio ${ }^{162}$ :

- Poliestireno expandido ${ }^{163}$. Es un material de célula cerrada. Está compuesto por la aglomeración de pequeños glóbulos de pocos milímetros de diámetro. Su peso específico está entre los $15-35 \mathrm{Kg} . / \mathrm{m}^{3}$. Es muy sensible a la acción de disolventes orgánicos, en particular a los disolventes aromáticos (benceno, tolueno) y clorados (tetracloruro de carbono, tricloroetileno, cloroetileno), a la acetona, al acetato de amilo, etc. Tiene que ser encolado siempre con adhesivos acuosos. No puede ser expuesto directamente a los agentes atmosféricos, sobre todo a los rayos solares, por ser un material muy sensible a la acción de la luz ultravioleta. En presencia de ésta, el polímero sintético, amarillea y se degradan sus propiedades mecánicas. Estas alteraciones son menos importantes en el poliestireno expandido de densidad $30-35 \mathrm{Kg}$. $/ \mathrm{m}^{3}$. Es inflamable, pero la propagación de la llama es impedida por la rápida fusión del producto. Las características positivas de este material es su ligereza, precio relativamente bajo y fácil trabajabilidad. Como soporte para pinturas murales arrancadas, necesita de una estructura de refuerzo. La facilidad con la que puede ser destruido cortándolo con un hilo metálico caliente, lo hacen servible también como estrato de intervención. Tiene además la capacidad de proteger los materiales frágiles de golpes y vibraciones.

\footnotetext{
${ }^{161}$ Resina epoxídica EC54L de la casa CAMATTINI s.p.a

${ }^{162}$ La fibra de vidrio tiene una densidad de 2'5. Este peso, relativamente alto y la posibilidad de que las fibras sufran el fenómeno del "creep" o "scorrimento viscoso", suponen un problema para mantener la plenitud del soporte. Además la elasticidad de estas fibras no es demasiado elevada.

${ }^{163}$ Ver las características técnicas en el Libro blanco de la Asociación Nacional de Poliestireno Expandido: http://www.anape.es. Se ha utilizado el de 1'7 mm de espesor.
} 
- Cloruro de polivinilo expandido ${ }^{164}$. Es un material de célula cerrada, que se presenta en hojas rígidas, semirrígidas o flexibles. Es menos sensible a los disolventes ordinarios que el poliestireno expandido, pero más soluble que el poliuretano. Resiste bastante bien los hidrocarburos alifáticos y aromáticos, y al alcohol etílico, pero es sensible a los disolventes clorados y al metiletilcetona. Es muy resistente a los microorganismos y a los agentes atmosféricos; no se deteriora por efecto de los rayos ultravioleta ni por presencia de humedad. Es el material más resistente de los que estamos analizando, no obstante, puede ser trabajado con facilidad para formar superficies curvas, con la ayuda de calor o con lámparas infrarrojas. Pero a alta temperatura ambiente puede deformarse si se somete a cargas considerables, por lo que, aunque no es necesario, se recomienda aplicar, cuando se use como soporte de pinturas murales arrancadas, una estructura de refuerzo en aluminio. En el comercio se encuentra el cloruro de polivinilo expandido (CADORITE) en láminas de 40-45 $\mathrm{mm}$ de espesor y densidad de $20,30,60,80$ y $90 \mathrm{Kg} . / \mathrm{m} 3$. Los soportes de grandes dimensiones requieren los de densidad fuerte $\left(80 \circ 90 \mathrm{Kg} . / \mathrm{m}^{3}\right)$. La Cadorite presenta una película superficial a baja expansión que puede provocar la curvatura del panel bajo la acción de una dilatación diferencial cuando se secciona en espesor, y se utiliza una sola de las caras originales. Se encuentra en el mercado otro tipo de cloruros de polivinilo expandido sin esta película superficial a baja expansión y ya cortado al espesor deseado (AIREX), que evitan el trabajo de preparación.

- Estructura alveolar de cartón ${ }^{165}$. No es bueno porque es higroscópico y mueve en presencia de humedad. Para evitar esto es habitual impregnar todo el cartón con resina.

- Poliuretano expandido ${ }^{166}$. Puede ser de célula abierta o cerrada. Químicamente es más resistente que el poliestireno. Es insoluble en la mayor parte de los disolventes, pero muy sensible a la acción destructora de los

\footnotetext{
${ }^{164}$ Se ha utilizado el CADORITE, distribuido por CTS España.

${ }^{165}$ Se ha utilizado de $2 \mathrm{~mm}$ y 1'5 $^{\prime} \mathrm{mm}$ de espesor. Ver características técnicas en http://www.grudem.es.

166 Extraído del interior de cartón pluma de $1^{\prime} 7 \mathrm{~mm}$ y de $1 \mathrm{~mm}$ de espesor. Ver características técnicas en http://www.poliuretanos.com.
} 
rayos ultravioleta, que lo hacen oscuro y frágil. Se puede encolar con la mayoría de los adhesivos solubles en disolvente, a causa de esta buena resistencia a los disolventes. En presentación rígida resiste bien a los microorganismos, pero si es flexible, es susceptible de ataques de microorganismos, por la presencia de plastificantes. El tipo rígido tiene unas propiedades mecánicas inferiores a las del cloruro de polivinilo expandido, y es más difícil de trabajar.

- Poliestireno extruído ${ }^{167}$.

\subsubsection{LA CAPA DE INTERVENCIÓN.}

Todos los soportes deben contener un estrato llamado "capa de intervención" que asegura la reversibilidad del mismo soporte en el caso de que en un futuro éste tuviese que ser extraído o sustituido. Se sitúa entre la obra arrancada y el nuevo soporte.

Los materiales usados como capa de intervención han sido:

* Papel de fractura predeterminada. Es un papel grueso que se puede abrir por la mitad estratigráficamente, ya que está formado por dos capas de fibra de celulosa natural y otra capa central con una porcentual de fibra sintética, que impide que el adhesivo pase de un lado a otro y viceversa. Esta capa intermedia es de color rosa o azul y es por donde se rompe con facilidad para eliminar el soporte en caso de necesidad. Mide $50 \mathrm{~cm}$. de ancho y se comercializa en bovinas de 10 o 20 metros.

- Termolen "p". Es un polietileno en lámina de $2 \mathrm{~mm}$ de espesor, con una densidad de $30 \mathrm{Kg} . / \mathrm{m}^{3}$.

- Tela de algodón (muletón). Es una tela de algodón con fibras tejidas envueltas en un acolchado de fibras sin tejer. Su grosor aproximado es de $3 \mathrm{~mm}$.

* Feltrina. Es fieltro de algodón pero más grueso, de 1'5 $\mathrm{mm}$. de grosor.

* Spherecore ${ }^{168}$. Se trata de un laminado de fibra de vidrio, que en el mercado se encuentra en diferentes

\footnotetext{
167 Se ha utilizado el de $2 \mathrm{~mm}$ de espesor. Ver características técnicas en http://www.ediltec.es.
} 
espesores, de 1, 2, 3, 4 y $5 \mathrm{~mm}$. El que se ha utilizado para la presente investigación es de $2 \mathrm{~mm}$.

- Poliuretano. Se presenta como hojas preespumadas, en cuyo caso se han extraído del núcleo interno de cartón pluma, despojándolo de los dos estratos de papel que lo envuelven, constituyendo la estructura sandwich del cartón pluma. Pero se ha utilizado también la proyección in situ de espuma de poliuretano.

* PVC expandido semirrígido. El cloruro de polivinilo expandido semirrígido es una espuma sintética reforzada que se presenta en el mercado en grosores desde 3 a 10 $\mathrm{mm}$., pero se suele usar entre 3 y $5 \mathrm{~mm}$. Es recomendable emplear el de poro más cerrado, porque, si es de tipo abierto, se corre el riesgo de que la resina penetre de una parte a la otra y no cumpliría la función para la cual lo empleamos, como estrato de intervención, que, por definición facilita la separación entre el nuevo soporte y la pintura arrancada. Otra alternativa podría ser usar resina con carga para que no penetre en el poro abierto. En este caso se ha usado el conocido comercialmente como Cadorite, de $1 \mathrm{~cm}$. de espesor.

* Poliestireno expandido. Se ha usado un poliestireno expandido de $1,5 \mathrm{~cm}$. de espesor.

* Corcho natural. Es un material que se ha usado mucho a lo largo de la historia, tanto de soporte como de capa de intervención. Actualmente está en desuso por ser un material natural que fácilmente sufre cambios dimensionales ante cualquier variación de las condiciones termohigrométricas ambientales. No obstante se ha decidido evaluar su comportamiento en alguna de las probetas, usando un corcho natural de $5 \mathrm{~mm}$ de espesor.

\footnotetext{
${ }^{168}$ Véase http://www.spheretex.com: Sphere.core $\mathrm{S}$ is a flat material made of glass tissues, which are volumised through the embedding of thermoplastic microspheres. Sphere.core $\mathbf{S}$ has similar characteristics as Sphere.core SP. The basic material however consists of glass fibers. Together with the external top layers, the material consequently contributes to a significantly improved laminate homogeneity. The "print blocking" characteristics are also better. Wet tear resistance is lower than with Sphere.core SP, which is why impregnation in the mould is recommended for processing. Sphere.core $\mathrm{S}$ allows particularly good surfaces of the shaped GRP component.
} 
* "Moostgummi". Se trata de un poliuretano laminado comercializado en un grosor de 1'5 mm. Es de color blanco y más flexible que las comunes láminas de poliuretano.

* Mortero de cal apagada, Acril 33 y Arlita. Se ha tomado como referencia la mezcla utilizada en los talleres del Centre de Restauracions de Béns Mobles, de Barcelona ${ }^{169}$ pero introduciendo la variación de utilizar Arlita en sustitución de la Perlita utilizada en dicho centro.

\subsubsection{ADHESIVOS.}

El soporte debe ser adherido a la capa de intervención, y a su vez ésta debe ser adherida al reverso de la obra arrancada. Pero este reverso, antes de proceder a la aplicación del nuevo soporte, debe ser tratado con diversas telas, con el fin de fortalecer el reverso de la obra, o en su caso, el soporte original que todavía permanezca en la obra (en el caso de obras arrancadas mediante la técnica del stacco).

Como adhesivos de la capa de intervención (tanto al nuevo soporte como al reverso de la pintura) hemos empleado:

- Carbonato cálcico y Acril 33 (este último al 50\% en agua).

- Beva O.F. Gel.

- Plextol B-500 + tolueno al 50\%.

- Acetato de polivinilo ${ }^{170}$.

- Espuma de poliuretano.

- Plextol B-500.

El reverso de los fragmentos de pintura (tomados de pinturas murales realizadas ex profeso) se ha tratado del mismo modo en todos los casos, aplicando una gasa de algodón con caseinato cálcico, que es el tratamiento que recibió en los años 60 la

${ }^{169}$ RANESI, R. "Arrancament i restauració de pintures murals romanes d'una domus del carrer Pere Martell de Tarragona". En Rescat $n^{\circ}$ 9. Butlletí del Servei de Restauració de Béns Mobles. Generalitat de Catalunya. Barcelona, 2001.

${ }^{170}$ Experimentamos con él porque fue un adhesivo muy utilizado en los años 30 en todo el mundo, y a partir de los años 60 en España; aunque hoy sabemos que produce ciertas alteraciones en las pinturas. 
pintura que nos ocupa. Sobre esta gasa, a modo de refuerzo, se ha aplicado otra tela, de lino, adherida con diferentes adhesivos:

- Carbonato cálcico y Acril 33 (éste último al 30, 20 o 5\% en agua).

- Plextol B-500

- Acril 33 al 20\% en agua desionizada.

- 1 parte de acetato de polivinilo + 1 parte de cal aérea.

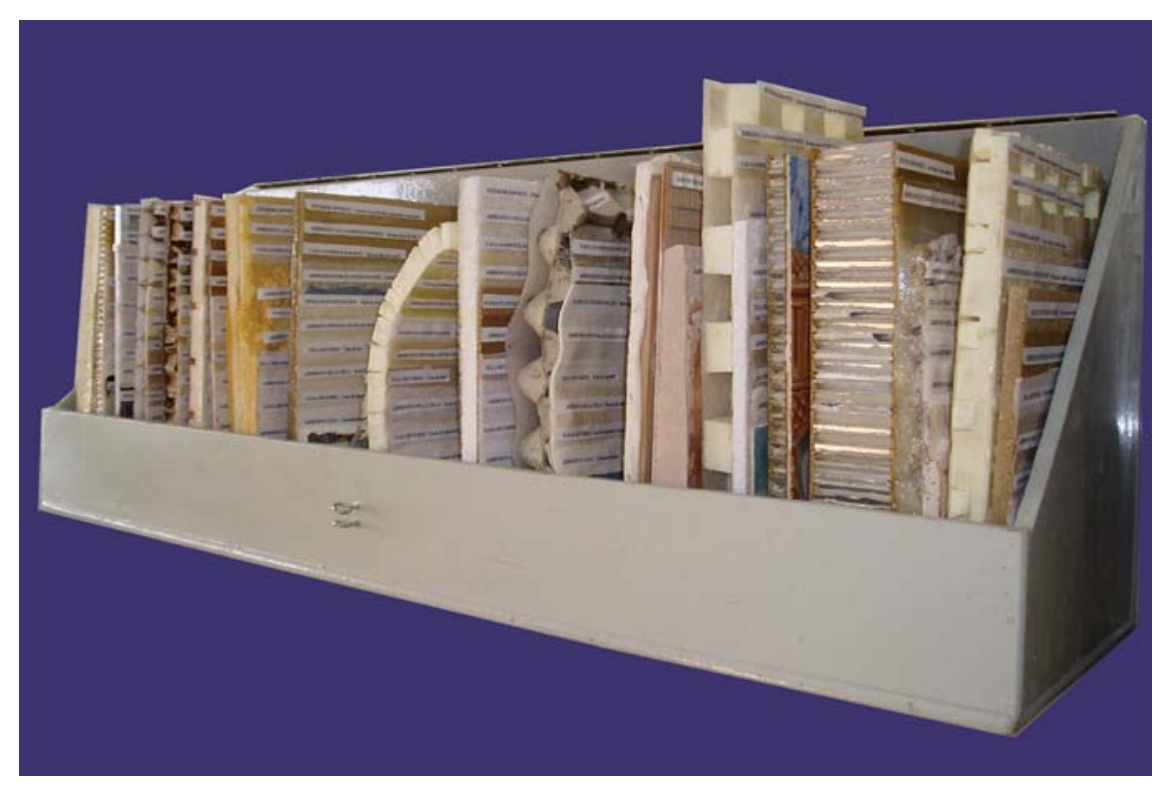

Fig. 87. Muestrario de diferentes tipos de nuevos soportes.

5.2.4. EXPERIMENTACIONES PRÁCTICAS.

Mostramos a continuación a modo de fichas, las características técnicas y materiales empleadas en al elaboración de estas probetas. Éstas han sido realizadas realizadas en esta investigación con el fin de extraer conclusiones válidas para aplicar un nuevo soporte a las pinturas que nos ocupan. 


\begin{tabular}{|c|c|c|}
\hline PROBETA N 1 & & \\
\hline FOTOGRAFÍA & 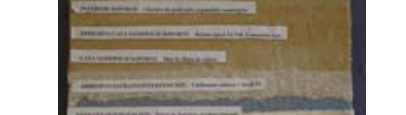 & 11 \\
\hline \multirow[t]{2}{*}{$\begin{array}{l}\text { PESO TOTAL En un } \\
\text { tamaño de } 30 \times 21 \mathrm{~cm} \text { : } \\
564 \mathrm{gr} .\end{array}$} & 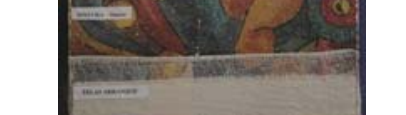 & \\
\hline & & OBSERVACIONES \\
\hline NUEVO SOPORTE & PVC expandido semirrígido & \multirow{3}{*}{$\begin{array}{l}\text { Conforma una estructura } \\
\text { sandwich rígida y estable, } \\
\text { con un espesor de } 1 \mathrm{~cm} \text {. }\end{array}$} \\
\hline $\begin{array}{l}\text { ADHESIVO DE LA } \\
\text { CAPA SANDWICH DEL } \\
\text { SOPORTE }\end{array}$ & $\begin{array}{l}\text { Resina epoxi EC } 54 \text { L } \\
\text { CAMATTINI s.p.a. }\end{array}$ & \\
\hline $\begin{array}{l}\text { CAPA SANDWICH DEL } \\
\text { SOPORTE }\end{array}$ & Matt de fibra de vidrio no tejida & \\
\hline $\begin{array}{l}\text { ADHESIVO DE LA } \\
\text { CAPA DE } \\
\text { INTERVENCION }\end{array}$ & $\begin{array}{l}\text { Carbonato cálcico + Acril } 33 \text { (al } \\
50 \% \text { en agua) }\end{array}$ & $\begin{array}{l}\text { Adhiere bien tanto al } \\
\text { soporte como a la capa de } \\
\text { intervención. }\end{array}$ \\
\hline $\begin{array}{l}\text { CAPA DE } \\
\text { INTERVENCIÓN }\end{array}$ & $\begin{array}{l}\text { Papel de fractura } \\
\text { predeterminada }\end{array}$ & $\begin{array}{l}\text { Supone un buen estrato } \\
\text { de intervención puesto } \\
\text { que facilita mucho la } \\
\text { separación de los estratos } \\
\text { a los que está adherido. }\end{array}$ \\
\hline $\begin{array}{l}\text { ADHESIVO PINTURA- } \\
\text { CAPA INTERVENCIÓN }\end{array}$ & $\begin{array}{l}\text { Carbonato cálcico +Acril } 33 \text { (al } \\
50 \% \text { en agua) }\end{array}$ & $\begin{array}{l}\text { Adhiere bien a la capa de } \\
\text { intervención como a la } \\
\text { tela. }\end{array}$ \\
\hline TELA REVERSO & Tela de lino & \\
\hline $\begin{array}{l}\text { MORTERO ADHESIVO } \\
\text { DE LA TELA }\end{array}$ & $\begin{array}{l}\text { Carbonato cálcico + Acril } 33 \text { (al } \\
50 \% \text { en agua) }\end{array}$ & Adhiere bien. \\
\hline GASA DEL REVERSO & Gasa de algodón (velatino) & \\
\hline GASA + ADHESIVO & $\begin{array}{l}\text { Gasa de algodón (velatino + } \\
\text { caseinato cálcico (1:3) }\end{array}$ & Adhiere bien. \\
\hline PINTURA & Stacco & \\
\hline $\begin{array}{l}\text { TELAS DEL } \\
\text { ARRANQUE }\end{array}$ & & \\
\hline
\end{tabular}




\begin{tabular}{|c|c|c|}
\hline PROBETA Nº 2 & 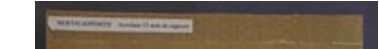 & 2 \\
\hline FOTOGRAFÍA & 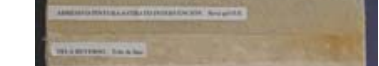 & \\
\hline \multirow{2}{*}{$\begin{array}{l}\text { PESO TOTAL En un } \\
\text { tamaño de } 30 \text { x } 21 \mathrm{~cm} \text { : } \\
359 \mathrm{gr} \text {. }\end{array}$} & & \\
\hline & & OBSERVACIONES \\
\hline NUEVO SOPORTE & Aerolam 13 mm. & $\begin{array}{l}\text { Conforma un soporte rígido } \\
\text { y estable. }\end{array}$ \\
\hline $\begin{array}{l}\text { ADHESIVO DE LA } \\
\text { CAPA DE } \\
\text { INTERVENCION }\end{array}$ & Beva gel & $\begin{array}{l}\text { Adhiere bien al soporte, } \\
\text { pero no a la capa de } \\
\text { intervención. }\end{array}$ \\
\hline $\begin{array}{l}\text { CAPA DE } \\
\text { INTERVENCIÓN }\end{array}$ & Termolen "p" & $\begin{array}{l}\text { Es una superficie } \\
\text { demasiado plástica, que no } \\
\text { admite el adhesivo. }\end{array}$ \\
\hline $\begin{array}{l}\text { ADHESIVO PINTURA- } \\
\text { CAPA INTERVENCIÓN }\end{array}$ & Beva gel & $\begin{array}{l}\text { Adhiere bien a la tela, pero } \\
\text { no al estrato de } \\
\text { intervención. }\end{array}$ \\
\hline TELA REVERSO & Tela de lino & \\
\hline $\begin{array}{l}\text { MORTERO ADHESIVO } \\
\text { DE LA TELA }\end{array}$ & $\begin{array}{l}\text { Carbonato cálcico }(7)+ \\
\text { carbonato de bario }(2)+\text { Acril } \\
33\end{array}$ & Adhiere bien. \\
\hline GASA DEL REVERSO & Gasa de algodón (velatino) & \\
\hline GASA + ADHESIVO & $\begin{array}{l}\text { Gasa de algodón (Velatino) + } \\
\text { Caseinato cálcico (1:3) }\end{array}$ & Adhiere bien. \\
\hline PINTURA & Stacco & \\
\hline $\begin{array}{l}\text { TELAS DEL } \\
\text { ARRANQUE }\end{array}$ & & \\
\hline
\end{tabular}




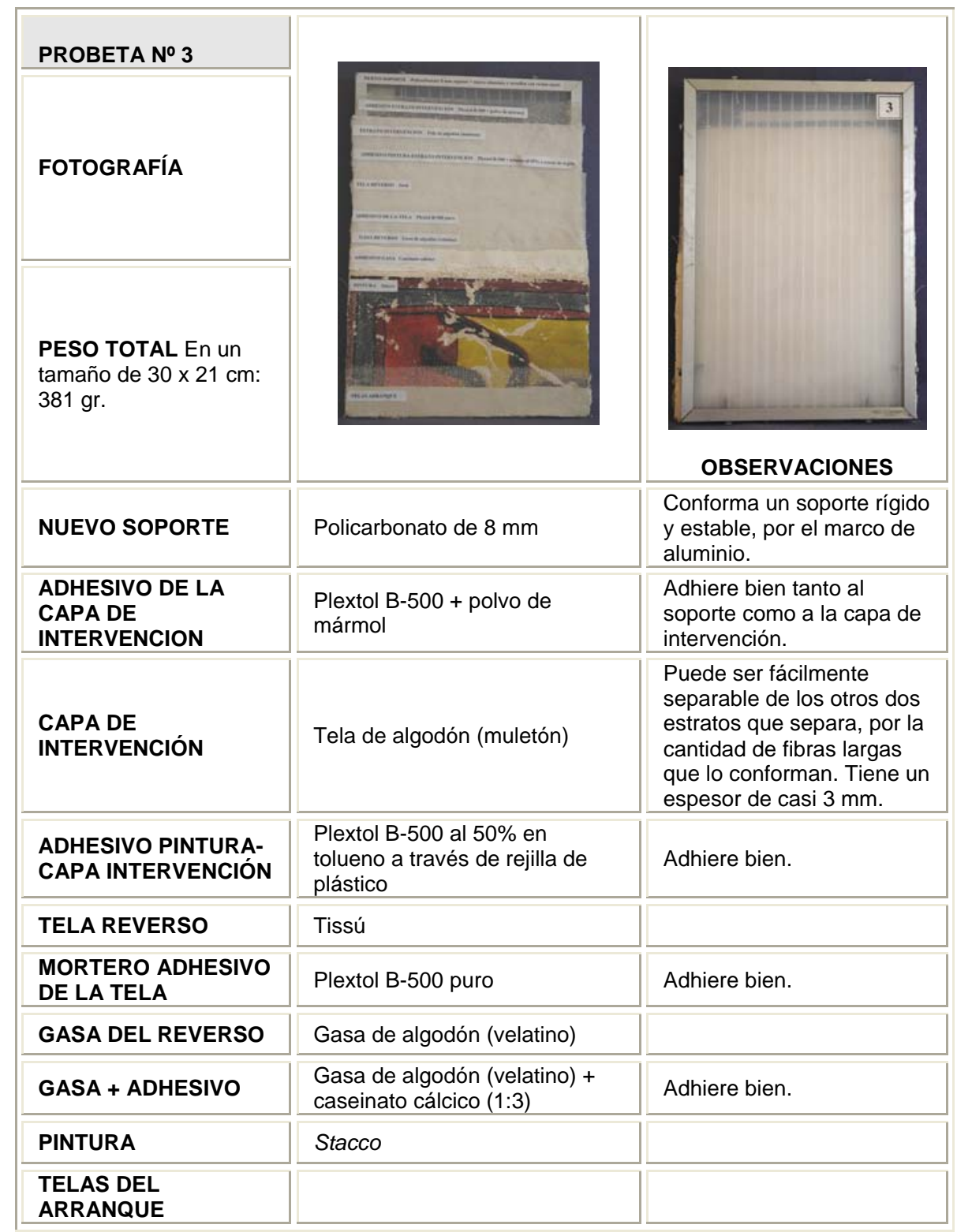




\begin{tabular}{|c|c|c|}
\hline PROBETA N 4 & & \\
\hline FOTOGRAFÍA & & \\
\hline \multirow[t]{2}{*}{$\begin{array}{l}\text { PESO TOTAL En un } \\
\text { tamaño de } 30 \text { × } 21 \mathrm{~cm} \text { : } \\
244 \mathrm{gr} \text {. }\end{array}$} & $=-\ldots$ & \\
\hline & & OBSERVACIONES \\
\hline NUEVO SOPORTE & $\begin{array}{l}\text { Estructura alveolar de cartón de } \\
2 \mathrm{~cm} \text { de espesor. }\end{array}$ & \multirow{3}{*}{$\begin{array}{l}\text { Conforma un soporte rígido } \\
\text { pero si la estructura de } \\
\text { cartón no se impregna de } \\
\text { resina epoxi, resulta poco } \\
\text { estable a los cambios de } \\
\text { temperatura y humedad así } \\
\text { como al ataque de } \\
\text { microorganismos o a la } \\
\text { acción del fuego. }\end{array}$} \\
\hline $\begin{array}{l}\text { ADHESIVO DE LA } \\
\text { CAPA SANDWICH } \\
\text { DEL SOPORTE }\end{array}$ & $\begin{array}{l}\text { Resina epoxi EC } 54 \text { L } \\
\text { CAMATTINI s.p.a. }\end{array}$ & \\
\hline $\begin{array}{l}\text { CAPA SANDWICH } \\
\text { DEL SOPORTE }\end{array}$ & $\begin{array}{l}\text { Resina epoxi + fibra de vidrio } \\
\text { no tejida }\end{array}$ & \\
\hline $\begin{array}{l}\text { ADHESIVO DE LA } \\
\text { CAPA DE } \\
\text { INTERVENCION }\end{array}$ & $\begin{array}{l}\text { Resina epoxi EC } 54 \mathrm{~L} \\
\text { CAMATTINI s.p.a. }\end{array}$ & $\begin{array}{l}\text { Adhiere bien a ambos } \\
\text { estratos, pero atraviesa la } \\
\text { capa de intervención } \\
\text { dejándola demasiado } \\
\text { rígida, característica que } \\
\text { puede dificultar una posible } \\
\text { reversibilidad del } \\
\text { tratamiento. }\end{array}$ \\
\hline $\begin{array}{l}\text { CAPA DE } \\
\text { INTERVENCIÓN }\end{array}$ & Feltina (fieltro más grueso) & $\begin{array}{l}\text { Absorbe mucho adhesivo } \\
\text { (resina epoxi), y queda } \\
\text { rígido. }\end{array}$ \\
\hline $\begin{array}{l}\text { ADHESIVO PINTURA- } \\
\text { CAPA } \\
\text { INTERVENCIÓN }\end{array}$ & Beva gel & Adhiere bien. \\
\hline TELA REVERSO & Lino & \\
\hline $\begin{array}{l}\text { MORTERO } \\
\text { ADHESIVO DE LA } \\
\text { TELA }\end{array}$ & Acril al $20 \%$ en agua & Adhesión más débil \\
\hline GASA DEL REVERSO & Gasa de algodón (velatino) & \\
\hline GASA + ADHESIVO & $\begin{array}{l}\text { Gasa de algodón (velatino) + } \\
\text { caseinato cálcico }(1: 3)\end{array}$ & \\
\hline PINTURA & Strappo & \\
\hline $\begin{array}{l}\text { TELAS DEL } \\
\text { ARRANQUE }\end{array}$ & & \\
\hline
\end{tabular}




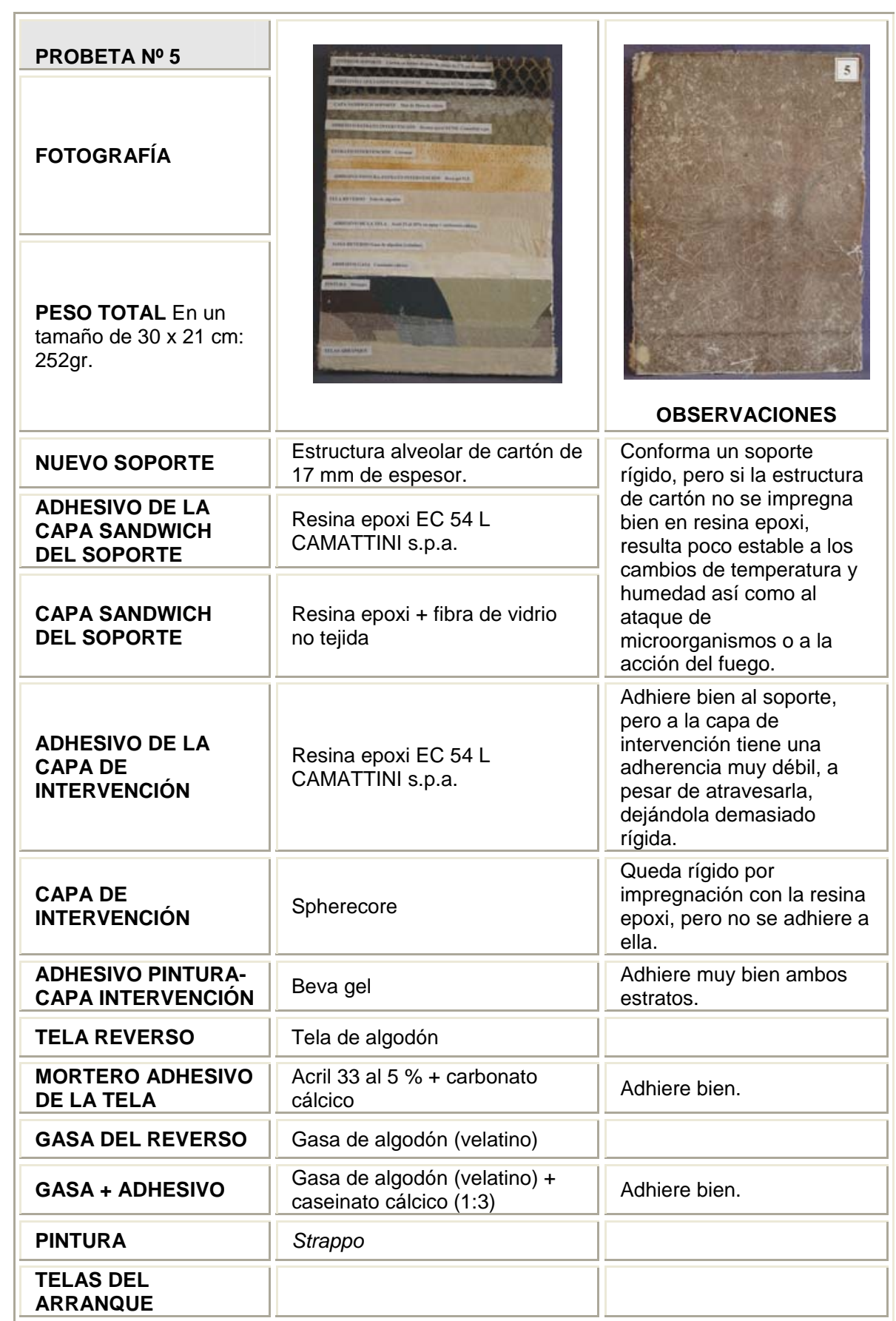




\begin{tabular}{|c|c|c|}
\hline PROBETA N ${ }^{\circ} 6$ & & 6 \\
\hline \multicolumn{3}{|l|}{ FOTOGRAFÍA } \\
\hline $\begin{array}{l}\text { PESO TOTAL En un } \\
\text { tamaño de } 30 \text { × } 21 \mathrm{~cm} \text { : } \\
348 \mathrm{gr} \text {. }\end{array}$ & 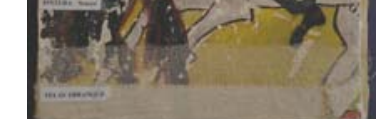 & \\
\hline & & OBSERVACIONES \\
\hline NUEVO SOPORTE & $\begin{array}{l}\text { Estructura en forma de } \\
\text { cuadrícula de madera de } \\
\text { balsa de } 6 \mathrm{~mm} \text { de grosor. } \\
\text { Espesor de } 2 \mathrm{~cm} \text {. }\end{array}$ & \multirow{3}{*}{$\begin{array}{l}\text { Conforma un soporte } \\
\text { rígido, pero si la estructura } \\
\text { de madera no se rebaña } \\
\text { en resina epoxi, resulta } \\
\text { poco estable a los cambios } \\
\text { de temperatura y humedad } \\
\text { así como al ataque de } \\
\text { microorganismos. Es de } \\
\text { construcción elaborada y } \\
\text { costosa. }\end{array}$} \\
\hline $\begin{array}{l}\text { ADHESIVO DE LA } \\
\text { CAPA SANDWICH DEL } \\
\text { SOPORTE }\end{array}$ & $\begin{array}{l}\text { Resina epoxi EC } 54 \text { L } \\
\text { CAMATTINI s.p.a. }\end{array}$ & \\
\hline $\begin{array}{l}\text { CAPA SANDWICH DEL } \\
\text { SOPORTE }\end{array}$ & $\begin{array}{l}\text { Resina epoxi + fibra de vidrio } \\
\text { no tejida }\end{array}$ & \\
\hline $\begin{array}{l}\text { ADHESIVO DE LA } \\
\text { CAPA DE } \\
\text { INTERVENCIÓN }\end{array}$ & $\begin{array}{l}\text { Resina epoxi EC } 54 \text { L } \\
\text { CAMATTINI s.p.a. }\end{array}$ & $\begin{array}{l}\text { Adhiere bien a ambos } \\
\text { estratos. }\end{array}$ \\
\hline $\begin{array}{l}\text { CAPA DE } \\
\text { INTERVENCIÓN }\end{array}$ & $\begin{array}{l}\text { Lámina de poliuretano o } \\
\text { poliestireno }\end{array}$ & $\begin{array}{l}\text { Podría cumplir bien su } \\
\text { función de estrato de } \\
\text { intervención, puesto que } \\
\text { no absorbe demasiado los } \\
\text { adhesivos. Se adhiere } \\
\text { bien, y sería fácilmente } \\
\text { cortable. }\end{array}$ \\
\hline $\begin{array}{l}\text { ADHESIVO PINTURA- } \\
\text { CAPA INTERVENCIÓN }\end{array}$ & Beva O.F. gel & $\begin{array}{l}\text { Adhiere muy bien ambos } \\
\text { estratos. }\end{array}$ \\
\hline TELA REVERSO & Tela de lino & \\
\hline $\begin{array}{l}\text { MORTERO ADHESIVO } \\
\text { DE LA TELA }\end{array}$ & $\begin{array}{l}\text { Acril } 33 \text { al } 5 \%+\text { carbonato } \\
\text { cálcico }\end{array}$ & Adhiere bien. \\
\hline GASA DEL REVERSO & Gasa de algodón (velatino) & \\
\hline GASA + ADHESIVO & $\begin{array}{l}\text { Gasa de algodón (velatino) + } \\
\text { caseinato cálcico }(1: 3)\end{array}$ & Adhiere bien. \\
\hline PINTURA & Strappo & \\
\hline $\begin{array}{l}\text { TELAS DEL } \\
\text { ARRANQUE }\end{array}$ & & \\
\hline
\end{tabular}




\begin{tabular}{|c|c|c|}
\hline PROBETA No 7 & 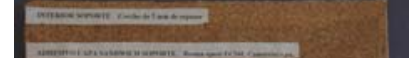 & 7 \\
\hline FOTOGRAFÍA & 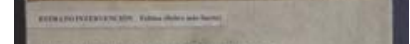 & \\
\hline \multirow[t]{2}{*}{$\begin{array}{l}\text { PESO TOTAL En } \\
\text { un tamaño de } 30 \mathrm{x} \\
21 \mathrm{~cm} \text { : } \\
286 \mathrm{gr} .\end{array}$} & 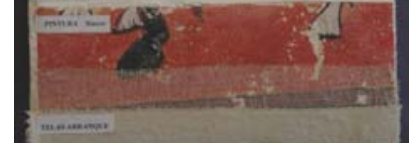 & \\
\hline & & OBSERVACIONES \\
\hline NUEVO SOPORTE & $\begin{array}{l}\text { Corcho natural de } 5 \mathrm{~mm} \text { de } \\
\text { espesor. }\end{array}$ & \multirow{3}{*}{$\begin{array}{l}\text { Conforma un soporte rígido } \\
\text { aunque no excesivamente } \\
\text { estable. }\end{array}$} \\
\hline $\begin{array}{l}\text { ADHESIVO DE LA } \\
\text { CAPA SANDWICH } \\
\text { DEL SOPORTE }\end{array}$ & $\begin{array}{l}\text { Resina epoxi EC } 54 \text { L } \\
\text { CAMATTINI s.p.a. }\end{array}$ & \\
\hline $\begin{array}{l}\text { CAPA SANDWICH } \\
\text { DEL SOPORTE }\end{array}$ & $\begin{array}{l}\text { Resina epoxi + fibra de vidrio no } \\
\text { tejida }\end{array}$ & \\
\hline $\begin{array}{l}\text { ADHESIVO DE LA } \\
\text { CAPA DE } \\
\text { INTERVENCION }\end{array}$ & $\begin{array}{l}\text { Resina epoxi EC } 54 \text { L } \\
\text { CAMATTINI s.p.a. }\end{array}$ & $\begin{array}{l}\text { Adhiere bien a ambos estratos, } \\
\text { pero atraviesa la capa de } \\
\text { intervención dejándola } \\
\text { demasiado rígida, } \\
\text { característica que puede } \\
\text { dificultar una posible } \\
\text { reversibilidad del tratamiento. }\end{array}$ \\
\hline $\begin{array}{l}\text { CAPA DE } \\
\text { INTERVENCIÓN }\end{array}$ & Feltrina & $\begin{array}{l}\text { Absorbe mucho adhesivo } \\
\text { (resina epoxi), y queda rígido. }\end{array}$ \\
\hline $\begin{array}{l}\text { ADHESIVO } \\
\text { PINTURA-CAPA } \\
\text { INTERVENCIÓN }\end{array}$ & Acetato de polivinilo & Adhiere bien. \\
\hline TELA REVERSO & Lino & \\
\hline $\begin{array}{l}\text { MORTERO } \\
\text { ADHESIVO DE LA } \\
\text { TELA }\end{array}$ & $\begin{array}{l}\text { Acetato de polivinilo }+ \text { cal } \\
\text { apagada en polvo }\end{array}$ & Adhiere bien. \\
\hline $\begin{array}{l}\text { GASA DEL } \\
\text { REVERSO }\end{array}$ & Gasa de algodón (velatino) & \\
\hline $\begin{array}{l}\text { GASA + } \\
\text { ADHESIVO }\end{array}$ & $\begin{array}{l}\text { Gasa de algodón (velatino) + } \\
\text { caseinato cálcico (1:3) }\end{array}$ & Adhiere bien \\
\hline PINTURA & Stacco & \\
\hline $\begin{array}{l}\text { TELAS DEL } \\
\text { ARRANQUE }\end{array}$ & & \\
\hline
\end{tabular}




\begin{tabular}{|c|c|c|}
\hline PROBETA № 8 & & 8 \\
\hline FOTOGRAFÍA & tom & \\
\hline \multirow[t]{2}{*}{$\begin{array}{l}\text { PESO TOTAL En un } \\
\text { tamaño de } 30 \text { x } 21 \mathrm{~cm} \text { : } \\
365 \mathrm{gr} \text {. }\end{array}$} & $-\omega^{2}$ & \\
\hline & & OBSERVACIONES \\
\hline SOPORTE & $\begin{array}{l}\text { Poliuretano de } 17 \mathrm{~mm} \text { de } \\
\text { espesor }\end{array}$ & \multirow{2}{*}{ Soporte rígido. } \\
\hline $\begin{array}{l}\text { CAPA SANDWICH } \\
\text { DEL SOPORTE }\end{array}$ & $\begin{array}{l}\text { Resina poliéster + matt de fibra } \\
\text { de vidrio }\end{array}$ & \\
\hline $\begin{array}{l}\text { ADHESIVO DE LA } \\
\text { CAPA SANDWICH } \\
\text { DEL SOPORTE }\end{array}$ & Resina de poliéster & $\begin{array}{l}\text { No se adhiere bien al } \\
\text { estrato del interior del } \\
\text { soporte: poliuretano. La } \\
\text { resina ha amarilleado } \\
\text { muchísimo. }\end{array}$ \\
\hline $\begin{array}{l}\text { ADHESIVO DE LA } \\
\text { CAPA DE } \\
\text { INTERVENCION }\end{array}$ & $\begin{array}{l}\text { Resina epoxi EC } 54 \text { L } \\
\text { CAMATTINI s.p.a. }\end{array}$ & $\begin{array}{l}\text { Adhiere bien ambos } \\
\text { estratos. }\end{array}$ \\
\hline $\begin{array}{l}\text { CAPA DE } \\
\text { INTERVENCIÓN }\end{array}$ & $\begin{array}{l}\text { Poliuretano o poli estireno } \\
\text { (relleno de cartón pluma) }\end{array}$ & $\begin{array}{l}\text { Podría cumplir bien su } \\
\text { función de estrato de } \\
\text { intervención, puesto que } \\
\text { no absorbe demasiado los } \\
\text { adhesivos, aunque sí se } \\
\text { adhiere bien, y sería } \\
\text { facilmente cortable. }\end{array}$ \\
\hline $\begin{array}{l}\text { ADHESIVO PINTURA- } \\
\text { CAPA INTERVENCIÓN }\end{array}$ & Beva gel & Adhiere bien. \\
\hline TELA REVERSO & Tela de algodón & \\
\hline $\begin{array}{l}\text { MORTERO ADHESIVO } \\
\text { DE LA TELA }\end{array}$ & Plextol B-500 & Adhiere bien. \\
\hline GASA DEL REVERSO & Gasa de algodón (velatino) & \\
\hline GASA + ADHESIVO & $\begin{array}{l}\text { Gasa de algodón (velatino) + } \\
\text { caseinato cálcico }(1: 3)\end{array}$ & Adhiere bien. \\
\hline PINTURA & Stacco & \\
\hline $\begin{array}{l}\text { TELAS DEL } \\
\text { ARRANQUE }\end{array}$ & & \\
\hline
\end{tabular}




\begin{tabular}{|c|c|c|}
\hline PROBETA N 9 & $=$ & \\
\hline FOTOGRAFÍA & & \\
\hline \multirow[t]{2}{*}{$\begin{array}{l}\text { PESO TOTAL En un } \\
\text { tamaño de } 30 \times 21 \mathrm{~cm} \text { : } \\
312 \mathrm{gr} \text {. }\end{array}$} & & \\
\hline & & OBSERVACIONES \\
\hline SOPORTE & $\begin{array}{l}\text { Poliuretano de } 9 \mathrm{~mm} \text { de } \\
\text { espesor }\end{array}$ & \multirow{3}{*}{$\begin{array}{l}\text { Conforma un soporte rígido } \\
\text { y estable. }\end{array}$} \\
\hline $\begin{array}{l}\text { ADHESIVO DE LA } \\
\text { CAPA SANDWICH } \\
\text { DEL SOPORTE }\end{array}$ & $\begin{array}{l}\text { Resina epoxi EC } 54 \text { L } \\
\text { CAMATTINI s.p.a. }\end{array}$ & \\
\hline $\begin{array}{l}\text { CAPA SANDWICH } \\
\text { DEL SOPORTE }\end{array}$ & $\begin{array}{l}\text { Resina epoxi + fibra de vidrio } \\
\text { tejida de } 160 \mathrm{gr} / \mathrm{m}^{2}\end{array}$ & \\
\hline $\begin{array}{l}\text { ADHESIVO DE LA } \\
\text { CAPA DE } \\
\text { INTERVENCION }\end{array}$ & Espuma de poliuretano & \multirow{3}{*}{$\begin{array}{l}\text { Cumple la función tanto de } \\
\text { adhesivo como de estrato } \\
\text { de intervención. Gran } \\
\text { ligereza. Buena } \\
\text { adherencia. Aplicación } \\
\text { costosa. Permite elegir el } \\
\text { grosor dependiendo del } \\
\text { peso que se le aplique } \\
\text { mientras está } \\
\text { polimerizando. }\end{array}$} \\
\hline $\begin{array}{l}\text { CAPA DE } \\
\text { INTERVENCIÓN }\end{array}$ & Espuma de poliuretano & \\
\hline $\begin{array}{l}\text { ADHESIVO PINTURA- } \\
\text { CAPA INTERVENCIÓN }\end{array}$ & Espuma de poliuretano & \\
\hline TELA REVERSO & Tela de algodón & \\
\hline $\begin{array}{l}\text { MORTERO ADHESIVO } \\
\text { DE LA TELA }\end{array}$ & $\begin{array}{l}\text { Acril } 33 \text { al } 10 \% \text { en agua + } \\
\text { carbonato cálcico }\end{array}$ & Adhiere bien. \\
\hline GASA DEL REVERSO & Gasa de algodón (velatino) & \\
\hline GASA + ADHESIVO & $\begin{array}{l}\text { Gasa de algodón (velatino) + } \\
\text { caseinato cálcico (1:3) }\end{array}$ & Adhiere bien. \\
\hline PINTURA & Stacco & \\
\hline $\begin{array}{l}\text { TELAS DEL } \\
\text { ARRANQUE }\end{array}$ & & \\
\hline
\end{tabular}




\begin{tabular}{|c|c|c|}
\hline PROBETA No 10 & & \\
\hline FOTOGRAFÍA & 20 & \\
\hline \multirow[t]{2}{*}{$\begin{array}{l}\text { PESO TOTAL En un } \\
\text { tamaño de } 30 \times 21 \\
\mathrm{~cm} \text { : } \\
226 \mathrm{gr} .\end{array}$} & 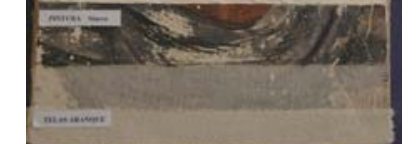 & - \\
\hline & & OBSERVACIONES \\
\hline SOPORTE & $\begin{array}{l}\text { Poliestireno extruído de } 2 \mathrm{~cm} \text { de } \\
\text { espesor. }\end{array}$ & \multirow{3}{*}{$\begin{array}{l}\text { Confiere un soporte rígido y } \\
\text { estable. }\end{array}$} \\
\hline $\begin{array}{l}\text { ADHESIVO DE LA } \\
\text { CAPA SANDWICH } \\
\text { DEL SOPORTE }\end{array}$ & $\begin{array}{l}\text { Resina epoxi EC } 54 \text { L } \\
\text { CAMATTINI s.p.a. }\end{array}$ & \\
\hline $\begin{array}{l}\text { CAPA SANDWICH } \\
\text { DEL SOPORTE }\end{array}$ & $\begin{array}{l}\text { Resina epoxi + fibra de vidrio } \\
\text { tejida (tipo mosquitera) }\end{array}$ & \\
\hline $\begin{array}{l}\text { ADHESIVO DE LA } \\
\text { CAPA DE } \\
\text { INTERVENCION }\end{array}$ & $\begin{array}{l}\text { Resina epoxi EC } 54 \text { L } \\
\text { CAMATTINI s.p.a. }\end{array}$ & $\begin{array}{l}\text { Adhiere bien ambos } \\
\text { estratos. }\end{array}$ \\
\hline $\begin{array}{l}\text { CAPA DE } \\
\text { INTERVENCIÓN }\end{array}$ & $\begin{array}{l}\text { PVC expandido semirrígido de } 1 \\
\mathrm{~cm} \text { de espesor }\end{array}$ & $\begin{array}{l}\text { Es un estrato de } \\
\text { intervención demasiado } \\
\text { grueso. }\end{array}$ \\
\hline $\begin{array}{l}\text { ADHESIVO } \\
\text { PINTURA-CAPA } \\
\text { INTERVENCIÓN }\end{array}$ & Beva gel & Adhiere bien. \\
\hline TELA REVERSO & Lino & \\
\hline $\begin{array}{l}\text { MORTERO } \\
\text { ADHESIVO DE LA } \\
\text { TELA }\end{array}$ & $\begin{array}{l}\text { Acril } 33 \text { al } 10 \% \text { en agua + } \\
\text { carbonato cálcico }\end{array}$ & Adhiere bien. \\
\hline $\begin{array}{l}\text { GASA DEL } \\
\text { REVERSO }\end{array}$ & Gasa de algodón (velatino) & \\
\hline GASA + ADHESIVO & $\begin{array}{l}\text { Gasa de algodón (velatino) + } \\
\text { caseinato cálcico (1:3) }\end{array}$ & Adhiere bien. \\
\hline PINTURA & Strappo & \\
\hline $\begin{array}{l}\text { TELAS DEL } \\
\text { ARRANQUE }\end{array}$ & & \\
\hline
\end{tabular}




\begin{tabular}{|c|c|c|}
\hline PROBETA N ${ }^{\circ} 11$ & & \\
\hline FOTOGRAFÍA & & \\
\hline \multirow[t]{2}{*}{$\begin{array}{l}\text { PESO TOTAL En un } \\
\text { tamaño de } 30 \times 21 \\
\text { cm: }\end{array}$} & & \\
\hline & & OBSERVACIONES \\
\hline SOPORTE & $\begin{array}{l}\text { Poliestireno extruído de } 2 \mathrm{~cm} \text { de } \\
\text { espesor, pero formando una } \\
\text { especie de tablero de ajedrez, } \\
\text { con espacios vacíos. }\end{array}$ & \multirow{3}{*}{$\begin{array}{l}\text { Soporte rígido y estable, } \\
\text { más ligero que el anterior, } \\
\text { pues la mitad del espacio } \\
\text { está ocupado por aire. Es de } \\
\text { costosa elaboración. }\end{array}$} \\
\hline $\begin{array}{l}\text { ADHESIVO DE LA } \\
\text { CAPA SANDWICH } \\
\text { DEL SOPORTE }\end{array}$ & $\begin{array}{l}\text { Resina epoxi EC } 54 \text { L } \\
\text { CAMATTINI s.p.a. }\end{array}$ & \\
\hline $\begin{array}{l}\text { CAPA SANDWICH } \\
\text { DEL SOPORTE }\end{array}$ & $\begin{array}{l}\text { Resina epoxi + fibra de vidrio no } \\
\text { tejida }\end{array}$ & \\
\hline $\begin{array}{l}\text { ADHESIVO DE LA } \\
\text { CAPA DE } \\
\text { INTERVENCION }\end{array}$ & $\begin{array}{l}\text { Plextol B-500 + polvo de } \\
\text { mármol }\end{array}$ & $\begin{array}{l}\text { Adhiere bien al soporte, pero } \\
\text { no al estrato de intervención. }\end{array}$ \\
\hline $\begin{array}{l}\text { CAPA DE } \\
\text { INTERVENCIÓN }\end{array}$ & Poliestireno expandido de $8 \mathrm{~mm}$ & $\begin{array}{l}\text { Es un estrato de } \\
\text { intervención demasiado } \\
\text { grueso, y poco estable, } \\
\text { sobre todo a la acción del } \\
\text { calor. }\end{array}$ \\
\hline $\begin{array}{l}\text { ADHESIVO } \\
\text { PINTURA-CAPA } \\
\text { INTERVENCIÓN }\end{array}$ & Plextol B-500 & No adhiere excesivamente. \\
\hline TELA REVERSO & Lino & \\
\hline $\begin{array}{l}\text { MORTERO } \\
\text { ADHESIVO DE LA } \\
\text { TELA }\end{array}$ & Plextol B-500 & Adhiere bien. \\
\hline $\begin{array}{l}\text { GASA DEL } \\
\text { REVERSO }\end{array}$ & Gasa de algodón (velatino) & \\
\hline GASA + ADHESIVO & $\begin{array}{l}\text { Gasa de algodón (velatino) + } \\
\text { caseinato cálcico }(1: 3)\end{array}$ & Adhiere bien. \\
\hline PINTURA & Stacco & \\
\hline $\begin{array}{l}\text { TELAS DEL } \\
\text { ARRANQUE }\end{array}$ & & \\
\hline
\end{tabular}




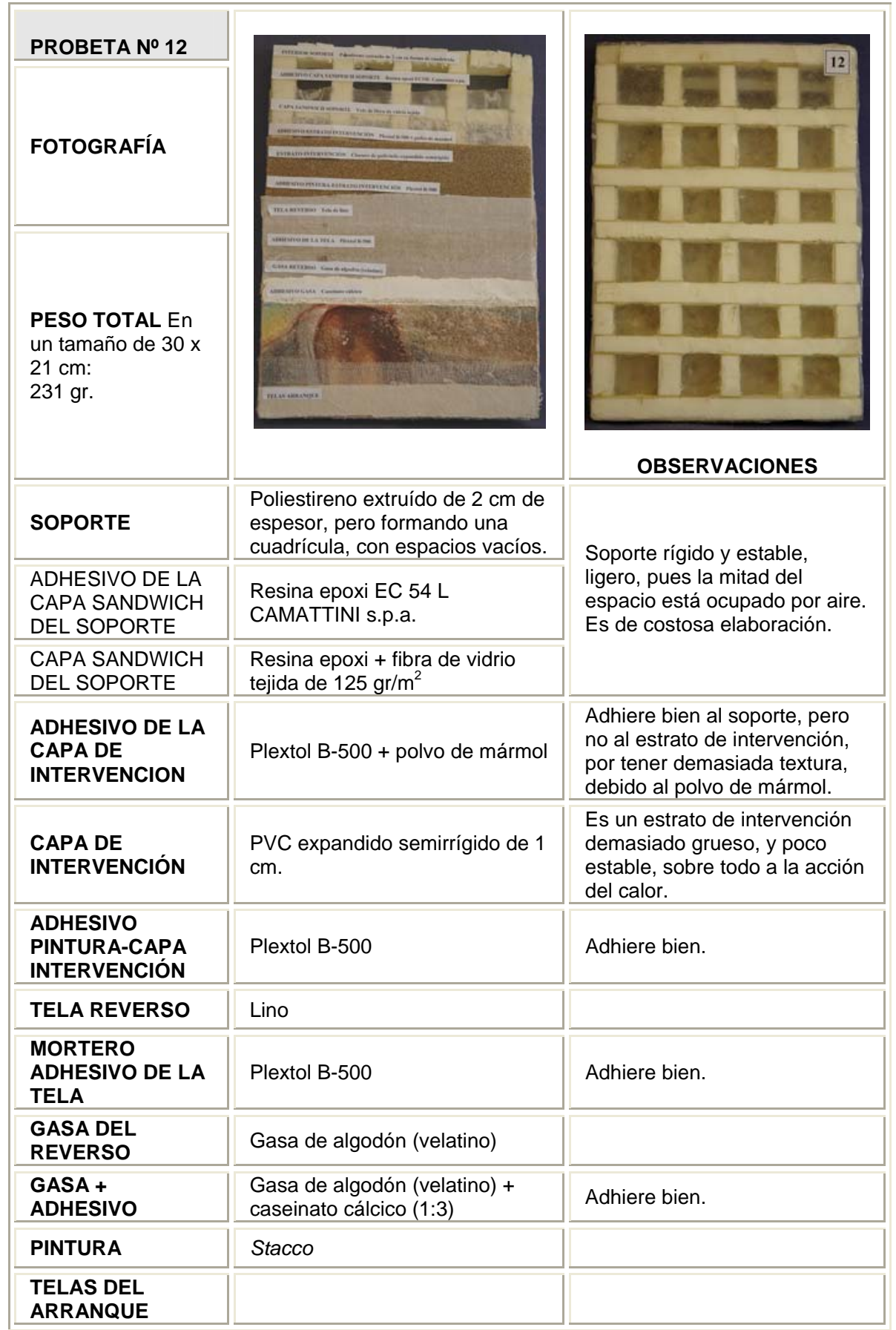




\begin{tabular}{|c|c|c|}
\hline PROBETA N 13 & & \\
\hline FOTOGRAFÍA & $-\ldots$ & \\
\hline $\begin{array}{l}\text { PESO TOTAL En un } \\
\text { tamaño de } 30 \times 21 \mathrm{~cm} \text { : } \\
289 \mathrm{gr} \text {. }\end{array}$ & 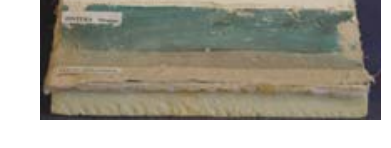 & 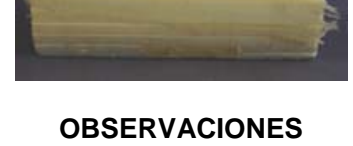 \\
\hline SOPORTE & $\begin{array}{l}\text { Poliestireno extruído de } 2 \mathrm{~cm} \\
\text { de espesor, curvado gracias a } \\
\text { hendiduras practicadas en } \\
\text { sentido horizontal en toda la } \\
\text { superficie. }\end{array}$ & \multirow{3}{*}{$\begin{array}{l}\text { Conforma un soporte de } \\
\text { superficie curva pero } \\
\text { irregular. Es de costosa } \\
\text { elaboración. }\end{array}$} \\
\hline $\begin{array}{l}\text { ADHESIVO DE LA } \\
\text { CAPA SANDWICH } \\
\text { DEL SOPORTE }\end{array}$ & $\begin{array}{l}\text { Resina epoxi EC } 54 \text { L } \\
\text { CAMATTINI s.p.a. }\end{array}$ & \\
\hline $\begin{array}{l}\text { CAPA SANDWICH } \\
\text { DEL SOPORTE }\end{array}$ & $\begin{array}{l}\text { Resina epoxi + fibra de vidrio } \\
\text { tejida de } 300 \mathrm{gr} / \mathrm{m}^{2}\end{array}$ & \\
\hline $\begin{array}{l}\text { ADHESIVO DE LA } \\
\text { CAPA DE } \\
\text { INTERVENCION }\end{array}$ & $\begin{array}{l}\text { Resina epoxi EC } 54 \text { L } \\
\text { CAMATTINI s.p.a. }\end{array}$ & $\begin{array}{l}\text { Adhiere bien a ambos } \\
\text { estratos, pero atraviesa la } \\
\text { capa de intervención } \\
\text { dejándola demasiado } \\
\text { rígida, característica que } \\
\text { puede dificultar una posible } \\
\text { reversibilidad del } \\
\text { tratamiento. }\end{array}$ \\
\hline $\begin{array}{l}\text { CAPA DE } \\
\text { INTERVENCIÓN }\end{array}$ & Tela de algodón (muletón) & $\begin{array}{l}\text { Absorbe mucho adhesivo } \\
\text { (resina epoxi), y queda } \\
\text { rígido, aunque con fibras } \\
\text { largas. Tiene un espesor } \\
\text { de casi } 3 \mathrm{~mm} \text {. }\end{array}$ \\
\hline $\begin{array}{l}\text { ADHESIVO PINTURA- } \\
\text { CAPA } \\
\text { INTERVENCIÓN }\end{array}$ & Beva gel & Adhiere bien. \\
\hline TELA REVERSO & Lino & \\
\hline $\begin{array}{l}\text { MORTERO ADHESIVO } \\
\text { DE LA TELA }\end{array}$ & $\begin{array}{l}\text { Acril } 33 \text { al } 10 \% \text { en agua + } \\
\text { carbonato cálcico }\end{array}$ & Adhiere bien. \\
\hline GASA DEL REVERSO & Gasa de algodón (velatino) & \\
\hline GASA + ADHESIVO & $\begin{array}{l}\text { Gasa de algodón (velatino) + } \\
\text { caseinato cálcico }(1: 3)\end{array}$ & Adhiere bien. \\
\hline PINTURA & Strappo & \\
\hline $\begin{array}{l}\text { TELAS DEL } \\
\text { ARRANQUE }\end{array}$ & & \\
\hline
\end{tabular}




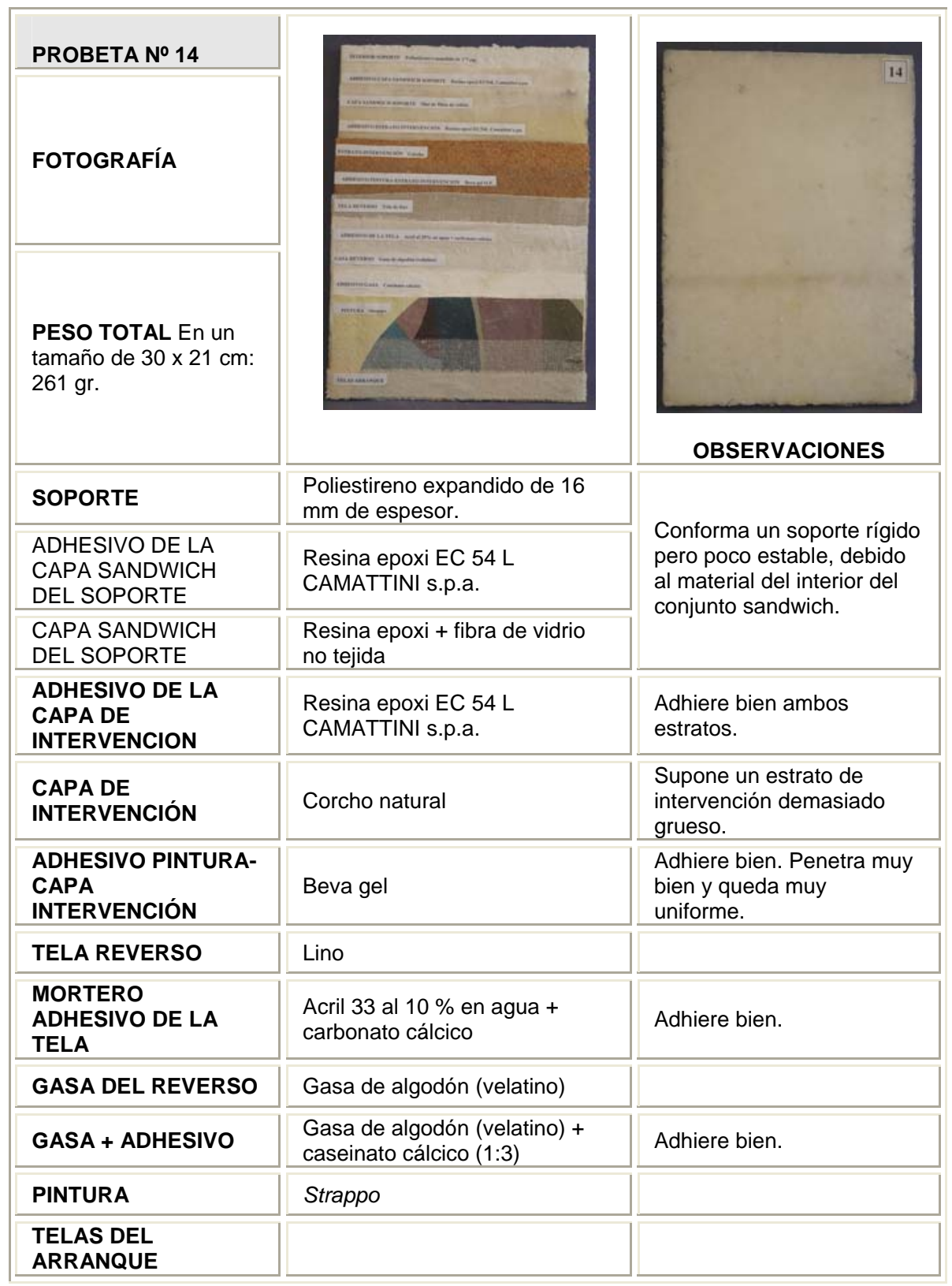




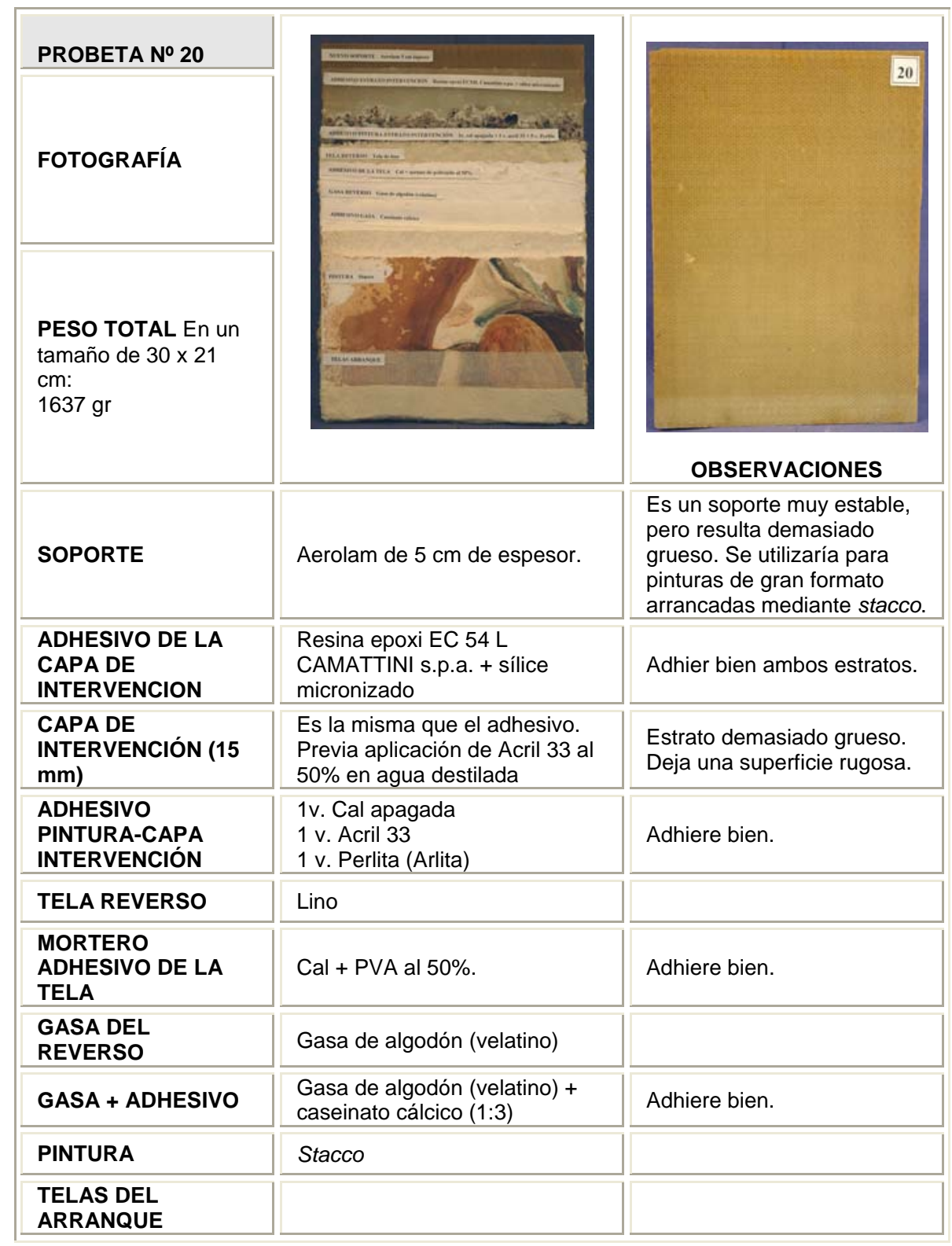


De estas probetas se pueden extraer datos sobre cada uno de los materiales, pudiendo establecer cuales resultarían más adecuados para confeccionar un nuevo soporte a la obra que nos ocupa. De las conclusiones extraídas procedemos a elaborar nuevas probetas de soporte que cumplan las características requeridas por las pinturas de la iglesia de los Santos Juanes de Valencia.

Teniendo en cuenta que el soporte ideal para las pinturas de la bóveda de la nave central de la iglesia de los Santos Juanes no debe superar, junto con la pintura y sus estratos subyacentes, unos 3-4 mm de espesor - que es el grosor del intonaco original-, se descartan todos los tipos de soporte investigados, que son los más comunes en la recolocación de pinturas murales arrancadas, pero de los materiales empleados para la elaboración de las primeras probetas, podemos extraer conclusiones y datos que servirán para pensar en un nuevo tipo de soporte, diferente a los investigados hasta el momento.

No obstante, de ellos se utilizarán algunos materiales para la confección de las nuevas probetas. Estos son:

- El Aerolam ${ }^{\circledR}$ (Ciba Geigy) es rígido, y la adaptación al soporte original hay que solicitarla directamente al fabricante.

- El poliestireno expandido es semirrígido, pero para su adaptación a la curvatura de la bóveda sería necesario practicarle diversos cortes para formar una retícula que le permitiera esa adaptabilidad.

- El poliuretano presenta los mismos inconvenientes que el poli estireno expandido, así como el poli estireno extruído.

- En cuanto al policarbonato, aun siendo estable, ligero y autoportante, no cumple el requisito de adaptabilidad a la superficie curva de la bóveda que nos ocupa.

- El Cloruro de polivinilo expandido semirrígido es el único soporte que cumple la característica ideal de flexibilidad y adaptabilidad a las curvaturas de la bóveda. Esta última propiedad de semi-rígido, le confiere mayor idoneidad para esta intervención que cualquier otro material. Además se trata de un material muy ligero, ya que es un material expandido, y de poco espesor, pues lo podemos encontrar en el mercado con un espesor mínimo de $3 \mathrm{~mm}$. Pero este espesor resulta excesivo para nuestra obral. Una variante de este material, usado en Florencia para la elaboración de soportes de pintura mural, es reticulada, con una malla de fibra de vidrio adherida a una de las caras. Esta retícula, al formar una pequeña cuadrícula hace más fácil la adaptabilidad a las curvaturas. 
88. Cloruro de polivinilo expandido semirrígido

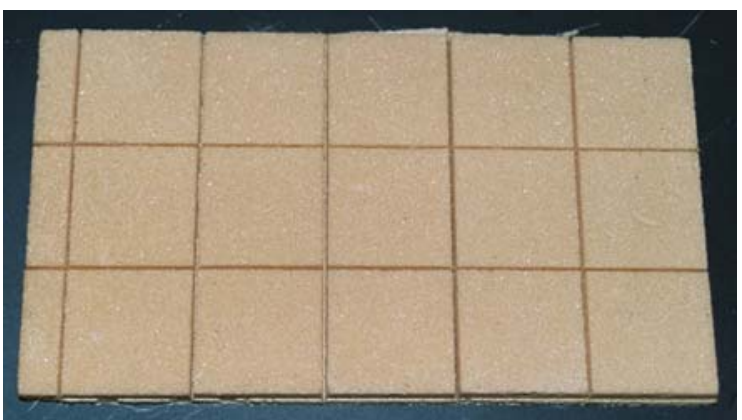

con retícula.

Por lo tanto se podría decir que ninguno de estos soportes servirían como soporte ideal para estas pinturas.

Observando todos los materiales usados en las probetas, podemos deducir que los más finos que podemos encontrar, son la fibra de vidrio o de carbono, ya sea matt o tejida, con resina, ya sea epoxi o de poliéster.

Por lo tanto las investigaciones se centrarán en este punto, elaborando nuevas probetas usando únicamente estos materiales.

Pero no hay que olvidar que todo nuevo soporte para pinturas murales arrancadas, debe constar de un estrato de intervención, así como de ciertos adhesivos usados para unir todos los estratos.

De entre los materiales estudiados como capa de intervención, resultan adecuados únicamente el papel de fractura predeterminada, el muletón, el poliuretano o poliestireno o el fieltro, pues cumplen la función de favorecer una posible eliminación del nuevo soporte sin dañar por ello la pintura original.

Resultarían pues inadecuados los estratos de intervención elaborados con materiales como poliestireno expandido, corcho natural, "moostgummy", espuma de poliuretano, cloruro de polivinilo expandido semi-rígido, por los motivos que se han expuesto en las tablas anteriores.

En cuanto a los adhesivos usados, los que mejores resultados han ofrecido en las probetas anteriormente descritas, han sido:

- Beva O.F. Gel®, adhesivo de fácil y rápida aplicación tanto para adherir la pintura a la capa de intervención, como para adherir la capa de intervención al nuevo soporte, ya que se 
trata de un solo producto ya preparado y listo para su utilización.

- Plextol B-500® (que también es un solo producto, puede ser espesado con tolueno. De modo que con un solo tipo de adhesivo, se pueden cubrir los dos tratamientos.

- También es de fácil aplicación por ser un solo producto, el acetato de polivinilo.

A priori no se descartan el resto de los adhesivos, aunque la Beva O.F. Gel, el Plextol B-500 y el acetato de polivinilo, son los que mejores resultados han ofrecido en las pruebas anteriormente realizadas.

A raíz de las conclusiones extraídas de estas 16 probetas, se han elaborado nuevas probetas combinando los materiales elegidos como los más adecuados.

Hemos elaborado 168 probetas de 3'5 x $10 \mathrm{~cm}$., con el fin de conseguir una muestra de la combinación entre sí de todos los materiales elegidos. De la elaboración de estas probetas se extraerán conclusiones para poder elaborar nuevos soportes a las probetas de arranques que ya se han separado de su soporte de madera contrachapada.

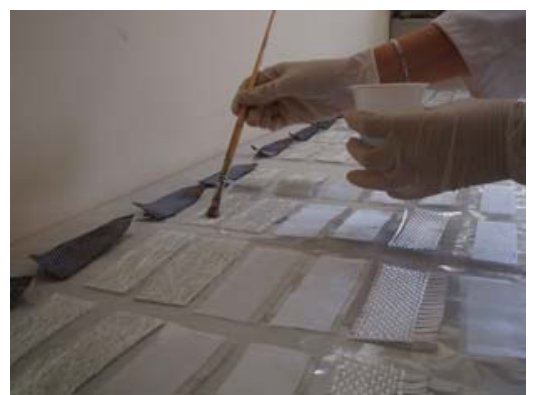

Fig. 88. Preparación de las probetas de nuevos soportes.

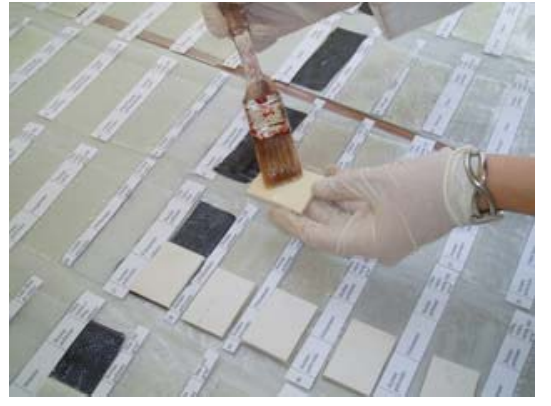

Fig. 89. Aplicación de la capa de intervención a las probetas de nuevos soportes. 
En la siguiente tabla se describe el estratificado de cada uno de los soportes ensayados:

\begin{tabular}{|c|c|c|c|c|}
\hline $\mathrm{N}^{\circ}$ & $\begin{array}{l}\text { ADHESIVO } \\
\text { CAPA } \\
\text { INTERVENCIÓN }\end{array}$ & $\begin{array}{l}\text { CAPA } \\
\text { INTERVENCIÓN }\end{array}$ & $\begin{array}{l}\text { ADHESIVO } \\
\text { SOPORTE }\end{array}$ & SOPORTE \\
\hline \multirow[t]{2}{*}{1} & $\begin{array}{l}\text { A. Resina } \\
\text { epoxi }\end{array}$ & \multirow[t]{2}{*}{ Fieltro } & \multirow[t]{2}{*}{$\begin{array}{l}\text { Resina } \\
\text { epoxi }\end{array}$} & \multirow[t]{2}{*}{$\begin{array}{l}\text { Fibra vidrio + fibra } \\
\text { carbono }\end{array}$} \\
\hline & $\begin{array}{l}\text { B. Acetato } \\
\text { polivinilo }\end{array}$ & & & \\
\hline \multicolumn{2}{|c|}{ OBSERVACIONES } & \multicolumn{3}{|c|}{$\begin{array}{l}\text { Las puntas se comban ligeramente hacia arriba. } \\
\text { Buena adhesión. } \\
\text { A. Demasiado rígido. El adhesivo ha atravesado el } \\
\text { estrato de fieltro } \\
\text { B. Demasiado flexible. }\end{array}$} \\
\hline \multirow[t]{2}{*}{2} & $\begin{array}{l}\text { A. Resina } \\
\text { epoxi }\end{array}$ & \multirow[t]{2}{*}{ Fieltro } & \multirow[t]{2}{*}{$\begin{array}{l}\text { Resina } \\
\text { epoxi }\end{array}$} & \multirow[t]{2}{*}{ Matt $300 \mathrm{gr} / \mathrm{m}^{2}$} \\
\hline & $\begin{array}{l}\text { B. Acetato } \\
\text { polivinilo }\end{array}$ & & & \\
\hline \multicolumn{2}{|c|}{ OBSERVACIONES } & \multicolumn{3}{|c|}{$\begin{array}{l}\text { Buena adhesión. } \\
\text { A. Demasiado rígido. El adhesivo ha atravesado el } \\
\text { estrato de fieltro } \\
\text { B. Flexibilidad adecuada. }\end{array}$} \\
\hline \multirow[t]{2}{*}{3} & $\begin{array}{l}\text { A. Resina } \\
\text { epoxi }\end{array}$ & \multirow[t]{2}{*}{ Fieltro } & \multirow[t]{2}{*}{$\begin{array}{l}\text { Resina } \\
\text { epoxi }\end{array}$} & \multirow[t]{2}{*}{ Matt $450 \mathrm{gr} / \mathrm{m}^{2}$} \\
\hline & $\begin{array}{l}\text { B. Acetato } \\
\text { polivinilo }\end{array}$ & & & \\
\hline \multicolumn{2}{|c|}{ OBSERVACIONES } & \multicolumn{3}{|c|}{$\begin{array}{l}\text { Buena adhesión. } \\
\text { A. Demasiado rígido. El adhesivo ha atravesado el } \\
\text { estrato de fieltro } \\
\text { B. Demasiado rígido. }\end{array}$} \\
\hline \multirow[t]{2}{*}{4} & $\begin{array}{l}\text { A. Resina } \\
\text { epoxi }\end{array}$ & \multirow[t]{2}{*}{ Fieltro } & \multirow[t]{2}{*}{$\begin{array}{l}\text { Resina } \\
\text { epoxi }\end{array}$} & \multirow[t]{2}{*}{$\begin{array}{l}\text { Fibra vidrio tejida } \\
125 \mathrm{gr} / \mathrm{m}^{2}\end{array}$} \\
\hline & $\begin{array}{l}\text { B. Acetato } \\
\text { polivinilo }\end{array}$ & & & \\
\hline \multicolumn{2}{|c|}{ OBSERVACIONES } & \multicolumn{3}{|c|}{$\begin{array}{l}\text { Buena adhesión. } \\
\text { A. Flexibilidad adecuada. El adhesivo ha atravesado } \\
\text { el estrato de fieltro } \\
\text { B. Demasiado flexible. }\end{array}$} \\
\hline
\end{tabular}




\begin{tabular}{|c|c|c|c|c|}
\hline \multirow[t]{2}{*}{5} & $\begin{array}{l}\text { A. Resina } \\
\text { epoxi }\end{array}$ & \multirow[t]{2}{*}{ Fieltro } & \multirow[t]{2}{*}{$\begin{array}{l}\text { Resina } \\
\text { epoxi }\end{array}$} & \multirow[t]{2}{*}{$\begin{array}{l}\text { Fibra vidrio tejida } \\
160 \mathrm{gr} / \mathrm{m}^{2}\end{array}$} \\
\hline & $\begin{array}{l}\text { B. Acetato } \\
\text { polivinilo }\end{array}$ & & & \\
\hline \multicolumn{2}{|c|}{ OBSERVACIONES } & \multicolumn{3}{|c|}{$\begin{array}{l}\text { Buena adhesión. } \\
\text { A. Flexibilidad adecuada. El adhesivo ha atravesado } \\
\text { el estrato de fieltro. Las puntas se comban } \\
\text { ligeramente hacia arriba. } \\
\text { B. Demasiado flexible. }\end{array}$} \\
\hline \multirow[t]{2}{*}{6} & $\begin{array}{l}\text { A. Resina } \\
\text { epoxi }\end{array}$ & \multirow[t]{2}{*}{ Fieltro } & \multirow[t]{2}{*}{$\begin{array}{l}\text { Resina } \\
\text { epoxi }\end{array}$} & \multirow[t]{2}{*}{$\begin{array}{l}\text { Fibra vidrio tejida } \\
300 \mathrm{gr} / \mathrm{m}^{2}\end{array}$} \\
\hline & $\begin{array}{l}\text { B. Acetato } \\
\text { polivinilo }\end{array}$ & & & \\
\hline \multicolumn{2}{|c|}{ OBSERVACIONES } & \multicolumn{3}{|c|}{$\begin{array}{l}\text { Buena adhesión. } \\
\text { A. Flexibilidad adecuada. El adhesivo ha atravesado } \\
\text { el estrato de fieltro. Las puntas se comban } \\
\text { ligeramente hacia arriba. } \\
\text { B. Demasiado flexible. }\end{array}$} \\
\hline \multirow[t]{2}{*}{7} & $\begin{array}{l}\text { A. Resina } \\
\text { epoxi }\end{array}$ & \multirow[t]{2}{*}{ Fieltro } & \multirow[t]{2}{*}{$\begin{array}{l}\text { Resina } \\
\text { epoxi }\end{array}$} & \multirow[t]{2}{*}{$\begin{array}{l}\text { Matt de velo fibra } \\
\text { de vidrio }\end{array}$} \\
\hline & $\begin{array}{l}\text { B. Acetato } \\
\text { polivinilo }\end{array}$ & & & \\
\hline \multicolumn{2}{|c|}{ OBSERVACIONES } & \multicolumn{3}{|c|}{$\begin{array}{l}\text { Buena adhesión. } \\
\text { A. Flexibilidad adecuada. El adhesivo ha atravesado } \\
\text { el estrato de fieltro. Las puntas se comban } \\
\text { ligeramente hacia arriba. } \\
\text { B. Demasiado flexible. }\end{array}$} \\
\hline \multirow[t]{2}{*}{8} & $\begin{array}{l}\text { A. Resina } \\
\text { epoxi }\end{array}$ & \multirow[t]{2}{*}{ Fieltro } & \multirow[t]{2}{*}{$\begin{array}{l}\text { Resina } \\
\text { poliéster }\end{array}$} & \multirow[t]{2}{*}{$\begin{array}{l}\text { Fibra vidrio + fibra } \\
\text { carbono }\end{array}$} \\
\hline & $\begin{array}{l}\text { B. Acetato } \\
\text { polivinilo }\end{array}$ & & & \\
\hline \multicolumn{2}{|c|}{ OBSERVACIONES } & \multicolumn{3}{|c|}{$\begin{array}{l}\text { Las puntas se comban ligeramente hacia arriba. } \\
\text { A. Flexibilidad adecuada. El adhesivo ha atravesado } \\
\text { el estrato de fieltro. Poca adherencia. } \\
\text { B. Demasiado flexible. Buena adherencia. }\end{array}$} \\
\hline \multirow[t]{2}{*}{9} & $\begin{array}{l}\text { A. Resina } \\
\text { epoxi }\end{array}$ & \multirow[t]{2}{*}{ Fieltro } & \multirow[t]{2}{*}{$\begin{array}{l}\text { Resina } \\
\text { poliéster }\end{array}$} & \multirow[t]{2}{*}{$\begin{array}{l}\text { Matt } 300 \mathrm{gr} / \mathrm{m}^{2} \\
\text { Buena adhesión. }\end{array}$} \\
\hline & $\begin{array}{l}\text { B. Acetato } \\
\text { polivinilo }\end{array}$ & & & \\
\hline \multicolumn{2}{|c|}{ OBSERVACIONES } & \multicolumn{3}{|c|}{$\begin{array}{l}\text { A. Flexibilidad adecuada. El adhesivo ha atravesado } \\
\text { el estrato de fieltro. Poca adherencia. } \\
\text { B. Flexibilidad adecuada. Buena adherencia. }\end{array}$} \\
\hline
\end{tabular}




\begin{tabular}{|c|c|c|c|c|}
\hline 10 & $\begin{array}{l}\text { A. Resina } \\
\text { epoxi } \\
\text { B. Acetato } \\
\text { polivinilo }\end{array}$ & Fieltro & $\begin{array}{l}\text { Resina } \\
\text { poliéster }\end{array}$ & Matt $450 \mathrm{gr} / \mathrm{m}^{2}$ \\
\hline \multicolumn{2}{|c|}{ OBSERVACIONES } & \multicolumn{3}{|c|}{$\begin{array}{l}\text { A. Demasiada rigidez. El adhesivo ha atravesado el } \\
\text { estrato de fieltro. Poca adherencia. } \\
\text { B. Demasiada rigidez. Buena adherencia. }\end{array}$} \\
\hline 11 & $\begin{array}{l}\begin{array}{l}\text { A. Resina } \\
\text { epoxi }\end{array} \\
\begin{array}{l}\text { B. Acetato } \\
\text { polivinilo }\end{array}\end{array}$ & Fieltro & $\begin{array}{l}\text { Resina } \\
\text { poliéster }\end{array}$ & $\begin{array}{l}\text { Fibra vidrio tejida } \\
125 \mathrm{gr} / \mathrm{m}^{2}\end{array}$ \\
\hline \multicolumn{2}{|c|}{ OBSERVACIONES } & \multicolumn{3}{|c|}{$\begin{array}{l}\text { Las puntas se comban ligeramente hacia arriba. } \\
\text { A. Flexibilidad adecuada. El adhesivo ha atravesado } \\
\text { el estrato de fieltro. Poca adherencia. } \\
\text { B. Demasiado flexible. Buena adherencia. }\end{array}$} \\
\hline 12 & $\begin{array}{l}\begin{array}{l}\text { A. Resina } \\
\text { epoxi }\end{array} \\
\begin{array}{l}\text { B. Acetato } \\
\text { polivinilo }\end{array}\end{array}$ & Fieltro & $\begin{array}{l}\text { Resina } \\
\text { poliéster }\end{array}$ & $\begin{array}{l}\text { Fibra vidrio tejida } \\
160 \mathrm{gr} / \mathrm{m}^{2}\end{array}$ \\
\hline \multicolumn{2}{|c|}{ OBSERVACIONES } & \multicolumn{3}{|c|}{$\begin{array}{l}\text { Las puntas se comban ligeramente hacia arriba. } \\
\text { A. Flexibilidad adecuada. El adhesivo ha atravesado } \\
\text { el estrato de fieltro. Poca adherencia. } \\
\text { B. Demasiado flexible. Buena adherencia. }\end{array}$} \\
\hline 13 & $\begin{array}{l}\begin{array}{l}\text { A. Resina } \\
\text { epoxi }\end{array} \\
\begin{array}{l}\text { B. Acetato } \\
\text { polivinilo }\end{array}\end{array}$ & Fieltro & $\begin{array}{l}\text { Resina } \\
\text { poliéster }\end{array}$ & $\begin{array}{l}\text { Fibra vidrio tejida } \\
300 \mathrm{gr} / \mathrm{m}^{2}\end{array}$ \\
\hline \multicolumn{2}{|c|}{ OBSERVACIONES } & \multicolumn{3}{|c|}{$\begin{array}{l}\text { A. Demasiada rigidez. El adhesivo ha atravesado el } \\
\text { estrato de fieltro. Poca adherencia. } \\
\text { B. Demasiado flexible. Buena adherencia. }\end{array}$} \\
\hline \multirow[t]{2}{*}{14} & $\begin{array}{l}\text { A. Resina } \\
\text { epoxi }\end{array}$ & \multirow[t]{2}{*}{ Fieltro } & \multirow[t]{2}{*}{$\begin{array}{l}\text { Resina } \\
\text { poliéster }\end{array}$} & \multirow[t]{2}{*}{$\begin{array}{l}\text { Matt de velo fibra } \\
\text { de vidrio }\end{array}$} \\
\hline & $\begin{array}{l}\text { B. Acetato } \\
\text { polivinilo }\end{array}$ & & & \\
\hline \multicolumn{2}{|c|}{ OBSERVACIONES } & \multicolumn{3}{|c|}{$\begin{array}{l}\text { A. Flexibilidad adecuada. El adhesivo ha atravesado } \\
\text { el estrato de fieltro. Poca adherencia. } \\
\text { B. Demasiado flexible. Buena adherencia. }\end{array}$} \\
\hline \multirow[t]{2}{*}{15} & $\begin{array}{l}\text { A. Resina } \\
\text { epoxi }\end{array}$ & \multirow[t]{2}{*}{ Muletón } & \multirow[t]{2}{*}{$\begin{array}{l}\text { Resina } \\
\text { epoxi }\end{array}$} & \multirow[t]{2}{*}{$\begin{array}{l}\text { Fibra vidrio + fibra } \\
\text { carbono }\end{array}$} \\
\hline & $\begin{array}{l}\text { B. Acetato } \\
\text { polivinilo }\end{array}$ & & & \\
\hline
\end{tabular}




\begin{tabular}{|c|c|c|c|c|}
\hline \multicolumn{2}{|c|}{ OBSERVACIONES } & \multicolumn{3}{|c|}{$\begin{array}{l}\text { Buena adhesión. } \\
\text { A. Demasiado rígido. El adhesivo ha atravesado el } \\
\text { estrato de fieltro. } \\
\text { B. Demasiado flexible. Las puntas se comban } \\
\text { ligeramente hacia abajo. }\end{array}$} \\
\hline \multirow[t]{2}{*}{16} & $\begin{array}{l}\text { A. Resina } \\
\text { epoxi }\end{array}$ & \multirow[t]{2}{*}{ Muletón } & \multirow[t]{2}{*}{$\begin{array}{l}\text { Resina } \\
\text { epoxi }\end{array}$} & \multirow[t]{2}{*}{ Matt $300 \mathrm{gr} / \mathrm{m}^{2}$} \\
\hline & $\begin{array}{l}\text { B. Acetato } \\
\text { polivinilo }\end{array}$ & & & \\
\hline \multicolumn{2}{|c|}{ OBSERVACIONES } & \multicolumn{3}{|c|}{$\begin{array}{l}\text { Buena adhesión. } \\
\text { A. Demasiado rígido. El adhesivo ha atravesado el } \\
\text { estrato de fieltro. } \\
\text { B. Flexibilidad adecuada. }\end{array}$} \\
\hline \multirow[t]{2}{*}{17} & $\begin{array}{l}\text { A. Resina } \\
\text { epoxi }\end{array}$ & \multirow[t]{2}{*}{ Muletón } & \multirow[t]{2}{*}{$\begin{array}{l}\text { Resina } \\
\text { epoxi }\end{array}$} & \multirow[t]{2}{*}{ Matt $450 \mathrm{gr} / \mathrm{m}^{2}$} \\
\hline & $\begin{array}{l}\text { B. Acetato } \\
\text { polivinilo }\end{array}$ & & & \\
\hline \multicolumn{2}{|c|}{ OBSERVACIONES } & \multicolumn{3}{|c|}{$\begin{array}{l}\text { Buena adhesión. } \\
\text { A. Demasiado rígido. El adhesivo ha atravesado e } \\
\text { estrato de fieltro. } \\
\text { B. Flexibilidad adecuada. }\end{array}$} \\
\hline \multirow[t]{2}{*}{18} & $\begin{array}{l}\text { A. Resina } \\
\text { epoxi }\end{array}$ & \multirow[t]{2}{*}{ Muletón } & \multirow[t]{2}{*}{$\begin{array}{l}\text { Resina } \\
\text { epoxi }\end{array}$} & \multirow[t]{2}{*}{$\begin{array}{l}\text { Fibra vidrio tejida } \\
125 \mathrm{gr} / \mathrm{m}^{2}\end{array}$} \\
\hline & $\begin{array}{l}\text { B. Acetato } \\
\text { polivinilo }\end{array}$ & & & \\
\hline \multicolumn{2}{|c|}{ OBSERVACIONES } & \multicolumn{3}{|c|}{$\begin{array}{l}\text { Buena adhesión. } \\
\text { A. Demasiado rígido. El adhesivo ha atravesado el } \\
\text { estrato de fieltro. } \\
\text { B. Demasiado flexible. }\end{array}$} \\
\hline \multirow[t]{2}{*}{19} & $\begin{array}{l}\text { A. Resina } \\
\text { epoxi }\end{array}$ & \multirow[t]{2}{*}{ Muletón } & \multirow[t]{2}{*}{$\begin{array}{l}\text { Resina } \\
\text { epoxi }\end{array}$} & \multirow[t]{2}{*}{$\begin{array}{l}\text { Fibra vidrio tejida } \\
160 \mathrm{gr} / \mathrm{m}^{2}\end{array}$} \\
\hline & $\begin{array}{l}\text { B. Acetato } \\
\text { polivinilo }\end{array}$ & & & \\
\hline \multicolumn{2}{|c|}{ OBSERVACIONES } & \multicolumn{3}{|c|}{$\begin{array}{l}\text { Buena adhesión. } \\
\text { A. Demasiado rígido. El adhesivo ha atravesado el } \\
\text { estrato de fieltro. } \\
\text { B. Demasiado flexible. }\end{array}$} \\
\hline \multirow[t]{2}{*}{20} & $\begin{array}{l}\text { A. Resina } \\
\text { epoxi }\end{array}$ & \multirow[t]{2}{*}{ Muletón } & \multirow[t]{2}{*}{$\begin{array}{l}\text { Resina } \\
\text { epoxi }\end{array}$} & \multirow[t]{2}{*}{$\begin{array}{l}\text { Fibra vidrio tejida } \\
300 \mathrm{gr} / \mathrm{m}^{2}\end{array}$} \\
\hline & $\begin{array}{l}\text { B. Acetato } \\
\text { polivinilo }\end{array}$ & & & \\
\hline \multicolumn{2}{|c|}{ OBSERVACIONES } & \multicolumn{3}{|c|}{$\begin{array}{l}\text { Buena adhesión. } \\
\text { A. Demasiado rígido. El adhesivo ha atravesado el } \\
\text { estrato de fieltro. } \\
\text { B. Demasiado flexible. }\end{array}$} \\
\hline
\end{tabular}




\begin{tabular}{|c|c|c|c|c|}
\hline \multirow[t]{2}{*}{21} & $\begin{array}{l}\text { A. Resina } \\
\text { epoxi }\end{array}$ & \multirow[t]{2}{*}{ Muletón } & \multirow[t]{2}{*}{$\begin{array}{l}\text { Resina } \\
\text { epoxi }\end{array}$} & \multirow[t]{2}{*}{$\begin{array}{l}\text { Matt de velo fibra } \\
\text { de vidrio }\end{array}$} \\
\hline & $\begin{array}{l}\text { B. Acetato } \\
\text { polivinilo }\end{array}$ & & & \\
\hline \multicolumn{2}{|c|}{ OBSERVACIONES } & \multicolumn{3}{|c|}{$\begin{array}{l}\text { Buena adhesión. } \\
\text { A. Demasiado rígido. El adhesivo ha atravesado el } \\
\text { estrato de fieltro. } \\
\text { B. Demasiado flexible. Las puntas se comban hacia } \\
\text { arriba. }\end{array}$} \\
\hline \multirow[t]{2}{*}{22} & $\begin{array}{l}\text { A. Resina } \\
\text { poliéster }\end{array}$ & \multirow[t]{2}{*}{ Muletón } & \multirow[t]{2}{*}{$\begin{array}{l}\text { Resina } \\
\text { poliéster }\end{array}$} & \multirow[t]{2}{*}{$\begin{array}{l}\text { Fibra vidrio + fibra } \\
\text { carbono }\end{array}$} \\
\hline & $\begin{array}{l}\text { B. Acetato } \\
\text { polivinilo }\end{array}$ & & & \\
\hline \multicolumn{2}{|c|}{ OBSERVACIONES } & \multicolumn{3}{|c|}{$\begin{array}{l}\text { A. Demasiado rígido. El adhesivo ha atravesado el } \\
\text { estrato de fieltro. Poca adherencia. } \\
\text { B. Demasiado flexible. Buena adherencia. }\end{array}$} \\
\hline \multirow[t]{2}{*}{23} & $\begin{array}{l}\text { A. Resina } \\
\text { poliéster }\end{array}$ & \multirow[t]{2}{*}{ Muletón } & \multirow[t]{2}{*}{$\begin{array}{l}\text { Resina } \\
\text { poliéster }\end{array}$} & \multirow[t]{2}{*}{ Matt $300 \mathrm{gr} / \mathrm{m}^{2}$} \\
\hline & $\begin{array}{l}\text { B. Acetato } \\
\text { polivinilo }\end{array}$ & & & \\
\hline \multicolumn{2}{|c|}{ OBSERVACIONES } & \multicolumn{3}{|c|}{$\begin{array}{l}\text { A. Demasiado rígido. El adhesivo ha atravesado el } \\
\text { estrato de fieltro. Poca adherencia. } \\
\text { B. Flexibilidad adecuada. Buena adherencia. }\end{array}$} \\
\hline \multirow[t]{2}{*}{24} & $\begin{array}{l}\text { A. Resina } \\
\text { poliéster }\end{array}$ & \multirow[t]{2}{*}{ Muletón } & \multirow[t]{2}{*}{$\begin{array}{l}\text { Resina } \\
\text { poliéster }\end{array}$} & \multirow[t]{2}{*}{ Matt $450 \mathrm{gr} / \mathrm{m}^{2}$} \\
\hline & $\begin{array}{l}\text { B.Acetato } \\
\text { polivinilo }\end{array}$ & & & \\
\hline \multicolumn{2}{|c|}{ OBSERVACIONES } & \multicolumn{3}{|c|}{$\begin{array}{l}\text { A. Demasiado rígido. El adhesivo ha atravesado el } \\
\text { estrato de fieltro. Poca adherencia. } \\
\text { B. Demasiado rígido. Buena adherencia. }\end{array}$} \\
\hline \multirow[t]{2}{*}{25} & $\begin{array}{l}\text { A. Resina } \\
\text { poliéster }\end{array}$ & \multirow[t]{2}{*}{ Muletón } & \multirow[t]{2}{*}{$\begin{array}{l}\text { Resina } \\
\text { poliéster }\end{array}$} & \multirow[t]{2}{*}{$\begin{array}{l}\text { Fibra vidrio tejida } \\
125 \mathrm{gr} / \mathrm{m}^{2}\end{array}$} \\
\hline & $\begin{array}{l}\text { B.Acetato } \\
\text { polivinilo }\end{array}$ & & & \\
\hline \multicolumn{2}{|c|}{ OBSERVACIONES } & \multicolumn{3}{|c|}{$\begin{array}{l}\text { A. Demasiado rígido. El adhesivo ha atravesado el } \\
\text { estrato de fieltro. Poca adherencia. } \\
\text { B. Demasiado flexible. Buena adherencia. }\end{array}$} \\
\hline \multirow[t]{2}{*}{26} & $\begin{array}{l}\text { A. Resina } \\
\text { poliéster }\end{array}$ & \multirow[t]{2}{*}{ Muletón } & \multirow[t]{2}{*}{$\begin{array}{l}\text { Resina } \\
\text { poliéster }\end{array}$} & \multirow[t]{2}{*}{$\begin{array}{l}\text { Fibra vidrio tejida } \\
160 \mathrm{gr} / \mathrm{m}^{2}\end{array}$} \\
\hline & $\begin{array}{l}\text { B.Acetato } \\
\text { polivinilo }\end{array}$ & & & \\
\hline \multicolumn{2}{|c|}{ OBSERVACIONES } & \multicolumn{3}{|c|}{$\begin{array}{l}\text { A. Demasiado rígido. El adhesivo ha atravesado el } \\
\text { estrato de fieltro. Poca adherencia. Las puntas se } \\
\text { han combado hacia arriba. } \\
\text { B. Demasiado flexible. Buena adherencia. }\end{array}$} \\
\hline
\end{tabular}




\begin{tabular}{|c|c|c|c|c|}
\hline \multirow[t]{2}{*}{27} & $\begin{array}{l}\text { A. Resina } \\
\text { poliéster }\end{array}$ & \multirow[t]{2}{*}{ Muletón } & \multirow[t]{2}{*}{$\begin{array}{l}\text { Resina } \\
\text { poliéster }\end{array}$} & \multirow[t]{2}{*}{$\begin{array}{l}\text { Fibra vidrio tejida } \\
300 \mathrm{gr} / \mathrm{m}^{2}\end{array}$} \\
\hline & $\begin{array}{l}\text { B.Acetato } \\
\text { polivinilo }\end{array}$ & & & \\
\hline \multicolumn{2}{|c|}{ OBSERVACIONES } & \multicolumn{3}{|c|}{$\begin{array}{l}\text { A. Demasiado rígido. El adhesivo ha atravesado el } \\
\text { estrato de fieltro. Poca adherencia. Las puntas se } \\
\text { han combado hacia arriba. } \\
\text { B. Demasiado flexible. Buena adherencia. }\end{array}$} \\
\hline \multirow[t]{2}{*}{28} & $\begin{array}{l}\text { A. Resina } \\
\text { poliéster }\end{array}$ & \multirow[t]{2}{*}{ Muletón } & \multirow[t]{2}{*}{$\begin{array}{l}\text { Resina } \\
\text { poliéster }\end{array}$} & \multirow[t]{2}{*}{$\begin{array}{l}\text { Matt de velo fibra } \\
\text { de vidrio }\end{array}$} \\
\hline & $\begin{array}{l}\text { B.Acetato } \\
\text { polivinilo }\end{array}$ & & & \\
\hline \multicolumn{2}{|c|}{ OBSERVACIONES } & \multicolumn{3}{|c|}{$\begin{array}{l}\text { A. Demasiado rígido. El adhesivo ha atravesado el } \\
\text { estrato de fieltro. Poca adherencia. Las puntas se } \\
\text { han combado hacia arriba. } \\
\text { B. Demasiado flexible. Buena adherencia. }\end{array}$} \\
\hline \multirow[t]{2}{*}{29} & $\begin{array}{l}\text { A. Resina } \\
\text { epoxi }\end{array}$ & \multirow[t]{2}{*}{ Poliuretano } & \multirow[t]{2}{*}{$\begin{array}{l}\text { Resina } \\
\text { epoxi }\end{array}$} & \multirow[t]{2}{*}{$\begin{array}{l}\text { Fibra vidrio + fibra } \\
\text { carbono }\end{array}$} \\
\hline & $\begin{array}{l}\text { B.Acetato } \\
\text { polivinilo }\end{array}$ & & & \\
\hline \multicolumn{2}{|c|}{ OBSERVACIONES } & \multicolumn{3}{|c|}{$\begin{array}{l}\text { Buena adherencia. } \\
\text { A. Demasiado flexible. } \\
\text { B. Demasiado flexible. Las puntas se han combado } \\
\text { hacia arriba. }\end{array}$} \\
\hline \multirow[t]{2}{*}{30} & $\begin{array}{l}\text { A. Resina } \\
\text { epoxi }\end{array}$ & \multirow[t]{2}{*}{ Poliuretano } & \multirow[t]{2}{*}{$\begin{array}{l}\text { Resina } \\
\text { epoxi }\end{array}$} & \multirow[t]{2}{*}{ Matt $300 \mathrm{gr} / \mathrm{m}^{2}$} \\
\hline & $\begin{array}{l}\text { B. Acetato } \\
\text { polivinilo }\end{array}$ & & & \\
\hline \multicolumn{2}{|c|}{ OBSERVACIONES } & \multicolumn{3}{|c|}{$\begin{array}{l}\text { A. Demasiado rígido. Adherencia poco homogénea. } \\
\text { Las puntas se han combado hacia arriba. } \\
\text { B. Demasiado rígido. Buena adherencia. Las puntas } \\
\text { se han combado hacia arriba. }\end{array}$} \\
\hline \multirow[t]{2}{*}{31} & $\begin{array}{l}\text { A. Resina } \\
\text { epoxi }\end{array}$ & \multirow[t]{2}{*}{ Poliuretano } & \multirow[t]{2}{*}{$\begin{array}{l}\text { Resina } \\
\text { epoxi }\end{array}$} & \multirow[t]{2}{*}{ Matt $450 \mathrm{gr} / \mathrm{m}^{2}$} \\
\hline & $\begin{array}{l}\text { B. Acetato } \\
\text { polivinilo }\end{array}$ & & & \\
\hline \multicolumn{2}{|c|}{ OBSERVACIONES } & \multicolumn{3}{|c|}{$\begin{array}{l}\text { A. Demasiado rígido. Adherencia poco homogénea. } \\
\text { B. Demasiado rígido. Escasa adherencia. Las } \\
\text { puntas se han combado hacia arriba. }\end{array}$} \\
\hline \multirow[t]{2}{*}{32} & $\begin{array}{l}\text { A. Resina } \\
\text { epoxi }\end{array}$ & \multirow[t]{2}{*}{ Poliuretano } & \multirow[t]{2}{*}{$\begin{array}{l}\text { Resina } \\
\text { epoxi }\end{array}$} & \multirow[t]{2}{*}{$\begin{array}{l}\text { Fibra vidrio tejida } \\
125 \mathrm{gr} / \mathrm{m}^{2}\end{array}$} \\
\hline & $\begin{array}{l}\text { B. Acetato } \\
\text { polivinilo }\end{array}$ & & & \\
\hline \multicolumn{2}{|c|}{ OBSERVACIONES } & \multicolumn{3}{|c|}{$\begin{array}{l}\text { A. Demasiado flexible. Buena adherencia. } \\
\text { B. Demasiado flexible. Escasa adherencia. }\end{array}$} \\
\hline
\end{tabular}




\begin{tabular}{|c|c|c|c|c|}
\hline \multirow[t]{2}{*}{33} & $\begin{array}{l}\text { A. Resina } \\
\text { epoxi }\end{array}$ & \multirow[t]{2}{*}{ Poliuretano } & \multirow[t]{2}{*}{$\begin{array}{l}\text { Resina } \\
\text { epoxi }\end{array}$} & \multirow[t]{2}{*}{$\begin{array}{l}\text { Fibra vidrio tejida } \\
160 \mathrm{gr} / \mathrm{m}^{2}\end{array}$} \\
\hline & $\begin{array}{l}\text { B. Acetato } \\
\text { polivinilo }\end{array}$ & & & \\
\hline \multicolumn{2}{|c|}{ OBSERVACIONES } & \multicolumn{3}{|c|}{$\begin{array}{l}\text { A. Demasiado flexible. Buena adherencia. } \\
\text { B. Demasiado flexible. Escasa adherencia. }\end{array}$} \\
\hline \multirow[t]{2}{*}{34} & $\begin{array}{l}\text { A. Resina } \\
\text { epoxi }\end{array}$ & \multirow[t]{2}{*}{ Poliuretano } & \multirow[t]{2}{*}{$\begin{array}{l}\text { Resina } \\
\text { epoxi }\end{array}$} & \multirow[t]{2}{*}{$\begin{array}{l}\text { Fibra vidrio tejida } \\
300 \mathrm{gr} / \mathrm{m}^{2}\end{array}$} \\
\hline & $\begin{array}{l}\text { B. Acetato } \\
\text { polivinilo }\end{array}$ & & & \\
\hline \multicolumn{2}{|c|}{ OBSERVACIONES } & \multicolumn{3}{|c|}{$\begin{array}{l}\text { A. Demasiado rígido. Adherencia poco homogénea } \\
\text { B. Demasiado rígido. Escasa adherencia. Las } \\
\text { puntas se han combado hacia arriba. }\end{array}$} \\
\hline \multirow[t]{2}{*}{35} & $\begin{array}{l}\text { A. Resina } \\
\text { epoxi }\end{array}$ & \multirow[t]{2}{*}{ Poliuretano } & \multirow[t]{2}{*}{$\begin{array}{l}\text { Resina } \\
\text { epoxi }\end{array}$} & \multirow[t]{2}{*}{$\begin{array}{l}\text { Matt de velo fibra } \\
\text { de vidrio }\end{array}$} \\
\hline & $\begin{array}{l}\text { B. Acetato } \\
\text { polivinilo }\end{array}$ & & & \\
\hline \multicolumn{2}{|c|}{ OBSERVACIONES } & \multicolumn{3}{|c|}{$\begin{array}{l}\text { A. Demasiado flexible. Buena adherencia. } \\
\text { B. Demasiado flexible. Escasa adherencia. }\end{array}$} \\
\hline \multirow[t]{2}{*}{36} & $\begin{array}{l}\text { A. Resina } \\
\text { poliéster }\end{array}$ & \multirow[t]{2}{*}{ Poliuretano } & \multirow[t]{2}{*}{$\begin{array}{l}\text { Resina } \\
\text { poliéster }\end{array}$} & \multirow[t]{2}{*}{$\begin{array}{l}\text { Fibra vidrio + fibra } \\
\text { carbono }\end{array}$} \\
\hline & $\begin{array}{l}\text { B. Acetato } \\
\text { polivinilo }\end{array}$ & & & \\
\hline \multicolumn{2}{|c|}{ OBSERVACIONES } & \multicolumn{3}{|c|}{$\begin{array}{l}\text { A. Demasiado flexible. Adherencia escasa y poco } \\
\text { homogénea. } \\
\text { B. Demasiado flexible. Escasa adherencia. }\end{array}$} \\
\hline \multirow[t]{2}{*}{37} & $\begin{array}{l}\text { A. Resina } \\
\text { poliéster }\end{array}$ & \multirow[t]{2}{*}{ Poliuretano } & \multirow[t]{2}{*}{$\begin{array}{l}\text { Resina } \\
\text { poliéster }\end{array}$} & \multirow[t]{2}{*}{ Matt $300 \mathrm{gr} / \mathrm{m}^{2}$} \\
\hline & $\begin{array}{l}\text { B. Acetato } \\
\text { polivinilo }\end{array}$ & & & \\
\hline \multicolumn{2}{|c|}{ OBSERVACIONES } & \multicolumn{3}{|c|}{$\begin{array}{l}\text { A. Flexibilidad adecuada. Buena adhesión. Las } \\
\text { puntas se comban ligeramente hacia arriba. } \\
\text { B. Flexibilidad adecuada. Adherencia escasa. Las } \\
\text { puntas se comban ligeramente hacia arriba. }\end{array}$} \\
\hline \multirow[t]{2}{*}{38} & $\begin{array}{l}\text { A. Resina } \\
\text { poliéster }\end{array}$ & \multirow[t]{2}{*}{ Poliuretano } & \multirow[t]{2}{*}{$\begin{array}{l}\text { Resina } \\
\text { poliéster }\end{array}$} & \multirow[t]{2}{*}{ Matt $450 \mathrm{gr} / \mathrm{m}^{2}$} \\
\hline & $\begin{array}{l}\text { B. Acetato } \\
\text { polivinilo }\end{array}$ & & & \\
\hline \multicolumn{2}{|c|}{ OBSERVACIONES } & \multicolumn{3}{|c|}{$\begin{array}{l}\text { A. Demasiado rígido. Adherencia poco homogénea. } \\
\text { B. Demasiado rígido. Escasa adherencia. Las } \\
\text { puntas se han combado ligeramente hacia arriba. }\end{array}$} \\
\hline \multirow[t]{2}{*}{39} & $\begin{array}{l}\text { A. Resina } \\
\text { poliéster }\end{array}$ & Poliuretano & $\begin{array}{l}\text { Resina } \\
\text { poliéster }\end{array}$ & $\begin{array}{l}\text { Fibra vidrio tejida } \\
125 \mathrm{gr} / \mathrm{m}^{2}\end{array}$ \\
\hline & $\begin{array}{l}\text { B. Acetato } \\
\text { polivinilo }\end{array}$ & & & \\
\hline
\end{tabular}




\begin{tabular}{|c|c|c|c|c|}
\hline \multicolumn{2}{|c|}{ OBSERVACIONES } & \multicolumn{3}{|c|}{$\begin{array}{l}\text { A. Demasiado rígido. Buena adherencia. } \\
\text { B. Demasiado rígido. Escasa adherencia. Las } \\
\text { puntas se han combado hacia abajo. }\end{array}$} \\
\hline \multirow[t]{2}{*}{40} & $\begin{array}{l}\text { A. Resina } \\
\text { poliéster }\end{array}$ & \multirow[t]{2}{*}{ Poliuretano } & \multirow[t]{2}{*}{$\begin{array}{l}\text { Resina } \\
\text { poliéster }\end{array}$} & \multirow[t]{2}{*}{$\begin{array}{l}\text { Fibra vidrio tejida } \\
160 \mathrm{gr} / \mathrm{m}^{2}\end{array}$} \\
\hline & $\begin{array}{l}\text { B. Acetato } \\
\text { polivinilo }\end{array}$ & & & \\
\hline \multicolumn{2}{|c|}{ OBSERVACIONES } & \multicolumn{3}{|c|}{$\begin{array}{l}\text { A. Demasiado rígido. Buena adherencia. } \\
\text { B. Demasiado rígido. Escasa adherencia. Las } \\
\text { puntas se han combado hacia abajo. }\end{array}$} \\
\hline \multirow[t]{2}{*}{41} & $\begin{array}{l}\text { A. Resina } \\
\text { poliéster }\end{array}$ & \multirow[t]{2}{*}{ Poliuretano } & \multirow[t]{2}{*}{$\begin{array}{l}\text { Resina } \\
\text { poliéster }\end{array}$} & \multirow[t]{2}{*}{$\begin{array}{l}\text { Fibra vidrio tejida } \\
300 \mathrm{gr} / \mathrm{m}^{2}\end{array}$} \\
\hline & $\begin{array}{l}\text { B. Acetato } \\
\text { polivinilo }\end{array}$ & & & \\
\hline \multicolumn{2}{|c|}{ OBSERVACIONES } & \multicolumn{3}{|c|}{$\begin{array}{l}\text { A. Demasiado rígido. Buena adherencia. } \\
\text { B. Demasiado rígido. Escasa adherencia. Las } \\
\text { puntas se han combado hacia abajo. }\end{array}$} \\
\hline \multirow[t]{2}{*}{42} & $\begin{array}{l}\text { A. Resina } \\
\text { poliéster }\end{array}$ & \multirow[t]{2}{*}{ Poliuretano } & \multirow[t]{2}{*}{$\begin{array}{l}\text { Resina } \\
\text { poliéster }\end{array}$} & \multirow[t]{2}{*}{$\begin{array}{l}\text { Matt de velo fibra } \\
\text { de vidrio }\end{array}$} \\
\hline & $\begin{array}{l}\text { B. Acetato } \\
\text { polivinilo }\end{array}$ & & & \\
\hline \multicolumn{2}{|c|}{ OBSERVACIONES } & \multicolumn{3}{|c|}{$\begin{array}{l}\text { A. Demasiado rígido. Buena adherencia. } \\
\text { B. Demasiado rígido. Escasa adherencia. Las } \\
\text { puntas se han combado hacia abajo. }\end{array}$} \\
\hline \multirow[t]{2}{*}{43} & $\begin{array}{l}\text { A. Resina } \\
\text { epoxi }\end{array}$ & \multirow[t]{2}{*}{ Spherecore } & \multirow[t]{2}{*}{$\begin{array}{l}\text { Resina } \\
\text { epoxi }\end{array}$} & \multirow[t]{2}{*}{$\begin{array}{l}\text { Fibra vidrio + fibra } \\
\text { carbono }\end{array}$} \\
\hline & $\begin{array}{l}\text { Acetato } \\
\text { polivinilo }\end{array}$ & & & \\
\hline \multicolumn{2}{|c|}{ OBSERVACIONES } & \multicolumn{3}{|c|}{$\begin{array}{l}\text { A. Demasiado rígido. Adherencia poco homogénea. } \\
\text { B. Demasiado flexible. Buena adherencia. }\end{array}$} \\
\hline \multirow[t]{2}{*}{44} & $\begin{array}{l}\text { A. Resina } \\
\text { epoxi }\end{array}$ & \multirow[t]{2}{*}{ Spherecore } & \multirow[t]{2}{*}{$\begin{array}{l}\text { Resina } \\
\text { epoxi }\end{array}$} & \multirow[t]{2}{*}{ Matt $300 \mathrm{gr} / \mathrm{m}^{2}$} \\
\hline & $\begin{array}{l}\text { B. Acetato } \\
\text { polivinilo }\end{array}$ & & & \\
\hline \multicolumn{2}{|c|}{ OBSERVACIONES } & \multicolumn{3}{|c|}{$\begin{array}{l}\text { A. Demasiado rígido. Adherencia escasa y poco } \\
\text { homogénea. } \\
\text { B. Demasiado rígido. Buena adherencia. }\end{array}$} \\
\hline \multirow[t]{2}{*}{45} & $\begin{array}{l}\text { A. Resina } \\
\text { epoxi }\end{array}$ & \multirow[t]{2}{*}{ Spherecore } & \multirow[t]{2}{*}{$\begin{array}{l}\text { Resina } \\
\text { epoxi }\end{array}$} & Matt $450 \mathrm{gr} / \mathrm{m}^{2}$ \\
\hline & $\begin{array}{l}\text { B. Acetato } \\
\text { polivinilo }\end{array}$ & & & \\
\hline \multicolumn{2}{|c|}{ OBSERVACIONES } & \multicolumn{3}{|c|}{$\begin{array}{l}\text { A. Demasiado rígido. Adherencia muy escasa y } \\
\text { poco homogénea. } \\
\text { B. Demasiado rígido. Buena adherencia. }\end{array}$} \\
\hline
\end{tabular}




\begin{tabular}{|c|c|c|c|c|}
\hline \multirow[t]{2}{*}{46} & $\begin{array}{l}\text { A. Resina } \\
\text { epoxi }\end{array}$ & \multirow[t]{2}{*}{ Spherecore } & \multirow[t]{2}{*}{$\begin{array}{l}\text { Resina } \\
\text { epoxi }\end{array}$} & \multirow[t]{2}{*}{$\begin{array}{l}\text { Fibra vidrio tejida } \\
125 \mathrm{gr} / \mathrm{m}^{2}\end{array}$} \\
\hline & $\begin{array}{l}\text { B. Acetato } \\
\text { polivinilo }\end{array}$ & & & \\
\hline \multicolumn{2}{|c|}{ OBSERVACIONES } & \multicolumn{3}{|c|}{$\begin{array}{l}\text { A. Flexibilidad adecuada. Adherencia muy escasa. } \\
\text { B. Demasiado flexible. Poca adherencia. }\end{array}$} \\
\hline \multirow[t]{2}{*}{47} & $\begin{array}{l}\text { A. Resina } \\
\text { epoxi }\end{array}$ & \multirow[t]{2}{*}{ Spherecore } & \multirow[t]{2}{*}{$\begin{array}{l}\text { Resina } \\
\text { epoxi }\end{array}$} & \multirow[t]{2}{*}{$\begin{array}{l}\text { Fibra vidrio tejida } \\
160 \mathrm{gr} / \mathrm{m}^{2}\end{array}$} \\
\hline & $\begin{array}{l}\text { B. Acetato } \\
\text { polivinilo }\end{array}$ & & & \\
\hline \multicolumn{2}{|c|}{ OBSERVACIONES } & \multicolumn{3}{|c|}{$\begin{array}{l}\text { A. Flexibilidad adecuada. Adherencia muy escasa. } \\
\text { B. Demasiado flexible. Poca adherencia. }\end{array}$} \\
\hline \multirow[t]{2}{*}{48} & $\begin{array}{l}\text { A. Resina } \\
\text { epoxi }\end{array}$ & \multirow[t]{2}{*}{ Spherecore } & \multirow[t]{2}{*}{$\begin{array}{l}\text { Resina } \\
\text { epoxi }\end{array}$} & \multirow[t]{2}{*}{$\begin{array}{l}\text { Fibra vidrio tejida } \\
300 \mathrm{gr} / \mathrm{m}^{2}\end{array}$} \\
\hline & $\begin{array}{l}\text { B. Acetato } \\
\text { polivinilo }\end{array}$ & & & \\
\hline \multicolumn{2}{|c|}{ OBSERVACIONES } & \multicolumn{3}{|c|}{$\begin{array}{l}\text { A. Flexibilidad adecuada. Adherencia muy escasa. } \\
\text { B. Demasiado flexible. Poca adherencia. }\end{array}$} \\
\hline \multirow[t]{2}{*}{49} & $\begin{array}{l}\text { A. Resina } \\
\text { epoxi }\end{array}$ & \multirow[t]{2}{*}{ Spherecore } & \multirow[t]{2}{*}{$\begin{array}{l}\text { Resina } \\
\text { epoxi }\end{array}$} & \multirow[t]{2}{*}{$\begin{array}{l}\text { Matt de velo fibra } \\
\text { de vidrio }\end{array}$} \\
\hline & $\begin{array}{l}\text { B. Acetato } \\
\text { polivinilo }\end{array}$ & & & \\
\hline \multicolumn{2}{|c|}{ OBSERVACIONES } & \multicolumn{3}{|c|}{$\begin{array}{l}\text { A. Flexibilidad adecuada. Adherencia muy escasa. } \\
\text { B. Demasiado flexible. Poca adherencia. }\end{array}$} \\
\hline \multirow[t]{2}{*}{50} & $\begin{array}{l}\text { A. Resina } \\
\text { poliéster }\end{array}$ & \multirow[t]{2}{*}{ Spherecore } & \multirow[t]{2}{*}{$\begin{array}{l}\text { Resina } \\
\text { poliéster }\end{array}$} & \multirow[t]{2}{*}{$\begin{array}{l}\text { Fibra vidrio + fibra } \\
\text { carbono }\end{array}$} \\
\hline & $\begin{array}{l}\text { B. Acetato } \\
\text { polivinilo }\end{array}$ & & & \\
\hline \multicolumn{2}{|c|}{ OBSERVACIONES } & \multicolumn{3}{|c|}{$\begin{array}{l}\text { A. Flexibilidad adecuada. Adherencia muy escasa. } \\
\text { B. Demasiado flexible. Poca adherencia. }\end{array}$} \\
\hline \multirow[t]{2}{*}{51} & $\begin{array}{l}\text { A. Resina } \\
\text { poliéster }\end{array}$ & \multirow[t]{2}{*}{ Spherecore } & \multirow[t]{2}{*}{$\begin{array}{l}\text { Resina } \\
\text { poliéster }\end{array}$} & \multirow[t]{2}{*}{ Matt $300 \mathrm{gr} / \mathrm{m}^{2}$} \\
\hline & $\begin{array}{l}\text { B. Acetato } \\
\text { polivinilo }\end{array}$ & & & \\
\hline \multicolumn{2}{|c|}{ OBSERVACIONES } & \multicolumn{3}{|c|}{$\begin{array}{l}\text { A. Demasiado rígido. Adherencia muy escasa y } \\
\text { poco homogénea. } \\
\text { B. Demasiado rígido. Buena adherencia. }\end{array}$} \\
\hline 52 & $\begin{array}{l}\text { A. Resina } \\
\text { poliéster }\end{array}$ & Spherecore & $\begin{array}{l}\text { Resina } \\
\text { poliéster }\end{array}$ & Matt $450 \mathrm{gr} / \mathrm{m}^{2}$ \\
\hline & $\begin{array}{l}\text { B. Acetato } \\
\text { polivinilo }\end{array}$ & & & \\
\hline & RVACIONES & $\begin{array}{l}\text { A. Demasiac } \\
\text { poco homog } \\
\text { B. Demasiac }\end{array}$ & $\begin{array}{l}\text { o. Adhere } \\
\text { o. Buena }\end{array}$ & $\begin{array}{l}\text { muy escasa y } \\
\text { erencia. }\end{array}$ \\
\hline
\end{tabular}




\begin{tabular}{|c|c|c|c|c|}
\hline \multirow[t]{2}{*}{53} & $\begin{array}{l}\text { A. Resina } \\
\text { poliéster }\end{array}$ & \multirow[t]{2}{*}{ Spherecore } & \multirow[t]{2}{*}{$\begin{array}{l}\text { Resina } \\
\text { poliéster }\end{array}$} & \multirow[t]{2}{*}{$\begin{array}{l}\text { Fibra vidrio tejida } \\
125 \mathrm{gr} / \mathrm{m}^{2}\end{array}$} \\
\hline & $\begin{array}{l}\text { B. Acetato } \\
\text { polivinilo }\end{array}$ & & & \\
\hline \multicolumn{2}{|c|}{ OBSERVACIONES } & \multicolumn{3}{|c|}{$\begin{array}{l}\text { A. Demasiado flexible. Adherencia escasa y poco } \\
\text { homogénea. } \\
\text { B. Demasiado flexible. Escasa adherencia. }\end{array}$} \\
\hline \multirow[t]{2}{*}{54} & $\begin{array}{l}\text { A. Resina } \\
\text { poliéster }\end{array}$ & \multirow[t]{2}{*}{ Spherecore } & \multirow[t]{2}{*}{$\begin{array}{l}\text { Resina } \\
\text { poliéster }\end{array}$} & \multirow[t]{2}{*}{$\begin{array}{l}\text { Fibra vidrio tejida } \\
160 \mathrm{gr} / \mathrm{m}^{2}\end{array}$} \\
\hline & $\begin{array}{l}\text { B. Acetato } \\
\text { polivinilo }\end{array}$ & & & \\
\hline \multicolumn{2}{|c|}{ OBSERVACIONES } & \multicolumn{3}{|c|}{$\begin{array}{l}\text { A. Demasiado flexible. Adherencia escasa y poco } \\
\text { homogénea. } \\
\text { B. Demasiado flexible. Escasa adherencia. }\end{array}$} \\
\hline \multirow[t]{2}{*}{55} & $\begin{array}{l}\text { A. Resina } \\
\text { poliéster }\end{array}$ & \multirow[t]{2}{*}{ Spherecore } & \multirow[t]{2}{*}{$\begin{array}{l}\text { Resina } \\
\text { poliéster }\end{array}$} & \multirow[t]{2}{*}{$\begin{array}{l}\text { Fibra vidrio tejida } \\
300 \mathrm{gr} / \mathrm{m}^{2}\end{array}$} \\
\hline & $\begin{array}{l}\text { B. Acetato } \\
\text { polivinilo }\end{array}$ & & & \\
\hline \multicolumn{2}{|c|}{ OBSERVACIONES } & \multicolumn{3}{|c|}{$\begin{array}{l}\text { A. Demasiado flexible. Adherencia escasa y poco } \\
\text { homogénea. } \\
\text { B. Demasiado flexible. Escasa adherencia. }\end{array}$} \\
\hline \multirow[t]{2}{*}{56} & $\begin{array}{l}\text { A. Resina } \\
\text { poliéster }\end{array}$ & \multirow[t]{2}{*}{ Spherecore } & \multirow[t]{2}{*}{$\begin{array}{l}\text { Resina } \\
\text { poliéster }\end{array}$} & \multirow[t]{2}{*}{$\begin{array}{l}\text { Matt de velo fibra } \\
\text { de vidrio }\end{array}$} \\
\hline & $\begin{array}{l}\text { B. Acetato } \\
\text { polivinilo }\end{array}$ & & & \\
\hline \multicolumn{2}{|c|}{ OBSERVACIONES } & \multicolumn{3}{|c|}{$\begin{array}{l}\text { A. Flexibilidad adecuada. Adherencia escasa y poco } \\
\text { homogénea. } \\
\text { B. Demasiado flexible. Escasa adherencia. }\end{array}$} \\
\hline \multirow[t]{2}{*}{57} & $\begin{array}{l}\text { A. Resina } \\
\text { poliéster }\end{array}$ & \multirow[t]{2}{*}{ Fieltro } & \multirow[t]{2}{*}{$\begin{array}{l}\text { Resina } \\
\text { epoxi }\end{array}$} & \multirow[t]{2}{*}{$\begin{array}{l}\text { Fibra vidrio + fibra } \\
\text { carbono }\end{array}$} \\
\hline & B. Beva gel & & & \\
\hline \multicolumn{2}{|c|}{ OBSERVACIONES } & \multicolumn{3}{|c|}{$\begin{array}{l}\text { Las puntas se comban ligeramente hacia arriba. } \\
\text { A. Flexibilidad adecuada. El adhesivo ha atravesado } \\
\text { el estrato de fieltro. Buena adherencia. } \\
\text { B. Demasiado flexible. Buena adherencia. }\end{array}$} \\
\hline \multirow[t]{2}{*}{58} & $\begin{array}{l}\text { A. Resina } \\
\text { epoxi }\end{array}$ & \multirow[t]{2}{*}{ Fieltro } & \multirow[t]{2}{*}{$\begin{array}{l}\text { Resina } \\
\text { epoxi }\end{array}$} & \multirow[t]{2}{*}{ Matt $300 \mathrm{gr} / \mathrm{m}^{2}$} \\
\hline & B. Beva gel & & & \\
\hline \multicolumn{2}{|c|}{ OBSERVACIONES } & \multicolumn{3}{|c|}{$\begin{array}{l}\text { A. Demasiado rígido. El adhesivo ha atravesado el } \\
\text { estrato de fieltro. Buena adherencia. } \\
\text { B. Flexibilidad adecuada. Buena adherencia. }\end{array}$} \\
\hline \multirow[t]{2}{*}{59} & $\begin{array}{l}\text { A. Resina } \\
\text { epoxi }\end{array}$ & Fieltro & $\begin{array}{l}\text { Resina } \\
\text { epoxi }\end{array}$ & Matt $450 \mathrm{gr} / \mathrm{m}^{2}$ \\
\hline & B. Beva gel & & & \\
\hline
\end{tabular}




\begin{tabular}{|c|c|c|c|c|}
\hline \multicolumn{2}{|c|}{ OBSERVACIONES } & \multicolumn{3}{|c|}{$\begin{array}{l}\text { A. Excesiva rigidez. El adhesivo ha atravesado el } \\
\text { estrato de fieltro. Buena adherencia. } \\
\text { B. Excesiva rigidez. Buena adherencia. }\end{array}$} \\
\hline \multirow[t]{2}{*}{60} & $\begin{array}{l}\text { A. Resina } \\
\text { epoxi }\end{array}$ & \multirow[t]{2}{*}{ Fieltro } & \multirow[t]{2}{*}{$\begin{array}{l}\text { Resina } \\
\text { epoxi }\end{array}$} & \multirow[t]{2}{*}{$\begin{array}{l}\text { Fibra vidrio tejida } \\
125 \mathrm{gr} / \mathrm{m}^{2}\end{array}$} \\
\hline & B. Beva gel & & & \\
\hline \multicolumn{2}{|c|}{ OBSERVACIONES } & \multicolumn{3}{|c|}{$\begin{array}{l}\text { A. Demasiado rígido. El adhesivo ha atravesado el } \\
\text { estrato de fieltro. Buena adherencia. } \\
\text { B. Demasiado flexible. Buena adherencia. }\end{array}$} \\
\hline \multirow[t]{2}{*}{61} & & \multirow[t]{2}{*}{ Fieltro } & Resina & Fibra vidrio tejida \\
\hline & B. Beva gel & & epoxi & \\
\hline \multicolumn{2}{|c|}{ OBSERVACIONES } & \multicolumn{3}{|c|}{$\begin{array}{l}\text { Las puntas se comban ligeramente hacia arriba. } \\
\text { A. Demasiado rígido. El adhesivo ha atravesado el } \\
\text { estrato de fieltro. Buena adherencia. } \\
\text { B. Demasiado flexible. Buena adherencia. }\end{array}$} \\
\hline \multirow[t]{2}{*}{62} & $\begin{array}{l}\text { A. Resina } \\
\text { epoxi }\end{array}$ & \multirow[t]{2}{*}{ Fieltro } & \multirow[t]{2}{*}{$\begin{array}{l}\text { Resina } \\
\text { epoxi }\end{array}$} & \multirow[t]{2}{*}{$\begin{array}{l}\text { Fibra vidrio tejida } \\
300 \mathrm{gr} / \mathrm{m}^{2}\end{array}$} \\
\hline & B. Beva gel & & & \\
\hline \multicolumn{2}{|c|}{ OBSERVACIONES } & \multicolumn{3}{|c|}{$\begin{array}{l}\text { A. Demasiado rígido. El adhesivo ha atravesado el } \\
\text { estrato de fieltro. Buena adherencia. } \\
\text { B. Demasiado flexible. Buena adherencia. }\end{array}$} \\
\hline \multirow[t]{2}{*}{63} & $\begin{array}{l}\text { A. Resina } \\
\text { epoxi }\end{array}$ & \multirow[t]{2}{*}{ Fieltro } & \multirow[t]{2}{*}{$\begin{array}{l}\text { Resina } \\
\text { epoxi }\end{array}$} & \multirow[t]{2}{*}{$\begin{array}{l}\text { Matt de velo fibra } \\
\text { de vidrio }\end{array}$} \\
\hline & B. Beva gel & & & \\
\hline \multicolumn{2}{|c|}{ OBSERVACIONES } & \multicolumn{3}{|c|}{$\begin{array}{l}\text { Las puntas se comban ligeramente hacia arriba. } \\
\text { A. Demasiado rígido. El adhesivo ha atravesado el } \\
\text { estrato de fieltro. Escasa adherencia. } \\
\text { B. Demasiado flexible. Buena adherencia. }\end{array}$} \\
\hline \multirow[t]{2}{*}{64} & $\begin{array}{l}\text { A. Resina } \\
\text { poliéster }\end{array}$ & \multirow[t]{2}{*}{ Fieltro } & \multirow[t]{2}{*}{$\begin{array}{l}\text { Resina } \\
\text { poliéster }\end{array}$} & \multirow[t]{2}{*}{$\begin{array}{l}\text { Fibra vidrio + fibra } \\
\text { carbono }\end{array}$} \\
\hline & B. Beva gel & & & \\
\hline \multicolumn{2}{|c|}{ OBSERVACIONES } & \multicolumn{3}{|c|}{$\begin{array}{l}\text { Las puntas se comban ligeramente hacia arriba. } \\
\text { A. Demasiado flexible. El adhesivo ha atravesado el } \\
\text { estrato de fieltro. Escasa adherencia. } \\
\text { B. Demasiado flexible. Buena adherencia. }\end{array}$} \\
\hline \multirow[t]{2}{*}{65} & $\begin{array}{l}\text { A. Resina } \\
\text { poliéster }\end{array}$ & \multirow[t]{2}{*}{ Fieltro } & \multirow[t]{2}{*}{$\begin{array}{l}\text { Resina } \\
\text { poliéster }\end{array}$} & \multirow[t]{2}{*}{ Matt $300 \mathrm{gr} / \mathrm{m}^{2}$} \\
\hline & B. Beva gel & & & \\
\hline \multicolumn{2}{|c|}{ OBSERVACIONES } & \multicolumn{3}{|c|}{$\begin{array}{l}\text { A. Demasiado rígido. El adhesivo ha atravesado el } \\
\text { estrato de fieltro. Escasa adherencia. } \\
\text { B. Demasiado rígido. Buena adherencia. }\end{array}$} \\
\hline 66 & $\begin{array}{l}\text { A. Resina } \\
\text { poliéster }\end{array}$ & Fieltro & $\begin{array}{l}\text { Resina } \\
\text { poliéster }\end{array}$ & Matt $450 \mathrm{gr} / \mathrm{m}^{2}$ \\
\hline & B. Beva gel & & & \\
\hline
\end{tabular}




\begin{tabular}{|c|c|c|c|c|}
\hline \multicolumn{2}{|c|}{ OBSERVACIONES } & \multicolumn{3}{|c|}{$\begin{array}{l}\text { A. Demasiado rígido. El adhesivo ha atravesado el } \\
\text { estrato de fieltro. Escasa adherencia. } \\
\text { B. Demasiado rígido. Buena adherencia. }\end{array}$} \\
\hline \multirow[t]{2}{*}{67} & $\begin{array}{l}\text { A. Resina } \\
\text { poliéster }\end{array}$ & \multirow[t]{2}{*}{ Fieltro } & \multirow[t]{2}{*}{$\begin{array}{l}\text { Resina } \\
\text { poliéster }\end{array}$} & \multirow[t]{2}{*}{$\begin{array}{l}\text { Fibra vidrio tejida } \\
125 \mathrm{gr} / \mathrm{m}^{2}\end{array}$} \\
\hline & B. Beva gel & & & \\
\hline \multicolumn{2}{|c|}{ OBSERVACIONES } & \multicolumn{3}{|c|}{$\begin{array}{l}\text { Las puntas se comban ligeramente hacia arriba. } \\
\text { A. Demasiado flexible. El adhesivo ha atravesado el } \\
\text { estrato de fieltro. Escasa adherencia. } \\
\text { B. Demasiado flexible. Buena adherencia. }\end{array}$} \\
\hline \multirow[t]{2}{*}{68} & $\begin{array}{l}\text { A. Resina } \\
\text { poliéster }\end{array}$ & \multirow[t]{2}{*}{ Fieltro } & \multirow[t]{2}{*}{$\begin{array}{l}\text { Resina } \\
\text { poliéster }\end{array}$} & \multirow[t]{2}{*}{$\begin{array}{l}\text { Fibra vidrio tejida } \\
160 \mathrm{gr} / \mathrm{m}^{2}\end{array}$} \\
\hline & B. Beva gel & & & \\
\hline \multicolumn{2}{|c|}{ OBSERVACIONES } & \multicolumn{3}{|c|}{$\begin{array}{l}\text { Las puntas se comban ligeramente hacia arriba. } \\
\text { A. Demasiado rígido. El adhesivo ha atravesado el } \\
\text { estrato de fieltro. Escasa adherencia. } \\
\text { B. Demasiado flexible. Buena adherencia. }\end{array}$} \\
\hline \multirow[t]{2}{*}{69} & $\begin{array}{l}\text { A. Resina } \\
\text { poliéster }\end{array}$ & \multirow[t]{2}{*}{ Fieltro } & \multirow[t]{2}{*}{$\begin{array}{l}\text { Resina } \\
\text { poliéster }\end{array}$} & \multirow[t]{2}{*}{$\begin{array}{l}\text { Fibra vidrio tejida } \\
300 \mathrm{gr} / \mathrm{m}^{2}\end{array}$} \\
\hline & B. Beva gel & & & \\
\hline \multicolumn{2}{|c|}{ OBSERVACIONES } & \multicolumn{3}{|c|}{$\begin{array}{l}\text { Las puntas se comban ligeramente hacia arriba. } \\
\text { A. Demasiado rígido. El adhesivo ha atravesado el } \\
\text { estrato de fieltro. Escasa adherencia. } \\
\text { B. Demasiado flexible. Buena adherencia. }\end{array}$} \\
\hline \multirow[t]{2}{*}{70} & $\begin{array}{l}\text { A. Resina } \\
\text { poliéster }\end{array}$ & \multirow[t]{2}{*}{ Fieltro } & \multirow[t]{2}{*}{$\begin{array}{l}\text { Resina } \\
\text { poliéster }\end{array}$} & \multirow[t]{2}{*}{$\begin{array}{l}\text { Matt de velo fibra } \\
\text { de vidrio }\end{array}$} \\
\hline & B. Beva gel & & & \\
\hline \multicolumn{2}{|c|}{ OBSERVACIONES } & \multicolumn{3}{|c|}{$\begin{array}{l}\text { A. Demasiado rígido. El adhesivo ha atravesado el } \\
\text { estrato de fieltro. Escasa adherencia. } \\
\text { B. Demasiado rígido. Buena adherencia. Las puntas } \\
\text { se comban hacia arriba. }\end{array}$} \\
\hline \multirow[t]{2}{*}{71} & $\begin{array}{l}\text { A. Resina } \\
\text { epoxi }\end{array}$ & \multirow[t]{2}{*}{ Muletón } & \multirow[t]{2}{*}{$\begin{array}{l}\text { Resina } \\
\text { epoxi }\end{array}$} & \multirow[t]{2}{*}{$\begin{array}{l}\text { Fibra vidrio + fibra } \\
\text { carbono }\end{array}$} \\
\hline & B. Beva gel & & & \\
\hline \multicolumn{2}{|c|}{ OBSERVACIONES } & \multicolumn{3}{|c|}{$\begin{array}{l}\text { A. Demasiado rígido. El adhesivo ha atravesado el } \\
\text { estrato de muletón. Buena adherencia. } \\
\text { B. Demasiado flexible. Buena adherencia. }\end{array}$} \\
\hline \multirow[t]{2}{*}{72} & $\begin{array}{l}\text { A. Resina } \\
\text { epoxi }\end{array}$ & \multirow[t]{2}{*}{ Muletón } & \multirow[t]{2}{*}{$\begin{array}{l}\text { Resina } \\
\text { epoxi }\end{array}$} & \multirow[t]{2}{*}{ Matt $300 \mathrm{gr} / \mathrm{m}^{2}$} \\
\hline & B. Beva gel & & & \\
\hline \multicolumn{2}{|c|}{ OBSERVACIONES } & $\begin{array}{l}\text { A. Dema } \\
\text { estrato d } \\
\text { B. Flexib }\end{array}$ & $\begin{array}{l}\text { do. El adhes } \\
\text { Buena ad } \\
\text { cuada. Bue }\end{array}$ & $\begin{array}{l}\text { ha atravesado el } \\
\text { encia. } \\
\text { adherencia. }\end{array}$ \\
\hline
\end{tabular}




\begin{tabular}{|c|c|c|c|c|}
\hline \multirow[t]{2}{*}{73} & $\begin{array}{l}\text { A. Resina } \\
\text { epoxi }\end{array}$ & \multirow[t]{2}{*}{ Muletón } & \multirow[t]{2}{*}{$\begin{array}{l}\text { Resina } \\
\text { epoxi }\end{array}$} & \multirow[t]{2}{*}{ Matt $450 \mathrm{gr} / \mathrm{m}^{2}$} \\
\hline & B. Beva gel & & & \\
\hline \multicolumn{2}{|c|}{ OBSERVACIONES } & \multicolumn{3}{|c|}{$\begin{array}{l}\text { A. Demasiado rígido. El adhesivo ha atravesado el } \\
\text { estrato de muletón. Buena adherencia. } \\
\text { B. Demasiado rígido. Buena adherencia. }\end{array}$} \\
\hline \multirow[t]{2}{*}{74} & $\begin{array}{l}\text { A. Resina } \\
\text { epoxi }\end{array}$ & \multirow[t]{2}{*}{ Muletón } & \multirow[t]{2}{*}{$\begin{array}{l}\text { Resina } \\
\text { epoxi }\end{array}$} & \multirow[t]{2}{*}{$\begin{array}{l}\text { Fibra vidrio tejida } \\
125 \mathrm{gr} / \mathrm{m}^{2}\end{array}$} \\
\hline & B. Beva gel & & & \\
\hline \multicolumn{2}{|c|}{ OBSERVACIONES } & \multicolumn{3}{|c|}{$\begin{array}{l}\text { A. Demasiado rígido. El adhesivo ha atravesado el } \\
\text { estrato de muletón. Buena adherencia. } \\
\text { B. Demasiado flexible. Buena adherencia. }\end{array}$} \\
\hline \multirow[t]{2}{*}{75} & $\begin{array}{l}\text { A. Resina } \\
\text { epoxi }\end{array}$ & \multirow[t]{2}{*}{ Muletón } & \multirow[t]{2}{*}{$\begin{array}{l}\text { Resina } \\
\text { epoxi }\end{array}$} & \multirow[t]{2}{*}{$\begin{array}{l}\text { Fibra vidrio tejida } \\
160 \mathrm{gr} / \mathrm{m}^{2}\end{array}$} \\
\hline & B. Beva gel & & & \\
\hline \multicolumn{2}{|c|}{ OBSERVACIONES } & \multicolumn{3}{|c|}{$\begin{array}{l}\text { A. Demasiado rígido. El adhesivo ha atravesado el } \\
\text { estrato de muletón. Buena adherencia. } \\
\text { B. Demasiado flexible. Buena adherencia. }\end{array}$} \\
\hline \multirow[t]{2}{*}{76} & $\begin{array}{l}\text { A. Resina } \\
\text { epoxi }\end{array}$ & \multirow[t]{2}{*}{ Muletón } & \multirow[t]{2}{*}{$\begin{array}{l}\text { Resina } \\
\text { epoxi }\end{array}$} & \multirow[t]{2}{*}{$\begin{array}{l}\text { Fibra vidrio tejida } \\
300 \mathrm{gr} / \mathrm{m}^{2}\end{array}$} \\
\hline & B. Beva gel & & & \\
\hline \multicolumn{2}{|c|}{ OBSERVACIONES } & \multicolumn{3}{|c|}{$\begin{array}{l}\text { A. Demasiado rígido. El adhesivo ha atravesado el } \\
\text { estrato de muletón. Buena adherencia. } \\
\text { B. Demasiado flexible. Buena adherencia. }\end{array}$} \\
\hline \multirow[t]{2}{*}{77} & $\begin{array}{l}\text { A. Resina } \\
\text { epoxi }\end{array}$ & \multirow[t]{2}{*}{ Muletón } & \multirow{2}{*}{$\begin{array}{l}\text { Resina } \\
\text { epoxi }\end{array}$} & \multirow[t]{2}{*}{$\begin{array}{l}\text { Matt de velo fibra } \\
\text { de vidrio }\end{array}$} \\
\hline & B. Beva gel & & & \\
\hline \multicolumn{2}{|c|}{ OBSERVACIONES } & \multicolumn{3}{|c|}{$\begin{array}{l}\text { A. Demasiado rígido. El adhesivo ha atravesado el } \\
\text { estrato de muletón. Buena adherencia. } \\
\text { B. Demasiado flexible. Buena adherencia. }\end{array}$} \\
\hline \multirow[t]{2}{*}{78} & $\begin{array}{l}\text { A. Resina } \\
\text { poliéster }\end{array}$ & \multirow[t]{2}{*}{ Muletón } & \multirow[t]{2}{*}{$\begin{array}{l}\text { Resina } \\
\text { poliéster }\end{array}$} & \multirow[t]{2}{*}{$\begin{array}{l}\text { Fibra vidrio + fibra } \\
\text { carbono }\end{array}$} \\
\hline & B. Beva gel & & & \\
\hline \multicolumn{2}{|c|}{ OBSERVACIONES } & \multicolumn{3}{|c|}{$\begin{array}{l}\text { A. Demasiado rígido. El adhesivo ha atravesado el } \\
\text { estrato de muletón. Escasa adherencia. } \\
\text { B. Demasiado flexible. Buena adherencia. }\end{array}$} \\
\hline 79 & $\begin{array}{l}\text { A. Resina } \\
\text { poliéster }\end{array}$ & Muletón & $\begin{array}{l}\text { Resina } \\
\text { poliéster }\end{array}$ & Matt $300 \mathrm{gr} / \mathrm{m}^{2}$ \\
\hline & B. Beva gel & & & \\
\hline $\mathrm{OB}$ & RVACIONES & $\begin{array}{l}\text { A. Demas } \\
\text { estrato de } \\
\text { B. Flexibi }\end{array}$ & $\begin{array}{l}\text { lo. El adhe } \\
\text { Escasa a } \\
\text { cuada. Bue }\end{array}$ & $\begin{array}{l}\text { ha atravesado el } \\
\text { rencia. } \\
\text { adherencia. }\end{array}$ \\
\hline
\end{tabular}




\begin{tabular}{|c|c|c|c|c|}
\hline \multirow[t]{2}{*}{80} & $\begin{array}{l}\text { A. Resina } \\
\text { poliéster }\end{array}$ & \multirow[t]{2}{*}{ Muletón } & \multirow{2}{*}{$\begin{array}{l}\text { Resina } \\
\text { poliéster }\end{array}$} & \multirow[t]{2}{*}{ Matt $450 \mathrm{gr} / \mathrm{m}^{2}$} \\
\hline & B. Beva gel & & & \\
\hline \multicolumn{2}{|c|}{ OBSERVACIONES } & \multicolumn{3}{|c|}{$\begin{array}{l}\text { A. Demasiado rígido. El adhesivo ha atravesado el } \\
\text { estrato de muletón. Escasa adherencia. } \\
\text { B. Demasiado rígido. Buena adherencia. }\end{array}$} \\
\hline \multirow[t]{2}{*}{81} & $\begin{array}{l}\text { A. Resina } \\
\text { poliéster }\end{array}$ & \multirow[t]{2}{*}{ Muletón } & \multirow[t]{2}{*}{$\begin{array}{l}\text { Resina } \\
\text { poliéster }\end{array}$} & \multirow[t]{2}{*}{$\begin{array}{l}\text { Fibra vidrio tejida } \\
125 \mathrm{gr} / \mathrm{m}^{2}\end{array}$} \\
\hline & B. Beva gel & & & \\
\hline \multicolumn{2}{|c|}{ OBSERVACIONES } & \multicolumn{3}{|c|}{$\begin{array}{l}\text { A. Demasiado rígido. El adhesivo ha atravesado el } \\
\text { estrato de muletón. Escasa adherencia. } \\
\text { B. Demasiado flexible. Buena adherencia. }\end{array}$} \\
\hline \multirow[t]{2}{*}{82} & $\begin{array}{l}\text { A. Resina } \\
\text { poliéster }\end{array}$ & \multirow[t]{2}{*}{ Muletón } & \multirow[t]{2}{*}{$\begin{array}{l}\text { Resina } \\
\text { poliéster }\end{array}$} & \multirow[t]{2}{*}{$\begin{array}{l}\text { Fibra vidrio tejida } \\
160 \mathrm{gr} / \mathrm{m}^{2}\end{array}$} \\
\hline & B. Beva gel & & & \\
\hline \multicolumn{2}{|c|}{ OBSERVACIONES } & \multicolumn{3}{|c|}{$\begin{array}{l}\text { A. Demasiado rígido. El adhesivo ha atravesado el } \\
\text { estrato de muletón. Escasa adherencia. } \\
\text { B. Demasiado flexible. Buena adherencia. }\end{array}$} \\
\hline \multirow[t]{2}{*}{83} & $\begin{array}{l}\text { A. Resina } \\
\text { poliéster }\end{array}$ & \multirow[t]{2}{*}{ Muletón } & \multirow[t]{2}{*}{$\begin{array}{l}\text { Resina } \\
\text { poliéster }\end{array}$} & \multirow[t]{2}{*}{$\begin{array}{l}\text { Fibra vidrio tejida } \\
300 \mathrm{gr} / \mathrm{m}^{2}\end{array}$} \\
\hline & B. Beva gel & & & \\
\hline \multicolumn{2}{|c|}{ OBSERVACIONES } & \multicolumn{3}{|c|}{$\begin{array}{l}\text { A. Demasiado rígido. El adhesivo ha atravesado el } \\
\text { estrato de muletón. Escasa adherencia. } \\
\text { B. Demasiado flexible. Buena adherencia. }\end{array}$} \\
\hline \multirow[t]{2}{*}{84} & $\begin{array}{l}\text { A. Resina } \\
\text { poliéster }\end{array}$ & \multirow[t]{2}{*}{ Muletón } & \multirow[t]{2}{*}{$\begin{array}{l}\text { Resina } \\
\text { poliéster }\end{array}$} & \multirow[t]{2}{*}{$\begin{array}{l}\text { Matt de velo fibra } \\
\text { de vidrio }\end{array}$} \\
\hline & B. Beva gel & & & \\
\hline \multicolumn{2}{|c|}{ OBSERVACIONES } & \multicolumn{3}{|c|}{$\begin{array}{l}\text { A. Demasiado rígido. El adhesivo ha atravesado el } \\
\text { estrato de muletón. Escasa adherencia. } \\
\text { B. Demasiado flexible. Buena adherencia. }\end{array}$} \\
\hline \multirow[t]{2}{*}{85} & $\begin{array}{l}\text { A. Resina } \\
\text { epoxi }\end{array}$ & \multirow[t]{2}{*}{ Poliuretano } & \multirow[t]{2}{*}{$\begin{array}{l}\text { Resina } \\
\text { epoxi }\end{array}$} & \multirow[t]{2}{*}{$\begin{array}{l}\text { Fibra vidrio + fibra } \\
\text { carbono }\end{array}$} \\
\hline & B. Beva gel & & & \\
\hline \multicolumn{2}{|c|}{ OBSERVACIONES } & $\begin{array}{l}\text { A. Demasia } \\
\text { B. Demasia }\end{array}$ & $\begin{array}{l}\text { ble. Adher } \\
\text { ble. Poca a }\end{array}$ & $\begin{array}{l}\text { ia muy escasa. } \\
\text { erencia. }\end{array}$ \\
\hline 86 & $\begin{array}{l}\text { A. Resina } \\
\text { epoxi }\end{array}$ & Poliuretano & $\begin{array}{l}\text { Resina } \\
\text { epoxi }\end{array}$ & Matt $300 \mathrm{gr} / \mathrm{m}^{2}$ \\
\hline & B. Beva gel & & & \\
\hline & RVACIONES & $\begin{array}{l}\text { A. Demasia } \\
\text { B. Flexibilid }\end{array}$ & $\begin{array}{l}\text { o. Adhere } \\
\text { zuada. Poc }\end{array}$ & $\begin{array}{l}\text { a muy escasa. } \\
\text { dherencia. }\end{array}$ \\
\hline 87 & $\begin{array}{l}\text { A. Resina } \\
\text { epoxi }\end{array}$ & Poliuretano & $\begin{array}{l}\text { Resina } \\
\text { epoxi }\end{array}$ & Matt $450 \mathrm{gr} / \mathrm{m}^{2}$ \\
\hline & B. Beva gel & & & \\
\hline
\end{tabular}




\begin{tabular}{|c|c|c|c|c|}
\hline \multicolumn{2}{|c|}{ OBSERVACIONES } & \multicolumn{3}{|c|}{$\begin{array}{l}\text { A. Demasiado rígido. Adherencia muy escasa. } \\
\text { B. Demasiado rígido. Poca adherencia. }\end{array}$} \\
\hline \multirow[t]{2}{*}{88} & $\begin{array}{l}\text { A. Resina } \\
\text { epoxi }\end{array}$ & \multirow[t]{2}{*}{ Poliuretano } & \multirow[t]{2}{*}{$\begin{array}{l}\text { Resina } \\
\text { epoxi }\end{array}$} & \multirow[t]{2}{*}{$\begin{array}{l}\text { Fibra vidrio tejida } \\
125 \mathrm{gr} / \mathrm{m}^{2}\end{array}$} \\
\hline & B. Beva gel & & & \\
\hline \multicolumn{2}{|c|}{ OBSERVACIONES } & \multicolumn{3}{|c|}{$\begin{array}{l}\text { A. Demasiado flexible. Buena adherencia. } \\
\text { B. Demasiado flexible. Poca adherencia. }\end{array}$} \\
\hline \multirow[t]{2}{*}{89} & $\begin{array}{l}\text { A. Resina } \\
\text { epoxi }\end{array}$ & \multirow[t]{2}{*}{ Poliuretano } & \multirow[t]{2}{*}{$\begin{array}{l}\text { Resina } \\
\text { epoxi }\end{array}$} & \multirow[t]{2}{*}{$\begin{array}{l}\text { Fibra vidrio tejida } \\
160 \mathrm{gr} / \mathrm{m}^{2}\end{array}$} \\
\hline & B. Beva gel & & & \\
\hline \multicolumn{2}{|c|}{ OBSERVACIONES } & \multicolumn{3}{|c|}{$\begin{array}{l}\text { A. Demasiado flexible. Buena adherencia. } \\
\text { B. Demasiado flexible. Poca adherencia. }\end{array}$} \\
\hline \multirow[t]{2}{*}{90} & $\begin{array}{l}\text { A. Resina } \\
\text { epoxi }\end{array}$ & \multirow[t]{2}{*}{ Poliuretano } & \multirow[t]{2}{*}{$\begin{array}{l}\text { Resina } \\
\text { epoxi }\end{array}$} & \multirow[t]{2}{*}{$\begin{array}{l}\text { Fibra vidrio tejida } \\
300 \mathrm{gr} / \mathrm{m}^{2}\end{array}$} \\
\hline & B. Beva gel & & & \\
\hline \multicolumn{2}{|c|}{ OBSERVACIONES } & \multicolumn{3}{|c|}{$\begin{array}{l}\text { A. Demasiado flexible. Adherencia muy escasa. } \\
\text { B. Demasiado flexible. Poca adherencia. }\end{array}$} \\
\hline \multirow[t]{2}{*}{91} & $\begin{array}{l}\text { A. Resina } \\
\text { epoxi }\end{array}$ & \multirow[t]{2}{*}{ Poliuretano } & \multirow[t]{2}{*}{$\begin{array}{l}\text { Resina } \\
\text { epoxi }\end{array}$} & \multirow[t]{2}{*}{$\begin{array}{l}\text { Matt de velo fibra } \\
\text { de vidrio }\end{array}$} \\
\hline & B. Beva gel & & & \\
\hline \multicolumn{2}{|c|}{ OBSERVACIONES } & \multicolumn{3}{|c|}{$\begin{array}{l}\text { A. Demasiado flexible. Buena adherencia. } \\
\text { B. Demasiado flexible. Poca adherencia. }\end{array}$} \\
\hline \multirow[t]{2}{*}{92} & $\begin{array}{l}\text { A. Resina } \\
\text { poliéster }\end{array}$ & \multirow[t]{2}{*}{ Poliuretano } & \multirow[t]{2}{*}{$\begin{array}{l}\text { Resina } \\
\text { poliéster }\end{array}$} & \multirow[t]{2}{*}{$\begin{array}{l}\text { Fibra vidrio + fibra } \\
\text { carbono }\end{array}$} \\
\hline & B. Beva gel & & & \\
\hline \multicolumn{2}{|c|}{ OBSERVACIONES } & \multicolumn{3}{|c|}{$\begin{array}{l}\text { A. Demasiado flexible. Adherencia muy escasa. } \\
\text { B. Demasiado flexible. Poca adherencia. }\end{array}$} \\
\hline \multirow[t]{2}{*}{93} & $\begin{array}{l}\text { A. Resina } \\
\text { poliéster }\end{array}$ & \multirow[t]{2}{*}{ Poliuretano } & \multirow[t]{2}{*}{$\begin{array}{l}\text { Resina } \\
\text { poliéster }\end{array}$} & Matt $300 \mathrm{gr} / \mathrm{m}^{2}$ \\
\hline & B. Beva gel & & & \\
\hline & RVACIONES & $\begin{array}{l}\text { A. Flexibilid } \\
\text { B. flexibilida }\end{array}$ & $\begin{array}{l}\text { uada. Adh } \\
\text { uada. Poce }\end{array}$ & $\begin{array}{l}\text { encia muy escasa. } \\
\text { dherencia. }\end{array}$ \\
\hline 94 & $\begin{array}{l}\text { A. Resina } \\
\text { poliéster }\end{array}$ & Poliuretano & $\begin{array}{l}\text { Resina } \\
\text { poliéster }\end{array}$ & Matt $450 \mathrm{gr} / \mathrm{m}^{2}$ \\
\hline & B. Beva gel & & & \\
\hline & RVACIONES & $\begin{array}{l}\text { A. Demasia } \\
\text { B. Demasia }\end{array}$ & $\begin{array}{l}\text { o. Adhere } \\
\text { o. Poca ac }\end{array}$ & $\begin{array}{l}\text { a muy escasa. } \\
\text { rencia. }\end{array}$ \\
\hline 94 & $\begin{array}{l}\text { A. Resina } \\
\text { poliéster }\end{array}$ & Poliuretano & $\begin{array}{l}\text { Resina } \\
\text { poliéster }\end{array}$ & $\begin{array}{l}\text { Fibra vidrio tejida } \\
125 \mathrm{gr} / \mathrm{m}^{2}\end{array}$ \\
\hline & B. Beva gel & & & \\
\hline
\end{tabular}




\begin{tabular}{|c|c|c|c|c|}
\hline \multicolumn{2}{|c|}{ OBSERVACIONES } & \multicolumn{3}{|c|}{$\begin{array}{l}\text { A. Demasiado flexible. Buena adherencia. } \\
\text { B. Demasiado flexible. Poca adherencia. }\end{array}$} \\
\hline \multirow[t]{2}{*}{96} & $\begin{array}{l}\text { A. Resina } \\
\text { poliéster }\end{array}$ & \multirow[t]{2}{*}{ Poliuretano } & \multirow[t]{2}{*}{$\begin{array}{l}\text { Resina } \\
\text { poliéster }\end{array}$} & \multirow[t]{2}{*}{$\begin{array}{l}\text { Fibra vidrio tejida } \\
160 \mathrm{gr} / \mathrm{m}^{2}\end{array}$} \\
\hline & B. Beva gel & & & \\
\hline \multicolumn{2}{|c|}{ OBSERVACIONES } & \multicolumn{3}{|c|}{$\begin{array}{l}\text { A. Demasiado flexible. Buena adherencia. } \\
\text { B. Demasiado flexible. Poca adherencia. }\end{array}$} \\
\hline \multirow[t]{2}{*}{97} & $\begin{array}{l}\text { A. Resina } \\
\text { poliéster }\end{array}$ & \multirow[t]{2}{*}{ Poliuretano } & \multirow[t]{2}{*}{$\begin{array}{l}\text { Resina } \\
\text { poliéster }\end{array}$} & \multirow[t]{2}{*}{$\begin{array}{l}\text { Fibra vidrio tejida } \\
300 \mathrm{gr} / \mathrm{m}^{2}\end{array}$} \\
\hline & B. Beva gel & & & \\
\hline \multicolumn{2}{|c|}{ OBSERVACIONES } & \multicolumn{3}{|c|}{$\begin{array}{l}\text { A. Demasiado flexible. Adherencia muy escasa. } \\
\text { B. Demasiado flexible. Poca adherencia. }\end{array}$} \\
\hline \multirow[t]{2}{*}{98} & $\begin{array}{l}\text { A. Resina } \\
\text { poliéster }\end{array}$ & \multirow[t]{2}{*}{ Poliuretano } & \multirow[t]{2}{*}{$\begin{array}{l}\text { Resina } \\
\text { poliéster }\end{array}$} & \multirow[t]{2}{*}{$\begin{array}{l}\text { Matt de velo fibra } \\
\text { de vidrio }\end{array}$} \\
\hline & B. Beva gel & & & \\
\hline \multicolumn{2}{|c|}{ OBSERVACIONES } & \multicolumn{3}{|c|}{$\begin{array}{l}\text { A. Demasiado flexible. Adherencia muy escasa. } \\
\text { B. Demasiado flexible. Poca adherencia. }\end{array}$} \\
\hline \multirow[t]{2}{*}{99} & $\begin{array}{l}\text { A. Resina } \\
\text { epoxi }\end{array}$ & \multirow[t]{2}{*}{ Spherecore } & \multirow[t]{2}{*}{$\begin{array}{l}\text { Resina } \\
\text { epoxi }\end{array}$} & \multirow[t]{2}{*}{$\begin{array}{l}\text { Fibra vidrio + fibra } \\
\text { carbono }\end{array}$} \\
\hline & B. Beva gel & & & \\
\hline \multicolumn{2}{|c|}{ OBSERVACIONES } & \multicolumn{3}{|c|}{$\begin{array}{l}\text { A. Demasiado flexible. Adherencia muy escasa. } \\
\text { B. Demasiado flexible. Buena adherencia } \\
\text { únicamente de la superficie que está en contacto } \\
\text { con el adhesivo. }\end{array}$} \\
\hline \multirow[t]{2}{*}{100} & $\begin{array}{l}\text { A. Resina } \\
\text { epoxi }\end{array}$ & \multirow[t]{2}{*}{$\begin{array}{l}\text { Spherecore } \\
\text { minada }\end{array}$} & \multirow[t]{2}{*}{$\begin{array}{l}\text { Resina } \\
\text { epoxi }\end{array}$} & \multirow[t]{2}{*}{ Matt $300 \mathrm{gr} / \mathrm{m}^{2}$} \\
\hline & B. Beva gel & & & \\
\hline \multicolumn{2}{|c|}{ OBSERVACIONES } & \multicolumn{3}{|c|}{$\begin{array}{l}\text { A. Demasiado rígido. Adherencia muy escasa. } \\
\text { B. Demasiado rígido. Buena adherencia únicamente } \\
\text { de la superficie que está en contacto con el } \\
\text { adhesivo. }\end{array}$} \\
\hline \multirow[t]{2}{*}{101} & $\begin{array}{l}\text { A. Resina } \\
\text { epoxi }\end{array}$ & \multirow[t]{2}{*}{$\begin{array}{l}\text { Papel fractura } \\
\text { predeterminada }\end{array}$} & \multirow[t]{2}{*}{$\begin{array}{l}\text { Resina } \\
\text { epoxi }\end{array}$} & \multirow[t]{2}{*}{ Matt $450 \mathrm{gr} / \mathrm{m}^{2}$} \\
\hline & B. Beva gel & & & \\
\hline $\mathrm{OB}$ & RVACIONES & $\begin{array}{l}\text { A. Flexibilidad a } \\
\text { adhesivo, queda } \\
\text { su función como } \\
\text { B. Flexibilidad a }\end{array}$ & $\begin{array}{l}\text { uada. El p } \\
\text { o demadia } \\
\text { trato de in } \\
\text { uada. Bue }\end{array}$ & $\begin{array}{l}\text { absorbe mucho } \\
\text { ígido y perdiendo } \\
\text { ención. } \\
\text { adherencia. }\end{array}$ \\
\hline 102 & $\begin{array}{l}\text { A. Resina } \\
\text { epoxi }\end{array}$ & Spherecore & $\begin{array}{l}\text { Resina } \\
\text { epoxi }\end{array}$ & $\begin{array}{l}\text { Fibra vidrio tejida } \\
125 \mathrm{gr} / \mathrm{m}^{2}\end{array}$ \\
\hline & B. Beva gel & & & \\
\hline
\end{tabular}




\begin{tabular}{|c|c|c|c|c|}
\hline \multicolumn{2}{|c|}{ OBSERVACIONES } & \multicolumn{3}{|c|}{$\begin{array}{l}\text { A. Demasiado flexible. Adherencia muy escasa. } \\
\text { B. Demasiado flexible. Buena adherencia } \\
\text { únicamente de la superficie que está en contacto } \\
\text { con el adhesivo. }\end{array}$} \\
\hline \multirow[t]{2}{*}{103} & $\begin{array}{l}\text { A. Resina } \\
\text { epoxi }\end{array}$ & \multirow[t]{2}{*}{$\begin{array}{l}\text { Papel fractura } \\
\text { predeterminada }\end{array}$} & \multirow[t]{2}{*}{$\begin{array}{l}\text { Resina } \\
\text { epoxi }\end{array}$} & \multirow[t]{2}{*}{$\begin{array}{l}\text { Fibra vidrio tejida } \\
160 \mathrm{gr} / \mathrm{m}^{2}\end{array}$} \\
\hline & B. Beva gel & & & \\
\hline \multicolumn{2}{|c|}{ OBSERVACIONES } & \multicolumn{3}{|c|}{$\begin{array}{l}\text { A. Demasiada flexibilidad. El papel absorbe mucho } \\
\text { adhesivo, quedando demadiado impregnado de } \\
\text { adhesivo y perdiendo su función como estrato de } \\
\text { intervención. Adherencia irregular. } \\
\text { B. Demasiada flexibilidad. Buena adherencia. }\end{array}$} \\
\hline \multirow[t]{2}{*}{104} & $\begin{array}{l}\text { A. Resina } \\
\text { epoxi }\end{array}$ & \multirow[t]{2}{*}{ Spherecore } & \multirow[t]{2}{*}{$\begin{array}{l}\text { Resina } \\
\text { epoxi }\end{array}$} & \multirow[t]{2}{*}{$\begin{array}{l}\text { Fibra vidrio tejida } \\
300 \mathrm{gr} / \mathrm{m}^{2}\end{array}$} \\
\hline & B. Beva gel & & & \\
\hline \multicolumn{2}{|c|}{ OBSERVACIONES } & \multicolumn{3}{|c|}{$\begin{array}{l}\text { A. Demasiado rígido. Adherencia muy escasa. } \\
\text { B. Demasiado flexible. Buena adherencia } \\
\text { únicamente de la superficie que está en contacto } \\
\text { con el adhesivo. }\end{array}$} \\
\hline \multirow[t]{2}{*}{105} & $\begin{array}{l}\text { A. Resina } \\
\text { epoxi }\end{array}$ & \multirow[t]{2}{*}{$\begin{array}{l}\text { Papel fractura } \\
\text { predeterminada }\end{array}$} & \multirow[t]{2}{*}{$\begin{array}{l}\text { Resina } \\
\text { epoxi }\end{array}$} & \multirow[t]{2}{*}{$\begin{array}{l}\text { Matt de velo fibra } \\
\text { de vidrio }\end{array}$} \\
\hline & B. Beva gel & & & \\
\hline \multicolumn{2}{|c|}{ OBSERVACIONES } & \multicolumn{3}{|c|}{$\begin{array}{l}\text { A. Demasiada flexibilidad. El papel absorbe mucho } \\
\text { adhesivo, quedando demadiado impregnado de } \\
\text { adhesivo y perdiendo su función como estrato de } \\
\text { intervención. Adherencia irregular. } \\
\text { B. Demasiada flexibilidad. Buena adherencia. }\end{array}$} \\
\hline \multirow[t]{2}{*}{106} & $\begin{array}{l}\text { A. Resina } \\
\text { poliéster }\end{array}$ & \multirow[t]{2}{*}{ Spherecore } & \multirow[t]{2}{*}{$\begin{array}{l}\text { Resina } \\
\text { poliéster }\end{array}$} & \multirow[t]{2}{*}{$\begin{array}{l}\text { Fibra vidrio + fibra } \\
\text { carbono }\end{array}$} \\
\hline & B. Beva gel & & & \\
\hline \multicolumn{2}{|c|}{ OBSERVACIONES } & \multicolumn{3}{|c|}{$\begin{array}{l}\text { A. Demasiado flexible. Adherencia muy escasa. } \\
\text { B. Demasiado flexible. Buena adherencia } \\
\text { únicamente de la superficie que está en contacto } \\
\text { con el adhesivo. }\end{array}$} \\
\hline \multirow[t]{2}{*}{107} & $\begin{array}{l}\text { A. Resina } \\
\text { poliéster }\end{array}$ & \multirow[t]{2}{*}{ Spherecore } & \multirow[t]{2}{*}{$\begin{array}{l}\text { Resina } \\
\text { poliéster }\end{array}$} & \multirow[t]{2}{*}{ Matt $300 \mathrm{gr} / \mathrm{m}^{2}$} \\
\hline & B. Beva gel & & & \\
\hline \multicolumn{2}{|c|}{ OBSERVACIONES } & \multicolumn{3}{|c|}{$\begin{array}{l}\text { A. Flexibilidad adecuada. Adherencia muy escasa. } \\
\text { B. Flexibilidad adecuada. Buena adherencia } \\
\text { únicamente de la superficie que está en contacto } \\
\text { con el adhesivo. }\end{array}$} \\
\hline \multirow[t]{2}{*}{108} & $\begin{array}{l}\text { A. Resina } \\
\text { poliéster }\end{array}$ & \multirow[t]{2}{*}{$\begin{array}{l}\text { Papel fractura } \\
\text { predeterminada }\end{array}$} & \multirow[t]{2}{*}{$\begin{array}{l}\text { Resina } \\
\text { poliéster }\end{array}$} & \multirow[t]{2}{*}{ Matt $450 \mathrm{gr} / \mathrm{m}^{2}$} \\
\hline & B. Beva gel & & & \\
\hline
\end{tabular}




\begin{tabular}{|c|c|c|c|c|}
\hline \multicolumn{2}{|c|}{ OBSERVACIONES } & \multicolumn{3}{|c|}{$\begin{array}{l}\text { A. Flexibilidad adecuada. El papel absorbe mucho } \\
\text { adhesivo, quedando demadiado impregnado de } \\
\text { adhesivo y perdiendo su función como estrato de } \\
\text { intervención. Adherencia irregular. } \\
\text { B. Flexibilidad adecuada. Buena adherencia. }\end{array}$} \\
\hline \multirow[t]{2}{*}{109} & $\begin{array}{l}\text { A. Resina } \\
\text { poliéster }\end{array}$ & \multirow[t]{2}{*}{ Spherecore } & \multirow[t]{2}{*}{$\begin{array}{l}\text { Resina } \\
\text { poliéster }\end{array}$} & \multirow[t]{2}{*}{$\begin{array}{l}\text { Fibra vidrio tejida } \\
125 \mathrm{gr} / \mathrm{m}^{2}\end{array}$} \\
\hline & B. Beva gel & & & \\
\hline \multicolumn{2}{|c|}{ OBSERVACIONES } & \multicolumn{3}{|c|}{$\begin{array}{l}\text { A. Demasiado flexible. Adherencia muy escasa. } \\
\text { B. Demasiado flexible. Buena adherencia } \\
\text { únicamente de la superficie que está en contacto } \\
\text { con el adhesivo. }\end{array}$} \\
\hline \multirow[t]{2}{*}{110} & $\begin{array}{l}\text { A. Resina } \\
\text { poliéster }\end{array}$ & \multirow[t]{2}{*}{$\begin{array}{l}\text { Papel fractura } \\
\text { predeterminada }\end{array}$} & \multirow[t]{2}{*}{$\begin{array}{l}\text { Resina } \\
\text { poliéster }\end{array}$} & \multirow[t]{2}{*}{$\begin{array}{l}\text { Fibra vidrio tejida } \\
160 \mathrm{gr} / \mathrm{m}^{2}\end{array}$} \\
\hline & B. Beva gel & & & \\
\hline \multicolumn{2}{|c|}{ OBSERVACIONES } & \multicolumn{3}{|c|}{$\begin{array}{l}\text { A. Demasiada flexibilidad. El papel absorbe mucho } \\
\text { adhesivo, quedando demadiado impregnado de } \\
\text { adhesivo y perdiendo su función como estrato de } \\
\text { intervención. Adherencia irregular. } \\
\text { B. Demasiada flexibilidad. Buena adherencia. }\end{array}$} \\
\hline \multirow[t]{2}{*}{111} & $\begin{array}{l}\text { A. Resina } \\
\text { poliéster }\end{array}$ & \multirow[t]{2}{*}{ Spherecore } & \multirow[t]{2}{*}{$\begin{array}{l}\text { Resina } \\
\text { poliéster }\end{array}$} & \multirow[t]{2}{*}{$\begin{array}{l}\text { Fibra vidrio tejida } \\
300 \mathrm{gr} / \mathrm{m}^{2}\end{array}$} \\
\hline & B. Beva gel & & & \\
\hline \multicolumn{2}{|c|}{ OBSERVACIONES } & \multicolumn{3}{|c|}{$\begin{array}{l}\text { A. Demasiado flexible. Adherencia muy escasa. } \\
\text { B. Demasiado flexible. Buena adhgerencia } \\
\text { únicamente de la superficie que está en contacto } \\
\text { con el adhesivo. }\end{array}$} \\
\hline \multirow[t]{2}{*}{112} & $\begin{array}{l}\text { A. Resina } \\
\text { poliéster }\end{array}$ & \multirow[t]{2}{*}{$\begin{array}{l}\text { Papel fractura } \\
\text { predeterminada }\end{array}$} & \multirow[t]{2}{*}{$\begin{array}{l}\text { Resina } \\
\text { poliéster }\end{array}$} & \multirow[t]{2}{*}{$\begin{array}{l}\text { Matt de velo fibra } \\
\text { de vidrio }\end{array}$} \\
\hline & B. Beva gel & & & \\
\hline \multicolumn{2}{|c|}{ OBSERVACIONES } & \multicolumn{3}{|c|}{$\begin{array}{l}\text { A. Demasiada flexibilidad. El papel absorbe mucho } \\
\text { adhesivo, quedando demadiado impregnado de } \\
\text { adhesivo y perdiendo su función como estrato de } \\
\text { intervención. Adherencia irregular. } \\
\text { B. Demasiada flexibilidad. Buena adherencia. }\end{array}$} \\
\hline \multirow[t]{2}{*}{113} & $\begin{array}{l}\text { A. Resina } \\
\text { epoxi }\end{array}$ & \multirow[t]{2}{*}{ Fieltro } & \multirow[t]{2}{*}{$\begin{array}{l}\text { Resina } \\
\text { epoxi }\end{array}$} & \multirow[t]{2}{*}{$\begin{array}{l}\text { Fibra vidrio + fibra } \\
\text { carbono }\end{array}$} \\
\hline & $\begin{array}{l}\text { B. Plextol B- } \\
500\end{array}$ & & & \\
\hline \multicolumn{2}{|c|}{ OBSERVACIONES } & \multicolumn{3}{|c|}{$\begin{array}{l}\text { Las puntas se comban ligeramente hacia arriba. } \\
\text { A. Demasiado rígido. El adhesivo ha atravesado el } \\
\text { estrato de fieltro. Buena adherencia. } \\
\text { B. Demasiado flexible. Buena adherencia. }\end{array}$} \\
\hline
\end{tabular}




\begin{tabular}{|c|c|c|c|c|}
\hline \multirow[t]{2}{*}{114} & $\begin{array}{l}\text { A. Resina } \\
\text { epoxi }\end{array}$ & \multirow[t]{2}{*}{ Fieltro } & \multirow[t]{2}{*}{$\begin{array}{l}\text { Resina } \\
\text { epoxi }\end{array}$} & \multirow[t]{2}{*}{ Matt $300 \mathrm{gr} / \mathrm{m}^{2}$} \\
\hline & $\begin{array}{l}\text { B. Plextol B- } \\
500\end{array}$ & & & \\
\hline \multicolumn{2}{|c|}{ OBSERVACIONES } & \multicolumn{3}{|c|}{$\begin{array}{l}\text { A. Demasiado rígido. El adhesivo ha atravesado el } \\
\text { estrato de fieltro. Buena adherencia. } \\
\text { B. Demasiado rígido. Buena adherencia. }\end{array}$} \\
\hline \multirow[t]{2}{*}{115} & $\begin{array}{l}\text { A. Resina } \\
\text { epoxi }\end{array}$ & \multirow[t]{2}{*}{ Fieltro } & \multirow[t]{2}{*}{$\begin{array}{l}\text { Resina } \\
\text { epoxi }\end{array}$} & \multirow[t]{2}{*}{ Matt $450 \mathrm{gr} / \mathrm{m}^{2}$} \\
\hline & $\begin{array}{l}\text { B. Plextol B- } \\
500\end{array}$ & & & \\
\hline \multicolumn{2}{|c|}{ OBSERVACIONES } & \multicolumn{3}{|c|}{$\begin{array}{l}\text { A. Demasiado rígido. El adhesivo ha atravesado el } \\
\text { estrato de fieltro. Buena adherencia. } \\
\text { B. Demasiado rígido. Buena adherencia. }\end{array}$} \\
\hline \multirow[t]{2}{*}{116} & $\begin{array}{l}\text { A. Resina } \\
\text { epoxi }\end{array}$ & \multirow[t]{2}{*}{ Fieltro } & \multirow[t]{2}{*}{$\begin{array}{l}\text { Resina } \\
\text { epoxi }\end{array}$} & \multirow[t]{2}{*}{$\begin{array}{l}\text { Fibra vidrio tejida } \\
125 \mathrm{gr} / \mathrm{m}^{2}\end{array}$} \\
\hline & $\begin{array}{l}\text { B. Plextol B- } \\
500\end{array}$ & & & \\
\hline \multicolumn{2}{|c|}{ OBSERVACIONES } & \multicolumn{3}{|c|}{$\begin{array}{l}\text { A. Flexibilidad adecuada. El adhesivo ha atravesado } \\
\text { el estrato de fieltro. Escasa adherencia. } \\
\text { B. Demasiado flexible. Buena adherencia. Las } \\
\text { puntas se comban ligeramente hacia arriba. }\end{array}$} \\
\hline \multirow[t]{2}{*}{117} & $\begin{array}{l}\text { A. Resina } \\
\text { epoxi }\end{array}$ & \multirow[t]{2}{*}{ Fieltro } & \multirow[t]{2}{*}{$\begin{array}{l}\text { Resina } \\
\text { epoxi }\end{array}$} & \multirow[t]{2}{*}{$\begin{array}{l}\text { Fibra vidrio tejida } \\
160 \mathrm{gr} / \mathrm{m}^{2}\end{array}$} \\
\hline & $\begin{array}{l}\text { B. Plextol B- } \\
500\end{array}$ & & & \\
\hline \multicolumn{2}{|c|}{ OBSERVACIONES } & \multicolumn{3}{|c|}{$\begin{array}{l}\text { A. Flexibilidad adecuada. El adhesivo ha atravesado } \\
\text { el estrato de fieltro. Escasa adherencia. } \\
\text { B. Demasiado flexible. Buena adherencia. }\end{array}$} \\
\hline \multirow[t]{2}{*}{118} & $\begin{array}{l}\text { A. Resina } \\
\text { epoxi }\end{array}$ & \multirow[t]{2}{*}{ Fieltro } & \multirow[t]{2}{*}{$\begin{array}{l}\text { Resina } \\
\text { epoxi }\end{array}$} & \multirow[t]{2}{*}{$\begin{array}{l}\text { Fibra vidrio tejida } \\
300 \mathrm{gr} / \mathrm{m}^{2}\end{array}$} \\
\hline & $\begin{array}{l}\text { B. Plextol B- } \\
500\end{array}$ & & & \\
\hline \multicolumn{2}{|c|}{ OBSERVACIONES } & \multicolumn{3}{|c|}{$\begin{array}{l}\text { A. Flexibilidad adecuada. El adhesivo ha atravesado } \\
\text { el estrato de fieltro. Escasa adherencia. } \\
\text { B. Demasiado flexible. Buena adherencia. }\end{array}$} \\
\hline \multirow[t]{2}{*}{119} & $\begin{array}{l}\text { A. Resina } \\
\text { epoxi }\end{array}$ & \multirow[t]{2}{*}{ Fieltro } & \multirow[t]{2}{*}{$\begin{array}{l}\text { Resina } \\
\text { epoxi }\end{array}$} & \multirow[t]{2}{*}{$\begin{array}{l}\text { Matt de velo fibra } \\
\text { de vidrio }\end{array}$} \\
\hline & $\begin{array}{l}\text { B. Plextol B- } \\
500\end{array}$ & & & \\
\hline \multicolumn{2}{|c|}{ OBSERVACIONES } & \multicolumn{3}{|c|}{$\begin{array}{l}\text { A. Flexibilidad adecuada. El adhesivo ha atravesado } \\
\text { el estrato de fieltro. Escasa adherencia. } \\
\text { B. Demasiado flexible. Buena adherencia. }\end{array}$} \\
\hline
\end{tabular}




\begin{tabular}{|c|c|c|c|c|}
\hline \multirow[t]{2}{*}{120} & $\begin{array}{l}\text { A. Resina } \\
\text { poliéster }\end{array}$ & \multirow[t]{2}{*}{ Fieltro } & \multirow[t]{2}{*}{$\begin{array}{l}\text { Resina } \\
\text { poliéster }\end{array}$} & \multirow[t]{2}{*}{$\begin{array}{l}\text { Fibra vidrio + fibra } \\
\text { carbono }\end{array}$} \\
\hline & $\begin{array}{l}\text { B. Plextol B- } \\
500\end{array}$ & & & \\
\hline \multicolumn{2}{|c|}{ OBSERVACIONES } & \multicolumn{3}{|c|}{$\begin{array}{l}\text { A. Demasiado rígido. El adhesivo ha atravesado el } \\
\text { estrato de fieltro. Escasa adherencia. } \\
\text { B. Demasiado flexible. Buena adherencia. }\end{array}$} \\
\hline \multirow[t]{2}{*}{121} & $\begin{array}{l}\text { A. Resina } \\
\text { poliéster }\end{array}$ & \multirow[t]{2}{*}{ Fieltro } & \multirow{2}{*}{$\begin{array}{l}\text { Resina } \\
\text { poliéster }\end{array}$} & \multirow[t]{2}{*}{ Matt $300 \mathrm{gr} / \mathrm{m}^{2}$} \\
\hline & $\begin{array}{l}\text { B. Plextol B- } \\
500\end{array}$ & & & \\
\hline \multicolumn{2}{|c|}{ OBSERVACIONES } & \multicolumn{3}{|c|}{$\begin{array}{l}\text { A. Flexibilidad adecuada. El adhesivo ha atravesado } \\
\text { el estrato de fieltro. Escasa adherencia. } \\
\text { B. Flexibilidad adecuada. Buena adherencia. }\end{array}$} \\
\hline \multirow[t]{2}{*}{122} & $\begin{array}{l}\text { A. Resina } \\
\text { poliéster }\end{array}$ & \multirow[t]{2}{*}{ Fieltro } & \multirow[t]{2}{*}{$\begin{array}{l}\text { Resina } \\
\text { poliéster }\end{array}$} & \multirow[t]{2}{*}{ Matt $450 \mathrm{gr} / \mathrm{m}^{2}$} \\
\hline & $\begin{array}{l}\text { B. Plextol B- } \\
500\end{array}$ & & & \\
\hline \multicolumn{2}{|c|}{ OBSERVACIONES } & \multicolumn{3}{|c|}{$\begin{array}{l}\text { A. Demasiado rígido. El adhesivo ha atravesado el } \\
\text { estrato de fieltro. Escasa adherencia. } \\
\text { B. Demasiado rígido. Buena adherencia. }\end{array}$} \\
\hline \multirow[t]{2}{*}{123} & $\begin{array}{l}\text { A. Resina } \\
\text { poliéster }\end{array}$ & \multirow[t]{2}{*}{ Fieltro } & \multirow[t]{2}{*}{$\begin{array}{l}\text { Resina } \\
\text { poliéster }\end{array}$} & \multirow[t]{2}{*}{$\begin{array}{l}\text { Fibra vidrio tejida } \\
125 \mathrm{gr} / \mathrm{m}^{2}\end{array}$} \\
\hline & $\begin{array}{l}\text { B. Plextol B- } \\
500\end{array}$ & & & \\
\hline \multicolumn{2}{|c|}{ OBSERVACIONES } & \multicolumn{3}{|c|}{$\begin{array}{l}\text { A. Demasiado flexible. El adhesivo ha atravesado el } \\
\text { estrato de fieltro. Escasa adherencia. } \\
\text { B. Demasiado flexible. Buena adherencia. Las } \\
\text { puntas se comban ligeramente hacia arriba. }\end{array}$} \\
\hline \multirow[t]{2}{*}{124} & $\begin{array}{l}\text { A. Resina } \\
\text { poliéster }\end{array}$ & \multirow[t]{2}{*}{ Fieltro } & \multirow[t]{2}{*}{$\begin{array}{l}\text { Resina } \\
\text { poliéster }\end{array}$} & \multirow[t]{2}{*}{$\begin{array}{l}\text { Fibra vidrio tejida } \\
160 \mathrm{gr} / \mathrm{m}^{2}\end{array}$} \\
\hline & $\begin{array}{l}\text { B. Plextol B- } \\
500\end{array}$ & & & \\
\hline \multicolumn{2}{|c|}{ OBSERVACIONES } & \multicolumn{3}{|c|}{$\begin{array}{l}\text { A. Demasiado rígido. El adhesivo ha atravesado el } \\
\text { estrato de fieltro. Escasa adherencia. } \\
\text { B. Demasiado flexible. Buena adherencia. }\end{array}$} \\
\hline \multirow[t]{2}{*}{125} & $\begin{array}{l}\text { A. Resina } \\
\text { poliéster }\end{array}$ & \multirow[t]{2}{*}{ Fieltro } & \multirow[t]{2}{*}{$\begin{array}{l}\text { Resina } \\
\text { poliéster }\end{array}$} & \multirow[t]{2}{*}{$\begin{array}{l}\text { Fibra vidrio tejida } \\
300 \mathrm{gr} / \mathrm{m}^{2}\end{array}$} \\
\hline & $\begin{array}{l}\text { B. Plextol B- } \\
500\end{array}$ & & & \\
\hline \multicolumn{2}{|c|}{ OBSERVACIONES } & \multicolumn{3}{|c|}{$\begin{array}{l}\text { A. Demasiado rígido. El adhesivo ha atravesado el } \\
\text { estrato de fieltro. Escasa adherencia. } \\
\text { B. Demasiado flexible. Buena adherencia. }\end{array}$} \\
\hline
\end{tabular}




\begin{tabular}{|c|c|c|c|c|}
\hline \multirow[t]{2}{*}{126} & $\begin{array}{l}\text { A. Resina } \\
\text { poliéster }\end{array}$ & \multirow[t]{2}{*}{ Fieltro } & \multirow[t]{2}{*}{$\begin{array}{l}\text { Resina } \\
\text { poliéster }\end{array}$} & \multirow[t]{2}{*}{$\begin{array}{l}\text { Matt de velo fibra } \\
\text { de vidrio }\end{array}$} \\
\hline & $\begin{array}{l}\text { B. Plextol B- } \\
500\end{array}$ & & & \\
\hline \multicolumn{2}{|c|}{ OBSERVACIONES } & \multicolumn{3}{|c|}{$\begin{array}{l}\text { A. Flexibilidad adecuada. El adhesivo ha atravesado } \\
\text { el estrato de fieltro. Escasa adherencia. } \\
\text { B. Demasiado flexible. Buena adherencia. }\end{array}$} \\
\hline \multirow[t]{2}{*}{127} & $\begin{array}{l}\text { A. Resina } \\
\text { epoxi }\end{array}$ & \multirow[t]{2}{*}{ Muletón } & \multirow[t]{2}{*}{$\begin{array}{l}\text { Resina } \\
\text { epoxi }\end{array}$} & \multirow[t]{2}{*}{$\begin{array}{l}\text { Fibra vidrio + fibra } \\
\text { carbono }\end{array}$} \\
\hline & $\begin{array}{l}\text { B. Plextol B- } \\
500\end{array}$ & & & \\
\hline \multicolumn{2}{|c|}{ OBSERVACIONES } & \multicolumn{3}{|c|}{$\begin{array}{l}\text { A. Demasiado rígido. El adhesivo ha atravesado el } \\
\text { estrato de muletón. Buena adherencia. } \\
\text { B. Demasiado flexible. Buena adherencia. }\end{array}$} \\
\hline \multirow[t]{2}{*}{128} & $\begin{array}{l}\text { A. Resina } \\
\text { epoxi }\end{array}$ & \multirow[t]{2}{*}{ Muletón } & \multirow{2}{*}{$\begin{array}{l}\text { Resina } \\
\text { epoxi }\end{array}$} & \multirow[t]{2}{*}{ Matt $300 \mathrm{gr} / \mathrm{m}^{2}$} \\
\hline & $\begin{array}{l}\text { B. Plextol B- } \\
500\end{array}$ & & & \\
\hline \multicolumn{2}{|c|}{ OBSERVACIONES } & \multicolumn{3}{|c|}{$\begin{array}{l}\text { A. Demasiado rígido. El adhesivo ha atravesado el } \\
\text { estrato de muletón. Buena adherencia. } \\
\text { B. Flexibilidad adecuada. Buena adherencia. }\end{array}$} \\
\hline \multirow[t]{2}{*}{129} & $\begin{array}{l}\text { A. Resina } \\
\text { epoxi }\end{array}$ & \multirow[t]{2}{*}{ Muletón } & \multirow{2}{*}{$\begin{array}{l}\text { Resina } \\
\text { epoxi }\end{array}$} & \multirow[t]{2}{*}{ Matt $450 \mathrm{gr} / \mathrm{m}^{2}$} \\
\hline & $\begin{array}{l}\text { B. Plextol B- } \\
500\end{array}$ & & & \\
\hline \multicolumn{2}{|c|}{ OBSERVACIONES } & \multicolumn{3}{|c|}{$\begin{array}{l}\text { A. Demasiado rígido. El adhesivo ha atravesado el } \\
\text { estrato de muletón. Buena adherencia. } \\
\text { B. Demasiado rígido. Buena adherencia. }\end{array}$} \\
\hline \multirow[t]{2}{*}{130} & $\begin{array}{l}\text { A. Resina } \\
\text { epoxi }\end{array}$ & \multirow[t]{2}{*}{ Muletón } & \multirow[t]{2}{*}{$\begin{array}{l}\text { Resina } \\
\text { epoxi }\end{array}$} & \multirow[t]{2}{*}{$\begin{array}{l}\text { Fibra vidrio tejida } \\
125 \mathrm{gr} / \mathrm{m}^{2}\end{array}$} \\
\hline & $\begin{array}{l}\text { B. Plextol B- } \\
500\end{array}$ & & & \\
\hline \multicolumn{2}{|c|}{ OBSERVACIONES } & \multicolumn{3}{|c|}{$\begin{array}{l}\text { A. Demasiado rígido. El adhesivo ha atravesado el } \\
\text { estrato de muletón. Buena adherencia. } \\
\text { B. Demasiado flexible. Buena adherencia. }\end{array}$} \\
\hline \multirow[t]{2}{*}{131} & $\begin{array}{l}\text { A. Resina } \\
\text { epoxi }\end{array}$ & \multirow[t]{2}{*}{ Muletón } & \multirow[t]{2}{*}{$\begin{array}{l}\text { Resina } \\
\text { epoxi }\end{array}$} & \multirow[t]{2}{*}{$\begin{array}{l}\text { Fibra vidrio tejida } \\
160 \mathrm{gr} / \mathrm{m}^{2}\end{array}$} \\
\hline & $\begin{array}{l}\text { B. Plextol B- } \\
500\end{array}$ & & & \\
\hline \multicolumn{2}{|c|}{ OBSERVACIONES } & \multicolumn{3}{|c|}{$\begin{array}{l}\text { A. Demasiado rígido. El adhesivo ha atravesado el } \\
\text { estrato de muletón. Buena adherencia. } \\
\text { B. Demasiado flexible. Buena adherencia. }\end{array}$} \\
\hline \multirow[t]{2}{*}{132} & $\begin{array}{l}\text { A. Resina } \\
\text { epoxi }\end{array}$ & Muletón & $\begin{array}{l}\text { Resina } \\
\text { epoxi }\end{array}$ & $\begin{array}{l}\text { Fibra vidrio tejida } \\
300 \mathrm{gr} / \mathrm{m}^{2}\end{array}$ \\
\hline & $\begin{array}{l}\text { B. Plextol B- } \\
500\end{array}$ & & & \\
\hline
\end{tabular}




\begin{tabular}{|c|c|c|c|c|}
\hline \multicolumn{2}{|c|}{ OBSERVACIONES } & \multicolumn{3}{|c|}{$\begin{array}{l}\text { A. Flexibilidad adecuada. El adhesivo ha atravesado } \\
\text { el estrato de muletón. Buena adherencia. } \\
\text { B. Demasiado flexible. Buena adherencia. }\end{array}$} \\
\hline \multirow[t]{2}{*}{133} & $\begin{array}{l}\text { A. Resina } \\
\text { epoxi }\end{array}$ & \multirow[t]{2}{*}{ Muletón } & \multirow{2}{*}{$\begin{array}{l}\text { Resina } \\
\text { epoxi }\end{array}$} & \multirow[t]{2}{*}{$\begin{array}{l}\text { Matt de velo fibra } \\
\text { de vidrio }\end{array}$} \\
\hline & $\begin{array}{l}\text { B. Plextol B- } \\
500\end{array}$ & & & \\
\hline \multicolumn{2}{|c|}{ OBSERVACIONES } & \multicolumn{3}{|c|}{$\begin{array}{l}\text { A. Demasiado rígido. El adhesivo ha atravesado el } \\
\text { estrato de muletón. Buena adherencia. } \\
\text { B. Demasiado flexible. Buena adherencia. }\end{array}$} \\
\hline \multirow[t]{2}{*}{134} & $\begin{array}{l}\text { A. Resina } \\
\text { poliéster }\end{array}$ & \multirow[t]{2}{*}{ Muletón } & \multirow[t]{2}{*}{$\begin{array}{l}\text { Resina } \\
\text { poliéster }\end{array}$} & \multirow[t]{2}{*}{$\begin{array}{l}\text { Fibra vidrio + fibra } \\
\text { carbono }\end{array}$} \\
\hline & $\begin{array}{l}\text { B. Plextol B- } \\
500\end{array}$ & & & \\
\hline \multicolumn{2}{|c|}{ OBSERVACIONES } & \multicolumn{3}{|c|}{$\begin{array}{l}\text { A. Demasiado rígido. El adhesivo ha atravesado el } \\
\text { estrato de muletón. Escasa adherencia. } \\
\text { B. Demasiado flexible. Buena adherencia. }\end{array}$} \\
\hline \multirow[t]{2}{*}{135} & $\begin{array}{l}\text { A. Resina } \\
\text { poliéster }\end{array}$ & \multirow[t]{2}{*}{ Muletón } & \multirow[t]{2}{*}{$\begin{array}{l}\text { Resina } \\
\text { poliéster }\end{array}$} & \multirow[t]{2}{*}{ Matt $300 \mathrm{gr} / \mathrm{m}^{2}$} \\
\hline & $\begin{array}{l}\text { B. Plextol B- } \\
500\end{array}$ & & & \\
\hline \multicolumn{2}{|c|}{ OBSERVACIONES } & \multicolumn{3}{|c|}{$\begin{array}{l}\text { A. Demasiado rígido. El adhesivo ha atravesado el } \\
\text { estrato de muletón. Buena adherencia. } \\
\text { B. Flexibilidad adecuada. Buena adherencia. }\end{array}$} \\
\hline \multirow[t]{2}{*}{136} & $\begin{array}{l}\text { A. Resina } \\
\text { poliéster }\end{array}$ & \multirow[t]{2}{*}{ Muletón } & \multirow[t]{2}{*}{$\begin{array}{l}\text { Resina } \\
\text { poliéster }\end{array}$} & \multirow[t]{2}{*}{ Matt $450 \mathrm{gr} / \mathrm{m}^{2}$} \\
\hline & $\begin{array}{l}\text { B. Plextol B- } \\
500\end{array}$ & & & \\
\hline \multicolumn{2}{|c|}{ OBSERVACIONES } & \multicolumn{3}{|c|}{$\begin{array}{l}\text { A. Demasiado rígido. El adhesivo ha atravesado el } \\
\text { estrato de muletón. Buena adherencia. } \\
\text { B. Flexibilidad adecuada. Buena adherencia. }\end{array}$} \\
\hline \multirow[t]{2}{*}{137} & $\begin{array}{l}\text { A. Resina } \\
\text { poliéster }\end{array}$ & \multirow[t]{2}{*}{ Muletón } & \multirow[t]{2}{*}{$\begin{array}{l}\text { Resina } \\
\text { poliéster }\end{array}$} & \multirow[t]{2}{*}{$\begin{array}{l}\text { Fibra vidrio tejida } \\
125 \mathrm{gr} / \mathrm{m}^{2}\end{array}$} \\
\hline & $\begin{array}{l}\text { B. Plextol B- } \\
500\end{array}$ & & & \\
\hline \multicolumn{2}{|c|}{ OBSERVACIONES } & \multicolumn{3}{|c|}{$\begin{array}{l}\text { A. Demasiado rígido. El adhesivo ha atravesado el } \\
\text { estrato de muletón. Escasa adherencia. } \\
\text { B. Demasiado flexible. Buena adherencia. }\end{array}$} \\
\hline \multirow[t]{2}{*}{138} & $\begin{array}{l}\text { A. Resina } \\
\text { poliéster }\end{array}$ & \multirow[t]{2}{*}{ Muletón } & \multirow[t]{2}{*}{$\begin{array}{l}\text { Resina } \\
\text { poliéster }\end{array}$} & \multirow[t]{2}{*}{$\begin{array}{l}\text { Fibra vidrio tejida } \\
160 \mathrm{gr} / \mathrm{m}^{2}\end{array}$} \\
\hline & $\begin{array}{l}\text { B. Plextol B- } \\
500\end{array}$ & & & \\
\hline \multicolumn{2}{|c|}{ OBSERVACIONES } & $\begin{array}{l}\text { A. Dema } \\
\text { estrato d } \\
\text { B. Dema }\end{array}$ & ble. Buena & $\begin{array}{l}\text { ha atravesado el } \\
\text { encia. } \\
\text { herencia. }\end{array}$ \\
\hline
\end{tabular}




\begin{tabular}{|c|c|c|c|c|}
\hline \multirow[t]{2}{*}{139} & $\begin{array}{l}\text { A. Resina } \\
\text { poliéster }\end{array}$ & \multirow[t]{2}{*}{ Muletón } & \multirow[t]{2}{*}{$\begin{array}{l}\text { Resina } \\
\text { poliéster }\end{array}$} & \multirow[t]{2}{*}{$\begin{array}{l}\text { Fibra vidrio tejida } \\
300 \mathrm{gr} / \mathrm{m}^{2}\end{array}$} \\
\hline & $\begin{array}{l}\text { B. Plextol B- } \\
500\end{array}$ & & & \\
\hline \multicolumn{2}{|c|}{ OBSERVACIONES } & \multicolumn{3}{|c|}{$\begin{array}{l}\text { A. Demasiado rígido. El adhesivo ha atravesado el } \\
\text { estrato de muletón. Buena adherencia. } \\
\text { B. Demasiado flexible. Buena adherencia. }\end{array}$} \\
\hline \multirow[t]{2}{*}{140} & $\begin{array}{l}\text { A. Resina } \\
\text { poliéster }\end{array}$ & \multirow[t]{2}{*}{ Muletón } & \multirow[t]{2}{*}{$\begin{array}{l}\text { Resina } \\
\text { poliéster }\end{array}$} & \multirow[t]{2}{*}{$\begin{array}{l}\text { Matt de velo fibra } \\
\text { de vidrio }\end{array}$} \\
\hline & $\begin{array}{l}\text { B. Plextol B- } \\
500\end{array}$ & & & \\
\hline \multicolumn{2}{|c|}{ OBSERVACIONES } & \multicolumn{3}{|c|}{$\begin{array}{l}\text { A. Demasiado rígido. El adhesivo ha atravesado el } \\
\text { estrato de muletón. Buena adherencia. Las puntas } \\
\text { se comban ligeramente hacia arriba. } \\
\text { B. Demasiado flexible. Buena adherencia. }\end{array}$} \\
\hline \multirow[t]{2}{*}{141} & $\begin{array}{l}\text { A. Resina } \\
\text { epoxi }\end{array}$ & \multirow[t]{2}{*}{ Poliuretano } & \multirow[t]{2}{*}{$\begin{array}{l}\text { Resina } \\
\text { epoxi }\end{array}$} & \multirow[t]{2}{*}{$\begin{array}{l}\text { Fibra vidrio + fibra } \\
\text { carbono }\end{array}$} \\
\hline & $\begin{array}{l}\text { B. Plextol B- } \\
500\end{array}$ & & & \\
\hline \multicolumn{2}{|c|}{ OBSERVACIONES } & \multicolumn{3}{|c|}{$\begin{array}{l}\text { A. Demasiado flexible. Adherencia muy escasa. } \\
\text { B. Demasiado flexible. Poca adherencia. }\end{array}$} \\
\hline \multirow[t]{2}{*}{142} & $\begin{array}{l}\text { A. Resina } \\
\text { epoxi }\end{array}$ & \multirow[t]{2}{*}{ Poliuretano } & \multirow[t]{2}{*}{$\begin{array}{l}\text { Resina } \\
\text { epoxi }\end{array}$} & \multirow[t]{2}{*}{ Matt $300 \mathrm{gr} / \mathrm{m}^{2}$} \\
\hline & $\begin{array}{l}\text { B. Plextol B- } \\
500\end{array}$ & & & \\
\hline \multicolumn{2}{|c|}{ OBSERVACIONES } & \multicolumn{3}{|c|}{$\begin{array}{l}\text { A. Flexibilidad adecuada. Adherencia muy escasa. } \\
\text { B. Flxibilidad adecuada. Poca adherencia. }\end{array}$} \\
\hline \multirow[t]{2}{*}{143} & $\begin{array}{l}\text { A. Resina } \\
\text { epoxi }\end{array}$ & \multirow[t]{2}{*}{ Poliuretano } & \multirow[t]{2}{*}{$\begin{array}{l}\text { Resina } \\
\text { epoxi }\end{array}$} & \multirow[t]{2}{*}{ Matt $450 \mathrm{gr} / \mathrm{m}^{2}$} \\
\hline & $\begin{array}{l}\text { B. Plextol B- } \\
500\end{array}$ & & & \\
\hline \multicolumn{2}{|c|}{ OBSERVACIONES } & \multicolumn{3}{|c|}{$\begin{array}{l}\text { A. Demasiado rígido. Buena adherencia. } \\
\text { B. Demasiado rígido. Poca adherencia. }\end{array}$} \\
\hline \multirow[t]{2}{*}{144} & $\begin{array}{l}\text { A. Resina } \\
\text { epoxi }\end{array}$ & \multirow[t]{2}{*}{ Poliuretano } & \multirow[t]{2}{*}{$\begin{array}{l}\text { Resina } \\
\text { epoxi }\end{array}$} & \multirow[t]{2}{*}{$\begin{array}{l}\text { Fibra vidrio tejida } \\
125 \mathrm{gr} / \mathrm{m}^{2}\end{array}$} \\
\hline & $\begin{array}{l}\text { B. Plextol B- } \\
500\end{array}$ & & & \\
\hline \multicolumn{2}{|c|}{ OBSERVACIONES } & \multicolumn{3}{|c|}{$\begin{array}{l}\text { A. Demasiado flexible. Buena adherencia. } \\
\text { B. Demasiado flexible. Poca adherencia. }\end{array}$} \\
\hline \multirow[t]{2}{*}{145} & $\begin{array}{l}\text { A. Resina } \\
\text { epoxi }\end{array}$ & Poliuretano & $\begin{array}{l}\text { Resina } \\
\text { epoxi }\end{array}$ & $\begin{array}{l}\text { Fibra vidrio tejida } \\
160 \mathrm{gr} / \mathrm{m}^{2}\end{array}$ \\
\hline & $\begin{array}{l}\text { B. Plextol B- } \\
500\end{array}$ & & & \\
\hline
\end{tabular}




\begin{tabular}{|c|c|c|c|c|}
\hline \multicolumn{2}{|c|}{ OBSERVACIONES } & \multicolumn{3}{|c|}{$\begin{array}{l}\text { A. Demasiado flexible. Buena adherencia. } \\
\text { B. Demasiado flexible. Poca adherencia. }\end{array}$} \\
\hline \multirow[t]{2}{*}{146} & $\begin{array}{l}\text { A. Resina } \\
\text { epoxi }\end{array}$ & \multirow[t]{2}{*}{ Poliuretano } & \multirow[t]{2}{*}{$\begin{array}{l}\text { Resina } \\
\text { epoxi }\end{array}$} & \multirow[t]{2}{*}{$\begin{array}{l}\text { Fibra vidrio tejida } \\
300 \mathrm{gr} / \mathrm{m}^{2}\end{array}$} \\
\hline & $\begin{array}{l}\text { B. Plextol B- } \\
500\end{array}$ & & & \\
\hline \multicolumn{2}{|c|}{ OBSERVACIONES } & \multicolumn{3}{|c|}{$\begin{array}{l}\text { A. Demasiado flexible. Adherencia muy escasa. } \\
\text { B. Demasiado flexible. Poca adherencia. }\end{array}$} \\
\hline \multirow[t]{2}{*}{147} & $\begin{array}{l}\text { A. Resina } \\
\text { epoxi }\end{array}$ & \multirow[t]{2}{*}{ Poliuretano } & \multirow[t]{2}{*}{$\begin{array}{l}\text { Resina } \\
\text { epoxi }\end{array}$} & \multirow[t]{2}{*}{$\begin{array}{l}\text { Matt de velo fibra } \\
\text { de vidrio }\end{array}$} \\
\hline & $\begin{array}{l}\text { B. Plextol B- } \\
500\end{array}$ & & & \\
\hline \multicolumn{2}{|c|}{ OBSERVACIONES } & \multicolumn{3}{|c|}{$\begin{array}{l}\text { A. Demasiado flexible. Buena adherencia. } \\
\text { B. Demasiado flexible. Poca adherencia. }\end{array}$} \\
\hline \multirow[t]{2}{*}{148} & $\begin{array}{l}\text { A. Resina } \\
\text { poliéster }\end{array}$ & \multirow[t]{2}{*}{ Poliuretano } & \multirow[t]{2}{*}{$\begin{array}{l}\text { Resina } \\
\text { poliéster }\end{array}$} & \multirow[t]{2}{*}{$\begin{array}{l}\text { Fibra vidrio + fibra } \\
\text { carbono }\end{array}$} \\
\hline & $\begin{array}{l}\text { B. Plextol B- } \\
500\end{array}$ & & & \\
\hline \multicolumn{2}{|c|}{ OBSERVACIONES } & \multicolumn{3}{|c|}{$\begin{array}{l}\text { A. Demasiado flexible. Adherencia muy escasa. } \\
\text { B. Demasiado flexible. Poca adherencia. }\end{array}$} \\
\hline \multirow[t]{2}{*}{149} & $\begin{array}{l}\text { A. Resina } \\
\text { poliéster }\end{array}$ & \multirow[t]{2}{*}{ Poliuretano } & \multirow[t]{2}{*}{$\begin{array}{l}\text { Resina } \\
\text { poliéster }\end{array}$} & \multirow[t]{2}{*}{ Matt $300 \mathrm{gr} / \mathrm{m}^{2}$} \\
\hline & $\begin{array}{l}\text { B. Plextol B- } \\
500\end{array}$ & & & \\
\hline \multicolumn{2}{|c|}{ OBSERVACIONES } & \multicolumn{3}{|c|}{$\begin{array}{l}\text { A. Flexibilidad adecuada. Adherencia muy escasa. } \\
\text { B. Demasiado flexible. Poca adherencia. }\end{array}$} \\
\hline \multirow[t]{2}{*}{150} & $\begin{array}{l}\text { A. Resina } \\
\text { poliéster }\end{array}$ & \multirow[t]{2}{*}{ Poliuretano } & \multirow[t]{2}{*}{$\begin{array}{l}\text { Resina } \\
\text { poliéster }\end{array}$} & \multirow[t]{2}{*}{ Matt $450 \mathrm{gr} / \mathrm{m}^{2}$} \\
\hline & $\begin{array}{l}\text { B. Plextol B- } \\
500\end{array}$ & & & \\
\hline \multicolumn{2}{|c|}{ OBSERVACIONES } & \multicolumn{3}{|c|}{$\begin{array}{l}\text { A. Flexibilidad adecuada. Buena adherencia. } \\
\text { B. Flexibilidad adecuada. Poca adherencia. }\end{array}$} \\
\hline \multirow[t]{2}{*}{151} & $\begin{array}{l}\text { A. Resina } \\
\text { poliéster }\end{array}$ & \multirow[t]{2}{*}{ Poliuretano } & \multirow[t]{2}{*}{$\begin{array}{l}\text { Resina } \\
\text { poliéster }\end{array}$} & \multirow[t]{2}{*}{$\begin{array}{l}\text { Fibra vidrio tejida } \\
125 \mathrm{gr} / \mathrm{m}^{2}\end{array}$} \\
\hline & $\begin{array}{l}\text { B. Plextol B- } \\
500\end{array}$ & & & \\
\hline OBS & RVACIONES & $\begin{array}{l}\text { A. Demasia } \\
\text { B. Demasia }\end{array}$ & $\begin{array}{l}\text { ble. Buena } \\
\text { ble. Poca }\end{array}$ & $\begin{array}{l}\text { herencia. } \\
\text { erencia. }\end{array}$ \\
\hline 152 & $\begin{array}{l}\text { A. Resina } \\
\text { poliéster }\end{array}$ & Poliuretano & $\begin{array}{l}\text { Resina } \\
\text { poliéster }\end{array}$ & $\begin{array}{l}\text { Fibra vidrio tejida } \\
160 \mathrm{gr} / \mathrm{m}^{2}\end{array}$ \\
\hline & $\begin{array}{l}\text { B. Plextol B- } \\
500\end{array}$ & & & \\
\hline
\end{tabular}




\begin{tabular}{|c|c|c|c|c|}
\hline \multicolumn{2}{|c|}{ OBSERVACIONES } & \multicolumn{3}{|c|}{$\begin{array}{l}\text { A. Demasiado flexible. Adherencia muy escasa. } \\
\text { B. Demasiado flexible. Poca adherencia. }\end{array}$} \\
\hline \multirow[t]{2}{*}{153} & $\begin{array}{l}\text { A. Resina } \\
\text { poliéster }\end{array}$ & \multirow[t]{2}{*}{ Poliuretano } & \multirow[t]{2}{*}{$\begin{array}{l}\text { Resina } \\
\text { poliéster }\end{array}$} & \multirow[t]{2}{*}{$\begin{array}{l}\text { Fibra vidrio tejida } \\
300 \mathrm{gr} / \mathrm{m}^{2}\end{array}$} \\
\hline & $\begin{array}{l}\text { B. Plextol B- } \\
500\end{array}$ & & & \\
\hline \multicolumn{2}{|c|}{ OBSERVACIONES } & \multicolumn{3}{|c|}{$\begin{array}{l}\text { A. Demasiado flexible. Adherencia muy escasa. } \\
\text { B. Demasiado flexible. Poca adherencia. }\end{array}$} \\
\hline \multirow[t]{2}{*}{154} & $\begin{array}{l}\text { A. Resina } \\
\text { poliéster }\end{array}$ & \multirow[t]{2}{*}{ Poliuretano } & \multirow[t]{2}{*}{$\begin{array}{l}\text { Resina } \\
\text { poliéster }\end{array}$} & \multirow[t]{2}{*}{$\begin{array}{l}\text { Matt de velo fibra } \\
\text { de vidrio }\end{array}$} \\
\hline & $\begin{array}{l}\text { B. Plextol B- } \\
500\end{array}$ & & & \\
\hline \multicolumn{2}{|c|}{ OBSERVACIONES } & \multicolumn{3}{|c|}{$\begin{array}{l}\text { A. Demasiado flexible. Adherencia muy escasa. } \\
\text { B. Demasiado flexible. Poca adherencia. }\end{array}$} \\
\hline \multirow[t]{2}{*}{155} & $\begin{array}{l}\text { A. Resina } \\
\text { epoxi }\end{array}$ & \multirow[t]{2}{*}{$\begin{array}{l}\text { Papel fractura } \\
\text { predeterminada }\end{array}$} & \multirow[t]{2}{*}{$\begin{array}{l}\text { Resina } \\
\text { epoxi }\end{array}$} & \multirow[t]{2}{*}{$\begin{array}{l}\text { Fibra vidrio + fibra } \\
\text { carbono }\end{array}$} \\
\hline & $\begin{array}{l}\text { B. Plextol B- } \\
500\end{array}$ & & & \\
\hline \multicolumn{2}{|c|}{ OBSERVACIONES } & \multicolumn{3}{|c|}{$\begin{array}{l}\text { A. Demasiada flexibilidad. El papel absorbe mucho } \\
\text { adhesivo, quedando demadiado impregnado de } \\
\text { adhesivo y perdiendo su función como estrato de } \\
\text { intervención. Adherencia irregular. } \\
\text { B. Demasiada flexibilidad. Buena adherencia. }\end{array}$} \\
\hline \multirow[t]{2}{*}{156} & $\begin{array}{l}\text { A. Resina } \\
\text { epoxi }\end{array}$ & \multirow[t]{2}{*}{$\begin{array}{l}\text { Papel fractura } \\
\text { predeterminada }\end{array}$} & \multirow[t]{2}{*}{$\begin{array}{l}\text { Resina } \\
\text { epoxi }\end{array}$} & \multirow[t]{2}{*}{ Matt $300 \mathrm{gr} / \mathrm{m}^{2}$} \\
\hline & $\begin{array}{l}\text { B. Plextol B- } \\
500\end{array}$ & & & \\
\hline \multicolumn{2}{|c|}{ OBSERVACIONES } & \multicolumn{3}{|c|}{$\begin{array}{l}\text { A. Flexibilidad adecuada. El papel absorbe mucho } \\
\text { adhesivo, quedando demadiado impregnado de } \\
\text { adhesivo y perdiendo su función como estrato de } \\
\text { intervención. Adherencia irregular. } \\
\text { B. Flexibilidad adecuada. Buena adherencia, } \\
\text { aunque queda demasiado plástico. }\end{array}$} \\
\hline \multirow[t]{2}{*}{157} & $\begin{array}{l}\text { A. Resina } \\
\text { epoxi }\end{array}$ & \multirow[t]{2}{*}{$\begin{array}{l}\text { Papel fractura } \\
\text { predeterminada }\end{array}$} & \multirow[t]{2}{*}{$\begin{array}{l}\text { Resina } \\
\text { epoxi }\end{array}$} & \multirow[t]{2}{*}{ Matt $450 \mathrm{gr} / \mathrm{m}^{2}$} \\
\hline & $\begin{array}{l}\text { B. Plextol B- } \\
500\end{array}$ & & & \\
\hline \multicolumn{2}{|c|}{ OBSERVACIONES } & \multicolumn{3}{|c|}{$\begin{array}{l}\text { A. Flexibilidad adecuada. El papel absorbe mucho } \\
\text { adhesivo, quedando demadiado impregnado de } \\
\text { adhesivo y perdiendo su función como estrato de } \\
\text { intervención. Adherencia irregular. } \\
\text { B. Flexibilidad adecuada. Buena adherencia. }\end{array}$} \\
\hline \multirow[t]{2}{*}{158} & $\begin{array}{l}\text { A. Resina } \\
\text { epoxi }\end{array}$ & \multirow[t]{2}{*}{$\begin{array}{l}\text { Papel fractura } \\
\text { predeterminada }\end{array}$} & \multirow[t]{2}{*}{$\begin{array}{l}\text { Resina } \\
\text { epoxi }\end{array}$} & \multirow[t]{2}{*}{$\begin{array}{l}\text { Fibra vidrio tejida } \\
125 \mathrm{gr} / \mathrm{m}^{2}\end{array}$} \\
\hline & $\begin{array}{l}\text { B. Plextol B- } \\
500\end{array}$ & & & \\
\hline
\end{tabular}




\begin{tabular}{|c|c|c|c|c|}
\hline \multicolumn{2}{|c|}{ OBSERVACIONES } & \multicolumn{3}{|c|}{$\begin{array}{l}\text { A. Demasiada flexibilidad. El papel absorbe mucho } \\
\text { adhesivo, quedando demadiado impregnado de } \\
\text { adhesivo y perdiendo su función como estrato de } \\
\text { intervención. Adherencia irregular. } \\
\text { B. Demasiada flexibilidad. Buena adherencia. }\end{array}$} \\
\hline \multirow[t]{2}{*}{159} & $\begin{array}{l}\text { A. Resina } \\
\text { epoxi }\end{array}$ & \multirow[t]{2}{*}{$\begin{array}{l}\text { Papel fractura } \\
\text { predeterminada }\end{array}$} & \multirow[t]{2}{*}{$\begin{array}{l}\text { Resina } \\
\text { epoxi }\end{array}$} & \multirow[t]{2}{*}{$\begin{array}{l}\text { Fibra vidrio tejida } \\
160 \mathrm{gr} / \mathrm{m}^{2}\end{array}$} \\
\hline & $\begin{array}{l}\text { B. Plextol B- } \\
500\end{array}$ & & & \\
\hline \multicolumn{2}{|c|}{ OBSERVACIONES } & \multicolumn{3}{|c|}{$\begin{array}{l}\text { A. Demasiada flexibilidad. El papel absorbe mucho } \\
\text { adhesivo, quedando demadiado impregnado de } \\
\text { adhesivo y perdiendo su función como estrato de } \\
\text { intervención. Adherencia irregular. } \\
\text { B. Demasiada flexibilidad. Buena adherencia. }\end{array}$} \\
\hline \multirow[t]{2}{*}{160} & $\begin{array}{l}\text { A. Resina } \\
\text { epoxi }\end{array}$ & \multirow[t]{2}{*}{$\begin{array}{l}\text { Papel fractura } \\
\text { predeterminada }\end{array}$} & \multirow[t]{2}{*}{$\begin{array}{l}\text { Resina } \\
\text { epoxi }\end{array}$} & \multirow[t]{2}{*}{$\begin{array}{l}\text { Fibra vidrio tejida } \\
300 \mathrm{gr} / \mathrm{m}^{2}\end{array}$} \\
\hline & $\begin{array}{l}\text { B. Plextol B- } \\
500\end{array}$ & & & \\
\hline \multicolumn{2}{|c|}{ OBSERVACIONES } & \multicolumn{3}{|c|}{$\begin{array}{l}\text { A. Demasiada flexibilidad. El papel absorbe mucho } \\
\text { adhesivo, quedando demadiado impregnado de } \\
\text { adhesivo y perdiendo su función como estrato de } \\
\text { intervención. Adherencia irregular. } \\
\text { B. Demasiada flexibilidad. Buena adherencia. }\end{array}$} \\
\hline \multirow[t]{2}{*}{161} & $\begin{array}{l}\text { A. Resina } \\
\text { epoxi }\end{array}$ & \multirow[t]{2}{*}{$\begin{array}{l}\text { Papel fractura } \\
\text { predeterminada }\end{array}$} & \multirow[t]{2}{*}{$\begin{array}{l}\text { Resina } \\
\text { epoxi }\end{array}$} & \multirow[t]{2}{*}{$\begin{array}{l}\text { Matt de velo fibra } \\
\text { de vidrio }\end{array}$} \\
\hline & $\begin{array}{l}\text { B. Plextol B- } \\
500\end{array}$ & & & \\
\hline \multicolumn{2}{|c|}{ OBSERVACIONES } & \multicolumn{3}{|c|}{$\begin{array}{l}\text { A. Demasiada flexibilidad. El papel absorbe mucho } \\
\text { adhesivo, quedando demadiado impregnado de } \\
\text { adhesivo y perdiendo su función como estrato de } \\
\text { intervención. Adherencia irregular. } \\
\text { B. Demasiada flexibilidad. Buena adherencia. }\end{array}$} \\
\hline \multirow[t]{2}{*}{162} & $\begin{array}{l}\text { A. Resina } \\
\text { poliéster }\end{array}$ & \multirow[t]{2}{*}{$\begin{array}{l}\text { Papel fractura } \\
\text { predeterminada }\end{array}$} & \multirow[t]{2}{*}{$\begin{array}{l}\text { Resina } \\
\text { poliéster }\end{array}$} & \multirow[t]{2}{*}{$\begin{array}{l}\text { Fibra vidrio + fibra } \\
\text { carbono }\end{array}$} \\
\hline & $\begin{array}{l}\text { B. Plextol B- } \\
500\end{array}$ & & & \\
\hline \multicolumn{2}{|c|}{ OBSERVACIONES } & \multicolumn{3}{|c|}{$\begin{array}{l}\text { A. Demasiada flexibilidad. El papel absorbe mucho } \\
\text { adhesivo, quedando demadiado impregnado de } \\
\text { adhesivo y perdiendo su función como estrato de } \\
\text { intervención. Adherencia irregular. } \\
\text { B. Demasiada flexibilidad. Buena adherencia. }\end{array}$} \\
\hline \multirow[t]{2}{*}{163} & $\begin{array}{l}\text { A. Resina } \\
\text { poliéster }\end{array}$ & \multirow[t]{2}{*}{$\begin{array}{l}\text { Papel fractura } \\
\text { predeterminada }\end{array}$} & \multirow[t]{2}{*}{$\begin{array}{l}\text { Resina } \\
\text { poliéster }\end{array}$} & \multirow[t]{2}{*}{ Matt $300 \mathrm{gr} / \mathrm{m}^{2}$} \\
\hline & $\begin{array}{l}\text { B. Plextol B- } \\
500\end{array}$ & & & \\
\hline
\end{tabular}




\begin{tabular}{|c|c|c|c|c|}
\hline \multicolumn{2}{|c|}{ OBSERVACIONES } & \multicolumn{3}{|c|}{$\begin{array}{l}\text { A. Demasiada flexibilidad. El papel absorbe mucho } \\
\text { adhesivo, quedando demadiado impregnado de } \\
\text { adhesivo y perdiendo su función como estrato de } \\
\text { intervención. Adherencia irregular. } \\
\text { B. Demasiada flexibilidad. Adhesión un poco } \\
\text { irregular. }\end{array}$} \\
\hline \multirow[t]{2}{*}{164} & $\begin{array}{l}\text { A. Resina } \\
\text { poliéster }\end{array}$ & \multirow[t]{2}{*}{$\begin{array}{l}\text { Papel fractura } \\
\text { predeterminada }\end{array}$} & \multirow[t]{2}{*}{$\begin{array}{l}\text { Resina } \\
\text { poliéster }\end{array}$} & \multirow[t]{2}{*}{ Matt $450 \mathrm{gr} / \mathrm{m}^{2}$} \\
\hline & $\begin{array}{l}\text { B. Plextol B- } \\
500\end{array}$ & & & \\
\hline \multicolumn{2}{|c|}{ OBSERVACIONES } & \multicolumn{3}{|c|}{$\begin{array}{l}\text { A. Flexibilidad adecuada. El papel absorbe mucho } \\
\text { adhesivo, quedando demadiado impregnado de } \\
\text { adhesivo y perdiendo su función como estrato de } \\
\text { intervención. Adherencia irregular. } \\
\text { B. Flexibilidad adecuada. Buena adherencia. }\end{array}$} \\
\hline \multirow[t]{2}{*}{165} & $\begin{array}{l}\text { A. Resina } \\
\text { poliéster }\end{array}$ & \multirow[t]{2}{*}{$\begin{array}{l}\text { Papel fractura } \\
\text { predeterminada }\end{array}$} & \multirow[t]{2}{*}{$\begin{array}{l}\text { Resina } \\
\text { poliéster }\end{array}$} & \multirow[t]{2}{*}{$\begin{array}{l}\text { Fibra vidrio tejida } \\
125 \mathrm{gr} / \mathrm{m}^{2}\end{array}$} \\
\hline & Plextol B-500 & & & \\
\hline \multicolumn{2}{|c|}{ OBSERVACIONES } & \multicolumn{3}{|c|}{$\begin{array}{l}\text { A. Demasiada flexibilidad. El papel absorbe mucho } \\
\text { adhesivo, quedando demadiado impregnado de } \\
\text { adhesivo y perdiendo su función como estrato de } \\
\text { intervención. Adherencia irregular. } \\
\text { B. Demasiada flexibilidad. Buena adherencia. }\end{array}$} \\
\hline \multirow[t]{2}{*}{166} & $\begin{array}{l}\text { A. Resina } \\
\text { poliéster }\end{array}$ & \multirow[t]{2}{*}{$\begin{array}{l}\text { Papel fractura } \\
\text { predeterminada }\end{array}$} & \multirow[t]{2}{*}{$\begin{array}{l}\text { Resina } \\
\text { poliéster }\end{array}$} & \multirow[t]{2}{*}{$\begin{array}{l}\text { Fibra vidrio tejida } \\
160 \mathrm{gr} / \mathrm{m}^{2}\end{array}$} \\
\hline & Plextol B-500 & & & \\
\hline \multicolumn{2}{|c|}{ OBSERVACIONES } & \multicolumn{3}{|c|}{$\begin{array}{l}\text { A. Demasiada flexibilidad. El papel absorbe mucho } \\
\text { adhesivo, quedando demadiado impregnado de } \\
\text { adhesivo y perdiendo su función como estrato de } \\
\text { intervención. Adherencia irregular. } \\
\text { B. Demasiada flexibilidad. Buena adherencia. }\end{array}$} \\
\hline \multirow[t]{2}{*}{167} & $\begin{array}{l}\text { A. Resina } \\
\text { poliéster }\end{array}$ & \multirow[t]{2}{*}{$\begin{array}{l}\text { Papel fractura } \\
\text { predeterminada }\end{array}$} & \multirow[t]{2}{*}{$\begin{array}{l}\text { Resina } \\
\text { poliéster }\end{array}$} & \multirow[t]{2}{*}{$\begin{array}{l}\text { Fibra vidrio tejida } \\
300 \mathrm{gr} / \mathrm{m}^{2}\end{array}$} \\
\hline & Plextol B-500 & & & \\
\hline \multicolumn{2}{|c|}{ OBSERVACIONES } & \multicolumn{3}{|c|}{$\begin{array}{l}\text { A. Demasiada flexibilidad. El papel absorbe mucho } \\
\text { adhesivo, quedando demadiado impregnado de } \\
\text { adhesivo y perdiendo su función como estrato de } \\
\text { intervención. Adherencia irregular. } \\
\text { B. Demasiada flexibilidad. Buena adherencia. }\end{array}$} \\
\hline \multirow[t]{2}{*}{168} & $\begin{array}{l}\text { A. Resina } \\
\text { poliéster }\end{array}$ & \multirow[t]{2}{*}{$\begin{array}{l}\text { Papel fractura } \\
\text { predeterminada }\end{array}$} & \multirow[t]{2}{*}{$\begin{array}{l}\text { Resina } \\
\text { poliéster }\end{array}$} & \multirow[t]{2}{*}{$\begin{array}{l}\text { Matt de velo fibra } \\
\text { de vidrio }\end{array}$} \\
\hline & Plextol B-500 & & & \\
\hline
\end{tabular}



adhesivo, quedando demasiado impregnado de adhesivo y perdiendo su función como estrato de intervención. Adherencia irregular. B. Demasiada flexibilidad. Buena adherencia.

A partir de los datos expuestos en estas tablas, se han descartado un gran número de soportes, teniendo en cuenta varios factores.

En este sentido las probetas seleccionadas por su adecuada adaptación a las necesidades de flexibilidad de estas pinturas son las probetas que mantienen una adecuada flexibilidad, es decir, aquellas que no son demasiado rígidas, y aquellas que no se comban. Los soportes seleccionados son: 2b, 4a, 5a, 6a, 8a, 9a, 11a, 12a, 16b, 17b, 23b, 37a, 46a, 48a, 49a, 50a, 56a, 57a, 58b, 72b, 86b, 93a, 93b, 101b, 107a, 107b, 108b, 116a, 117a, 118a, 119a, 121a, 121b, 126 a, 128b, 132a, 135b, 136b, 142a, 142b, 149a, $150 a, 150 b, 156 b, 157 b$ y $164 b$.

Otro factor a tener en cuenta es la buena adhesión entre los diferentes estratos. Tras la valoración de las probetas, presentan una óptima adherencia y cohesión homogénea entre los estratos. Estos soportes son: 2b, 4a, 5a, 6a, 16b, 17b, 23b, 37a, 57a, 58b, 72b, 101b, 107a, 107b, 108b, 121a, 121b, 128b, 132a, 135b, 136b, 150a, $156 \mathrm{~b}$ y $164 \mathrm{~b}$.

De estas probetas, hay algunas que han sufrido cierta deformación, por levantamiento de las esquinas, y otras en las que el adhesivo ha atravesado el estrato de intervención dejándolo demasiado rígido. Descartando éstas, siguiendo todas las premisas establecidas, las probetas más adecuadas serían las siguientes: $2 \mathrm{~b}$, 16b, 17b, 23b, 58b, 72b, 101b, 108b, 121b, 128b, 135b, 136b, 150a, $156 \mathrm{~b}, 157 \mathrm{~b}$ y $164 \mathrm{~b}$.

Sin embargo no todos estos soportes resultan adecuadas por su grosor, eliminando los que resultan demasiado gruesos, se consideran máso: 2b, 58b, 101b, 108b, 121b, 150a, 156b y 164b.

Por último, otro factor a tener en cuenta es el peso del conjunto del soporte. Para ello, se han pesado cada uno de los soportes ensayados, que miden $35 \mathrm{~cm}^{2}$, para luego calcular cuánto pesaría 1 $\mathrm{m}^{2}$ a lo que habría que sumarle el peso de la pintura con los estratos de tela y caseinato cálcico que se le aplica por el reverso ${ }^{171}$.

\footnotetext{
${ }^{171}$ Ver en ANEXO II la tabla $\mathrm{n}^{\circ}$ 1, en la que se muestra el peso de cada una de las probetas de los soportes. Se ha utilizado una balanza de precisión Gram Precision Serie BH. BH300. Cap.: 300g. Div.: 0,01 g
} 
Teniendo en cuenta el peso de las probetas, las de menor peso $\operatorname{son}^{172}$ : 2b, 58b, 101b, 108b, 121b, 150a , 156b, 157b y 164b.

\begin{tabular}{|c|c|c|c|c|c|}
\hline 2 & $\begin{array}{l}\text { B. Acetato } \\
\text { polivinilo }\end{array}$ & Fieltro & $\begin{array}{l}\text { Resina } \\
\text { epoxi }\end{array}$ & \multicolumn{2}{|c|}{ Matt $300 \mathrm{gr} / \mathrm{m}^{2}$} \\
\hline \multicolumn{2}{|c|}{ OBSERVACIONES } & \multicolumn{2}{|c|}{$\begin{array}{l}\text { B. Flexibilidad adecuada. } \\
\text { Buena adhesión. }\end{array}$} & PESO & $\begin{array}{l}2022,8 \\
\mathrm{gr} . / \mathrm{m}^{2}\end{array}$ \\
\hline 58 & B. Beva gel & Fieltro & $\begin{array}{l}\text { Resina } \\
\text { epoxi }\end{array}$ & \multicolumn{2}{|c|}{ Matt $300 \mathrm{gr} / \mathrm{m}^{2}$} \\
\hline \multicolumn{2}{|c|}{ OBSERVACIONES } & \multicolumn{2}{|c|}{$\begin{array}{l}\text { B. Flexibilidad adecuada. } \\
\text { Buena adherencia. }\end{array}$} & PESO & $\begin{array}{l}1700 \\
\mathrm{gr} . / \mathrm{m}^{2}\end{array}$ \\
\hline 101 & B. Beva gel & $\begin{array}{l}\text { Papel fractura } \\
\text { predeterminada }\end{array}$ & $\begin{array}{l}\text { Resina } \\
\text { epoxi }\end{array}$ & \multicolumn{2}{|c|}{ Matt $450 \mathrm{gr} / \mathrm{m}^{2}$} \\
\hline \multicolumn{2}{|c|}{ OBSERVACIONES } & \multicolumn{2}{|c|}{$\begin{array}{l}\text { B. Flexibilidad adecuada. } \\
\text { Buena adherencia. }\end{array}$} & PESO & $\begin{array}{l}2302,8 \\
\mathrm{gr} . / \mathrm{m}^{2}\end{array}$ \\
\hline 108 & B. Beva gel & $\begin{array}{l}\text { Papel fractura } \\
\text { predeterminada }\end{array}$ & $\begin{array}{l}\text { Resina } \\
\text { poliéster }\end{array}$ & \multicolumn{2}{|c|}{$\begin{array}{l}\text { Matt } 450 \\
\mathrm{gr} / \mathrm{m}^{2}\end{array}$} \\
\hline \multicolumn{2}{|c|}{ OBSERVACIONES } & \multicolumn{2}{|c|}{$\begin{array}{l}\text { B. Flexibilidad adecuada. } \\
\text { Buena adherencia. }\end{array}$} & PESO & $\begin{array}{l}1902,8 \\
\mathrm{gr} . / \mathrm{m}^{2}\end{array}$ \\
\hline 121 & $\begin{array}{l}\text { B. Plextol B- } \\
500\end{array}$ & Fieltro & $\begin{array}{l}\text { Resina } \\
\text { poliéster }\end{array}$ & \multicolumn{2}{|c|}{ Matt $300 \mathrm{gr} / \mathrm{m}^{2}$} \\
\hline \multicolumn{2}{|c|}{ OBSERVACIONES } & \multicolumn{2}{|c|}{$\begin{array}{l}\text { B. Flexibilidad adecuada. } \\
\text { Buena adherencia. }\end{array}$} & PESO & $\begin{array}{l}1542,8 \\
\mathrm{gr} . / \mathrm{m}^{2}\end{array}$ \\
\hline 150 & $\begin{array}{l}\text { A. Resina } \\
\text { poliéster }\end{array}$ & Poliuretano & $\begin{array}{l}\text { Resina } \\
\text { poliéster }\end{array}$ & \multicolumn{2}{|c|}{ Matt $450 \mathrm{gr} / \mathrm{m}^{2}$} \\
\hline \multicolumn{2}{|c|}{ OBSERVACIONES } & \multicolumn{2}{|c|}{$\begin{array}{l}\text { A. Flexibilidad adecuada. } \\
\text { Buena adherencia. }\end{array}$} & PESO & $\begin{array}{l}1554,2 \\
\mathrm{gr} . / \mathrm{m}^{2}\end{array}$ \\
\hline 156 & $\begin{array}{l}\text { B. Plextol B- } \\
500\end{array}$ & $\begin{array}{l}\text { Papel fractura } \\
\text { predeterminada }\end{array}$ & $\begin{array}{l}\text { Resina } \\
\text { epoxi }\end{array}$ & \multicolumn{2}{|c|}{$\begin{array}{l}\text { Matt } 300 \\
\mathrm{gr} / \mathrm{m}^{2}\end{array}$} \\
\hline \multicolumn{2}{|c|}{ OBSERVACIONES } & \multicolumn{2}{|c|}{$\begin{array}{l}\text { A. Flexibilidad adecuada. } \\
\text { Buena adherencia, } \\
\text { aunque queda } \\
\text { demasiado plástico. }\end{array}$} & PESO & $\begin{array}{l}1277,1 \\
\mathrm{gr} . / \mathrm{m}^{2}\end{array}$ \\
\hline
\end{tabular}

${ }^{172}$ Ver Anexo $\mathrm{n}^{\circ} \mathrm{V}$. 


\begin{tabular}{|c|c|c|c|c|c|}
\hline 157 & $\begin{array}{l}\text { B. Plextol B- } \\
500\end{array}$ & $\begin{array}{l}\text { Papel fractura } \\
\text { predeterminada }\end{array}$ & $\begin{array}{l}\text { Resina } \\
\text { epoxi }\end{array}$ & & $\begin{array}{l}\text { tt } 450 \\
m^{2}\end{array}$ \\
\hline \multicolumn{2}{|c|}{ OBSERVACIONES } & \multicolumn{2}{|c|}{$\begin{array}{l}\text { A. Flexibilidad adecuada. } \\
\text { Buena adherencia. }\end{array}$} & PESO & $\begin{array}{l}1500 \\
\mathrm{gr} . / \mathrm{m}^{2}\end{array}$ \\
\hline 164 & $\begin{array}{l}\text { B. Plextol B- } \\
500\end{array}$ & $\begin{array}{l}\text { Papel fractura } \\
\text { predeterminada }\end{array}$ & $\begin{array}{l}\text { Resina } \\
\text { poliéster }\end{array}$ & \multicolumn{2}{|c|}{$\begin{array}{l}\text { Matt } 450 \\
\mathrm{gr} / \mathrm{m}^{2}\end{array}$} \\
\hline \multicolumn{2}{|c|}{ OBSERVACIONES } & \multicolumn{2}{|c|}{$\begin{array}{l}\text { A. Flexibilidad adecuada. } \\
\text { Buena adherencia. }\end{array}$} & PESO & $\begin{array}{l}1665,7 \\
\mathrm{gr} . / \mathrm{m}^{2}\end{array}$ \\
\hline
\end{tabular}

Estas últimas probetas, han sido sometidas a dos ciclos distintos en cámara climática ${ }^{173}$, con el fin de comprobar si se producía alguna degradación en alguno de los materiales que conforman cada soporte.

El primer ciclo se ha establecido en tramos de 12 horas, de las cuales en las primeras 4 horas, se ha mantenido una temperatura de $40^{\circ} \mathrm{C}$ y H.R. de $20 \%$. Pasadas 1 ' 48 horas se produce un descenso brusco de la temperatura $\left(\mathrm{a} 4^{\circ} \mathrm{C}\right)$ y un aumento de la H.R. (a $\left.80 \%\right)$. Estas últimas variables se han mantenido durante 4 horas, y durante la siguiente $1^{\prime} 48 \mathrm{~h}$, se ha vuelto a subir a $40^{\circ} \mathrm{C}$ de temperatura y a bajar a $20 \%$ de H.R., empezando de nuevo el ciclo.

Pasada una semana se ha aplicado la misma temporalización, pero durante las primeras 4 horas se ha programado $40^{\circ} \mathrm{C}$ con $80 \%$ de H.R., y las otras 4 horas, a $4^{\circ} \mathrm{C}$ y $20 \%$ de H.R.

Tras la observación de las probetas, finalizados los ciclos programados se ha determinado que el resultado ha sido positivo, pues ninguna de las probetas ha cambiado ni dimensionalmente ni en aspecto, no produciéndose ninguna alteración de los materiales.

Las principales conclusiones extraídas de estas probetas son que la fibra más adecuada por su rigidez, con cierto grado de flexibilidad es la fibra de vidrio no tejida, es decir, Matt de fibra de vidrio de 300 $\mathrm{gr} / \mathrm{m}^{2}$, o de $450 \mathrm{gr} / \mathrm{m}^{2}$, pues ofrecen la rigidez necesaria para mantener la planitud de la pintura, pero a la vez ofrece cierta flexibilidad, suficiente para adaptar el soporte con la pintura a la curvatura de la bóveda.

Las resinas, ya sea epoxi o poliéster, por lo general confieren demasiada rigidez a los estratos de intervención, por lo que el resto de adhesivos han funcionado mejor. El adhesivo que ha ofrecido mejores resultados es la Beva O.F. Gel., pues es un adhesivo de

\footnotetext{
${ }^{173}$ Cámara climática DYCOMETAL con regulador DI-100.
} 
contacto que se aplica directamente en frío sin necesidad de mezclarlo con otro producto. Es por esto muy cómodo y rápido de aplicar, y ofrece un grado de adhesión idóneo.

En cuanto al estrato de intervención, se ha desestimado la utilización del muletón de algodón por su excesivo grosor, ofreciendo mejores resultados el fieltro o el papel de fractura predeterminada. En cuanto a la reversibilidad del estrato de intervención, el que mejor comportamiento ofrece, es el papel de fractura predeterminada.

No obstante, y teniendo en cuenta el reducido tamaño de estas probetas, se han confeccionado nuevos soportes a las probetas que teníamos de pinturas murales arrancadas. Hemos aplicado a cada una de las probetas un soporte distinto, interviniendo como factores muy importantes a tener en cuenta, el adhesivo de la capa de intervención al reverso de la pintura, la capa de intervención, el adhesivo del soporte a la capa de intervención y el soporte propiamente dicho.

Para facilitar la extracción de conclusiones, se ha elaborado la siguiente tabla:

\begin{tabular}{|c|c|c|c|c|c|}
\hline № & $\begin{array}{l}\text { ADHESIVO } \\
\text { CAAA } \\
\text { INTERVENCION }\end{array}$ & $\begin{array}{l}\text { CAPA } \\
\text { INTERVENCIÓN }\end{array}$ & $\begin{array}{l}\text { ADHESIVO } \\
\text { SOPORTE }\end{array}$ & SOPORTE & OBSERVACIONES \\
\hline 1 & $\begin{array}{l}\text { Acetato } \\
\text { de } \\
\text { polivinilo }\end{array}$ & Fieltro & $\begin{array}{l}\text { Resina } \\
\text { epoxi }\end{array}$ & $\begin{array}{l}\text { Velo de } \\
\text { fibra de } \\
\text { vidrio }\end{array}$ & $\begin{array}{l}\text { Demasiado } \\
\text { flexible. El estrato } \\
\text { de fibra de vidrio } \\
\text { se separa del } \\
\text { fieltro. }\end{array}$ \\
\hline 2 & $\begin{array}{l}\text { Beva } \\
\text { gel }\end{array}$ & Fieltro & $\begin{array}{l}\text { Resina } \\
\text { epoxi }\end{array}$ & $\begin{array}{l}\text { Fibra de } \\
\text { vidrio } \\
\text { tejida de } \\
300 \mathrm{gr} / \mathrm{m}^{2}\end{array}$ & $\begin{array}{l}\text { Demasiado } \\
\text { flexible. Los tres } \\
\text { estratos están } \\
\text { bien adheridos. }\end{array}$ \\
\hline 3 & $\begin{array}{l}\text { Plextol } \\
\text { B-500 }\end{array}$ & Fieltro & $\begin{array}{l}\text { Resina } \\
\text { poliéster }\end{array}$ & $\begin{array}{l}\text { Matt de } \\
\text { fibra de } \\
\text { vidrio de } \\
450 \mathrm{gr} / \mathrm{m}^{2}\end{array}$ & $\begin{array}{l}\text { Rigidez-flexibilidad } \\
\text { adecuada. Los } \\
\text { tres estratos están } \\
\text { perfectamente } \\
\text { adheridos. }\end{array}$ \\
\hline 4 & $\begin{array}{l}\text { Acetato } \\
\text { de } \\
\text { polivinilo }\end{array}$ & Muletón & $\begin{array}{l}\text { Resina } \\
\text { poliéster }\end{array}$ & $\begin{array}{l}\text { Fibra de } \\
\text { vidrio } \\
\text { tejida de } \\
125 \mathrm{gr} / \mathrm{m}^{2}\end{array}$ & $\begin{array}{l}\text { Demasiado } \\
\text { flexible y mullido. } \\
\text { Los tres estratos } \\
\text { están bien } \\
\text { adheridos entre sí. }\end{array}$ \\
\hline 5 & $\begin{array}{l}\text { Beva } \\
\text { gel }\end{array}$ & Muletón & $\begin{array}{l}\text { Resina } \\
\text { epoxi }\end{array}$ & $\begin{array}{l}\text { Fibra de } \\
\text { vidrio } \\
\text { tejida de } \\
160 \mathrm{gr} / \mathrm{m}^{2}\end{array}$ & $\begin{array}{l}\text { Demasiado } \\
\text { flexible y mullido. } \\
\text { Los tres estratos } \\
\text { están bien } \\
\text { adheridos entre sí. }\end{array}$ \\
\hline
\end{tabular}




\begin{tabular}{|c|c|c|c|c|c|}
\hline 6 & $\begin{array}{l}\text { Plextol } \\
\text { B-500 }\end{array}$ & Muletón & $\begin{array}{l}\text { Resina } \\
\text { epoxi }\end{array}$ & $\begin{array}{l}\text { Matt de } \\
\text { fibra de } \\
\text { vidrio de } \\
300 \mathrm{gr} / \mathrm{m}^{2}\end{array}$ & $\begin{array}{l}\text { Rigidez-flexibilidad } \\
\text { adecuada. } \\
\text { Demasiado } \\
\text { mullido. Los tres } \\
\text { estratos están } \\
\text { perfectamente } \\
\text { adheridos. }\end{array}$ \\
\hline 7 & $\begin{array}{l}\text { Acetato } \\
\text { de } \\
\text { polivinilo }\end{array}$ & Spherecore & $\begin{array}{l}\text { Resina } \\
\text { poliéster }\end{array}$ & $\begin{array}{l}\text { Velo de } \\
\text { fibra de } \\
\text { vidrio }\end{array}$ & $\begin{array}{l}\text { Demasiado } \\
\text { flexible y mullido. } \\
\text { El Spherecore no } \\
\text { se adhiere bien a } \\
\text { ninguno de los } \\
\text { dos adhesivos } \\
\text { utilizados. }\end{array}$ \\
\hline 8 & $\begin{array}{l}\text { Beva } \\
\text { gel }\end{array}$ & Spherecore & $\begin{array}{l}\text { Resina } \\
\text { poliéster }\end{array}$ & $\begin{array}{l}\text { Fibra de } \\
\text { vidrio } \\
\text { tejida de } \\
300 \mathrm{gr} / \mathrm{m}^{2}\end{array}$ & $\begin{array}{l}\text { Rigidez-flexibilidad } \\
\text { adecuada. } \\
\text { Demasiado } \\
\text { mullido. El } \\
\text { Spherecore no se } \\
\text { adhiere bien a } \\
\text { ninguno de los } \\
\text { dos adhesivos } \\
\text { utilizados. }\end{array}$ \\
\hline 9 & $\begin{array}{l}\text { Plextol } \\
\text { B-500 }\end{array}$ & Spherecore & $\begin{array}{l}\text { Resina } \\
\text { epoxi }\end{array}$ & $\begin{array}{l}\text { Matt de } \\
\text { fibra de } \\
\text { vidrio de } \\
450 \mathrm{gr} / \mathrm{m}^{2}\end{array}$ & $\begin{array}{l}\text { Demasiado rígido. } \\
\text { El Spherecore no } \\
\text { se adhiere bien a } \\
\text { ninguno de los } \\
\text { dos adhesivos } \\
\text { utilizados. }\end{array}$ \\
\hline 10 & $\begin{array}{l}\text { Acetato } \\
\text { de } \\
\text { polivinilo }\end{array}$ & $\begin{array}{l}\text { Poliestireno o } \\
\text { poliuretano } \\
\text { (relleno de } \\
\text { cartón } \\
\text { pluma) }\end{array}$ & $\begin{array}{l}\text { Resina } \\
\text { epoxi }\end{array}$ & $\begin{array}{l}\text { Fibra de } \\
\text { vidrio } \\
\text { tejida de } \\
125 \mathrm{gr} / \mathrm{m}^{2}\end{array}$ & $\begin{array}{l}\text { Rigidez-flexibilidad } \\
\text { adecuada. La fibra } \\
\text { de vidrio no se } \\
\text { adhiere } \\
\text { uniformemente. }\end{array}$ \\
\hline 11 & $\begin{array}{l}\text { Beva } \\
\text { gel }\end{array}$ & $\begin{array}{l}\text { Papel de } \\
\text { fractura } \\
\text { predetermina } \\
\text { da }\end{array}$ & $\begin{array}{l}\text { Resina } \\
\text { poliéster }\end{array}$ & $\begin{array}{l}\text { Fibra de } \\
\text { vidrio } \\
\text { tejida de } \\
160 \mathrm{gr} / \mathrm{m}^{2}\end{array}$ & $\begin{array}{l}\text { Demasiada } \\
\text { flexibilidad. El } \\
\text { estrato de } \\
\text { intervención se } \\
\text { adhiere } \\
\text { perfectamente a } \\
\text { ambos estratos. }\end{array}$ \\
\hline 12 & $\begin{array}{l}\text { Plextol } \\
\text { B-500 }\end{array}$ & $\begin{array}{l}\text { Poliestireno o } \\
\text { poliuretano } \\
\text { (relleno de } \\
\text { cartón } \\
\text { pluma) }\end{array}$ & $\begin{array}{l}\text { Resina } \\
\text { poliéster }\end{array}$ & $\begin{array}{l}\text { Matt de } \\
\text { fibra de } \\
\text { vidrio de } \\
300 \mathrm{gr} / \mathrm{m}^{2}\end{array}$ & $\begin{array}{l}\text { Excesiva rigidez. } \\
\text { El estrato de } \\
\text { intervención no se } \\
\text { adhiere } \\
\text { adecuadamente al } \\
\text { reverso de la } \\
\text { pintura. }\end{array}$ \\
\hline
\end{tabular}


Los productos que mejores resultados han ofrecido son: como soporte, el matt de fibra de vidrio de $450 \mathrm{gr} / \mathrm{m}^{2}$, reforzado con resina epoxi; Beva Gel O.F., como adhesivo de la capa de intervención a ambos lados, y el papel de fractura predeterminada, como estrato de intervención.

Otro punto importante es el tamaño y la forma del nuevo soporte. Consideramos que existen cuatro posibilidades:

* Soporte que abarque el mismo tamaño que el panel actual.

- Soporte que abarque solamente la pintura original.

* Soporte que abarque la pintura original con un borde sobre el que aplicar los anclajes.

* Soporte que abarque la pintura original y unas pestañas que sobresalgan y sirvan para colocar los anclajes.

Para decidir el tipo de soporte a aplicar, hemos elaborado una probeta de soporte con las 4 posibilidades, y la hemos atornillado a un panel que simula el muro de yeso.

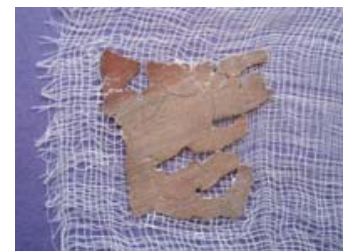

Fig. 91. Fragmento de pintura original al que se le aplicará un nuevo soporte.

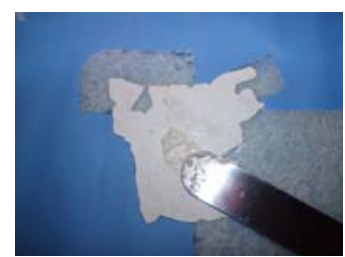

Fig. 94. Aplicación de papel de fractura predeterminada como estrato de intervención.

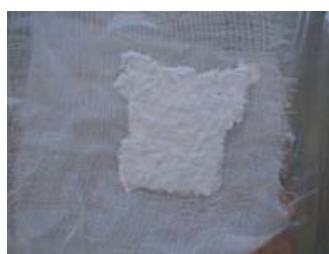

Fig. 92. Consolidación del reverso con gasa y caseinato cálcico.

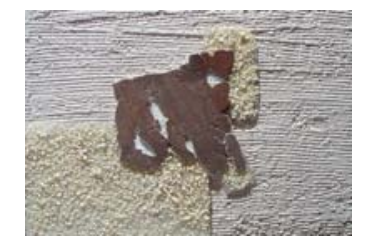

Fig. 95. Pintura adherida al nuevo soporte al que se le ha aplicado una capa de árido con resina acrílica para favorecer el agarre del mortero de estucado para la posterior reintegración.

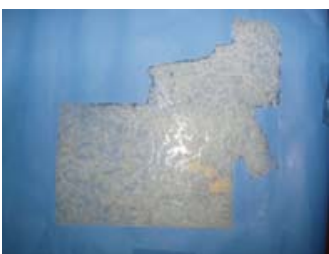

Fig. 93. Un mismo soporte de resina y fibra de vidrio con las 4 posibilidades propuestas.

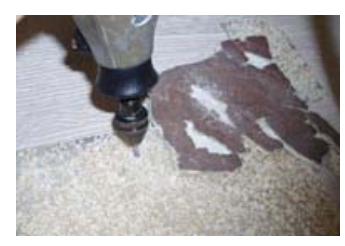

Fig. 96. Proceso de perforado del nuevo soporte. 


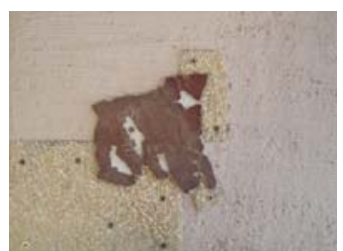

Fig. 97. Soporte ya atornillado a la probeta que simula el muro.

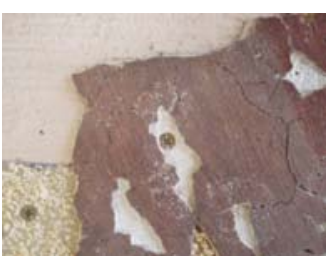

Fig. 98. Detalle de los tornillos tanto en las pestañas exteriores como en las lagunas interiores de la pintura.

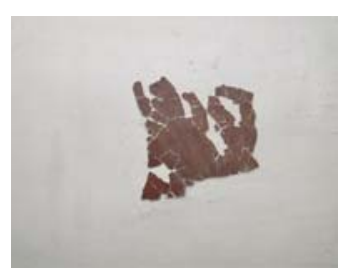

Fig. 99. Zona ya estucada sobre los cuatro tipos de solución del soporte.

Una vez aplicado el mortero que servirá de base para la reintegración, hemos podido extraer las siguientes conclusiones:

* El soporte que abarca el mismo tamaño que el panel actual, funciona bien con el mortero de estucado, pero en el caso de encontrarnos con paneles que no unan bien o que se solapen entre ellos, este sistema supondría un problema. Además se cargaría la bóveda con peso innecesario.

* El soporte que abarca solamente la pintura original presenta el problema de la ubicación de los anclajes. Habría que depender únicamente de las lagunas internas de cada fragmento de pintura original, y cabe la posibilidad de que muchos de los paneles no cuenten con dichas lagunas.

* El soporte que abarca la pintura original con un borde sobre el que aplicar los anclajes, nos parece el sistema más adecuado, puesto que el aumento de peso es relativamente escaso, pero contamos con una zona perimetral alrededor de todo el fragmento de pintura sobre el que aplicar los puntos de anclaje, sin olvidar que se deberían colocar también en las lagunas internas de cada fragmento de pintura original, siempre que éstas lo permitan.

- El soporte que abarca la pintura original y tiene unas pestañas que sobresalen, tiene la ventaja de contar con pequeñas zonas donde colocar los anclajes, pero puede crear tensiones, provocando el agrietamiento del mortero que se le aplicará como preparación para la reintegración. 


\subsubsection{PROPUESTA DE APLICACIÓN DE UN NUEVO SOPORTE A UN FRAGMENTO DE LAS PINTURAS DE PALOMINO EN LA IGLESIA DE LOS SANTOS JUANES DE VALENCIA.}

Realizadas ya todas las pruebas expuestas en los capítulos anteriores, en este apartado se define cuál sería el soporte que proponemos como más adecuado en el caso concreto de estas pinturas.

El conjunto de pintura-telas-nuevo soporte debe mantenerse dentro de los límites de espesor y peso que permita ser recolocado en el lugar de origen, sin alterar para ellos las características dimensionales del edificio que las alberga, y atendiendo a los elementos arquitectónicos que la circundan.

Además el nuevo soporte debe garantizar la continuidad de la obra en el tiempo, por lo que se tendrá en cuenta, que este soporte debe mantener la pintura en las condiciones ideales para que no le afecten las variaciones termo-higrométricas, que podrían perjudicar dicha perdurabilidad.

Hay que establecer las características que debe tener el soporte ideal para estas pinturas observando las particularidades de las mismas.

Ante el gran tamaño de la pintura y su posición, que en muchas zonas es completamente horizontal, el tipo de soporte a elegir será predominantemente ligero. $Y$ ya que en la bóveda queda una zona de pintura original, habrá que procurar que la pintura repuesta quede al mismo nivel que la original, por lo que el grosor del soporte debería ser igual o algo inferior al grosor de los morteros originales de dicha pintura. Este grosor no supera los $4 \mathrm{~mm}$.

Otra de las características que requiere el soporte ideal para estas pinturas es que sea flexible, para conseguir una fácil adaptabilidad a las curvaturas de la bóveda. Por lo que debe ser un soporte fino, de poco espesor, pero a la vez resistente y con gran poder de sujeción, para evitar futuras deformaciones del soporte que repercutan en la obra. Al igual que lo harían los movimientos de dilatación, por lo que el coeficiente de dilatación térmica debe ser mínimo. Los materiales que constituyen el soporte deben ser estables, pues se busca que el tratamiento sea duradero. Deben ser materiales inmunes a la presencia de microorganismos, humedad o fuego. $Y$ otra de las características fundamentales de este nuevo soporte es que debe albergar correctamente la pintura, teniendo en cuenta el peso de ésta junto con las telas y el caseinato cálcico del reverso.

El reverso de la obra no hay que tratarlo con la adhesión de más telas, pues, aunque el caseinato está quebradizo y habrá que sustituirlo, las telas de algodón colocadas en la intervención de 1960 
siguen cumpliendo su función de regularizar el reverso. Pero sí es necesaria la adhesión de una capa de intervención que facilite la reversibilidad de ese nuevo soporte en el caso de que en algún momento resulte inadecuado.

Un problema que se plantea a la hora de abordar la elaboración de un nuevo soporte, es la curvatura de la bóveda. El nuevo soporte que se aplique a estas pinturas, debe respetar la curvatura original de la bóveda.

Este problema podemos solucionarlo confeccionando un nuevo soporte semi-rígido, es decir, que tenga la suficiente rigidez como para mantener la planitud de la obra, pero al mismo tiempo que sea lo suficientemente flexible como para poder adaptar el conjunto de pintura con nuevo soporte a la curvatura de la bóveda en el momento que se sujete por medio de los anclajes específicos.

\subsection{ENSAYOS DE SISTEMAS DE ANCLAJE DEL SOPORTE AL MURO.}

Cuando se arranca una pintura, ésta no siempre se devuelve al lugar de origen, sin embargo, para mantener en lo posible la integridad de la obra, aunque ésta se arranque por motivos justificados, debería ser recolocada en su ubicación original, sobre todo si se trata de un fragmento de una obra -como es el caso que nos ocupa-, y no de una obra completa.

Hay varias opciones para abordar este tratamiento, ya sea adhiriendo el fragmento arrancado con un mortero adhesivo, sin necesidad de aplicar un nuevo soporte; ya sea aplicándole a dicho fragmento un nuevo soporte, para lo cual hay que tener en cuenta el grosor de la obra original, además del sistema de anclaje de dicho soporte -portador de la obra arrancada-, al muro.

Entendemos como "morteros adhesivos" aquellos morteros que permitan adherir al muro el fragmento de pintura arrancado, con el fin de recolocarlo en su lugar de origen.

Los morteros adhesivos son útiles cuando el fragmento a adherir es de reducidas dimensiones. Hemos investigado sobre la aplicación de morteros para la readhesión a su lugar de origen de fragmentos circulares de frescos con arriccio de yeso, hechos con sacabocados ${ }^{174}$. Pero este procedimiento se ha descartado, dado que la obra que nos

174 SORIANO SANCHO, P; OSCA PONS, J.; ROIG PICAZO, P. "Análisis de la metodología de arranques parciales de pintura mural: un caso práctico". En Libro de Actas del XIV Congreso de Conservación y Restauración de Bienes Culturales. Ed. Ayuntamiento de Valladolid. Volumen II. Valladolid, 2002. Págs. 785-799. 
ocupa será recolocada en un nuevo soporte autoportante, y por lo tanto requiere de un sistema de anclaje más complejo.

En este caso, además el fragmento alcanza ciertas dimensiones que impedirían la adhesión con un simple mortero.

Otro sistema de anclaje de un nuevo soporte al muro, y el más utilizado, es el atornillado al muro de pletinas o guías en las que se insertan otras guías que van unidas al soporte. Este sistema supone el practicar hendiduras en el muro original por dónde colocar las pletinas, de lo contrario el soporte junto con la pintura sobresaldrá respecto del nivel en el que se encontraba en origen.

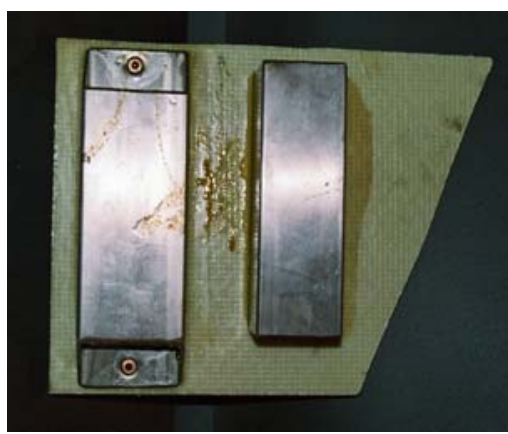

Fig. 100. Pletinas metálicas atornilladas a un soporte de Aerolam.

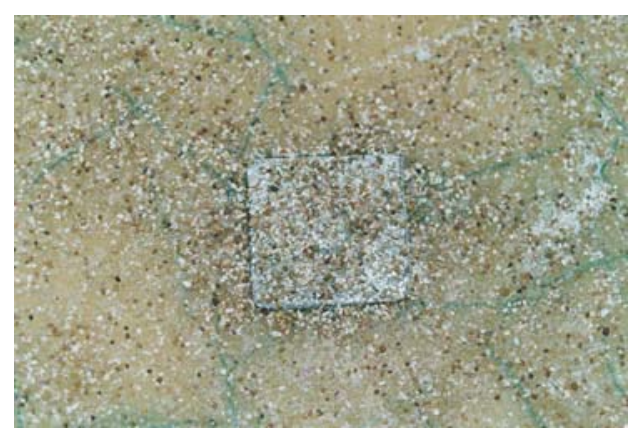

Fig. 101. Arandela del sistema de anclaje, en la parte del anverso, que quedará cubierta por el mortero que sirva para estucar las lagunas.

Mediante este sistema las pletinas van atornilladas y adheridas al soporte. Los tornillos que atraviesan el soporte, se dejan a nivel y se estuca la zona para conseguir una superficie homogénea donde aplicar la pintura arrancada. 


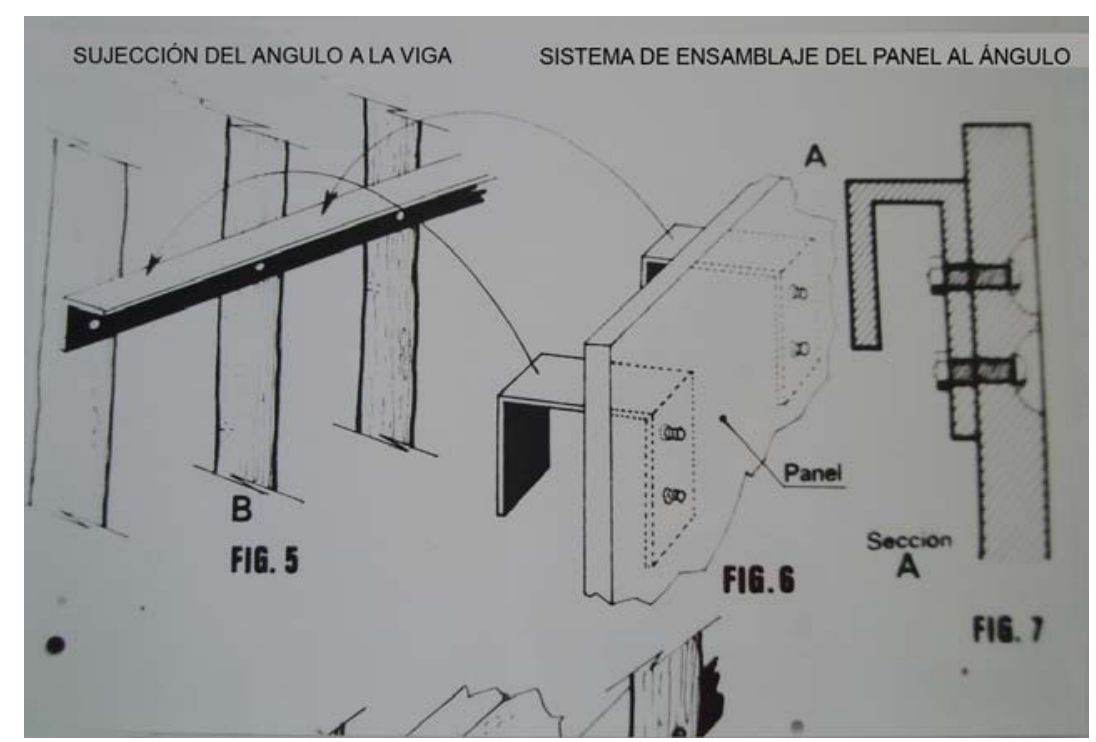

Fig. 102. Esquema de un tipo de anlaje por medio de ángulos metálicos.

En paredes verticales y rectas, se puede aplicar un sistema de anclaje parecido al usado para colgar cuadros. En este caso, las pletinas metálicas, que se colocan en el reverso del soporte a modo de refuerzo, servirán también de punto de anclaje, donde se practicará un orificio por el que entre el anclaje que esté colocado en el muro. Este sistema es menos adecuado en bóvedas o cúpulas, ya que la fuerza no se reparte equitativamente, y se corre el riesgo de deformaciones en el soporte.

Siempre hay que tener en cuenta que el grosor del soporte junto con la pintura arrancada, debe ser igual o menor al de la obra original, y el sistema de anclaje no deberá sobrepasar este grosor.

Lógicamente, los sistemas de anclaje, deben permitir que en un momento dado el soporte pueda ser extraído, junto con la obra que sustenta, del muro sobre el que ha sido colocado.

Para ello existen en el mercado varios sistemas, como la utilización de anclajes con cabeza de expansión ${ }^{175}$ que, insertados en zonas donde no haya pintura original, atraviesan el nuevo soporte y, una vez han penetrado en el muro, se expanden de modo que quedan anclados a la bóveda sin posibilidad de retroceso.

El problema de este sistema es que los nuevos soportes, una vez colocados no pueden ser extraídos, por lo que el tratamiento resultaría,

\footnotetext{
${ }^{175}$ La casa HILTI ofrece una amplia gama de este tipo de anclajes. Ver http://www.hilti.es
} 
en última instancia, irreversible. En este sentido y para facilitar un posible desmontaje futuro de alguno de los soportes, existe un sistema de anclaje que supone la combinación del sistema anterior, con cabeza de expansión, con un sistema que atornille al muro el conjunto de la obra con su nuevo soporte, sin evitar por ello su eventual extracción.

Este sistema consiste en la inserción en el muro de un anclaje estriado de cabeza de expansión, pero con la mitad del interior hueco y estriado para la inserción de un tornillo. Se insertaría parte del tubo en el muro, dejando fuera de él tantos milímetros como mida de espesor el nuevo soporte de las pinturas. En contacto con el muro habría una arandela metálica.

Por otro lado, al nuevo soporte se le debe practicar un orificio equivalente al tamaño del diámetro del tubo que se ha insertado en el muro, de tal manera que el nuevo soporte pueda ser colocado sobre el muro, y a través del orificio, insertar un tornillo, que luego será cubierto con el mismo material que se haya utilizado para estucar tanto los faltantes de película pictórica, como las uniones entre distintos paneles. El trabajo de insertar los anclajes en el muro debe ser minucioso y muy estudiado, pues hay que colocar el nuevo soporte con la pintura mural en su ubicación correcta.

Como ejemplo de sistemas de anclaje de nuevos soportes de pinturas murales, nombraremos el caso de las pinturas de la Basílica Superior de Asís, donde, para anclar al muro los paneles fragmentados con los restos de pintura recuperados tras el terremoto de 1991, se han usado pernos de acero inoxidable de la casa HILTI, distribuyéndolos de modo equilibrado en los espacios sin pintura. Una vez colocados todos los fragmentos del nuevo soporte, las uniones se han sellado con una pasta a base de resina epoxídica ${ }^{176}$.

Sin embargo, los fragmentos de los arcos han sido anclados al muro mediante un mortero compuesto por $1 / 2$ parte de arena gris, 1 parte de resina acrílica (Primal B60A) y 1 parte de Perlita. Como hemos reseñado en el capítulo anterior, se había dejado sobrante de red de cloruro de polivinilo, este sobrante de red sirve para fijarla al muro con tacos para pared y tornillos y arandelas de acero inoxidable ${ }^{177}$.

\footnotetext{
${ }^{176}$ BASILE, Giuseppe; P. Nicola GIANDOMENICO. "Dall'utopia alla relata. Notizie dall cantiere dei dipinti in frammenti della Basílica Superiore di San Francesco in Assisi". En Convengo internazionale di studi. 26-28 settembre 2002. Tipografía Metastasio. Assisi, 2002: IL RESTAURO DELLA VELA DI SAN GIROLAMO.

177 BASILE, Giuseppe; P. Nicola GIANDOMENICO. "Dall'utopia alla relata. Notizie dall cantiere dei dipinti in frammenti della Basílica Superiore di San Francesco in Assisi". En Convengo internazionale di studi. 26-28 settembre 2002. Tipografía Metastasio. Assisi, 2002. Pág. 33: IL RESTAURAO DEI DIPINTI IN FRAMMENTI DEL COSTOLONE DI SAN GIROLAMO.
} 


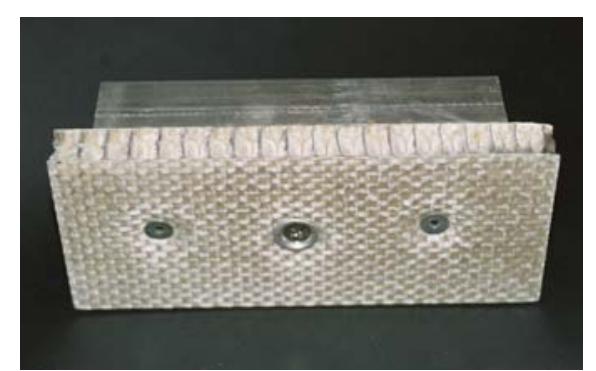

Fig. 103. Sistema de anclaje donde los tornillos quedan bajo el nivel de la superficie del soporte.

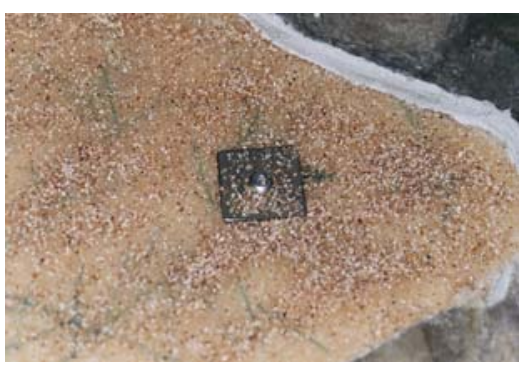

Fig. 104. Sobre el tornillo de anclaje se aplica una capa rugosa o texturada que facilite el agarre del mortero de estucado.

Otro sistema sería la combinación de un anclaje de expansión y un mortero. Pero este mortero, en lugar de ser adhesivo, que dificultaría la tarea de reversibilidad, podría ser también de expansión.

En el campo de la conservación y restauración de pintura mural, es habitual el uso de morteros de expansivos, sobre todo, para rellenar huecos en consolidaciones de abolsamientos. Este tipo de morteros se caracterizan por la falta de propiedades adhesivas y resistencias mecánicas, por lo que son fácilmente reversibles.

Los ensayos en laboratorio de distintos tipos de anclaje para sujetar el nuevo soporte con la pintura, se han efectuado a partir del estudio teórico realizado sobre este tema.

Hemos descartado, a priori, los sistemas de anclaje que suponen la adición al soporte de guías metálicas por el reverso, para incrustarlas en otras, que estarían sujetas al muro, por considerar que no hay suficiente espacio entre la bóveda y el nuevo soporte como para aumentar tanto el volumen de éste.

Proponemos por ello la utilización de anclajes con cabeza de expansión ${ }^{13}$ que, insertados en zonas donde no haya pintura original, atraviesan el nuevo soporte y, una vez han penetrado en el muro, se expanden de modo que quedan anclados a la bóveda sin posibilidad de retroceso.

Se ha experimentado con este sistema, y hemos llegado a la conclusión de que no resulta adecuado, puesto que, una vez anclados los nuevos soportes, no pueden ser extraídos, por lo que el tratamiento resulta, en última instancia, irreversible. En este sentido y para facilitar un posible desmontaje futuro de alguno de los soportes, hemos pensado en una combinación de este sistema de anclajes con cabeza de expansión con un sistema que atornille al muro el panel, sin evitar por ello su eventual extracción. 
Este sistema consiste en la inserción en el muro de un anclaje estriado de cabeza de expansión, pero con la mitad del interior hueco y estriado para la inserción de un tornillo. Se inserta parte del tubo en el muro, dejando fuera de él tantos centímetros como tenga de espesor el nuevo soporte de las pinturas. En contacto con el muro se coloca una arandela metálica.
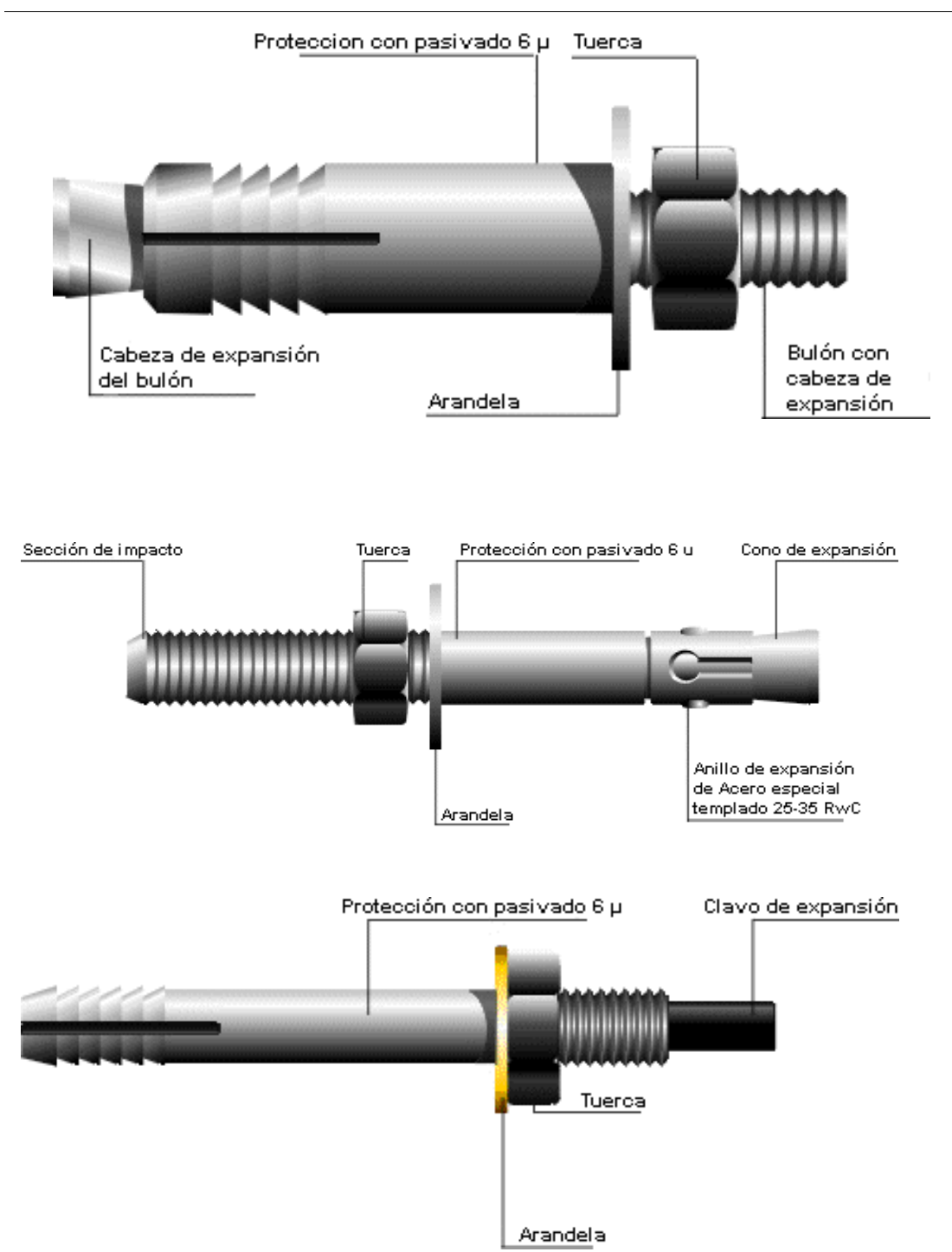

Fig. 105. Imagenes de distintos tipos de tornillo con cabeza de expansión, de la marca HILTI. 
Al nuevo soporte le hemos practicado un orificio equivalente al tamaño del diámetro del tubo que se ha insertado en el muro, de tal manera que el nuevo soporte puede ser colocado sobre el muro, y a través del orificio, hemos insertado un tornillo, que luego será cubierto con el mismo material que se haya utilizado tanto para estucar los faltantes de película pictórica, como las uniones entre distintos paneles. El trabajo de insertar los anclajes en el muro debe ser minucioso y muy estudiado, pues hay que colocar el nuevo soporte con la pintura mural en su ubicación correcta.

Se ha experimentado el anclaje de probetas de pinturas murales arrancadas a las que se les habían aplicado nuevos soportes a un muro de características similares a la bóveda de Santos Juanes.

Antes de proceder al anclaje se ha preparado la superficie de yeso mediante un lijado, pasando a practicar los orificios dónde se iban a insertar los tacos de expansión ensayados, que son los que se muestran en las figuras 107 y 108.

Con el fin de regularizar e homogeneizar la superficie, se ha enlucido con un mortero de ligeramente expansivo ${ }^{178}$, de modo que al aplicar el nuevo soporte con la pintura, no quede ningún hueco o vacío entre el nuevo soporte y el muro, pues podría favorecer la acumulación de suciedad y pequeñas microcondensaciones por eventuales incrementos de humedad.

Este mortero, es débilemente adhesivo, pero fácilmente eliminable, puesto que sus resistencias mecánicas son muy bajas.

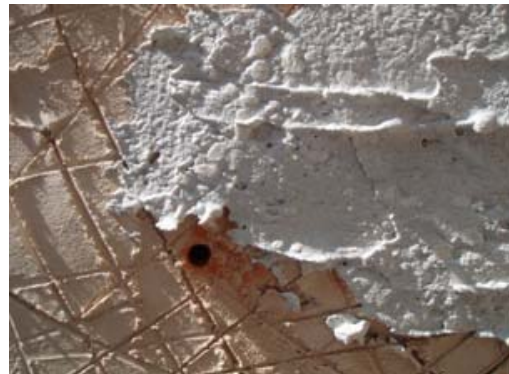

Fig. 106. Mortero expansivo aplicado sobre el enlucido de yeso y orificio para insertar el taco.

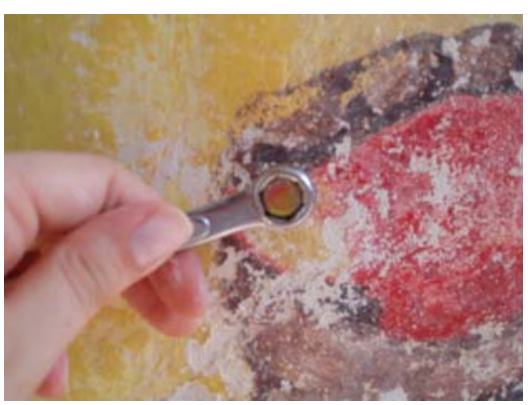

Fig. 107. Atornillado del taco de expansión.

178 Aluminato de bario, compuesto por: 30\% polvo de mármol o arena tamizada; $33 \%$ hidróxido cálcico (grassello); 34\% Primal AC-33 (o similar); 2,7\% hidróxido de bario (octohidrato) y $0,3 \%$ aluminio en polvo. 
Una vez extendido el mortero expansivo, se ha aplicado inmediatamente el nuevo soporte con la pintura, presionando ligeramente, y se han atornillado los anclajes con cabeza de expansión.

Se han utilizado dos tipos de tornillos:

- Los primeros contienen una válvula interna que al desenroscar el tornillo para incrustar en el muro únicamente el taco, queda suelta, por lo que dificulta su inserción en el muro junto con el taco.

- Los segundos, llevan la válvula dentro del mismo taco, de modo que no se mueve hasta que no se atornilla.

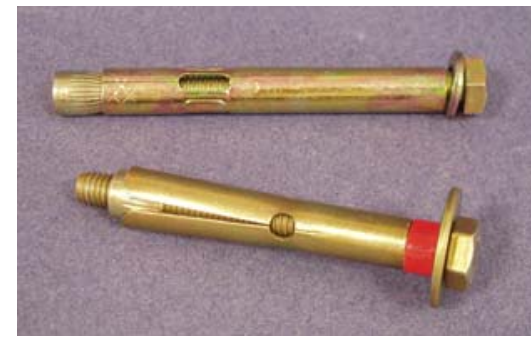

Fig. 108. Tornillo HILTI con cabeza de expansión a través de un cono suelto dentro del taco.

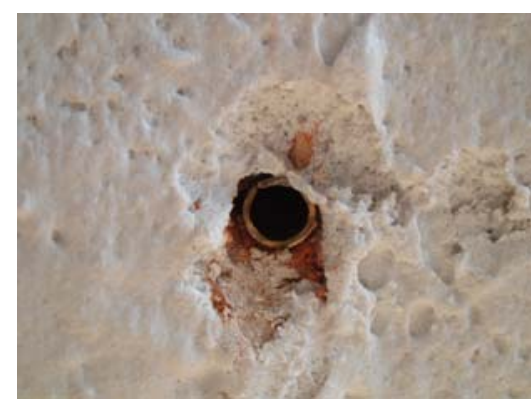

Fig. 110. Imagen del primer tipo de taco utilizado.

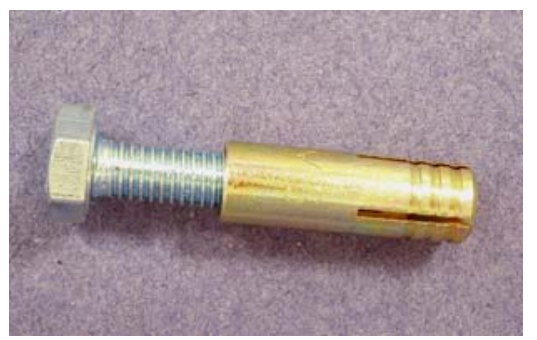

Fig. 109. Tornillo HILTI con cabeza de expansión, siendo expandible el propio taco.

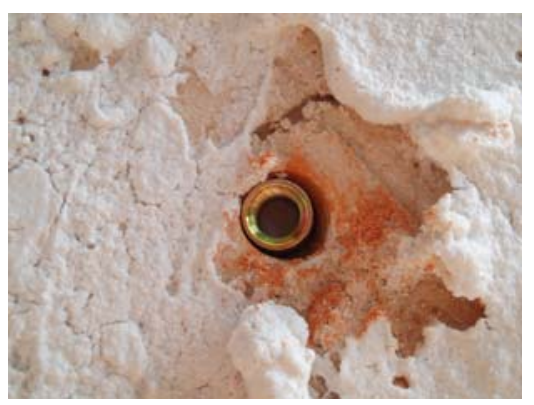

Fig. 111. Imagen del otro tipo de taco utilizado.

Para solucionar el impedimento que supone en el primer caso la válvula suelta, hemos utilizado una pequeña cantidad de cinta adhesiva transparente para unir provisionalmente la válvula al taco, con el fin de que no se pierda dentro del muro cuando se introduce en él. Esta pequeña cinta no impide la expansión del taco al introducir el tornillo. 
El resultado ha sido parecido en ambos sistemas, pues el soporte queda perfectamente fijado a la superficie mediante los anclajes, y sin ningún tipo de separación respecto al muro, por la previa aplicación del mortero de expansión.

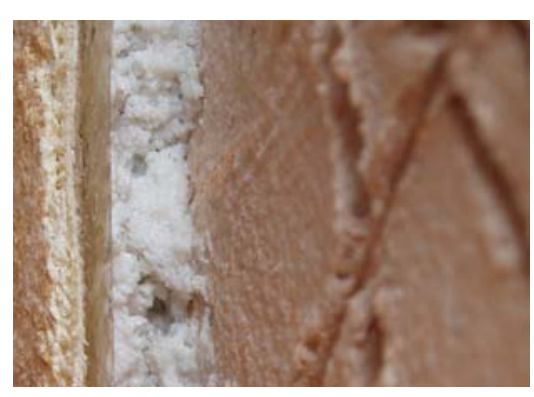

Fig. 112. Imagen del mortero de expansión entre el nuevo soporte y el muro.

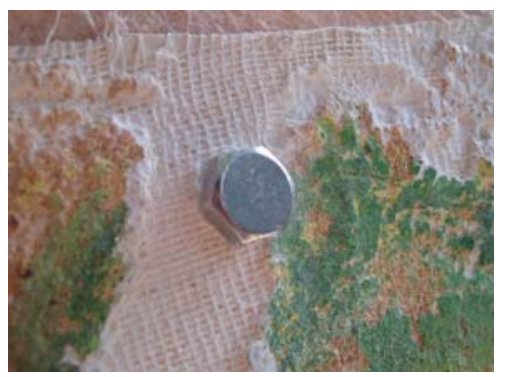

Fig. 113. Imagen del segundo tipo de anclaje ya aplicado.

La diferencia de ambos tipos de anclaje es en cuanto a profundidad de inserción de los tacos, puesto que cada uno tiene una longitud diferente:

- El primer tipo de anclaje presenta el inconveniente de que la válvula interna está suelta y hay que unirla al taco con una cinta adhesiva que luego permanece en el interior del muro, añadiendo así, aunque en cantidades mínimas, un elemento extraño a la fábrica de la bóveda.

- El segundo tipo presenta el inconveniente de que al ser más corto, si el orificio practicado previamente, atraviesa una rosca de ladrillo y queda en un hueco, se corre el peligro de que el taco caiga en ese hueco. Esto se soluciona haciendo el orificio muy justo de modo que el taco entre $y$ quede incrustado sin posibilidad de movimiento.

Un inconveniente que presentan los dos tipos de anclaje es que la cabeza del tornillo es demasiado gruesa, por lo que sobresale del nivel de la pintura. Se propone, limar las cabezas de los tornillos para hacerlas más delgadas y puedan ser estucadas una vez atornillados los anclajes a la bóveda. Este trabajo se puede efectuar mediante un torno de limado. 


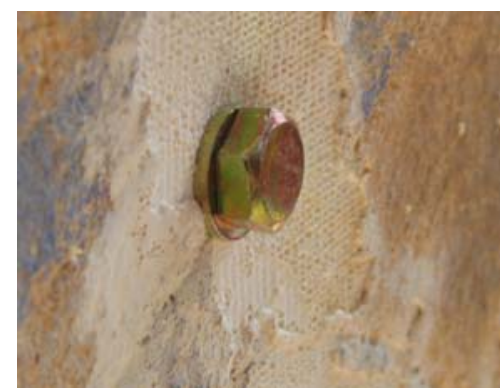

Fig. 114. Imagen del orificio para la inserción del taco

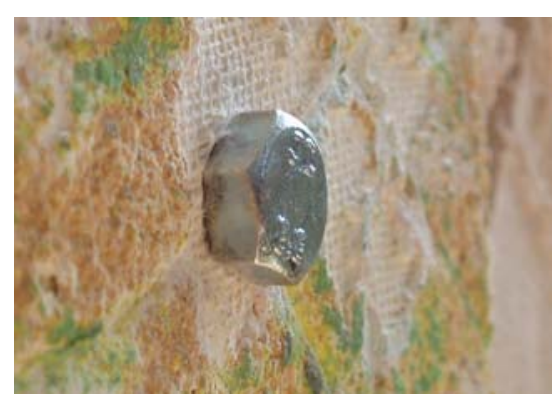

Fig. 115. Imagen del orificio para la inserción del taco

Consideramos que el sistema de anclaje del soporte al muro es un tema complejo en el que influyen factores complementarios a la propia restauración, como la carga que puede sujetar cada tipo de anclaje; se deben estudiar los diferentes anclajes según las distintas zonas de la bóveda, unas compuestas de rosca de ladrillo y otras en las que nos encontramos directamente con los arcos góticos de piedra, etc.

Por todo ello consideramos más oportuno abrir una línea de investigación que profundice en estos aspectos a partir de la presente investigación.

\subsubsection{PROPUESTA DE APLICACIÓN DE UN SISTEMA DE ANCLAJE A UN FRAGMENTO DE LAS PINTURAS DE PALOMINO EN LA IGLESIA DE LOS SANTOS JUANES DE VALENCIA.}

Un problema muy importante que se deriva de las características concretas de estas pinturas es la reubicación de cada fragmento de pintura dentro de cada uno de los paneles.

Partiendo de la base de que estas pinturas ya han sido arrancadas y reubicadas en la bóveda de origen, consideramos que existen dos posibilidades. Una de ellas es emitir un voto de confianza a la actuación del taller de los Gudiol, suponiendo que colocaron los fragmentos dentro de cada panel, con criterio. Como sabemos, las pinturas fueron arrancadas después de que éstas hubiesen sufrido grandes pérdidas tras el incendio de 1936. De ello se deriva un gran número de lagunas en la superficie pictórica que dificulta la correcta ubicación de los fragmentos que han perdurado.

Por ello planteamos otra posibilidad para asegurarnos la correcta ubicación de todos los fragmentos restantes. 
Dentro del equipo de trabajo que se encarga de la restauración de las pinturas de la bóveda de la nave central de la iglesia de los Santos Juanes de Valencia, hay un grupo de investigadores responsable de la digitalización de la única imagen que se ha encontrado completa de la bóveda antes del incendio. Pero dicha imagen, posee una gran deformación. Como plantean en los múltiples proyectos de investigación sobre la Iglesia d elos Santos Juanes de Valencia, dirigidos por la Dra. Pilar Roig Picazo, se pretende informatizar la imagen para eliminar digitalmente la deformación presente en la fotografía original, para poder tener así una visión más cercana a la realidad de la pintura de Palomino. Se trata de desproyectar la imagen, para poderla adaptar, a tamaño real sobre la bóveda, intentando que las zonas que quedan de original coincidan en la fotografía.

Aunque dicha fotografía es en blanco y negro, lo que supone un problema para los tratamientos de reintegración estudiados en las tesis anteriormente nombradas, no presenta ningún problema para el objetivo que se plantea a continuación.

Si esta fotografía careciese de deformación, ampliándola a tamaño real, se podría usar como plantilla para la ubicación correcta de los fragmentos, una vez éstos fuesen despojados de su actual soporte de madera, para poder adherirlos correctamente a su nuevo soporte. 


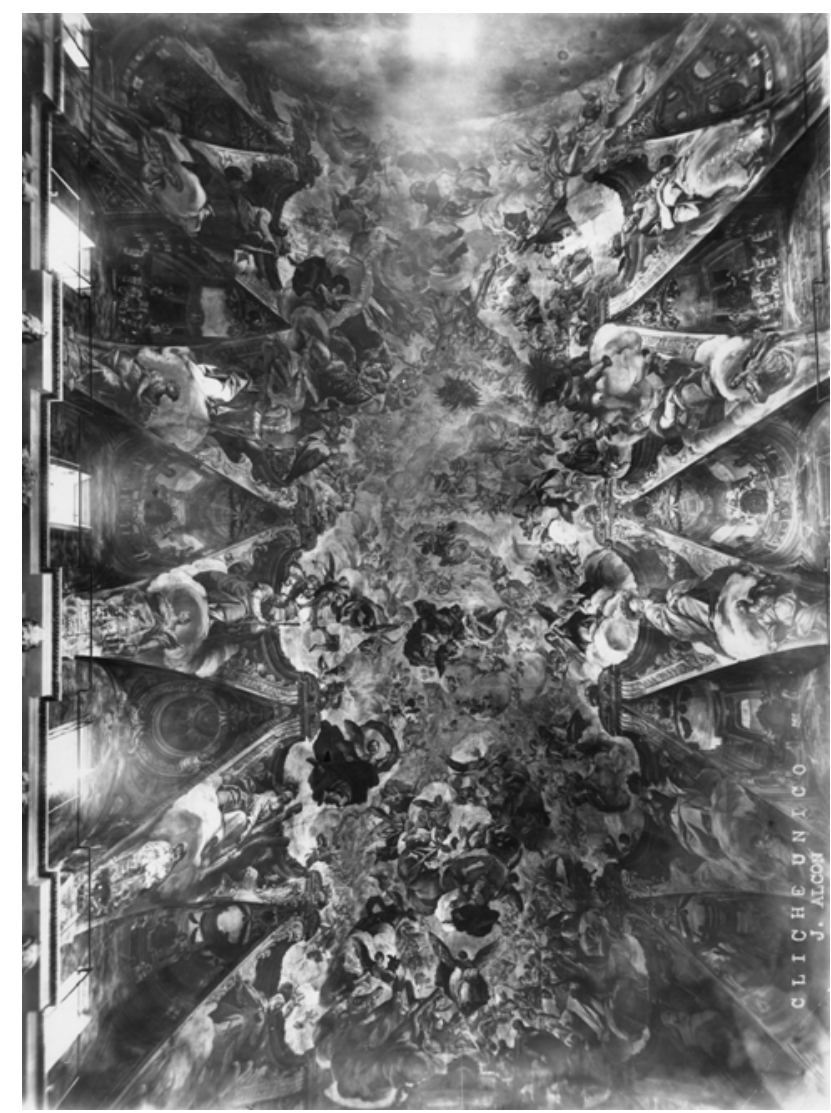

Fig. 116. Fotografía de la bóveda tomada antes del incendio de 1936. (J. Alcón).

Una solución similar se ha aplicado en la recomposición de la Vela de San Girolamo, perteneciente a las pinturas murales de la Basílica Superior de Asís, que tras el terremoto sufrido en 1997, quedaron divididas en miles de fragmentos ${ }^{179}$. Para este propósito, se posicionaron los fragmentos de pintura original sobre una fotografía a tamaño natural reelaborada sobre los datos restituidos de relieves fotogramétricos. Los perfiles de dichos fragmentos fueron marcados sobre papel transparente, de modo que quedara plasmada tanto la

179 BASILE, Giuseppe; P. Nicola GIANDOMENICO. "Dall'utopia alla realtà. Notizie dal cantiere dei dipinti in frammenti della Basílica Superiore di San Francesco in Assisi". En Convengo internazionale di studi. 26-28 settembre 2002. Tipografía Metastasio. Assisi, 2002. Pág. 27: IL RESTAURO DELLA VELA DI SAN GIROLAMO. 
forma como la posición de cada uno de los fragmentos. Este papel transparente se utilizó a modo de "cartón" para trasladar ese posicionamiento de los fragmentos al estrato de intervención del nuevo soporte, por medio de la técnica del estarcido. Los fragmentos se adhirieron a éste por medio de un mortero de sílice expandida y emulsión acrílica.

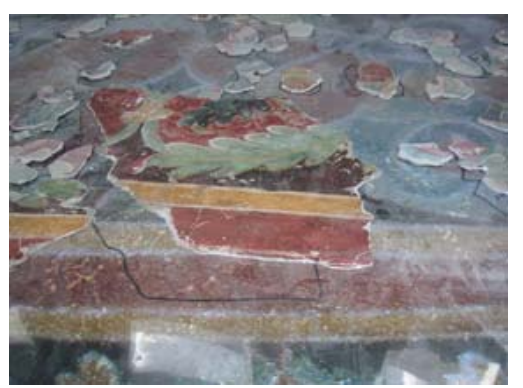

Fig. 117. Fotografía tomada en los talleres de la Basílica de Asís. Posicionamiento de los fragmentos de pintura sobre la fotografía de la obra para su identificación.

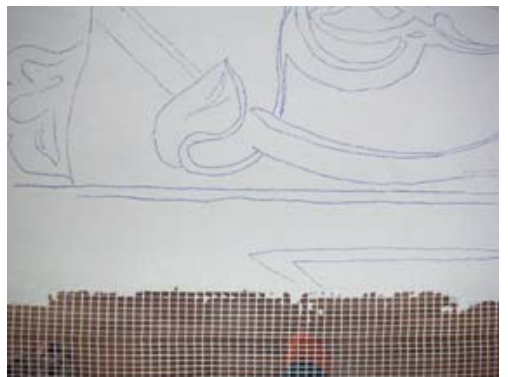

Fig. 119. Fotografía tomada en los talleres de la Basílica de Asís. Dibujo ya trasladado sobre el mortero de reintegración volumétrica.

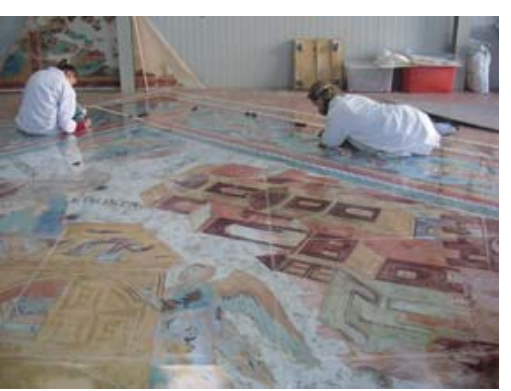

Fig. 118. Fotografía tomada en los talleres de la Basílica de Asís. Calco de la fotografía para trasladar el dibujo al mortero de reintegración volumétrica.

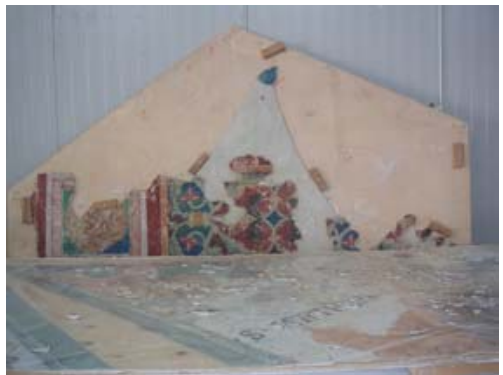

Fig. 120. Fotografía tomada en los talleres de la Basílica de Asís. Fragmentos de pintura original ya adheridos al mortero de reintegración.

Teniendo en cuenta todas las consideraciones anteriores, el planteamiento propuesto para estas pinturas es el siguiente:

Cada fragmento de pintura original debería quedar separado de los repintes por medio de cortes de bisturí antes de ser protegidos.

Únicamente los fragmentos de pintura original deberían protegerse para ser despojados de su actual soporte de madera contrachapada, con un estrato de gasa de algodón y otro de crinolina de algodón, que como hemos visto son las telas que ofrecen una mejor protección. Teniendo en cuenta las conclusiones extraídas sobre los adhesivos, 
estas telas deberían ser adheridas a la superficie pictórica original mediante cola de gelatina.

Una vez protegida la pintura original, se separaría del soporte de madera mediante la acción mecánica, levantando el conjunto de pintura + protección, con la ayuda de la inserción de barras metálicas, con puntas redondeadas para no dañar ningún estrato, entre el soporte de madera y la pintura.

Una vez separada la pintura del soporte de madera, se procedería al tratamiento del reverso, sólo en caso necesario, con la aplicación de una mano de caseinato cálcico para readherir las telas que fueron aplicadas en la restauración de los años 60.

Llegados a este punto, ya se debería colocar la obra en un nuevo soporte que, vistas las conclusiones extraídas en el punto anterior de este capítulo, debería constar de un estrato Matt de fibra de vidrio no tejida, de $450 \mathrm{gr} / \mathrm{m}^{2}$, con resina epoxi, un estrato de intervención de papel de fractura predeterminada, adherido con Beva O.F. Gel, tanto al soporte como a la pintura.

Una vez colocado cada fragmento, faltaría ubicarlo en su situación correcta en la bóveda. Para ello, se traspasaría el dibujo original de la pintura de Palomino, tomado a partir de la fotografía en blanco y negro de antes del incendio, ya retocada.

Teniendo como referencia este dibujo sobre la superficie de la bóveda, se iría colocando cada fragmento en su justa ubicación, mediante un sistema de anclaje adecuado. 


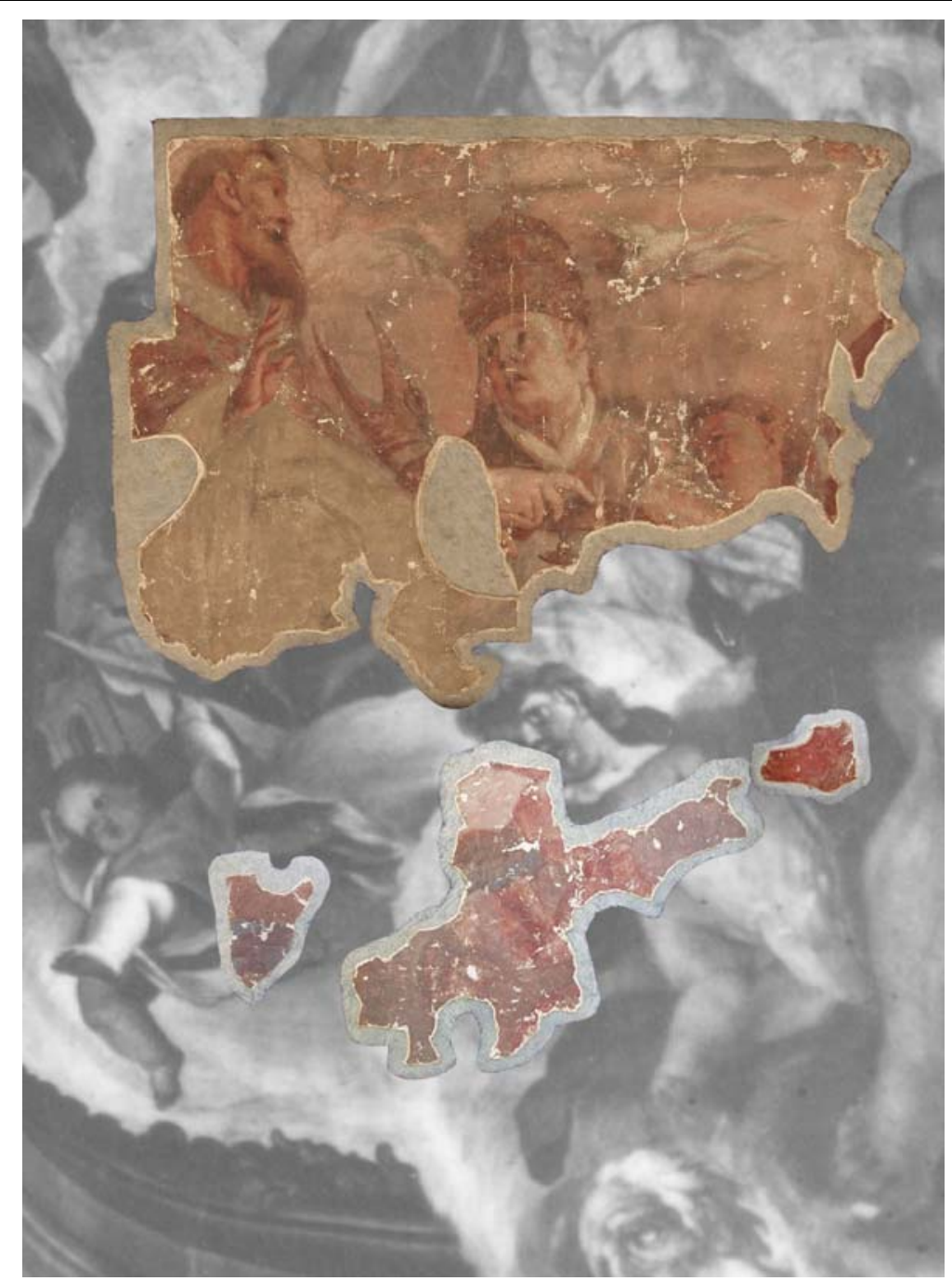

Fig. 121. Simulación de cómo quedarían los fragmentos de pintura ya colocados sobre nuevo soporte en la fotografía anterior al incendio, para su correcta ubicación en la bóveda.

Este es un aspecto muy importante a tener en cuenta para la intervención integral en esta pintura, pues uno de los principales problemas que presenta el estado de conservación de la obra en estos momentos es el potencial peligro de desprendimiento de los actuales paneles de madera que sujetan las pinturas arrancadas.

Estas pinturas, que suman un total de $450 \mathrm{~m}^{2}$, fueron colocadas en 90 paneles de madera. 
Se ha hecho un estudio sobre la colocación actual de los paneles de madera, registrando todos los repintes, para observar la cantidad de repintes que presenta cada uno de los fragmentos de pintura original en su interior. Estos repintes, ubicados dentro de un gran fragmento de pintura original, nos podrían servir como zona neutra donde colocar los anclajes.

Deberían estudiarse los puntos de anclaje que hacen falta para cada uno de los paneles, dependiendo del tamaño y de la posibilidad de colocarlos en zonas de pérdidas de pintura original, ofreciendo así mayor seguridad de agarre. Este punto de la investigación no puede realizarse sin el previo montaje de un andamio que permita estudiar uno a uno todos los paneles que conforman la bóveda.

Además de la utilización de este sistema de anclaje, habría que preparar el muro para recibir dichos anclajes que sujetasen la pintura con su nuevo soporte. En la restauración de los años 60, se enlució toda la parte de la bóveda donde se arrancaron las pinturas, con una capa de yeso. Se insertaron en la fábrica de la bóveda tacos de madera sobre los que clavaban los paneles de madera con la pintura. Esta capa de yeso sobresale del nivel del intonaco original que queda en el tercio de bóveda que no fue arrancado, por lo que sería conveniente eliminarlo. Incluso en la zona limítrofe de ambos tratamientos, hay fragmentos de pintura original no arrancada que queda cubierta por este yeso.

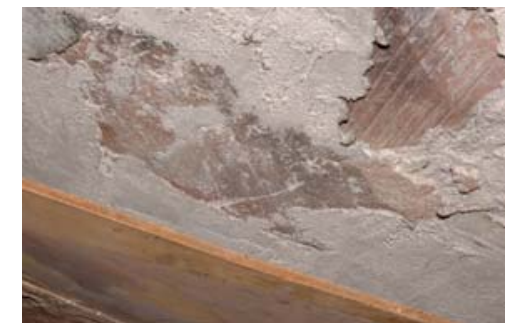

Fig. 122. Fotografía en la que se aprecia el enlucido de yeso bajo los paneles de madera.

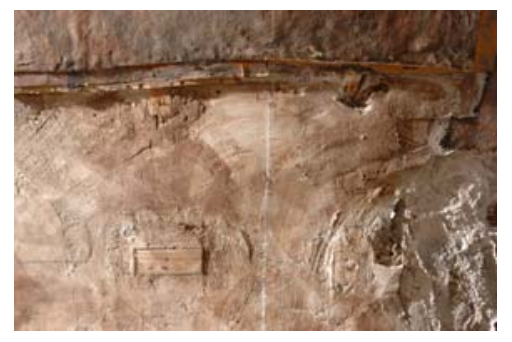

Fig. 123. Fotografía en la que se aprecia el enlucido de yeso y los tacos de madera que sirven para clavar los paneles. 


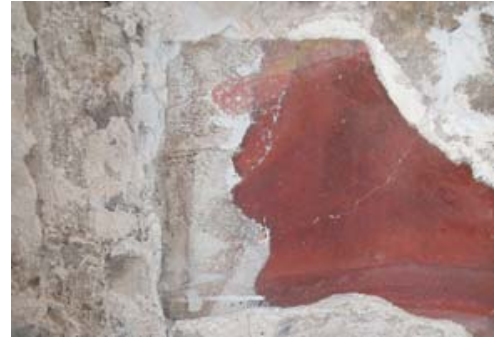

Fig. 124. Fotografía en la que se aprecia el yeso aplicado en la intervención de los años 60 sobre pintura original no arrancada.

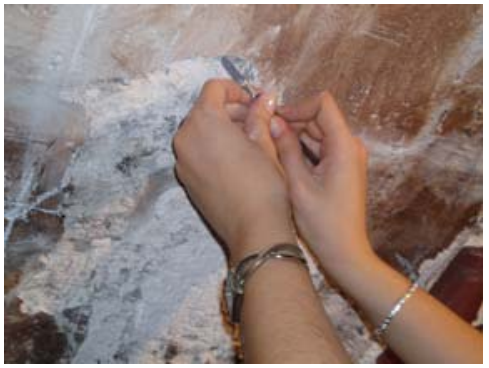

Fig. 126. Proceso de eliminación mecánica del yeso que se aplicó en la intervención de los años 60.

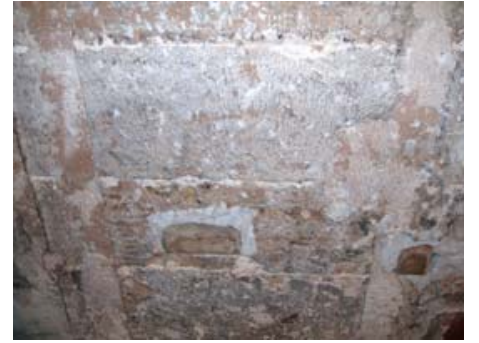

Fig. 125. Arco de piedra bajo la zona donde estaba ubicado el panel que estamos tratando, con los tacos de madera incrustados en él.

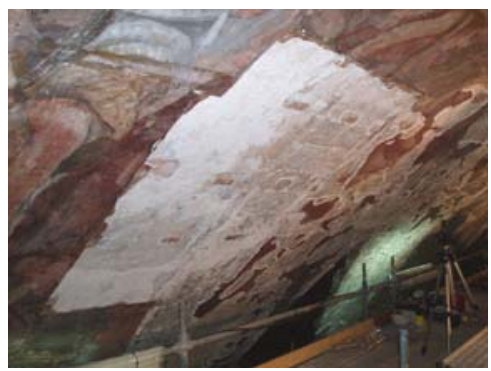

Fig. 127. Zona del panel que estamos tratando, una vez eliminado el yeso aplicado en la intervención de los años 60

Una vez despojada la bóveda del yeso, quedaría una superficie irregular. Si colocásemos directamente sobre esta superficie la pintura con su nuevo soporte, correríamos el riesgo de que se produjesen ciertos movimientos que, podrían ser perjudiciales para la pintura.

El tratamiento que se propone es lijar la superficie hasta conseguir que esté $2 \mathrm{~mm}$ por debajo de la pintura original adyacente. Aun así, la superficie quedaría irregular, por lo que el nuevo soporte, aunque estuviese atornillado al muro con muchos puntos de anclaje, no estaría totalmente en contacto con una superficie subyacente homogénea. Esto no implicaría un posible desprendimiento de los paneles, pero podría provocar movimientos indeseados en la pintura. Para subsanar esta irregularidad de la superficie, se propone aplicar un mortero ligero que no sobrepase el volumen acordado de $2 \mathrm{~mm}$ bajo el nivel de la pintura original, sino que debería simplemente cubrir los huecos de la irregularidad de la superficie, dejándola homogénea. 
Antes de la aplicación de este mortero, debería estudiarse detenidamente los puntos de anclaje que le hacen falta a cada panel en concreto y, teniendo el "cartón"180 de dicha zona, se trasladaría el dibujo de la zona a la bóveda por medio de estarcido, pudiendo trasladar así la ubicación de cada punto de anclaje y pudiendo perforar la superficie en los puntos deseados. Deberían insertarse, a modo provisional en los orificios creados, pequeñas varillas que sobresaliesen del nivel del mortero, para no perder la referencia de la ubicación de los puntos de anclaje.

Seguidamente, podría aplicarse un mortero expansivo, tipo aluminato cálcico o de bario. Este tipo de mortero, al tener resistencias mecánicas muy bajas (similares e incluso inferiores a las de un mortero de cal y arena) es altamente reversible por medios mecánicos. Además, siendo impermeable y liso el reverso del nuevo soporte aplicado a las pinturas arrancadas, el mortero de expansión quedaría adherido únicamente a la bóveda, y no al nuevo soporte, permitiendo una mayor facilidad para poner y quitar este último.

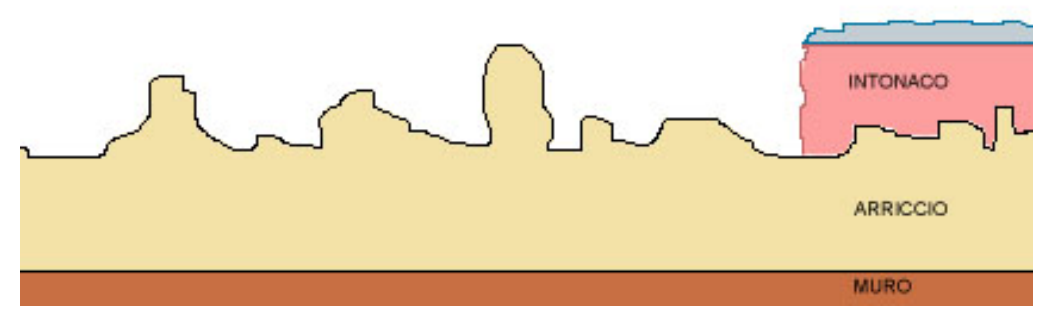

Fig. 128. Dibujo explicativo del estado del arriccio al desclavar el soporte de madera.

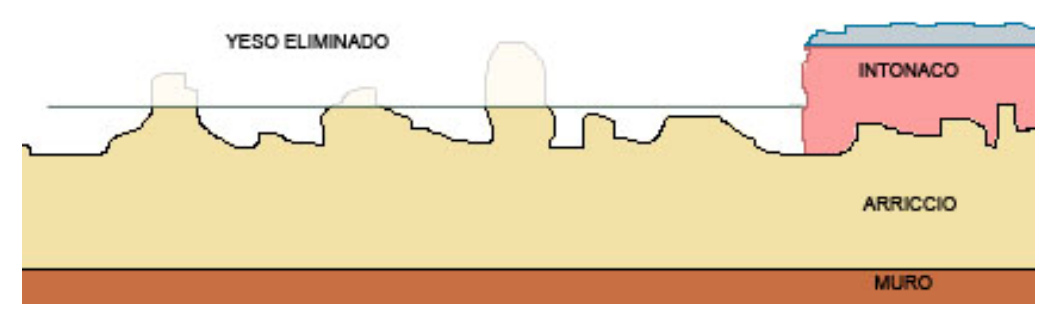

Fig. 129. Dibujo explicativo de la fase de lijado de la superficie de yeso del arriccio. ${ }^{180}$ El "cartón" o plantilla se debería extraer de la fotografía tomada antes del indendio de
1936, ya retocada, con la deformación eliminada, e impresa a tamaño real. 


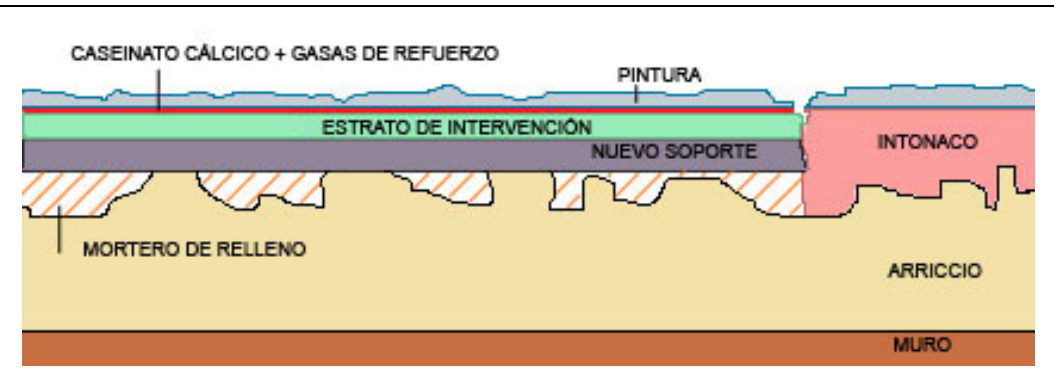

Fig. 130. Dibujo explicativo de la colocación del nuevo soporte con la pintura arrancada y aplicación de un mortero de relleno para las salvar irregularidades del arriccio.

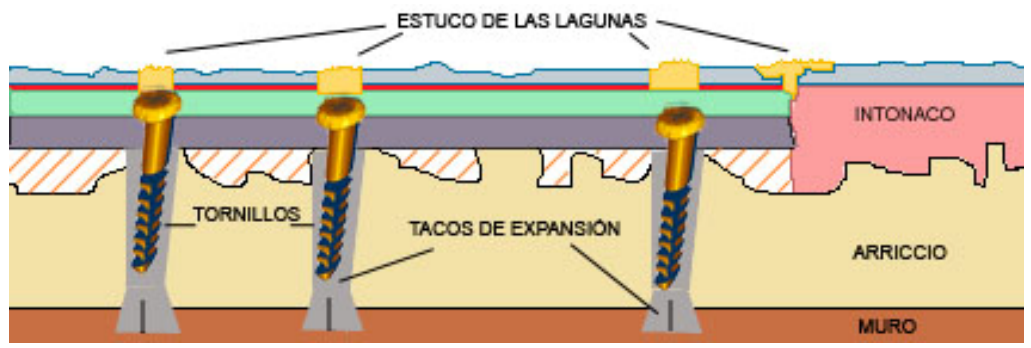

Fig. 131. Dibujo explicativo de la colocación de anclajes en la bóveda para sujetar los nuevos soportes con la pintura arrancada.

Inmediatamente, antes de que empezase a expandirse el mortero, se aplicaría el nuevo soporte con la pintura, ejerciendo una ligera presión para que quedase al nivel del resto de la pintura que no fue arrancada. El mortero que desbordase por los lados, se eliminaría. 


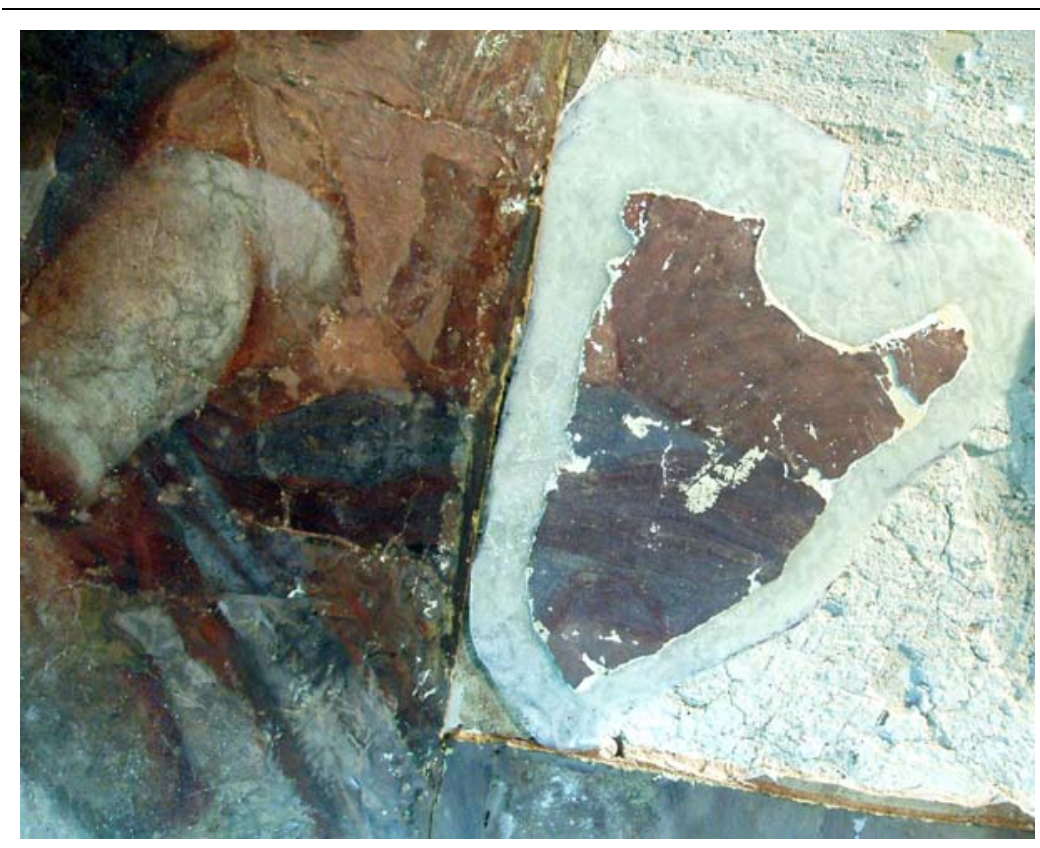

Fig. 132. Imagen de la colocación provisional de un fragmento del panel de pintura mural arrancada.

Como se aprecia en la Fig. 132 hay fragmentos de pintura que son contiguos a otros, por lo que habría que cortar el soporte sobrante con el fin de que ambos fragmentos acoplasen perfectamente. Habría que estudiar por ello los límites exactos de cada uno de los paneles, proceso que no puede realizarse sin el previo montaje de un andamio que permita acceder a la bóveda.

No obstante, como hemos explicado anteriormente, el proceso de reposicionamiento de los fragmentos de pintura mural arrancada en la bóveda, queda condicionado a la realización de la adaptación de la fotografía anterior al incendio, pues en la actualidad desconocemos la ubicación de cada fragmento en el conjunto de la bóveda.

Una vez colocados todos los fragmentos sobre la bóveda, el aspecto debería ser similar al que conserva la parte de la bóveda que no fue arrancada y que está siendo intervenida en la actualidad. De este modo, las lagunas de ambas partes de la bóveda podrían ser tratadas de igual forma, así este proceso de estucado y reintegración daría unidad a todo el conjunto de las pinturas de Palomino en la bóveda de la nave central de la Iglesia de los Santos Juanes de Valencia. 




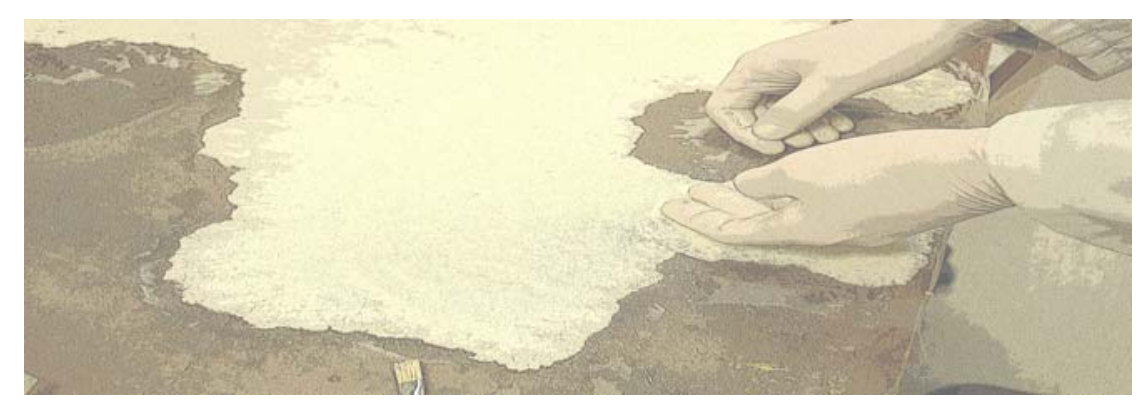

CAPÍTULO VI

IL PROCESSO DI RESTAURO IN UNO DEI PANELLI DI PITTURA STRAPPATA DALLA VOLTA DELLA CHIESA DI SANTOS JUANES DI VALENCIA

APLICACIÓN DEL PROCESO SOBRE UN FRAGMENTO DE PINTURA MURAL DE LA BÓVEDA DE LA NAVE CENTRAL DE LA IGLESIA DE LOS SANTOS JUANES DE 




\section{IL PROCESSO DI RESTAURO IN UNO DEI PANELLI DI PITTURA STRAPPATA DALLA VOLTA DELLA CHIESA DI SANTOS JUANES DI VALENCIA}

Già tratte tutte le conclusioni, prima di applicare nella prattica il trattamento di distacco dei frammenti di pittura reale dal pannello è necessario seguire prima una serie di punti:

- Elaborazione del calco delle parti della pittura originale per conservare la posizione attuale dei frammenti sul supporto, anche se sappiamo che è molto probabile che la posizione attuale di questi frammenti, non sia quella originale. Per questo, sarebbe necessario confrontare, la posizione dei frammenti originali della pittura con la posizione di quelli stessi frammenti nella fotografia che si conserva delle pitture prima di subire l'incendio.

* Pulitura delle impurità e degli elementi estranei alla propria pittura.

* Consolidamento della superficie dopo la pulitura.

Abbiamo elaborato un calco in cui si riflettono i profili dei frammenti di pittura originale all'interno del pannello. II motivo per l'elaborazione di questo calco è avere un riferimento della posizione in cui i Gudiol rimisero i frammenti della pittura al nuovo supporto di legno.

Non sappiamo se questa posizione è quella corretta, ma anche il testimone del lavoro che hanno fatto i restauratori catalani durante gli anni 60 risulta interessante dtanto da volerne conservare i riferimenti posizionali.

Prima di procedere al trattamento di pulitura della superficie pittorica, abbiamo effettuato una serie di prove di pulitura, per scegliere il metodo migliore da usare nell'insieme del lavoro.

Nel seguente schema si vede la posizione di ogni prova di pulitura: 

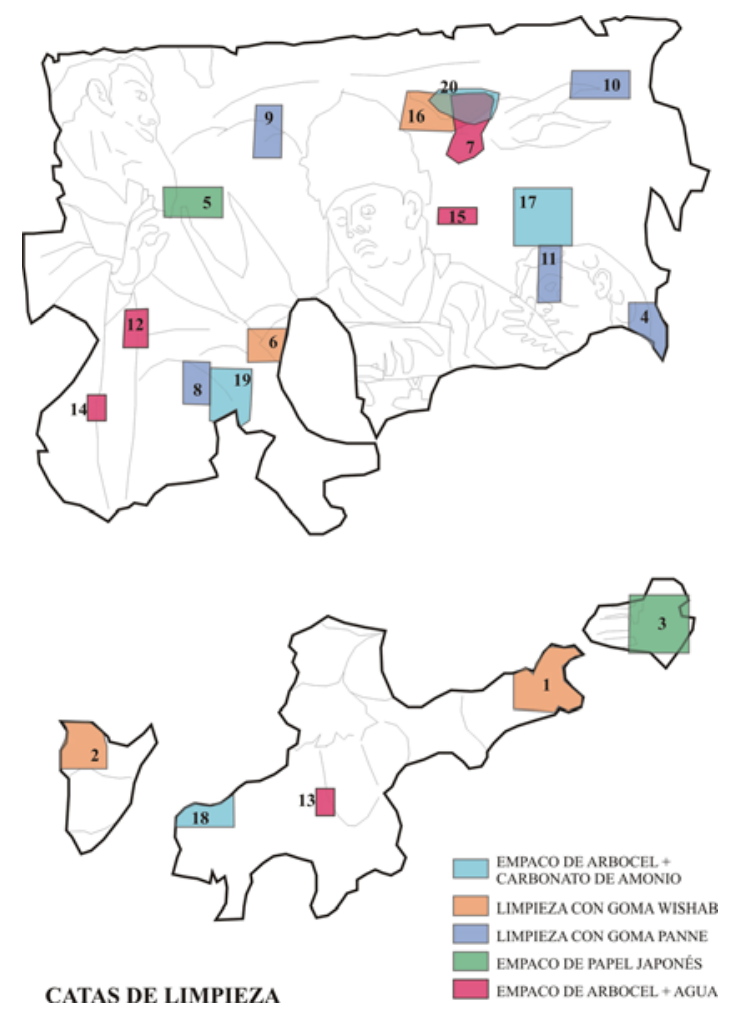

Fig. 133. Diagramma spiegativo delle prove di pulitura che abbiamo fatto sulla superficie pittorica originale del pannello di pittura murale strappata.

Dopo avere fatto queste prove di pulitura, abbiamo deciso pulire con impacchi di Arbocel BC-200 + ammonio carbonato, giacché elimina molto bene tanto la sporco quanto le ridipitture a vernice.

Questa metodologia è stata utilizzata per la pulizia di tutta la superficie. Abbiamo applicato gli impacchi a traverso 3 fogli di carta giapponese di $11 \mathrm{gr}$.

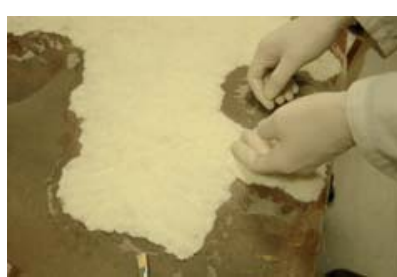

Fig. 134. Applicazione d'un impacco di Arbocel e ammonio carbonato per pulire la superficie pittorica. 


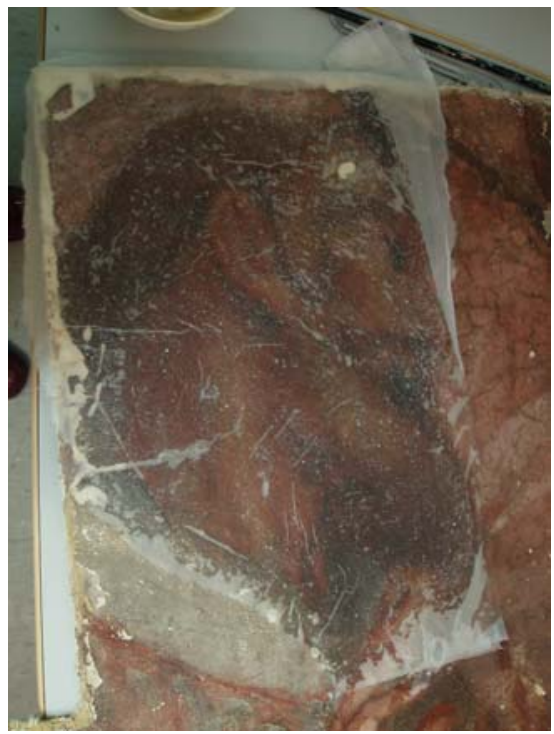

Fig. 135. Applicazione di tre fogli di carta giapponese prima di applicare l'impacco di cellulosa.

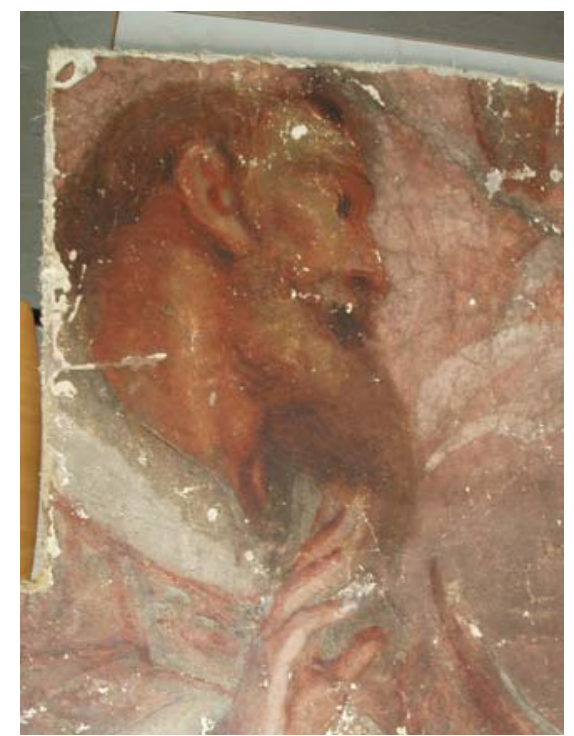

Fig. 136. Immagine d' una delle figure del pannello già pulito.

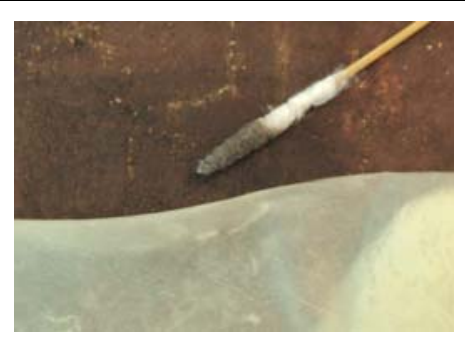

Fig. 137. Pulitura dei resti $d i$ ridipittura mediante un bastoncito con cotone impregnato di ammoniaca.
Abbiamo ripulito i resti delle ridipitture che non sono stati eliminati completamente per mezzo di impacchi di carbonato di ammonio, utilizzando un bastoncino per pulitura con cotone, ed una soluzione di ammoniaca a $10 \%$ in acqua.

Dopo la pulitura di tutta la superficie, sono rimaste le zone che brillano possibilmente perche è ancora rimasta colla dello strappo degli anni 60 nella superficie. Se osserviamo la pittura con luce U.V., possiamo vedere che queste zone brillanti danno una riflessione differente dal resto della superficie, di un colore giallastro. Ciò possibilmente si debba alla presenza di colla o di vernice. 


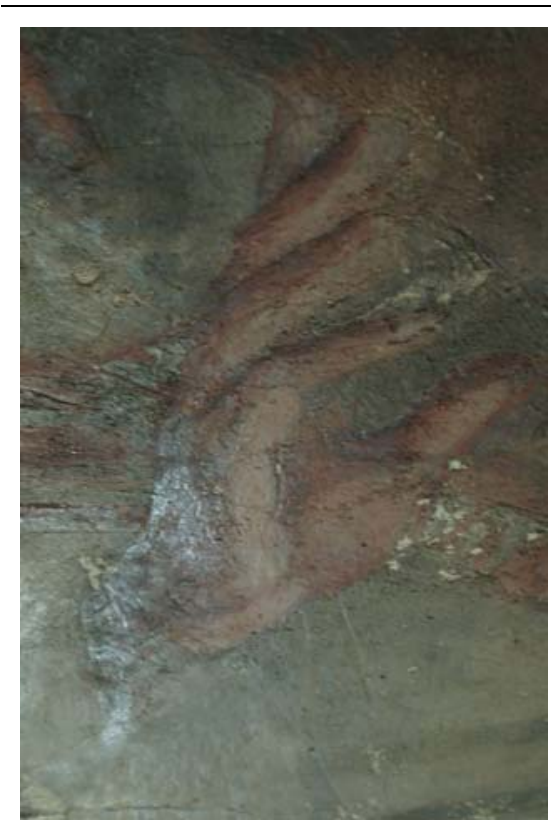

Fig. 138. Immagine con luce radente della zona della mano nella quale si vede l'eccesso di brillo.

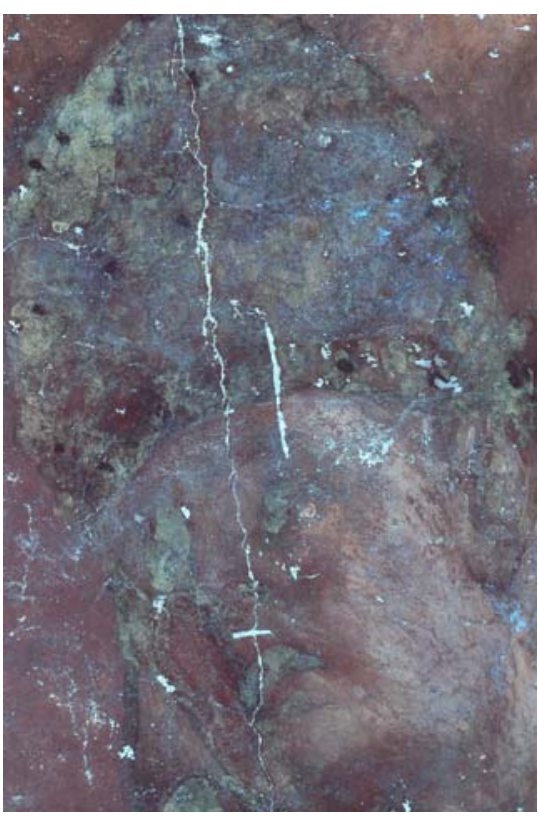

Fig. 140. Immagine con luce U.V. nella quale si vedono giallastre le zone che appaiono brillati con luce naturale.

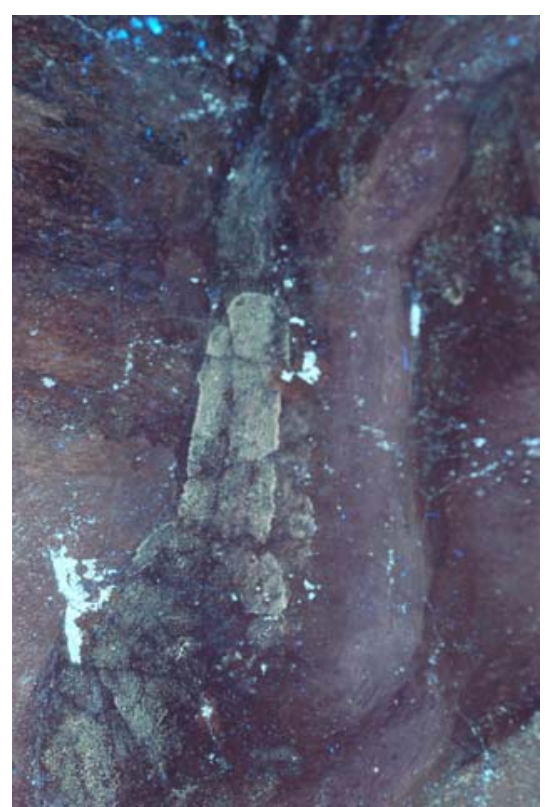

Fig. 139. Immagine con luce U.V. nella quale si vede la zona di brillo che corresponde alla fotografia anteriore, che qui si vede in colore giallastro.

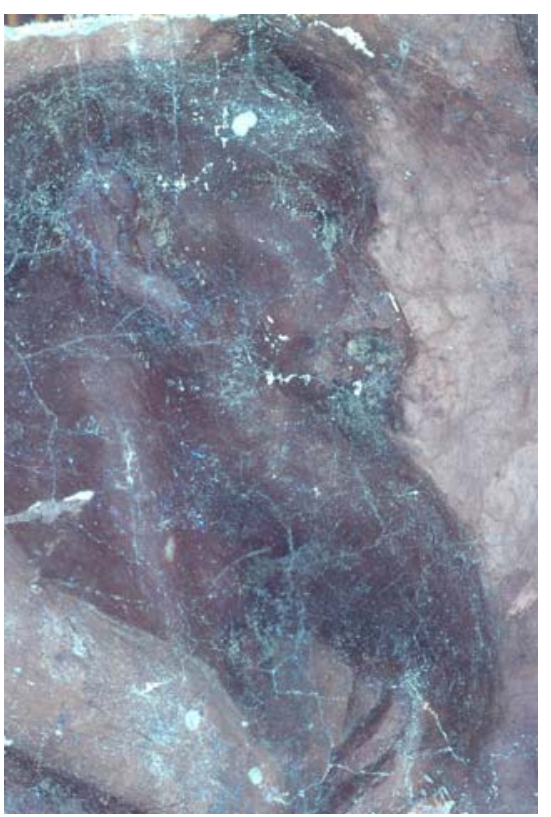

Fig. 141. Immagine con luce U.V. nella quale si vedono giallastre le zone che appaiono brillati con luce naturale. 
Per eliminare questi punti brillanti abbiamo provato con una soluzione enzimatica per l'eliminazione di sostanze proteiche. Abbiamo provato con differenti periodi d'applicazione, per arrivare alla conclusione di quale è il periodo d'applicazione più adatto, cioè: fra 8 e 10 minuti. Nonostante, la pulitura non è stata molto spettacolare, poiché continuano a rimanere $\mathrm{i}$ resti

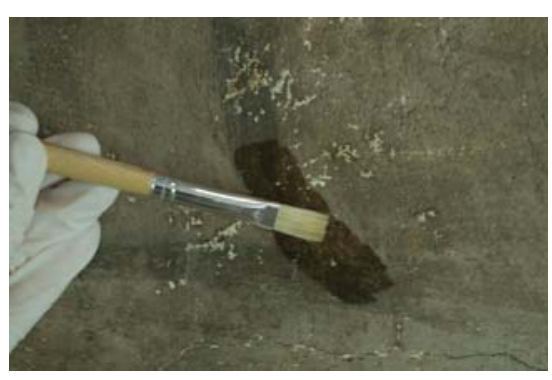

Fig. 142. Applicazione della soluzione enzimatica per l'eliminazione di sostanze proteiche.

brillanti nella superficie.

Ciò può essere dovuto a che gli enzimi non attuano in presenza di metalli, e la maggior parte dei pigmenti usati in questa opera, sono ossidi di ferro, quindi, nel momento in cui gli enzimi attraversano lo strato brillante ed entrano in contatto con i metalli dei pigmenti, perdono la loro forza e la loro efficacia.

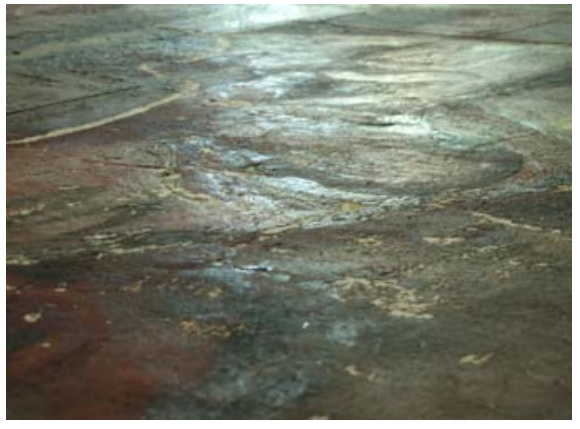

Fig. 143. Immagine con luce radente d'una zona con brilli.

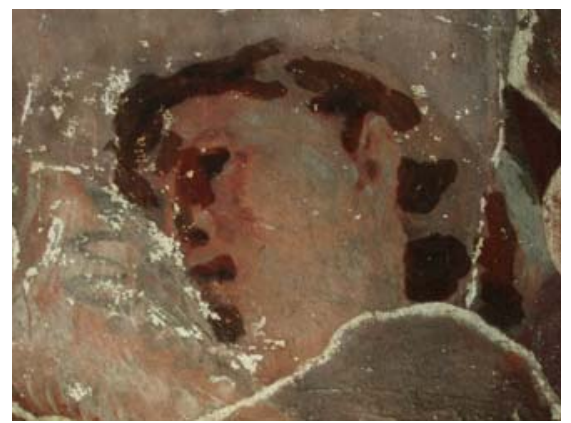

Fig. 144. Immagine nella quale si vedono macchie scure che corrispondono alle zone dove si è applicata la zoluzione enzimatica.

Eliminate la maggior parte delle zone brillanti, il seguente punto logico nel trattamento di questo lavoro è il consolidamento della superficie pittorica.

Come metodo di consolidamento della superficie pittorica, prima di fare gli altri trattamenti, abbiamo applicato un trattamento di idrossido di bario solamente nei tre frammenti inferiori della pittura ed in una zona di piccole dimensioni del frammento superiore. 
Questo trattamento suppone un linea di ricerca di una'altra tesi che è in processo di dottorato, perciò è in quella tesi dove si spiegheranno le ragioni per cui si è stato fatto questo tipo di trattamento.

Come punto precedente alla protezione della superficie, abbiamo effettuato dei tagli intorno al perimetro dei frammenti della pittura originale, allo scopo di separare del supporto di legno solamente questi frammenti, e non le ridipitture fatte durante gli anni 60. Questi tagli, fatti a 3 o 4 millimetri del perimetro della pittura, sono stati effettuati con l'aiuto meccanico di un mini-disco di taglio; e per assicurarci che il disco aveva attraversato tutti gli strati, lo stucco e i tessuti, abbiamo rifatto i tagli con un bisturi.

II fatto di farli a pochi millimetri dal perimetro reale della pittura originale è motivato dalla migliore conservazione di questa pittura originale, che potrebbe subire danni nel caso di effettuare tagli troppo vicini ad essa.

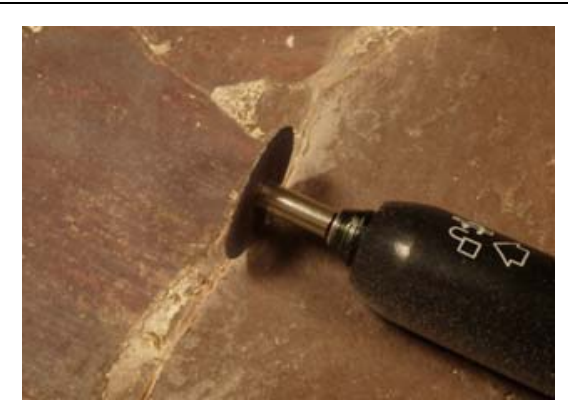

Fig. 145. Processo di taglio del perimetro della pittura originale.

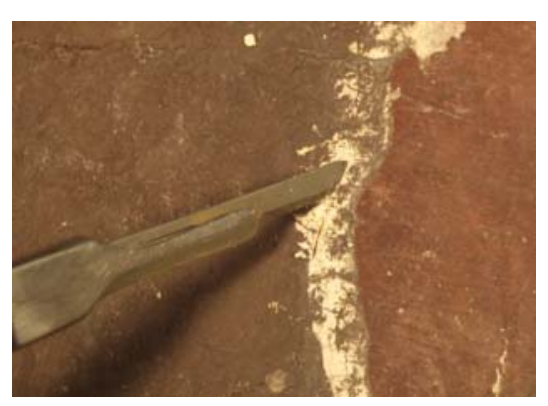

Fig. 146. Processo di taglio col bisturi.

Passato il tempo richiesto per la corretta carbonatazione dell'idrossido di bario, abbiamo fatto la protezione della superficie pittorica ed il trattamento successivo della separazione del supporto di compensato di legno.

È stata usata, per la protezione, garza di cotone (veladina), e tessuto di cotone (crinolina) aderite con della colla di gelatina in una proporzione al 16\%, come avevamo già spiegato nelle conclusioni delle provette fatte precedentemente allo scopo di conoscere il metodo più adatto per la protezione di questa opera. 


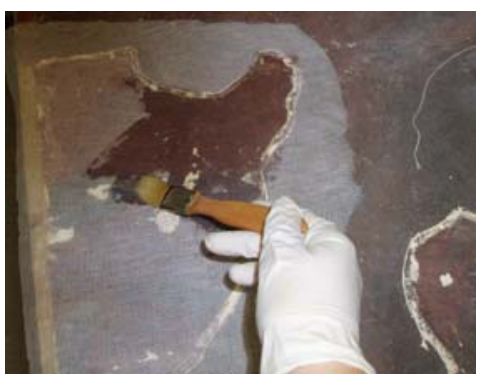

Fig. 147. Aplicazione della colla sopra la garza di protezione della pittura originale.

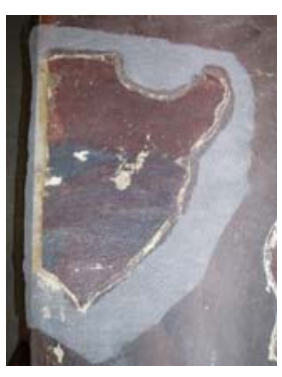

Fig. 148. Garza già aderida superficie pittorica.

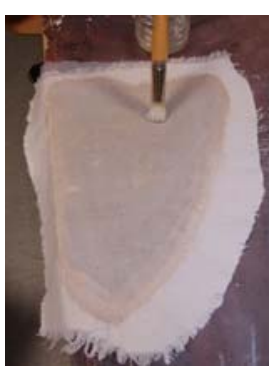

Fig. 149. Adhesión con cola de la tela de algodón.

Già protetta e asciutta la superficie, abbiamo fatto la separazione, con mezzi meccanici dei frammenti della pittura originali dal supporto di legno. Abbiamo usato per esso, spatole metalliche fine, con le estremità arrotondate, per evitare tagli nei tessuti o nella pittura. Queste spatole sono state inserite fra i tessuti del retro della pittura, ed il legno di supporto.

La forza meccanica delle spatole, con l'aiuto della forza da strappo, sono state sufficienti per ottenere una buona separazione di entrambi gli strati, senza la necessità dell' aiuto di umidità per riattivare l'adesivo che li ha uniti, che era già stato riattivato con l'umidità dell'adesivo della protezione.
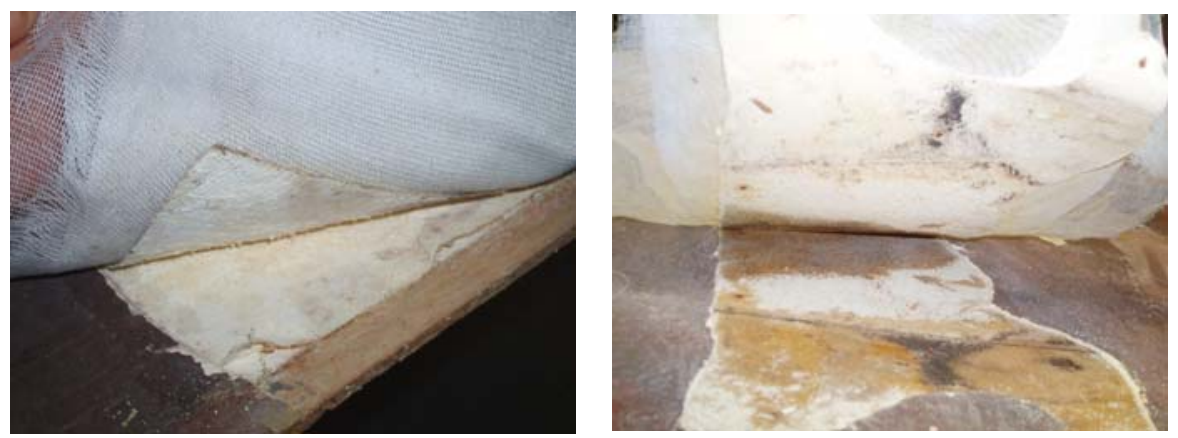

Fig. 150 e 151. Processo di separazione della pittura protetta dal pannello di legno.

Distaccata già la pittura con il suo strato di garza e quello di tessuto con il caseato di calce, il tessuto ${ }^{181}$ del verso si distacca facilmente, perchè, come abbiamo visto nel capitolo I, i Gudiol hanno applicato un

${ }^{181}$ Questo tessuto ha una trama di 22 fili per $\mathrm{cmq}$ e un ordito di 24 fili per $\mathrm{cmq}$. 
caseato di calce con poco potere adesivo (8 parti di calce e 1 parte di caseina). Questo fatto ha provvocato che il tessuto si sia aderito a mala pena, ragione per cui l'eliminazione è facile.

Per separare il tessuto di cotone dalla garza ${ }^{182}$ si è applicata soltanto la forza meccanica di strappo, e il tessuto è venuto fuori tutto intero.
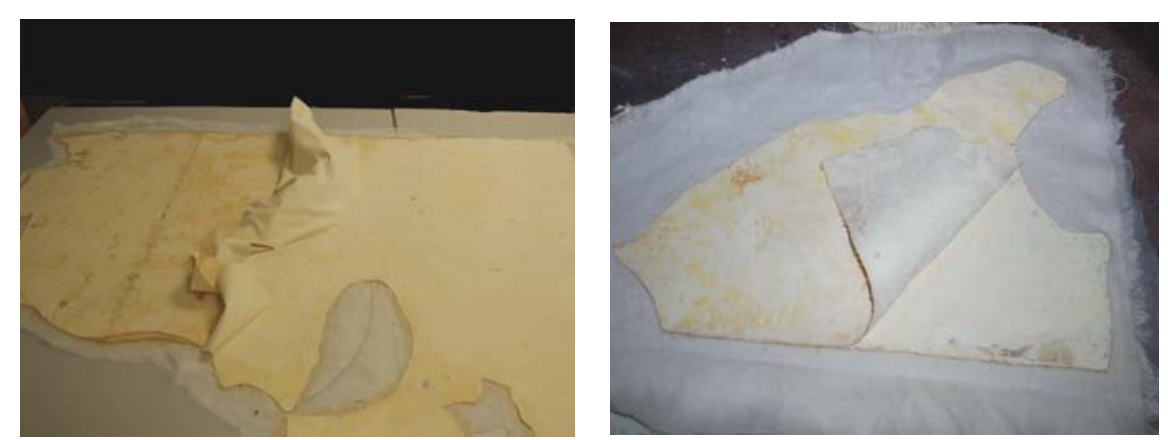

Fig. 152 e 153. Processo di separazione del tessuto di cotone con l'azione meccanica

Considerando che l'eliminazione della garza non è stata necessaria, poiché la maggior parte di questa si aderisce perfettamente al retro della pittura. Soltanto abbiamo considerato consigliabile eliminare la garza in uno dei piccoli frammenti di pittura, perchè era totalemente staccata. Con l'eliminzione della garza, inoltre si sono anche eliminate le ridipitture, cosí, le lacune sono rimaste pulite.

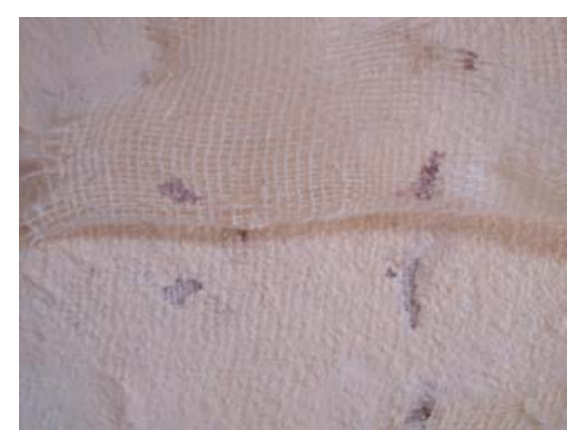

L'azione meccanica del bisturi è stata richiesta per ridurre lo strato di caseato di calce e lasciare la garza libera.

Fig. 154. Immagene in cui si vede come le ridipitture vanno via ataccate alla garza.

${ }^{182}$ Questa garza ha una trama di 8 fili per cmq e un ordito di 10 fili per cmq. 


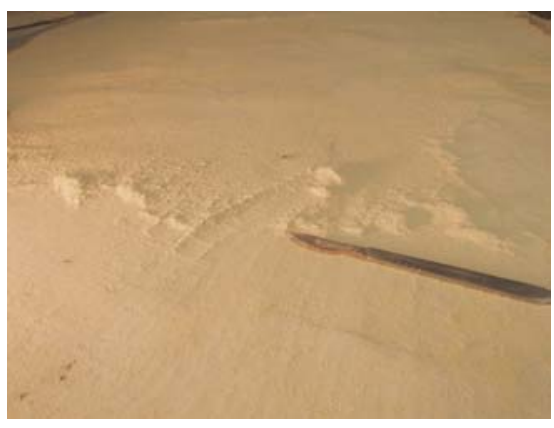

Fig. 155. Processo de riduzione del caseato di calce dal verso dell'opera.

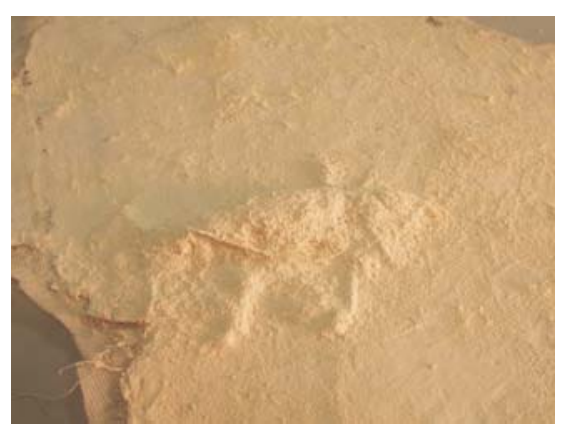

Fig. 156. Polvere risultante del processo di riduzione del del caseato di calce dal verso dell'opera.

È rimasto il retro della pittura libera degli elementi alieni, ma pure, ha bisogno d'un processo di consolidamento per ristabilire la stabilità del poco supporto originale che è rimasto.

Abbiamo deciso di applicare una garza aderita con caseato di calce, ma con una proporzione differente, con un potere aderente più alto di quello usato dai fratelli Gudiol nel ripristino degli anni 60. Questo caseato di calce è stato fatto con 3 parti di calce aerea, fornito dalla CTS, e 1 parte di caseina lattica. A questa miscela abbiamo aggiunto un $2 \%$ di Acril 33, per renderla più appiccicosa ed elastica.

II motivo di questa scelta, è il fatto di non volere continuare ad aggiungere degli elementi alieni all'opera. Nel momento del restauro degli anni 60 il caseato di calce era un elemento alieno all'opera, ma dopo quell'intervento, questo materiale è diventato un elemento costituente della propria opera, ragione per la quale se ora applicassimo un altro adesivo concolidante, saremmo sovraccaricando all'opera di trattamenti molto diversi che potrebbero, a lungo termine, dannarla.

Il caseato di calce è, in più, un prodotto molto compatibile alla malta di calce e sabbia, quello si transforma in carbonato calcico quando asciuga.

Nel verificare l'alta tensione superficiale della miscela, che ha impedito la penetrazione corretta nella malta originale dal retro del dipinto, abbiamo deciso applicarne precedentemente una miscela d'alcool e acqua a 50\%. Ci siamo verificati così, che la miscela del caseato di calce, che è stata elaborata abbastanza liquida, ha penetrato sufficientemente per consolidare questa malta originale. 


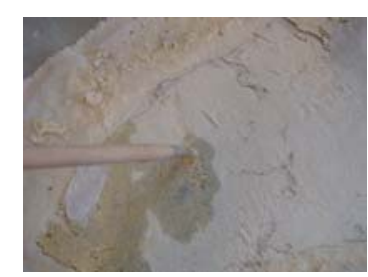

Fig. 157. Aplicazione a pennello del tensoattivo al retro dell'opera dei

frammenti piccoli.

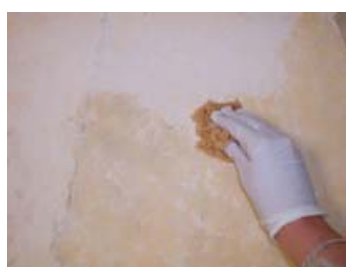

Fig. 158. Aplicazione a spugna del tensoattivo al retro dell'opera frammento grande.

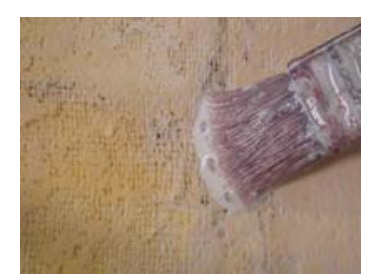

Fig. 159. Prima Aplicazione mano di caseato di calce molto liquido.

Assicurata già la penetrazione corretta del consolidante, abbiamo applicato la garza, con lo scopo d' evitare che fissuri il caseato di calce mentre asciuga, ed evita così i movimenti possibili durante il processo di essiccamento. Per l'adesione di questa garza abbiamo usato un caseato di calce ispessito con della polvere di pietra pomice, che oltre ad ispessire, conferisce idraulicità alla miscela. Ci siamo assicurati così che le parti interne del caseato di calce, carbonatino tanto quanto le più esterne.

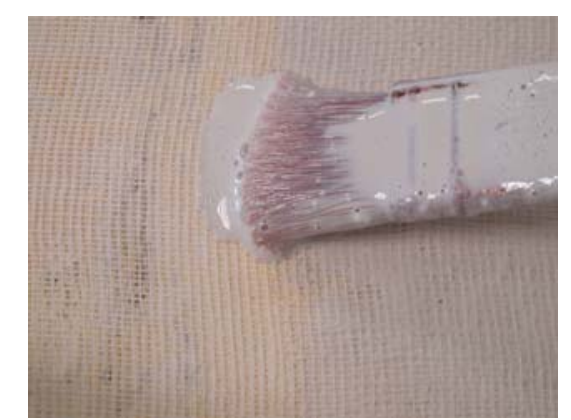

Fig. 160. Processo d'applicazione del caseato di calce ispessito al retro dell'opera.

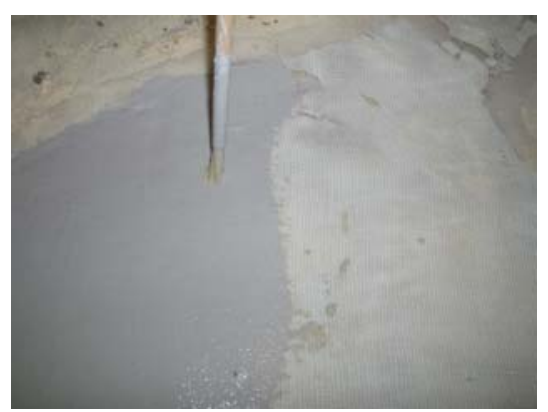

Fig. 161. Processo d'applicazione del caseato di calce ispessito al retro dell'opera.

Abbiamo lasciato asciugare il retro della pittura durante un giorno, prima dell'applicazione dello strato d'intervento.

Abbiamo fatto un nuovo supporto con fibra di vetro di $\mathrm{gr} 450 . \mathrm{m}^{2}$, e resina epoxi. È stato tagliato un bordo di 2 centimetri circa intorno al perimetro della pittura originale, per avere un margine dove disporre gli ancoraggi che unirano il nuovo supporto alla parete della volta. Per esso, abbiamo usato il calco che avevamo fatto della superficie pittorica originale. Dopo aver tagliato la forma desiderata in fibra di vetro, abbiamo 
disposto ogni frammento su un lamina di melinex, per evitare l'adesione del nuovo supporto alla superficie di lavoro durante il processo.

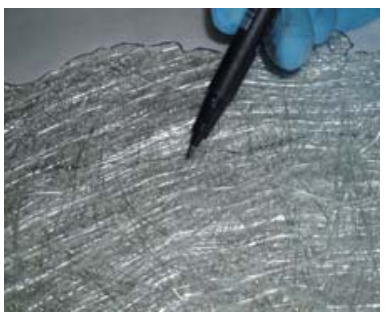

Fig. 162. Segnando il profilo della pintura sulla fibra di vetro per tagliarla.

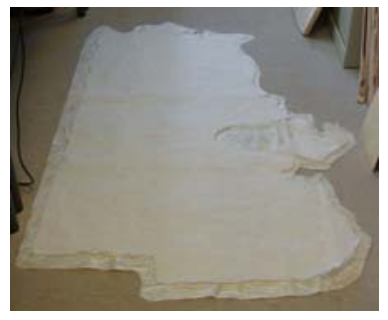

Fig. 163. Fibra di vetro già tagliata eseguendo la forma del calco della pintura originale.

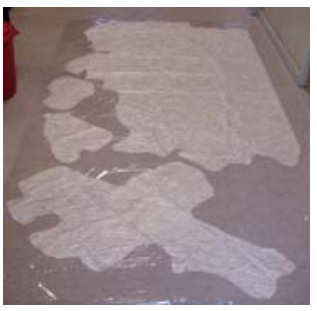

Fig. 164. I quattro frammenti di fibra di vetro che conformerano il supporto per i quattro frammenti di pintura strappata che ha il pannello che stiamo studiando.

Abbiamo applicato la resina epoxi con un rullo metallico speciale, ed abbiamo protetto tutti i frammenti con una lamina di melinex, per farli asciugare sotto peso.

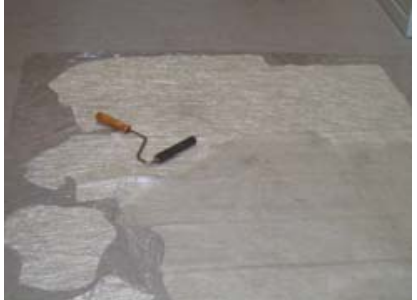

Fig. 165. applicazione della resina sopra la fibra di vidrio.

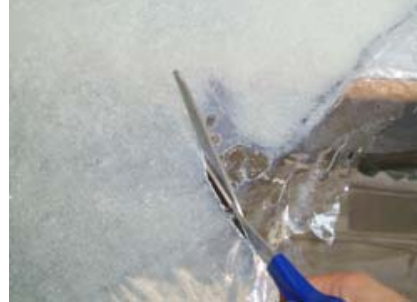

Fig. 166. Processo di taglio della fibra di vetro già polimerizzata che eccede del perimetro segnato.

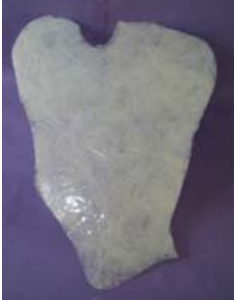

Fig. 167. Supporto di fibra di vetro e resina di uno dei frammenti di pittura.

Il nuovo supporto, una volta asciutto, deve essere adattato per la buona adesione dello strato di intervento; quello sarà disposto fra i rupporto e la pittura strappata. Per esso che abbiamo carteggiato la superficie con un levigatrice elettrica, allo scopo di aprire il poro della resina, e per lasciare una struttura adatta per la stretta perfetta adesione del adesivo. 


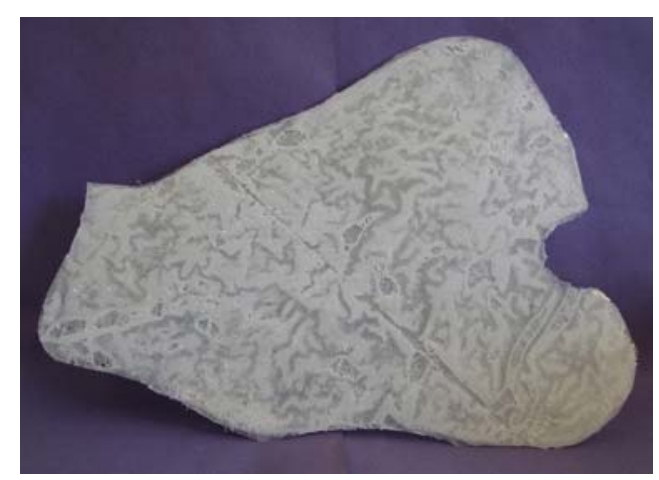

Fig. 168. Uno dei supporti già carteggiati.

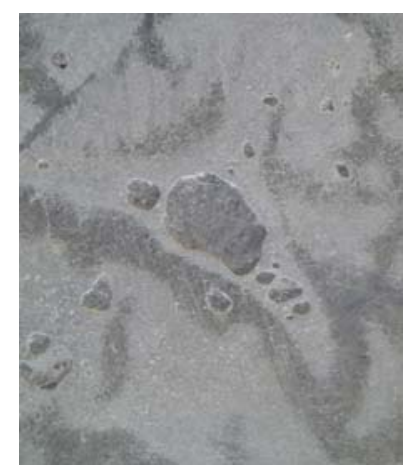

Fig. 169. Particolare dell'aspetto della superficie del supporto già carteggiato.

Lo strato di intervento più adatto per questo lavoro, come abbiamo visto in capitoli precedenti, abbiamo considerato che è la carta a frattura predeterminata. Questa carta è stata tagliata seguendo il contorno del frammento di pittura originale, ed il nuovo supporto con Beva si è aderito tanto al reverso della pittura quanto al nuevo supporto con Beva O.F.

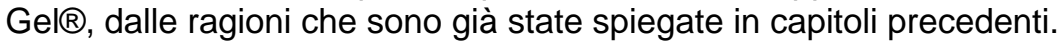

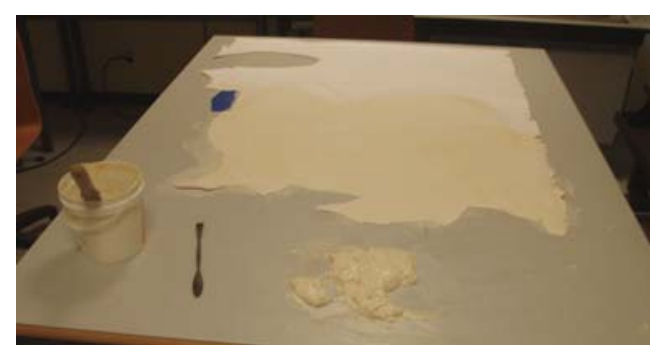

Fig. 170. Processo d'applicazione della Beva O.F. Gel alla carta a frattura predeterminata.

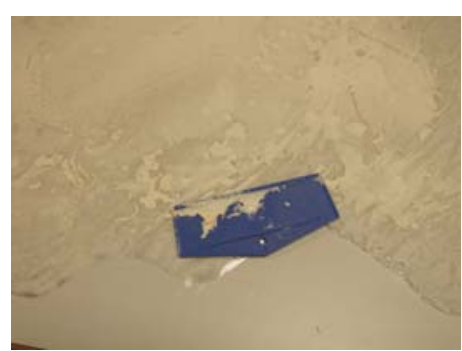

Fig. 171. Processo d'applicazione della Beva O.F.Gel al supporto in fibra di veetro e resina.

Applicato l'adesivo a entrambi i lati della carta a frattura predeterminata, ed aderito tanto al supporto quanto alla pittura, abbiamo applicato del peso fino all'essiccamento del adesivo.

Assicurato già il prefecto assicamento dell'adesivo d'unione di tutti gli strati del nuovo supporto, abbiamo proceduto a togliere la protezione della pellicola pittorica, per mezzo dell'applicazione di umidità controllata, con l'uso di spazzole e di spugne naturali per un'eliminazione perfetta dell'adesivo di protezione e il primo strato di tessuto. Anche se per eliminare la garza in contatto con la pellicola pittorica, e per mantenere umida e calda la superficie, abbiamo applicato un impacco di impasto di 
cellulosa con acqua deionizada attraverso di uno strato di carta giapponese. Per l'eliminazione della colla abbiamo usato anche l'azione del vapore d'acqua.

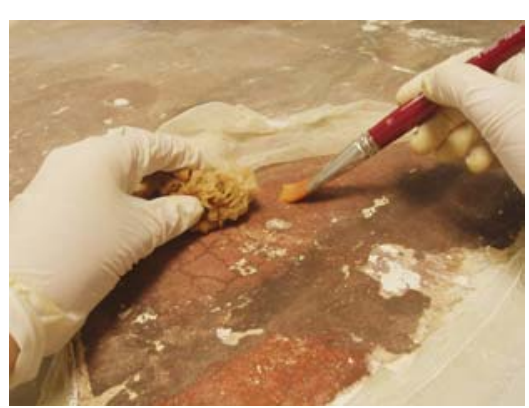

Fig. 172. Processo d'eliminazine del primo strato di tessuto di protezione.

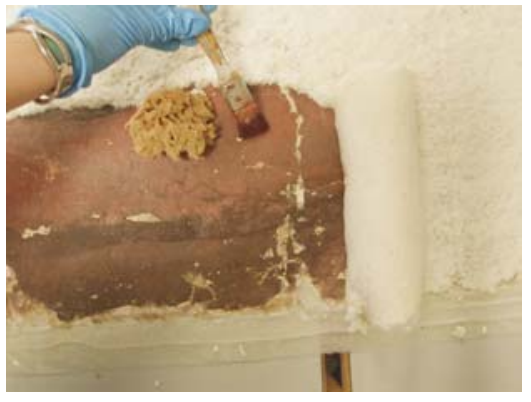

Fig. 174. Processo di pulitura dopo l'eliminazione della garza.

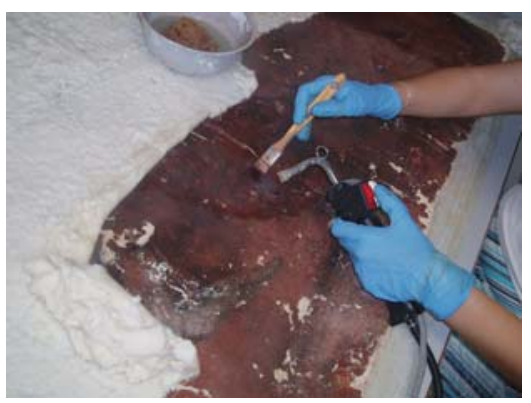

Fig. 176. Processo di pulitura con vapore d'acqua.

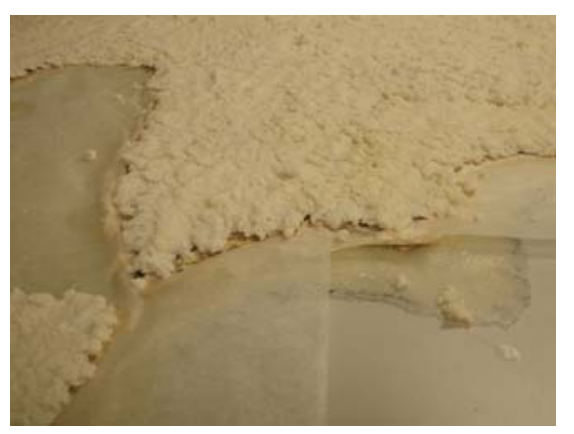

Fig. 173. Impacco di impasto di cellulosa per reattivare la colla di protezione.

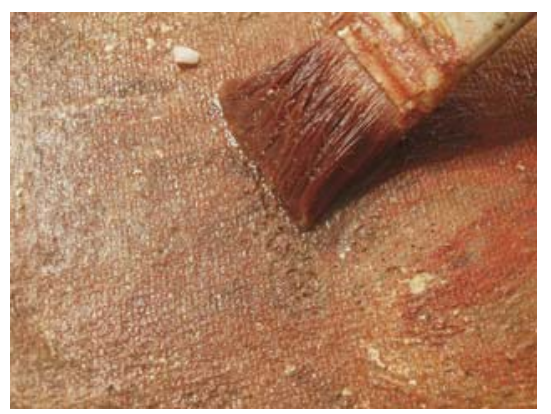

Fig. 175. Particolare in cui vediamo la colla sulla superficie pittorica.

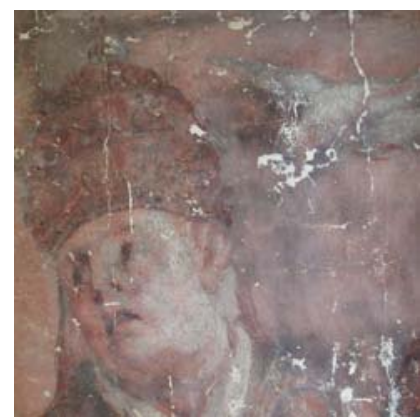

Fig. 177. Particolare d'una zona già pulita di resti di colla.

Protetta ed asciutta la pittura, per assicurarci l'eliminazione totale della colla di protezione sono state ripetute le misure colorimetriche nei punti 
sui quali erano state prese prima del processo di protezione, con il fine di confrontarli ed osservare se ci sono stati dei cambiamenti nella colorazione dei pigmenti.

Come abbiamo visto nelle tabelle comparative esposte nel punto 10.3.2 dell'Annesso III, i cambiamenti colorimetrici subiti dai pigmenti sono stati minimi, questo dato ci fa capire che abbiamo eliminato completamente la colla utilizzata nel processo di protezione.

Abbiamo anche fatto un paragone tra fotografia prese al microscopio prima della pulitura, fotografie prese dopo la pulitura e fotografie prese dopo l'eliminazione della protezione. Anche in questo tipo di fotografia abbiamo osservato pochi cambiamenti con rispetto alle fotografie prese dopo la pulitura e quelle prese dopo l'eliminazione della preotezione, questo fatto ci dà la garanzia del non cambiamento ottico della superficie pittorica. Ma la differenza fra quelle prese pirma e dopo la pulitura è abbastanza notevole.

Per finire l'intervento di questo frammento di pittura murale strappata dalla volta della chiesa dei Santos Juanes di Valencia, abbiamo tagliato con bisturi tanto il perimetro del vecchio stucco che eccede dal perimetro reale della pittura originale, quanto le rimanenze di garza e carta di frattura predeterminata che eccedono il perimetro dell'opera. Affidando quindi l'opera pronta per essere stuccata con lo stesso materiale con cui saranno stuccate lelagune della parte della volta che non è stata strappata, e per essere trasferita alla volta ed essere riassegnata nel posto d'origine.

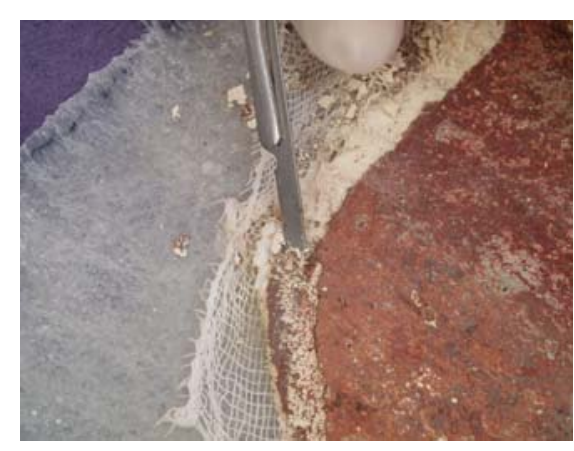

Fig. 178. Processo d'eliminazione delo vecchio stucco sul perímetro dell'opera.

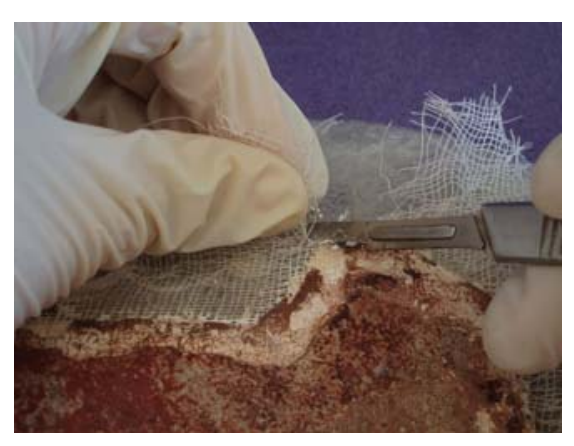

Fig. 179. Processo di taglio del remanente di garza e carta a fractura predeterminata.

L'ultimo paso nel proceso di restauro di quest'opera è costituito dall'ancoraggio del nuovo supporto alle mura della volta per mezzo di viti e tasselli d'espansione. Nonostante, questo punto viene lasciato, come abbiamo spiegato nel capitolo precedente come una linea aperta di 
ricerca, perche richiede una exaustiva ricerca lasciando la porta aperta a una nuova tesi di dottorato.

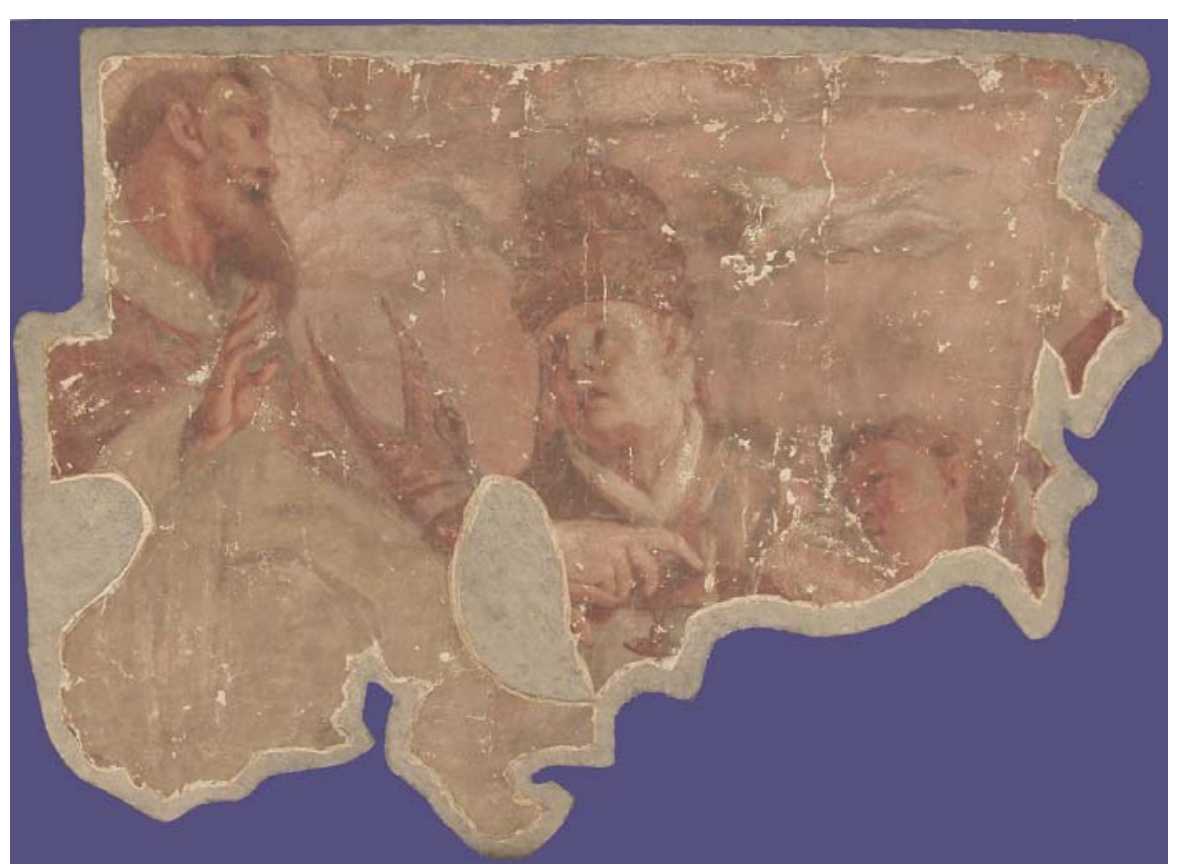

Fig. 180. Immagine finale del frammento grande traslocato al nuovo supporto.

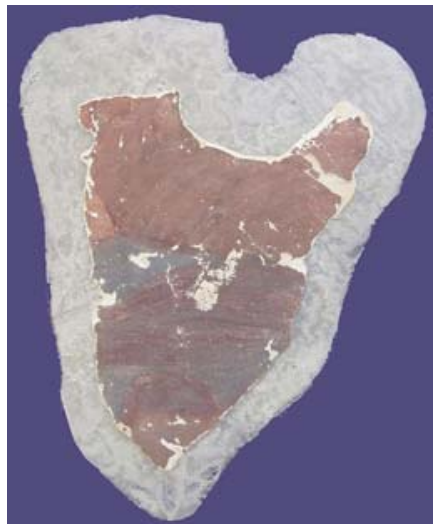

Fig. 181. Immagine finale d'uno dei frammenti piccoli traslocati al nuovo supporto.

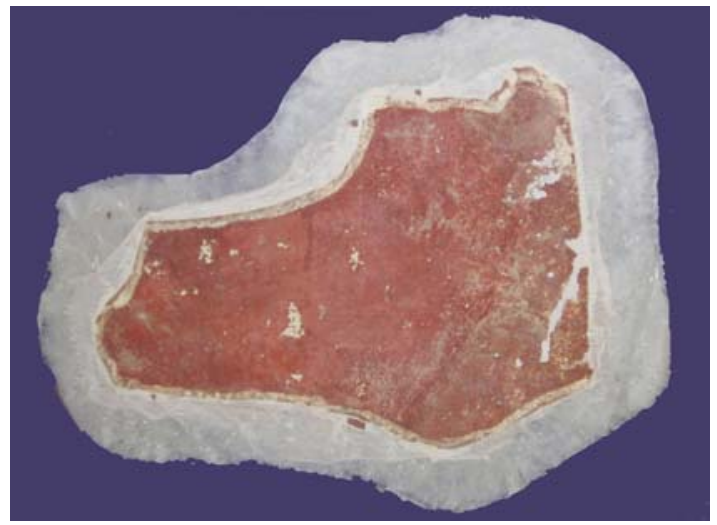

Fig. 182. Immagine finale d'un altro dei frammenti piccoli traslocati al nuovo supporto. 


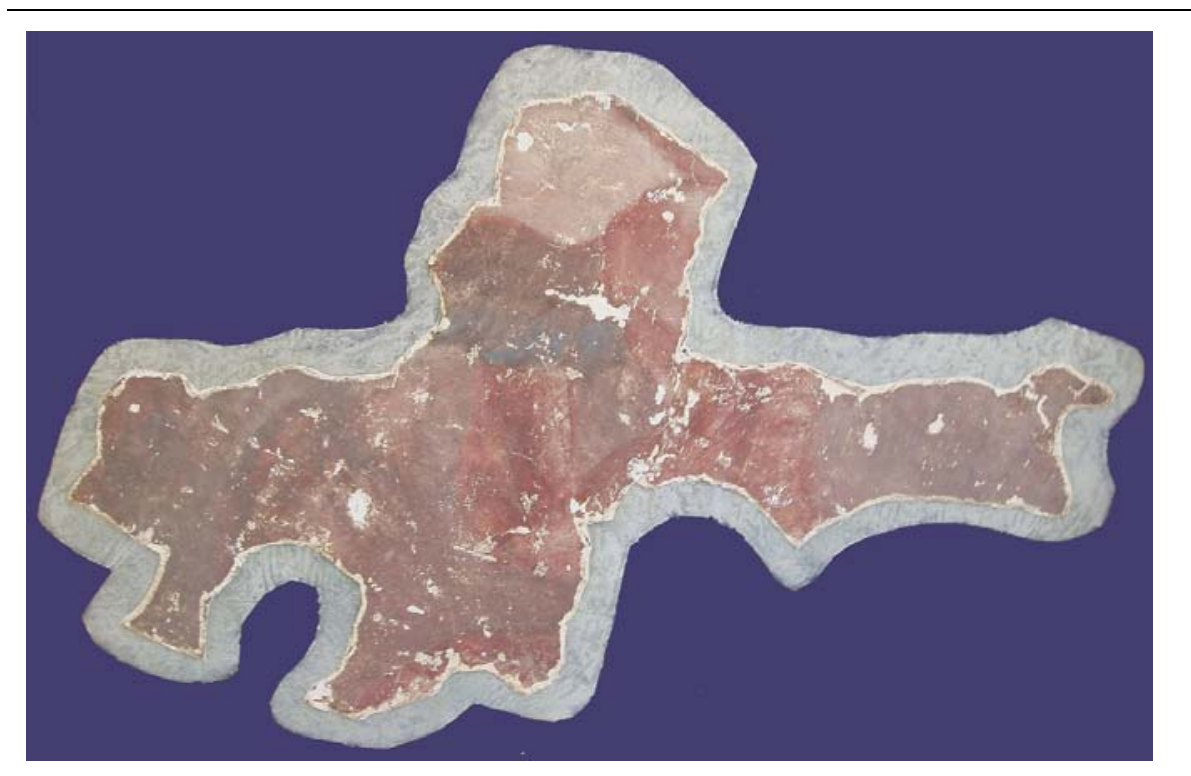

Fig. 183. Immagine del frammento mediano traslocato al nuovo supporto.

Le ridipitture fatte nell'intervento degli anni 60 sono rimaste nel supporto di legno, potendole conservare per future ricerche sul modo di fare dei restauratori di quel tempo. 


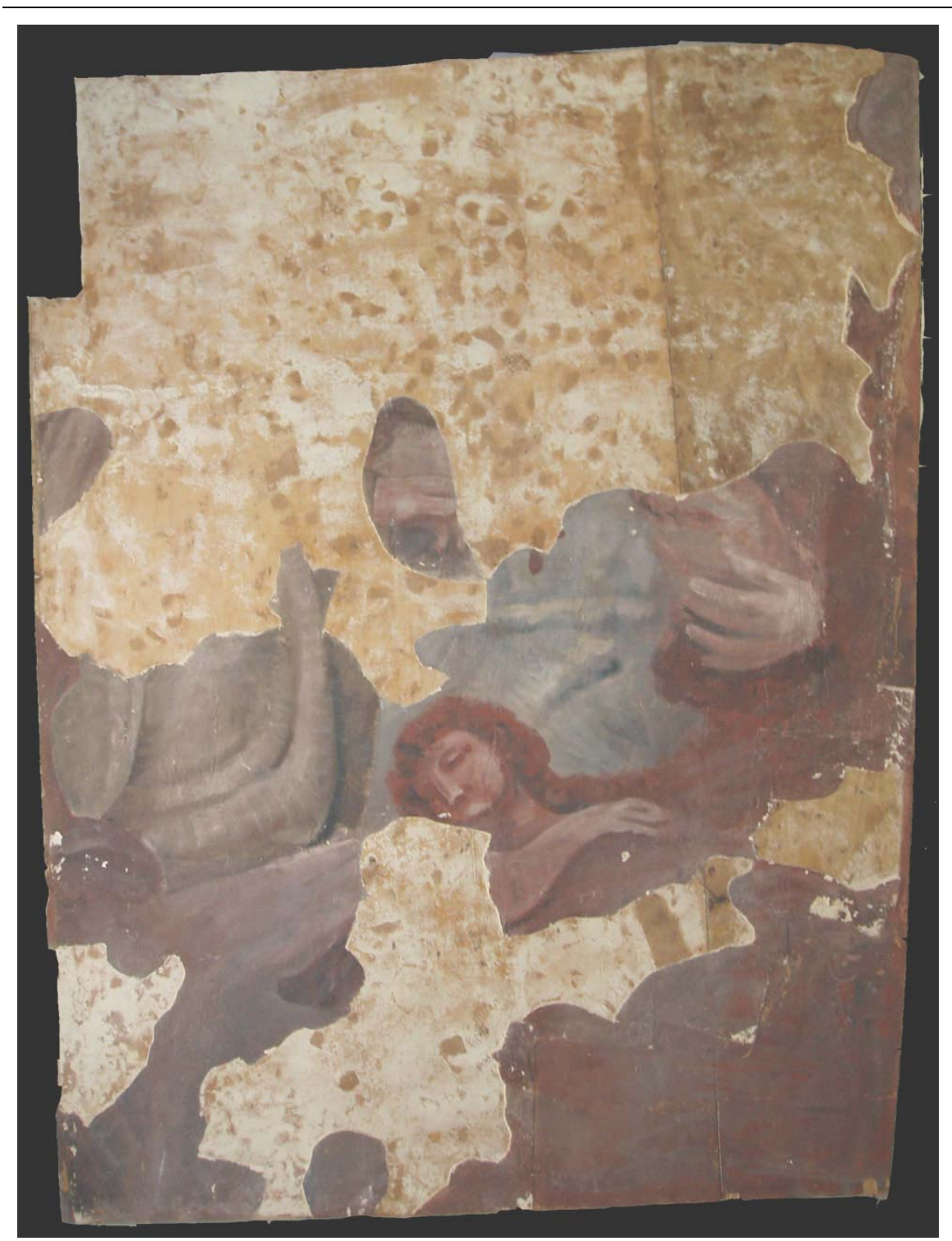

Fig. 184. Immagine del vecchio supporto di legno con le ridipitture fatte nell'intervento degli anni 60 . 
SEGUIMIENTO DEL PROCESO LLEVADO A CABO EN UNO DE LOS PANELES DE PINTURA MURAL ARRANCADA DE LA BÓVEDA DE LA NAVE CENTRAL DE LA IGLESIA DE LOS SANTOS JUANES DE VALENCIA.

Una vez extraídas una serie de conclusiones, antes de proceder a la aplicación práctica del tratamiento de separación de los fragmentos de pintura real del panel hay que seguir una serie de pasos previos:

* Elaboración de un calco de las partes de pintura original para conservar la ubicación actual de los fragmentos sobre el soporte, aunque sabemos que es muy probable que la ubicación que presentan ahora dichos fragmentos, no sea la original. Habría que comparar, para ello, la ubicación de los fragmentos de pintura original con la ubicación de esos mismos fragmentos en la fotografía que se conserva de las pinturas antes de sufrir el incendio.

* Limpieza de impurezas y elementos ajenos a la propia pintura.

* Consolidación de la superficie tras la limpieza.

Hemos elaborado un calco en el que se reflejan los contornos de los fragmentos de pintura original, ubicados dentro del panel. El motivo de la elaboración de tal calco es tener una referencia exacta de la posición en la que el equipo de los Gudiol adhirieron los fragmentos de pintura a su nuevo soporte de madera.

Desconocemos si esta ubicación es la correcta, pero aun como testigo del trabajo que realizaron los restauradores catalanes en los años 60 resulta interesante conservar referencias de dicha ubicación.

Antes de proceder al tratamiento de limpieza de la superficie pictórica, hemos llevado a cabo una serie de catas de limpieza, para elegir a partir de ellas el mejor método a utilizar en el conjunto de la obra.

Después de realizar estas catas de limpieza, hemos decidido limpiar con empacos de Arbocel BC-200 + carbonato de amonio, pues elimina muy bien tanto la suciedad como los repintes.

Se ha procedido a la limpieza de toda la superficie siguiendo esta metodología. Se ha aplicado los empacos a través de tres estratos de papel japonés de $11 \mathrm{gr}$.

Los restos de repintes que no se han eliminado completamente mediante los empacos de carbonato de amonio, se han repasado con la aplicación mediante hisopo de algodón, de amoniaco al $10 \%$ en agua.

Después de la limpieza de toda la superficie, quedan zonas brillantes posiblemente por restos de cola en superficie. Si observamos la pintura con luz U.V., podemos ver que en estas zonas brillantes da una reflectancia distinta del resto de la superficie, con un color amarillento, debido a la presencia de cola o barniz.

Estas manchas brillantes se han intentado eliminar con una solución enzimática para eliminación de sustancias proteicas. Se ha probado con diferentes tiempos de aplicación, para llegar a la conclusión de que el tiempo de aplicación más adecuado es entre los 8 y los 10 minutos. Aun así, siguen quedando restos brillantes en superficie. Esto puede deberse a que las enzimas se desinhiben en presencia de metales, y la mayoría de los pigmentos presentes en esta obra, son óxidos de hierro, por lo tanto, en el momento en que las enzimas atraviesan la capa brillante y entran en contacto con los metales de los pigmentos presentes en la obra, se desinhiben, perdiendo totalmente su efectividad.

Eliminados pues la mayoría de los brillos, el siguiente paso lógico en el tratamiento de esta obra es la consolidación de la superficie pictórica. 
Como método de consolidación de la superficie pictórica, antes de proceder al resto de tratamientos, se ha aplicado hidróxido de bario ${ }^{183}$ únicamente en los tres fragmentos inferiores de la pintura y en una zona de pequeñas dimensiones del fragmento superior.

Como paso previo a la protección de la superficie, hemos efectuado unos cortes alrededor del perímetro de los fragmentos de pintura original, con el fin de separar del soporte de madera únicamente estos fragmentos, y no los repintes realizados en los años 60 . Estos cortes, realizados a 3 o $4 \mathrm{~mm}$ del perímetro de la pintura, se han llevado a cabo con la ayuda de mini-discos de corte mecánicos; y para asegurarnos de que el disco había atravesado todos los estratos de estuco y telas, hemos repasado los cortes con un bisturí.

El hecho de realizarlos a unos milímetros del perímetro real de la pintura original se justifica por la mejor conservación de dicha pintura original, que podría dañarse en el caso de efectuar el corte demasiado ajustado al perimetro.

Para evitar que quedase polvo en superficie que impidiese la buena adhesión de las telas de protección, hemos aspirado toda la superficie con un aspirador de baja potencia para controlar mejor el proceso. Posteriormente hemos lavado la superficie con agua desionizada, con la ayuda de una esponja natural blanda.

Pasado el tiempo requerido para la correcta carbonatación del hidróxido de bario, hemos procedido a la protección de la superficie pictórica y al posterior tratamiento de separación del soporte de contrachapado de madera.

Se ha utilizado para la protección, gasa de algodón, y tela de algodón adheridas con cola de gelatina en una proporción al 16\%, como se había establecido en las conclusiones de las probetas realizadas previamente con el fin de conocer el método más adecuado para la protección de esta obra.

Una vez protegida y seca la superficie, hemos procedido a la separación, por medios mecánicos de los fragmentos de pintura original de su soporte de madera. Hemos utilizado para ello, espátulas metálicas finas, de puntas redondeadas, para evitar cortes en la tela 0 pintura. Estas espátulas se han insertado entre las telas del reverso de la pintura, y la madera de soporte.

La fuerza mecánica de las espátulas, con la ayuda de la fuerza de estirado, han sido suficientes para conseguir una buena separación de ambos estratos, sin la necesidad de aportación de humedad para reblandecer el adhesivo que las unía, ya reactivado con la humedad del adhesivo de la protección.

Una vez separada la pintura junto con su estrato de gasa y el de tela con caseinato cálcico, la tela ${ }^{184}$ del reverso se separa fácilmente, pues, los Gudiol aplicaron un caseinato cálcico con poco poder adhesivo (8 partes de cal y 1 parte de caseína). Este hecho ha ocasionado que la tela esté escasamente adherida, por lo que es fácil su eliminación.

Para separar la tela respecto de la gasa ${ }^{185}$ únicamente se ha ejercido cierta fuerza mecánica de estirado, y la tela ha salido entera.

Mientras que la eliminación de la gasa no ha sido necesaria, puesto que la mayor parte de esta se encuentra perfectamente adherida al reverso de la pintura. Únicamente hemos considerado conveniente eliminar la gasa en uno de los fragmentos pequeños de pintura, pues estaba totalmente suelta. Al eliminar la gasa, se han eliminado también los repintes que había sobre ella, quedando limpios los faltantes de película pictórica.

Se ha requerido la acción mecánica del bisturí para rebajar el estrato de caseinato cálcico y dejar libre la gasa.

\footnotetext{
${ }^{183}$ Tratamiento realizado por Iñaki Gárate Llombart.

184 Este tejido tiene una trama de 22 hilos por $\mathrm{cm}^{2}$ y una urdimbre de 24 hilos por $\mathrm{cm}^{2}$.

${ }^{185}$ Esta gasa tiene una trama de 8 hilos por $\mathrm{cm}^{2}$ y una urdimbre de 10 hilos por $\mathrm{cm}^{2}$.
} 
Ha quedado pues el reverso de la pintura libre de elementos ajenos a ella, pero a su vez, necesita de la consolidación para restablecer la estabilidad del poco soporte original que queda.

Hemos optado por la aplicación de una gasa adherida con caseinato cálcico, pero con una proporción distinta a la empelada en la restauración de los años 60 . Este caseinato cálcico se ha confeccionado con 3 partes de cal aérea y 1 parte de caseína láctica. A esta mezcla le hemos añadido un $2 \%$ de adhesivo plástico, para hacerla más adhesiva y elástica.

El motivo de esta elección, es no seguir añadiendo elementos ajenos a la obra. En su momento el caseinato cálcico sí era un elemento extraño a la obra, pero después de la intervención de los años 60, en la que se aplicó este tratamiento, éste ha entrado a formar parte constituyente de la obra misma, por lo que si ahora aplicásemos otro adhesivo consolidante, estaríamos sobrecargando a la obra de tratamientos muy diferentes que podrían, a la larga, perjudicarla.

El caseinato cálcico es, además, un producto muy afín al mortero de cal y arena, que al secar se convierte en carbonato cálcico.

Al comprobar la alta tensión superficial de la mezcla que impedía la correcta penetración en el mortero original por el reverso de la pintura, hemos decidido aplicar previamente una mano de alcohol y agua al 50\%. Hemos conseguido así, que la mezcla de caseinato cálcico, que se ha elaborado bastante líquido, penetrase lo suficiente como para consolidar dicho mortero original.

Ya asegurada la correcta penetración del consolidante, hemos aplicado la gasa, que cumple la función de evitar que agriete el caseinato cálcico al secar, y evita así posibles movimientos durante el proceso de secado. Para la adhesión de esta gasa hemos utilizado un caseinato cálcico espesado con piedra pómez en polvo ${ }^{186}$.

Hemos dejado secar el reverso de la pintura antes de aplicarle el estrato de intervención.

Hemos confeccionado un nuevo soporte con matt de fibra de vidrio de $450 \mathrm{gr} / \mathrm{m}^{2}$, y resina epoxi. Se ha cortado dejándo unos $2 \mathrm{~cm}$. alrededor del perímetro de la pintura original, para tener un margen dónde colocar los anclajes que unirán el nuevo soporte al muro de la bóveda. Para ello, hemos utilizado un calco que se ha hecho de la superficie pictórica. Después de tener la forma deseada en fibra de vidrio, hemos colocado cada fragmento sobre una lámina de melinex, para evitar la adhesión del nuevo soporte a la superficie de trabajo durante el proceso.

Hemos aplicado la resina epoxi con un rodillo metálico, y hemos cubierto todos los fragmentos con una lámina de melinex, para dejarlos secar bajo peso.

El nuevo soporte, una vez seco, debe ser adecuado para la buena adhesión de la capa de intervención que se colocará entre éste y la pintura arrancada. Para ello hemos lijado la superficie con el fin de abrir el poro de la resina, y dejar una textura adecuada para el perfecto agarre del adhesivo.

El estrato de intervención más adecuado para esta obra consideramos que es el papel de fractura predeterminada. Este papel se ha cortado siguiendo el perfil del fragmento de pintura original, y se ha adherido tanto al reverso de la pintura como al nuevo soporte con Beva O.F. Gel®.

Una vez aplicado el adhesivo por ambos lados del papel de fractura predeterminada, y adherido tanto al soporte como a la pintura, hemos aplicado peso hasta el secado de dicho adhesivo.

\footnotetext{
${ }^{186} 1$ volumen de caseina láctica hidratada + 3 volúmes de grassello di calce + $2 \%$ de Acril $33+1$ volúmen de piedra pómez en polvo.
} 
Asegurado el perfecto secado del adhesivo de unión de todos los estratos del nuevo soporte, hemos procedido a la desprotección de la película pictórica, mediante la aplicación de humedad controlada, con la utilización de brochas y esponjas naturales para una perfecta eliminación del adhesivo de protección, para la eliminación de la primera capa de tela. Mientras que para eliminar la gasa en contacto con la película pictórica, y mantener húmeda y caliente la superficie, se ha aplicado un empaco de pasta de celulosa con agua desionizada a través de una capa de papel japonés. Para la eliminación de la cola nos hemos servido de la acción del vapor de agua.

Una vez desprotegida y seca la pintura, para asegurarnos de la total eliminación de la cola de protección se han repetido las mediciones colorimétricas en los puntos en los que se habían tomado antes del proceso de protección, con el fin de compararlas y observar si ha habido algún cambio en la coloración de los pigmentos.

Como se ve en las tablas comparativas expuestas en el punto 10.3.2 del Anexo III, los cambios colorimétricos sufridos por los pigmentos han sido mínimos, lo que nos da a entender que hemos eliminado totalmente la cola utilizada en el proceso de protección.

También se ha realizado una comparativa de fotografías tomadas a través de microscopio entre aquellas realizadas antes de la limpieza, después de la limpieza y después de la desprotección. También en este tipo de fotografías observamos pocos cambios respecto a las fotografías de después de la limpieza y las de después de la desprotección, lo que nos da garantías de que no ha cambiado la superficie pictórica. Mientras que la diferencia entre antes y después de la limpieza es bastante notable ${ }^{187}$.

Para finalizar la intervención de este fragmento de pintura mural arrancada de la bóveda de la iglesia de los Santos Juanes de Valencia, hemos cortado con bisturí tanto el perímetro de estuco antiguo que sobresale del perímetro real de pintura original, como el sobrante de gasa y papel de fractura predeterminada que excede del perímetro de la obra. Dejando así la obra a punto para ser estucada con los mismos materiales que se usarán para estucar las lagunas de la parte de la bóveda no arrancada, y para ser trasladada a la bóveda y reubicada en el lugar de origen.

El último paso en el proceso de restauración de esta obra consiste en el anclaje del nuevo soporte al muro de la bóveda mediante tornillos y tacos de expansión. No obstante, este punto se deja, como hemos explicado en el capítulo anterior como una línea de investigación abierta, pues exige una exhaustiva investigación susceptible de emprender una nueva tesis doctoral.

Los repintes realizados en la intervención de los años 60 han permanecido adheridos al soporte de madera, pudiéndose conservar para futuras investigaciones sobre el modo de proceder de los restauradores de esa época.

187 Ver tablas comparativas de las fotografías tomadas a través de microscopio, en el Anexo VII. 




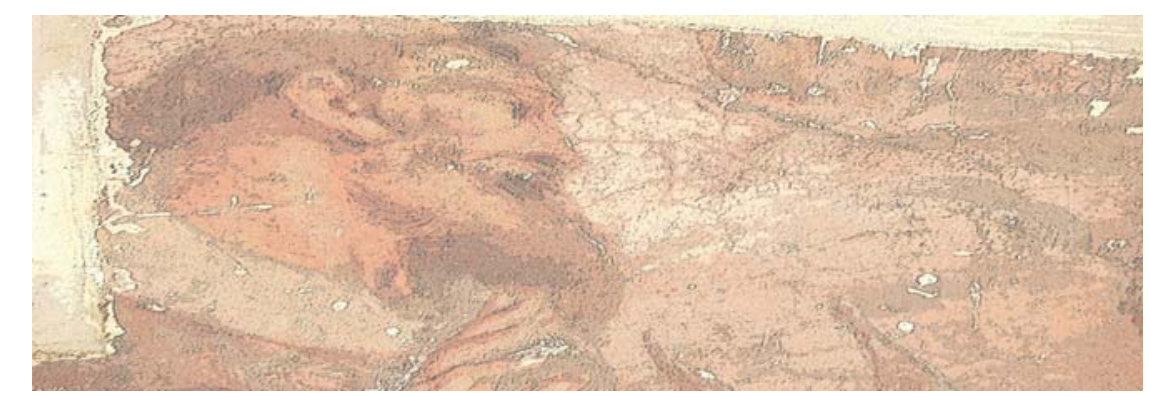

CONCLUSIONI CONCLUSIONES 




\section{CONCLUSIONI}

Siccome questa tesi di dottorato si presenta con l'obiettivo di ottenere il titolo di doctor europeus, le conclusioni devono essere scritte in lingua europea diversa da quelle ufficiali dello Stato Spagnolo, perciò le conclusioni si redigono di seguito sia in spagnolo cosí come in Italiano.

Gli obbiettivi principali di questa tesi sono stati la realizzazione di uno studio sui nuovi supporti per dipinti murali distaccati per proporre ed applicare un nuovo supporto ad un frammento di affresco strappato dalla volta della navata centrale della chiesa dei Santos Juanes di Valencia.

Questo obbiettivo primario, l'abbiamo raggiunto applicando la seguente metodologia:

In primo luogo, abbiamo effettuato una revisione delle tecniche di distacco di pittura murale, con la definizione delle tecniche da strappo, stacco e stacco a massello. Inoltre abbiamo anche valutato lo sviluppo di queste tecniche nel trascorso della storia, per mezzo della revisione di numerosa bibliografia di origine principalmente spagnola ed italiana. Conoscendo le tecniche usate lungo la storia, e studiando sulla tecnica concreta dello strappo usata dalla bottega dei Gudiol (incaricata degli strappi delle pittura che stiamo studiando), abbiamo capito meglio lo stato di conservazione attuale delle pitture: gli affreschi di Antonio Palomino, strappati dalla volta della chiesa dei Santos Juanes di Valencia fra 1958 e 1963. Dopo lo strappo, compiuto in tre fasi, le pitture furono arrotolate e trasportate in una bottega a Barcellona. Là, fu assottigliato il retro dei dipinti per eliminare i resti della malta originale, e furono consolidate con caseato calcico, rinforzate con uno strato di garza di cotone e un altro strato di tessuto piú spesso di lino o di cotone. Furono sprotette e successivamente furono aderite sui pannelli di compensato di legno, con un prodotto cellulosico (Glutin). Le lacune furono stuccate e reintegrate con dei pigmenti a vernice, e le unioni fra i differenti pannelli, furono sigillate con della cera d'ape. Così restaurate furono riportate di nuovo a Valencia, per la loro rimessa sulla volta. Questo lavoro fu fatto inchiodando i pannelli con dei chiodi a dei tasselli di legno, che erano stati inseriti nella volta quando questa venne intonacata con gesso.

Adesso i pannelli sono in larga misura staccati dalla volta; e questo suppone un pericolo di caduta, in più i movimenti del legno del supporto hanno causato fessure e separazioni nelle unioni fra i pannelli, così come delle deformazioni degli stessi, che non seguono più la forma della volta.

Dopo queste analisi, abbiamo raggiunto la conclusione che queste pitture hanno bisogno di un nuovo supporto, ragione per cui abbiamo effettuato uno studio sui supporti applicati attraverso la storia ai dipinti distaccati. Abbiamo fatto una revisione bibliografica, ed abbiamo 
elaborato delle provette di laboratorio che imitano differenti supporti usati in tempi diversi e da diversi centri di restauro.

Per applicare un nuovo supporto a queste pitture, in primo luogo abbiamo dovuto togliere il supporto di legno, per cui abbiamo dovuto proteggere la pittura prima di realizzare questa separazione di entrambi gli strati.

Abbiamo analizzato diversi metodi di separazione della pittura dal suo supporto di legno, ed abbiamo concluso che il metodo migliore sarebbe applicare la protezione alla pittura, come se stessimo realizzando un nuovo strappo, (ma con minore grado di adesività) e finalmente effettuare la separazione per mezzo di un' azione meccanica.

Con lo scopo di stabilire che tipo di protezione sarebbe più adatta per separare quest'opera dal suo supporto di legno, che come abbiamo spiegato non è idoneo, abbiamo fatto una serie di provette di laboratorio imitando la superficie pittorica dell'opera di Palomino.

Abbiamo effettuato una prima serie di provette per identificare le proporzioni adeguate degli adesivi da usare nelle seguenti provette. Queste prime prove sono state effettuate su delle pitture ad affresco con l'arriccio di gesso e l'intonaco di calce e sabbia, imitando la tecnica di Palomino. Abbiamo concluso che le proporzioni più adatte dei diversi adesivi sono: Paraloid B-72 (15 gr.), dissolto in acetone ( $\mathrm{ml}$. 50.); carboximetilcelulosa (3 gr.) dissolta in acqua deionizzata ( $\mathrm{ml}$. 100.); alcool polivinilico (5 gr.) dissolto in acqua di deionizzata ( $\mathrm{ml}$. 50.); colla di gelatina (8 gr.) dissolta in acqua deionizzata (ml. 50.); Plexisol ( $\mathrm{ml} .20$.) dissolto in white spirit ( $\mathrm{ml}$. 50.) e una miscela di carboximetilcellulosa (5 gr. nel ml. 50.) ed alcool polivinilico (2 gr. nel $\mathrm{ml}$. 50.) dissolti in acqua deionizzata.

In base a queste proporzioni, abbiamo applicato le protezioni differenti, con diversi tessuti (muletón di cotone, tessuto di cotone, Spherecore, feltro e tessuto di canapa), sulle provette dipinte ad affresco poi strappate, consolidate sul retro con caseato calcico ed aderite con un adesivo cellulosico alle piastre di compensato di legno.

Queste provette ci hanno permesso concludere quale era la protezione più adatta in base alle sue caratteristiche di facilità di separazione di entrambi gli strati, ma inoltre ci hanno permesso sperimentare con differenti metodi per conoscere qual' era l'adesivo che lasciava la minor quantitá di residui nella superficie pittorica, aspetto che ci interessa molto. Poiché l'opera ha subito già parecchi incendi ed uno strappo, ci interessa applicare una protezione che eviti qualsiasi danno aggiunto alla pittura.

Per conoscere la reversibilità degli adesivi usati, abbiamo effettuato la comparazione tra le fotografie fatte con microscopio ottico, tanto alle provette quanto alla pittura originale, prima e dopo il processo di pulitura, come quelle riprese prima della protezione e quelle riprese dopo 
quest'ultimo processo. I cambiamenti che si valutano sono pricipalmente fra le fotografie iniziali e quelle riprese dopo la pulitura, ma fra quest' ultime e quelle riprese dopo l'eliminazione dell'adesivo, non si osservano dei cambiamenti.

Un'altro tipo d'analisi fatto su queste provette sono le misure colorimetriche, che ci hanno permesso confrontare le misure prese prima dell'applicazione dell'adesivo e quelle prese dopo l'eliminazione di quest'adesivo. Le conclusioni tratte da queste prove sono che gli adesivi che hanno variato in minor grado i colori dei campioni, sono la carboximetilcelulosa, la miscela di Carboximetilcelulosa ed alcool polivinilico, e la colla di gelatina.

Inoltre abbiamo fatto l'analisi dei campioni prelevati dalle provette, con Spettroscopia Infrarrossa per trasformata di Fourier, per conoscere la quantità di resti d'adesivo che rimangono sulla superficie pittorica, anche queste analisi hanno concluso che sono rimasti meno resti adesivi nelle provette protette con la carboximetilcelulosa,con la miscela di carboximetilcelulosa e alcool polivinilico, e con la colla di gelatina.

Nonostante che l'ordine d'enumerazione, quí sopra scritto, corrisponde anche all' ordine crescente di quantitá di residui in superficie pittorica, abbiamo utilizzato nell'applicazione della protezione del pannello di pittura originale la colla di gelatina, giacchè gli adesivi considerati più reversibili secondo le analisi fatti, non avevano sufficiente potere adesivo per la pittura che ci occupa. La colla di gelatina risulta più adattata per le sue proprietà adesive, per la sua facilità d'applicazione ed eliminazione, che contribuiscono alla sua reversibilità.

Questa protezione è stata quinidi fatta con colla di gelatina, aderendo sulla superficie pittorica originale una garza di cotone ed un tessuto di cotone. Una volta asciutta la protezione è stata separata la pittura con $\mathrm{i}$ tessuti dal supporto di legno per mezzo di azione meccanica, con l'inserzione di spatole metalliche fini e con la punta arrotondata.

Questo adesivo è adatto solo se viene usato come si é fatto su questo frammento di pittura, cioè, proteggendo la pittura, applicando il nuovo supporto e sproteggendola in un periodo di tempo relativamente corto. Nel caso che la pittura fosse separata del suo supporto di legno, dovrebbe essere rimessa in un nuovo supporto e sprotetta immediatamente, altrimenti la pittura potrebbe subire dei danni dovuti alla contrazione della colla di gelatina, che subisce dei cambiamenti dimensionali con l'umidità e la temperatura. Nel caso in cui la pittura dovesse essere separata del supporto di legno e dovesse rimanere così per molto tempo prima dell'applicazione del nuovo supporto, consideriamo che sarebbe più consigliabile usare come adesivo per la protezione, una resina acrilica (Paraloid B-72). Anche se sappiamo che la sua reversibilità può essere minore rispetto a quella della colla di gelatina, eviteremmo i problemi derivati da quest'ultima quando rimane applicata per lungo tempo. 
Con l'obbiettivo di stabilire quale tipo di supporto sarebbe più adatto a queste pitture, abbiamo elaborato una serie di provette prendendo come riferimento tipi di supporti che sono stati usati attraverso la storia. Dopo un primo studio e valutazione delle posibilità esistenti, abbiamo elaborato una serie di 168 provette, avendo come riferimento i risultati derivati dalle prime ricerche realizzate nel campo dei supporti inerti per dipinti murali. Abbiamo considerato che gli adesivi più adatti per queste pitture sono: Plextol B-500, Beva O.F. Gel ed acetato polivinilico. Come supporto: fibra di vetro di differenti consistenze, tessuto e senza tessere, con resina di poliestere o resina epoxi; e come strato di intervento: carta di frattura predeterminata, feltro, muletón e lamina di poliuretano. Queste provette sono state analizzate atendendo al loro spessore, il loro peso, la relativa flessibilità e l'adesione tra i vari strati.

Dopo l'analisi di queste 168 piccole provette, abbiamo concluso che soltanto 9 erano adatte alla pittura di cui ci occupiamo; sono quelle formate da matt di fibra di vetro di $300 \mathrm{gr} . / \mathrm{m}^{2}$ o di gr $450 \mathrm{gr} . / \mathrm{m}^{2}$, come supporto, Beva O.F. Gel, o Plextol B-500 come adesivo e carta a frattura predeterminata o feltro come strato d'intervento. Queste ultime provette selezionate sono state sottomesse aun ciclo estremo nella macchina d' invecchiamento, ed infine si conclude che la provetta che è a priori più adatta è quella formata da una matt di fibre di vetro di $450 \mathrm{gr} . / \mathrm{m}^{2}$ con resina epoxi come supporto, Beva O.F. Gel, come adesivo dello strato di intervento tanto al supporto quanto al retro della pittura; e carta a frattura predeterminata, come strato d'intervento.

Consideriamo che il supporto scelto, di fibra di vetro e resina epoxi, compie tutte le premesse di leggerezza, flessibilità o adattabilità alla superficie, stabilità dimensionale, coefficente minimo di espansione termica, spessore uguale o inferiore a quello del malta originale della pittura, reversibilità, impermeabilità, resistenza agli agenti atmosferici, resistenza agli agenti biologici, resistenza meccanica, resistenza ai solventi ed all'acqua, facilitá di fabbricazione e spesa minima e che sia non infiammabile.

Abbiamo scelto la carta a frattura predeterminata come strato d'intervento perché lo consideriamo il più adatto in quanto alla sua funzione di separazione di entrambi gli strati, così come al poco spessore. È un prodotto creato per il campo del restauro di pittura murale, ragioni per cui è un materiale molto studiato, così come l'adesivo di Beva o.F. Gel.

Deciso qual' era il supporto più adatto a queste pitture, si è studiato che formato e che forma di questo supporto era piú adatta per l'applicazione sui frammenti del pannello della pittura oggetto di questo studio. 
Con questo fine abbiamo fatto un'altro tipo di prove finalizzate a estudiar la forma del supporto. Si é considerata la possibilità d'applicare il supporto dello stesso formato di quello del pannello attuale, inserendone i frammenti da cui è costituito ciascuno dei pannelli; o applicare un supporto ad ogni frammento separato del supporto.

Nel primo caso, abbiamo visto lo svantaggio di considerare come corretta la posizione dei frammenti di pittura originali all'interno di ogni pannello. Considerando che il secondo caso ci permetterebbe riassegniare $\mathrm{i}$ frammenti di pittura originale nella relativa posizione corretta, perché sarebbe giusto che ogni frammento avesse il proprio supporto, separato degli altri.

Dobbiamo considerare in questo sistema che dobbiamo lasciare uno spazio dove inserire gli ancoraggi che uniscono la pittura e il loro nuovo supporto alla parete della volta. Nelle provette che sono state elaborate, abbiamo sperimentato con 4 forme di supporto diverse:

In primo luogo, quello che include lo stesso formato del pannello di legno attuale, che genera i problemi che abbiamo appena spiegato.

In secondo luogo, quello che include solamente la forma del frammento di pittura originale, che ha dei problema di non avere spazio dove inserire ancoraggi.

In terzo luogo, dobbiamo lasciare linguette di fibra di vetro e resina che fuoriescano dal perimetro della pittura originale, e inserire in queste linguette gli ancoraggi. Questo sistema genera i problemi di tensionamento nella malta applicata per stuccare le lacune.

E quarto luogo, lasciare un bordo a tutto il perimetro della pittura, che serva a distribuire gli ancoraggi.

Dopo aver fatto le provette, che sono state stuccate con una malta simile a quella che sarà usata nella zona della volta che stà essendo restaurata in questo momento, abbiamo concluso che il sistema migliore per lasciare lo spazio per ancoraggi nel nuovo supporto, è quest' ultimo: elaborare il supporto con la stessa forma dell'originale ma di 2 centimetri più grande, in modo da lasciargli un bordo lungo il perimetro della pittura originale.

Così l'abbiamo fatto nel supporto realizzato per i 4 frammenti di pittura originale di Palomino che conformano il pannello oggetto di questo studio.

L'obiettivo di stabilire che tipo di ancoraggio risulta più adatto per rimettere i frammenti di pittura murale strappata e rimessa su un nuovo supporto, l'abbiamo fatto in modo teorico ed in provette di laboratorio, lasciando le conclusioni derivate da queste come proposta d'intervento. Abbiamo considerato l'applicazione di un sistema d' ancoraggio di espansione, che consiste in un ancoraggio meccanico, cioè, l'inserzione nella parete di tasselli che si espandono quando viene inserita la vite che 
ha attraversato il nuovo supporto. Pero proponiamo la combinazione di questo sistema d' ancoraggio meccanico con un sistema di rinforzo adesivo, che regolarizzi la superficie della volta, in modo che tutto il supporto di fibra di vetro sia completamente in contatto con la parete, per evitare che ci siano sacchetti di aria fra parete e supporto. Abbiamo sperimentato in provette di laboratorio l'applicazione di due tipi diversi di viti ad espansione, e l'applicazione di una malta espansiva a base di aluminato di bario, fra l'arriccio di gesso che riguarda la parete ed il nuovo supporto delle pitture. Tuttavia, non abbiamo rimesso i frammenti di pittura del pannello oggetto di questo studio - con il suo nuovo supporto- sulla volta perche non conosciamo con esattezza la posizione corretta di questi frammenti.

Per questo, dipendiamo dalla sproiezione di una fotografia della volta presa prima dell' incendio del 1936, che sta effettuando un gruppo di ricerca del Dipartimento di Comunicazione della E.T.S.I. Telecomunicazioni, in collaborazione con il gruppo I+D+I di restauro di pittura murale del Istituto di Restauro del Patrimonio dell'Università Politecnia di Valencia.

Questo gruppo, sta effettuando la sproiezione di una fotografia della volta, con l'obbiettivo di conoscere con esattezza la decorazione delle lagune della parte della volta che non è stata strappata, e che si trova in fase di restauro in questo momento dal gruppo di restauro di pittura murale del Dipartimento di Conservazione e Restuaro dei Beni Culturali dell'UPV, grazie "all'accordo fra l' arcivescovato di Valencia, il Comune di Valencia, la ditta Aguas de Valencia, la ditta LUBASA e I'Università Politecnica di Valencia.

Quando venga realizzato questo lavoro con la fotografia, essa potrà essere usata come base per rimettere i frammenti di pittura, che sono stati strappati, esattamente nel suo posto originale.

Dopo l'applicazione del processo completo ad un frammento di pittura murale strappata dalla volta della chiesa dei Santos Juanes di Valencia precedentemente studiato nelle provette, tanto di protezione quanto di separazione della pittura del suo supporto di legno come dell'applicazione di un nuovo supporto -, possiamo concludere che il risultato è stato soddisfacente. La pittura non ha subito danni, non sono rimasti resti di adesivo nella superficie, e l'insieme della pittura-strato d' intervento-nuovo supporto è sufficientemente rigida da reggere correttamente la pittura ma é anche sufficientemente flessibile da permetterle l'adattamento alla curvatura della volta. 


\section{CONCLUSIONES}

Teniendo en cuenta que esta tesis doctoral se presentará con el objeto de obtener el título de doctor europeus, las conclusiones deben ser redactadas en lengua europea distinta de las lenguas oficiales del Estado español, por lo que a continuación las conclusiones se redactarán tanto en español como en italiano.

Los objetivos principales de esta tesis han sido llevar a cabo un estudio sobre nuevos soportes para pinturas murales arrancadas, con el fin de proponer y aplicar un nuevo soporte a un fragmento de la pintura mural arrancada de la bóveda de la nave central de la Iglesia de los Santos Juanes de Valencia.

Este objetivo principal lo hemos llevado a cabo aplicando la siguiente metodología:

En primer lugar, hemos efectuado una revisión de las diversas técnicas de arranque de pintura mural, definiendo las técnicas de strappo, stacco y stacco a massello. Hemos evaluado también la evolución de estas técnicas a lo largo de la historia, mediante la revisión de numerosa bibliografía, principalmente española e italiana. Conociendo las técnicas de arranque usadas a lo largo de la historia, e investigando sobre la técnica concreta de strappo utilizada por el taller de los Gudiol (encargadas del arranque de las pinturas objeto de esta investigación), hemos comprendido mejor el estado de conservación actual de las pinturas: la obra mural de Antonio Palomino, arrancada de la bóveda de la iglesia de los Santos Juanes de Valencia entre 1958 y 1963. Tras el arranque, realizado en tres fases, las pinturas fueron enrolladas y transportadas a un taller en Barcelona. Allí, fueron despojadas de los restos de mortero original que conservaban en el reverso, fueron consolidadas con caseinato cálcico, reforzado con un estrato de gasa de algodón y otra más tupida de lino en unos casos y algodón en otros. Fueron desprotegidas y posteriormente adheridas a paneles de contrachapado de madera, con un producto celulósico (Glutin). Las lagunas fueron estucadas y reintegradas con pigmentos al barniz, y las uniones entre los distintos paneles, fueron selladas con una masilla a base de cera de abeja. Así restauradas fueron devueltas a Valencia, para su recolocación en la bóveda. El trabajo se realizó sujetando los paneles con clavos a unos tacos de madera que habían sido empotrados en el soporte mural asegurándolos con el propio enlucido de yeso de la bóveda.

Actualmente estos paneles de madera no presentan una buena sujeción o anclaje a su soporte en un gran número de puntos de la bóveda, lo cual supone un riesgo potencial de desprendimiento. Además los movimientos de la madera han provocado grietas y separaciones en las uniones entre los paneles, así como deformaciones que impiden seguir la forma de la bóveda.

Tras este análisis, se ha llegado a la conclusión de que las pinturas necesitan un nuevo soporte, por lo que hemos llevado a cabo un estudio sobre los soportes aplicados a lo largo de la historia a pinturas murales arrancadas, siguiendo tanto una revisión bibliográfica, como la elaboración de probetas de laboratorio imitando distintos soportes utilizados en diferentes épocas y por diferentes centros de restauración.

Para aplicar un nuevo soporte a estas pinturas, primero debían ser despojadas de su soporte de madera, por lo que debían ser protegidas antes de proceder a esta separación de ambos estratos.

Hemos analizado distintos métodos de separación de la pintura de su soporte de madera, y hemos concluido que el mejor método es aplicar una protección a la pintura, como si se fuera a realizar un nuevo strappo, (pero empleando un producto con menor poder adhesivo), y finalmente efectuar la separación mediante acción mecánica.

Con el fin de establecer qué tipo de protección resultaría más idónea para separar esta obra de su soporte de madera que, como hemos explicado no resulta adecuado, se han elaborado una serie de probetas de laboratorio imitando la superficie pictórica de la obra de Palomino. 
Hemos llevado a cabo una primera serie de probetas para identificar las proporciones más adecuadas de los adhesivos a utilizar en las probetas elaboradas después. Estas primeras pruebas se han realizado sobre pinturas al fresco con arriccio de yeso e intonaco de cal y arena, imitando la técnica de Palomino. Se ha concluido en ellas que las proporciones más adecuadas de los distintos adhesivos son: Paraloid B-72 (15 gr.), disuelto en acetona (50 ml.); carboximetilcelulosa (3 gr.) disuelta en agua desionizada (100 $\mathrm{ml}$.); alcohol polivinílico (5 gr.) disuelta en agua desionizada (50 ml.); cola de gelatina (8 gr.) disuelta en agua desionizada (50 ml.); Plexisol P $550(20 \mathrm{ml}$.) disuelto en white spirit (50 $\mathrm{ml}$.) y una mezcla de carboximetilcelulosa (5 gr. en $50 \mathrm{ml}$.) y alcohol polivinílico (2 gr. en 50 $\mathrm{ml}$.) disuelta en agua desionizada.

A partir de estas proporciones, hemos aplicado distintas protecciones, con diferentes telas (muletón de algodón, tela de algodón, Spherecore, fieltro y arpillera), sobre probetas elaboradas a partir de pinturas al fresco que habían sido arrancadas, tratadas con caseinato cálcico por el reverso y adheridas con un adhesivo celulósico a placas de contrachapado de madera.

Estas probetas nos han permitido concluir cuál era la protección más adecuada en cuanto a facilidad de separación de los dos estratos, pero también nos han permitido experimentar con distintos métodos para conocer cuál era el adhesivo que deja menor cantidad de restos en la superficie pictórica, aspecto que nos interesa mucho. Puesto que la obra ya ha sufrido varios incendios y un arranque, interesa aplicar una protección que evite cualquier daño añadido a la obra.

Para conocer la reversibilidad de los adhesivos utilizados, hemos efectuado una comparativa de fotografías hechas a través de microscopio óptico, tanto a las probetas como a la pintura original, comparando las tomadas antes del proceso de limpieza, las que se habían tomado antes de la protección y las tomadas después de este último proceso. Los cambios que se aprecian son sobre todo entre las fotografías iniciales y aquellas tomadas después de la limpieza, pero entre éstas últimas y las tomadas después de la desprotección, no se aprecian apenas cambios.

Otro tipo de análisis realizado sobre estas probetas, ha sido la realización de mediciones colorimétricas, comparando las mediciones tomadas antes de la aplicación del adhesivo y las tomadas después de la eliminación de éste. Las conclusiones extraídas de estas pruebas son que los adhesivos que han variado en menor medida los colores de las muestras, corresponden a la mezcla de Carboximetilcelulosa y alcohol polivinílico, y la cola de gelatina.

Hemos realizado también análisis de muestras tomadas de las probetas, por Espectroscopía Infrarroja por trasformada de Fourier (FTIR) para conocer la cantidad de restos de adhesivo que quedan en la superficie pictórica, también estos análisis han concluido que quedaban menos restos de adhesivo en las probetas protegidas con carboximetilcelulosa, mezcla de carboximetilcelulosa y alcohol polivinílico, y cola de gelatina.

Aun siendo éste el orden de menor cantidad de restos sobre la superficie pictórica, en la aplicación de la protección del panel de pintura original, hemos usado cola de gelatina, pues los adhesivos considerados más reversibles según los análisis realizados, no tenían suficiente poder adhesivo para la pintura que nos ocupa. La cola de gelatina resultaba más adecuada por sus propiedades adhesivas, por su facilidad de aplicación y eliminación, contribuyendo a su reversibilidad.

La protección de la pintura se ha realizado finalmente con cola de gelatina, adhiriendo sobre la superficie pictórica original una gasa y una tela de algodón. Una vez seca la protección, se ha separado la pintura junto con las telas de su soporte de madera por medio de acción mecánica, con la inserción de espátulas metálicas finas de punta redondeada.

Este adhesivo solo resultaría adecuado si se usa como se ha hecho sobre este fragmento de pintura, es decir, protegiendo la pintura, aplicando el nuevo soporte y desprotegiendo en un periodo de tiempo relativamente corto. En el caso de que la pintura 
fuera separada de su soporte de madera, ésta debería ser recolocada en un nuevo soporte y desprotegida, de lo contrario la obra podría sufrir daños por la contracción de la cola de gelatina, que varía dimensionalmente con los cambios de humedad y temperatura. En el supuesto de que la pintura tuviera que ser separada del soporte de madera y tuviera que pasar mucho tiempo antes de aplicar el nuevo soporte, consideramos que sería más conveniente utilizar como adhesivo para la protección una resina acrílica (Paraloid B-72). Aunque sabemos que su reversibilidad puede ser menor con respecto a la cola de gelatina, evitaríamos así, los problemas de contracción y tensiones derivados de esta última cuando lleva aplicada largo tiempo.

Con el objetivo de establecer qué tipo de soporte resultaría más adecuado para estas pinturas, hemos elaborado una serie de probetas tomando como referencia distintos tipos de soportes usados para pinturas murales a lo largo de la historia. Tras un primer estudio y valoración de las múltiples posibilidades existentes, se ha elaborado una serie de 168 probetas, tomando como referencia los resultados derivados del primer acercamiento experimental al campo de los soportes inertes para pintura mural. Los adhesivos más adecuados para este caso se ha considerado que son: Plextol B-500, Beva O.F. Gel y Acetato de Polivinilo. Como soporte propiamente dicho: fibra de vidrio de distintos gramajes, tejida y no tejida, con resina epoxi o reina de poliéster. Y como estrato de intervención: papel de fractura predeterminada, fieltro, muletón y lámina de poliuretano. Estas probetas han sido analizadas teniendo en cuenta su grosor, su peso, su flexibilidad y la adherencia de las diversas capas.

Tras el análisis de estas 168 pequeñas probetas, hemos concluido que solamente 9 resultaban adecuadas para la pintura que nos ocupa; son las formadas por matt de fibra de vidrio de $300 \mathrm{gr} . / \mathrm{m}^{2}$ o de $450 \mathrm{gr} . \mathrm{m}^{2}$, como soporte, Beva O.F. Gel, o Plextol B- 500 como adhesivo y papel de fractura predeterminada o fieltro como estrato de intervención. Estas últimas probetas seleccionadas han sido sometidas a un ciclo extremo en la cámara de envejecimiento, y finalmente se concluye que la probeta que resulta a priori más adecuada es la formada por matt de fibra de vidrio de $450 \mathrm{gr} . / \mathrm{m}^{2}$ con resina epoxi como soporte, Beva O.F. Gel, como adhesivo de la capa de intervención tanto al soporte como al reverso de la pintura; y papel de fractura predeterminada, como estrato de intervención.

Pensamos que el soporte elegido, de fibra de vidrio y resina epoxi, cumple con todas las premisas de ligereza, flexibilidad o adaptabilidad a la superficie, estabilidad dimensional, coeficiente de dilatación térmica mínimo, grosor igual o inferior al del mortero original de la pintura, reversibilidad, Impermeabilidad, resistencia a los agentes atmosféricos, resistencia a los agentes biológicos, resistencias mecánicas, resistencia a disolventes y al agua, facilidad de fabricación y coste mínimo y que sea ignífugo.

Hemos elegido el papel de fractura predeterminada como estrato de intervención por considerarlo el más adecuado en cuanto a facilidad de separación de ambos estratos, así como al escaso espesor. Se trata de un producto creado para el campo de la restauración de pintura mural, por lo que es un material que ofrece las máximas garantías de estabilidad.

Decidido cuál era el soporte más adecuado para estas pinturas, nos planteamos el tamaño y la forma de dicho soporte, a la hora de aplicarlo a los fragmentos del panel de obra real.

Hemos elaborado por ello otro tipo de pruebas, en relación a la forma del soporte. Hemos estudiado la posibilidad de aplicar el soporte del mismo tamaño que el panel actual, insertando en él los fragmentos de que consta cada uno de los paneles; o aplicar un soporte a cada fragmento por separado.

En el primer caso, vimos el inconveniente de tener que tomar por acertada la ubicación actual de los fragmentos de pintura original dentro de cada panel. Mientras que el segundo caso, nos permitiría reubicar los fragmentos de pintura original en su localización correcta, pues también sería viable que cada uno de los fragmentos tuviera su propio soporte, separado de los demás. 
Lo que hay que tener en cuenta en este sistema es que se debe dejar un espacio donde se puedan insertar los anclajes que unan la pintura con su nuevo soporte al tabique mural, en definitiva el autentico soporte de la pintura. En las probetas elaboradas, se ha experimentado con cuatro formas de soporte diferentes:

En primer lugar, aquella que abarca el mismo tamaño del panel actual de madera, que plantea los problemas que acabamos de explicar.

En segundo lugar, el que abarca únicamente la forma del fragmento de pintura original, que plantea el problema de no tener espacio donde insertar los anclajes.

En tercer lugar, dejar unas pestañas de fibra de vidrio y resina que sobresalgan del perímetro de la pintura original, e insertar en estas pestañas los anclajes. Este sistema crea problemas de tensión en el mortero que se aplica encima para estucar las lagunas.

$\mathrm{Y}$ en cuarto lugar, dejar un borde por todo el perímetro de la obra, que sirva para colocar los anclajes.

Después de haber realizado las probetas, que han sido estucadas con un mortero similar al que se utilizará en la zona de la bóveda que está siendo intervenida en estos momentos, hemos concluido que el mejor sistema para dejar espacio para los anclajes en el nuevo soporte, es éste último: elaborar el soporte con la misma forma del original pero 2 $\mathrm{cm}$. más grande, de manera que quede un borde alrededor del perímetro de la pintura original.

Así se ha efectuado en el soporte realizado para los cuatro fragmentos de pintura original de Palomino que conformaban el panel objeto de este estudio.

El objetivo de establecer qué tipo de anclaje resulta más adecuado para reubicar los fragmentos de pintura mural arrancada y colocada en su nuevo soporte, al muro de la bóveda, lo hemos abordado de manera teórica y en probetas de laboratorio, dejando las conclusiones extraídas de ellas como propuesta de intervención. Hemos planteado la aplicación de un sistema de anclaje de expansión, que consiste en un anclaje mecánico, es decir, la inserción en el muro de tacos que se expanden cuando se les inserta el tornillo que ha atravesado el nuevo soporte. Pero planteamos la combinación de este sistema de anclaje mecánico con un sistema de refuerzo adhesivo, que regularice la superficie de la bóveda, de manera que todo el soporte de fibra de vidrio esté totalmente en contacto con el muro, para evitar que haya bolsas de aire entre el muro y el soporte. Hemos experimentado en probetas de laboratorio la aplicación de dos tipos distintos de tornillos de expansión, y la aplicación de un mortero de expansión a base de aluminato de bario, entre el revoque de yeso que recubre el muro y el nuevo soporte que alberga las pinturas. No obstante, no hemos reubicado los fragmentos de pintura del panel objeto de este estudio -con su nuevo soporte- sobre la bóveda por no conocer con exactitud la ubicación correcta de dichos fragmentos.

Para ello, es necesaria la desproyección de la única fotografía que conocemos de la bóveda antes del incendio de 1936, tarea que está llevando a cabo actualmente por un grupo de investigadores del departamento de Comunicaciones de la E.T.S.I. Telecomunicaciones, en colaboración con el grupo de I+D+I de restauración de Pintura mural del Instituto de Restauración del Patrimonio de la Universidad Politécnica de Valencia.

Este equipo, está llevando a cabo la desproyección de una fotografía de la bóveda, con el objetivo de conocer con exactitud la decoración de las lagunas de la parte de la bóveda que no fue arrancada, y que está siendo restaurada en estos momentos por el equipo de Restauración de Pintura Mural del Departamento de Conservación y Restauración de Bienes Culturales de la UPV, gracias al Convenio suscrito entre el Arzobispado de Valencia, Ayuntamiento de Valencia, Aguas de Valencia y LUBASA y la Universidad Politécnica de Valencia.

Una vez se realice la desproyección de la fotografía, ésta podrá utilizarse como plantilla para recolocar los fragmentos de pintura que fueron arrancados, a su lugar de origen exacto. 
Después de aplicar a un fragmento de pintura mural arrancada de la bóveda de la iglesia de los Santos Juanes de Valencia el proceso completo -previamente estudiado en las probetas que consiste tanto en la protección como en la separación de la pintura de su soporte de madera y la aplicación de un nuevo soporte-, podemos concluir que el resultado ha sido satisfactorio. La pintura no ha sufrido daños apreciables, no han quedado restos de adhesivo en superficie, y el conjunto de pintura-estrato de intervención-nuevo soporte es lo suficientemente rígido como para sujetar correctamente la obra pero también lo suficientemente flexible como para que se pueda adaptar a la curvatura de la bóveda. 




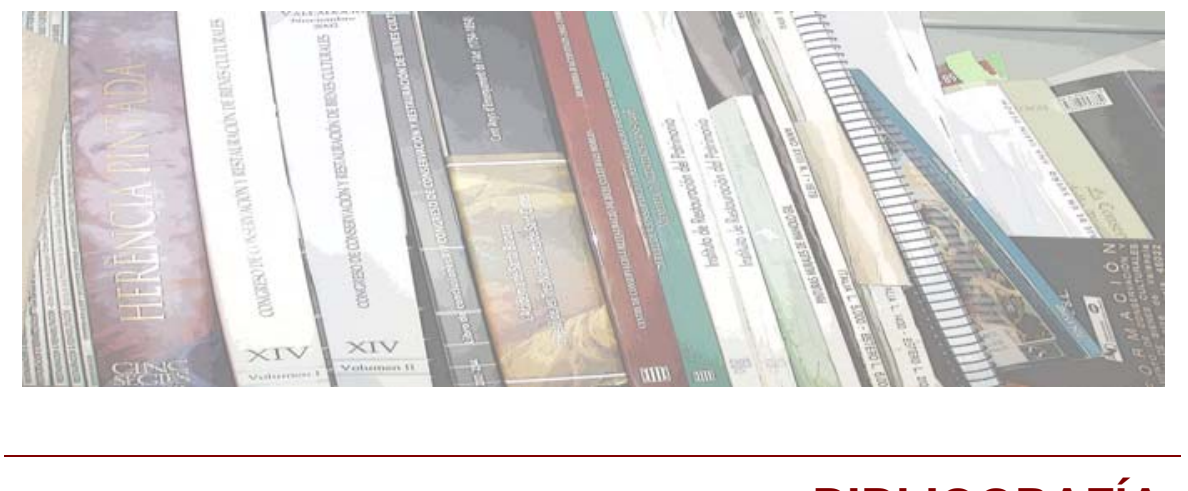

BIBLIOGRAFÍA 




\section{BIBLIOGRAFÍA}

\subsection{MONOGRAFÍAS.}

- BELTRAMI, Cristina; BERNARDINI, Cecilia. "Il consolidamento della pellicola pittorica nei dipinti murali del XX secolo". En Arte contemporanea. Conservazione e restauro. Nardini Editore. Fiesole, 1994.

- BÉRCHEZ, J. Iglesia de los Santos Juanes (o Iglesia de San Juan del Mercado). En Catálogo de monumentos y conjuntos de la comunidad valenciana. II (Paterna-Zucaina). Consellería de Cultura, Educación y Ciencia de la Generalitat Valenciana. Servicio de Patrimonio arquitectónico. Valencia, 1983.

- BOTTICELLI, Guido. Metodologia di restauro delle pitture murali. Centro Di della edifimi srl. Firenze, 1992.

- BRANDI, Cesare. Teoría de la restauración. Alianza Forma. Madrid, 1992. Versión española de María Ángeles Toajas Roger.

- CALVo, Ana. Conservación y restauración. Materiales, técnicas y procedimientos. De la A a la Z. Ed. del Serbal. Barcelona, 1997.

- CHIANTORE, Oscar. "Le materie plastiche dell'arte contemporaneo e la loro trasformazione e decadimento" En Arte contemporanea. Conservazione e restauro. Nardini Editore. Fiesole, 1994.

- CONTI, Alessandro. Manuale di restauro. Einaudi editori. Torino, 1996.

- CONTI, Alessandro. Storia del restauro e della conservazione delle opere d'arte. Electa editrice. Milano, 1973.

- D’Alconzo, Paola. Picturae excisae. Conservazione e restauro dei dipinti ercolanesi e pompeiani tra XVIII e XIX secolo. L'Erma di Bretschneider. Roma, 2002.

- DÍAZ MARTOS, Arturo. Restauración y conservación del arte pictórico. Arte Restauro, S.A. Madrid, 1975.

- DOERNER, Max. Los materiales de pintura y su empleo en el arte. Quinta edición. Editorial Reverté, S.A. Barcelona, 1991.

- ESCUDERO, C. y otros. Catálogo de obras restauradas. Centro de conservación y Restauración de Bienes Culturales de Castilla 
y León. Junta de Castilla y León. Consejería de Educación y Cultura. Valladolid, 1999.

- FAZI, Benedetta; VITTORINI, Bruno. Nuove tecniche di foderatura. Le tele vaticane di Pietro da Cortona ad Urbino. Nardini editore. Firenze, 1995.

- FERNÁNDEZ ARENAS, José. Introducción a la conservación del patrimonio y técnicas artísticas. Ariel. Barcelona, 1996.

- FERRER MORALES, Ascensión. La pintura mural. Su soporte, conservación, restauración y las técnicas modernas. Universidad de Sevilla. Sevilla, 1995.

- FORNI, Ulisse. Manuale del pittore restauratore. Firenze, 1866.

- GuAtTANI, G.A. Memorie enciclopediche romane sulle belle arti, antichità ... Salomon BAV. Roma, 1809.

- GUDIOL COROMINAS, Eulàlia. Josep Gudiol Ricart. Patronat d'estudis osonencs. Vic, 1997.

- KNIGHT, Eugénie. "Tra non foderatura e uso ragionato degli adesivi da rifodero". En Arte contemporanea. Conservazione e restauro. Nardini Editore. Fiesole, 1994.

- MACARRón MigueL, Ana Ma. Historia de la Conservación y la restauración. Desde la antigüedad hasta el siglo XX. Ed. Tecnos. Madrid, 2002.

- MAIURI, Amadeo. Ercolano. Itinerari dei Musei e monumenti d'Italia. Ministero della Pubblica Istruzione. Direzione Generale delle antichità e Belle Arti. Istituto Poligrafico dello Stato. Libreria dello Stato. Roma, 1954.

- MATTEINI, Mauro; MOLES, Argangelo. La chimica nel restauro. I materiali dell'arte pittorica. Nardini Editore. Firenze, 2002.

- MORA, Paolo y Laura; PHILIPPOT, Paul. La conservazione delle pitture murali. II edizione a cura di Bresciani s.r.l. Editrice Compositori. Bologna, 2001.

- PERUSINI, Giuseppina. Introduzione al restauro: Stiria, Teorie, Tecniche. Del Bianco. Udine, 1985.

- PIVA, Gino. "Il trasporto dei dipinti nel sistema antico e moderno, secondo le opere di Secco-Suardo e del professore R. Mancia" L'arte del restauro. Editore Ulrico Hoelpi. Milano, 1966.

- PLINIUS CAIUS SECUNDUS. Naturalis historia. Tratada y anotada por el doctor Francisco Hernández. Cap. XXXV p.154. Visor libros. Madrid, 1998. 
- PROCACCI, Ugo. Del distacco degli affreschi e della loro conservazione. Firenze, 1957.

- PROCACCI, Ugo. La tecnica dei dipinti murali e il loro distacco. Del catalogo: Affreschi da Firenze dal XIII al XVI secolo. Palazzo Reale, aprile-giugno 1971. Milano, 1971.

- ROIG PICAZO, Pilar; BosCH REIG, Ignacio. La iglesia de los Santos Juanes de Valencia. Proceso de intervención pictórica 1936-1990. Servicio de Publicaciones de la Universidad Politécnica de Valencia. Valencia, 1990.

- RUSPI, Carlo. Metodo per distaccare gli affreschi dai muri e riportarli sulle tela proposto dal cavalier Carlo Ruspi e pubblicato per cura di Ercole Ruspi. Tipografia Enrico Sinimberghi. Roma, 1864.

- SECCO-SUARDO, G. "Del trasporto dei dipinti dal muro" capitolo III. Il restauratore dei dipinti. Ulrico Hoelpi. Milano, 1927.

- VASARI, Giorgio. La vida de los más excelentes arquitectos, pintores y escultores italianos desde Cimabue a nuestros tiempos (Antología). Editorial Tecnos, S.A. Madrid, 1998.

- VV.AA. Arranque y traslado a un nuevo soporte de la pintura mural realizada por Joaquín Michavila. Universidad Politécnica de Valencia. Valencia 1998.

- VV.AA. Restauri in Piamonte 1968/1971. Soprintendenza alle Gallerie e alle opere d'Arte del Piamonte. Torino-Galeria Sabando. Maggio 1971. Ed. D'Arte Fratelli Pozzo.Torino, 1971.

- VV.AA. Catálogo de obras restauradas. Centro de Conservación y Restauración de Bienes Culturales de Castilla y León. Junta de Castilla y León. Consejería de Educación y Cultura. Valladolid, 1999.

- VV.AA. Guida al recupero, ricomposizione e restauro di dipinti murali in frammenti. L'esperienza della Basílica di San Francesco di Assisi. I.C.R. Roma, 2001.

- VITRUVIUS MARCUS POLLIO. De architectura libri decem. Libro II, Cap. VIII. (Los 10 libros de la arquitectura. Traducción de José Luís Olivar Domingo. Alianza Forma. Madrid, 2000).

- XARRIÉ, Josep Maria. Restauració d'obres d'art a Catalunya. Publicacions de l'Abadia de Montserrat. Barcelona, 2002. 


\subsection{ARTÍCULOS EN BOLETINES Y REVISTAS.}

- ALBERS, Géraldine; MOREL, Philippe. "Pelegrino Tibaldi e Marco Pino alla Trinità dei Monti. Un affresco ritrovato, Pietro Palmaroli e le origini dello "stacco"'. En Bolletino d'Arte 48. Anno LXXIII. Serie IV. Marzo-Aprile 1988. Istituto Poligrafico dello Stato. Roma, 1988.

- ARMENGol, Conxa; FAges, Mireia; RoviRA, Pere; SAMANIEGO, Silvia. "Recuperació i restauració de pintures murals a l'oli de Pere Viver", en $V$ Reunió Tècnica de conservació i Restauració. Museu Marítim de Barcelona 20 i 21 d'octubre de 1995. Edita el Grup Técnic. Associació professional dels conservadors-restauradors de Catalunya. Barcelona, 1998.

- BANDINI, F.; BOTTICELLI, G.; DANTI, C. "Tecniche esperimentali per lo strappo di una pittura murale a tempera grassa su un affresco preesistente". En O.P.D. Restauro. Quaderni dell'Opificio delle Pietre Dure e Laboratori di Restauro di Firenze. 1-1986. Opuslibri. Firenze, 1986.

- BONI, Michela. "Il restauro dei dipinti murali nella prima metà del XIX secolo a Bologna". En Bollettino dell'Istituto Centrale per il Restauro. Nuova serie $n^{\circ}$ 4. 2002. Nardini editore. Firenze, 2002.

- BORRELLI VLAD, Licia. "II distacco delle tombe Golini I e II di Orvieto". En Bollettino dell'Istituto Centrale del Restauro. 5-6. Istituto poligrafico dello Stato. Roma, 1951.

- BORRELLI VLAD, Licia. "II trasporto di una tomba dipinta rinvenuta sulla via portuense". En Bollettino dell'Istituto Centrale del Restauro. 11-12. Istituto poligrafico dello Stato. Roma, 1952.

- BORRELLI VLAD, Licia. "II distacco delle pitture della tomba del Letto funebre". En Bollettino dell'Istituto Centrale del Restauro. 17-18. Istituto poligrafico dello Stato. Roma, 1954.

- BORRELLI VLAD, Licia. "Distacchi e restauri di pitture della casa di Livia al Palatino". En Bollettino dell'Istituto Centrale del Restauro. 19-20. Istituto poligrafico dello Stato. Roma, 1955.

- BorRELLI VLAD, Licia. "Il distacco di due frammenti della tomba del Colle". En Bollettino dell'Istituto Centrale del Restauro. 27-28. Istituto poligrafico dello Stato. Roma, 1957.

- BORRELLI VLAD, Licia. "Il distacco delle pitture del Grande cubiculo della casa dei Grifi". En Bollettino dell'Istituto Centrale del Restauro. 27-28. Istituto poligrafico dello Stato. Roma, 1957. 
- BORRELLI VLAD, Licia. "Il distacco della parete absidata dell'Aula Isiaca". En Bollettino dell'Istituto Centrale del Restauro. 27-28. Istituto poligrafico dello atato. Roma, 1957.

- BORRELLI VLAD, Licia. "Il distacco di due pitture della Domus transitoria con qualche noticia sulla técnica di Fabullus". En Bollettino dell'Istituto Centrale del Restauro. 29-30. Istituto poligrafico dello Stato. Roma, 1957.

- BORRELLI VLAD, Licia. "Il distacco delle pitture di una tomba tarquiniese di recente scoperta". En Bollettino dell'Istituto Centrale del Restauro. 34-35. Istituto poligrafico dello Stato. Roma, 1958.

- BRAMBILla BARCILON, Pinin. "Impiego di materie plastiche espanse in opere di restauro di Lombardia. Suporti curvilinei in poliestere armato". En Bollettino dell'Istituto Centrale del Restauro. Istituto poligrafico dello Stato. Roma, 1965.

- CADIANO DE AZEVEDO, Michelangelo. "II distacco delle pitture della Tomba del Triclinio". En Bollettino dell'Istituto Centrale del Restauro. Istituto poligrafico dello Stato. Roma, 1950.

- CADIANO DE AZEVEDO, Michelangelo. "Il distacco delle pitture della Tomba delle Bighe". En Bollettino dell'Istituto Centrale del Restauro. 2. Istituto poligrafico dello Stato. Roma, 1950.

- CADIANO DE AZEVEDO, Michelangelo. "Conservazione e restauro preso i greggi e i romani". En Bollettino dell'Istituto Centrale del Restauro. 9-10. Istituto poligrafico dello Stato. Roma, 1952.

- CADIANO DE AZEVEDO, Michelangelo. "Il distacco degli affreschi romani del museo di Mariemont (Belgio)". En Bollettino dell'Istituto Centrale del Restauro. 19-20. Istituto poligrafico dello Stato. Roma, 1955.

- CADIANO DE AZEVEDO, Michelangelo. "Il restauro degli affreschi romani del museo di Mariemont (Belgio)". En Bollettino dell'Istituto Centrale del Restauro. 11-12. Istituto poligrafico dello Stato. Roma, 1952.

- CARANI, Maria Lucia. "Restauri in San Miniato al Monte a Firenze: il problema della ricollocazione degli affreschi e delle sinopie". En Kermes, arte e tecnica del restauro. Anno III $n^{\circ} 7$. Gennaio/aprile 1990. Cronache del restauro. Nardini editore. Firenze, 1990.

- CARITÀ, Roberto. "Considerazioni sui telai per affreschi trasportati su tela". En Bollettino dell'Istituto Centrale del Restauro. 11-12. Istituto poligrafico dello Stato. Roma, 1952. 
- CARITÀ, Roberto. "Supporti per gli affreschi rimosi". En Bollettino dell'Istituto Centrale del Restauro. 36. Istituto poligrafico dello Stato. Roma, 1958.

- CYIELMAN, Mario. "Dodici frammenti di pittura murale romana". En OPD. Rivista dell'Opificio delle Piedtre Dure e Laboratorio di Restauro di Firenze. 2-1990. Centro Di. Firenze, 1990.

- ELIZALDE, I. "Una técnica curiosa" en Razón y Fe. Revista mensual hispanoamericana publicada por los Padres de la Compañía de Jesús. Año 47. Tomo 135. Madrid, 1947.

- ESCOHOTADO, Ma Teresa. "Las películas delgadas como adhesivos". En R\&R Restauración y Rehabilitación. № 24 enero 1999. Edita Prensa Española General de Revistas, S.A. Madrid, 1999.

- GóNZALEZ PASCUAL, Margarita. "La conservación del suelo pintado con figuras humanas más antiguo del Próximo Oriente". En Pátina. Escuela superior de conservación y restauración de bienes culturales de Madrid. Junio 1999. Época II $n^{\circ} 9$. Iluminación y conservación. Madrid, 1999.

- GONZÁLEZ PENA, Ma Luisa; RUIZ-VILLAR RUIZ, Lucrecia. "Informe sobre la restauración del mosaico romano de la c/Tudela en Tarazona". En Turiaso VI. Centro de estudios turiasonense. Institución Fernando el Católico. C.S.IC. Tarazona, 1985.

- LIBERTI, Salvatore. "Sui supporti rigidi per il trasporto degli affreschi". En Bollettino dell'Istituto Centrale del Restauro. 5-6. Istituto poligrafico dello Stato. Roma, 1951.

- MAIURI, Amadeo. "Note su di un nuovo dipinto ercolanese". En Bollettino d'Arte. Año XXXI. Fascículo XI. Serie tercera. La Libreria dello Stato. Roma, 1938.

- MARTELLOTTI, Giovanna. "Esperienze operative su strappi e stacchi esguiti in umbria tra XIX e XX secolo. Estratto da Giovanni Secco Suardo. La cultura del restauro tra tutela e conservazioni dell'opera d'arte". Supplemento al $\mathrm{n}^{\circ} 98$ del "Bollettino d'Arte del Ministero per i Beni Culturali e ambientali. Istituto Poligrafico e Zecca dello Stato. Libreria dello Stato. Roma.

- MAZZINI, Franco. "Impiego di materie plastiche espanse in opere di restauro in Lombardia". En Bollettino dell'Istituto Centrale del Restauro. Istituto poligrafico dello Stato. Roma, 1965.

- MORA, Paolo; TORRACA, Giorgio. "Appendice I. Schede di restauro: la tomba della Scrofa Nera. Nuovi supporti per 
affreschi staccati". En Bollettino dell'Istituto Centrale del Restauro. Istituto poligrafico dello Stato. Roma, 1965.

- MORALES RAMíREZ, Susana. "Finalización de la restauración del techo abovedado de la Casa de los Delfines. Realización del soporte inerte". En Kausis. Revista de la Escuela Taller de Restauración de pintura mural de Aragón. № 2. Diciembre 2004. Ed. Revista de la Escuela Taller de Restauración de pintura mural de Aragón. Zaragoza, 2004.

- NOVELL i CARNÉ, Teresa. "Arrancament i traspàs de les pintures murals del carrer de Lledó". En Butlletí del Museu d'Art de Catalunya 6 2002. Mnac. Barcelona, 2003.

- PARRINI, Paolo L.; CASAZZA, Ornella; PIZZIGONI, Giuseppe. "I materiali compositi nel restauro científico degli affreschi: il supporto delle sinopie di Masaccio e Masolino". En Quaderni del restauro. La Capella Brancacci. La scienza per Masaccio, Masolino e Filipino Lippi. Olivetti. Milano, 1992.

- RANESI, R. "Arrancament i restauració de pintures murals romanes d'una domus del carrer Pere Martell de Tarragona". En Rescat $n^{\circ}$ 9. Butlletí del Servei de Restauració de Béns Mobles. Generalitat de Catalunya. Barcelona, 2001.

- RASPI SERRA, J. "Nuovi supporti per affreschi staccati". En Bollettino dell'Istituto Centrale del Restauro. Istituto poligrafico dello Stato. Roma, 1965.

- RINALDI, Simona. "Un inedito di Cavalcaselle sul distacco degli affreschi". En Ricerche di storia dell'arte. 1997.

- RODRÍGUEZ SANCHO, Isabel. "Evolución de los soportes para reforzar y trasladar pinturas. Algunos ejemplos (primera parte)". En Pátina. Escuela superior de conservación y restauración de bienes culturales de Madrid. Junio 1995. №7. Madrid, 1995.

- RODRÍGUEZ SANCHO, Isabel; GARCía MOLINA, Ma José; RODRÍGUEZ LORITE, Miguel ángel. "Diseño y estudio de nuevos soportes traslúcidos y transparentes con aplicación en el campo pictórico y en el de la restauración". En Pátina. Escuela superior de conservación y restauración de bienes culturales de Madrid. Junio 1999. Época II nº 9. Iluminación y conservación. Madrid, 1999.

- ROIG PICAZO, Pilar y BOSCH REIG, Ignacio. "Arranque y traslado de una pintura mural a un nuevo soporte y espacio arquitectónico. Primera parte". En R\&R Restauración $y$ Rehabilitación. No 21 octubre 1998. Edita Prensa Española General de Revistas, S.A. Madrid, 1998. 
- ROIG PICAZO, Pilar y BOSCH REIG, Ignacio. "Arranque y traslado de una pintura mural a un nuevo soporte y espacio arquitectónico. Segunda parte". En R\&R Restauración y Rehabilitación. № 22 noviembre 1998. Edita Prensa Española General de Revistas, S.A. Madrid, 1998.

- ROIG PICAZO, P. (1999). "Digital imaging for the Restoration of the Wall paintings in the Church of Los Santos Juanes in Valencia, Spain". En Kermes. Art conservation Restoration. № 34 January - April 1999. Nardini Editore. Fiesole.

- TONEU, M. "Prócés d'adaptació de les pintures romàniques de Sant Sadurní d'Osormort i Sant Martí del Brull en els nous suports d'alumini" En Rescat $n^{\circ}$ 12. Butlletí del Servei de Restauració de Béns Mobles. Generalitat de Catalunya. Barcelona, 2002.

- URBANI, Giovanni; TORRACA, Giorgio. Nuovi supporti per affreschi staccati. Bollettino dell'Istituto Centrale del Restauro. Istituto poligrafico dello Stato. Roma, 1965.

- XARRIÉ, Josep Maria. 'L'Oceanus, stacco a massello d'una pintura mural romana del jaciment dels Munts (Alta fulla)". En RESCAT. Butlletí de Restauració de Béns Mobles. № 6. Desembre 1998. Generalitat de Catalunya. Departament de Cultura. Barcelona, 1998. 


\subsection{ARTÍCULOS EN ACTAS DE CONGRESOS.}

- BASILE, Giuseppe; P. Nicola GIANDOMENICO. "Dall'utopia alla relata. Notizie dall cantiere dei dipinti in frammenti della Basílica Superiore di San Francesco in Assisi". En Convengo internazionale di studi. 26-28 settembre 2002. Tipografía Metastasio. Assisi, 2002.

- BRAMBILLA BARCILON, Pinin. "Storia e problemi dello strappo di affreschi in Lombardia". En Geschichte der Restaurierung in Europa: Akten des Internationalen Kongresses "Restauriergeschichte", Basel, 1991. Band II / Schweizerische Verband für Koiservierung und Resstaurieung. Seuzach, Switzerland. Worms: Wernersche Verlagsgesellschaft, 1993.

- CICIRELLI, Caterina; VANACORE, Stefano. "Problemi di consolidamento e fissaggio strati preparatori e pellicola pittorica. Interventi pre-distacco in ambiente umindo". En Atti del Convegno: Consolidanti e protettivi in uso sui materiali inorganici inorganici porosi di interesse artistico ed archeologico. Trento 25 - 27 Febbraio 1990. $3^{\circ}$ Incontri di restauro. Provincia autonoma di Trento. Servizio Beni Culturali. Trento, 2000.

- COLOMBINI, M.P.; FUOCO, R.; GIACOMELLI, A.; MUSCATELLO, B; BARACCHINI, C.; CAPÓN, G. "Pulitura a tergo di affreschi strappati: caratterizzazione chimica del materiale proteico". En Scienza e beniculturali XI 1995. La pulitura delle superfici dell'architettura. Atti del convegno di studi.Bressanone. Edizioni Arcadia Ricerche. Venezia, 1995.

- DE LA COLINA TEJADA, Leonor; MEJÍA GARCíA, Carlos; DE LA COLINA BOTELLO, Manuel. "Prototipo de soporte para una pintura mural al fresco". En VIII Congrés de Conservació de Béns Culturals. Ponències i comunicacions. Valencia, 20, 21, 22, 23 setembre 1990. Actas recopiladas por Pilar Roig Picazo. UPV. Conselleria de Cultura Educació i Ciència. València, 1990.

- DEL SERRA, Alfio; TINTORI, Leonetto. "Nuove metodologie nel distacco degli affreschi". En Atti del convegno sul restauro delle opere d'arte. Opificio delle Pietre Dure e Laboratorio di Restauro di Firenze. Firenze 2-7 novembre. Volume I. Testo Edizioni Polistampa. Firenze, 1981.

- ESCRIG MORENO, Ma José; PUERTES TORRENT, Consuelo. "Arranque, restauración y reintegración informatizada de un zócalo mural de un palacio civil islámico en Játiva (Valencia)". En XII Congreso de Conservación y Restauración de Bienes Culturales. Alicante del 28 al 31 de octubre de 1998. Ed. 
Generalitat Valenciana. Conselleria de Cultura Educació i Ciència, Direcció General de Patrimoni Artístic. Octubre 1998.

- FERNÁNDEZ GARCíA, Guillermo; GARCíA MOLINA, Ma José; GONZÁLEZ PASCUAL, Margarita; SANZ CRUZADO, Laura; PÉREZ MEDINA, Diana. "El legado de la Tía Sandalia: consolidación, arranque y montaje de la obra para el futuro Museo Etnográfico Local de Villacañas (Toledo). En VIII Congrés de Conservació i Restauració de Béns Culturals. Ponències $i$ Comunicacions. València, 20, 21, 22, 23 setembre 1990. Generaliat Valenciana. Actas recopiladas por Pilar Roig Picazo. UPV. Conselleria de Cultura, Educació i Ciència. València, 1990.

- FERRONI, Enzo, DINI, Dino. "Esperienze sul sequestro di nitrati con tributilfosfato per il distacco e la conservazione degli affreschi". En: Atti della XLIX riunione (Siena, 23-27 settembre 1967) Volume II. Società italiana per el progresso delle scienze. S.I.P.S. Roma, 1968. pp. 919-932.

- KIERKEGAARD, Bo. "Examples of strappo of mural modern frescoes". En Restauro degli affreschi : esperienze, metodologie e criteri di conservazione (Brescia, 5-9 Luglio 1993). IRECOOP Emilia Romagna, Italy. Commission of European Communities. Brussels, Belgium. S.I.: IRECOOP Emilia Romagna, 1993.

- LEPORE, Giuseppe ; ZACCARIA, Mirco. "Il recupero e il restauro di dipinti parietali di epoca romana: l'esperienza di Suasa (Ancona)". En Atti del Convegno : Consolidanti e protettivi in uso sui materiali inorganici inorganici porosi di interesse artistico ed archeologico. Trento 25 - 27 Febbraio 1990. $3^{\circ}$ Incontri di restauro. Provincia autonoma di Trento. Servizio Beni Culturali. Trento, 2000.

- MÉNDEZ mANZANO, Agustín; MORET GARCíA-MAURIÑO, Aureliano. Traslado a lienzo de una pintura mural de grandes dimensiones original de Manuel Millares. En actas del IV congreso de Conservación de Bienes Culturales. Palma de Mallorca. 29 de octubre al 1 de noviembre de 1982. instituto de conservación y restauración de obras de arte. Comité Español del ICOM. Gráficas solana. Madrid, 1984.

- MONFORTE ESPALlARGAS, Alfonso. "Conservación, restauración y reposición del conjunto mural de la ermita de San Fructuoso. Bierge. (Huesca)". En XI Congreso de Conservación y Restauración de Bienes Culturales. Castellón 3, 4, 5 y 6 de octubre de 1996. Servei de publicacions. Diputació de Castelló. Castelló, 1996.

- MONRAVAL, Magdalena; KROUGLY, Laurence. "Las pinturas murales de la Capilla de la Universitat de València. Estudi general. Proceso de arranque y salvamento (1988)". En VIII 
Congrés de Conservació i Restauració de Béns Culturals. Ponències i Comunicacions. València, 20, 21, 22, 23 setembre 1990. Generalitat Valenciana. Actas recopiladas por Pilar Roig Picazo. UPV. Conselleria de Cultura, Educació i Ciència. València, 1990.

- MONRAVAL, Magdalena; KROUGLY, Laurence. "Las pinturas murales de la Capilla de la Universitat de València. Estudi general. Trabajo práctico de transferencia a un nuevo soporte". En VIII Congrés de Conservació i Restauració de Béns Culturals. Ponències i Comunicacions. València, 20, 21, 22, 23 setembre 1990. Generaliat Valenciana. Actas recopiladas por Pilar Roig Picazo. UPV. Conselleria de Cultura, Educació i Ciència. València, 1990.

- PARRINI, Paolo; MILANO, Mario. "Carte a frattura predeterminata a base di fibrilla sintetiche poliofeniliche". En Atti del Convengo sul Restauro delle opere d'arte. Orificio delle Pietre Dure e Laboratorio di Restauro di Firenze. Volume I. Edizioni Polistampa. Firenze, 1981.

- RODRÍGUEZ SANCHO, Isabel. "Soportes rígido-inertes para el traslado de pinturas. Estudio de su deformación estructural al ser sometidos a la acción degradante de la humedad y temperatura en una cámara de niebla salina". En $X$ Congreso de Conservación y Restauración de Bienes Culturales. Cuenca, del 29 de septiembre al 2 de octubre de 1994. Edita Andrés Escalera y M ${ }^{\mathrm{a}}$ Carmen Pérez. Cuenca, 1994.

- ROIG PICAZO, Pilar. "La iglesia de los Santos Juanes de Valencia. Proceso de intervención desde el año 1936 hasta nuestros días". En Actas del VI congreso de Conservación de Bienes Culturales. Tarragona, 29 de mayo al 1 de junio de 1986. Generalitat de Catalunya. Departament de Cultura. Centre de Conservació i Restauració de Béns Culturals Mobles. Barcelona, 1988.

- ROIG PICAZO, P.; BOSCH REIG, I; ALONSO, J.L.; DOMÉNECH CARBÓ, M.T.; MUÑOZ VIÑAS, S. (1994) "Aproximación al estudio de la obra de Antonio Palomino: los frescos de la bóveda de la Iglesia parroquial de los Santos Juanes de Valencia". En el libro de actas del Congreso Nacional Madrid en el contexto de lo hispánico desde la época de los descubrimientos". Tomo II. Departamento de historia del arte II. Facultad de Geografía e Historia (U.C.M). Madrid.

- SORIANO SANCHO, P; OSCA PONS, J.; ROIG PICAZO, P. "Análisis de la metodología de arranques parciales de pintura mural: un caso práctico". En Libro de Actas del XIV Congreso de Conservación y Restauración de Bienes Culturales. Ed. 
Ayuntamiento de Valladolid. Volumen II. Valladolid, 2002. Páginas 785-799.

- SUARDI, Giuseppina. "II restauro dell'ingreso principale del Castello di malpaga: annotazioni sulla pulitura degli affreschi cinquecentestiche di G.B. Castello". En Atti convegno scienza e beniculturali. Bressanone.1995. 


\subsection{TESIS.}

- AghajANI ESFAHANI, Hosein. Distacco e operazioni di restauro eseguito sull'affresco rappresentante "Flagellazione di Cristo" proveniente da Genova "Monumento di Santa Maria in Castello". Tesina dell'Istituto Centrale per il Restauro. Corso 1971-1974. Roma.

- CONTI, Cristina. Lo stacco e lo strappo delle pitture murali nei casi di incontroversa necessità: vantaggi e svantaggi dei due procedimenti. Tesi di diploma del Corso Triennale. Relatori: Dott. Cristina Danti. Res. Antonello Pandolfo. Opificio delle Pietre Dure e Laboratorio di Restauro. Firenze, 1984.

- MARIOTTI, Paola. Supporti impiegati per il distacco e strappo delle pitture murali, in sostituzione dell'originale, dalle origini ad oggi. Ricerca tecnica sui materiali e sui metodi di impiego. Letture di comportamento. Tesi. Settore affrechi. Opificio delle Pietre Dure. Firenze 1983.

- MARTíNEZ BAZÁN, Ma Luisa. Determinación de los colores existentes en la decoración al fresco, ejecutada por A. Palomino, en un fragmento de la nave central de la Iglesia de los Santos Juanes en Valencia / tesis doctoral dirigida por Pilar Roig Picazo. Departamento de Conservación y Restauración de Bienes Culturales. Universidad Politécnica de Valencia. Valencia, 1999.

- OSCA PONS, Julia. La consolidación de pinturas murales: la obra de Palomino en Valencia / tesis doctoral dirigida por Pilar Roig Picazo. Departamento de Conservación y Restauración de Bienes Culturales. Universidad Politécnica de Valencia. Valencia, 1998.

- REGIDOR ROS, José Luís. Estabilidad, protección y aceptación de las impresiones Ink Jet en procesos de creación y conservación de obras de arte / tesis doctoral dirigida por Pilar Roig Picazo; codirigida por $\mathrm{M}^{\mathrm{a}}$ Luisa Martínez Bazán Departamento de Conservación y Restauración de Bienes Culturales. Universidad Politécnica de Valencia. Valencia, 2004.

- SÁNCHEZ PONS, Mercedes. Revisión de Técnicas y criterios en torno a la reintegración de pinturas murales al fresco. Aplicación en las pinturas murales de la bóveda de la iglesia de los Santos Juanes de Valencia. I tesis doctoral dirigida por Ignacio Bosch Reig. Departamento de Conservación y Restauración de Bienes Culturales. Universidad Politécnica de Valencia. Valencia, 2002.

- SARTEANESI, Chiara. II manuale di Giovanni Secco-Suardo e le moderne tecniche di restauro. Tesi di laurea. Università degli 
studi di Firenze. Facoltà di lettere e filosofia. Istituto di Storia dell'Arte. Anno accademico 1982-1983. Prof. Mina Gregori. Firenze, 1983.

- VALCÁRCEL ANDRÉS, Juan. Estudio de la técnica empleada por Antonio Palomino en los frescos de la Real Basílica de la Virgen de los Desamparados de Valencia a partir de su análisis con radiación de diferentes longitudes de onda. / tesis doctoral dirigida por Julia Osca Pons. Departamento de Conservación y Restauración de Bienes Culturales. Universidad Politécnica de Valencia. Valencia, 2004.

- ZALBIDEA MUÑOZ, Antonia. La técnica del cartonaje en Giambattista Tiepolo y sus posibles influencias en artistas españoles. I tesis doctoral dirigida por Pilar Roig Picazo. Departamento de Conservación y Restauración de Bienes Culturales. Universidad Politécnica de Valencia. Valencia, 2004. 


\subsection{PÁGINAS WEB.}

- http://www.international.icomos.org/charters/wallpaintings sp.ht $\underline{\mathrm{m}}$

- http://www.hilti.es

- http://www.ediltec.es.

- http://www.poliuretanos.com.

- http://www.grudem.es.

- http://www.anape.es

- http://www.maderuelo.com

- http://www.romanicoaragones.com

- http://www.diariodelaltoaragon.es

- http://www.museoprado.mcu.es

- http://www.imageserver.library.unr.edu

- http://www.getty.edu

- http://www.ehu.es

- http://carloerbareagenti.com

- http://www.spheretex.com

\subsection{DICCIONARIOS.}

- VV.AA. Dizionario della pittura e dei pittori. Vol. S-T. Giulio Einaudi Editore. Torino, 1994. p. 316-317 y 391. 




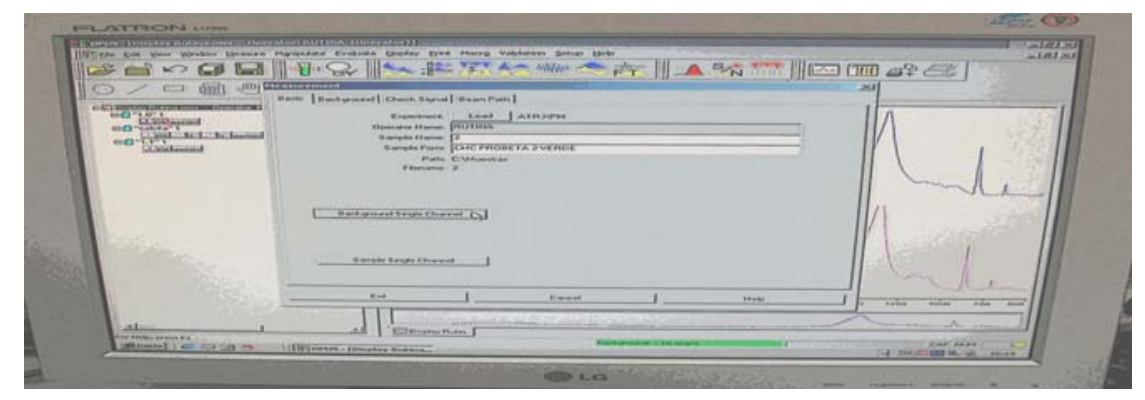

ANEXOS 




\section{ANEXOS}

9.1. ANEXO I. Correspondencia de D. Domingo Fletcher.

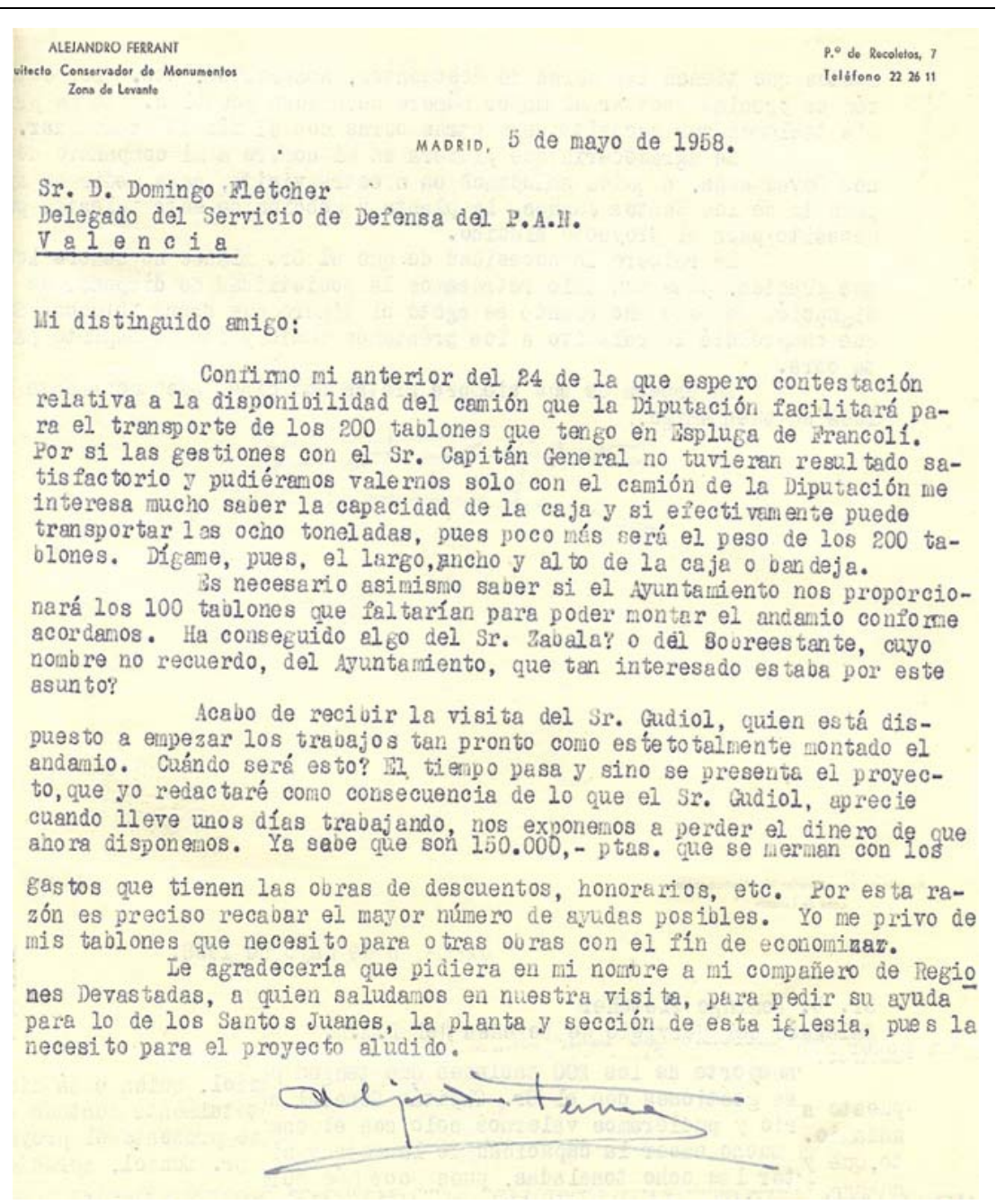

Fig.185. Carta $n^{\circ}$ 7. De Alejandro Ferrant a Domingo Fletcher. 5 de mayo de 1958. 


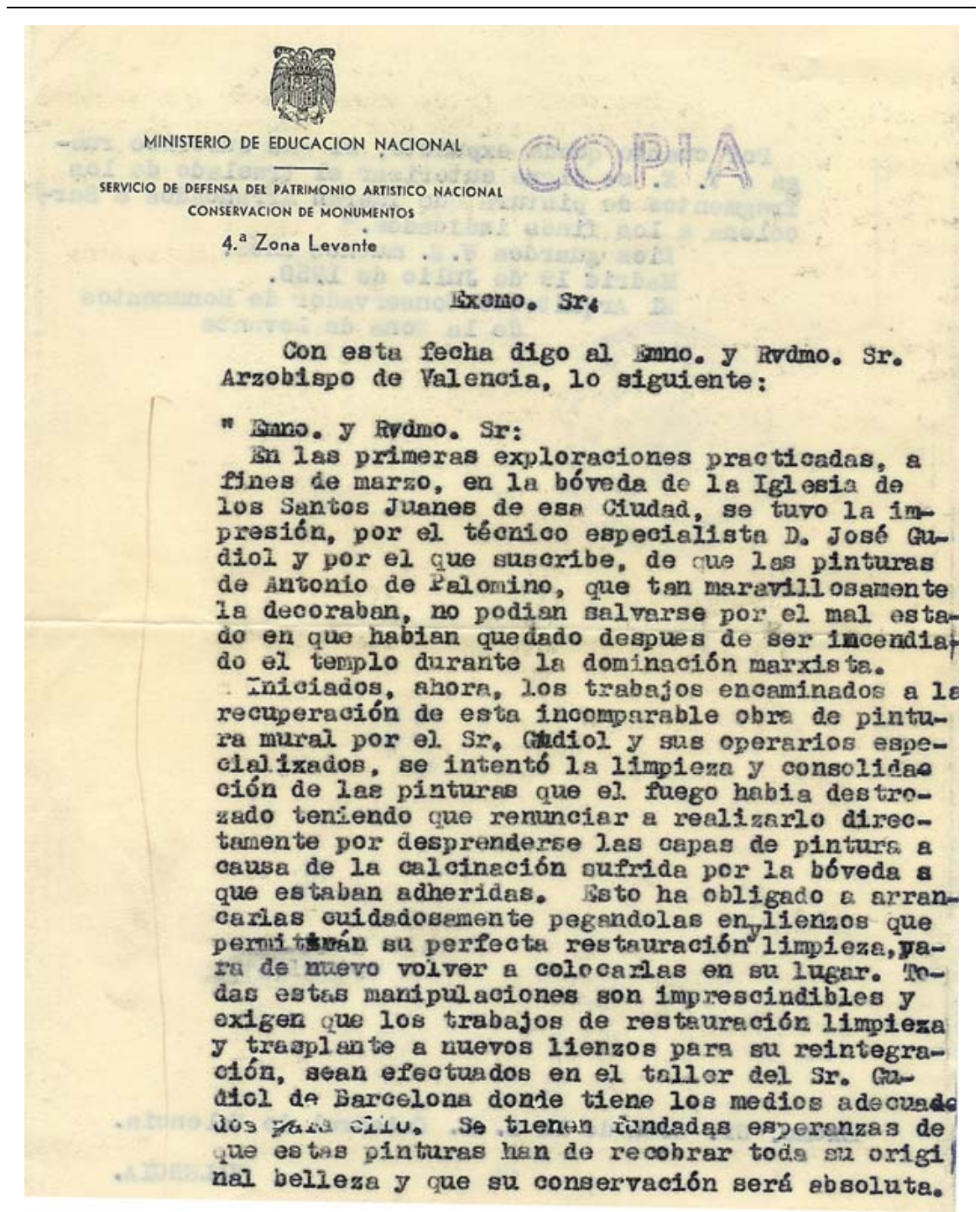

Fig.186. Carta $n^{\circ}$ 9. De Alejandro Ferrant al Deán de la Catedral, al Párroco de Santos Junaes y al Arzobispo de Valencia. 19 de julio de 1958. 


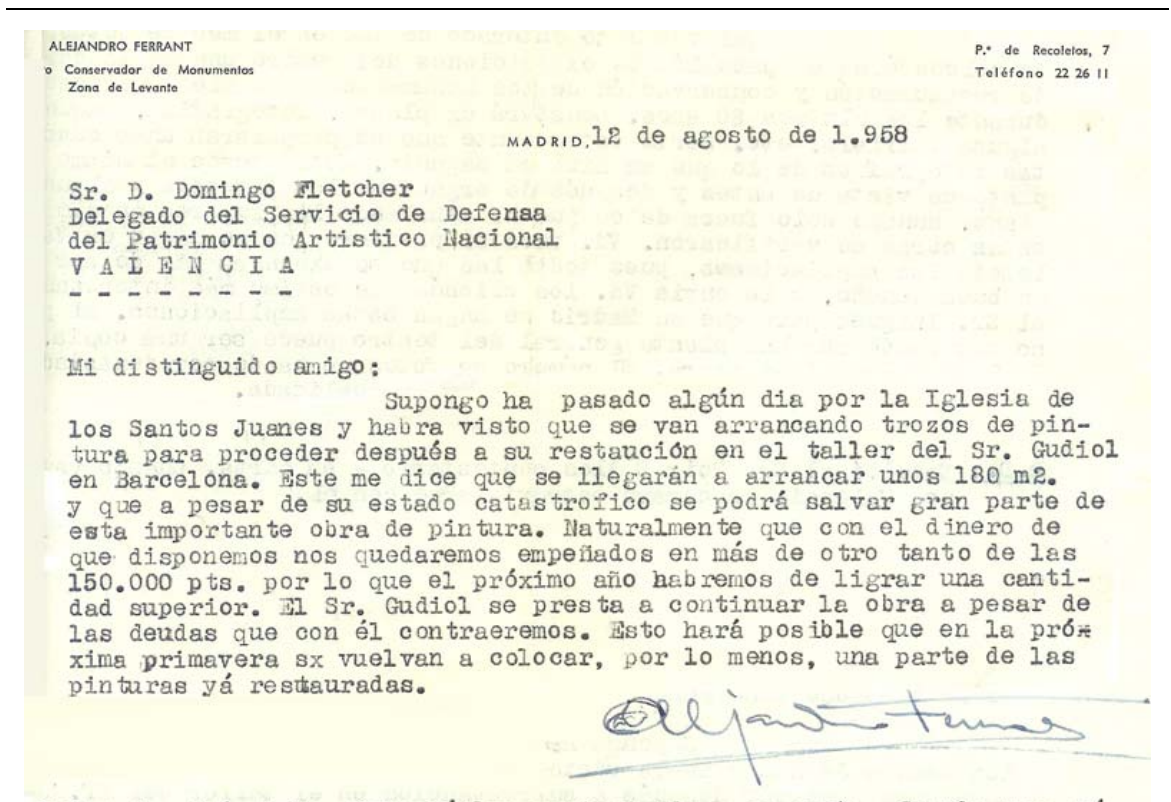

D.D.: Ascribí al Sr. Roig D'Alos contestando a su carta. Cuando vaya yó por Valencia procuraré entrevistarme con él.

Fig.187. Cartan 11. De Alejandro Ferrant a Domingo Fletcher. 12 de agosto de 1958.

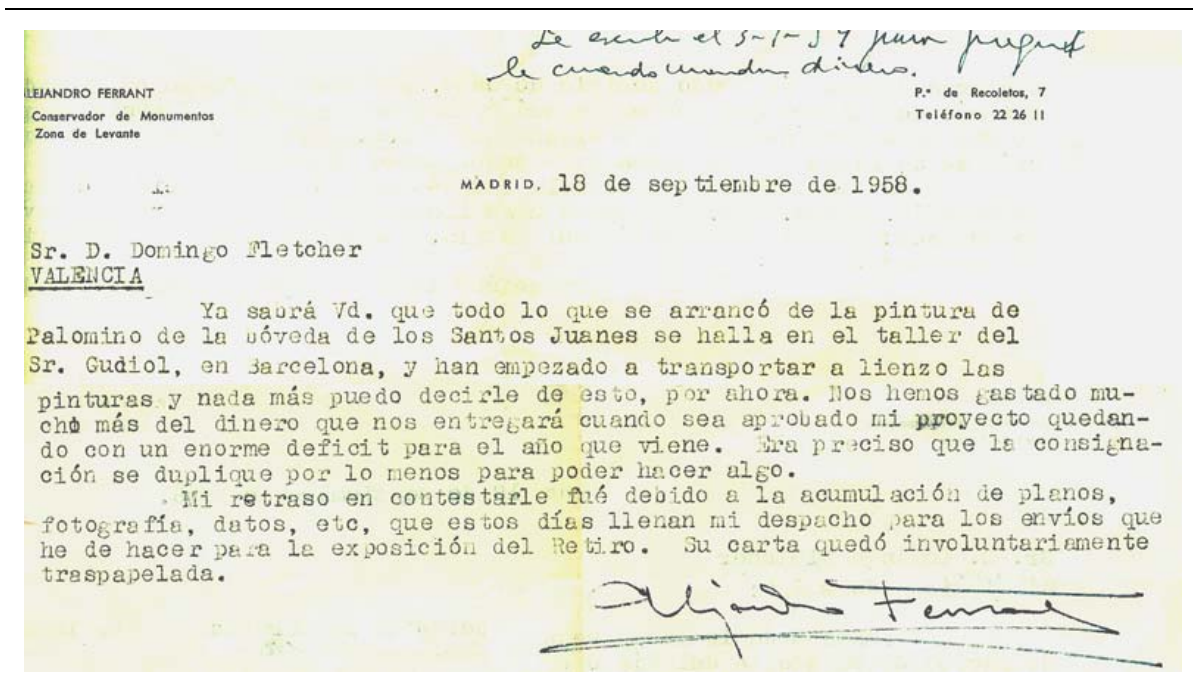

Fig.188. Carta n 13. De Alejandro Ferrant a Domingo Fletcher. 18 de septiembre de 1958. 


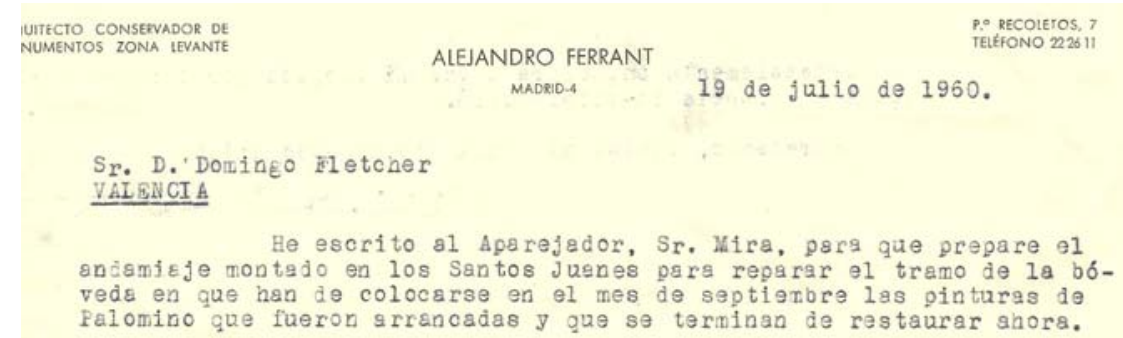

Fig.189. Carta $\mathrm{n}^{\circ}$ 15. De Alejandro Ferrant a Domingo Fletcher. 19 de julio de 1960.

Kateu.- Los tres entreganos al hijo del Sr. Gallego Burín los mencionados documentos. - Todavía no me ha telefoneado para darme cuec ta de 10 que su padre opina de 10 'recibido. - Io he ofrecido al Sr. Castells entrevistarme con el Subdireotor General dé Arquiteotura jara ver si el Hinisterio de la Vivienda. oolaboraría en esta obra del lluseo cátedralicio, Ja que la Catedral no tuvo

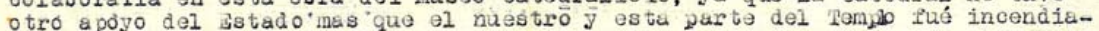
da on la revolución marxista.

on la ravolución marxista. tedral no fú́ invertida más que una jarte y queda bastante dinero he decidido tedral bo tue ince la puerta del peluvertiro lal . mb entusiasmados con la idea y tan pronto como me envion lab maldes dar ven tanal que les propuse obtuvieran con la escala de bonberos, yo caloulare 10 que puede costar la obra, alnque, ja les adverti, quo no se podria realizar y que hiorla de solicitase de unos dís, hacia el 240 el 25 estaré en Valencia y hablaremos de todss estas cosas.

Le agradecería que 10 que se publicara, comentando nuestra labor me 10 enviara.

$\mathrm{He}$ tenido carta del Sr. Gudion manifestándome he terminado su trabajo de instalsoín en las obra de los Santos Juanes en las pinturas restauradas de - Palomino. - Istá desilusionado por la fal ba de interés que, dice, han mostrado los val encianos por esta obra tan importante.- Supongo que Vd. la vió.Ife gustaría conocer su opinión de como ha quedado.

Fig.190. Carta $n^{\circ}$ 16. De Alejandro Ferrant a Domingo Fletcher. 14 de noviembre de 1960 


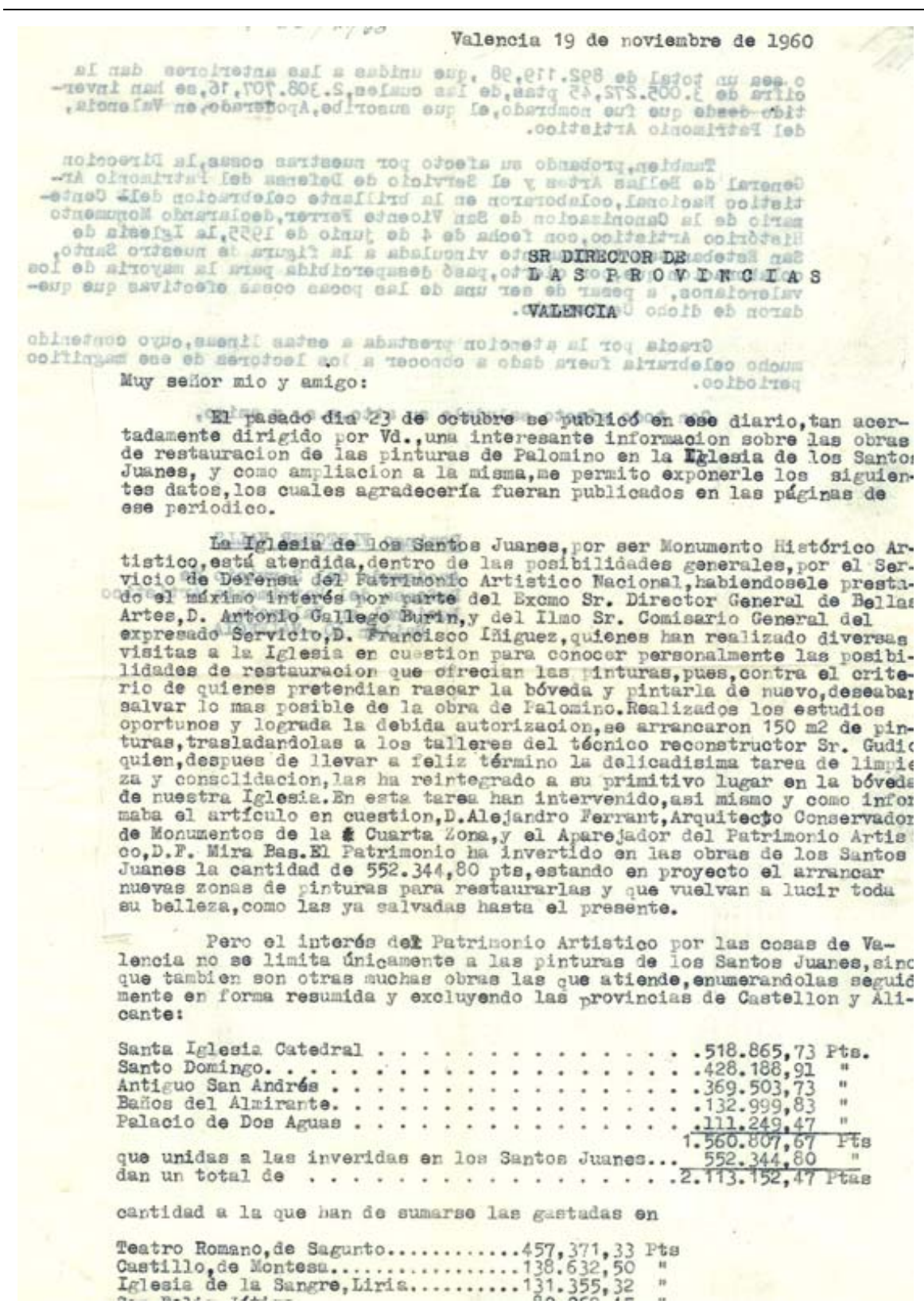

Fig. 191. Carta $n^{\circ}$ 17. De Domingo Fletcher al diario Las Proviencias. 19 de noviembre de 1960. 
In Barcelona he visto 10 que hes ta aho ra se lleva restalrado de las pintue 'as, de Fal onino, de los Santos Juanes, que efomple tarén lo ya colocad, pues como d. sabe, he presentado un proyecto para que $10 s$ tramos do $10 s$ pies, dos o pres, uede visible, la boveda go ica al derruir la que sirvio part pintar 2aelomino. erardo Buzzas, que así se 21 ama tan mentado cantero, marchara a Villena, para la estauración de un cubo del Castillo, y ouando lo tenga terminado volveŕ́ a Vales 1a, para tominar 10 de la bóveda de los santos Juanes.

In espera de sus gratas no tioies y con un saludo pera 1. Leopoldo, reciba va. o tro muy cordial de su buen amigo,

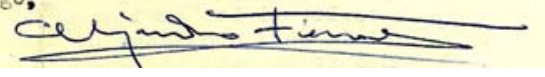

Fig. 192. Carta $\mathrm{n}^{\circ}$ 18. De Alejandro Ferrant a Domingo Fletcher. 20 de mayo de 1962.

Dentro de pocos dias serán trasladadas desdo Barcelona a Valencia, las lor por colocadas en la bóveda de los ginturas, ya

Fig. 193. Carta $\mathrm{n}^{0}$ 19. De Alejandro Ferrant a Domingo Fletcher. 12 de julio de 1962. 


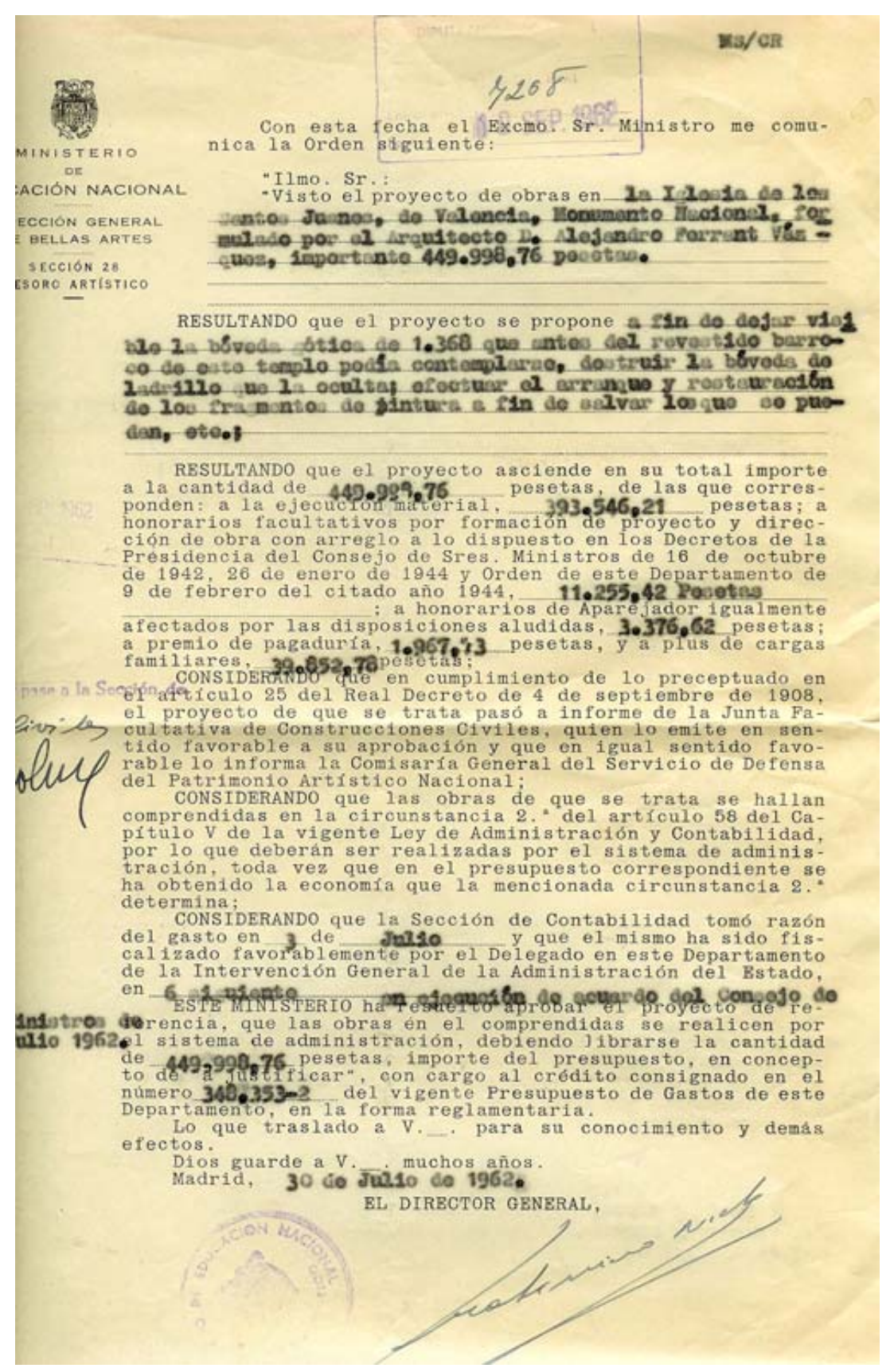

Fig. 194. Carta $n^{\circ}$ 20. De Gratiniano Nieto al Presidente de la Diputación. 30 de julio de 1962. 


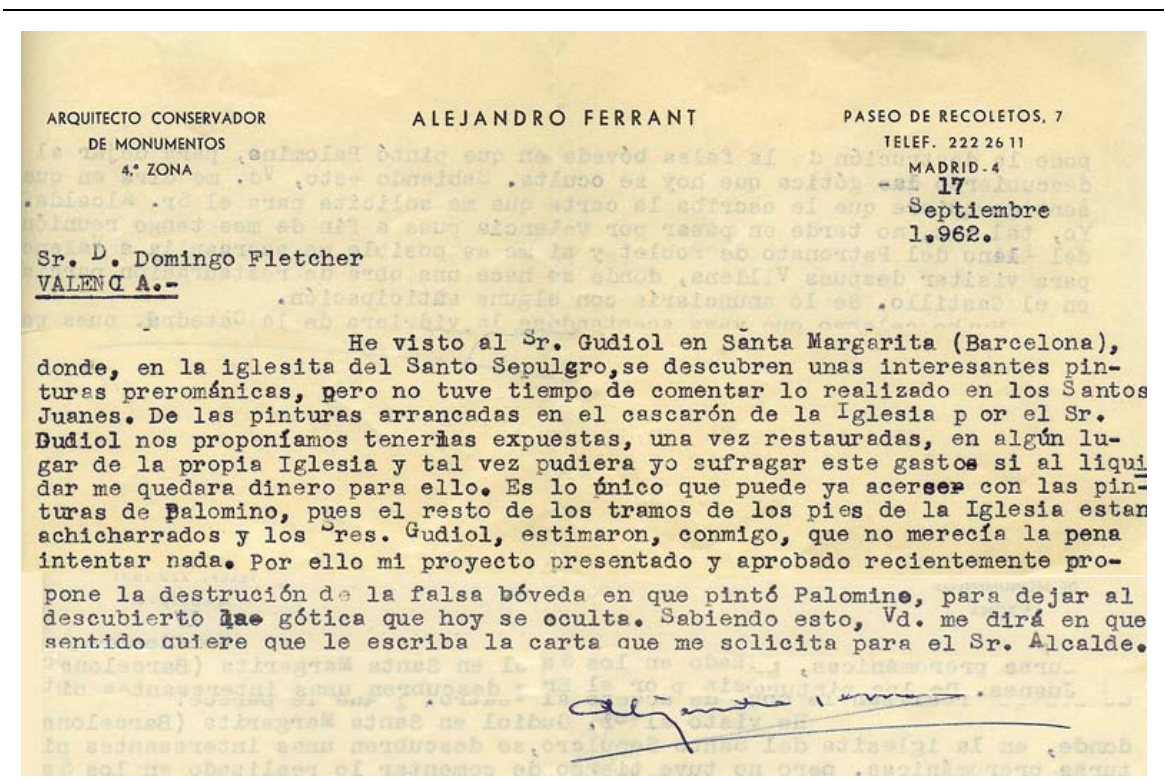

Fig. 195. Carta $n^{\circ}$ 21. De Alejandro Ferrant a Domingo Fletcher. 17 de septiembre de 1962. 


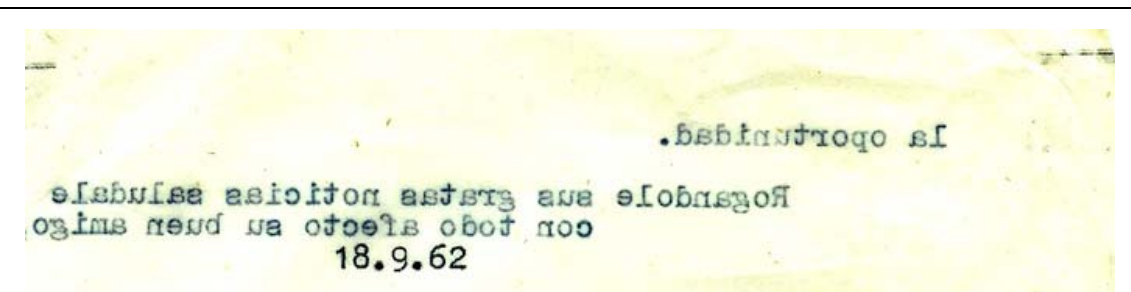

\section{SR D ALEJANDRO FERRANT MADRID \\ Mi distinguido amigo:}

Hace unos dias tuve el gusto de escribicle referente al asunto de los Santos Juanes y ahora vuelvo sobre el particular porque el sr. Cura de dicha Iglesia vino ayer a verme para consultame sobre un oficio recibido de]. winisterio, Pecha de salida el $4 / 9 / 62$ y fecha de redaccion el $30 / 7 / 62$, en el que se habla de la concesion de $449.998,76 \mathrm{p}$ destinadas a "dejar visible la bóveda gótica de 1368 que antes del revestido barroco de este templ podia contemplarse, destruir la bóveda de ladrilio que la oculta; efectuar el arranque y restauracion de 103 framentos de pintura a fin de salvar los que se puedan, etc.".

E1 citado sr. Cura me preguntó si se trata ba de una rueva consignacion, manifestandole por $m$ parte que lo mas seguro es que esta concesion sea la correspondiente a lo que ya se ha hecho, pero sin poderselo afirmar categóricamente, por lo que le prometi escribirle a Va solicitando ia informacion necesaria para orientar a este sr. Ruego, pue me diga algo a este respecto.

Fig. 196. Carta $\mathrm{n}^{\circ}$ 22. De Domingo Fletcher a Alejandro Ferrant. 18 de septiembre de 1962.

Con relacion a 10 que me pregunta respecto a los Santos Juenes puedo decirle que efectivamente las $449.998,76$ pesetas son de uns nueva consignación, para las obras que $\mathrm{V}_{\mathrm{d}}$. Indica, pero como de la consienación anterior no tendré dinero suficiente para abonar al Sr. Guliol el importe de las pinturas ultimamente colocadas, habrá de mermarse algo de esta nueva cantidad. De todas maneras creo que todo o casi todo podrá hacorse. Creo tendremos tịmpo duranté nuestra visita de hablar de esto con el Sr. Cura Párioco y con Vd:

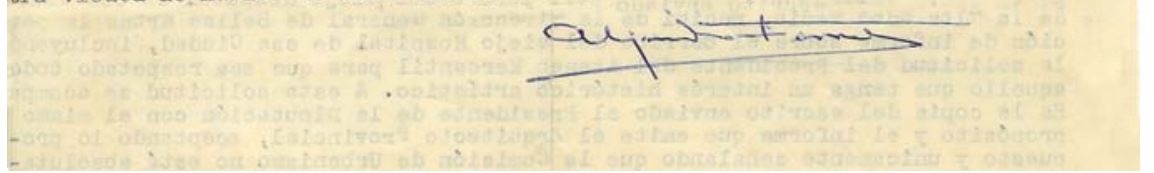

Fig. 197. Carta $n^{\circ}$ 23. De Alejandro Ferrant a Domingo Fletcher. 19 de septiembre de 1962. 
Todavia no se cuanto podré ir por Valencia, pues estoy enredado con lo: proyectos que mo faltan, He tenido noticias del $\mathrm{Sr}$. lira dieiendome que el sábado pactos a poco cue creo queda de la pinture de Palomino de los Santos Juanes.

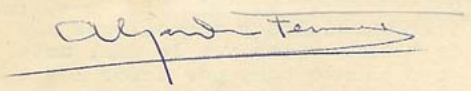

Fig. 198. Carta $\mathrm{n}^{\circ}$ 25. De Alejandro Ferrant a Domingo Fletcher. 25 de junio de 1963.

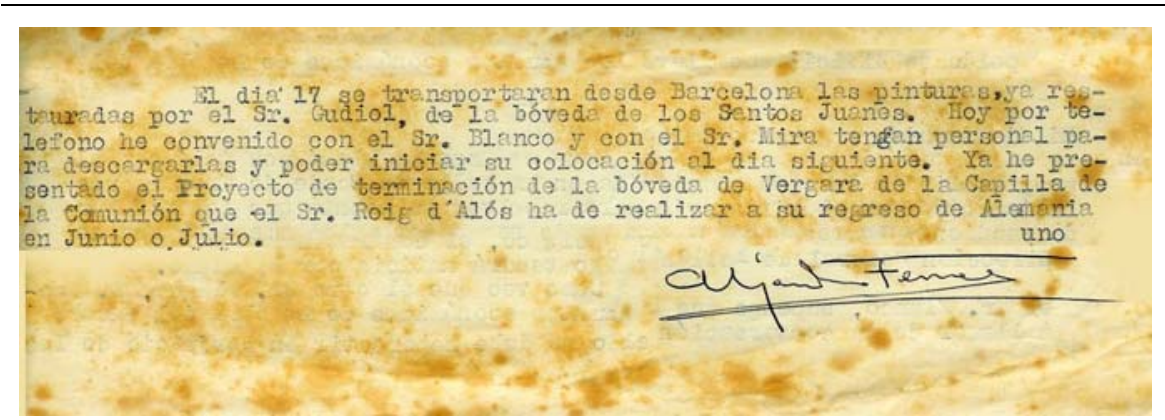

Fig. 199. Carta $\mathrm{n}^{\circ}$ 31. De Alejandro Ferrant a Domingo Fletcher. 11 de mayo de 1965.

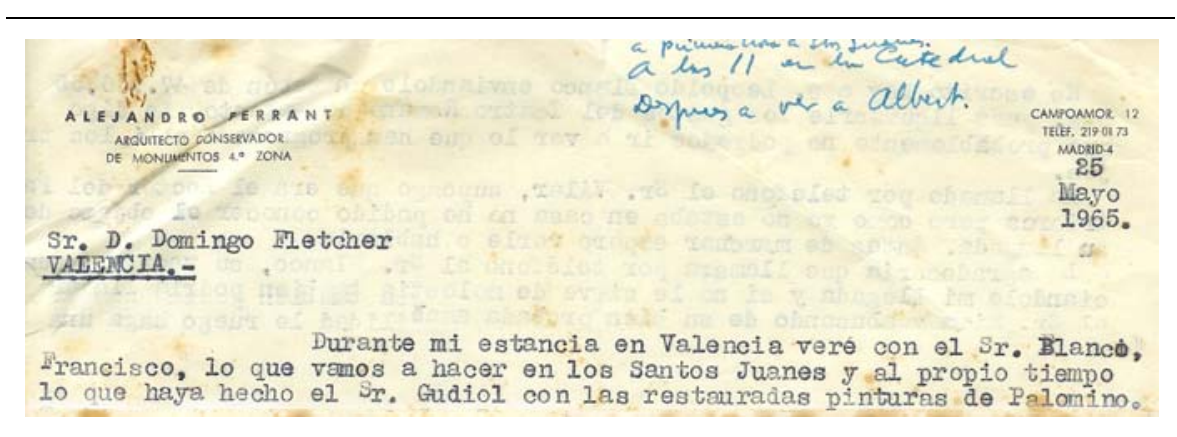

Fig.200. Carta $\mathrm{n}^{\circ}$ 33. De Alejandro Ferrant a Domingo Fletcher.25 de mayo de 1965. 


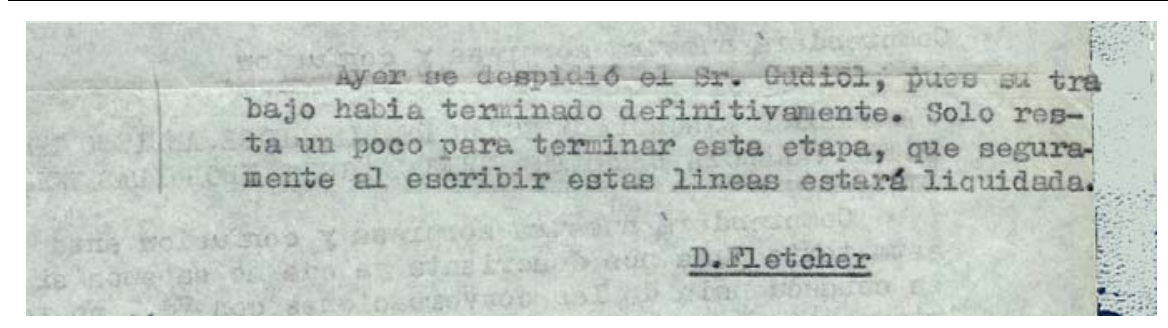

Fig. 201. Carta ${ }^{\circ}$ 34. De Alejandro Ferrant a Domingo Fletcher. 3 de junio de 1965.

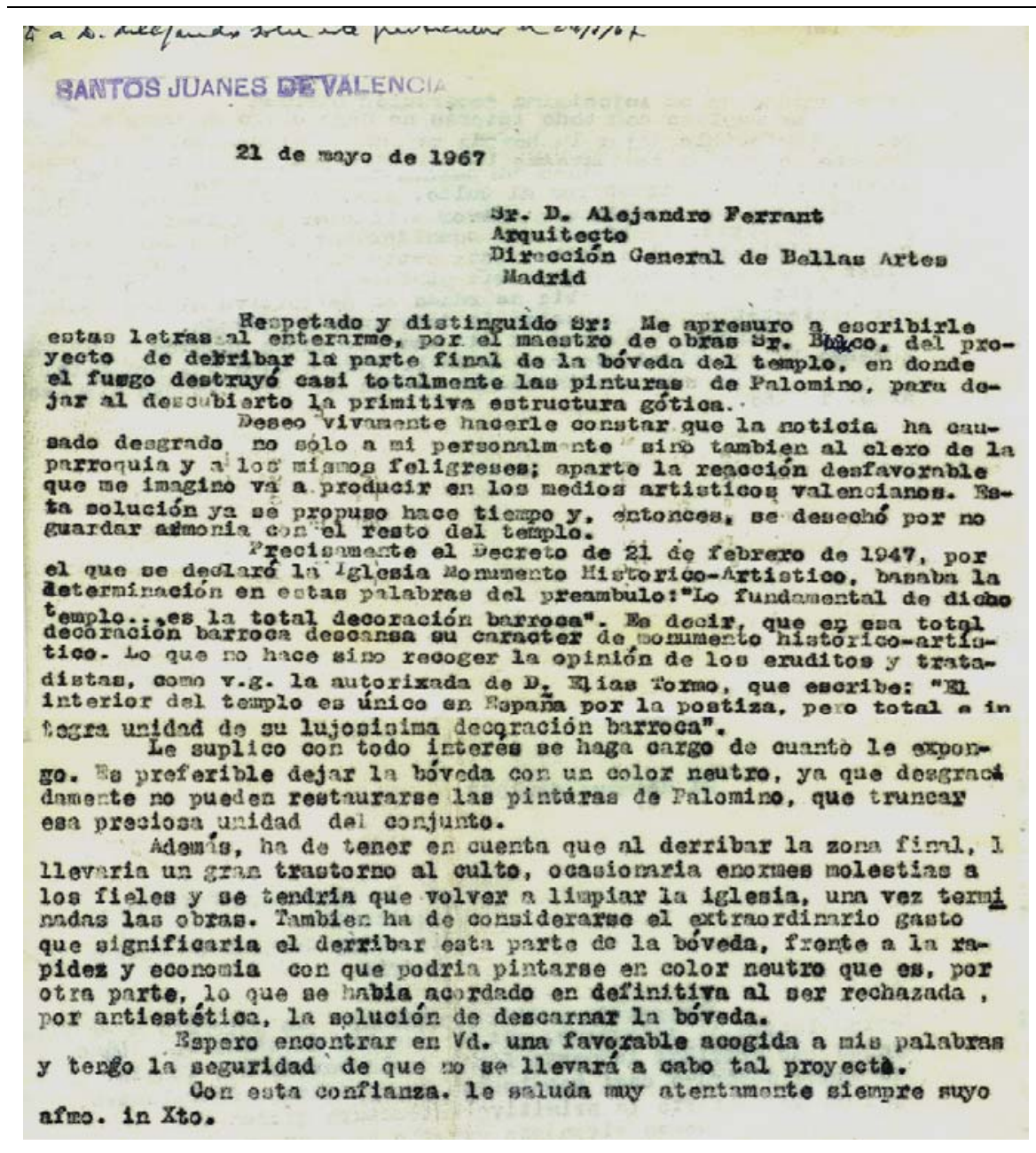

Fig. 202. Carta $n^{\circ}$ 43. Del Párroco de Santos Juanes a Alejandro Ferrant. 21 de mayo de 1967. 
9.2. ANEXO II. Tablas de las probetas de análisis de diferentes concentraciones de adhesivos.

\begin{tabular}{|c|c|c|c|c|}
\hline ADHESIVO & SPHERECORE & ARPILLERA & FIELTRO & $\begin{array}{l}\text { LONETA } \\
\text { DE } \\
\text { ALGODÓN }\end{array}$ \\
\hline $\begin{array}{l}\text { PARALOID + } \\
\text { TOLUENO } \\
5 \mathrm{gr} / 50 \mathrm{ml}\end{array}$ & $\begin{array}{l}\text { No se } \\
\text { adhiere nada }\end{array}$ & $\begin{array}{l}\text { No se } \\
\text { adhiere nada }\end{array}$ & $\begin{array}{l}\text { No se } \\
\text { adhiere nada }\end{array}$ & $\begin{array}{l}\text { No se } \\
\text { adhiere } \\
\text { nada }\end{array}$ \\
\hline $\begin{array}{l}\text { PARALOID + } \\
\text { TOLUENO } \\
10 \mathrm{gr} / 50 \mathrm{ml}\end{array}$ & $\begin{array}{l}\text { No se } \\
\text { adhiere nada }\end{array}$ & $\begin{array}{l}\text { No se } \\
\text { adhiere nada }\end{array}$ & $\begin{array}{l}\text { Se adhiere } \\
\text { muy poco }\end{array}$ & $\begin{array}{l}\text { No se } \\
\text { adhiere } \\
\text { nada }\end{array}$ \\
\hline $\begin{array}{l}\text { PARALOID + } \\
\text { TOLUENO } \\
15 \mathrm{gr} / 50 \mathrm{ml}\end{array}$ & $\begin{array}{l}\text { Se adhiere } \\
\text { muy poco }\end{array}$ & $\begin{array}{l}\text { Se adhiere } \\
\text { muy poco }\end{array}$ & $\begin{array}{l}\text { Se adhiere } \\
\text { muy poco }\end{array}$ & Se adhiere \\
\hline $\begin{array}{l}\text { PARALOID + } \\
\text { ACETONA } \\
5 \mathrm{gr} / 50 \mathrm{ml}\end{array}$ & $\begin{array}{l}\text { Se adhiere } \\
\text { bien }\end{array}$ & $\begin{array}{l}\text { Se adhiere } \\
\text { muy poco }\end{array}$ & $\begin{array}{l}\text { Se adhiere } \\
\text { muy poco }\end{array}$ & $\begin{array}{l}\text { Se adhiere } \\
\text { muy poco }\end{array}$ \\
\hline $\begin{array}{l}\text { PARALOID + } \\
\text { ACETONA } \\
10 \mathrm{gr} / 50 \mathrm{ml}\end{array}$ & $\begin{array}{l}\text { Se adhiere } \\
\text { muy bien }\end{array}$ & Se adhiere & Se adhiere & $\begin{array}{l}\text { Se adhiere } \\
\text { muy poco }\end{array}$ \\
\hline $\begin{array}{l}\text { PARALOID + } \\
\text { ACETONA } \\
15 \mathrm{gr} / 50 \mathrm{ml}\end{array}$ & $\begin{array}{l}\text { Se adhiere } \\
\text { muy bien }\end{array}$ & $\begin{array}{l}\text { Se adhiere } \\
\text { muy bien }\end{array}$ & $\begin{array}{l}\text { Se adhiere } \\
\text { muy bien }\end{array}$ & $\begin{array}{l}\text { Se adhiere } \\
\text { bien }\end{array}$ \\
\hline $\begin{array}{l}\text { CMC + AGUA } \\
2 \mathrm{gr} / 50 \mathrm{ml}\end{array}$ & $\begin{array}{l}\text { Se adhiere } \\
\text { demasiado }\end{array}$ & $\begin{array}{l}\text { Se adhiere } \\
\text { demasiado }\end{array}$ & $\begin{array}{l}\text { Se adhiere } \\
\text { muy bien }\end{array}$ & $\begin{array}{l}\text { Se adhiere } \\
\text { muy bien }\end{array}$ \\
\hline $\begin{array}{l}\text { CMC + AGUA } \\
3 \mathrm{gr} / 100 \mathrm{ml}\end{array}$ & $\begin{array}{l}\text { Se adhiere } \\
\text { muy bien }\end{array}$ & $\begin{array}{l}\text { Se adhiere } \\
\text { muy bien }\end{array}$ & $\begin{array}{l}\text { Se adhiere } \\
\text { muy bien }\end{array}$ & $\begin{array}{l}\text { Se adhiere } \\
\text { bien }\end{array}$ \\
\hline $\begin{array}{l}\text { CMC + AGUA } \\
5 \mathrm{gr} / 200 \mathrm{ml}\end{array}$ & Se adhiere & Se adhiere & $\begin{array}{l}\text { Se adhiere } \\
\text { bien }\end{array}$ & Se adhiere \\
\hline $\begin{array}{l}\text { ALCOHOL } \\
\text { POLIVINÍLICO } \\
+ \text { AGUA } \\
2 \mathrm{gr} / 50 \mathrm{ml}\end{array}$ & $\begin{array}{l}\text { Se adhiere } \\
\text { muy poco }\end{array}$ & $\begin{array}{l}\text { Se adhiere } \\
\text { muy poco }\end{array}$ & Se adhiere & $\begin{array}{l}\text { Se adhiere } \\
\text { muy poco }\end{array}$ \\
\hline $\begin{array}{l}\text { ALCOHOL } \\
\text { POLIVINÍLICO } \\
+ \text { AGUA } \\
3 \mathrm{gr} / 50 \mathrm{ml}\end{array}$ & $\begin{array}{l}\text { Se adhiere } \\
\text { muy poco }\end{array}$ & $\begin{array}{l}\text { Se adhiere } \\
\text { muy poco }\end{array}$ & $\begin{array}{l}\text { Se adhiere } \\
\text { muy poco }\end{array}$ & $\begin{array}{l}\text { Se adhiere } \\
\text { muy poco }\end{array}$ \\
\hline $\begin{array}{l}\text { ALCOHOL } \\
\text { POLIVINÍLICO }\end{array}$ & Se adhiere & Se adhiere & Se adhiere & Se adhiere \\
\hline
\end{tabular}




\begin{tabular}{|c|c|c|c|c|}
\hline $\begin{array}{l}+ \text { AGUA } \\
5 \mathrm{gr} / 50 \mathrm{ml}\end{array}$ & bien & & & \\
\hline $\begin{array}{l}\text { COLETTA } \\
\text { ITALIANA + } \\
\text { AGUA } \\
2 \mathrm{ml} / 50 \mathrm{ml}\end{array}$ & $\begin{array}{l}\text { No se } \\
\text { adhiere nada }\end{array}$ & $\begin{array}{l}\text { No se } \\
\text { adhiere nada }\end{array}$ & $\begin{array}{l}\text { Se adhiere } \\
\text { muy poco }\end{array}$ & $\begin{array}{l}\text { No se } \\
\text { adhiere } \\
\text { nada }\end{array}$ \\
\hline $\begin{array}{l}\text { COLETTA } \\
\text { ITALIANA + } \\
\text { AGUA } \\
4 \mathrm{ml} / 50 \mathrm{ml}\end{array}$ & $\begin{array}{l}\text { Se adhiere } \\
\text { muy poco }\end{array}$ & $\begin{array}{l}\text { Se adhiere } \\
\text { muy poco }\end{array}$ & Se adhiere & $\begin{array}{l}\text { Se adhiere } \\
\text { muy poco }\end{array}$ \\
\hline $\begin{array}{l}\text { COLETTA } \\
\text { ITALIANA + } \\
\text { AGUA } \\
8 \mathrm{ml} / 50 \mathrm{ml}\end{array}$ & Se adhiere & Se adhiere & $\begin{array}{l}\text { Se adhiere } \\
\text { muy bien }\end{array}$ & $\begin{array}{l}\text { Se adhiere } \\
\text { muy bien }\end{array}$ \\
\hline $\begin{array}{l}\text { COLETTA } \\
\text { ITALIANA + } \\
\text { AGUA } \\
12 \mathrm{ml} / 50 \mathrm{ml}\end{array}$ & $\begin{array}{l}\text { Se adhiere } \\
\text { demasiado }\end{array}$ & $\begin{array}{l}\text { Se adhiere } \\
\text { demasiado }\end{array}$ & $\begin{array}{l}\text { Se adhiere } \\
\text { demasiado }\end{array}$ & $\begin{array}{l}\text { Se adhiere } \\
\text { demasiado }\end{array}$ \\
\hline $\begin{array}{l}\text { PLEXISOL + } \\
\text { WHITE SPIRIT } \\
10 \mathrm{ml} / 50 \mathrm{ml}\end{array}$ & $\begin{array}{l}\text { Se adhiere } \\
\text { muy poco }\end{array}$ & $\begin{array}{l}\text { Se adhiere } \\
\text { muy poco }\end{array}$ & $\begin{array}{l}\text { Se adhiere } \\
\text { muy poco }\end{array}$ & $\begin{array}{l}\text { Se adhiere } \\
\text { muy poco }\end{array}$ \\
\hline $\begin{array}{l}\text { PLEXISOL + } \\
\text { WHITE SPIRIT } \\
20 \mathrm{ml} / 50 \mathrm{ml}\end{array}$ & $\begin{array}{l}\text { Se adhiere } \\
\text { bien }\end{array}$ & Se adhiere & $\begin{array}{l}\text { Se adhiere } \\
\text { bien }\end{array}$ & $\begin{array}{l}\text { Se adhiere } \\
\text { bien }\end{array}$ \\
\hline $\begin{array}{l}\text { PLEXISOL } \\
\text { PURO (que ya } \\
\text { viene disuelto } \\
\text { al } 40 \% \text { ) }\end{array}$ & $\begin{array}{l}\text { Se adhiere } \\
\text { muy bien }\end{array}$ & $\begin{array}{l}\text { Se adhiere } \\
\text { muy bien }\end{array}$ & $\begin{array}{l}\text { Se adhiere } \\
\text { bien }\end{array}$ & $\begin{array}{l}\text { Se adhiere } \\
\text { demasiado }\end{array}$ \\
\hline $\begin{array}{l}\text { ALCOHOL } \\
\text { POLIVINÍLICO } \\
\text { en AGUA } \\
2 \mathrm{gr} / 50 \mathrm{ml} \\
+ \text { CMC en } \\
\text { AGUA } \\
5 \mathrm{gr} / 200 \mathrm{ml}\end{array}$ & $\begin{array}{l}\text { No se } \\
\text { adhiere nada }\end{array}$ & $\begin{array}{l}\text { Se adhiere } \\
\text { muy poco }\end{array}$ & $\begin{array}{l}\text { Se adhiere } \\
\text { bien }\end{array}$ & $\begin{array}{l}\text { Se adhiere } \\
\text { muy poco }\end{array}$ \\
\hline $\begin{array}{l}\text { ALCOHOL } \\
\text { POLIVINÍLICO } \\
\text { en AGUA } \\
3 \mathrm{gr} / 50 \mathrm{ml} \\
+ \text { CMC en } \\
\text { AGUA } \\
3 \mathrm{gr} / 100 \mathrm{ml}\end{array}$ & $\begin{array}{l}\text { Se adhiere } \\
\text { muy poco }\end{array}$ & $\begin{array}{l}\text { Se adhiere } \\
\text { muy poco }\end{array}$ & Se adhiere & $\begin{array}{l}\text { Se adhiere } \\
\text { muy poco }\end{array}$ \\
\hline $\begin{array}{l}\text { ALCOHOL } \\
\text { POLIVINÍLICO } \\
\text { en AGUA } \\
5 \mathrm{gr} / 50 \mathrm{ml} \\
+ \text { CMC en } \\
\text { AGUA } \\
2 \mathrm{gr} / 50 \mathrm{ml}\end{array}$ & $\begin{array}{l}\text { Se adhiere } \\
\text { bien }\end{array}$ & $\begin{array}{l}\text { Se adhiere } \\
\text { bien }\end{array}$ & $\begin{array}{l}\text { Se adhiere } \\
\text { muy bien }\end{array}$ & $\begin{array}{l}\text { Se adhiere } \\
\text { bien }\end{array}$ \\
\hline
\end{tabular}


9.3. ANEXO III. Tablas de fotografías con luz ultravioleta.

\begin{tabular}{|c|c|c|c|c|}
\hline $\mathbf{N}^{\circ}$ & ADHESIVO & OBSERVACIONES & $\begin{array}{c}\text { FOTOGRAFÍA } \\
\text { ANTES }\end{array}$ & $\begin{array}{l}\text { FOTOGRAFÍA } \\
\text { DESPUÉS }\end{array}$ \\
\hline 1.1 & CMC & $\begin{array}{l}\text { No se aprecia ningún } \\
\text { cambio de } \\
\text { reflectancia de la } \\
\text { radiación ultravioleta. }\end{array}$ & & \\
\hline 1.2 & $\mathrm{CMC}$ & $\begin{array}{l}\text { No se aprecia ningún } \\
\text { cambio de } \\
\text { reflectancia de la } \\
\text { radiación ultravioleta. }\end{array}$ & & \\
\hline 2.1 & CMC & $\begin{array}{l}\text { No se aprecia ningún } \\
\text { cambio de } \\
\text { reflectancia de la } \\
\text { radiación ultravioleta. }\end{array}$ & & \\
\hline 2.2 & CMC & $\begin{array}{l}\text { No se aprecia ningún } \\
\text { cambio de } \\
\text { reflectancia de la } \\
\text { radiación ultravioleta. }\end{array}$ & & \\
\hline 3.1 & $\begin{array}{ll}\text { Cola } & \text { de } \\
\text { gelatina } & \end{array}$ & $\begin{array}{l}\text { No se aprecia ningún } \\
\text { cambio de } \\
\text { reflectancia de la } \\
\text { radiación ultravioleta. }\end{array}$ & & \\
\hline 3.2 & $\begin{array}{ll}\text { Cola } & \text { de } \\
\text { gelatina } & \end{array}$ & $\begin{array}{lr}\text { Se aprecia una } \\
\text { reflectancia } & \text { amarilla } \\
\text { en la } & \text { última } \\
\text { fotografía. } & \end{array}$ & & \\
\hline 4.1 & $\begin{array}{ll}\text { Cola } & \text { de } \\
\text { gelatina } & \end{array}$ & $\begin{array}{l}\text { No se aprecia ningún } \\
\text { cambio de } \\
\text { reflectancia de la } \\
\text { radiación ultravioleta. }\end{array}$ & & \\
\hline 4.2 & $\begin{array}{ll}\text { Cola } & \text { de } \\
\text { gelatina } & \end{array}$ & $\begin{array}{l}\text { No se aprecia ningún } \\
\text { cambio de } \\
\text { reflectancia de la } \\
\text { radiación ultravioleta. }\end{array}$ & & \\
\hline
\end{tabular}




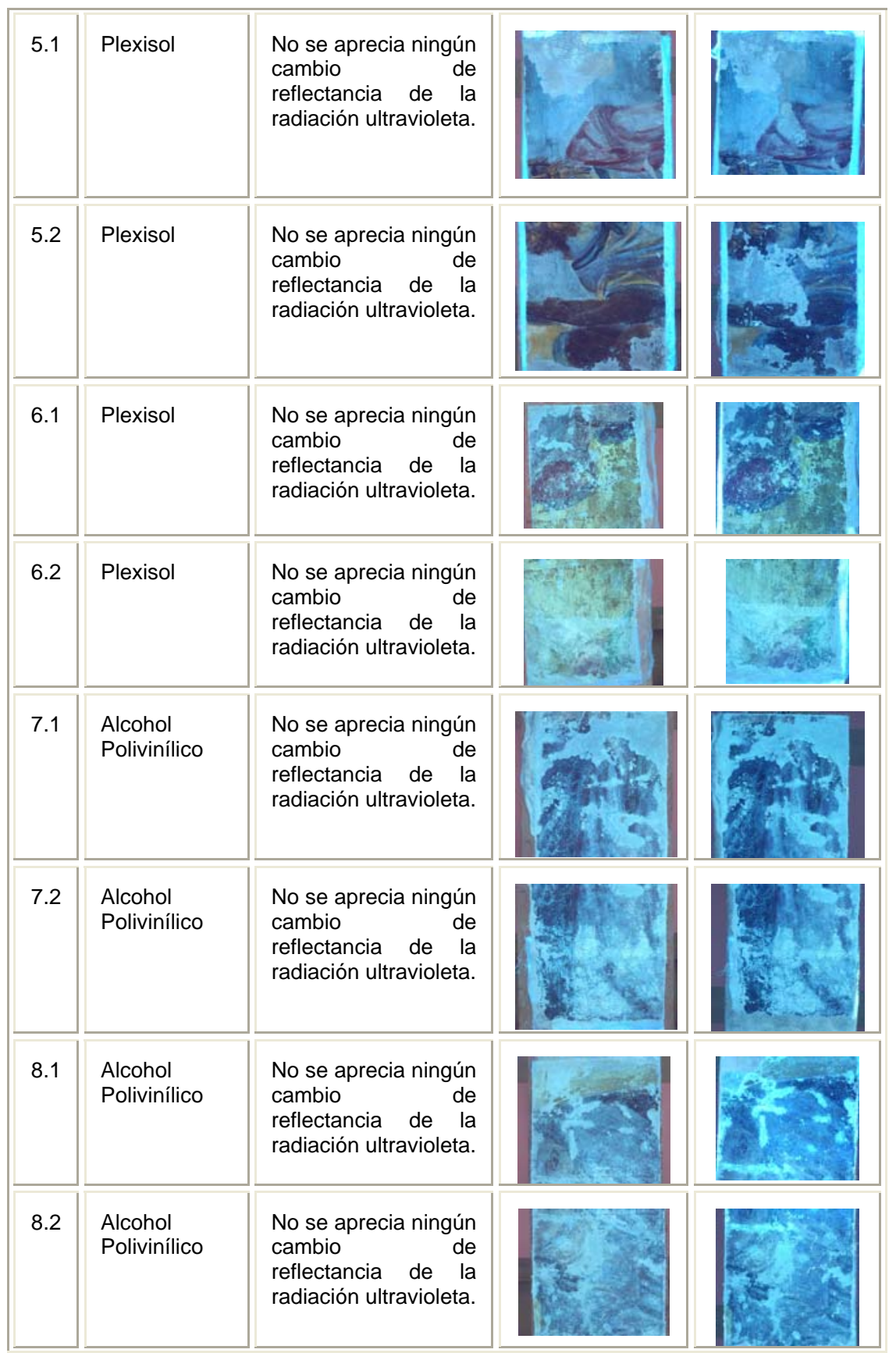




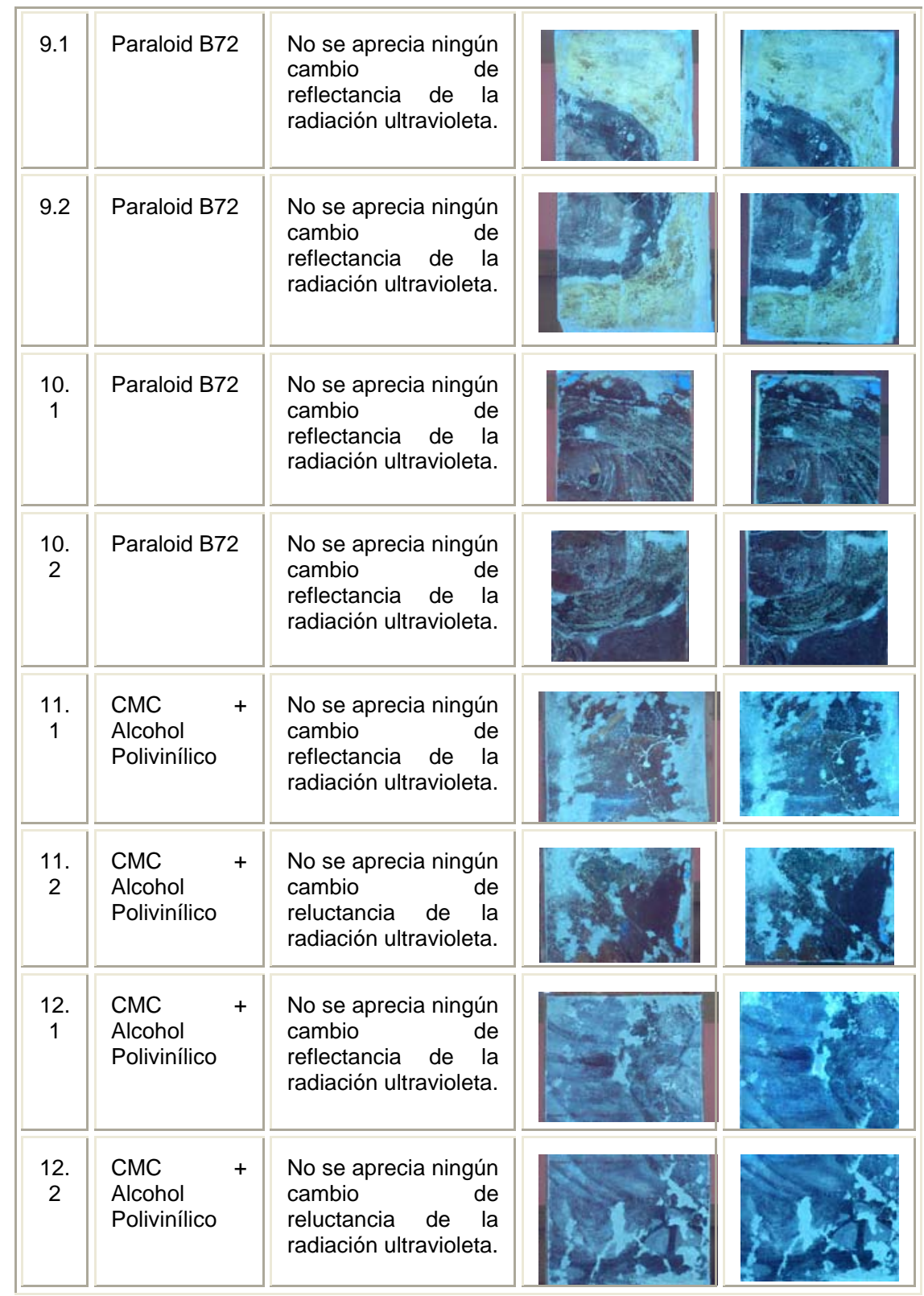


9.4. ANEXO IV. Tablas de los resultados de las mediciones colorimétricas.

9.4.1. Mediciones colorimétricas de las probetas de laboratorio.

\section{ANTES}

Fecha: 13.04.05

Medidor: Espectrofotómetro Minolta CM-2600d ( 1 )

Operador: Pilar Soriano Sancho

CONDICION 1 (S/I+E/100)

Observador: $10^{\circ}$

Iluminante: D65

\begin{tabular}{|c|c|c|c|c|c|c|c|c|c|c|}
\hline \multirow{2}{*}{$\begin{array}{c}\text { m SCl } \\
\begin{array}{c}\text { Muestra } \\
n^{\circ}\end{array} \\
\end{array}$} & \multirow[b]{2}{*}{ Nombre } & \multirow[b]{2}{*}{ Estado } & \multirow[b]{2}{*}{$Y(1)$} & \multirow[b]{2}{*}{$x(1)$} & \multirow[b]{2}{*}{$y(1)$} & \multirow[b]{2}{*}{$L^{*}(1)$} & \multirow[b]{2}{*}{$a^{*}(1)$} & \multirow[b]{2}{*}{$b^{*}(1)$} & \multirow[b]{2}{*}{$C^{*}(1)$} & \multirow[b]{2}{*}{ h (1) } \\
\hline & & & & & & & & & & \\
\hline 1 & Ac1.2 & $\mathrm{m}$ & 29,31 & 0,448 & 0,346 & 61,05 & 36,40 & 23,59 & 43,38 & 32,92 \\
\hline 2 & Ac1.3 & $\mathrm{m}$ & 25,00 & 0,411 & 0,340 & 57,08 & 26,49 & 15,15 & 30,52 & 29,75 \\
\hline 3 & Ac1.4 & $\mathrm{m}$ & 17,09 & 0,349 & 0,319 & 48,38 & 13,32 & 1,19 & 13,43 & 124,61 \\
\hline 4 & Ac1.5 & $\mathrm{m}$ & 53,20 & 0,331 & 0,344 & 77,99 & 2,21 & 6,68 & 7,04 & 71,62 \\
\hline 5 & Ac1.6 & $\mathrm{m}$ & 27,39 & 0,290 & 0,314 & 59,33 & $-2,91$ & $-7,17$ & 7,74 & 247,82 \\
\hline 6 & Ac2.1 & $\mathrm{m}$ & 22,19 & 0,371 & 0,379 & 54,23 & 3,24 & 18,03 & 18,32 & 79,81 \\
\hline 7 & Ac2.3 & $\mathrm{m}$ & 53,32 & 0,361 & 0,378 & 78,04 & 1,15 & 22,08 & 22,11 & 87,00 \\
\hline 8 & Ac2.5 & $\mathrm{m}$ & 46,74 & 0,319 & 0,364 & 74,02 & $-9,80$ & 10,43 & 14,31 & 133,24 \\
\hline 9 & Ac3.1 & $\mathrm{m}$ & 14,46 & 0,329 & 0,406 & 44,88 & 13,40 & 16,16 & 21,00 & 129,73 \\
\hline 10 & Ac3.3 & $\mathrm{m}$ & 42,34 & 0,373 & 0,371 & 71,11 & 7,63 & 20,55 & 21,92 & 69,65 \\
\hline 11 & Ac3.4 & $\mathrm{m}$ & 58,43 & 0,367 & 0,368 & 80,98 & 6,99 & 20,93 & 22,07 & 71,52 \\
\hline 12 & Ac3.5 & $\mathrm{m}$ & 33,89 & 0,293 & 0,316 & 64,88 & $-2,75$ & $-6,76$ & 7,30 & 247,83 \\
\hline 13 & Ac4.1 & $\mathrm{m}$ & 29,44 & 0,439 & 0,342 & 61,17 & 35,33 & 21,12 & 41,16 & 30,87 \\
\hline 14 & Ac4. 2 & $\mathrm{~m}$ & 28,63 & 0,447 & 0,344 & 60,45 & 36,63 & 22,71 & 43,09 & 31,80 \\
\hline 15 & Ac4.3 & $\mathrm{m}$ & 18,26 & 0,353 & 0,327 & 49,80 & 12,60 & 3,45 & 13,06 & 15,32 \\
\hline 16 & Ac4.4 & $\mathrm{m}$ & 27,97 & 0,287 & 0,312 & 65,73 & $-3,24$ & $-8,78$ & 9,36 & 249,73 \\
\hline 17 & Ac4.5 & $\mathrm{m}$ & 27,97 & 0,293 & 0,336 & 59,86 & $-9,08$ & $-1,20$ & 9,16 & 187,50 \\
\hline 18 & Ac4.7 & $\mathrm{m}$ & 24,11 & 0,294 & 0,366 & 56,20 & $\begin{array}{c}- \\
16,61 \\
\end{array}$ & 5,76 & 17,59 & 160,88 \\
\hline 19 & Ac5.1 & $\mathrm{m}$ & 62,92 & 0,323 & 0,353 & 83,40 & $-4,92$ & 8,64 & 9,95 & 119,68 \\
\hline 20 & Ac5.3 & $\mathrm{m}$ & 36,25 & 0,320 & 0,369 & 66,71 & $\begin{array}{c}- \\
10,30\end{array}$ & 11,05 & 15,10 & 133,00 \\
\hline 21 & Ac5.4 & $\mathrm{m}$ & 47,28 & 0,294 & 0,328 & 74,37 & $-7,25$ & $-3,95$ & 8,25 & 208,56 \\
\hline 22 & Ac5.5 & $\mathrm{m}$ & 24,64 & 0,444 & 0,344 & 56,72 & 33,93 & 21,05 & 39,93 & 31,82 \\
\hline
\end{tabular}




\begin{tabular}{|c|c|c|c|c|c|c|c|c|c|c|}
\hline 23 & Ac5.6 & $\mathrm{m}$ & 68,92 & 0,353 & 0,363 & 86,47 & 3,75 & 17,68 & 18,07 & 78,03 \\
\hline 24 & Ac5.7 & $\mathrm{m}$ & 31,46 & 0,410 & 0,397 & 62,90 & 9,89 & 31,60 & 33,12 & 72,62 \\
\hline 25 & Ac6.1 & $\mathrm{m}$ & 55,28 & 0,418 & 0,439 & 79,20 & 0,68 & 53,62 & 53,63 & 89,27 \\
\hline 26 & Ac6.3 & $\mathrm{m}$ & 58,70 & 0,348 & 0,349 & 81,13 & 7,05 & 11,48 & 13,48 & 58,39 \\
\hline 27 & Ac6.4 & $\mathrm{m}$ & 26,57 & 0,407 & 0,334 & 58,58 & 27,94 & 13,14 & 30,88 & 25,09 \\
\hline 28 & Ac6.6 & $\mathrm{m}$ & 54,62 & 0,328 & 0,377 & 78,82 & $\begin{array}{c}- \\
11,73 \\
\end{array}$ & 16,39 & 20,16 & 125,58 \\
\hline 29 & Ac7.1 & $\mathrm{m}$ & 9,12 & 0,251 & 0,255 & 36,21 & 2,92 & 19,57 & 19,78 & 278,49 \\
\hline 30 & Ac7.2 & $\mathrm{m}$ & 27,09 & 0,284 & 0,297 & 59,06 & 0,75 & 12,30 & 12,33 & 273,41 \\
\hline 31 & Ac7.4 & $\mathrm{m}$ & 40,03 & 0,295 & 0,310 & 69,49 & 0,14 & $-8,64$ & 8,64 & 270,92 \\
\hline 32 & Ac8.1 & $\mathrm{m}$ & 22,61 & 0,295 & 0,299 & 54,66 & 4,06 & $-9,90$ & 10,70 & 292,30 \\
\hline 33 & Ac8.4 & $\mathrm{m}$ & 32,79 & 0,315 & 0,329 & 63,99 & 1,00 & $-0,26$ & 1,04 & 344,96 \\
\hline 34 & Ac8.5 & $\mathrm{m}$ & 51,09 & 0,335 & 0,337 & 76,73 & 6,23 & 5,07 & 8,07 & 39,30 \\
\hline 35 & Ac8.6 & $\mathrm{m}$ & 28,23 & 0,364 & 0,342 & 60,10 & 12,78 & 9,32 & 15,82 & 35,82 \\
\hline 36 & Ac9.1 & $\mathrm{m}$ & 13,22 & 0,324 & 0,332 & 43,09 & 2,32 & 1,13 & 2,59 & 26,01 \\
\hline 37 & Ac9.3 & $\mathrm{m}$ & 33,75 & 0,377 & 0,367 & 64,77 & 9,42 & 18,57 & 20,82 & 63,11 \\
\hline 38 & Ac9.4 & $\mathrm{m}$ & 32,18 & 0,361 & 0,336 & 63,49 & 14,79 & 7,73 & 16,69 & 27,56 \\
\hline 39 & Ac9.5 & $\mathrm{m}$ & 62,26 & 0,425 & 0,430 & 83,05 & 6,06 & 54,88 & 55,21 & 83,71 \\
\hline 40 & Ac10.1 & $\mathrm{m}$ & 33,32 & 0,378 & 0,362 & 64,42 & 11,31 & 17,21 & 20,59 & 56,68 \\
\hline 41 & Ac10.3 & $\mathrm{m}$ & 27,31 & 0,384 & 0,358 & 59,26 & 13,59 & 16,20 & 21,15 & 50,02 \\
\hline 42 & Ac10.4 & $\mathrm{m}$ & 18,97 & 0,316 & 0,375 & 50,65 & $\begin{array}{c}- \\
11,01 \\
\end{array}$ & 9,65 & 14,64 & 138,76 \\
\hline 43 & Ac11.1 & $\mathrm{m}$ & 45,86 & 0,306 & 0,327 & 73,44 & $-1,46$ & $-2,38$ & 2,82 & 234,87 \\
\hline 44 & Ac11.2 & $\mathrm{m}$ & 12,30 & 0,317 & 0,326 & 41,69 & 2,11 & $-0,70$ & 2,26 & 341,56 \\
\hline 45 & Ac11.3 & $\mathrm{m}$ & 26,19 & 0,368 & 0,366 & 58,21 & 6,41 & 15,68 & 16,94 & 67,78 \\
\hline 46 & Ac11.5 & $\mathrm{m}$ & 13,87 & 0,332 & 0,356 & 44,05 & $-1,46$ & 6,77 & 6,93 & 102,23 \\
\hline 47 & Ac12.1 & $\mathrm{m}$ & 19,65 & 0,298 & 0,289 & 51,44 & 7,98 & $\begin{array}{c}- \\
11,57\end{array}$ & 14,05 & 304,62 \\
\hline 48 & Ac12.4 & $\mathrm{m}$ & 33,54 & 0,303 & 0,314 & 64,59 & 2,06 & $-6,27$ & 6,60 & 288,17 \\
\hline 49 & Ac12.6 & $\mathrm{m}$ & 44,47 & 0,311 & 0,330 & 72,54 & $-0,83$ & $-0,73$ & 1,12 & 217,62 \\
\hline 50 & Ac12.7 & $\mathrm{m}$ & 8,68 & 0,264 & 0,278 & 35,37 & $-0,09$ & $\begin{array}{c}- \\
13,54 \\
\end{array}$ & 13,54 & 269,64 \\
\hline
\end{tabular}




\section{DESPUES}

Fecha: 29.04.05/25.05.05

Medidor: Espectrofotómetro Minolta CM-2600d ( 1 )

Operador: Pilar Soriano Sancho

CONDICION 1 (S/I+E/100)

Observador: $10^{\circ}$

lluminante: D65

\begin{tabular}{|c|c|c|c|c|c|c|c|c|c|c|}
\hline $\mathrm{SCl}$ & & & & & & & & & & \\
\hline $\begin{array}{c}\text { Muestra } \\
n^{\circ}\end{array}$ & Nombre & Estado & $Y(2)$ & $x(2)$ & $y(2)$ & $L^{*}(2)$ & $a^{\star}(2)$ & $\mathbf{b}^{\star}(2)$ & $C^{\star}(2)$ & h (2) \\
\hline 1 & Ac1.2 & $\mathrm{m}$ & 30,20 & 0,454 & 0,350 & 61,83 & 36,82 & 26,30 & 45,25 & 35,53 \\
\hline 2 & Ac1.3 & $\mathrm{m}$ & 24,01 & 0,415 & 0,340 & 56,09 & 27,15 & 15,45 & 31,24 & 29,61 \\
\hline 3 & Ac1.4 & $\mathrm{m}$ & 16,97 & 0,343 & 0,317 & 48,22 & 12,28 & 0,12 & 12,28 & 120,47 \\
\hline 4 & Ac1.5 & $\mathrm{m}$ & 56,53 & 0,328 & 0,342 & 79,91 & 1,79 & 5,59 & 5,87 & 71,94 \\
\hline 5 & Ac1.6 & $\mathrm{m}$ & 24,37 & 0,287 & 0,310 & 56,44 & $-2,36$ & $-8,15$ & 8,49 & 253,50 \\
\hline 6 & Ac2.1 & $\mathrm{m}$ & 20,38 & 0,378 & 0,384 & 52,26 & 3,58 & 19,59 & 19,92 & 79,68 \\
\hline 7 & Ac2.3 & $\mathrm{m}$ & 50,61 & 0,364 & 0,382 & 76,44 & 0,80 & 23,49 & 23,50 & 88,05 \\
\hline 8 & Ac2.5 & $\mathrm{m}$ & 44,84 & 0,319 & 0,365 & 72,79 & $\begin{array}{c}- \\
10,36 \\
\end{array}$ & 10,58 & 14,81 & 134,41 \\
\hline 9 & Ac3.1 & & 13,02 & 0,328 & 0,414 & 42,77 & $\begin{array}{c}- \\
14,78 \\
\end{array}$ & 16,79 & 22,38 & 131,36 \\
\hline 10 & Ac3.3 & $\mathrm{m}$ & 41,88 & 0,379 & 0,376 & 70,79 & 7,99 & 22,82 & 24,18 & 70,70 \\
\hline 11 & Ac3.4 & $\mathrm{m}$ & 56,31 & 0,372 & 0,372 & 79,79 & 7,40 & 22,51 & 23,70 & 71,80 \\
\hline 12 & Ac3.5 & $\mathrm{m}$ & 31,40 & 0,294 & 0,319 & 62,85 & $-3,29$ & $-5,64$ & 6,53 & 239,78 \\
\hline 13 & Ac4.1 & $\mathrm{m}$ & 28,22 & 0,450 & 0,343 & 60,08 & 37,20 & 22,94 & 43,71 & 31,66 \\
\hline 14 & Ac4. 2 & $\mathrm{~m}$ & 30,94 & 0,453 & 0,347 & 62,45 & 38,11 & 25,21 & 45,70 & 33,48 \\
\hline 15 & Ac4.3 & $\mathrm{m}$ & 18,36 & 0,353 & 0,327 & 49,93 & 12,62 & 3,52 & 13,10 & 15,57 \\
\hline 16 & Ac4.4 & & 25,68 & 0,279 & 0,302 & 57,70 & $-2,58$ & $\begin{array}{c}- \\
11,43 \\
\end{array}$ & 11,72 & 257,25 \\
\hline 17 & Ac4.5 & $\mathrm{m}$ & 25,37 & 0,292 & 0,336 & 57,43 & $-9,09$ & $-1,29$ & 9,18 & 188,08 \\
\hline 18 & Ac4.7 & $\mathrm{m}$ & 19,24 & 0,297 & 0,371 & 50,96 & $\begin{array}{c}- \\
15,77\end{array}$ & 6,88 & 17,22 & 156,15 \\
\hline 19 & Ac5.1 & $\mathrm{m}$ & 56,67 & 0,327 & 0,358 & 79,99 & $-5,02$ & 10,59 & 11,73 & 115,36 \\
\hline 20 & Ac5.3 & & 34,25 & 0,330 & 0,374 & 65,13 & $-8,17$ & 13,46 & 15,74 & 121,26 \\
\hline 21 & Ac5.4 & $\mathrm{m}$ & 61,41 & 0,329 & 0,350 & 82,59 & $-1,06$ & 8,73 & 8,80 & 97,03 \\
\hline 22 & Ac5.5 & $\mathrm{m}$ & 19,79 & 0,475 & 0,347 & 51,60 & 37,80 & 25,50 & 45,60 & 34,00 \\
\hline 23 & Ac5.6 & $\mathrm{m}$ & 62,50 & 0,356 & 0,366 & 83,18 & 3,68 & 18,59 & 18,95 & 78,80 \\
\hline 24 & Ac5.7 & $\mathrm{m}$ & 26,31 & 0,431 & 0,406 & 58,33 & 12,24 & 35,67 & 37,71 & 71,05 \\
\hline 25 & Ac6.1 & $\mathrm{m}$ & 52,21 & 0,426 & 0,446 & 77,41 & 0,74 & 57,34 & 57,35 & 89,29 \\
\hline 26 & Ac6.3 & $\mathrm{m}$ & 39,76 & 0,399 & 0,374 & 69,30 & 14,76 & 25,38 & 29,36 & 59,82 \\
\hline
\end{tabular}




\begin{tabular}{|c|c|c|c|c|c|c|c|c|c|c|}
\hline 27 & Ac6.4 & $\mathrm{m}$ & 18,34 & 0,432 & 0,339 & 49,90 & 29,47 & 16,09 & 33,57 & 28,64 \\
\hline 28 & Ac6.6 & & 65,77 & 0,336 & 0,370 & 84,87 & $-6,53$ & 16,58 & 17,83 & 111,42 \\
\hline 29 & Ac7.1 & $\mathrm{m}$ & 13,76 & 0,265 & 0,274 & 43,88 & 1,61 & 16,59 & 16,66 & 275,54 \\
\hline 30 & Ac7.2 & $\mathrm{m}$ & 34,29 & 0,283 & 0,296 & 65,19 & 0,90 & 13,89 & 13,93 & 273,72 \\
\hline 31 & Ac7.4 & $\mathrm{m}$ & 40,96 & 0,298 & 0,315 & 70,15 & $-0,19$ & $-7,00$ & 7,00 & 268,43 \\
\hline 32 & Ac8.1 & $\mathrm{m}$ & 19,94 & 0,292 & 0,294 & 51,77 & 4,52 & 11,09 & 11,98 & 292,19 \\
\hline 33 & Ac8.4 & & 27,60 & 0,319 & 0,331 & 59,52 & 1,74 & 0,74 & 1,91 & 20,75 \\
\hline 34 & Ac8.5 & $\mathrm{m}$ & 48,71 & 0,340 & 0,339 & 75,27 & 7,64 & 6,40 & 9,97 & 39,97 \\
\hline 35 & Ac8.6 & $\mathrm{m}$ & 25,41 & 0,376 & 0,342 & 57,48 & 15,85 & 10,60 & 19,07 & 33,78 \\
\hline 36 & Ac9.1 & $\mathrm{m}$ & 10,80 & 0,326 & 0,333 & 39,25 & 2,64 & 1,44 & 3,00 & 28,58 \\
\hline 37 & Ac9.2 & $\mathrm{m}$ & 14,33 & 0,319 & 0,330 & 44,70 & 1,84 & 0,32 & 1,87 & 9,97 \\
\hline 38 & Ac9.3 & $\mathrm{m}$ & 27,56 & 0,392 & 0,374 & 59,49 & 11,03 & 21,52 & 24,18 & 62,87 \\
\hline 39 & Ac9.4 & & 25,89 & 0,380 & 0,340 & 57,92 & 17,92 & 10,70 & 20,87 & 30,87 \\
\hline 40 & Ac9.5 & $\mathrm{m}$ & 62,15 & 0,427 & 0,432 & 82,99 & 5,94 & 55,87 & 56,18 & 83,93 \\
\hline 41 & Ac10.1 & $\mathrm{m}$ & 36,91 & 0,400 & 0,386 & 67,21 & 10,69 & 28,30 & 30,25 & 69,30 \\
\hline 42 & Ac10.4 & $\mathrm{m}$ & 16,15 & 0,330 & 0,400 & 47,03 & $\begin{array}{c}- \\
12,21 \\
\end{array}$ & 15,72 & 20,11 & 127,72 \\
\hline 43 & Ac11.1 & $\mathrm{m}$ & 44,82 & 0,305 & 0,326 & 72,77 & $-1,79$ & $-2,81$ & 3,38 & 234,94 \\
\hline 44 & Ac11.2 & $\mathrm{m}$ & 10,65 & 0,321 & 0,328 & 38,99 & 2,53 & 0,17 & 2,54 & 123,69 \\
\hline 45 & Ac11.3 & $\mathrm{m}$ & 25,67 & 0,378 & 0,373 & 57,72 & 7,02 & 18,62 & 19,90 & 69,33 \\
\hline 46 & Ac.11.5. & & 12,91 & 0,331 & 0,352 & 42,61 & $-0,70$ & 5,77 & 5,82 & 96,30 \\
\hline 47 & Ac.12.1. & & 17,22 & 0,304 & 0,291 & 48,51 & 8,85 & 10,03 & 13,40 & 311,36 \\
\hline 48 & Ac12.4 & $\mathrm{m}$ & 31,69 & 0,302 & 0,313 & 63,09 & 2,01 & $-6,43$ & 6,76 & 287,39 \\
\hline 49 & Ac12.6 & $\mathrm{m}$ & 49,18 & 0,314 & 0,333 & 75,56 & $-0,59$ & 0,65 & 0,88 & 131,96 \\
\hline 50 & Ac12.7 & $\mathrm{m}$ & 7,92 & 0,258 & 0,270 & 33,82 & 0,52 & 15,17 & 15,19 & 271,87 \\
\hline
\end{tabular}




\section{DIFERENCIA ANTES-DESPUES}

Fecha: 13.04.05 -29.04.05/25.05.05

Medidor: Espectrofotómetro Minolta CM-2600d ( 1 )

Operador: Pilar Soriano Sancho

CONDICION 1 (S/I+E/100)

Observador: $10^{\circ}$

lluminante: D65

\begin{tabular}{|c|c|c|c|c|c|c|c|c|c|c|}
\hline \multicolumn{11}{|c|}{ Incrementos de coordenadas Yxy } \\
\hline $\mathrm{N}^{\circ}$ & Nombre & $Y(1)$ & $Y(2)$ & $\Delta \mathrm{Y}$ & $x(1)$ & $x(2)$ & $\Delta \mathrm{x}$ & $y(1)$ & $y(2)$ & $\Delta y$ \\
\hline 1 & Ac1.2 & 29,31 & 30,20 & 0,89 & 0,448 & 0,454 & 0,006 & 0,346 & 0,350 & 0,005 \\
\hline 2 & Ac1.3 & 25,00 & 24,01 & $-1,00$ & 0,411 & 0,415 & 0,004 & 0,340 & 0,340 & 0,000 \\
\hline 3 & & 17,09 & 16,97 & $-0,12$ & 0,349 & 0,343 & $\begin{array}{c}- \\
0,006\end{array}$ & 0,319 & 0,317 & $\begin{array}{c}- \\
0,002 \\
\end{array}$ \\
\hline 4 & & 53,20 & & 3,33 & & 0,328 & $\overline{-}$ & & 0,342 & $\begin{array}{c}- \\
0,002\end{array}$ \\
\hline 5 & Ac1.6 & 27,39 & 24,37 & $-3,02$ & 0,290 & 0,287 & $\begin{array}{c}- \\
0,002 \\
\end{array}$ & 0,314 & 0,310 & $\begin{array}{c}- \\
0,004 \\
\end{array}$ \\
\hline 6 & Ac2.1 & 22,19 & 20,38 & $-1,80$ & 0,371 & 0,378 & 0,007 & 0,379 & 0,384 & 0,005 \\
\hline 7 & Ac2.3 & 53,32 & 50,61 & $-2,71$ & 0,361 & 0,364 & 0,003 & 0,378 & 0,382 & 0,004 \\
\hline 8 & Ac2.5 & 46,74 & 44,84 & $-1,90$ & 0,319 & 0,319 & $\begin{array}{c}- \\
0,001 \\
\end{array}$ & 0,364 & 0,365 & 0,001 \\
\hline 9 & Ac3.1 & 14,46 & 13,02 & $-1,44$ & 0,329 & 0,328 & 0,002 & 0,406 & 0,414 & 0,008 \\
\hline 10 & Ac3.3 & 42,34 & 41,88 & $-0,47$ & 0,373 & 0,379 & 0,006 & 0,371 & 0,376 & 0,005 \\
\hline 11 & Ac3.4 & 58,43 & 56,31 & $-2,12$ & 0,367 & 0,372 & 0,005 & 0,368 & 0,372 & 0,003 \\
\hline 12 & Ac3.5 & 33,89 & 31,40 & $-2,49$ & 0,293 & 0,294 & 0,001 & 0,316 & 0,319 & 0,003 \\
\hline 13 & Ac4.1 & 29,44 & 28,22 & $-1,22$ & 0,439 & 0,450 & 0,010 & 0,342 & 0,343 & 0,001 \\
\hline 14 & Ac4.2 & 28,63 & 30,94 & 2,30 & 0,447 & 0,453 & 0,006 & 0,344 &, 347 & 0,003 \\
\hline 15 & Ac4.3 & 18,26 & 18,36 & 0,10 & 0,353 & 0,353 & 0,000 & 0,327 & 0,327 & 0,000 \\
\hline 16 & Ac4.4 & 27,97 & 25,68 & $-2,29$ & 0,287 & 0,279 & 0,008 & 0,312 & 0,302 & $\begin{array}{c}- \\
0,010\end{array}$ \\
\hline 17 & Ac4.5 & 27,97 & 25,37 & $-2,59$ & 0,293 & 0,292 & $\begin{array}{c}- \\
0,001 \\
\end{array}$ & 0,336 & 0,336 & 0,000 \\
\hline 18 & Ac4.7 & 24,11 & 19,24 & $-4,88$ & 0,294 & 0,297 & 0,003 & 0,366 & 0,371 & 0,006 \\
\hline 19 & Ac5.1 & 62,92 & 56,67 & $-6,25$ & 0,323 & 0,327 & 0,004 & 0,353 & 0,358 & 0,005 \\
\hline 20 & Ac5.3 & 36,25 & 34,25 & $-2,00$ & 0,320 & 0,330 & 0,010 & 0,369 & 0,374 & 0,005 \\
\hline 21 & Ac5.4 & 47,28 & 61,41 & 14,12 & 0,294 & 0,329 & 0,036 & 0,328 & 0,350 & 0,022 \\
\hline 22 & Ac5.5 & 24,64 & 19,79 & $-4,84$ & 0,444 & 0,475 & 0,031 & 0,344 & 0,347 & 0,004 \\
\hline 23 & Ac5.6 & 68,92 & 62,50 & $-6,43$ & 0,353 & 0,356 & 0,003 & 0,363 & 0,366 & 0,003 \\
\hline
\end{tabular}




\begin{tabular}{|c|c|c|c|c|c|c|c|c|c|c|}
\hline 24 & Ac5.7 & 31,46 & 26,31 & $-5,16$ & 0,410 & 0,431 & 0,020 & 0,397 & 0,406 & 0,009 \\
\hline 25 & Ac6.1 & 55,28 & 52,21 & $-3,06$ & 0,418 & 0,426 & 0,008 & 0,439 & 0,446 & 0,008 \\
\hline 26 & Ac6.3 & 58,70 & 39,76 & 18,94 & 0,348 & 0,399 & 0,051 & 0,349 & 0,374 & 0,025 \\
\hline 27 & Ac6.4 & 26,57 & 18,34 & $-8,23$ & 0,407 & 0,432 & 0,025 & 0,334 & 0,339 & 0,005 \\
\hline 28 & Ac6.6 & 54,62 & 65,77 & 11,14 & 0,328 & 0,336 & 0,008 & 0,377 & 0,370 & 0,007 \\
\hline 29 & Ac7.1 & 9,12 & 13,76 & 4,64 & 0,251 & 0,265 & 0,014 & 0,255 & 0,274 & 0,019 \\
\hline 30 & Ac7.2 & 27,09 & 34,29 & 7,20 & 0,284 & 0,283 & 0,001 & 0,297 & 0,296 & 0,002 \\
\hline 31 & Ac7.4 & 40,03 & 40,96 & 0,93 & 0,295 & 0,298 & 0,003 & 0,310 & 0,315 & 0,004 \\
\hline 32 & Ac8.1 & 22,61 & 19,94 & $-2,67$ & 0,295 & 0,292 & 0,003 & 0,299 & 0,294 & 0,005 \\
\hline 33 & Ac8.4 & 32,79 & 27,60 & $-5,19$ & 0,315 & 0,319 & 0,004 & 0,329 & 0,331 & 0,002 \\
\hline 34 & Ac8.5 & 51,09 & 48,71 & $-2,38$ & 0,335 & 0,340 & 0,006 & 0,337 & 0,339 & 0,002 \\
\hline 35 & Ac8.6 & 28,23 & 25,41 & $-2,82$ & 0,364 & 0,376 & 0,012 & 0,342 & 0,342 & 0,000 \\
\hline 36 & Ac9.1 & 13,22 & 10,80 & $-2,42$ & 0,324 & 0,326 & 0,003 & 0,332 & 0,333 & 0,001 \\
\hline 37 & Ac9.3 & 33,75 & 14,33 & 19,42 & 0,377 & 0,319 & 0,057 & 0,367 & 0,330 & 0,037 \\
\hline 38 & Ac9.4 & 32,18 & 27,56 & $-4,62$ & 0,361 & 0,392 & 0,031 & 0,336 & 0,374 & 0,038 \\
\hline 39 & Ac9.5 & 62,26 & 25,89 & 36,37 & 0,425 & 0,380 & 0,046 & 0,430 & 0,340 & 0,090 \\
\hline 40 & Ac10.1 & 33,32 & 62,15 & 28,83 & 0,378 & 0,427 & 0,049 & 0,362 & 0,432 & 0,070 \\
\hline 41 & Ac10.3 & 27,31 & 36,91 & 9,60 & 0,384 & 0,400 & 0,016 & 0,358 & 0,386 & 0,028 \\
\hline 42 & Ac10.4 & 18,97 & 16,15 & $-2,81$ & 0,316 & 0,330 & 0,014 & 0,375 & 0,400 & 0,026 \\
\hline 43 & Ac11.1 & 45,86 & 44,82 & $-1,04$ & 0,306 & 0,305 & 0,001 & 0,327 & 0,326 & $\begin{array}{c}- \\
0,001\end{array}$ \\
\hline 44 & Ac11.2 & 12,30 & 10,65 & $-1,65$ & 0,317 & 0,321 & 0,004 & 0,326 & 0,328 & 0,002 \\
\hline 45 & Ac11.3 & 26,19 & 25,67 & $-0,52$ & 0,368 & 0,378 & 0,009 & 0,366 & 0,373 & 0,007 \\
\hline 46 & Ac11.5 & 13,87 & 12,91 & $-0,96$ & 0,332 & 0,331 & 0,001 & 0,356 & 0,352 & 0,004 \\
\hline 47 & Ac12.1 & 19,65 & 17,22 & $-2,43$ & 0,298 & 0,304 & 0,006 & 0,289 & 0,291 & 0,002 \\
\hline 48 & Ac12.4 & 33,54 & 31,69 & $-1,84$ & 0,303 & 0,302 & 0,001 & 0,314 & 0,313 & 0,001 \\
\hline 49 & Ac12.6 & 44,47 & 49,18 & 4,71 & 0,311 & 0,314 & 0,003 & 0,330 & 0,333 & 0,003 \\
\hline 50 & Ac12.7 & 8,68 & 7,92 & $-0,76$ & 0,264 & 0,258 & 0,006 & 0,278 & 0,270 & 0,008 \\
\hline
\end{tabular}




\section{DIFERENCIA ANTES-DESPUES}

Fecha: 13.04.05 -29.04.05/25.05.05

Medidor: Espectrofotómetro Minolta CM-2600d ( 1 )

Operador: Pilar soriano

CONDICION 1 (S/I+E/100)

Observador: $10^{\circ}$

Iluminante: D65

\begin{tabular}{|c|c|c|c|c|c|c|c|c|c|c|}
\hline \multicolumn{11}{|c|}{ Incrementos de coordenadas $L^{*} C^{*} h^{\circ}$} \\
\hline $\mathrm{N}^{\circ}$ & Nombre & $L^{*}(1)$ & $L^{*}(2)$ & $\Delta \mathrm{L}$ & $C^{*}(1)$ & $C^{*}(2)$ & $\Delta \mathrm{C}$ & h (1) & h (2) & $\Delta \mathbf{h}^{\circ}$ \\
\hline 1 & Ac1.2 & 61,05 & 61,83 & 0,77 & 43,38 & 45,25 & 1,86 & 32,92 & 35,53 & 2,61 \\
\hline 2 & Ac1.3 & 57,08 & 56,09 & $-0,98$ & 30,52 & 31,24 & 0,72 & & 29,61 & $-0,13$ \\
\hline 3 & Ac1.4 & 48,38 & 48,22 & $-0,15$ & 13,43 & 12,28 & $-1,14$ & 124,61 & 120,47 & $-4,14$ \\
\hline 4 & Ac1.5 & 77,99 & 79,91 & 1,92 & 7,04 & 5,87 & $-1,17$ & & & 0,33 \\
\hline 5 & Ac1.6 & 59,33 & 56,44 & $-2,90$ & 7,74 & 8,49 & 0,75 & 247,82 & 253,50 & 5,68 \\
\hline 6 & Ac2.1 & 54,23 & 52,26 & $-1,96$ & 18,32 & 19,92 & 1,60 & 79,81 & 79,68 & $-0,14$ \\
\hline 7 & Ac2.3 & 78,04 & 76,44 & $-1,60$ & 22,11 & 23,50 & 1,39 & 87,00 & 88,05 & 1,05 \\
\hline 8 & Ac2.5 & 74,02 & 72,79 & $-1,24$ & 14,31 & 14,81 & 0,50 & 133,24 & 134,41 & 1,17 \\
\hline 9 & Ac3.1 & 44,88 & 42,77 & $-2,10$ & 21,00 & 22,38 & 1,38 & 129,73 & 131,36 & 1,63 \\
\hline 10 & Ac3.3 & 71,11 & 70,79 & $-0,32$ & 21,92 & 24,18 & 2,26 & 69,65 & 70,70 & 1,05 \\
\hline 11 & Ac3.4 & 80,98 & 79,79 & $-1,19$ & 22,07 & 23,70 & 1,63 & & & 0,28 \\
\hline 12 & Ac3.5 & & & $-2,03$ & & & & & & $-8,05$ \\
\hline 13 & & & & & & & & & & \\
\hline 14 & & 60,45 & & 2,00 & & 45,70 & & & & 1,68 \\
\hline 15 & Ac4.3 & 49,80 & 49,93 & 0,12 & 13,06 & 13,10 & 0,04 & 15,32 & 15,57 & 0,25 \\
\hline 16 & Ac4.4 & 65,73 & 57,70 & $-8,03$ & 9,36 & 11,72 & 2,35 & 249,73 & 257,25 & 7,52 \\
\hline 17 & Ac4.5 & 59,86 & 57,43 & $-2,42$ & 9,16 & 9,18 & 0,02 & 187,50 & 188,08 & 0,58 \\
\hline 18 & Ac4.7 & 56,20 & 50,96 & $-5,24$ & 17,59 & 17,22 & $-0,36$ & 160,88 & 156,15 & $-4,73$ \\
\hline 19 & Ac5.1 & 83,40 & 79,99 & $-3,41$ & 9,95 & 11,73 & 1,78 & 119,68 & 115,36 & $-4,32$ \\
\hline 20 & Ac5.3 & 66,71 & 65,13 & $-1,57$ & 15,10 & 15,74 & 0,64 & 133,00 & 121,26 & $-11,74$ \\
\hline 21 & Ac5.4 & 74,37 & 82,59 & 8,22 & 8,25 & 8,80 & 0,55 & 208,56 & 97,03 & \\
\hline 22 & Ac5.5 & 56,72 & 51,60 & $-5,12$ & 39,93 & 45,60 & 5,67 & 31,82 & 34,00 & 2,18 \\
\hline 23 & Ac5.6 & 86,47 & 83,18 & $-3,29$ & 18,07 & 18,95 & 0,88 & 78,03 & 78,80 & 0,77 \\
\hline 24 & Ac5.7 & 62,90 & 58,33 & $-4,57$ & 33,12 & 37,71 & 4,60 & & & $-1,57$ \\
\hline 25 & Ac6.1 & 79,20 & 77,41 & $-1,79$ & 53,63 & 57,35 & 3,72 & & & 0,02 \\
\hline 26 & Ac6.3 & 81,13 & 69,30 & 11,83 & 13,48 & 29,36 & 15,88 & 58,39 & 59,82 & 1,42 \\
\hline 27 & Ac6.4 & 58,58 & 49,90 & $-8,67$ & 30,88 & 33,57 & 2,69 & 25,09 & 28,64 & 3,54 \\
\hline
\end{tabular}




\begin{tabular}{|c|c|c|c|c|c|c|c|c|c|c|}
\hline 28 & Ac6.6 & 78,82 & 84,87 & 6,05 & 20,16 & 17,83 & $-2,32$ & 125,58 & 111,42 & $-14,1 /$ \\
\hline 29 & Ac7.1 & 36,21 & 43,88 & 7,68 & 19,78 & 16,66 & $-3,12$ & 278,49 & 275,54 & $-2,95$ \\
\hline 30 & Ac7.2 & 59,06 & 65,19 & 6,14 & 2,33 & 13,93 & 1,60 & 273,41 & 273,72 & 0,31 \\
\hline 31 & Ac7.4 & 69,49 & 70,15 & 0,65 & 64 & 00 & $-1,64$ & 270,92 & 268,43 & 49 \\
\hline 32 & Ac8.1 & 4,66 & .77 & -2 & 0,70 & ,98 & 28 & & & \\
\hline 33 & & & & & & & & & & \\
\hline 34 & Ac8.5 & 76,73 & 75,27 & -1 , & 07 & 97 & 1,90 & 9,30 & 39,97 & 0,66 \\
\hline 35 & Ac8.6 & 60,10 & 57,48 & $-2,6$ & 15,82 & 9,07 & 3,2 & & 3,78 & 04 \\
\hline 36 & Ac9.1 & 43,09 & 9,25 & $-3,85$ & .59 & 00 & 42 & 0,01 & 3,58 & 2,58 \\
\hline 37 & Ac9.3 & 64,77 & 44,70 & 20,07 & 20,82 & 1,87 & 18,95 & 63,11 & & $-53,15$ \\
\hline 38 & Ac9.4 & 63,49 & 59,49 & $-4,00$ & 16,69 & 24,18 & 7,49 & 27,56 & 62,87 & 35,30 \\
\hline 39 & Ac9.5 & 83,05 & 57,92 & 25,13 & 55,21 & 20,87 & 34,34 & 83,71 & 30,87 & $-52,84$ \\
\hline 40 & Ac10.1 & 64,42 & 82,99 & 18,57 & 20,59 & 56,18 & 35,59 & 56,68 & 83,93 & 27,25 \\
\hline 41 & Ac10.3 & 59,26 & 67,21 & & 21,15 & 30,25 & 9,10 & 50,02 & 69,30 & 19,28 \\
\hline 42 & Ac10.4 & 50,65 & 47,03 & & 14,64 & 20,11 & & 138,76 & 127,72 & \\
\hline 43 & Ac11.1 & 3,44 & & & & & & & & \\
\hline 44 & Ac11.2 & 41,69 & & & & & 0,27 & 341,56 & & 217,86 \\
\hline 45 & Ac11.3 & 58,21 & 57,72 & $-0,5$ & 16,94 & 19,90 & 2,96 & 67,78 & 69,33 & 1,55 \\
\hline 46 & Ac11.5 & 44,05 & 42,61 & $-1,43$ & & 5,82 & $-1,10$ & 102,23 & 96,30 & $-5,93$ \\
\hline 47 & Ac12.1 & 51,44 & 48,51 & $-2,92$ & 14,05 & 13,40 & $-0,65$ & 304,62 & 311,36 & 6,74 \\
\hline 48 & Ac12.4 & 64,59 & 63,09 & $-1,50$ & 6,60 & 6,76 & 0,16 & 288,17 & 287,39 & $-0,78$ \\
\hline 49 & Ac12.6 & 72,54 & 75,56 & 3,0 & & 0,88 & $-0,24$ & 217,62 & 131,96 & $-85,66$ \\
\hline 50 & Ac12.7 & 35,37 & 33,82 & $-1,55$ & 13,54 & 15,19 & 1,65 & 269,64 & 271,87 & 2,23 \\
\hline
\end{tabular}


DIFERENCIA ANTES-DESPUES

Fecha: 13.04.05 -29.04.05/25.05.05

Medidor: Espectrofotómetro Minolta CM-2600d ( 1 )

Operador: Pilar Soriano Sancho

CONDICION 1 (S/I+E/100)

Observador: $10^{\circ}$

Iluminante: D65

Incrementos de coordenadas $L^{*} a^{*} b^{*}$ y Diferencia de Color

\begin{tabular}{|c|c|c|c|c|c|c|c|c|c|c|c|c|}
\hline $\mathrm{N}^{\circ}$ & ombre & (1) & (2) & L & (1) & *(2) & a & *(1) & *(2) & $\Delta b$ & $\Delta \mathrm{E}$ & \\
\hline 1 & Ac1.2 & 61,05 & 61,83 & 0,77 &, 40 & 36.82 & 0,42 & 23,59 & 2630 & 2,70 & 2,84 & \\
\hline 2 & Ac1.3 & & & & & & ,66 & 5,15 & & & ,22 & \\
\hline 3 & Ac1.4 & 8,38 & 3,22 & $-0,15$ & 3,32 & 2,28 & 1,04 & ,19 & 12 & $-1,07$ & .50 & \\
\hline 4 & Ac1.5 & 9 &, 91 & 1,92 & & & 0,43 & 68 & 59 & $-1,09$ & 25 & \\
\hline 5 & Ac1.6 & & & $-2,90$ & & & 0,55 & $-7,17$ & $-8,15$ & $-0,9 \varepsilon$ &, 11 & \\
\hline 6 & Ac2.1 & & & $-1,90$ & & & 0,34 & 18,03 & 19,59 & 1,56 & 2,53 & \\
\hline 7 & Ac2.3 & & & 160 & & & 0,35 & 2,08 & 3,49 & 1, & 16 & \\
\hline 8 & & & & & & & & & & & & \\
\hline 9 & Ac3.1 & & & $-2,10$ & & & $-1,38$ & 16,16 & 16,79 & 0,63 & 2,59 & \\
\hline 10 & Ac3.3 & & & $-0,32$ & & & 0,36 & 20,55 & 22,82 & 2,2 & 2,32 & \\
\hline 11 & Ac3.4 & & & $-1,19$ & & 40 & 0,41 & 20,93 & 22,51 & 1,5 & 2,02 & \\
\hline 12 & Ac3.5 & & & $-2,03$ & & ,29 & $-0,53$ & $-6,76$ & $-5,64$ & 1,1 & 2,38 & \\
\hline 13 & Ac4.1 & & & $-1,09$ & & 7,20 & 1,87 & 21,12 & 22,94 & 1,82 & , ,83 & \\
\hline 14 & Ac4. 2 & & & 2,00 & & , & 1,49 & $2<, r \perp$ & $\angle 5, \angle \perp$ & 2,50 & 3,53 & \\
\hline 15 & Ac4.3 & & & 010 & & & 0,02 & & 3,52 & & & \\
\hline 16 & & & & & & & 0,66 & & & & & \\
\hline 17 & & & & 20 & & $-9,09$ & - 0 - & -120 & -129 & $-0,09$ & 242 & \\
\hline 18 & Ac4.7 & & & $-5,24$ & & & 0,84 & ,76 & ,88 & 1,12 &, 42 & \\
\hline 19 & Ac5.1 & & &, 41 & & & $-0,09$ & & & & & \\
\hline 20 & Ac5.3 & & & $-1,5 /$ & & & 2,13 & 11,05 & 13,46 & 2,41 & 0,00 & \\
\hline 21 & Ac5.4 & & & 8,22 & & & 0,1 (3) & & & 12,68 & 10,00 & \\
\hline 22 & & & & $-5,12$ & & & 3,87 & & & & 1,01 & \\
\hline 23 & Ac5.6 & & & $-3,29$ & & & $-0,07$ & 17,68 & 18,59 & 0,91 & 3,41 & \\
\hline 24 & Ac5.7 & & & $-4,57$ & & & 2,35 & 31,60 & 35,67 & 4,07 & 655 & \\
\hline 25 & Ac6.1 & & & $1, i v$ & & & 0,06 & & & & & \\
\hline 26 & Ac6.3 & & & - & & & 7,71 & 11,48 & 25,38 & $13,9 c$ & 19,82 & \\
\hline
\end{tabular}




\begin{tabular}{|c|c|c|c|c|c|c|c|c|c|c|c|c|}
\hline & & & & 1 , & & & & & & & & \\
\hline & Ac6.4 & 58,58 & 49,90 & $-8,67$ & 27,94 & 29,47 & 1,52 & 13, & & 2,96 & 9,29 & $8^{\circ}$ \\
\hline & Ac6.6 & & & & $\stackrel{-}{11,73}$ & & 5,20 & & & 0,19 & 7,98 & $11^{\circ}$ \\
\hline & Ac7.1 & & & 7,68 & & & $-1,31$ & $\begin{array}{c}- \\
19,57\end{array}$ & $\begin{array}{c}- \\
16,59\end{array}$ & 2,98 & 8,34 & $10^{\circ}$ \\
\hline & Ac7.2 & & & 6,14 & & 0,90 & 0,16 & $\begin{array}{c}- \\
12,30 \\
\end{array}$ & $\begin{array}{c}- \\
13,89 \\
\end{array}$ & $-1,59$ & 6,34 & $15^{\circ}$ \\
\hline & Ac7.4 & 69,49 & & 0,65 & & $-0,19$ & $-0,33$ & $-8,64$ & $-7,00$ & 1,64 & 1,79 & $44^{\circ}$ \\
\hline & Ac8.1 & & 51,77 & $-2,90$ & 4,06 & 4,52 & 0,47 & $-9,90$ & $\begin{array}{c}- \\
11,09 \\
\end{array}$ & $-1,19$ & 3,17 & $27^{\circ}$ \\
\hline & Ac8.4 & & & & & 1,74 & 0,74 & & & 1,00 & 4,64 & $17^{\circ}$ \\
\hline & Ac8.5 & & 75,27 & $-1,46$ & 6,23 & 7,64 & 1,41 & 5,07 & 6,40 & 1,33 & 2,43 & $35^{\circ}$ \\
\hline 35 & Ac8.6 & 60,10 & 57,48 & $-2,62$ & 12,78 & 15,85 & 3,07 & 9,32 & 10,60 & 1,29 & 4,24 & $18^{\circ}$ \\
\hline 36 & Ac9.1 & 43,09 & 39,25 & $-3,85$ & 2,32 & 2,64 & 0,31 & 1,13 & 1,44 & 0,31 & 3,87 & $21^{\circ}$ \\
\hline & Ac9.3 & 64,77 & 44,70 & 20,07 & 9,42 & 1,84 & $-7,58$ & 18,57 & 0,32 & $\begin{array}{c}- \\
18,25\end{array}$ & 28,16 & $3^{\circ}$ \\
\hline 38 & Ac9.4 & 63,49 & 59,49 & $-4,00$ & 14,79 & 11,03 & $-3,77$ & 7,73 & 21,52 & 13,79 & 14,84 & $6^{\circ}$ \\
\hline & Ac9.5 & 83,05 & 57,92 & $\begin{array}{c}- \\
25,13 \\
\end{array}$ & 6,06 & 17,92 & 11,86 & 54,88 & 10,70 & $\begin{array}{c}- \\
44,17 \\
\end{array}$ & 52,19 & $1^{\circ}$ \\
\hline 40 & Ac10.1 & 64,42 & 82,99 & 18,57 & 11,31 & 5,94 & $-5,37$ & & 55,87 & 38,66 & 43,23 & $2^{\circ}$ \\
\hline & Ac10.3 & 59,26 & & 7,95 & 13,59 & 10,69 & $-2,89$ & & 28,30 & 12,09 & 14,76 & $7^{\circ}$ \\
\hline 42 & Ac10.4 & 50,65 & 47,03 & $-3,62$ & $\begin{array}{c}- \\
11,01 \\
\end{array}$ & $\begin{array}{c}- \\
12,21 \\
\end{array}$ & $-1,21$ & 9,65 & 15,72 & 6,07 & 7,17 & $13^{\circ}$ \\
\hline 43 & Ac11.1 & & & $-0,67$ & $-1,46$ & $-1,79$ & $-0,33$ & & $-2,81$ & $-0,43$ & 0,86 & $49^{\circ}$ \\
\hline 44 & Ac11.2 & 41,69 & 38,99 & $-2,70$ & 2,11 & 2,53 & 0,41 & $-0,70$ & 0,17 & 0,87 & 2,86 & $30^{\circ}$ \\
\hline 45 & Ac11.3 & 58,21 & 57,72 & $-0,50$ & 6,41 & 7,02 & 0,61 & 15,68 & 18,62 & 2,94 & 3,04 & $29^{\circ}$ \\
\hline 46 & Ac11.5 & 44,05 & 42,61 & $-1,43$ & $-1,46$ & $-0,70$ & 0,77 & 6,77 & 5,77 & $-1,00$ & 1,91 & $43^{\circ}$ \\
\hline 47 & Ac12.1 & 51,44 & 48,51 & $-2,92$ & 7,98 & 8,85 & 0,87 & $\begin{array}{c}- \\
11,57 \\
\end{array}$ & $\begin{array}{c}- \\
10,03\end{array}$ & 1,54 & 3,41 & $24^{\circ}$ \\
\hline 48 & Ac12.4 & 64,59 & 63,09 & $-1,50$ & 2,06 & 2,01 & $-0,05$ & $-6,27$ & $-6,43$ & $-0,17$ & 1,51 & $45^{\circ}$ \\
\hline 49 & Ac12.6 & 72,54 & 75,56 & 3,02 & $-0,83$ & $-0,59$ & 0,24 & $-0,73$ & 0,65 & 1,38 & 3,33 & $26^{\circ}$ \\
\hline 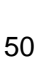 & Ac12.7 & 35,37 & 33,82 & $-1,55$ & $-0,09$ & 0,52 & 0,61 & $\begin{array}{c}- \\
13,54\end{array}$ & $\begin{array}{c}- \\
15,17 \\
\end{array}$ & $-1,63$ & 2,33 & \\
\hline
\end{tabular}


DIFERENCIA ANTES-DESPUES

Fecha: 13.04.05 -29.04.05/25.05.05

Medidor: Espectrofotómetro Minolta CM-2600d ( 1 )

Operador: Pilar Soriano Sancho

CONDICION 1 (S/I+E/100)

Observador: $10^{\circ}$

Iluminante: D65

Incrementos L*a*b* y Diferencia de Color. Valores ordenados por E

\begin{tabular}{|c|c|c|c|c|c|c|c|c|c|c|c|c|}
\hline $\mathbf{N}^{\mathbf{2}}$ & Nombre & $L^{*}(1)$ & $L^{*}(2)$ & $\Delta \mathrm{L}$ & $a^{*}(1)$ & $a^{*}(2)$ & $\Delta \mathbf{a}$ & $b^{*}(1)$ & $b^{\star}(2)$ & $\Delta b$ & $\Delta \mathrm{E}$ & orden \\
\hline 39 & Ac9.5 & 83,05 & 57,92 & 25,13 & 6,06 & 17,92 & 11,86 & 54,88 & 10,70 & 44,17 & 52,19 & $1^{0}$ \\
\hline 40 & Ac10.1 & 64,42 & 82,99 & 18,57 & 11,31 & 5,94 & $-5,37$ & 17,21 & 55,87 & 38,66 & 43,23 & $2^{\circ}$ \\
\hline 37 & Ac9.3 & 64,77 & 44,70 & ${ }^{-}$ & 9,42 & 1,84 & $-7,58$ & 18,57 & 0,32 & 18,25 & 28,16 & $3^{\circ}$ \\
\hline 26 & Ac6.3 & 81,13 & 69,30 & 11,83 & 7,05 & 14,76 & 7,71 & 11,48 & 25,38 & 13,90 & 19,82 & $4^{\circ}$ \\
\hline 21 & Ac5.4 & 74,37 & 82,59 & 8,22 & $-7,25$ & $-1,06$ & 6,19 & $-3,95$ & 8,73 & 12,68 & 16,33 & $5^{\circ}$ \\
\hline 38 & Ac9.4 & 63,49 & 59,49 & $-4,00$ & 14,79 & 11,03 & $-3,77$ & 7,73 & 21,52 & 13,79 & 14,84 & $6^{\circ}$ \\
\hline 41 & Ac10.3 & 59,26 & 67,21 & 7,95 & 13,59 & 10,69 & $-2,89$ & 16,20 & 28,30 & 12,09 & 14,76 & $7^{\circ}$ \\
\hline 27 & Ac6.4 & 58,58 & 49,90 & $-8,67$ & 27,94 & 29,47 & 1,52 & 13,14 & 16,09 & 2,96 & 9,29 & $8^{\circ}$ \\
\hline 16 & Ac4.4 & 65,73 & 57,70 & $-8,03$ & $-3,24$ & $-2,58$ & 0,66 & $-8,78$ & 11,43 & $-2,64$ & 8,48 & $9^{\circ}$ \\
\hline 29 & Ac7.1 & 36,21 & 43,88 & 7,68 & 2,92 & 1,61 & $-1,31$ & $\begin{array}{c}- \\
19,57 \\
\end{array}$ & $\begin{array}{c}- \\
16,59 \\
\end{array}$ & 2,98 & 8,34 & $10^{\circ}$ \\
\hline 28 & Ac6.6 & 78,82 & 84,87 & 6,05 & 11,73 & $-6,53$ & 5,20 & 16,39 & 16,58 & 0,19 & 7,98 & $11^{\circ}$ \\
\hline 22 & Ac5.5 & 56,72 & 51,60 & $-5,12$ & 33,93 & 37,80 & 3,87 & 21,05 & 25,50 & 4,45 & 7,81 & $12^{\circ}$ \\
\hline 42 & Ac10.4 & 50,65 & 47,03 & $-3,62$ & $\begin{array}{c}- \\
11,01\end{array}$ & $\begin{array}{c}- \\
12,21\end{array}$ & $-1,21$ & 9,65 & 15,72 & 6,07 & 7,17 & $13^{\circ}$ \\
\hline 24 & Ac5.7 & 62,90 & 58,33 & $-4,57$ & 9,89 & 12,24 & 2,35 & 31,60 & 35,67 & 4,07 & 6,55 & $14^{\circ}$ \\
\hline 30 & Ac7.2 & 59,06 & 65,19 & 6,14 & 0,75 & 0,90 & 0,16 & 12,30 & 13,89 & $-1,59$ & 6,34 & $15^{\circ}$ \\
\hline 18 & Ac4.7 & 56,20 & 50,96 & $-5,24$ & $\begin{array}{c}- \\
16,61 \\
\end{array}$ & $\begin{array}{c}- \\
15,77 \\
\end{array}$ & 0,84 & 5,76 & 6,88 & 1,12 & 5,42 & $16^{\circ}$ \\
\hline 33 & Ac8.4 & 63,99 & 59,52 & $-4,47$ & 1,00 & 1,74 & 0,74 & $-0,26$ & 0,74 & 1,00 & 4,64 & $17^{\circ}$ \\
\hline 35 & Ac8.6 & 60,10 & 57,48 & $-2,62$ & 12,78 & 15,85 & 3,07 & 9,32 & 10,60 & 1,29 & 4,24 & $18^{\circ}$ \\
\hline 25 & Ac6.1 & 79,20 & 77,41 & $-1,79$ & 0,68 & 0,74 & 0,06 & 53,62 & 57,34 & 3,72 & 4,13 & $19^{\circ}$ \\
\hline 19 & Ac5.1 & 83,40 & 79,99 & $-3,41$ & $-4,92$ & $-5,02$ & $-0,09$ & 8,64 & 10,59 & 1,95 & 3,93 & $20^{\circ}$ \\
\hline 36 & Ac9.1 & 43,09 & 39,25 & $-3,85$ & 2,32 & 2,64 & 0,31 & 1,13 & 1,44 & 0,31 & 3,87 & $21^{\circ}$ \\
\hline 20 & Ac5.3 & 66,71 & 65,13 & $-1,57$ & 10,30 & $-8,17$ & 2,13 & 11,05 & 13,46 & 2,41 & 3,58 & $22^{\circ}$ \\
\hline 14 & Ac4.2 & 60,45 & 62,45 & 2,00 & 36,63 & 38,11 & 1,49 & 22,71 & 25,21 & 2,50 & 3,53 & $23^{\circ}$ \\
\hline
\end{tabular}




\begin{tabular}{|c|c|c|c|c|c|c|c|c|c|c|c|c|}
\hline 47 & Ac12.1 & 51,44 & 48,51 & $-2,92$ & 7,98 & 8,85 & 0,87 & 11,57 & $\begin{array}{c}- \\
10,03 \\
\end{array}$ & 1,54 & 3,41 & $24^{\circ}$ \\
\hline 23 & Ac5.6 & 86,47 & 83,18 & $-3,29$ & 3,75 & 3,68 & $-0,07$ & 17,68 & 18,59 & 0,91 & 3,41 & $25^{\circ}$ \\
\hline 49 & Ac12.6 & 72,54 & 75,56 & 3,02 & $-0,83$ & $-0,59$ & 0,24 & $-0,73$ & 0,65 & 1,38 & 3,33 & $26^{\circ}$ \\
\hline 32 & Ac8.1 & 54,66 & 51,77 & $-2,90$ & 4,06 & 4,52 & 0,47 & $-9,90$ & 11,09 & $-1,19$ & 3,17 & $27^{\circ}$ \\
\hline 5 & Ac1.6 & 59,33 & 56,44 & $-2,90$ & $-2,91$ & $-2,36$ & 0,55 & $-7,17$ & $-8,15$ & $-0,98$ & 3,11 & $28^{\circ}$ \\
\hline 45 & Ac11.3 & 58,21 & 57,72 & $-0,50$ & 6,41 & 7,02 & 0,61 & 15,68 & 18,62 & 2,94 & 3,04 & $29^{\circ}$ \\
\hline 44 & Ac11.2 & 41,69 & 38,99 & $-2,70$ & 2,11 & 2,53 & 0,41 & $-0,70$ & 0,17 & 0,87 & 2,86 & $30^{\circ}$ \\
\hline 1 & Ac1.2 & 61,05 & 61,83 & 0,77 & 36,40 & 36,82 & 0,42 & 23,59 & 26,30 & 2,70 & 2,84 & $31^{\circ}$ \\
\hline 13 & Ac4.1 & 61,17 & 60,08 & $-1,09$ & 35,33 & 37,20 & 1,87 & 21,12 & 22,94 & 1,82 & 2,83 & $32^{\circ}$ \\
\hline 9 & Ac3.1 & 44,88 & 42,77 & $-2,10$ & 13,40 & $\begin{array}{c}- \\
14,78 \\
\end{array}$ & $-1,38$ & 16,16 & 16,79 & 0,63 & 2,59 & $33^{\circ}$ \\
\hline 6 & Ac2.1 & 54,23 & 52,26 & $-1,96$ & 3,24 & 3,58 & 0,34 & 18,03 & 19,59 & 1,56 & 2,53 & $34^{\circ}$ \\
\hline 34 & Ac8.5 & 76,73 & 75,27 & $-1,46$ & 6,23 & 7,64 & 1,41 & 5,07 & 6,40 & 1,33 & 2,43 & $35^{\circ}$ \\
\hline 17 & Ac4.5 & 59,86 & 57,43 & $-2,42$ & $-9,08$ & $-9,09$ & $-0,01$ & $-1,20$ & $-1,29$ & $-0,09$ & 2,42 & $36^{\circ}$ \\
\hline 12 & Ac3.5 & 64,88 & 62,85 & $-2,03$ & $-2,75$ & $-3,29$ & $-0,53$ & $-6,76$ & $-5,64$ & 1,11 & 2,38 & $37^{\circ}$ \\
\hline 50 & Ac12.7 & 35,37 & 33,82 & $-1,55$ & $-0,09$ & 0,52 & 0,61 & $\begin{array}{c}- \\
13,54 \\
\end{array}$ & $\begin{array}{c}- \\
15,17 \\
\end{array}$ & $-1,63$ & 2,33 & $38^{\circ}$ \\
\hline 10 & Ac3.3 & 71,11 & 70,79 & $-0,32$ & 7,63 & 7,99 & 0,36 & 20,55 & 22,82 & 2,27 & 2,32 & $39^{\circ}$ \\
\hline 4 & Ac1.5 & 77,99 & 79,91 & 1,92 & 2,21 & 1,79 & $-0,43$ & 6,68 & 5,59 & $-1,09$ & 2,25 & $40^{\circ}$ \\
\hline 7 & Ac2.3 & 78,04 & 76,44 & $-1,60$ & 1,15 & 0,80 & $-0,35$ & 22,08 & 23,49 & 1,41 & 2,16 & $41^{\circ}$ \\
\hline 11 & Ac3.4 & 80,98 & 79,79 & $-1,19$ & 6,99 & 7,40 & 0,41 & 20,93 & 22,51 & 1,58 & 2,02 & $42^{\circ}$ \\
\hline 46 & Ac11.5 & 44,05 & 42,61 & $-1,43$ & $-1,46$ & $-0,70$ & 0,77 & 6,77 & 5,77 & $-1,00$ & 1,91 & $43^{\circ}$ \\
\hline 31 & Ac7.4 & 69,49 & 70,15 & 0,65 & 0,14 & $-0,19$ & $-0,33$ & $-8,64$ & $-7,00$ & 1,64 & 1,79 & $44^{\circ}$ \\
\hline 48 & Ac12.4 & 64,59 & 63,09 & $-1,50$ & 2,06 & 2,01 & $-0,05$ & $-6,27$ & $-6,43$ & $-0,17$ & 1,51 & $45^{\circ}$ \\
\hline 3 & Ac1.4 & 48,38 & 48,22 & $-0,15$ & 13,32 & 12,28 & $-1,04$ & 1,19 & 0,12 & $-1,07$ & 1,50 & $46^{\circ}$ \\
\hline 8 & Ac2.5 & 74,02 & 72,79 & $-1,24$ & $-9,80$ & $\begin{array}{c}- \\
10,36\end{array}$ & $-0,56$ & 10,43 & 10,58 & 0,15 & 1,37 & $47^{\circ}$ \\
\hline 2 & Ac1.3 & 57,08 & 56,09 & $-0,98$ & 26,49 & 27,15 & 0,66 & 15,15 & 15,45 & 0,30 & 1,22 & $48^{\circ}$ \\
\hline 43 & Ac11.1 & 73,44 & 72,77 & $-0,67$ & $-1,46$ & $-1,79$ & $-0,33$ & $-2,38$ & $-2,81$ & $-0,43$ & 0,86 & $49^{\circ}$ \\
\hline 15 & Ac4.3 & 49,80 & 49,93 & 0,12 & 12,60 & 12,62 & 0,02 & 3,45 & 3,52 & 0,07 & 0,14 & $50^{\circ}$ \\
\hline
\end{tabular}


9.4.2. Mediciones colorimétricas del fragmento de pintura mural arrancada de la bóveda de la nave central de la iglesia de los Santos Juanes.

\section{PANEL SANTOS JUANES}

Estudio colorimétrico realizado para PILAR SORIANO

Medidor: Espectrofotómetro Minolta CM-2600d (2)

Operador: Marisa Martínez Bazán

COND. 6 Iluminante D65

(S/I+E/100) Observador patrón $10^{\circ}$

SCI/SCE

UV $100 \%$

Area S

Fechas: 5 Abril 2005 / 23 junio 2005

TRAS LA LIMPIEZA (5 Abril 2005)

\begin{tabular}{|c|c|c|c|c|c|c|c|c|c|c|}
\hline $\mathbf{v}^{\circ}$ & Nombre & Estado & $y 1$ & x1 & y1 & $\underline{L} \underline{1}^{\prime}$ & $a^{*} 1$ & $b^{* 1}$ & C*1 & h 1 \\
\hline 1 & 1.1. & $\mathrm{SCl}$ & 12,31 & 0,392 & 0,354 & 41,71 & 13,25 & 12,47 & 18,20 & 43,29 \\
\hline 2 & 1.2. & $\mathrm{SCl}$ & 8,17 & ,336 & 0,342 & 34,34 & 2,66 & 3,77 & 4,62 & 54,71 \\
\hline 3 & 1.3. & $\mathrm{SCl}$ & 38,65 &, 35 &, 35 & 68,49 & 6,88 & 9,48 & 11,72 & 4,01 \\
\hline 4 & 2.1. & $\mathrm{SCl}$ & 8,73 & 0,367 & 0,344 & 35,45 & 97 & 6,87 & 11,30 & 37,47 \\
\hline 5 & 2.2 & $\mathrm{SCl}$ & 13,25 & 36 & 34 & & 7,3 & 6,7 & 9,97 & 2,65 \\
\hline 6 & 2.3 & $\mathrm{SCl}$ & 33,33 & 0,363 & 0,353 & & & & 16,00 & 52,50 \\
\hline 7 & 2.4 & $\mathrm{SCl}$ & & & & & & & & 71,15 \\
\hline 8 & 3.1 . & $\mathrm{SCl}$ & 11,01 & 346 & 0,336 & & & & & \\
\hline 9 & & $\mathrm{SCl}$ & 22,18 & 0,341 & 0,351 & 54,21 & & & & 72,56 \\
\hline 10 & 4.1. & $\mathrm{SCl}$ & 13,16 & 0,359 & 0,352 & & $=2$ & & & 4,47 \\
\hline 11 & 4.2 & $\mathrm{SCl}$ & 22,50 & 0,378 & 0,355 & 54,53 & 12,06 & 13,51 & 18,11 & 48,24 \\
\hline 12 & 4.3 & $\mathrm{SCl}$ & 0 & ,344 & 0,346 & 34,16 & & & & 55,28 \\
\hline 13 & 5.1 . & $\mathrm{SCl}$ & 15,26 & ,347 & 0,351 & 45,99 & 3,7 & 3 & 39 & 63,83 \\
\hline 14 & 5.2 & $\mathrm{SCl}$ & 23,33 & 343 & 353 & 55,39 & 4 & 4 & & 3,43 \\
\hline 15 & 5.3 & $\mathrm{SCl}$ & 28,32 & 344 &, 348 & 60,18 & & & & 61,56 \\
\hline 16 & 5.4 & $\mathrm{SCl}$ & & & & & & & & 71,59 \\
\hline 17 & 6.1. & $\mathrm{SCl}$ & & & & & & & & 51,95 \\
\hline 18 & 6.2. & $\mathrm{SCl}$ & & & & & & & & 53,84 \\
\hline 19 & 6.3. & $\mathrm{SCl}$ & 24,23 & 0,345 & 0,350 & 56,32 & & & & 64,68 \\
\hline 20 & & $\mathrm{SCl}$ & 10,30 & 0,353 & 0,342 & 38,38 & 6,81 & 5,67 & 8,86 & 39,80 \\
\hline 21 & 7.1. & $\mathrm{SCl}$ & & ,381 & & & & & 17,22 & 41,22 \\
\hline 22 & 7.2 . & $\mathrm{SCl}$ & & 338 & & 34,47 & 2,83 & 3,93 & 4,85 & 54,24 \\
\hline 23 & 7.3. & $\mathrm{SCl}$ & 32,17 & 0,35 & 0,35 & 63,48 & 3,68 & 9,88 & 10,54 & 69,57 \\
\hline
\end{tabular}


PANEL SANTOS JUANES

Estudio colorimétrico realizado para PILAR SORIANO

Operador: Marisa Martínez Bazán

Medidor: Espectrofotómetro Minolta CM-2600d (2)

\begin{tabular}{l|l} 
COND. 6 & Iluminante D65 \\
(S/I+E/100) & Observador patrón $10^{\circ}$ \\
& SCl/SCE \\
UV 100\% \\
Area S
\end{tabular}

Fechas: 5 Abril 2005 / 23 junio 2005

\section{TRAS LA DESPROTECCION (23 junio 2005)}

\begin{tabular}{|c|c|c|c|c|c|c|c|c|c|}
\hline Nombre & Estado & Y2 & $\times 2$ & y2 & $L * 2$ & $a * 2$ & $b * 2$ & $C * 2$ & h2 \\
\hline 1.1 & $\mathrm{SCl} / 100$ & 13,24 & 0,395 & 0,354 & 43,11 & 14,25 & 13,12 & 19,37 & 42,63 \\
\hline 1.2 & $\mathrm{SCl} / 100$ & 7,44 & 0,336 & 0,341 & 32,78 & 2,69 & 3,39 & 4,33 & 51,56 \\
\hline 1.3 & $\mathrm{SCl} / 100$ & 38,47 & 0,348 & 0,348 & 68,37 & 6,53 & 9,52 & 11,54 & 55,55 \\
\hline 2.1 & $\mathrm{SCl} / 100$ & 8,27 & 0,370 & 0,345 & 34,54 & 9,05 & 7,21 & 11,57 & 38,54 \\
\hline 2.2 & $\mathrm{SCl} / 100$ & 11,32 & 0,363 & 0,346 & 40,11 & 8,13 & 7,58 & 11,12 & 43,04 \\
\hline 2.3 & $\mathrm{SCl} / 100$ & 30,91 & 0,367 & 0,355 & 62,43 & 9,69 & 13,52 & 16,63 & 54,39 \\
\hline 2.4 & $\mathrm{SCl} / 100$ & 25,09 & 0,351 & 0,357 & 57,16 & 3,74 & 10,88 & 11,51 & 71,03 \\
\hline 3.1 & $\mathrm{SCl} / 100$ & 10,15 & 0,355 & 0,339 & 38,11 & 7,79 & 5,21 & 9,37 & 33,75 \\
\hline 3.3 & $\mathrm{SCl} / 100$ & 21,74 & 0,342 & 0,351 & 53,75 & 2,61 & 7,95 & 8,37 & 71,83 \\
\hline 4.1 & $\mathrm{SCl} / 100$ & 14,71 & 0,359 & 0,351 & 45,24 & 6,86 & 8,86 & 11,21 & 52,24 \\
\hline 4.2 & $\mathrm{SCl} / 100$ & 23,70 & 0,371 & 0,354 & 55,79 & 10,55 & 12,54 & 16,39 & 49,92 \\
\hline 4.3 & $\mathrm{SCl} / 100$ & 10,11 & 0,343 & 0,343 & 38,04 & 4,03 & 4,81 & 6,27 & 50,01 \\
\hline 5.1 & $\mathrm{SCl} / 100$ & 18,45 & 0,342 & 0,348 & 50,04 & 3,39 & 6,92 & 7,70 & 63,90 \\
\hline 5.2 & $\mathrm{SCl} / 100$ & 23,67 & 0,341 & 0,352 & 55,75 & 2,31 & 8,16 & 8,49 & 74,18 \\
\hline 5.3 & $\mathrm{SCl} / 100$ & 31,12 & 0,344 & 0,348 & 62,61 & 4,82 & 8,47 & 9,74 & 60,37 \\
\hline 5.4 & $\mathrm{SCl} / 100$ & 38,34 & 0,343 & 0,352 & 68,27 & 3,33 & 9,94 & 10,49 & 71,49 \\
\hline 6.1 & $\mathrm{SCl} / 100$ & 38,71 & 0,357 & 0,351 & 68,54 & 8,60 & 11,98 & 14,75 & 54,34 \\
\hline 6.2 & $\mathrm{SCl} / 100$ & 8,50 & 0,339 & 0,343 & 34,99 & 3,13 & 4,15 & 5,20 & 52,97 \\
\hline 6.3 & $\mathrm{SCl} / 100$ & 22,53 & 0,347 & 0,353 & 54,58 & 3,67 & 8,96 & 9,68 & 67,73 \\
\hline 6.4 & $\mathrm{SCl} / 100$ & 11,39 & 0,352 & 0,342 & 40,23 & 6,74 & 5,62 & 8,77 & 39,81 \\
\hline 7.1 & $\mathrm{SCl} / 100$ & 14,39 & 0,391 & 0,351 & 44,79 & 14,44 & 12,56 & 19,13 & 41,02 \\
\hline 7.2 . & $\mathrm{SCl} / 100$ & 6,81 & 0,346 & 0,344 & 31,37 & 4,18 & 4,60 & 6,22 & 47,74 \\
\hline 7.3 & $\mathrm{SCl} / 100$ & 32,27 & 0,348 & 0,355 & 63,57 & 3,86 & 10,80 & 11,47 & 70,34 \\
\hline
\end{tabular}




\section{PANEL SANTOS JUANES}

Estudio colorimétrico realizado para PILAR SORIANO

Operador: Marisa Martínez Bazán

Medidor: Espectrofotómetro Minolta CM-2600d (2)

$\begin{array}{ll}\text { COND. } 6 & \text { Iluminante D65 } \\ \text { (S/I+E/100) } & \text { Observador patrón 10 } \\ & \text { SCI/SCE } \\ \text { UV 100\% } \\ \text { Area S }\end{array}$

Fechas: 5 Abril 2005 / 23 junio 2005

\section{DIFERENCIA ENTRE AMBAS MEDICIONES}

\begin{tabular}{|c|c|c|c|c|c|c|c|c|c|}
\hline Nombre & $\Delta \mathrm{Y}$ & $\Delta \mathbf{x}$ & $\Delta y$ & $\Delta \mathrm{L}^{*}$ & $\Delta \mathbf{a}^{*}$ & $\Delta \mathbf{b}^{*}$ & $\Delta \mathrm{C}^{*}$ & $\Delta \mathbf{h}$ & $\Delta \mathrm{E}$ \\
\hline 1.1 & 0,92 & 0,003 & 0,000 & 1,41 & 1,00 & 0,64 & 1,17 & $-0,66$ & 1,84 \\
\hline 1.2 & $-0,73$ & $-0,001$ & $-0,001$ & $-1,56$ & 0,03 & $-0,37$ & $-0,28$ & $-3,16$ & 1,60 \\
\hline 1.3 & $-0,17$ & $-0,001$ & 0,000 & $-0,13$ & $-0,36$ & 0,04 & $-0,17$ & 1,54 & 0,38 \\
\hline 2.1 & $-0,46$ & 0,003 & 0,001 & $-0,91$ & 0,08 & 0,34 & 0,28 & 1,07 & 0,98 \\
\hline 2.2 & $-1,93$ & 0,007 & 0,002 & $-2,99$ & 0,80 & 0,83 & 1,15 & 0,38 & 3,21 \\
\hline 2.3 & $-2,42$ & 0,003 & 0,003 & $-2,00$ & $-0,05$ & 0,83 & 0,63 & 1,88 & 2,16 \\
\hline 2.4 & $-2,05$ & 0,002 & 0,002 & $-1,94$ & 0,17 & 0,41 & 0,45 & $-0,12$ & 1,99 \\
\hline 3.1 & $-0,86$ & 0,009 & 0,003 & $-1,49$ & 1,20 & 1,26 & 1,69 & 2,81 & 2,29 \\
\hline 3.3 & $-0,43$ & 0,001 & 0,000 & $-0,45$ & 0,17 & 0,18 & 0,22 & $-0,73$ & 0,51 \\
\hline 4.1 & 1,55 & 0,001 & $-0,001$ & 2,23 & 0,67 & 0,18 & 0,54 & $-2,23$ & 2,34 \\
\hline 4.2 & 1,20 & $-0,007$ & $-0,001$ & 1,26 & $-1,51$ & $-0,97$ & $-1,73$ & 1,69 & 2,20 \\
\hline 4.3 & 2,03 & $-0,002$ & $-0,003$ & 3,89 & 0,53 & $-0,25$ & 0,12 & $-5,27$ & 3,93 \\
\hline 5.1 & 3,19 & $-0,005$ & $-0,003$ & 4,05 & $-0,31$ & $-0,61$ & $-0,69$ & 0,07 & 4,11 \\
\hline 5.2 & 0,34 & $-0,002$ & $-0,001$ & 0,36 & $-0,23$ & $-0,38$ & $-0,43$ & 0,75 & 0,57 \\
\hline 5.3 & 2,80 & 0,000 & 0,000 & 2,43 & 0,33 & 0,19 & 0,32 & $-1,19$ & 2,46 \\
\hline 5.4 & 1,65 & 0,000 & 0,000 & 1,22 & 0,10 & 0,23 & 0,25 & $-0,10$ & 1,25 \\
\hline 6.1 & $-0,05$ & 0,003 & 0,003 & $-0,04$ & 0,13 & 1,16 & 1,01 & 2,39 & 1,17 \\
\hline 6.2 & 1,58 & 0,000 & 0,000 & 3,39 & 0,28 & 0,25 & 0,36 & $-0,87$ & 3,41 \\
\hline 6.3 & $-1,70$ & 0,001 & 0,002 & $-1,74$ & $-0,35$ & 0,46 & 0,28 & 3,05 & 1,83 \\
\hline 6.4 & 1,09 & $-0,002$ & 0,000 & 1,85 & $-0,06$ & $-0,05$ & $-0,08$ & 0,01 & 1,85 \\
\hline 7.1 & $-1,45$ & 0,010 & 0,002 & $-1,98$ & 1,48 & 1,21 & 1,91 & $-0,19$ & 2,76 \\
\hline 7.2 . & $-1,43$ & 0,009 & 0,001 & $-3,10$ & 1,35 & 0,67 & 1,37 & $-6,50$ & 3,45 \\
\hline 7.3 & 0,10 & 0,003 & 0,002 & 0,08 & 0,18 & 0,93 & 0,93 & $-6,50$ & 0,95 \\
\hline
\end{tabular}


9.5 ANEXO V. Tablas de análisis de muestras con Espectroscopia I.R. por transformada de Fourier.

9.5.1.Análisis de muestras tomadas de las probetas.
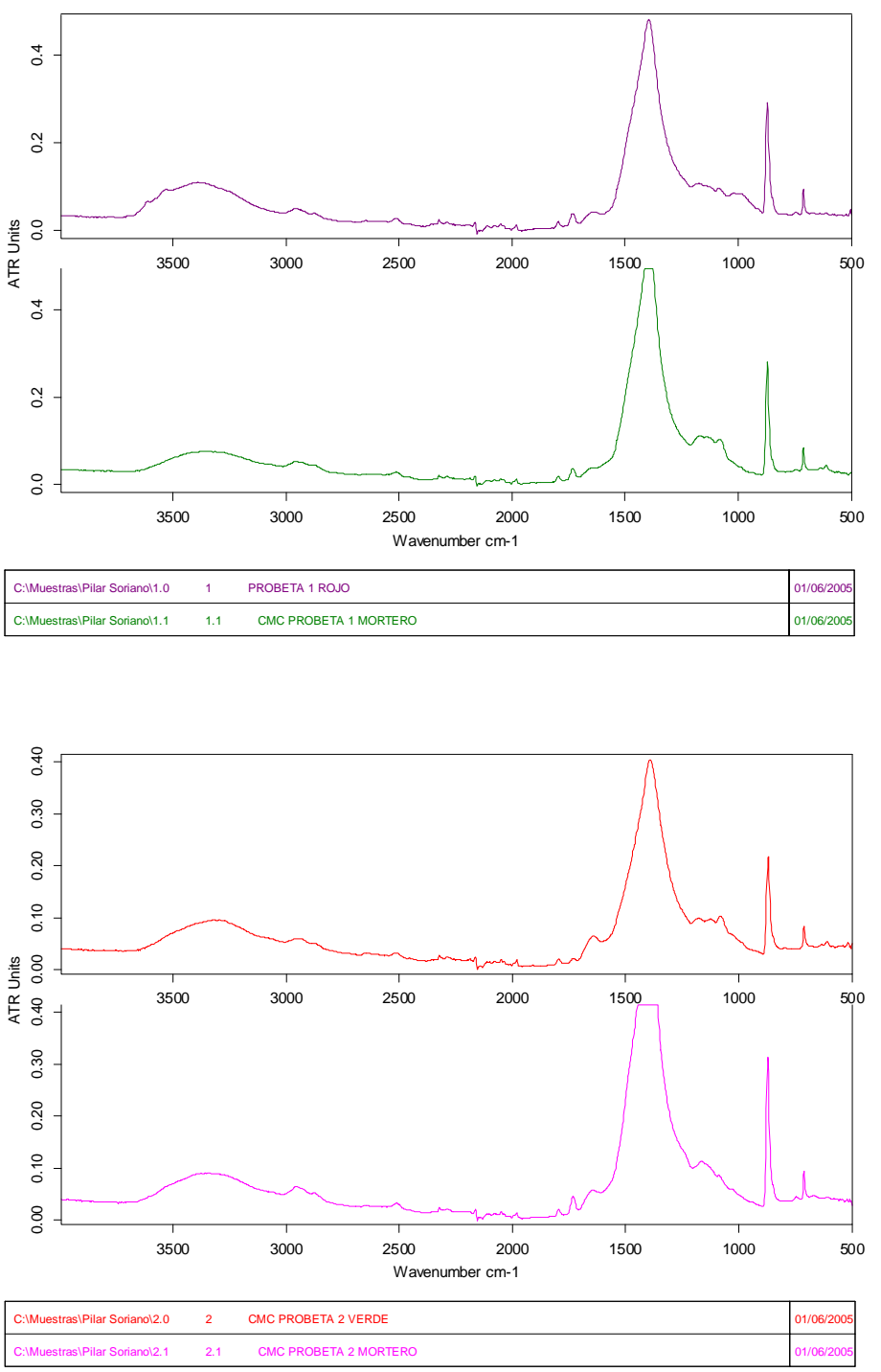


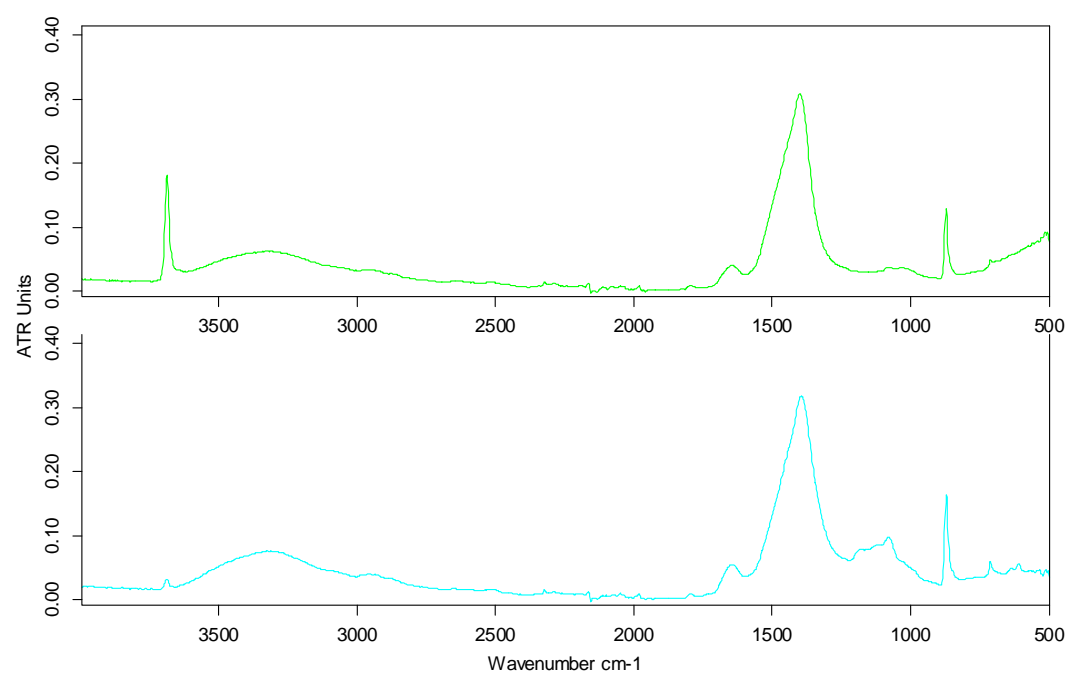

\begin{tabular}{|lll|l|}
\hline C:IMuestras IPilar Sorianol3.0 & 3 & COLETA PROBETA 3 VERDE & 01/06/2005 \\
\hline C:IMuestrasIPillar Sorianol3.1 & 3.1 & COLETA PROBETA 3 MORTERO & $01 / 06 / 2005$ \\
\hline
\end{tabular}

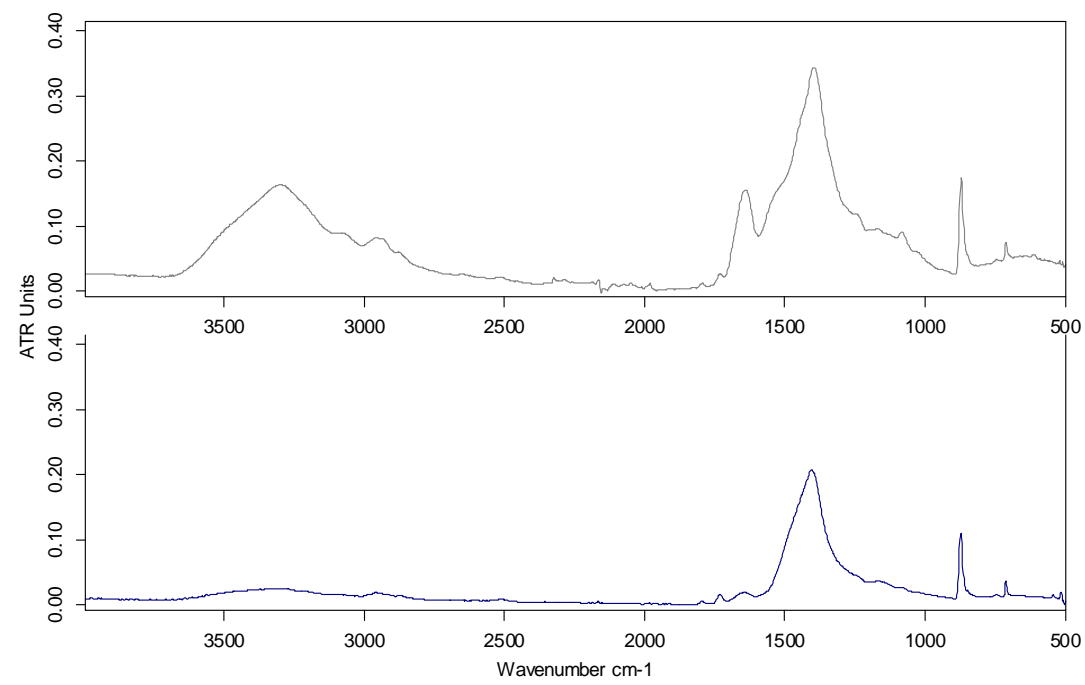

\begin{tabular}{|llc|c|}
\hline C:IMuestras IPilar Sorianol4.0 & 4 & COLETA PROBETA 4 VERDE & 01/06/2005 \\
\hline C:IMuestrasIPilar Sorianol4.1 & 4.1 & COLETA PROBETA 4 MORTERO & 01/06/2005 \\
\hline
\end{tabular}



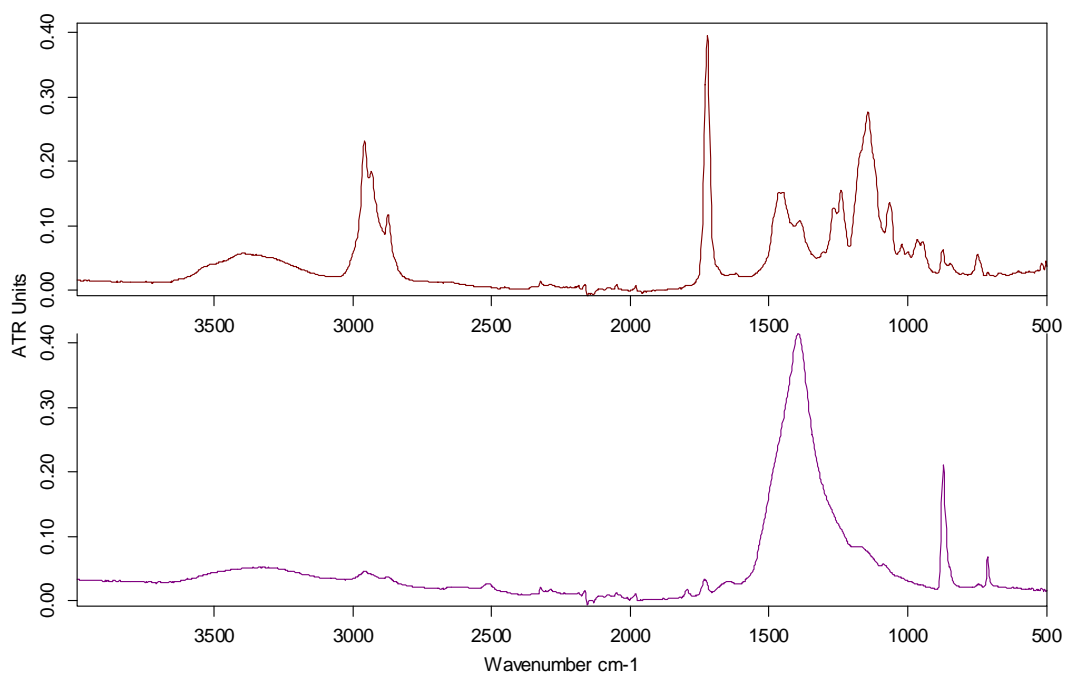

\begin{tabular}{|lcc|c|}
\hline C:IMuestrasIPilar Sorianol5.0 & 5 & PLEXSOL PROBETA 5 TURQUESA & 01/06/2005 \\
\hline C:IMuestrasIPilar Sorianol5.1 & 5.1 & PLEXSOL PROBETA 5 MORTERO & $0106 / 2005$ \\
\hline
\end{tabular}
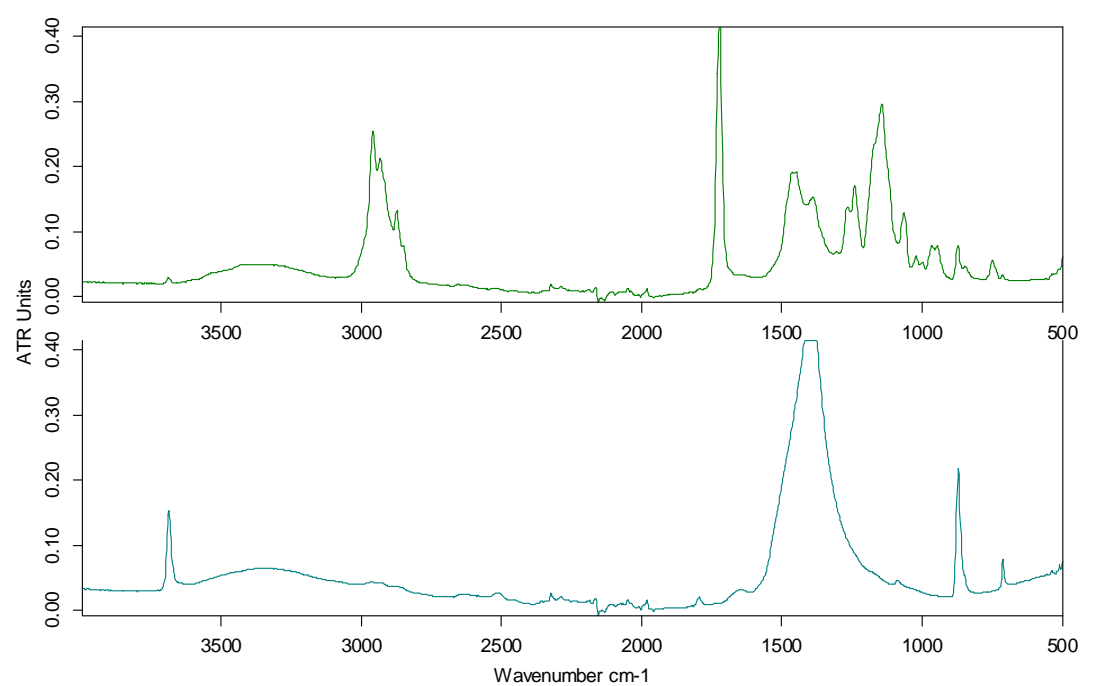

\begin{tabular}{|lcc|c|}
\hline C:IMuestrasIPilar Sorianol6.0 & 6 & PLEXSOL PROBETA 6 AMARILLO & 01/06/2005 \\
\hline C:IMuestrasIPilar Sorianol6.1 & 6.1 & PLEXSOL PROBETA 6 MORTERO & $01 / 06 / 2005$ \\
\hline
\end{tabular} 


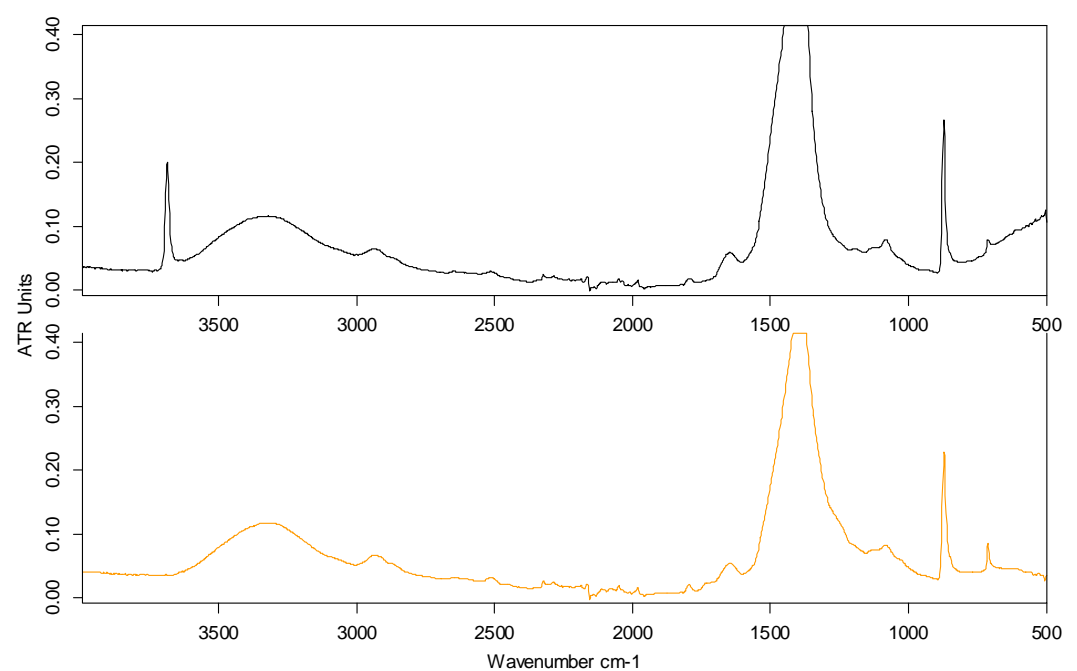

\begin{tabular}{|lcc|c|}
\hline C:IMuestrasIPilar Sorianol7.0 & 7 & ALCOHOL POLIVINILICO PROBETA 7 AZUL & 01/06/2005 \\
\hline C:IMuestras IPilar Sorianol7.1 & 7.1 & ALCOHOL POLIVINILLICO PROBETA 7 MORTERO & $01 / 06 / 2005$ \\
\hline
\end{tabular}

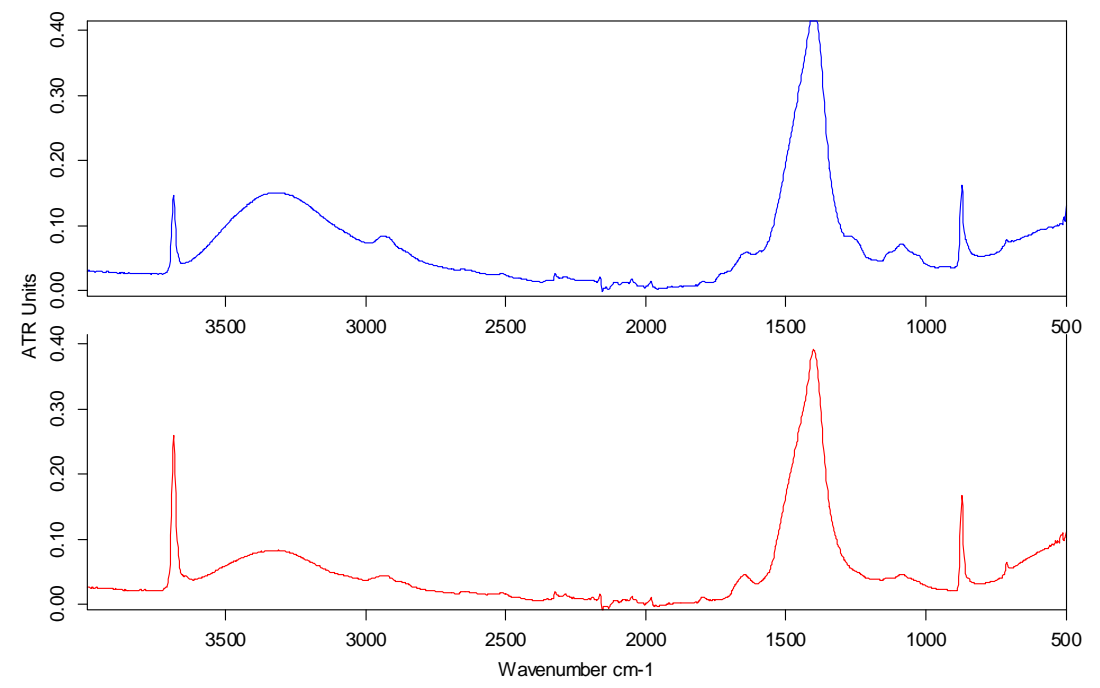

\begin{tabular}{|lcc|c|}
\hline C:IMuestrasIPilar Sorianol8.0 & 8 & ALCOHOL POLIVINILICO PROBETA 8 AZUL & $01 / 06 / 2005$ \\
\hline C:IMuestras IPilar Sorianol8.1 & 8.1 & ALCOHOL POLIVINIILICO PROBETA 8 MORTERO & 01/06/2005 \\
\hline
\end{tabular} 

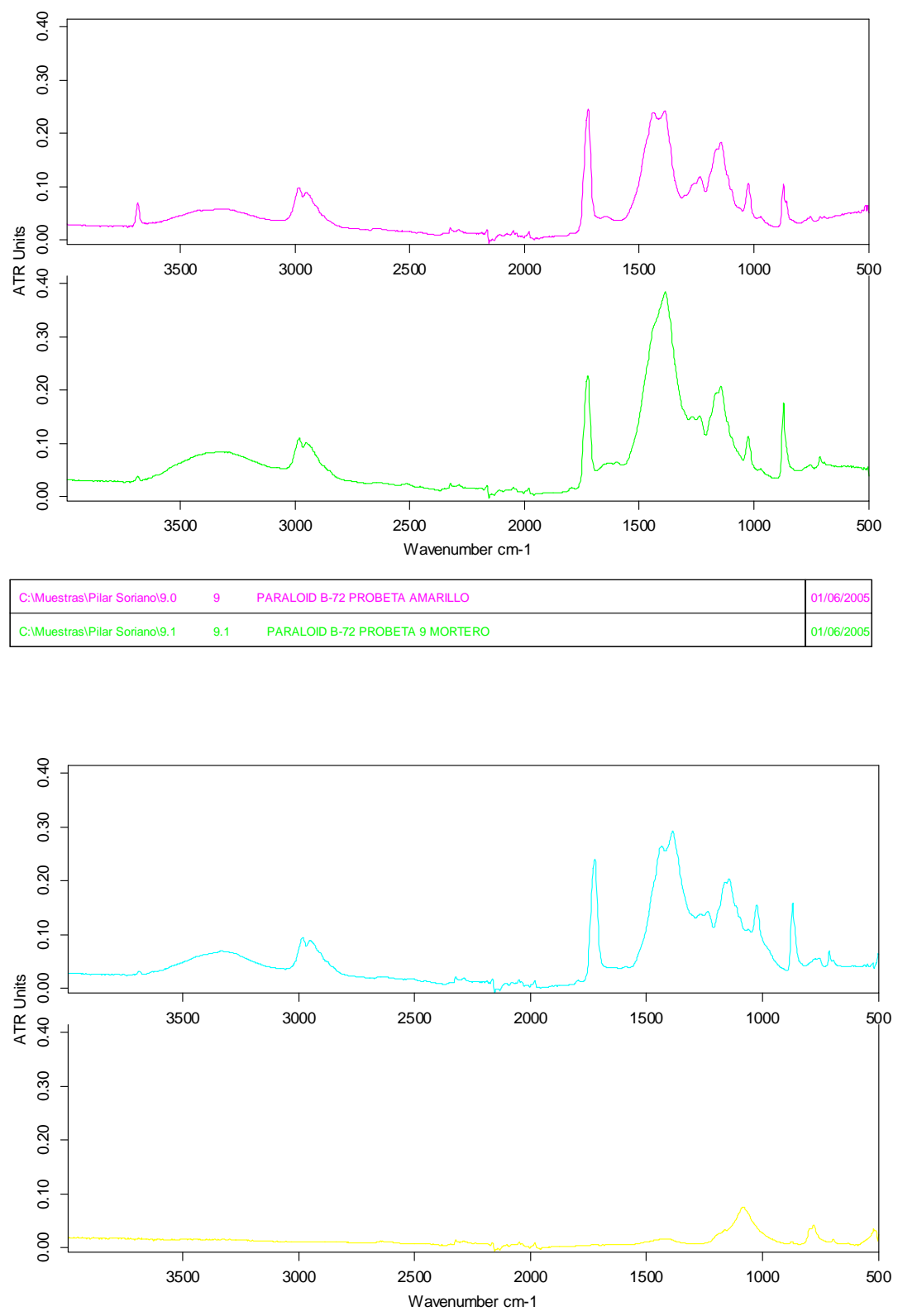

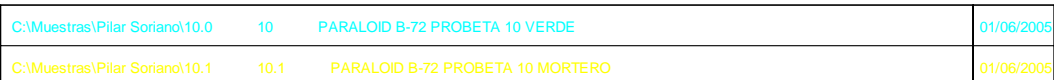




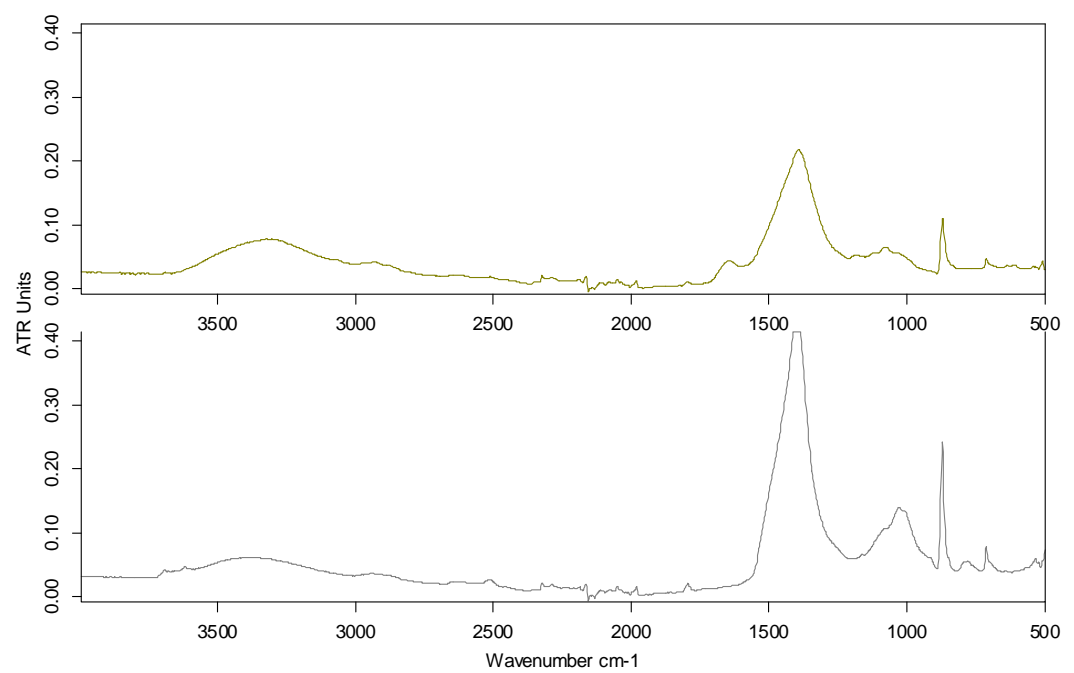

\begin{tabular}{|lcc|c|c|}
\hline C:IMuestrasIPilar Sorianol11.0 & 11 & CMC+ALCOHOL POLIVINILLICO PROBETA 11 ALMAGRA & 01/06/2005 \\
\hline C:IMuestrasIPilar Sorianol11.1 & 11.1 & CMC+ALCOHOL POLIVINILIICO PROBETA 11 MORTERO & 01/06/2005 \\
\hline
\end{tabular}

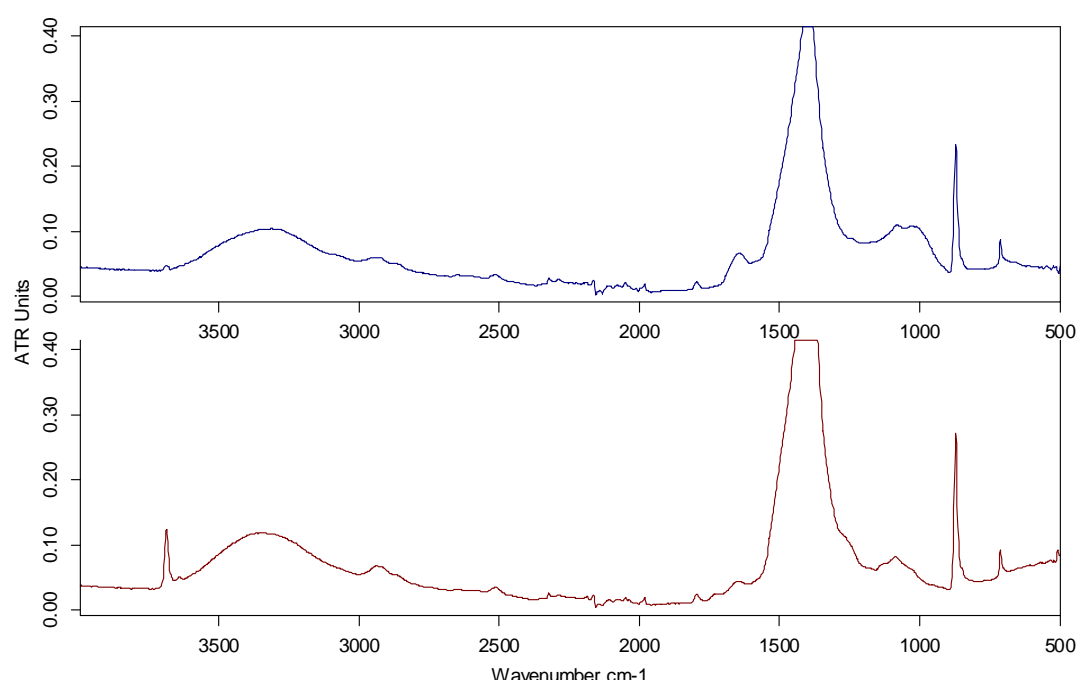

\begin{tabular}{|llc|l|}
\hline C:IMuestrasIPilar Sorianol12.0 & 12 & CMC+ALCOHOL POLIVINILICO PROBETA 12 AÑIL & 01/06/2005 \\
\hline C:IMuestrasIPilar Sorianol12.1 & 12.1 & CMC+ALCOHOL POLIVINILICO PROBETA 12 MORTERO & 01/06/2005 \\
\hline
\end{tabular}


9.5.2. Análisis de muestras tomadas de los adhesivos utilizados, en estado puro.
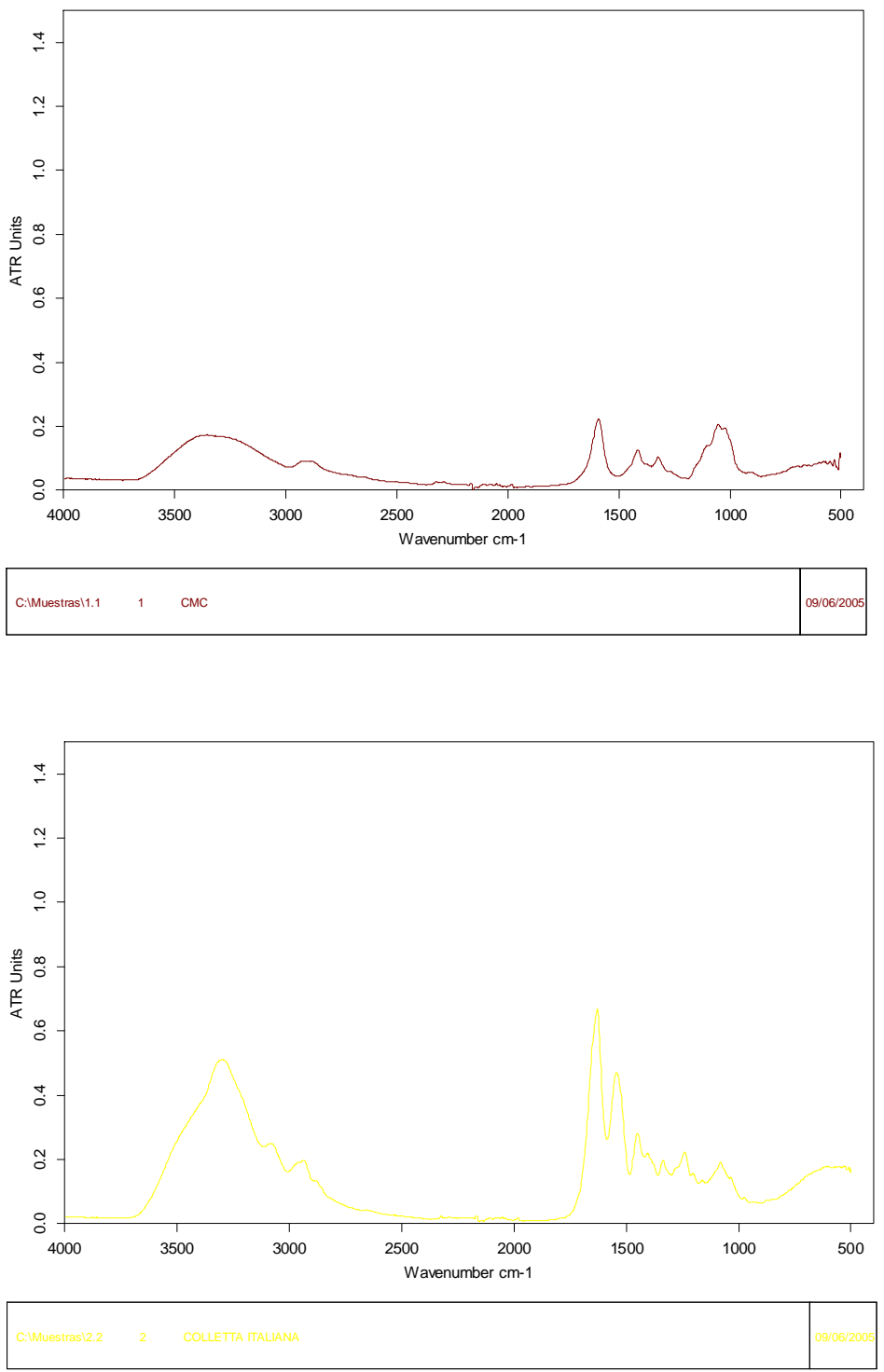


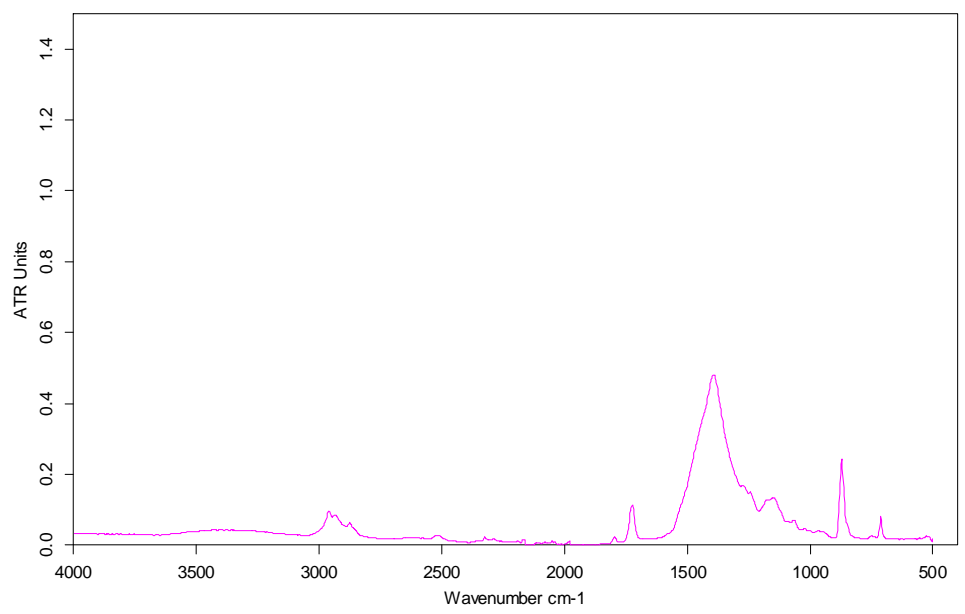

\begin{tabular}{|lll|l|}
\hline C:Muestrasi3.0 & 3 & PLEXSOL & $09 / 06 / 2005$ \\
\hline
\end{tabular}

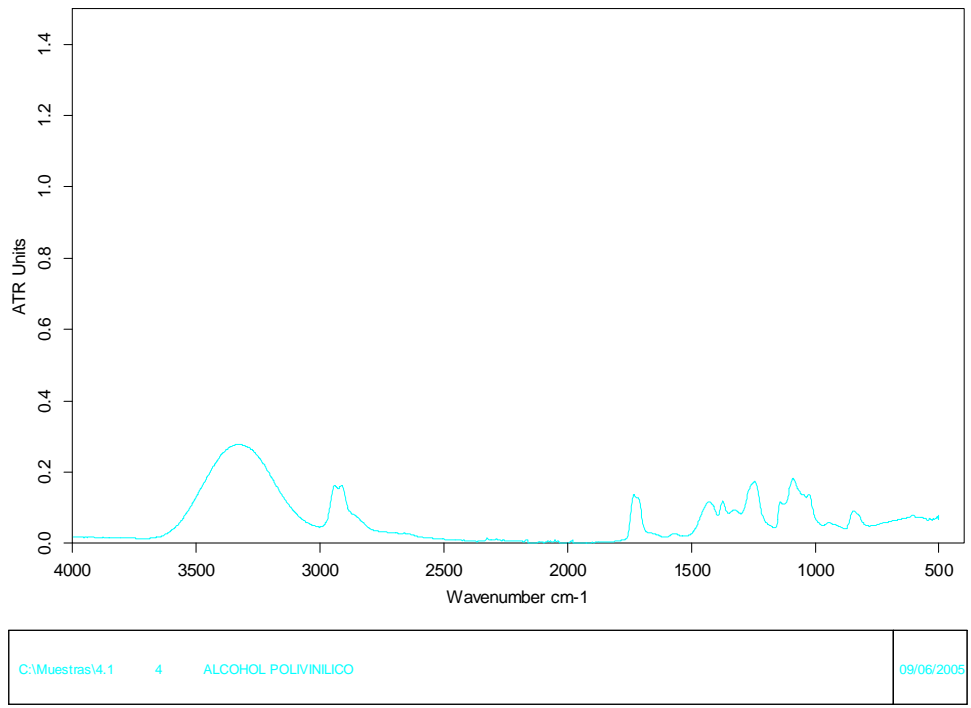




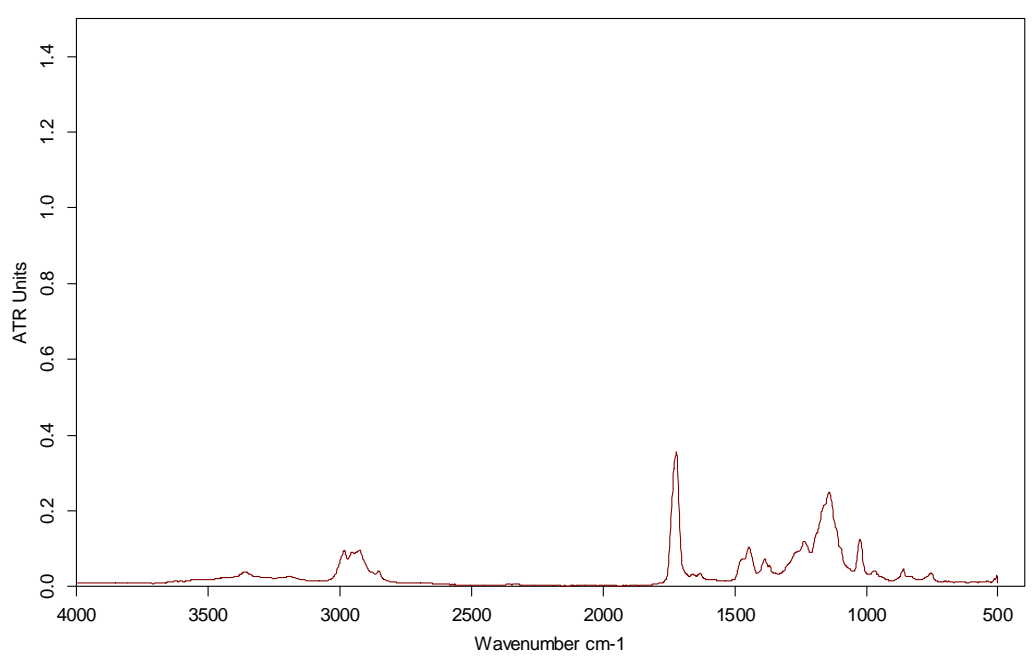

\begin{tabular}{|lll|l|}
\hline C:IMuestrasl5.1 & 5 & PARALOID B-72 & 09/06/2005 \\
\hline
\end{tabular}
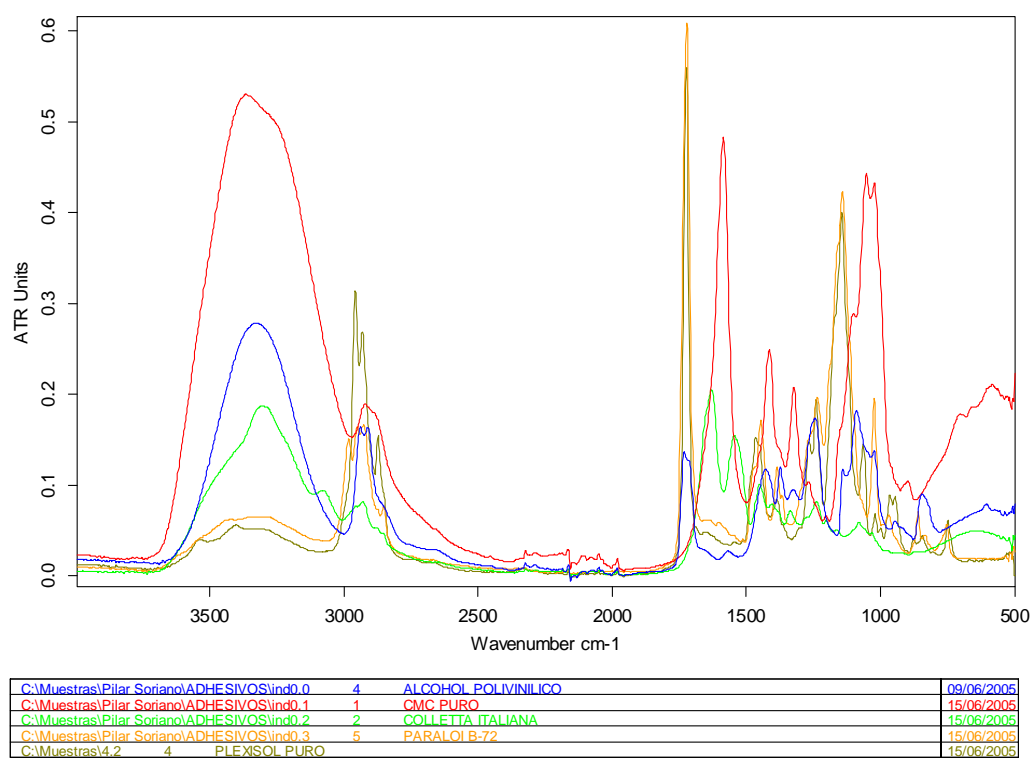
9.5.3.Comparativa de las muestras tomadas de las probetas y de los espectros de cada adhesivo.

Con el fin de ver más claramente los componentes de cada una de las muestras analizadas y poder extraer conclusiones al respecto, adjuntamos los gráficos en los que aparece la muestra de cada una de las probetas junto con la correspondiente al adhesivo utilizado en dicha probeta, en estado puro.

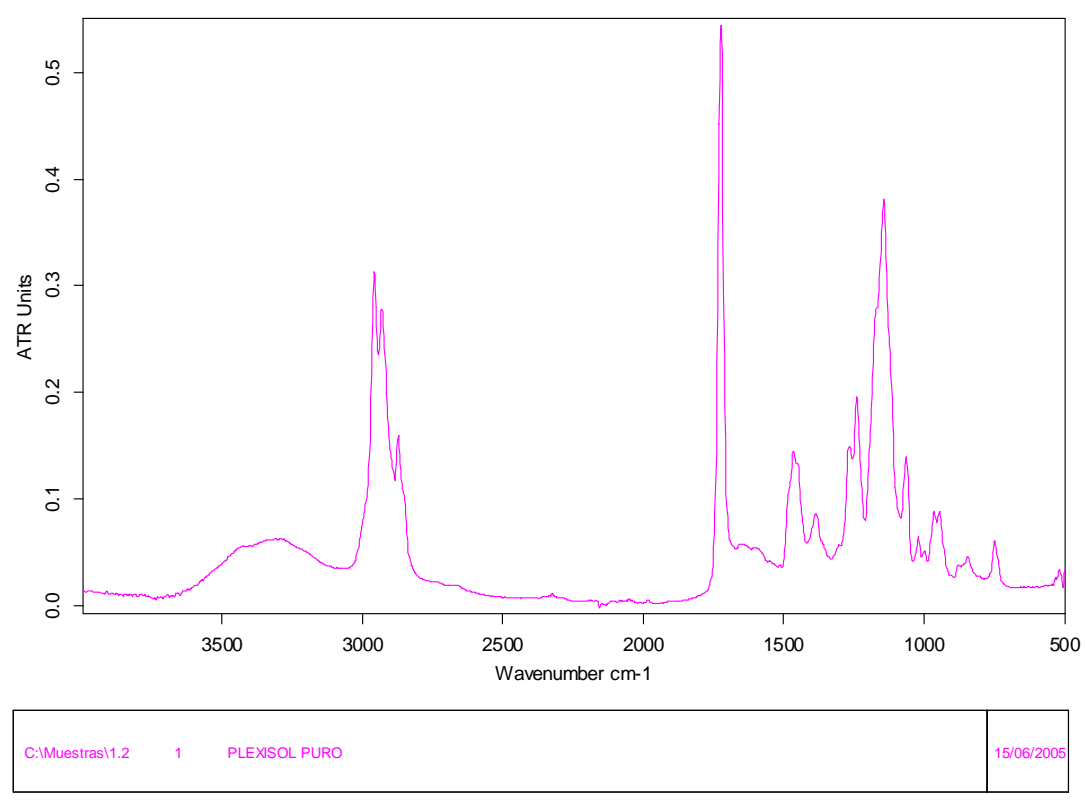




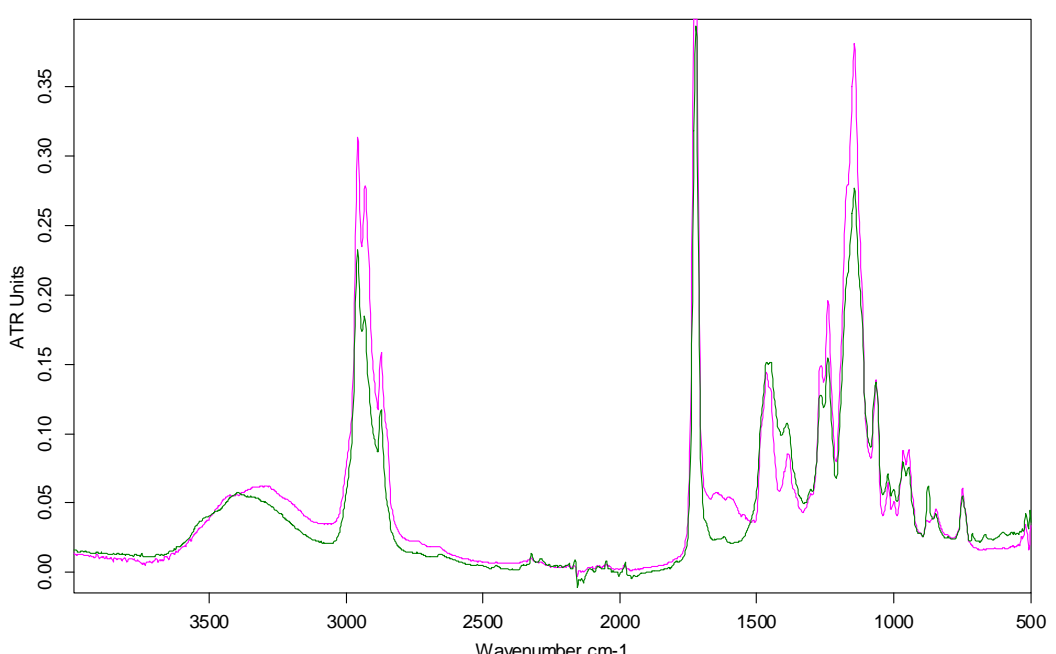

\begin{tabular}{|lcc|c|}
\hline C:IMuestrasIPilar Sorianol5.0 & 5 & PLEXSOL PROBETA 5 TURQUESA & 01/06/2005 \\
\hline C:IMuestrasIPilar Sorianolindo.0 & 1 & PLEXSOL PURO & $15 / 06 / 2005$ \\
\hline
\end{tabular}

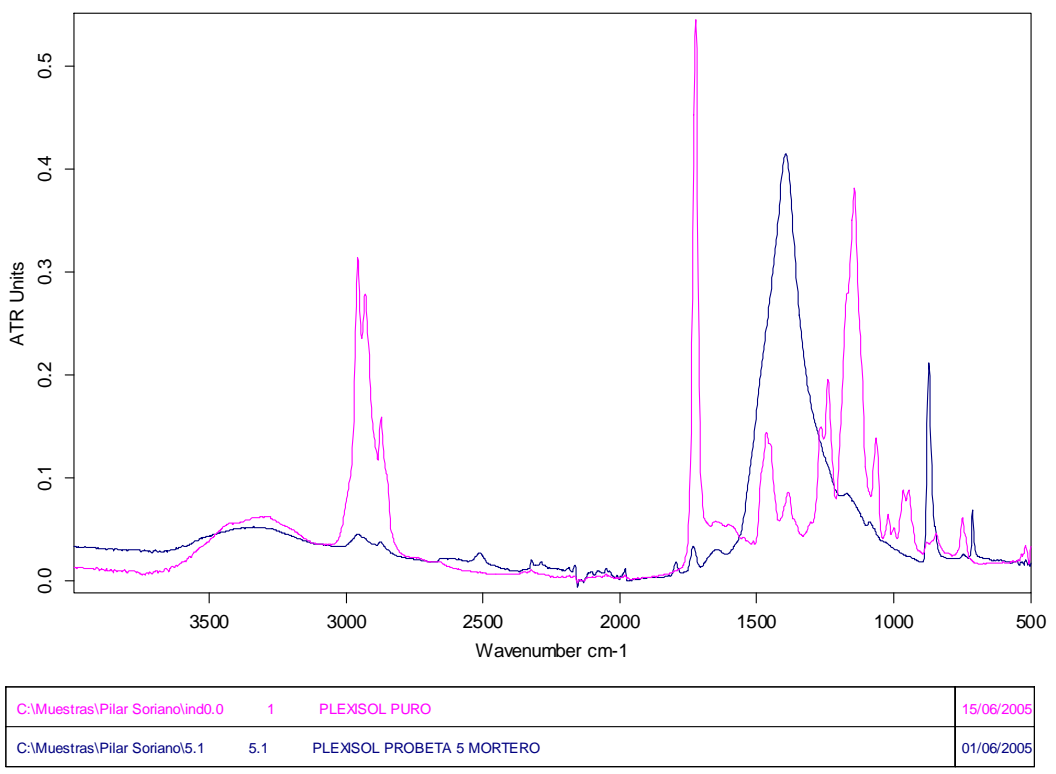




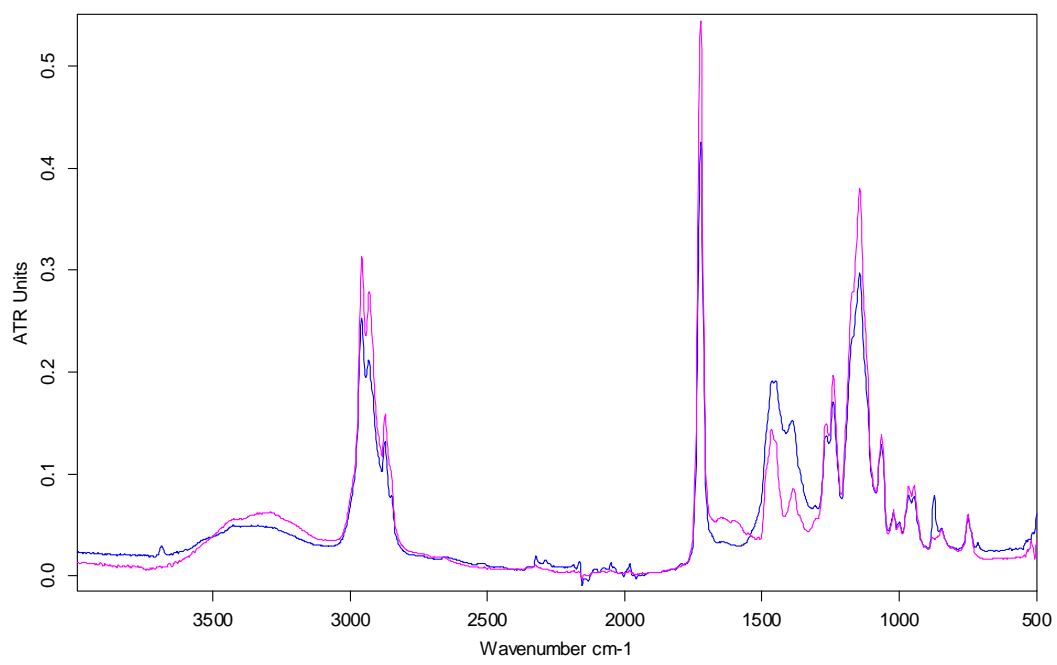

\begin{tabular}{|lcc|c|}
\hline C:IMuestrasIPilar Sorianolindo.0 & 1 & PLEXSOL PURO & $15 / 06 / 2005$ \\
\hline C:IMuestras PPilar Sorianol6.0 & 6 & PLEXISOL PROBETA 6 AMARILLO & 01/06/2005 \\
\hline
\end{tabular}

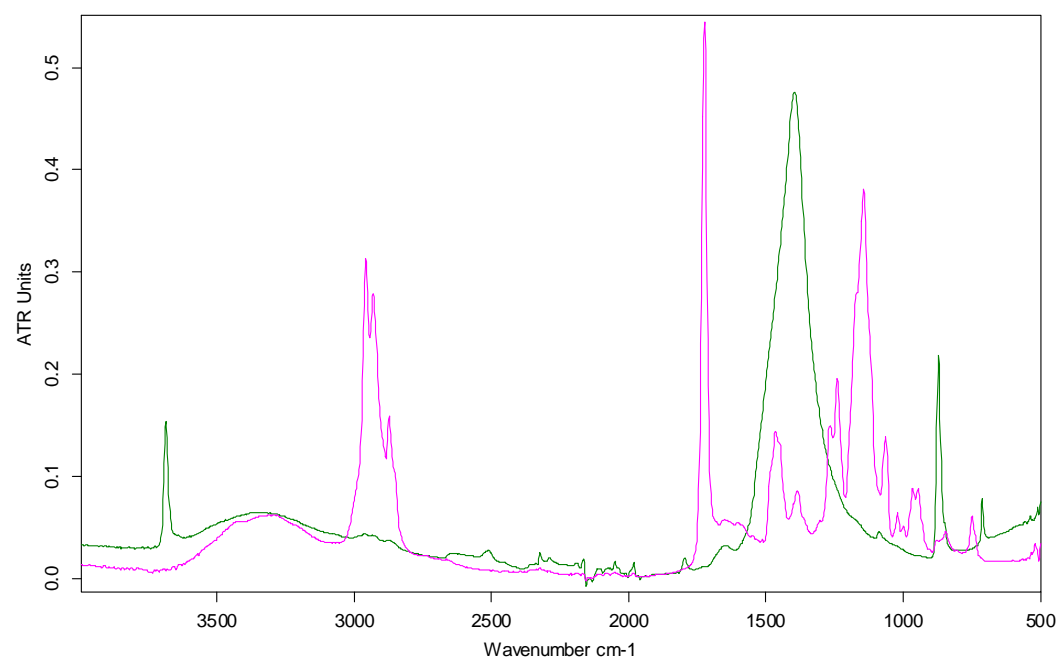

\begin{tabular}{|lcl|l|}
\hline C:IMuestrasIPilar Sorianolindo.0 & 1 & PLEXSOL PURO & $15 / 06 / 2005$ \\
\hline C:IMuestrasIPilar Sorianol6.1 & 6.1 & PLEXSOL PROBETA 6 MORTERO & 01/06/2005 \\
\hline
\end{tabular}



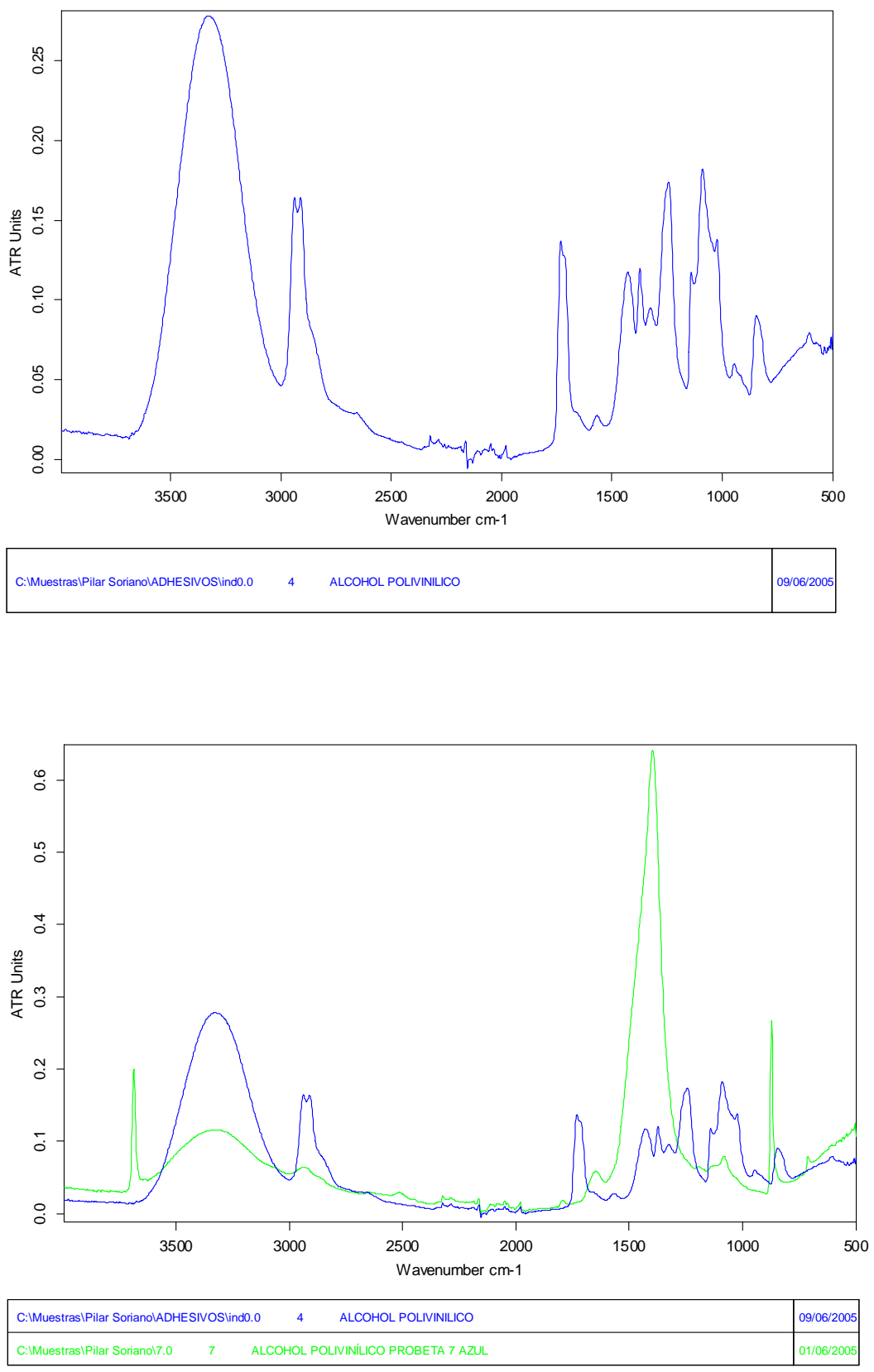


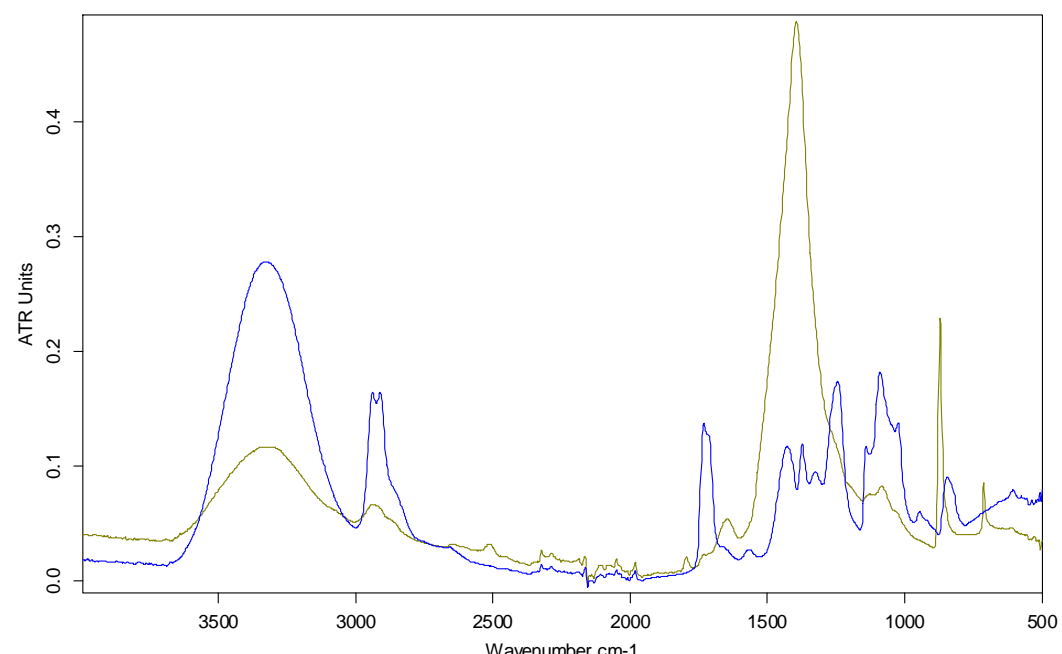

\begin{tabular}{|lccc|c|}
\hline C:IMuestrasIPilar SorianolADHESIVOSlindo.0 & 4 & ALCOHOL POLIVINILICO & $09 / 06 / 2005$ \\
\hline C:IMuestrasIPilar Sorianol7.1 & 7.1 & ALCOHOL POLIVINILICO PROBETA 7 MORTERO & $01 / 06 / 2005$ \\
\hline
\end{tabular}

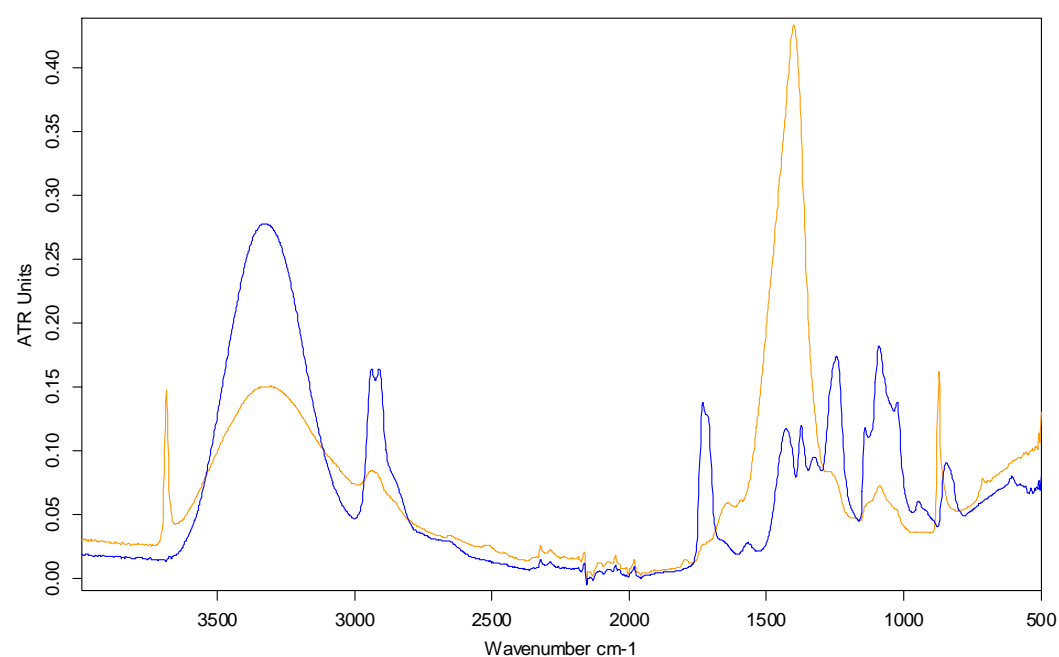

\begin{tabular}{|lccc|c|}
\hline C:IMuestrasIPilar SorianolADHESIVOSlindo.0 & 4 & ALCOHOL POLIVINILICO & $09 / 06 / 2005$ \\
\hline C:IMuestrasIPilar Sorianol8.0 & 8 & ALCOHOL POLIVINIILICO PROBETA 8 AZUL & $01 / 06 / 2005$ \\
\hline
\end{tabular} 


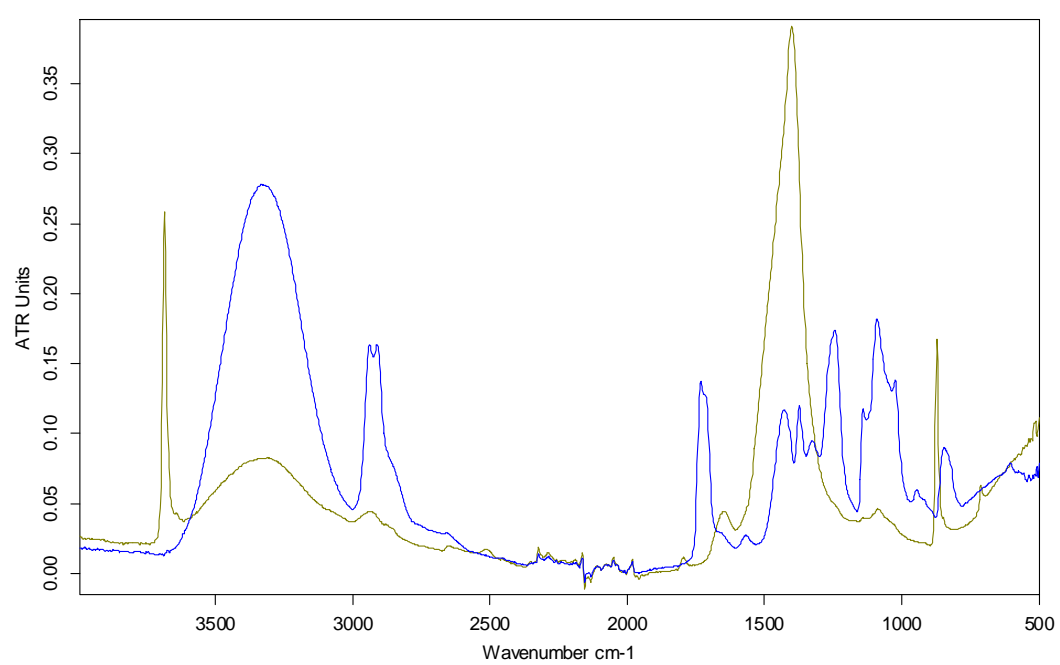

\begin{tabular}{|lccc|c|}
\hline C:IMuestrasIPilar SorianolADHESIVOSlindo.0 & $4 \quad$ ALCOHOL POLIVINLICO & 09/06/2005 \\
\hline C:IMuestrasIPPilar Sorianol8.1 & 8.1 & ALCOHOL POLIVINILICO PROBETA 8 MORTERO & 01/06/2005 \\
\hline
\end{tabular}

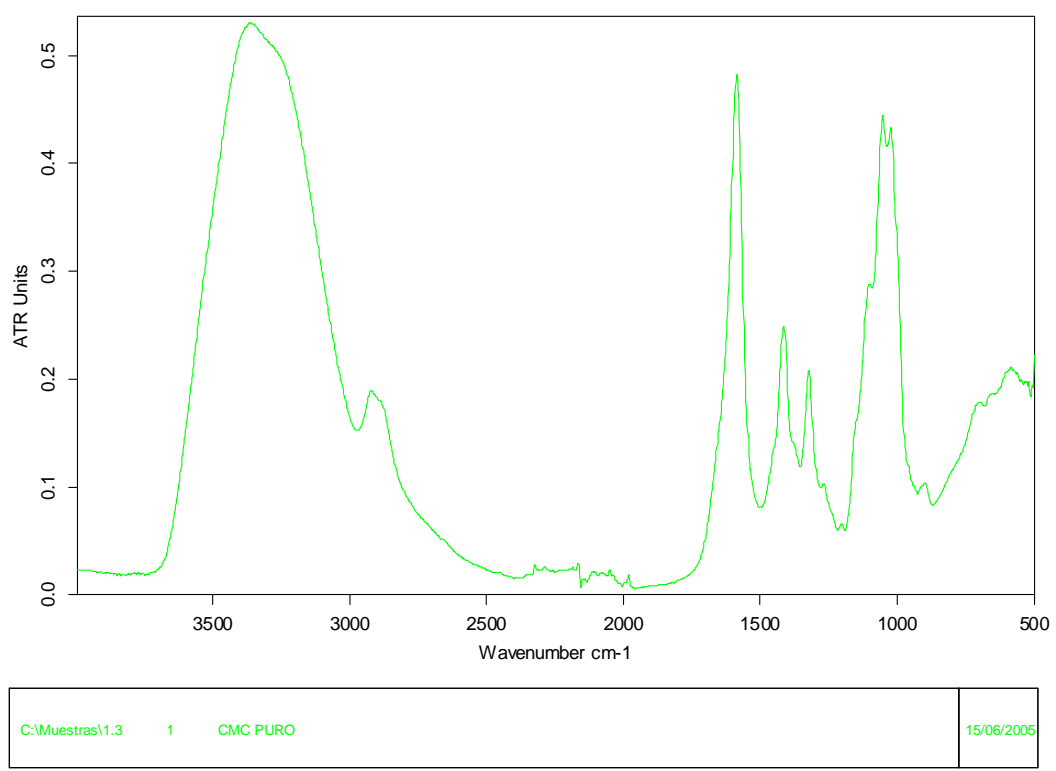




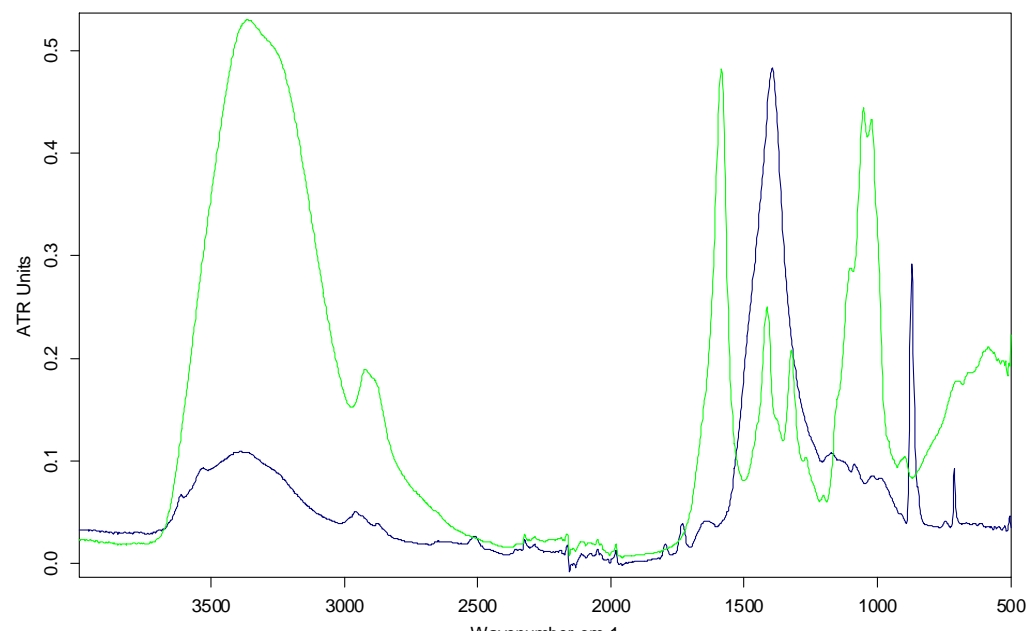

\begin{tabular}{|lc|c|}
\hline C:IMuestras1.3.3 1 CMC PURO & 15/06/2005 \\
\hline C:IMuestrasIPilar Sorianol1.0 & $1 \quad$ PROBETA 1 ROJO & 01/06/2005 \\
\hline
\end{tabular}

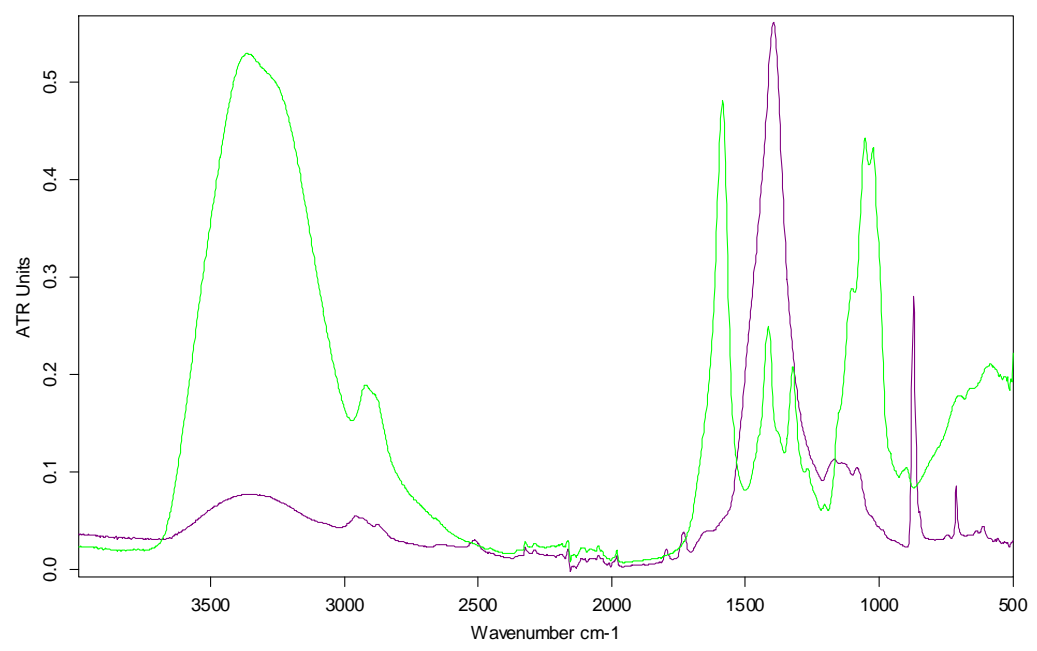

\begin{tabular}{|lcc|c|}
\hline C:IMuestras 11.3 1 CMC PURO & $15 / 06 / 2005$ \\
\hline C:IMuestrasIPilar Sorianol1.1 & $1.1 \quad$ CMC PROBETA 1 MORTERO & $01 / 06 / 2005$ \\
\hline
\end{tabular}




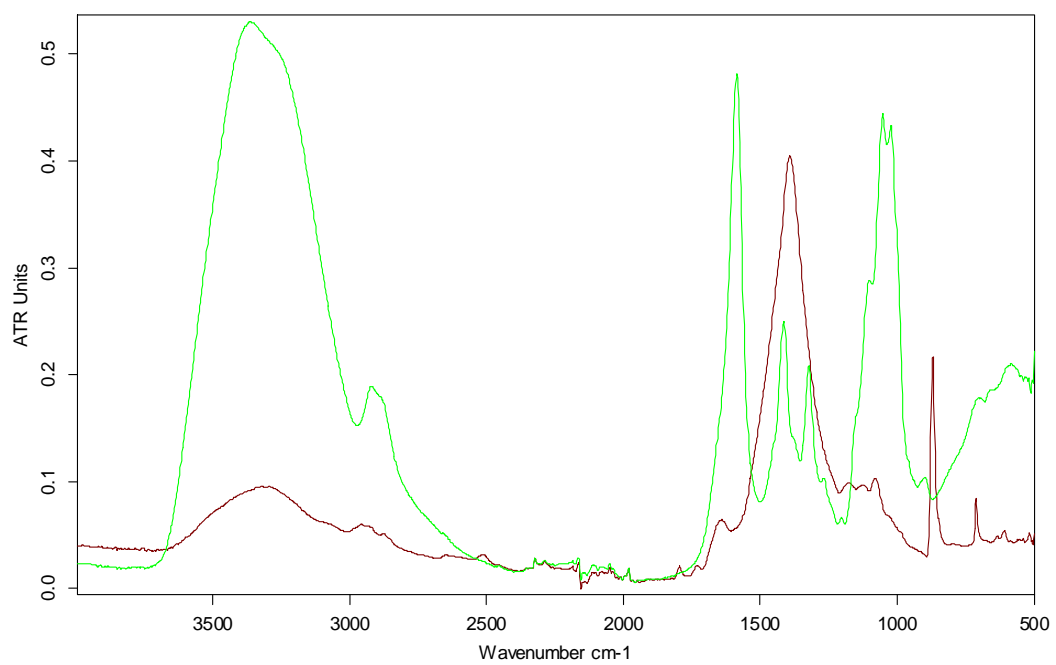

\begin{tabular}{|ll|l|}
\hline C:IMuestras 11.3 1 CMC PURO & $15 / 00 / 2005$ \\
\hline C:IMuestras IPilar Sorianol2.0 2 CMC PROBETA 2 VERDE & 01/06/2005 \\
\hline
\end{tabular}

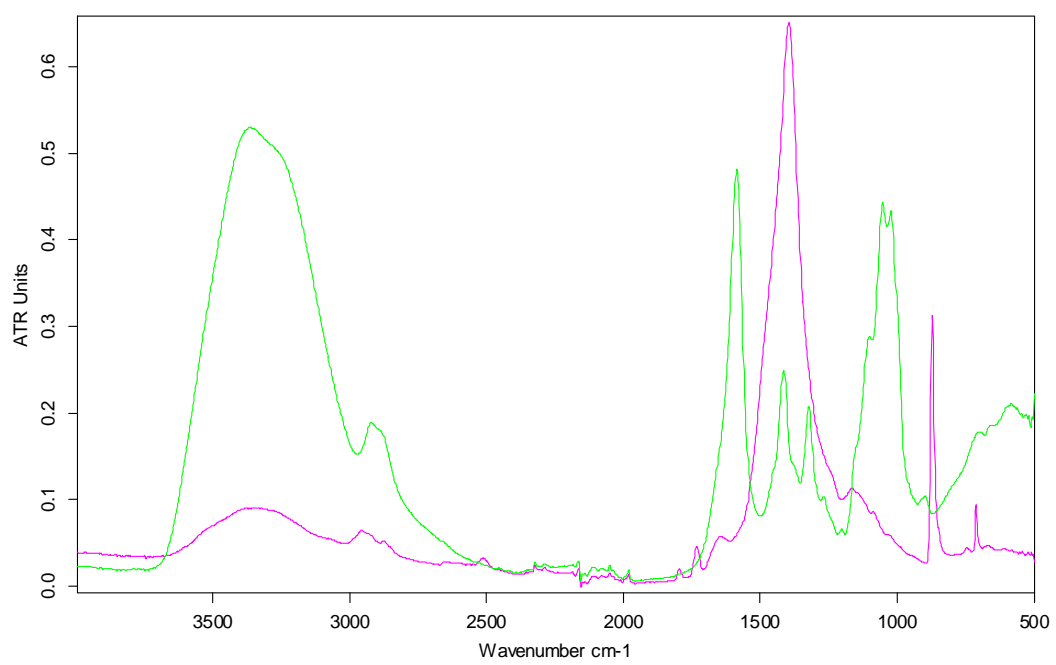

\begin{tabular}{|lcl|l|}
\hline C:IMuestras/1.3 1 CMC PURO & 15/06/2005 \\
\hline C:IMuestrasIPilar Sorianol2.1 & $2.1 \quad$ CMC PROBETA 2 MORTERO & $01 / 06 / 2005$ \\
\hline
\end{tabular}



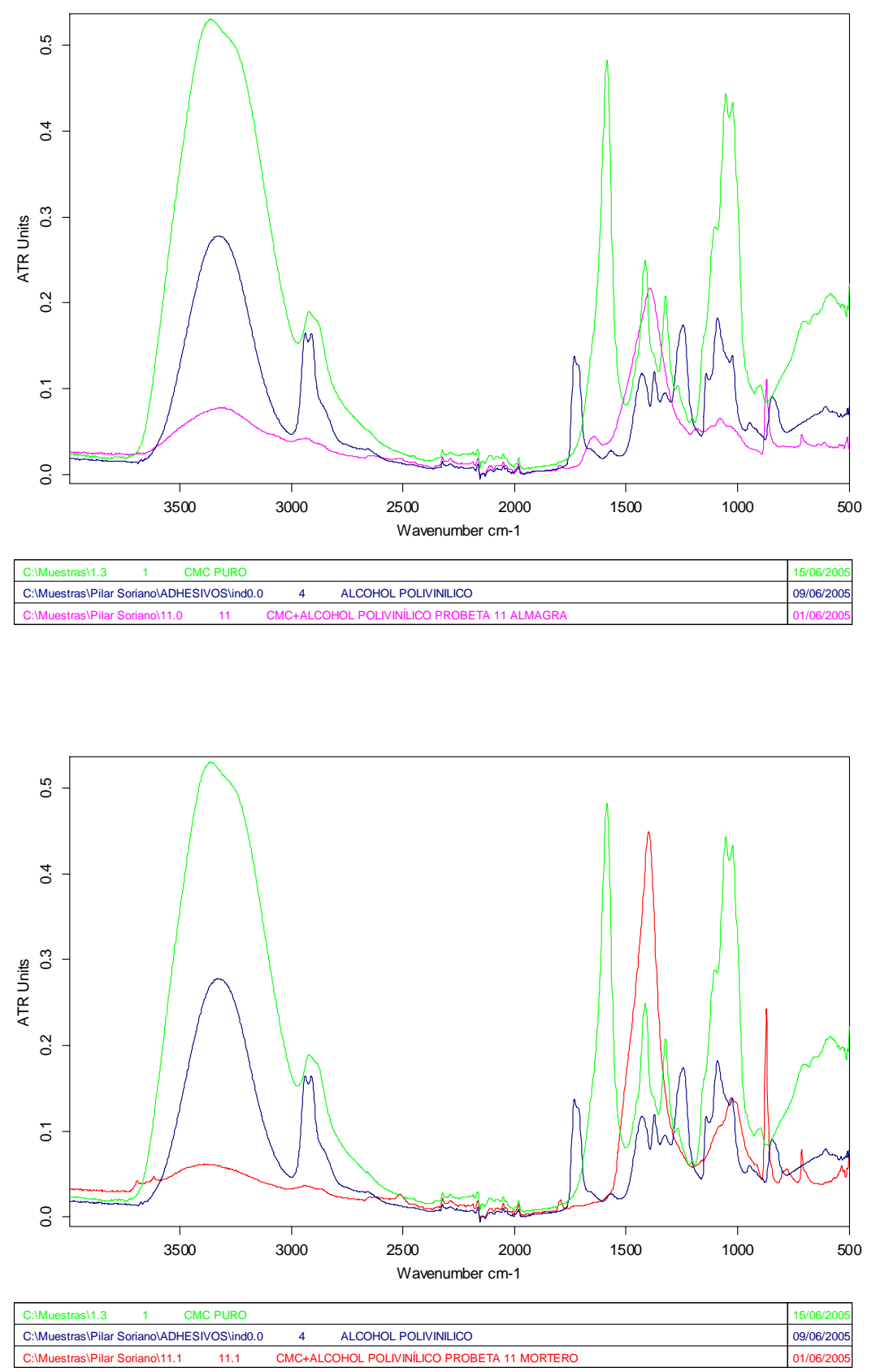

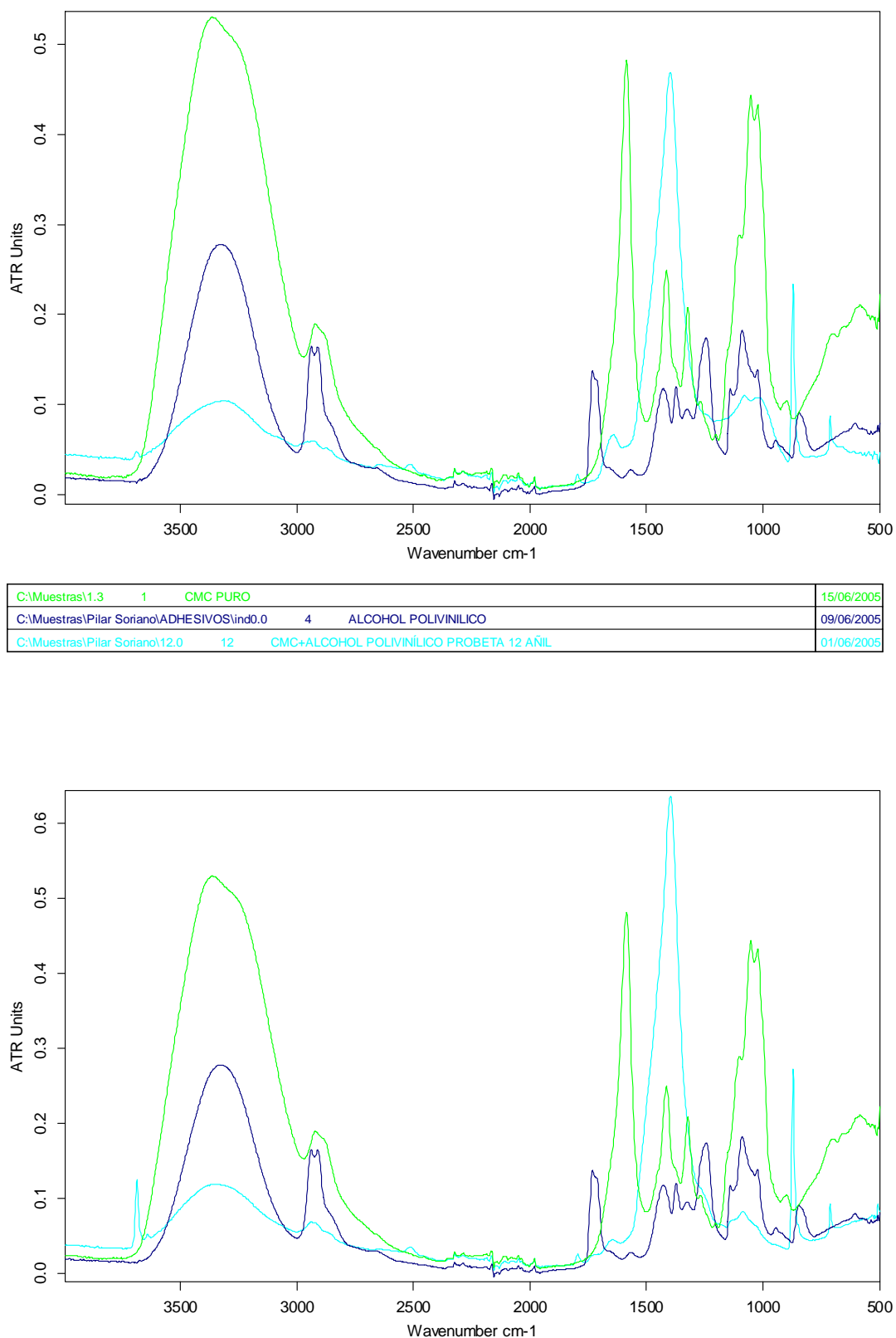

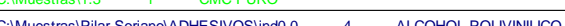




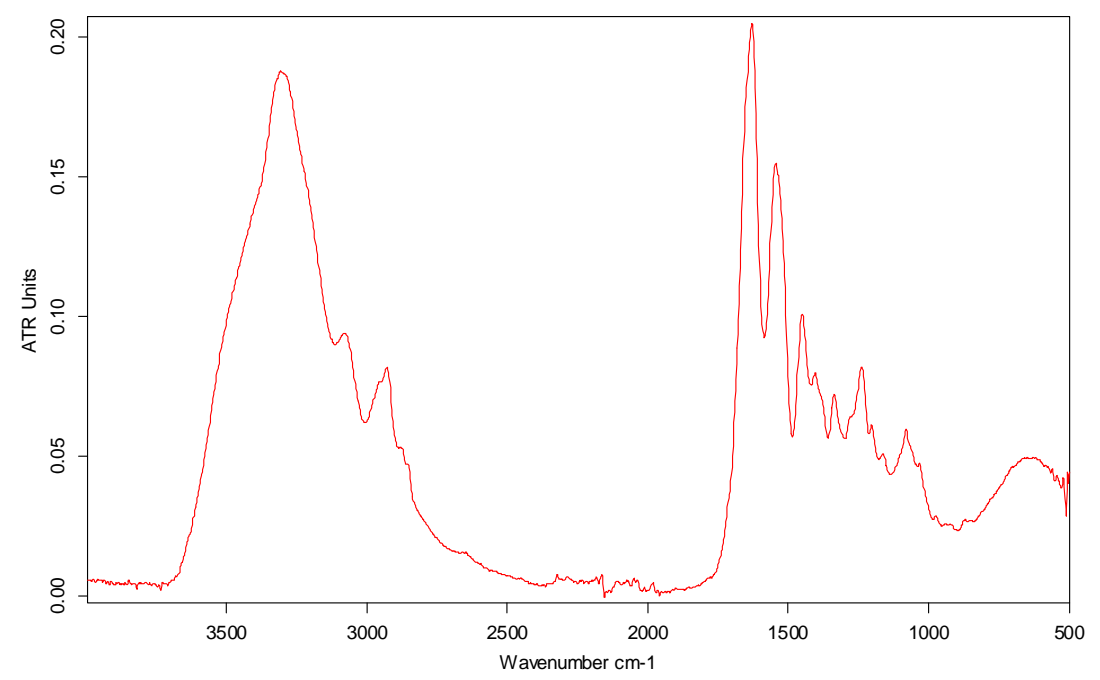

C:IMuestrasIPilar Soriano|ADHESIVOSlindo.2 2 COLLETTA ITALIANA $15 / 06 / 2005$

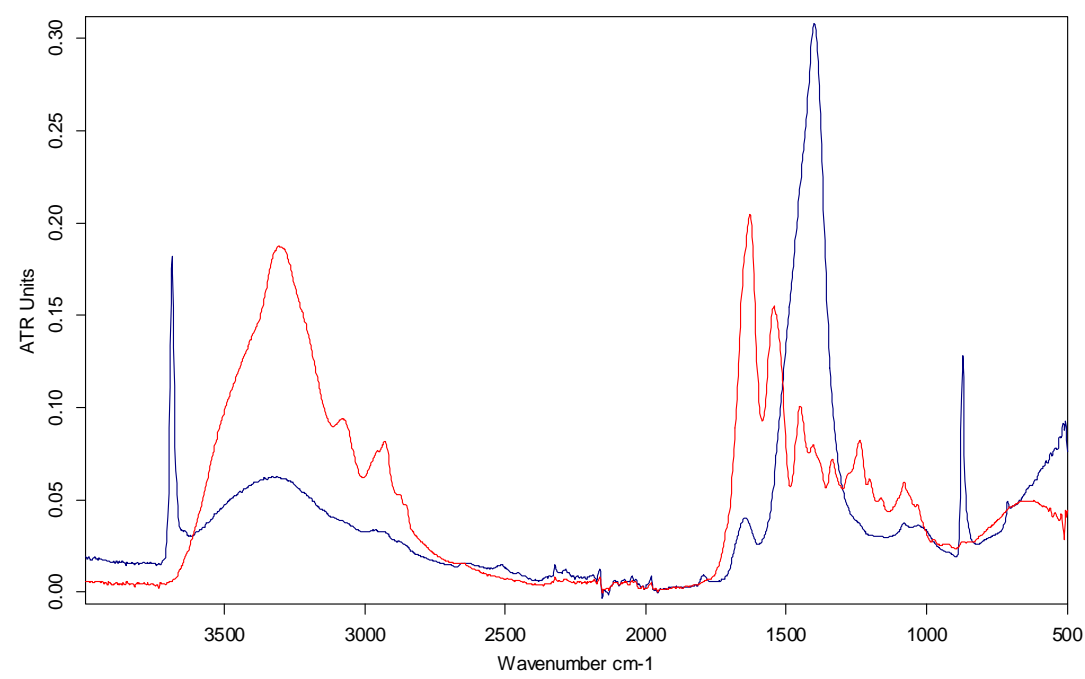

\begin{tabular}{|lccc|c|}
\hline C:MuestrasIPilar SorianolADHESIVOSlind0.2 & $2 \quad$ COLLETTA ITALIANA & 15/06/2005 \\
\hline C:IMuestrasIPilar Sorianol3.0 & $3 \quad$ COLETA PROBETA 3 VERDE & 01/06/2005 \\
\hline
\end{tabular} 


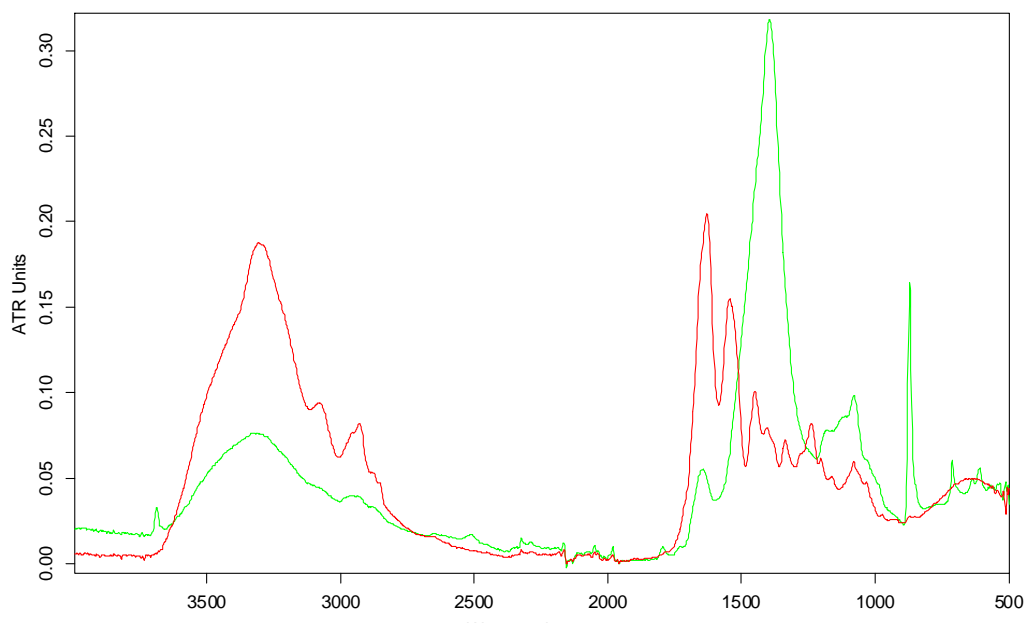

Wavenumber cm-1

\begin{tabular}{|lccc|c|}
\hline C:IMuestrasIPilar SorianolADHESIVOSlindo. 2 & 2 & COLLETTA ITALIANA & $15 / 06 / 2005$ \\
\hline C:IMuestrasIPilar Sorianol3.1 & 3.1 & COLETA PROBETA 3 MORTERO & $01 / 06 / 2005$ \\
\hline
\end{tabular}

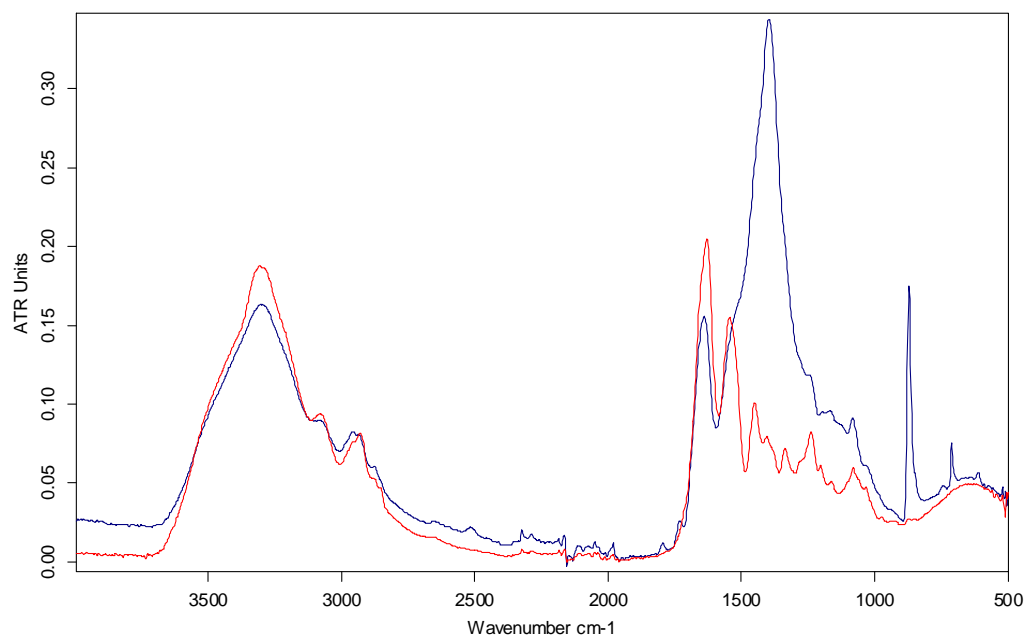

\begin{tabular}{|lcc|c|c|}
\hline C:IMuestrasIPilar SorianolADHESIVOSlindo. 2 & $2 \quad$ COLLETTA ITALIANA & 15/06/2005 \\
\hline C:IMuestrasIPilar Sorianol4.0 & $4 \quad$ COLETA PROBETA 4 VERDE & 01/06/2005 \\
\hline
\end{tabular} 


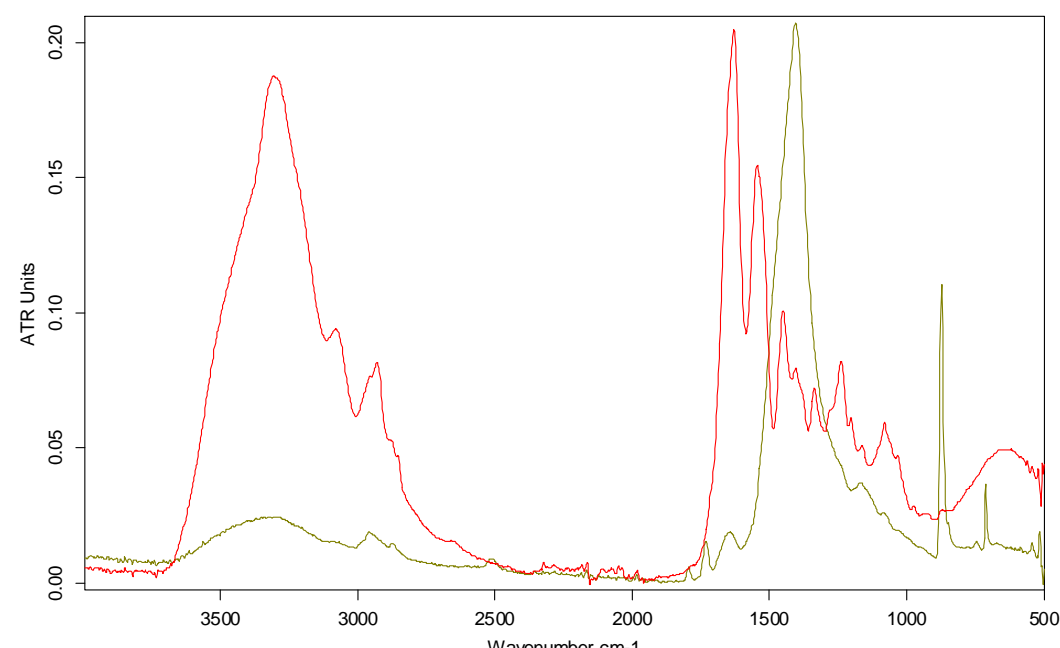

\begin{tabular}{|lccc|c|}
\hline C:IMuestrasIPilar SorianolADHESIVOSlindo.2 & 2 & COLLETTA ITALIANA & $15 / 06 / 2005$ \\
\hline C:IMuestrasIPilar Sorianol4.1 & 4.1 & COLETA PROBETA 4 MORTERO & $01 / 06 / 2005$ \\
\hline
\end{tabular}

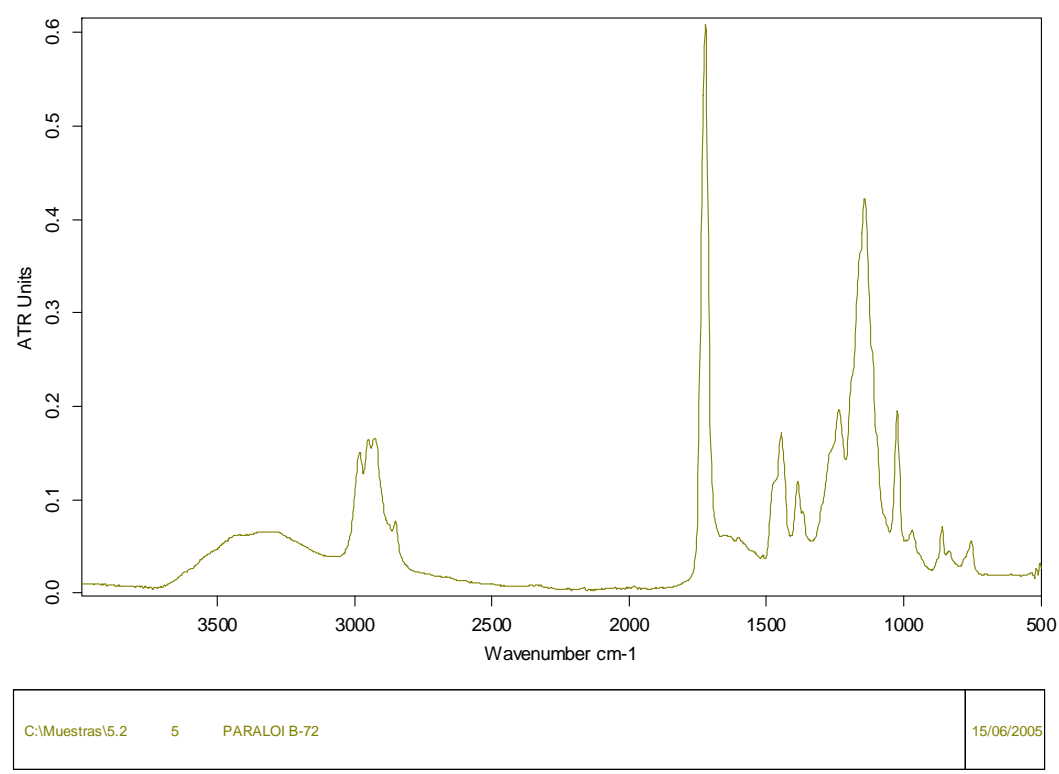




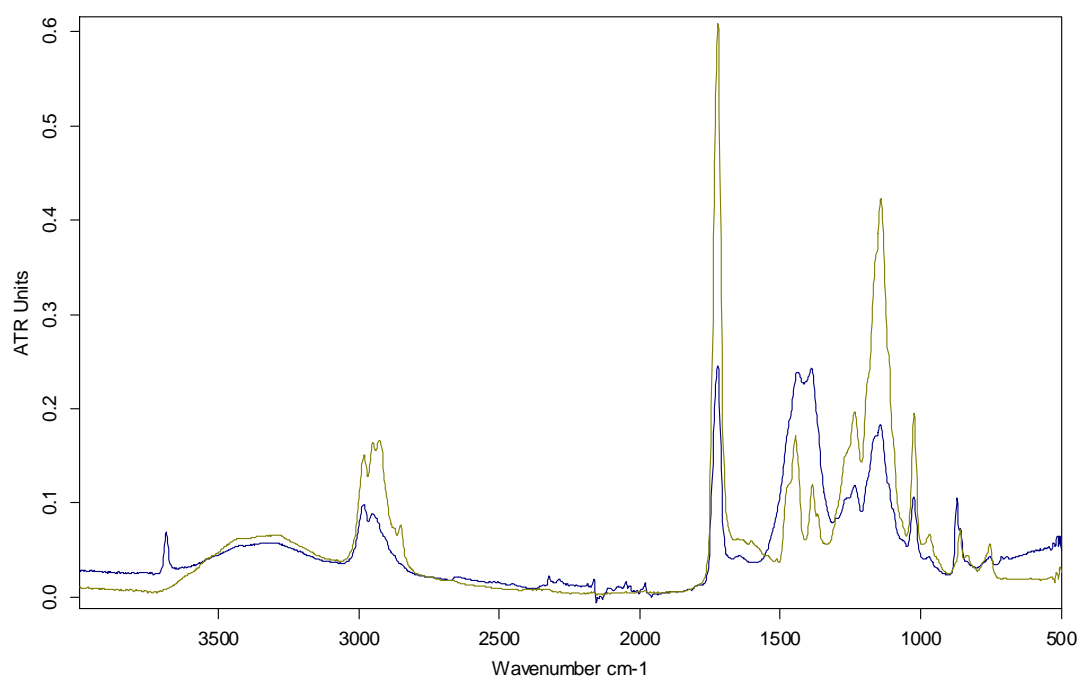

\begin{tabular}{|lcc|c|}
\hline C:IMuestras15.2 & 5 & PARALOI B-72 & 15/06/2005 \\
\hline C:IMuestrasIPilar Sorianol9.0 & 9 & PARALOID B-72 PROBETA AMARILLO & 01/06/2005 \\
\hline
\end{tabular}

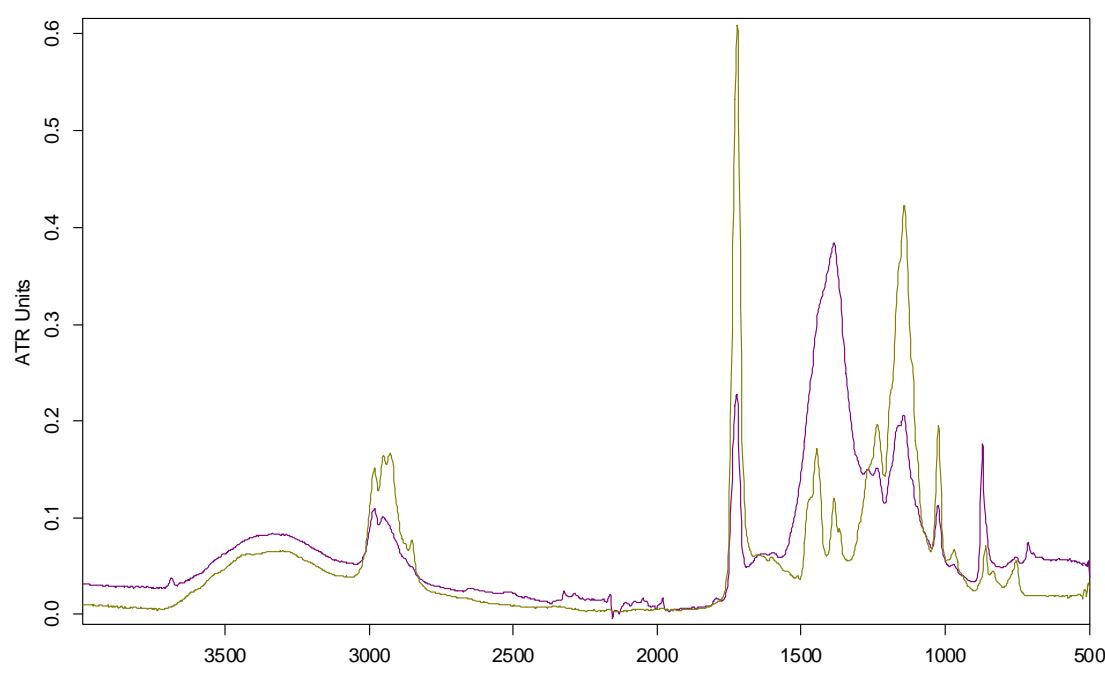

\begin{tabular}{|lcc|c|}
\hline C:IMuestras 15.2 & 5 & PARALOI B-72 & $15 / 06 / 2005$ \\
\hline C:IMuestras IPilar Sorianol9.1 & $9.1 \quad$ PARALOID B-72 PROBETA 9 MORTERO & 01/06/2005 \\
\hline
\end{tabular} 


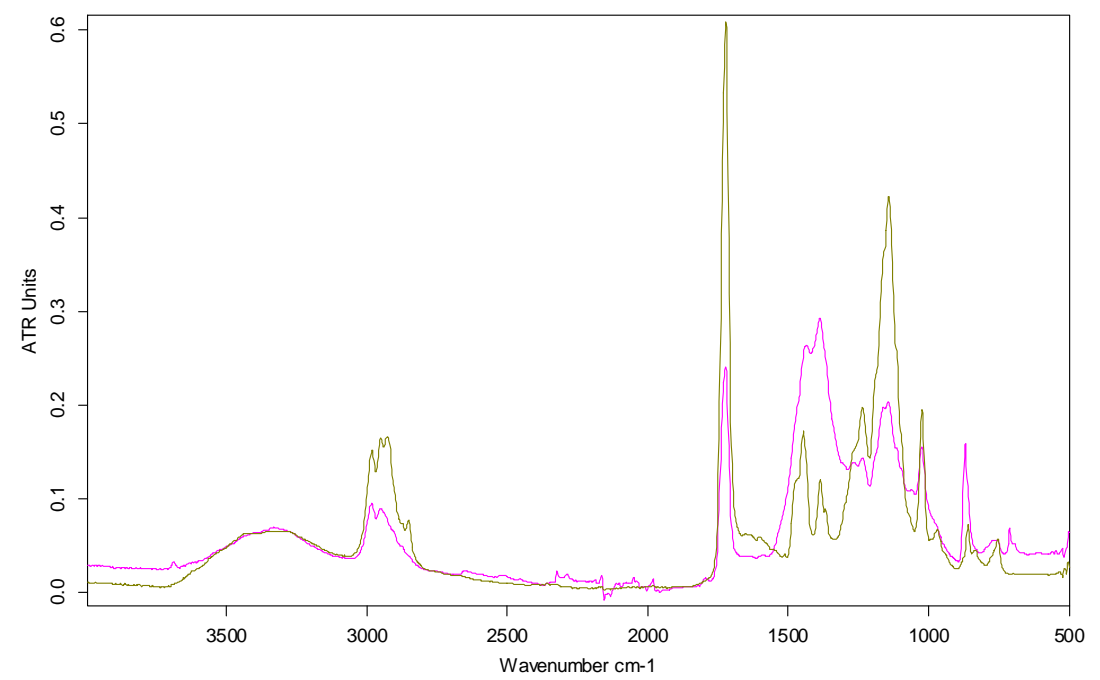

\begin{tabular}{|lcl|l|}
\hline C:Muestras|5.2 & 5 & PARALOI B-72 & 15/06/2005 \\
\hline C:IMuestras IPilar Sorianol10.0 & 10 & PARALOID B-72 PROBETA 10 VERDE & 01/06/2005 \\
\hline
\end{tabular}

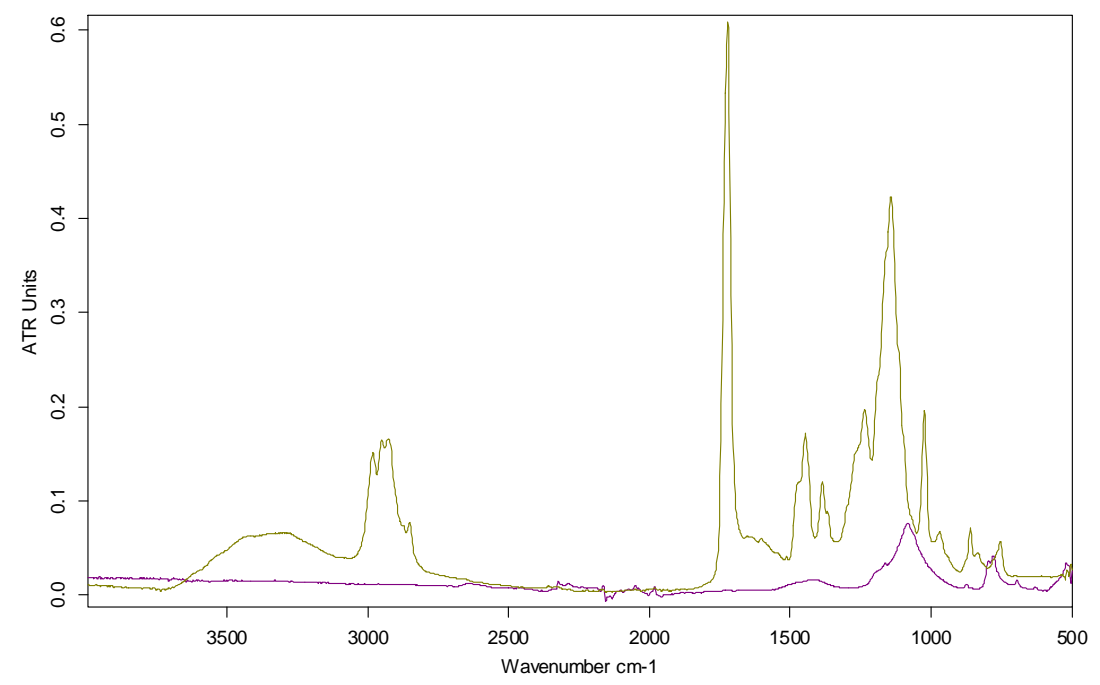

\begin{tabular}{|lcc|c|}
\hline C:Muestras|5.2 & 5 & PARALOI B-72 & 15/06/2005 \\
\hline C:IMuestrasIPilar Sorianol10.1 & 10.1 & PARALOID B-72 PROBETA 10 MORTERO & 01/06/2005 \\
\hline
\end{tabular} 
9.6. ANEXO VI. Tabla de mediciones de peso de probetas.

\begin{tabular}{|c|c|c|}
\hline $\begin{array}{l}\mathrm{N}^{\circ} \\
\text { PROBETA }\end{array}$ & PESO PROBETA (gr./35 cm ${ }^{2}$ ) & PESO gr./1 $\mathrm{m}^{2}$ de soporte \\
\hline 1 & 3,51 & 1002,857143 \\
\hline 2 & 7,08 & 2022,857143 \\
\hline 3 & 7,63 & 2180 \\
\hline 4 & 2,96 & 845,7142857 \\
\hline 5 & 3,11 & 888,5714286 \\
\hline 6 & 4,19 & 1197,142857 \\
\hline 7 & 3,28 & 937,1428571 \\
\hline 8 & 3,12 & 891,4285714 \\
\hline 9 & 5,45 & 1557,142857 \\
\hline 10 & 6,48 & 1851,428571 \\
\hline 11 & 2,88 & 822,8571429 \\
\hline 12 & 3,31 & 945,7142857 \\
\hline 13 & 4,07 & 1162,857143 \\
\hline 14 & 3,31 & 945,7142857 \\
\hline 15 & 3,7 & 1057,142857 \\
\hline 16 & 6,63 & 1894,285714 \\
\hline 17 & 8,01 & 2288,571429 \\
\hline 18 & 3,22 & 920 \\
\hline 19 & 3,29 & 940 \\
\hline 20 & 4,62 & 1320 \\
\hline 21 & 3,81 & 1088,571429 \\
\hline 22 & 3,8 & 1085,714286 \\
\hline 23 & 5,88 & 1680 \\
\hline 24 & 7,34 & 2097,142857 \\
\hline 25 & 4,01 & 1145,714286 \\
\hline 26 & 3,77 & 1077,142857 \\
\hline 27 & 4,54 & 1297,142857 \\
\hline 28 & 4,6 & 1314,285714 \\
\hline 29 & 2,45 & 700 \\
\hline 30 & 5,09 & 1454,285714 \\
\hline
\end{tabular}




\begin{tabular}{|c|c|c|}
\hline 31 & 8,77 & 2505,714286 \\
\hline 32 & 2,22 & 634,2857143 \\
\hline 33 & 2,23 & 637,1428571 \\
\hline 34 & 3,66 & 1045,714286 \\
\hline 35 & 2,37 & 677,1428571 \\
\hline 36 & 2,48 & 708,5714286 \\
\hline 37 & 5,15 & 1471,428571 \\
\hline 38 & 6,15 & 1757,142857 \\
\hline 39 & 2,28 & 651,4285714 \\
\hline 40 & 2,03 & 580 \\
\hline 41 & 2,98 & 851,4285714 \\
\hline 42 & 2,01 & 574,2857143 \\
\hline 43 & 2,75 & 785,7142857 \\
\hline 44 & 5,7 & 1628,571429 \\
\hline 45 & 8,32 & 2377,142857 \\
\hline 46 & 2,39 & 682,8571429 \\
\hline 47 & 2,48 & 708,5714286 \\
\hline 48 & 3,62 & 1034,285714 \\
\hline 49 & 2,24 & 640 \\
\hline 50 & 1,91 & 545,7142857 \\
\hline 51 & 5,07 & 1448,571429 \\
\hline 52 & 5,8 & 1657,142857 \\
\hline 53 & 2,15 & 614,2857143 \\
\hline 54 & 2,03 & 580 \\
\hline 55 & 2,68 & 765,7142857 \\
\hline 56 & 2,02 & 577,1428571 \\
\hline 57 & 3,37 & 962,8571429 \\
\hline 58 & 5,95 & 1700 \\
\hline 59 & 7,44 & 2125,714286 \\
\hline 60 & 3,45 & 985,7142857 \\
\hline 61 & 3,45 & 985,7142857 \\
\hline 62 & 4,23 & 1208,571429 \\
\hline 63 & 3,5 & 1000 \\
\hline
\end{tabular}




\begin{tabular}{|c|c|c|}
\hline 64 & 3,28 & 937,1428571 \\
\hline 65 & 6,19 & 1768,571429 \\
\hline 66 & 7,14 & 2040 \\
\hline 67 & 2,98 & 851,4285714 \\
\hline 68 & 2,99 & 854,2857143 \\
\hline 69 & 3,81 & 1088,571429 \\
\hline 70 & 3,24 & 925,7142857 \\
\hline 71 & 4,03 & 1151,428571 \\
\hline 72 & 6,33 & 1808,571429 \\
\hline 73 & 8,42 & 2405,714286 \\
\hline 74 & 4,08 & 1165,714286 \\
\hline 75 & 4,23 & 1208,571429 \\
\hline 76 & 5,12 & 1462,857143 \\
\hline 77 & 4,37 & 1248,571429 \\
\hline 78 & 4,09 & 1168,571429 \\
\hline 79 & 6,86 & 1960 \\
\hline 80 & 8,35 & 2385,714286 \\
\hline 81 & 3,51 & 1002,857143 \\
\hline 82 & 3,88 & 1108,571429 \\
\hline 83 & 4,49 & 1282,857143 \\
\hline 84 & 4,6 & 1314,285714 \\
\hline 85 & 2,57 & 734,2857143 \\
\hline 86 & 5,1 & 1457,142857 \\
\hline 87 & 7,9 & 2257,142857 \\
\hline 88 & 2,56 & 731,4285714 \\
\hline 89 & 2,77 & 791,4285714 \\
\hline 90 & 3,4 & 971,4285714 \\
\hline 91 & 2,62 & 748,5714286 \\
\hline 92 & 2,72 & 777,1428571 \\
\hline 93 & 4,96 & 1417,142857 \\
\hline 94 & 6,92 & 1977,142857 \\
\hline 95 & 2,32 & 662,8571429 \\
\hline 96 & 2,15 & 614,2857143 \\
\hline
\end{tabular}




\begin{tabular}{|c|c|c|}
\hline 97 & 3,21 & 917,1428571 \\
\hline 98 & 2,73 & 780 \\
\hline 99 & 2,3 & 657,1428571 \\
\hline 100 & 5,77 & 1648,571429 \\
\hline 101 & 8,06 & 2302,857143 \\
\hline 102 & 1,98 & 565,7142857 \\
\hline 103 & 2,29 & 654,2857143 \\
\hline 104 & 3,54 & 1011,428571 \\
\hline 105 & 2,44 & 697,1428571 \\
\hline 106 & 2,29 & 654,2857143 \\
\hline 107 & 4,56 & 1302,857143 \\
\hline 108 & 6,66 & 1902,857143 \\
\hline 109 & 2,06 & 588,5714286 \\
\hline 110 & 2,01 & 574,2857143 \\
\hline 111 & 2,84 & 811,4285714 \\
\hline 112 & 2,06 & 588,5714286 \\
\hline 113 & 3,5 & 1000 \\
\hline 114 & 6,16 & 1760 \\
\hline 115 & 7,51 & 2145,714286 \\
\hline 116 & 2,82 & 805,7142857 \\
\hline 117 & 3,23 & 922,8571429 \\
\hline 118 & 4,06 & 1160 \\
\hline 119 & 3,22 & 920 \\
\hline 120 & 3,34 & 954,2857143 \\
\hline 121 & 5,4 & 1542,857143 \\
\hline 122 & 7,67 & 2191,428571 \\
\hline 123 & 3,04 & 868,5714286 \\
\hline 124 & 3,1 & 885,7142857 \\
\hline 125 & 3,9 & 1114,285714 \\
\hline 126 & 2,91 & 831,4285714 \\
\hline 127 & 3,99 & 1140 \\
\hline 128 & 6,59 & 1882,857143 \\
\hline 129 & 9,13 & 2608,571429 \\
\hline
\end{tabular}




\begin{tabular}{|c|c|c|}
\hline 130 & 3,68 & 1051,428571 \\
\hline 131 & 3,9 & 1114,285714 \\
\hline 132 & 4,18 & 1194,285714 \\
\hline 133 & 4,61 & 1317,142857 \\
\hline 134 & 4,1 & 1171,428571 \\
\hline 135 & 6,72 & 1920 \\
\hline 136 & 8,08 & 2308,571429 \\
\hline 137 & 3,95 & 1128,571429 \\
\hline 138 & 4,26 & 1217,142857 \\
\hline 139 & 4,91 & 1402,857143 \\
\hline 140 & 4,59 & 1311,428571 \\
\hline 141 & 2,43 & 694,2857143 \\
\hline 142 & 4,65 & 1328,571429 \\
\hline 143 & 5,91 & 1688,571429 \\
\hline 144 & 2,46 & 702,8571429 \\
\hline 145 & 2,36 & 674,2857143 \\
\hline 146 & 3,54 & 1011,428571 \\
\hline 147 & 3,14 & 897,1428571 \\
\hline 148 & 2,49 & 711,4285714 \\
\hline 149 & 4,08 & 1165,714286 \\
\hline 150 & 5,44 & 1554,285714 \\
\hline 151 & 2,34 & 668,5714286 \\
\hline 152 & 2,4 & 685,7142857 \\
\hline 153 & 2,72 & 777,1428571 \\
\hline 154 & 2,23 & 637,1428571 \\
\hline 155 & 2,69 & 768,5714286 \\
\hline 156 & 4,47 & 1277,142857 \\
\hline 157 & 5,25 & 1500 \\
\hline 158 & 2,57 & 734,2857143 \\
\hline 159 & 2,21 & 631,4285714 \\
\hline 160 & 3,19 & 911,4285714 \\
\hline 161 & 2,74 & 782,8571429 \\
\hline 162 & 2,18 & 622,8571429 \\
\hline
\end{tabular}


Anexos

\begin{tabular}{|l|l|l|}
\hline 163 & 3,97 & 1134,285714 \\
\hline 164 & 5,83 & 1665,714286 \\
\hline \hline 165 & 2,08 & 594,2857143 \\
\hline 166 & 1,67 & 477,1428571 \\
\hline 167 & 2,53 & 722,8571429 \\
\hline 168 & 1,66 & 474,2857143 \\
\hline
\end{tabular}


9.7. ANEXO VII. Comparativa de fotografías tomadas a través de microscopio óptico antes y después de la limpieza del panel, y después de la desprotección.
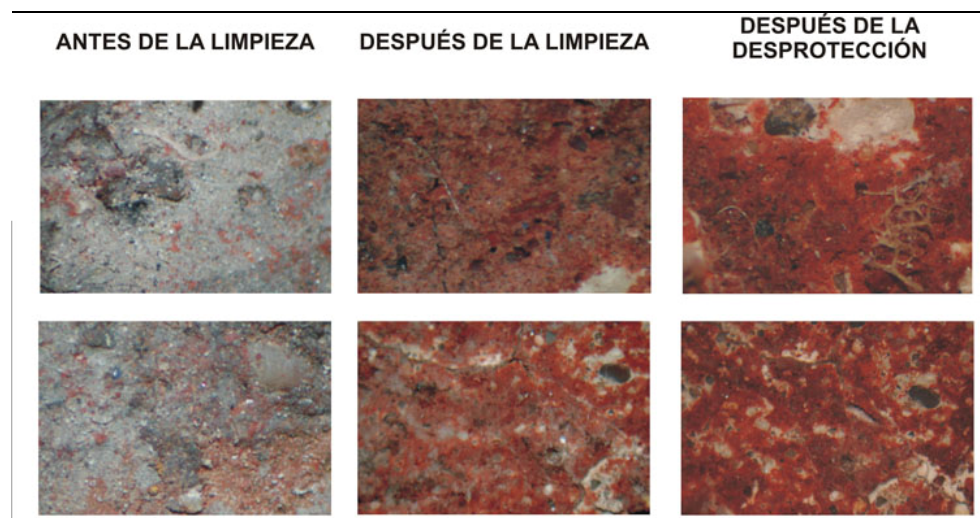

MUESTRA 1
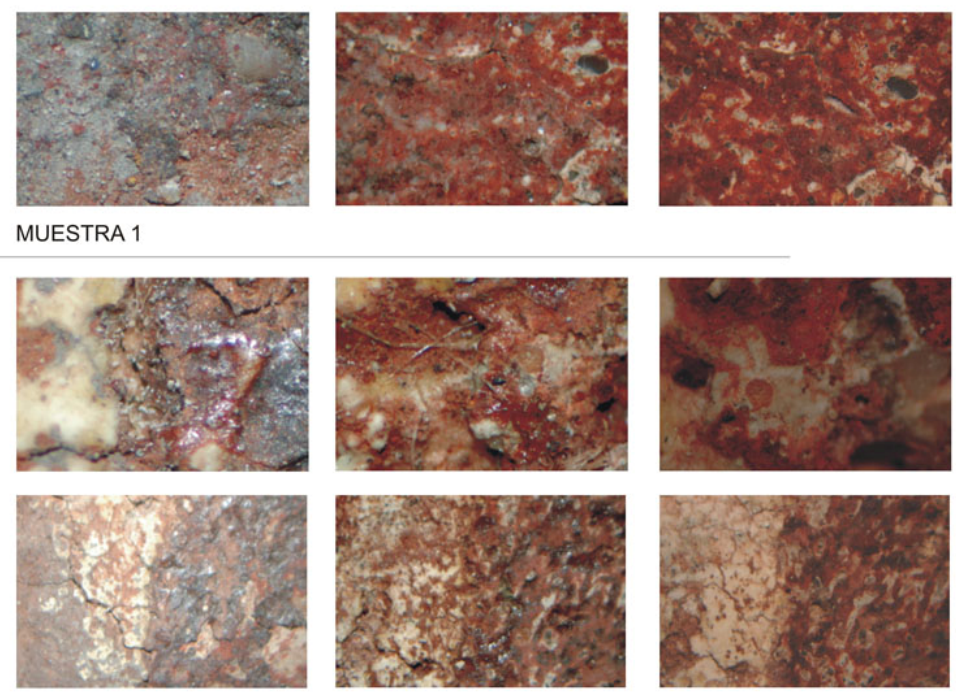

MUESTRA 2
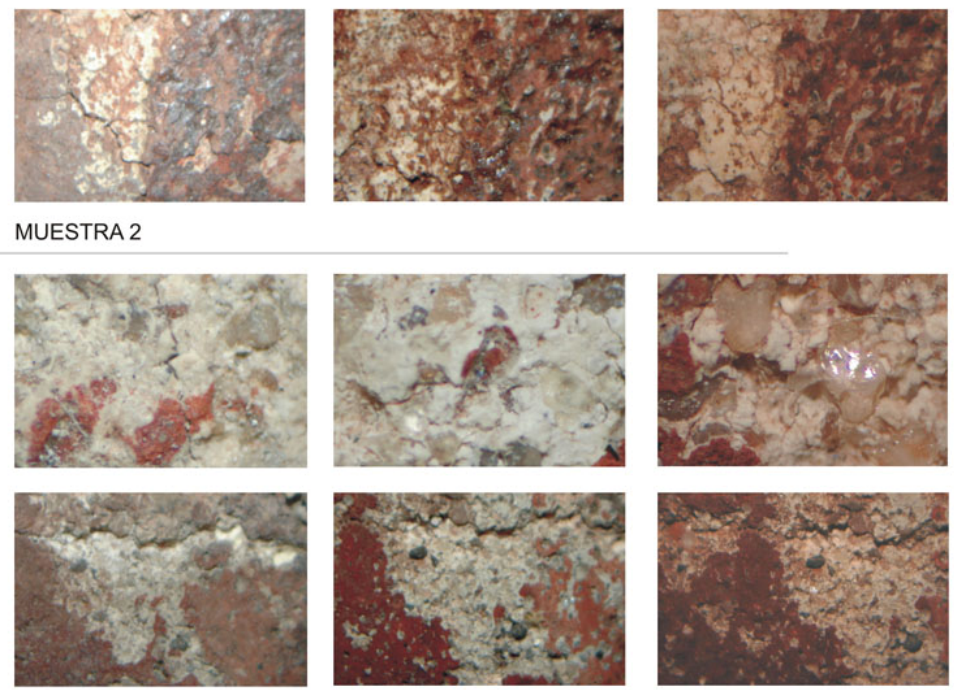

MUESTRA 3

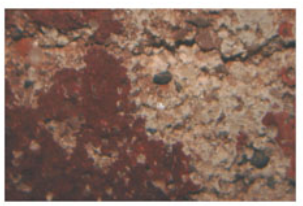



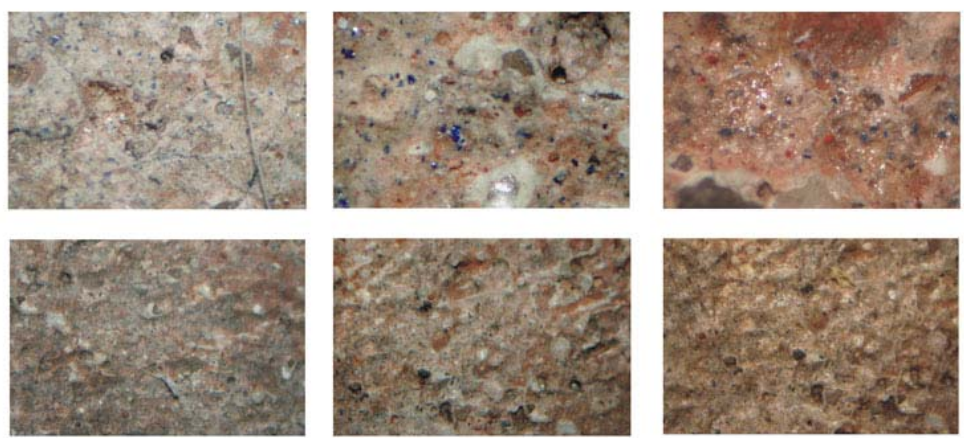

MUESTRA 4
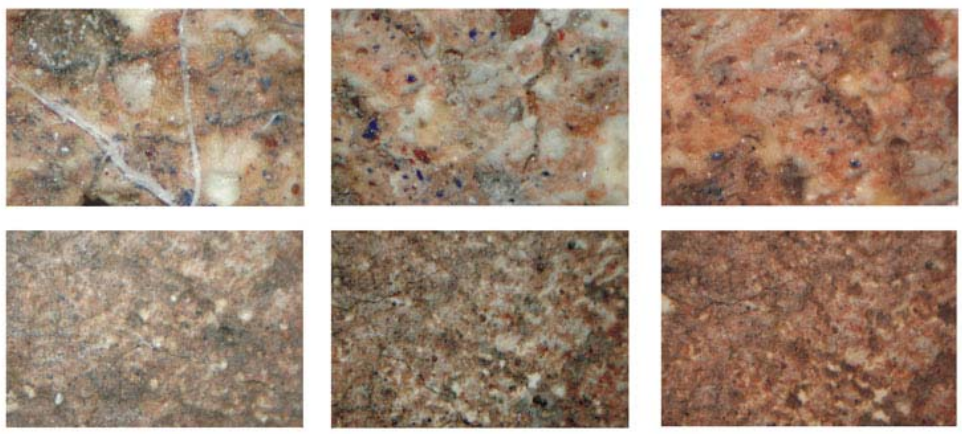

MUESTRA 5
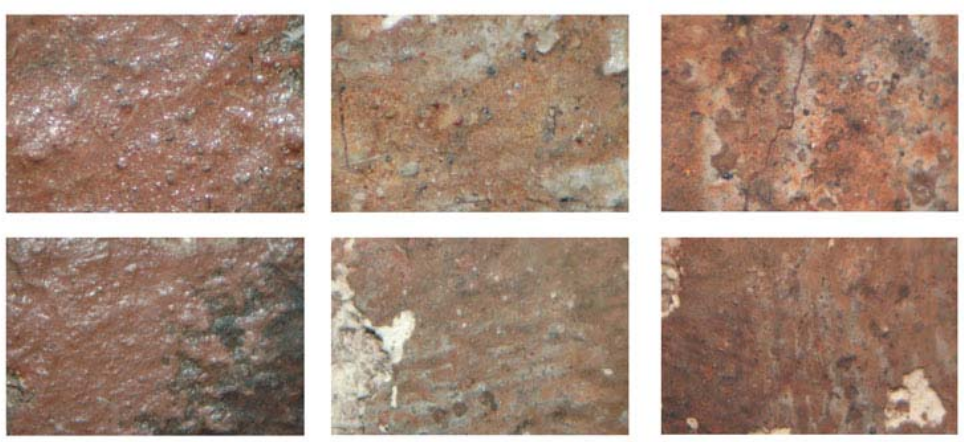

MUESTRA 6 

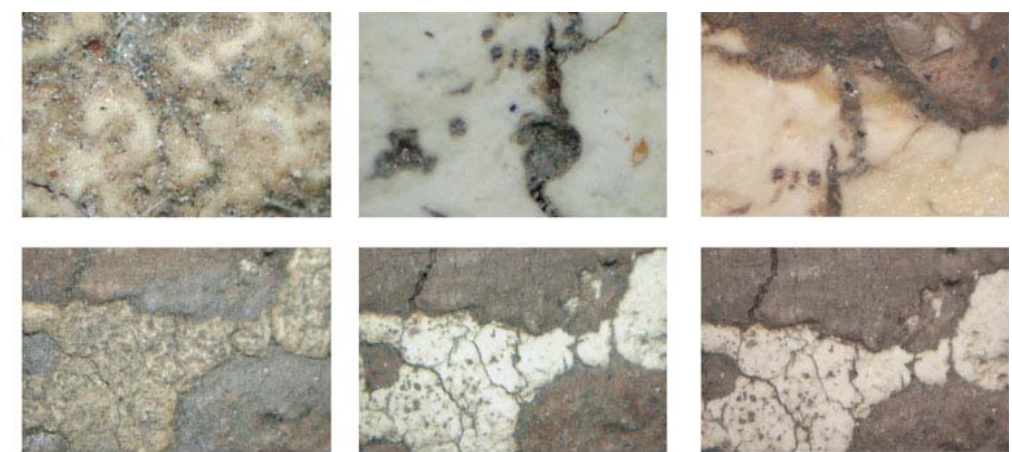

MUESTRA 7
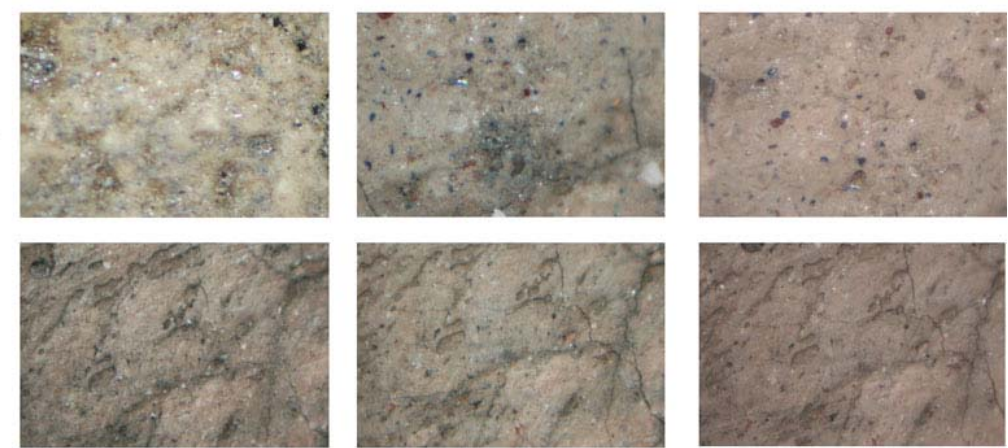

MUESTRA 8
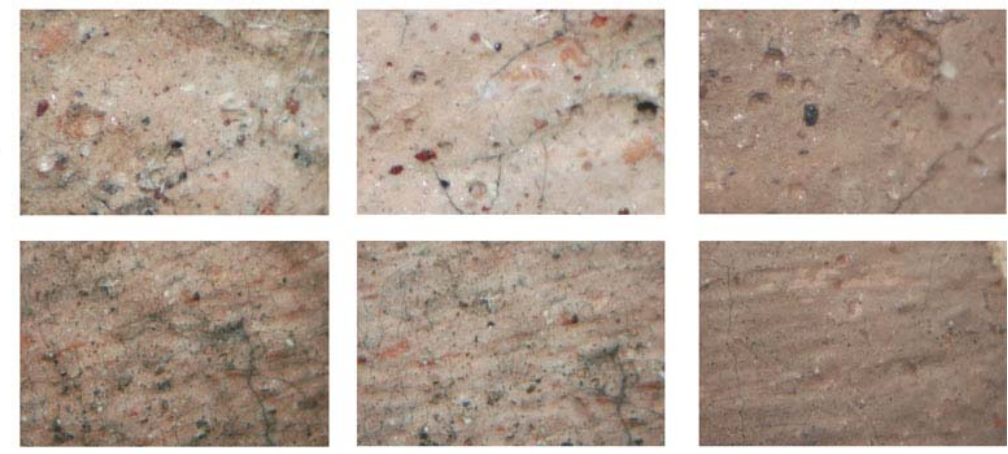

MUESTRA 9 

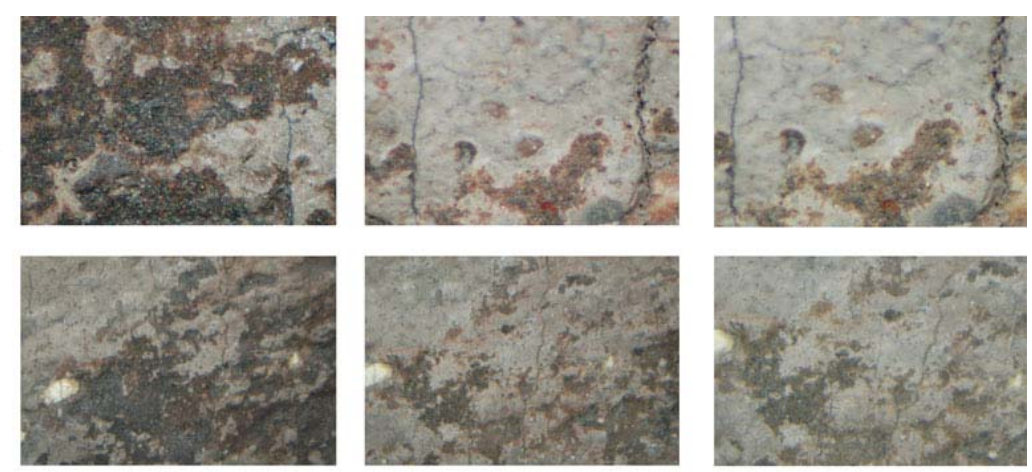

MUESTRA 10
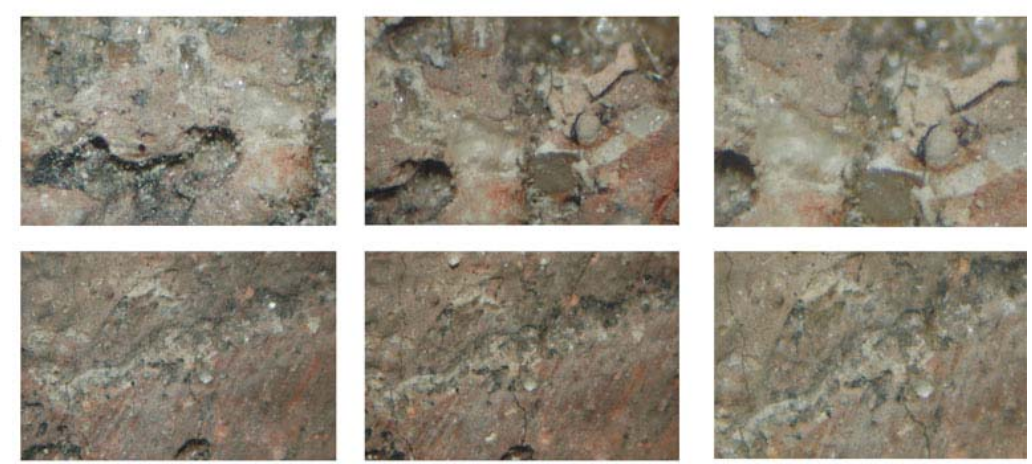

MUESTRA 11
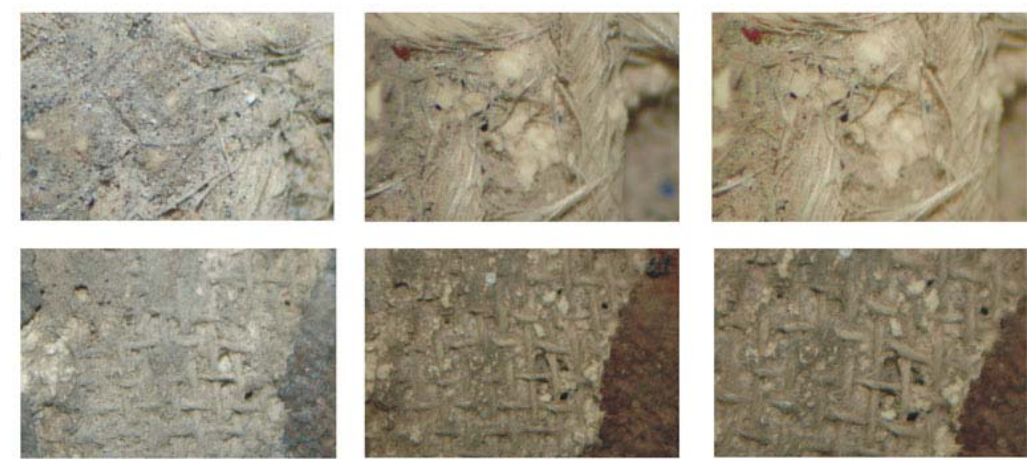

MUESTRA 12 

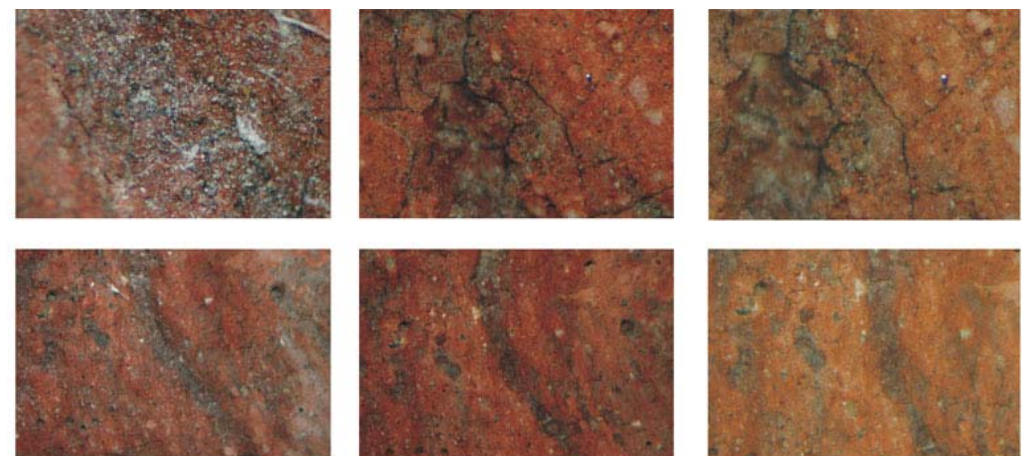

MUESTRA 13
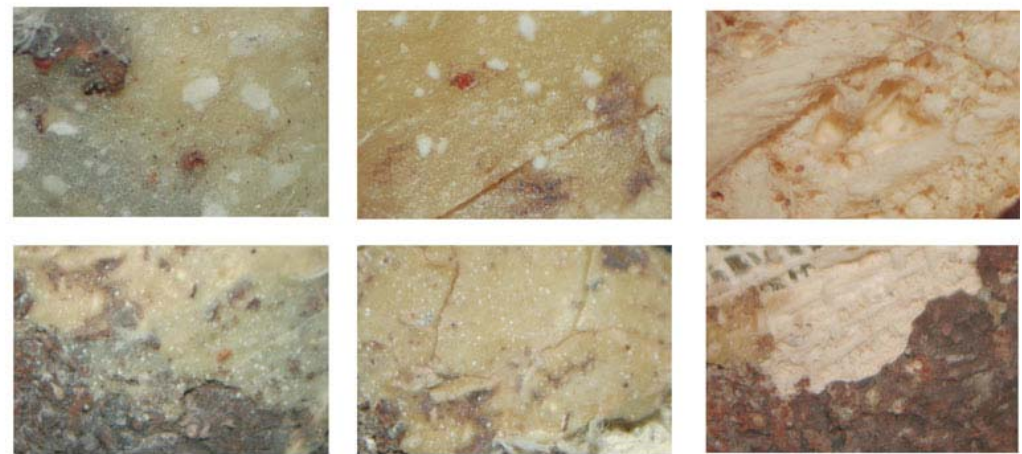

MUESTRA 14
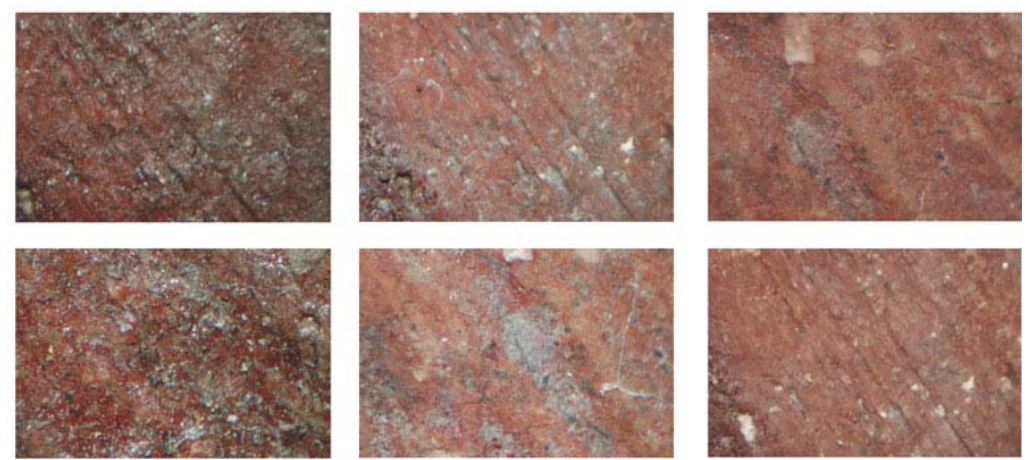

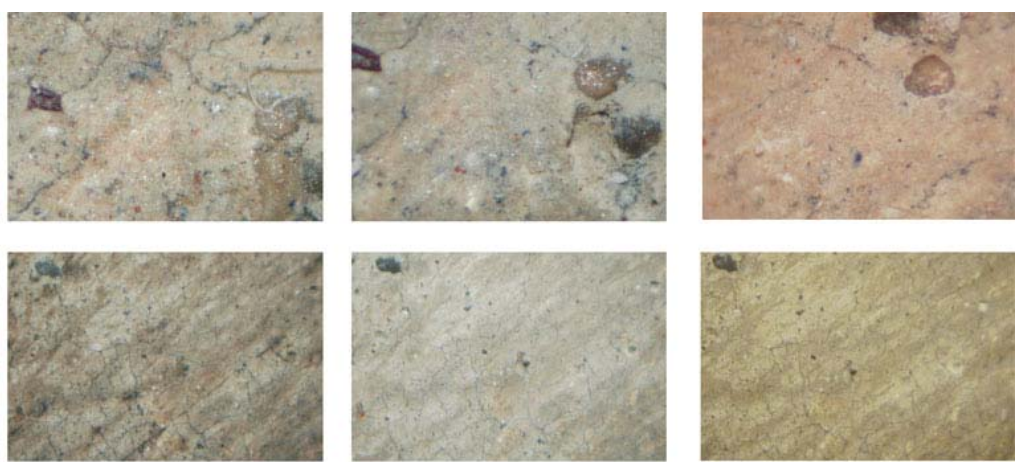

MUESTRA 16
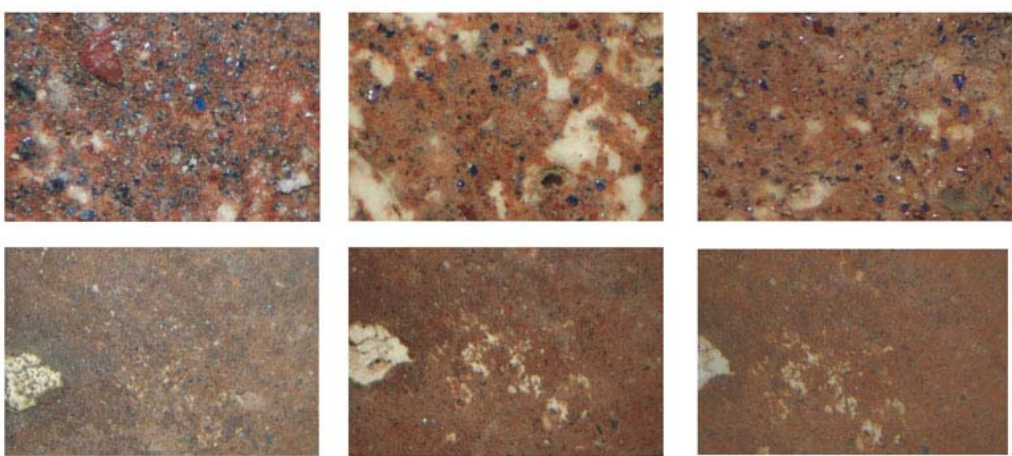

MUESTRA 17
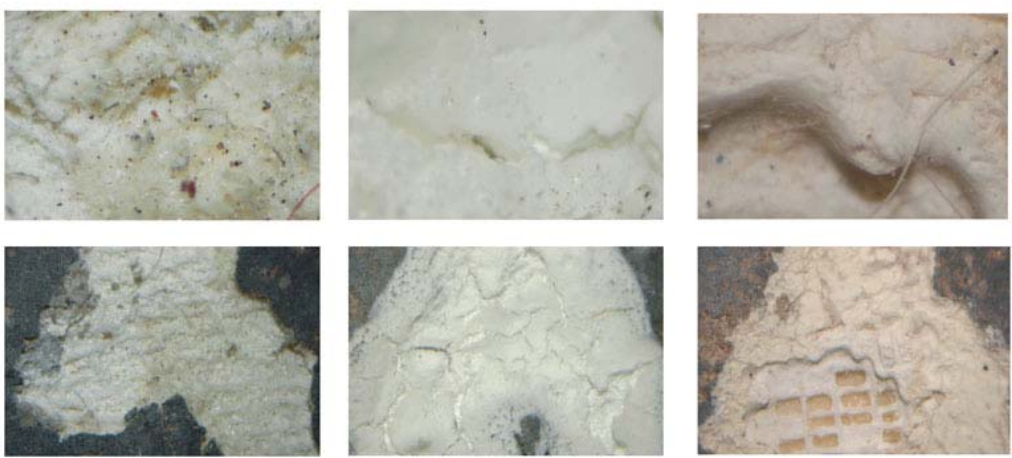

MUESTRA 18 